BNWL-1901 (Rev. 1)

UC-79b

Special Distribution

A STATE OF THE ART REVIEW

OF DEGRADATION PROCESSES

IN LMFBR MATERIALS

Volume I. MECHANICAL PROPERTIES

August 25, 1975

Contributors: J. L. Brimhall

P. D. Cohn

I. S. Levy

C. Pavlov

E. B. Schwenk

Compiled By: R. L. Dillon

I. S. Levy

Prepared for the U.S. Nuclear Regulatory Commission Under Related Services Contract TD0 695 to the Prime Contract E(45-1):1830 with U.S. Energy Research and Development Administration

BATTELLE

PACIFIC NORTHWEST LABORATORIES

Richland, Washington 99352 
IMTRODUCTION AND GENERAL INDEX

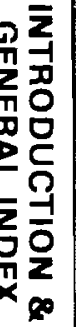



GENERAL INDEX

Volume I

Forward and Technical Summary

1.0 Swelling

2.0 Effect of Irradiation on Tensile Properties

3.0 Effect of Irradiation on High Strain Rate Properties

4.0 Effect of Irradiation on Creep-Rupture Properties

5.0 Effect of Irradiation on Fatigue Properties

6.0 Effect of Irradiation on Weld Performance

7.0 Effect of Fuel Clad Interactions on Mechanical Properties

8.0 Effect of Sodium Coolant Interactions on Mechanical Properties

\section{Volume II}

Forward and Technical Summary

9.0 Corrosion and Mass Transfer

10.0 Erosion.

11.0 Wear and Self Welding

12.0 Sodium-Water Reactions

13.0 Corrosion (External) 


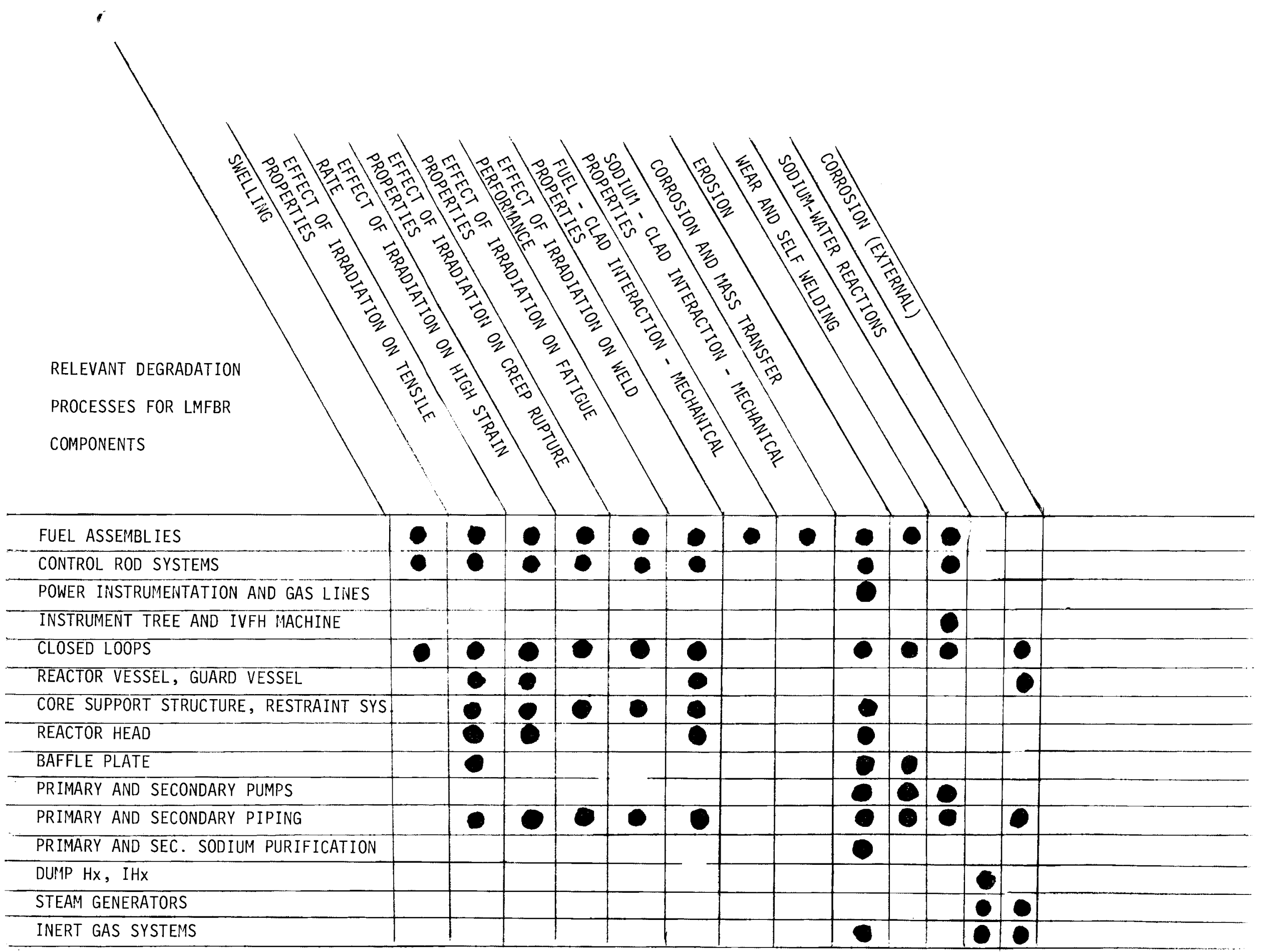


FORWARD

Since April of 1972, Battelle-Northwest has been charged with providing to Licensing - Fast Reactor Project Branch any assistance required in dealing with specific LMFBR materials problems. In partial fulfillment of these responsibilities, BNW has undertaken the preparation of technical summaries of metal degradation processes which are known to occur in sodiumcooled reactor service. As the LMFBR materials summaries are presently conceived, a two-phase study will be required. This document comprises the first phase and constitutes a review of degradation processes to metals in sodium reactor service. The degradation processes which will be discussed include those affecting mechanical properties (i.e., neutron irradiation, thermal exposure and sodium- and fuel-clad interaction) as well as environmental effects specific to sodium coolants (mass transfer and corrosion, fretting and wear, erosion, etc.); synergism is not considered here.

The second phase of the review of LMFBR materials degradation is a component by component consideration of reactor systems. Components will be discussed in the context of the degradation processes to which they are susceptible under expected service conditions. In this way, the component design will be compared with the requirements imposed by the anticinated service conditions--both in normal operation and under upset conditions, power transients and loss of cooling; syneraism is considered here.

LMFBR materials technology is a rapidly changing science with many critical questions awaiting resolution from planned experiments or experiments currently in progress. As a result, some viewpoints now generally accepted on the basis of currently available data may qive way to different concepts as more information is obtained. Since the purpose of this stateof-the-art summary is to supply Licensing with reliable materials information 


\section{$i i$}

usable in connection with LMFBR license application reviews, it is essential to keep the document current with the new experimental information and improved interpretation. We have, therefore, prepared this LMFBR materials degradation summary in a format compatible with periodic updating. The basic accommodations to updating are these:

- The summary is prepared in loose-leaf format to simplify replacement of sections which have required revision.

- Each topic is comprised of sections that are complete entities (i.e., tables, figures, references) for ease of replacement.

- A list of revisions will be supplied and kept current with textual modifications.

- Each page is dated for comparison with the revision list.

- Finally a distribution list will be kept current (with Licensing - Fast Reactor Project

Branch assistance) so that revisions can be supplied directly to all document holders. Copies are numbered to simplify accountability.

The highly structured outline from which the text is prepared is immediately noticeable. This organized presentation has been adapted to assist the reader in finding the material he wants and to minimize the textual changes when revisions are required. There has been a conscious endeavor to provide all the information the reader will require in considering a materials question. While the sources are always identified, it is intended that reference to them will be necessary only in unusual cases. With self sufficiency of the state-of-the-art document as a major objective, data compilations and figures are freely used. Definitive work of all dates has been referenced, but heavy emphasis has been placed on sources of the last three or four years. There are very good reasons 


\section{iii}

for this policy--principally that only in the most recent work have experimental conditions been well enough defined to preclude significant but unrecognized variations from the nominal.

In the preparation of this document, all available sources of information on materials degradation have been used. Through the auspices of our sponsor we have had access to certain proprietary information, both domestic and foreign. Usually this proprietary information has been supplied on the basis of a limited and clearly designated circulation. Consequently, this document must be distributed with these restrictions in mind.

The document is published in two volumes:

$$
\begin{aligned}
& \text { Volume I - Mechanical Properties } \\
& \text { Volume II - Corrosion Behavior }
\end{aligned}
$$

Component Application Guides have been included in the document. These guides, one for each chapter, as wel1 as a Summary Guide for the complete document, are intended to aid the reader in more easily finding materials information relevant to a particular reactor component of interest.

The Summary Guides (one to each volume) are inserted after the Table of Contents for each volume; each chapter guide is inserted after the List of Figures for each chapter. 



\section{Copyright Acknowledgments}

The contributors wish to acknowledge the following publishers who have granted permission to reproduce figures and tables from their publications for use within this document:

Publisher

American Nuclear Society

American Society for Testing Materials
John Wiley \& Sons, Inc.

Gordon \& Breach, Science Publishers, Inc.
International Nickel Co., Inc.

Nuclear Engineering International

The Iron \& Steel Institute

(The Metals Society)
State-of-Art-Review

Figure $\begin{array}{r}1.3 \cdot 2 \cdot 2-1 \\ 1.3 \cdot 3 \cdot 1-3 \\ 2.3 \cdot 2 \cdot 2-1\end{array}$

Figure $5.1 .2 .1 .1-1$

$5.1 .2 .1 .2-1$

$5.1 \cdot 2 \cdot 2 \cdot 3 \cdot 1-1$

$5 \cdot 1 \cdot 2 \cdot 3 \cdot 2-2$

5.3.2-1 through -7

10.3.2.2-1

$10.3 \cdot 2.2-2$

10.3.2.3-1

$10.3 \cdot 3-1$

$10.4 .2-3$

Figure 13.3.3.1-1

Table 13.3.2.1-1 through -3

13.3.3.1-1

$13.6 .2-1$

$13.6 .2-2$

Figure 13.2.5-1

Table 13.2.1-1

Figure 13.4.2.1-1

Table 13.3.2.3-1 through -3

13.4.2.1-2

Figure 13.1.4-1

$13.1 .4-2$

Figure 13.5.3.1-1 



\subsection{SWELLING}

This chapter discusses the experimental parameters which affect material swelling in the radiation environment of a fast reactor. The data have been obtained by immersion density measurements, diametral change measurements and transmission electron microscopy. The data presented cover principally 304 and 316 stainless steel which have been irradiated in EBR-II. The principal limitations are the limited data on cold worked 316 stainless steel and the lack of high fluence data. In particular, existing data on cold worked 316 stainless steel extends to $25 \times 10^{22} \mathrm{n} / \mathrm{cm}^{2}$, whereas goal exposures for the demonstration LMFBR are greater than $2 \times 10^{23} \mathrm{n} / \mathrm{cm}^{2}$. This means that extrapolation must be made from a gathering of all existing lower fluence data. British data have not been used in extrapolation or predictions because compositional and heat treatment differences may lead to different swelling behavior. The data are applicable to the swelling of any component if the experimental conditions for that component are known, in particular the neutron spectrum, temperature and stress state of the component. At present, there is a lack of experimental data on spectral effects and the effects of stress on swelling have yet to be fully resolved.

\subsection{EFFECT OF IRRADIATION ON TENSILE PROPERTIES}

The effects on tensile properties of irradiation fluence and temperature, test temperature, reactor variables and material variables are discussed. Tensile data reported in this chapter were from several material sources, only one of which -- the 304 stainless steel tested at HEDL -- is prototypic of material to be used in LMFBR, i.e., produced to RDT specifications. The other materials -- the 304 stainless steel and nickel-base alloys tested at GE, the Ti-modified 316 stainless steel tested at ORNL, and the annealed and $20 \%$ cold-worked 316 stainless steel tested at HEDL -- produce properties representative only of nominal 
values for these materials. In particular, the cold-work 316 stainless steel is not in its prototypic, tubular form for LMFBR usage, and the Ti-modified 316 stainless steel is a development alloy.

The data are limited to very low fluence levels for the $20 \%$ cold-worked 316 stainless steel; fluence levels for 304 stainless steel are generally applicable to LMFBR requirements.

Tensile data are applicable to the pressure vessel and to core components other than fuel pins; design criteria for these components call for $10 \%$ residual tensile elongation at end of service life. For the pressure vessel and for components other than portions of the inner and outer shield, these criteria are expected to be met; for the latter it appears the fluence levels are too high to ensure the $10 \%$ residual elongation.

$(3 / 31 / 73)$

\subsection{EFFECT OF IRRADIATION ON HIGH STRAIN-RATE PROPERTIES}

The effects on high strain-rate properties of irradiation fluence and temperature, test temperature, strain-rate, reactor variables and material variables are discussed. High strain-rate data reported in this chapter are from several sources; the 304 stainless steel and $20 \%$ cold-worked 316 stainless steel represent prototypic FFTF heats and product forms purchased to RDT specifications; the nickel alloys represent nominal ASTM heat specifications.

The data are 1 imited by very low fluence levels, particularly for high strain-rate tensile tests. Since these data indicate no significant increase in uniform elongation with strain-rate, ordinary tensile data may be used to approximate high strain-rate properties at higher fluences. Using this approximation, the 10\% residual ductility criteria for 304 stainless steel appears to be met for the pressure vessel and for components other than portions of the inner and outer shield in FFTF, for which the fluence is too high. Simulated transient tests on $20 \%$ cold-worked 316 stainless steel tubing indicates that a fuel pin integrity limit of $0.7 \%$, which includes $0.5 \%$ strain due to upsets and transients, is probably not conservative. 


\subsection{IRRADIATION EFFECTS ON CREEP-RUPTURE PROPERTIES}

The effects on creep-rupture properties of irradiation fluence and temperature, test temperature, reactor variables and material variables are discussed. The creep-rupture data reported in this chapter are from several sources, onty one of which -- the $20 \%$ cold-worked 316 stainless steel tested at HEDL -- represents a prototypic FFTF heat and product form produced to RDT specifications; the data for the annealed 316 stainiess steel tested at HEDL and at ORNL and the annealed 304 stainiess steel tested at ORNL represent nominal values for these materials procured to ASTM specifications.

The data are limited by very low fluence levels for the cold-worked 316 stainless steel, the only alloy for which creep criteria are established for LMFBRs (for fuel cladding). The current design criteria are $\leq 0.2 \%$ steady state strain and $\leq 0.5 \%$ added creep and/or high strain-rate tensile strain for transient events. Steady state strains as low as $0.18 \% \triangle D / D$ are produced even after low fluences at test temperatures near

irradiation temperatures. At test temperatures approximately $200^{\circ} \mathrm{F}$ higher than the irradiation temperature (i.e., a simulation of a transient event), post-irradiation creep ductilities are usually $\ll 1.0 \%$, even at low fluences. Lower ductilities would be expected at reference fluences. The possibility exists that a non-damaging irradiation-creep can occur that will allow greater fuel pin strain during steady state operation; however, the mechanism would not be available to increase strain during transients.

$(6 / 3 / 74)$

\subsection{IRRADIATION EFFECTS ON FATIGUE}

This chapter discusses the nature of fatigue data and the factors that affect fatigue 1 ifetime, where possibie, with respect to anticipated LMFBR operating conditions. Practical 1 imitations of the application of fatigue data for structural component evaluation are discussed. Methods of characterizing fatigue lifetimes in specimens under low- and high-cycle fatigue and fatigue crack growth are presented; application to components is 
limited by difficulties of applying specimen data to the more complex, loaded components.

Irradiation effects on fatigue properties of austenitic stainless steels are discussed. The data are limited, and in some cases sparse, with respect to anticipated LMFBR operational conditions and thus do not as yet provide a satisfactory bas is for fatigue design limits. Data on irradiated specimens are confined mainly to unnotched low-cycle fatique and selected creep-fatique test conditions. The principal limitations is the small amount of data on cold-worked material and exposure levels that extend to about $2 \times 10^{22} \mathrm{n} / \mathrm{cm}^{2}$, only for a small number of specimens, whereas goal exposures for the demonstration LMFBR may be as high as $2 \times 10^{23} \mathrm{n} / \mathrm{cm}^{2}$ or more. A satisfactory base had been developed for unirradiated fatigue crack growth ( $f c g$ ) including a range of simulated LMFBR environmental conditions and cold work. The effect of irradiation on fcg is 1 imited to one 304 stainless steel specimen and one 316 stainless steel specimen irradiated in EBR-II to $21.2 \times 10^{22} \mathrm{n} / \mathrm{cm}^{2}$. More data from different fluence levels, irradiation and test temperatures and environments are necessary to make rational extrapolations to anticipated LMFBR irradiation and operating conditions. (10/25/74)

\subsection{EFFECT OF IRRADIATION ON WELD PERFORMANCE}

The effects of irradiation and material condition on the tensile and high strain-rate properties of weldments are discussed. Post-irradiation creep data are not yet available. The data reported in this chapter were for materials representing prototypic FFTF 304 stainless steel pipe and vessel forms and both standard and developmental weld metals and processes.

The data are for fluence levels up to $7 \times 10^{21} \mathrm{n} / \mathrm{cm}^{2}$, $E>0.1 \mathrm{MEV}$. Irradiation lowers the ductility of welds, and this decrease is most severe at the higher temperatures.

Welds in radial shields in FFTF can be exposed to fluence levels higher than that at which $10 \%$ total elongation can be expected. Moreover, for TIG welds of 308 in 304 stainless steel base metal the fluence limits may allow the $10 \%$ elongation 
criterion but would not allow 10\% uniform elongation, which is probably the more relevant criterion for transient considerations.

$(6 / 3 / 74)$

\subsection{FUEL CLAD INTERACTION}

The steady state requirement for fuel performance is basically an integral pin throughtout its lifetime with strain not to exceed $0.3 \%$. Plastic strains for irradiation conditions and claddings somewhat different than current LMFBR prototypes have exceeded $0.5 \%$. Current EBR-II irradiations for FFTF have not shown plastic strains in excess of $\sim 0.2 \%$. The strain capability between 0.3 to $0.7 \%$ for the prototype cladding under LMFBR transient conditions has not been demonstrated. The clad fluences now being extrapolated to LMFBR applications range from 20 to $30 \%$ of EOL fluence. Additionally, a single 304 stainless steel datum indicates zero creep strain at about $75 \%$ of the FFTF goal fluence of $2 \times 10^{23}$.

Considerable data exist which demonstrate a plastic deformation capability in excess of $0.2 \%$ at burnups near LMFBR goals but at $\sim 30 \%$ of the fluence. Except for the fluence level, these pins probably experienced the full extent of expected fuel clad interactions.

Fuel clad chemical interactions appear to be within projected limits, $\sim 2$ mils (EOL) at rated consitions. Data with excess penetrations have been considered inapplicable due to non-prototype clad and pellet chemical conditions. However, additional data are needed to provide full support of the current limit.

Data are currently being obtained as part of the LMFBR fuels test program to demonstrate transient strain limits and fuel clad interaction effects at full fluence and rated conditions. The possibly lowered transient failure ductility of irradiated material may lead to a greater number of fuel failures during accidents. The lowered failure threshold may change accident peak energy due to earlier fuel expulsion and thus may also change the consequences of power excursion accidents.

$(6 / 3 / 74)$

\subsection{EFFECT OF SODIUM COOLANT INTERACTIONS ON MECHANICAL PROPERTIES}

The effect of flowing sodium under carburizing and noncarburizing conditions on composition, microstructure, and mechanical properties are discussed. 
The data are limited to unirradiated conditions for a few alloys; data on $20 \%$ cold-worked 316 stainless steel, the FFTF and CRBRP cladding alloy are unavailable.

The available data on 304 stainless steel and annealed 316 stainless steel indicate substantial degradation occurs in stress rupture life and ductility at either high temperature in a non-carburizing environment or at high and low temperatures in a carburizing environment. The combined effects of sodium interaction and neutron irradiation would be expected to be more severe than the effects of either alone.

Some effects on the residual ductility of the 304 stainless steel pressure vessel at the upper temperatures may occur; further data are required. The potential for deleterious effects to fuel cladding and other core components should not be overlooked; further data are also required here.

$(6 / 3 / 74)$

\subsection{CORROSION AND MASS TRANSFER}

The corrosion and deposition of reactor structural materials is important because structural entities can be weakened, pressure barriers can be penetrated, radioactive material from the core can be transferred to relatively unshielded positions and the important function of heat transfer can be impeded. The corrosion of engineering materials in liquid sodium systems is examined by subdivision into the various parameters important in understanding and predicting the magnitude and type of the corrosion. The treatment of data is primarily oriented toward conventional sodium system materials. The data are largely ex-reactor loops of GE, Westinghouse, Argonne, AI, French and British. In-reactor data are just now becoming available in the temperature range, fluence, sodium purity, velocity, etc., to be typical of LMFBR design conditions.

It is frequently desired to know the maximum rate of corrosion, mass transfer, interstitial leaking, or radioactive buildup for a given reactor system. The selected application of the ex-reactor loop data to the expected corrosion in the reactor will probably yield results as accurately as the conditions (temperature, oxygen, etc.) in the system are anticipated. There has been no indications that recent refinements in testing and oxygen measurement have given 
rise to unexpected corrosion rates. However, care must be used in considering the low oxygen concentrations that the experimentor did indeed know the correct oxygen concentration.

The rare occurrence of shallow intergranular attack in loop piping has not been satisfactorily explained and must be considered an indistinct possibility yet to be explained. Inasmuch as the large reactor systems will probably operate at very low stable oxygen concentrations accurate estimates of corrosion will have to be based on accurate knowledge of the true oxygen concentration. $(3 / 31 / 73)$

10. EROSION

Pre-service, quantitative, characterization of the erosion problem for even familiar working environments is not possible on the basis of present knowledge of this damage agency. Where there is the possibility for corrosion-assisted erosion, as in the LMFBR systems, then theoretical assistance is even weaker. Historical review of possibly relevant experience is of very limited value.

Erosion by solid particle impingement is expected to be an insignificant damage factor in LMFBR systems. Conceivably, some solid particle intrusion of the liquid metal circuits could result from various corrosion processes. A quantity of solid particles sufficient to present an erosion hazard should, however, force the earliest possible attention to this problem and corrective action against the initiating corrosion process.

Liquid particle impingement on the containment envelope of the LMFBR heat transfer system is not expected to persist beyond presumably short transients. Persistent-potentially damaging-two phase regimes in the liquid metal circuits would be a derivative of improper design, or selection, of circuit components, or gross inattention to system operating parameters. Such factors are also pertinent to cavitation erosion. The goal of zero, or very low, incidence of cavitation will be more difficult to achieve than will the corresponding goal for liquid particle impingement. With respect to circuit design, there is now a substantial body of guidelines for minimizing the possibility of cavitation erosion, e.g., elimination of abrupt flow section changes, gross roughness, flow obstacles which force rapid acceleration of the fluid. However, 
pump design to accommodate a wide spectrum of operating conditions presents more subtle problems. It is expected that the greatest potential for significant erosion from cavitation resides in such circuit elements where high performance goals may force a close approach to the two phase regime under some operating circumstances. $(10 / 25 / 74)$

\section{WEAR AND SELF WELDING}

The continuous, intermittent or occasional movement of two objects held in position to each other by a bearing surface is a fundamental necessity for a complex machine like a reactor.

The laboratory studies attempting to identify the parameters of this complex interaction have been reviewed as well as the various operating mechanisms where data are available. The data from reactors that have been or are operational, mechanism testing, and design studies by AI, HEDL, GE, and WARD provide a broad base for the lower temperature reactions. The increased corrosion, mass transport, material softening, etc., that takes place with the higher temperatures contemplated for LMFBRs make the applicability of some of these data questionable. The increased testing taking place in prototypic LMFBR conditions will soon give data which will be more applicable to the severe conditions in and above the core. An optimization of oxygen concentration may well be the result of trying to improve corrosion and mass transport (Section 9) as wear and self welding. The optimized value will probably be quite low and less than $5 \mathrm{ppm}$ to reduce the degree of system activation.

$(3 / 31 / 73)$

\section{SODIUM-WATER REACTIONS}

Sodium-heated steam generators are designed with the realization that occasional contact of sodium and water are inevitable. The primary design goals are minimization of the possibility of leaks and rapid detection of a leak should one occur.

The potential damage resulting from a given leak situation depends in a complex way on system parameters, such as leak size, tube material, geometry, temperature, sodium flow rate, and pressure differentials. The best appreciation of potential leak-caused damage is therefore obtained by experiment, i.e., using simulated leaks under conditions closely duplicating expected steam generator 
service conditions. Some qualitative insight can be gained by an understanding of relevant thermodynamic and solubility data, though these are frequently inconsistent and, of course, strictly applicable only to equilibrium situations, and so cannot bear directly on the analysis of damage from pressure pulses or metal wastage.

The early detection of small leaks remains one of the major problems facing the designers of sodium-steam systems. The ideal detector would have an instant response time, regardless of its location relative to the leak. Acoustic detectors appear to offer a great deal of promise, and development work is proceeding in this area.

$(6 / 3 / 74)$

\subsection{EXTERNAL CORROSION PROCESSES}

The subject of this chapter is the potential corrosion problems associated with sodium excursions beyond the planned containment envelope.

Degradation processes considered in the chapter are:

a. Corrosion processes in which there is exchange of ambient species- $-\mathrm{N}_{2}, \mathrm{O}_{2}, \mathrm{H}_{2} \mathrm{O}$ (vapor and 1 iquid)--with the sodium.

b. Corrosion processes in which there is limited exchange in the above respect because of thermal insulation and various protective envelopes.

c. Corrosion and mass transfer effects associated with sodium events in which nitrogen is a principal ambient species. Discussion of corrosion behavior under unstressed and stressed conditions is also presented.

The quality of much of the corrosion data employed in Chapter 13 might be challenged by various students of sodium corrosion. This is a natural consequence of a problem area which does not submit easily to theoretical analysis, and does not enjoy the advantage of clearcut experimental data in many important respects of structural material degradation. A principal conclusion of the chapter is that caustic corrosion processes have not received the attention they merit, and this conclusion is directed primarily toward the low alloy, ferritic, materials. 
Probable location and cause of sodium leaks and spills are not likely to be predictable until details of plant design and operation are known. The history of sodium facility operation shows that leaks have been discovered by operators inspecting the system visually rather than by the leak detection system.

At CRFBR operating temperatures and in areas covered by nitrogen plus $1 \%$ oxygen atmosphere sodium leaks may be expected to produce corrosion rates of tens to hundreds of mils/year. During shutdown, when the system is maintained at lower temperatures and where stresses equal or exceed yield stress for the material, stress corrosion cracking can occur much more quickly. 


\section{SWELLING}

$\frac{\text { 里 }}{\frac{\text { m}}{\mathbf{m}}}$ 


\subsection{SWELLING}

TABLE OF CONTENTS

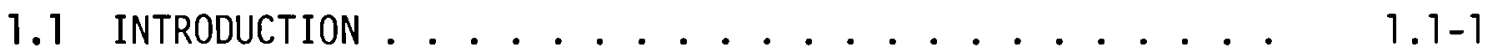

1.2 MAJOR FACTORS INFLUENCING SWELLING ....... 1.2.1-1

1.2 .1 Introduction ................. 1.2.1-1

1.2 .2 Fluence ................... 1.2.2-1

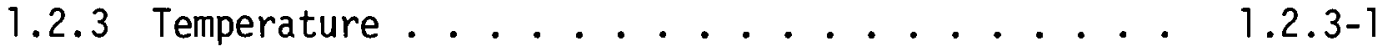

1.3 OTHER FACTORS INFLUENCING SWELLING . . . . . . 1.3.1-1

1.3 .1 Introduction ............ 1.3.1-1

1.3.2 Effect of Reactor Variables ........ 1.3.2.1-1

1.3.2.1 Effect of Flux (Dose Rate) ..... 1.3.2.1-1

1.3.2.2 Effect of Spectrum . . . . . . 1.3.2.2-1

1.3.2.3 Effect of Helium Production .... 1.3.2.3-1

1.3.2.4 Effect of Stress . . . . . . . 1.3.2.4-1

1.3.3 Effect of Material Variables ....... 1.3.3.1-1

1.3.3.1 Effects of Alloy Composition ..... 1.3.3.1-1

1.3.3.2 Effect of Cold Work . . . . . . 1.3.3.2-1

1.4 GENERAL SIGNIFICANCE OF SWELLING TO LMFBR

PERFORMANCE .....................1-1

1.4.1 Introduction .............. 1.4.1-1

1.4.2 General Implications of Swelling to LMFBR

Component Behavior ................2.1-1

1.4.2.1 Fuel Element Cladding and Fuel

Element Support ........ 1.4.2.1-1

1.4.2.2 Core Structural Components . . . . . 1.4.2.2-1

1.4.2.3 Pressure Vessel . . . . . . 1.4.2.3-1 


\section{LIST OF FIGURES}

FIGURE

Page

1.2.2-1 Swelling vs Fluence in Annealed 304

Stainless Steel........... 1.2.2-2

1.2.2-2 Swelling vs Fluence in Annealed 304

Stainless Steel........... 1.2.2-3

1.2.2-3 Swelling vs Fluence in Annealed 304

Stainless Steel .......... 1..2.2-4

1.2.2-4 Fluence Dependence of Swelling in Thimble

Materials for Different Temperature Ranges. 1.2.2-6

1.2.2-5 Swelling in Solution Treated Type 316

Stainless Steel.......... 1.2.2-8

1.2.2-6 Plot of Void Volume (Swelling) vs Neutron

Fluence for S.T. 316 Using Equation (7) . 1.2.2-10

1.2.2-7 Swelling vs Dose for 316 Stainless Steel

Bombarded with Energetic Particles and

Ions as Indicated.......... 1.2.2-11

1.2.2-8 Swelling vs Dose for 316 Stainless Steel

Bombarded with Energetic Particles and

Ions as Indicated.......... 1.2.2-12

1.2.2-9 Swelling vs Dose for 304 Stainless Steel

Bombarded with Energetic Particles and

Ions as Indicated........... 1.2.2-13

1.2.3-1 Temperature Dependence of Swelling Based on Equation (1) for 304 and Equation (4) for 316 in Section 1.2.2 ....... 1.2.3-2

1.2.3-2 Relation Between Void Volume Fraction and Temperature in Irradiated Type 304

Stainless Stee1.......... 1.2.3-3

1.3.2.2-1 Damage Function for 1.0\% Swelling in Annealed SS 304 Irradiated at $450^{\circ} \mathrm{C}$. . . 1.3.2.2-2

1.3.2.3-1 Helium Production in SS for Different Reactor Spectra......... 1.3.2.3-2

1.3.3.1-1 Swelling of Various Austenitic Alloys ... 1.3.3.1-2

1.3.3.1-2 Swelling Versus Dose in Nickel ..... 1.3.3.1-3

1.3.3.1-3 Swelling Versus Fluence in Nickel-Base Alloys ............... 1.3.3.1-4

1.3.3.2-1 Graphic Relationship Between Swelling and Cold Work Level for 316 Stainless Steel . 1.3.3.2-3

1.3.3.2-2 Swelling of $50 \%$ C.W. 304 SS as a Function of Irradiation Temperature ...... 1.3.3.2-4 
1.3.3.2-3 Void Number Density Data . . . . . . 1.3.3.2-6

1.4.2.1-1 Cladding Dilation from Radiation-Induced Swelling in Three Fast Reactors ... . 1.4.2.1-2

1.4.2.2-1 Elongation of Wrapper-tube Walls due to Swelling (End of Life) ........ 1.4.2.2-2

1.4.2.2-2 Dilation of Wrapper Tubes due to Swelling (End of Life) ........ 1.4.2.2-3

1.4.2.2-3 Free (Unrestrained) Bowing of Assemblies Due to Differential Elongation (End of Life)............... 1.4.2.2-4

1.4.2.2-4 Bowing Profiles of Assemblies with Topend Restraint and In-Core Spacer Pads (End of Life).......... 1... 1..2.2-5 

1.0 SWELLING
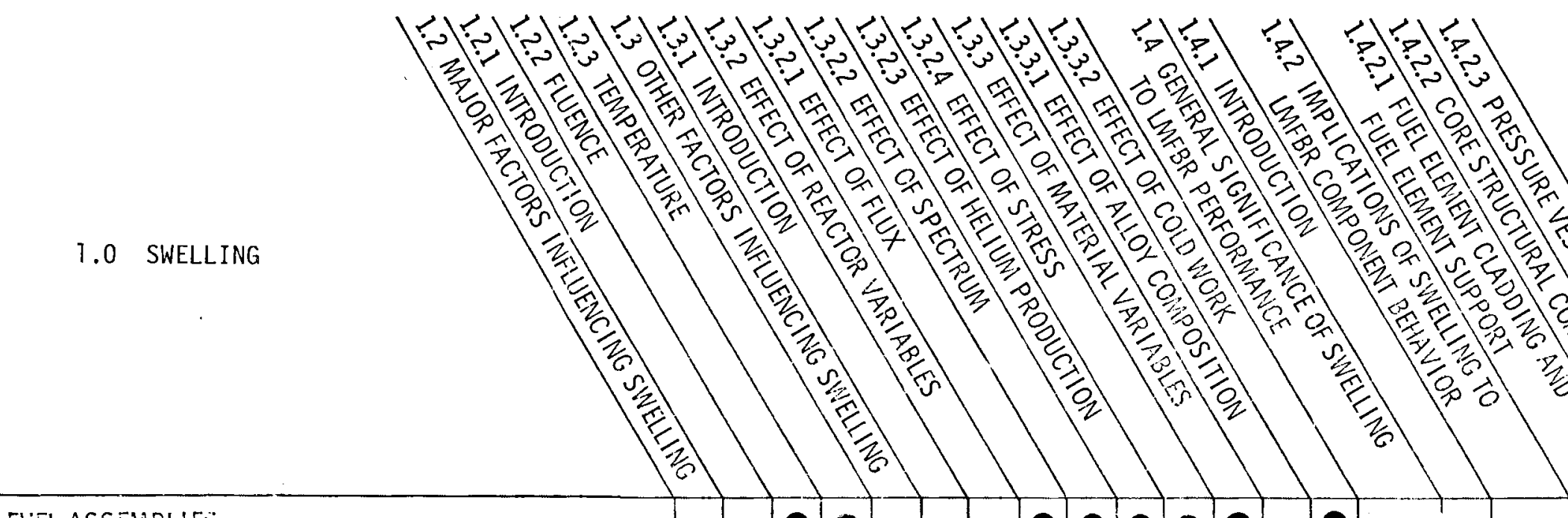

FUEL ASSEMBLIES

CONTROL ROD SYSTEMS

POMER INSTRUNEEITATION AND GAS LINES

INSTRUMEIT TREE AND VFH MACHINE

CLOSED LOUPS

REACTC? VESSEL, CUARD VESSEL

CORE SUPPORT STRUCTURE, RESTRAINT SYSTEM

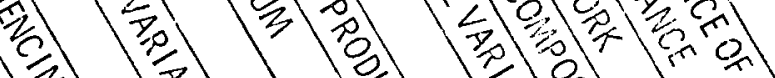

REACTOR HEAD

BAFFLE P!ATE

PRIMARY AND SECONDARY PUMPS

PRIMARY AND SECONDARY PIPING

PRIMARY AND SECONDARY SODIUM PURIFICATION

DUMP $\mathrm{HX}, \mathrm{IHX}$

SIEATIG NERATORS

INERT GAS SYSTENS 



\subsection{SWELLING}

\section{$1.1 \quad$ INTRODUCTION}

The swelling of metals during neutron irradiation was only discovered about five years ago, but has been extensively studied since that time. Qualitatively, the reasons for swelling can be explained in some detail. The bombardment by neutrons during irradiation results in many atoms being displaced from their atom positions. The number of displacements is directly proportional to the duration of irradiation (i.e., neutron fluence). The atoms that are displaced and come to rest in the interstices are known as interstitials, and the vacant sites left behind are known as vacancies. These interstitials and vacancies migrate throughout the crystal and may mutually annihilate one another or become annihilated at some internal defect such as a crystal boundary. A certain fraction of these vacancies and interstitials may coalesce with their own kind. At low temperatures, they precipitate out in the form of plates of extra atoms (interstitial dislocation loops) or missing atoms (vacancy dislocation loops). The lattice expansion of the interstitial loops is essentially counterbalanced by the contraction of the vacancy loops. At higher temperatures, which are generally greater than 0.3 of the melting point and at a sufficiently high fluence, the vacancies prefer to coalesce into three-dimensional holes or voids. The extra atoms represented by these voids go into increasing the volume of the crystal. The result is a net expansion or swelling of the metal. Therefore, in this report we are concerned with that temperature range and with those fluences in which voids form to produce swelling of engineering significance.

While the qualitative descriptions of swelling are known, the quantitative relationships between swelling, fluence, and temperature are less well defined. The various reactor and material parameters which affect swelling further contribute to the complexity of the phenomenon. It will be the purpose of this section of the report to discuss the generally accepted conclusions about swelling, point out the current 


\section{$1.1-2$}

unresolved problem areas and discuss in a general way, significance of swelling to FTR and LMFBR performance. This section will further be limited to structural components and fuel cladding. Swelling of the fuel itself is not discussed. 


\subsection{MAJOR FACTORS INFLUENCING SWELLING}

1.2.1 Introduction

The two major factors which control swelling in reactor materials are the neutron fluence or exposure and the temperature. These two factors will be discussed separately although their effects are interrelated. For example, the dependence of the swelling on the fluence is different depending on the particular reactor temperature. However, in the section on fluence, data is only presented for a constant temperature or a limited temperature region, and in the section on temperature effects, the data are presented for a constant fluence. 


\subsubsection{Fluence}

There are several basic conclusions which serve as a basis for examining the fluence dependence of metal swelling. 1) There is a fluence threshold that must be exceeded in order to get measurable swelling. 2) The swelling increases continually with fluence within the temperature range of void formation. 3) No saturation or indication of saturation in swelling has yet been shown conclusively in neutron irradiated stainless steel. The important issues that must be resolved are: i) What is the best quantitative relationship to use between swelling and fluence so that reliable extrapolations can be made, and ii) will saturation in the swelling occur?

At the present time, there are several expressions in use which relate swelling to fluence for the 304 and 316 solution treated (S.T.) type stainless steels. The empirical expression developed by workers at KEDL to predict swelling in S.T. 304 is of the form: ${ }^{(1)}$

$$
\% \frac{\Delta V}{V_{0}}=A(\Phi t)^{m}+B
$$

where $\% \frac{\Delta V}{V_{0}}=\%$ change in volume

$$
\begin{array}{ll}
\mathrm{A} & =2.65 \times 10^{-8}(\alpha)^{3}-1.54 \times 10^{-5}\left(\alpha^{2}\right)+2.24 \times 10^{-3}(\alpha) \\
\mathrm{m} & =0.872+2.98 \times 10^{-3} \mathrm{~T} \\
\alpha & =\mathrm{T}-348 \\
\phi \mathrm{t} & =\text { fluence in units of } 10^{22} \mathrm{n} / \mathrm{cm}^{2}(\mathrm{E}>0.1 \mathrm{MeV}) \\
\mathrm{B} & =0.2[1-\exp (-1.12 \mathrm{t})] / \mathrm{f} 1+\exp [0.1(\mathrm{~T}-480)]\} \\
\mathrm{T} & =\text { temperature in }{ }^{\circ} \mathrm{C} .
\end{array}
$$

The fit of this equation to the data for several different temperature regimes is shown in Figures $1.2 .2-1$ through $1.2 .2-3^{(1)}$ This equation is limited to fluences less than $1 \times 10^{23} \mathrm{n} / \mathrm{cm}^{2}$.

Data from S.T. 304 samples with fluences up to $1.5 \times 10^{23} \mathrm{n} / \mathrm{cm}^{2}$ ( $\mathrm{E}>0.1 \mathrm{MeV}$ ) have recently been acquired ${ }^{(2)}$ It was found by workers at HEDL that a linear relationship between swelling and fluence with a damping factor at low fluences gave as good a fit as the 


\subsection{2-2}

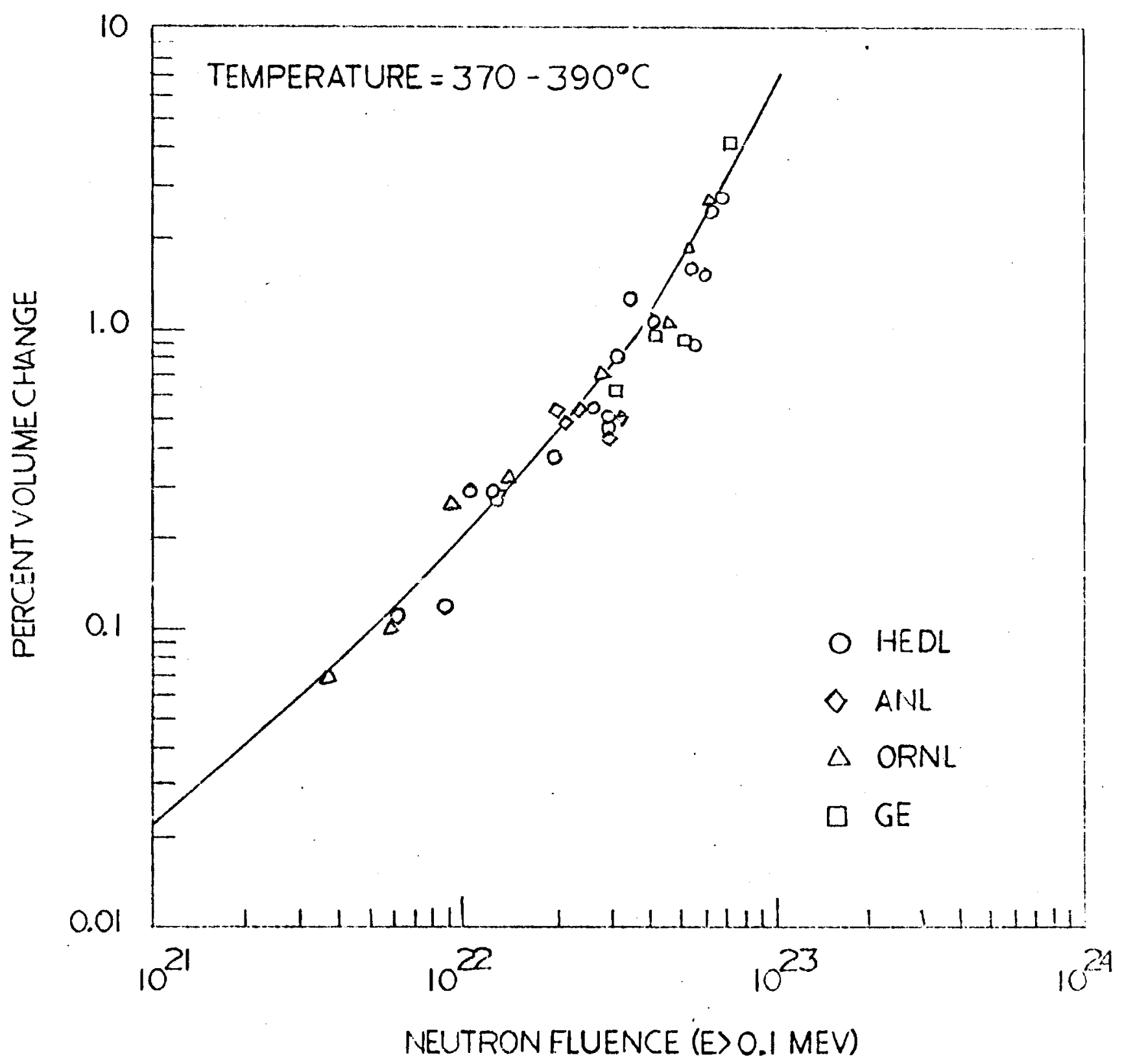

Figure 1.2.2-1 Swelling vs Fluence in Annealed 304 Stainless Steel 


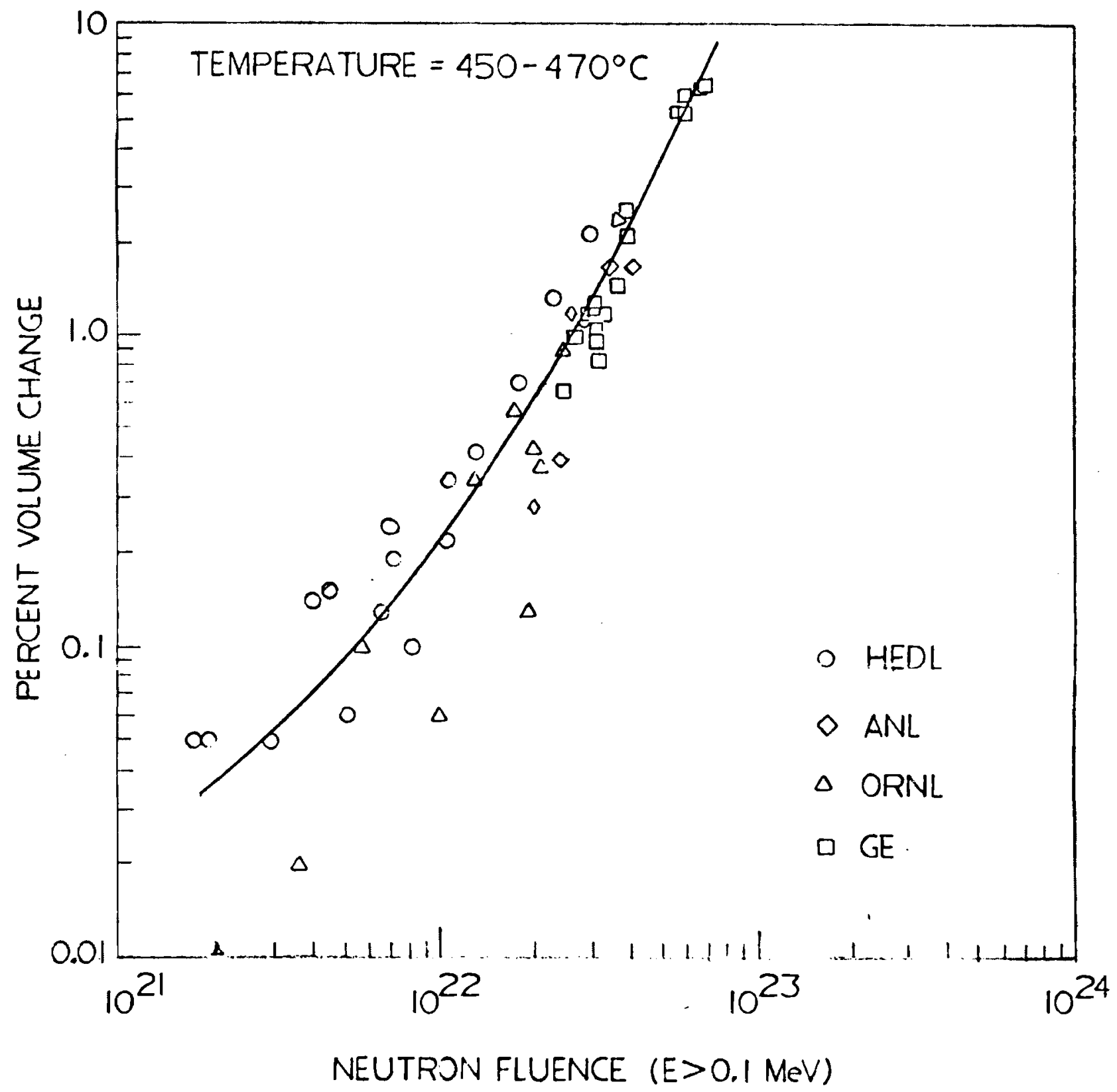

Figure 1.2.2-2 Swelling vs Fluence in Annealed 304 Stainless Steel 


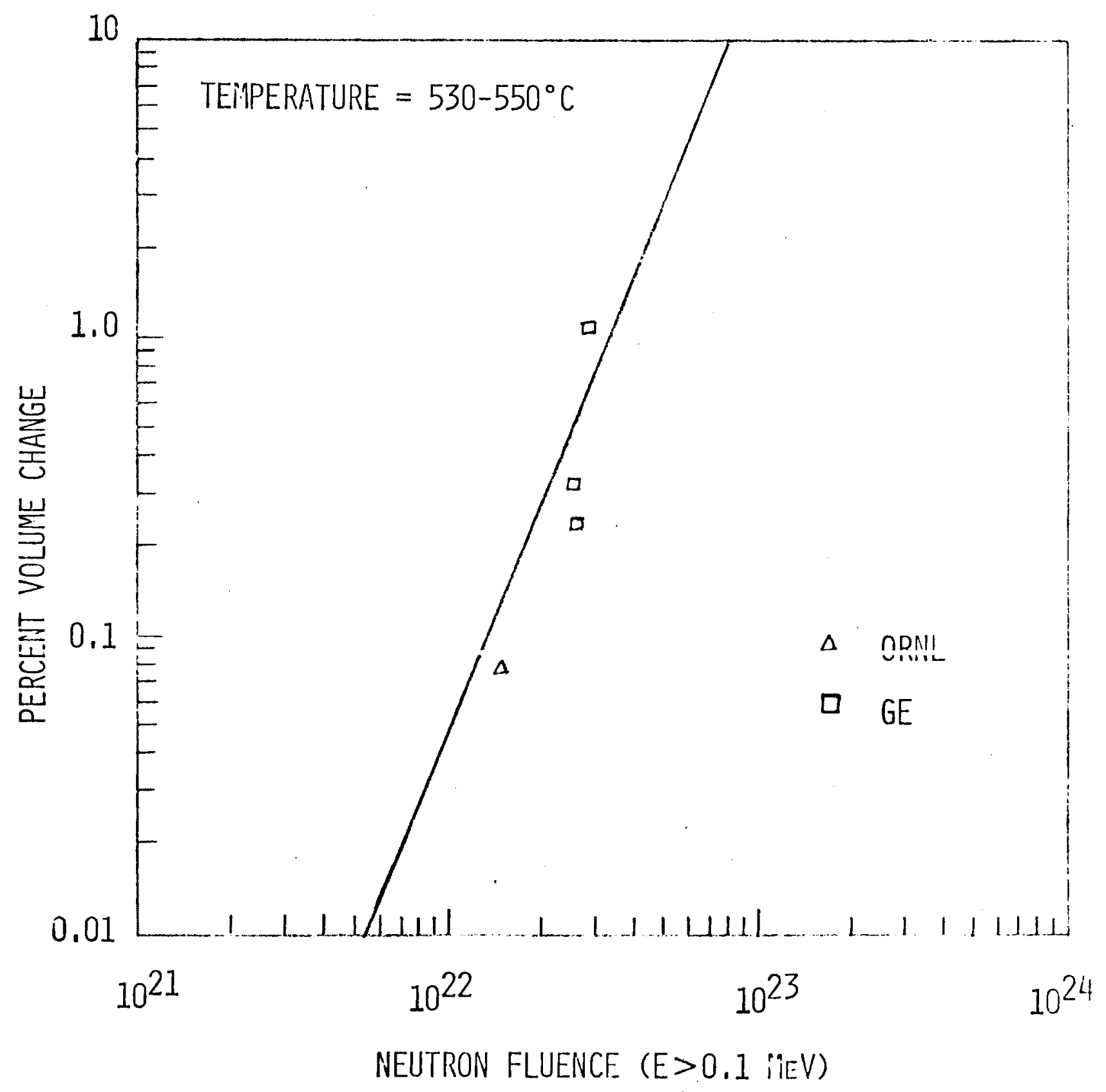

Figure 1.2.2-3 Swelling vs Fluence in Annealed 304 Stainless Steel 
power law. (3) The expression is of the form

$$
\begin{aligned}
\% \Delta V / V & =A[\phi t-2 A \tanh (\phi t / 2 A)] \\
A & =3.79 \times 10^{11} \varepsilon^{-36000} / \mathrm{RT} \\
T & =\text { temperature in }{ }^{\circ} \mathrm{K}
\end{aligned}
$$

At high fluences:

$$
\% \Delta V / V \rightarrow A[\phi t-2 A]
$$

The fit of this equation to the data is shown in Figure $1.2 .2-4^{(3)}$ for three temperature regimes. Both equations 1 and 2 are plotted. Within certain fluence ranges, both equations give a good fit to the data. Extrapolating to higher fluences will give much different results, however, depending on whether a linear or power law relationship is used.

The British have fitted their data for 316 stainless steel to a linear expression with an initial induction period. The expression is of the form

$$
\% \Delta V / V_{0}=A\left[\phi t-\phi t_{0}\right]
$$

where $A$ and $\phi t_{0}$ are constants.

The British have fitted this equation to U.S. 304 data and claim as good a fit as a power law relationship. (4)

U.S. workers at HEDL have fitted data from S.T. 316 to a power law relationship similar to equation (1). ${ }^{(5)}$ The expression for S.T. 316 is of the form:

$$
\begin{gathered}
\% \Delta V / V=\left(\frac{\phi t}{10^{22}}\right)^{N(T)} F(T) \\
N(T)=\frac{2+3 \exp [0.05(T-475)]}{1+\exp [0.05(T-475)]} \\
F(T)=\frac{\exp [0.09(T-340)]}{1+\exp [0.09(T-340)]}\left\{\frac{0.022}{1+\exp [.05(T-600)}+\frac{.06}{1+\exp [.06(T-40)]}\right\}
\end{gathered}
$$




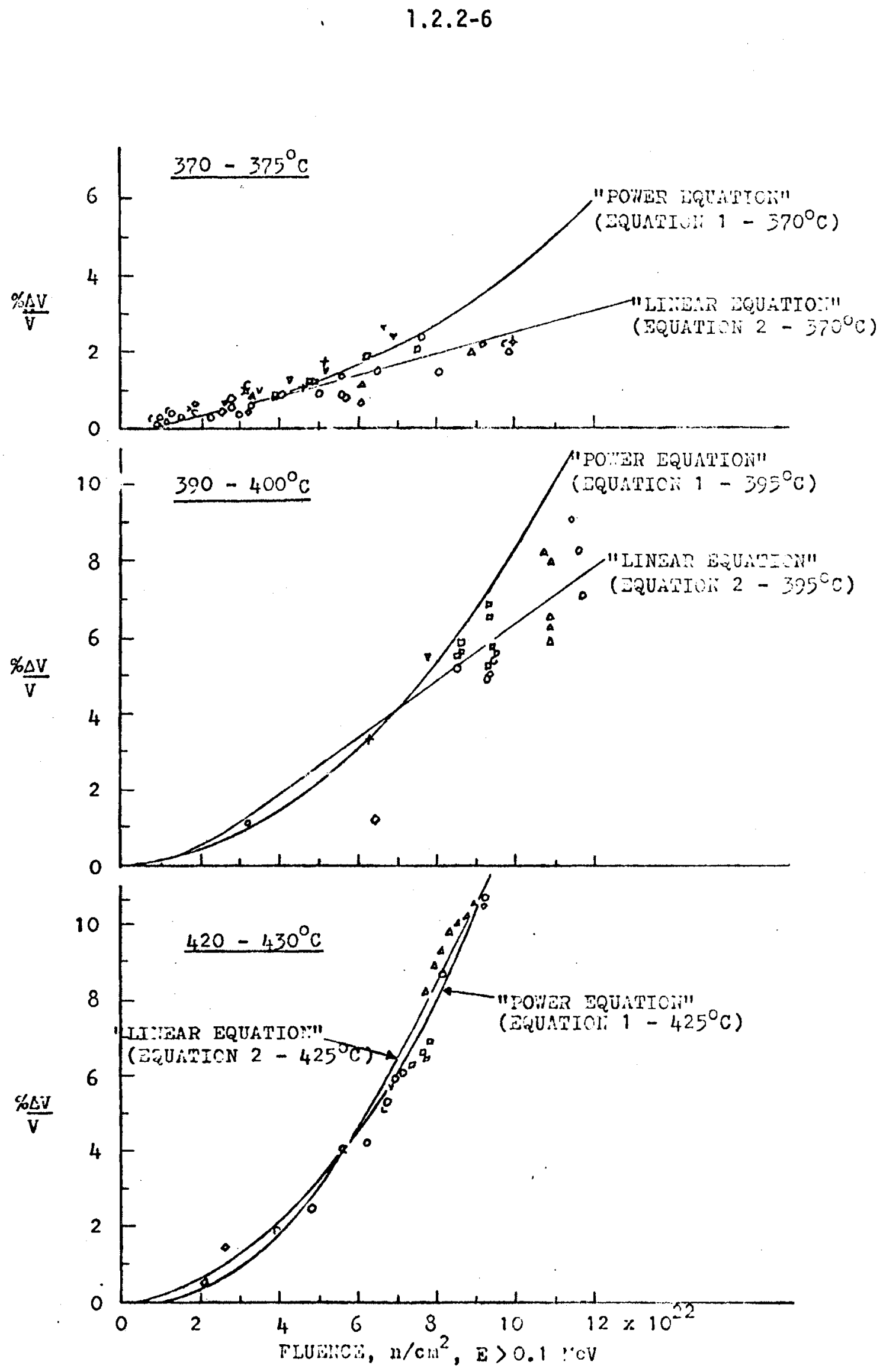

Figure 1.2:2-4 Fluence Dependence of Swelling in Thimble Material for Different Temperature Ranges 
The fit of the data to this equation is shown in Figure 1.2.2-5 for several temperature regimes. (5) No attempt has yet been made to fit the 316 U.S. data to a linear expression. With the acquisition of more data, a satisfactory linear fit may emerge as was the case in the 304 .

Workers at GE-BRDO have used a power law relationship for swelling for both 304,321 , and 316 stainless steel. ${ }^{(6)}$ For 304 , swelling is given by

$$
\% \Delta V / V=(\phi t)^{1.57} \exp \left(-35.01+\frac{2.968 \times 10^{4}}{T}-\frac{6.567 \times 10^{6}}{T^{2}}\right) .
$$

and for 321 and cold worked 316

$$
\% \Delta V / V=8.9 \times 10^{-2}(\phi t)^{1.5} \exp \left(-3.14+\frac{5.04}{T}-\frac{1.66 \times 10^{6}}{T^{2}}\right)
$$

where $\phi t=$ fluence $\times 10^{-22} \mathrm{n} / \mathrm{cm}^{2}$

$$
T=\text { temperature in degrees centigrade. }
$$

The analys is used to derive these equations did not consider the recent high fluence data on 304 (up to $1.5 \times 10^{23} \mathrm{n} / \mathrm{cm}^{2}$ ).

It is plainly evident from the rather large spread in the data that either a power law or linear expression could be fitted to the data within a certain fluence region. Some work has shown that when only data for which the temperature is known accurately is used, the exponent is closer to one rather than 2 to 3 . Other investigators predict a decrease in the exponent with increasing fluence. In addition, experiments on pure metals generally show either a linear dependence on fluence with eventual saturation or a gradually decreasing exponent with increasing fluence. The trend in the analyses indicate that an exponent near one or a linear dependence of swelling on fluence may give the best fit to the data particularly at high fluences. Equation ( 1 ) is expected to be modified along these lines as more data is acquired.

For S.T. 316, equation (4) is currently being used to predict nominal swelling values. Recent work by HEDL on the microscopic 


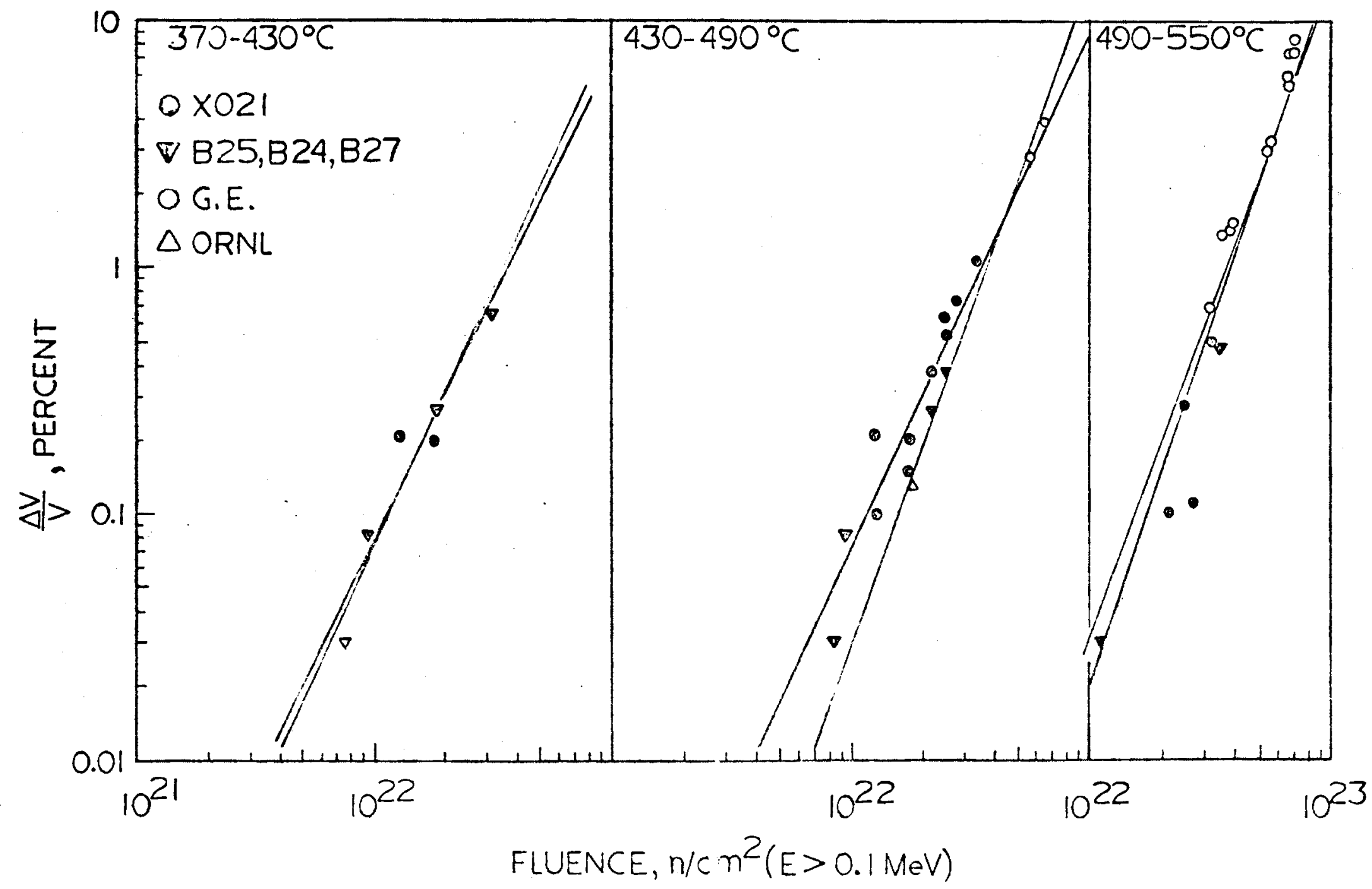

-
$i$
1

Figure 1.2.2-5 Swelling in Solution Treated Type 316 Stainless Steel 
analysis of void formation in 316 has resulted in a different expression for void swelling. (7) The equation is

$$
\% \Delta V / V=\frac{\pi}{6} \times 10^{-9} \cdot K(T)\left[(\phi t)^{D(T)} \exp E(T)\right]
$$

where $K(T)=.48+0.2 \times 10^{-4}$ for $T<873$

$$
=1.28 \text { for } T>873
$$

$$
\begin{aligned}
& D(T)=0.72+[1.7 /\{1+\exp 0.04(700-T)\}] \\
& E(T)=49.46-0.02432 T-9440 / T
\end{aligned}
$$

$\mathrm{T}=$ temperature in ${ }^{\circ} \mathrm{K}$

$\phi t=$ neutron fluence in units of $10^{22} \mathrm{n} / \mathrm{cm}^{2}\left(\begin{array}{ll}E & 0.1 \mathrm{MeV}\end{array}\right)$

This equation is plotted in Figure 1.2.2-6 as a function of neutron fluence. ${ }^{(7)}$ As yet there has been no attempt at reconciling this equation with the earlier equation (4).

Lack of high fluence data $\left(>1 \times 10^{23} \mathrm{n} / \mathrm{cm}^{2}\right)$ particularly in 316 has precluded accurate predictions of swelling. Systematic studies of swelling as a function of temperature and fluence are lacking since much of the data comes from reactor components. Data must be reported in terms of temperature ranges and fluence ranges. At the present time, equation (1) for S.T. 304 and equation (4) for S.T. 316 are being used for swelling predictions within the restrictions of the data. As more data is acquired and data gaps are filled, modifications of the existing relationships can be expected.

Although data from ion bombardment studies is not being used for design purposes, a brief discussion of some of the important results does shed some light on the swelling problem, particularly saturation.

Bombardment with high energy ions and electrons is presently used to simulate the damage produced by neutrons. The results from ion bombardment are not used in design equations, but they can be used to forecast, at least qualitatively, swelling behavior at very high fluences. The results from ion bombardment experiments are plotted for S.T. 316 in Figure 1.2.2-7 and 1.2.2-8, and for S.T. 304 in Figure 1.2.2-9. Some of the curves previously shown in Figures 1.2.2-3 


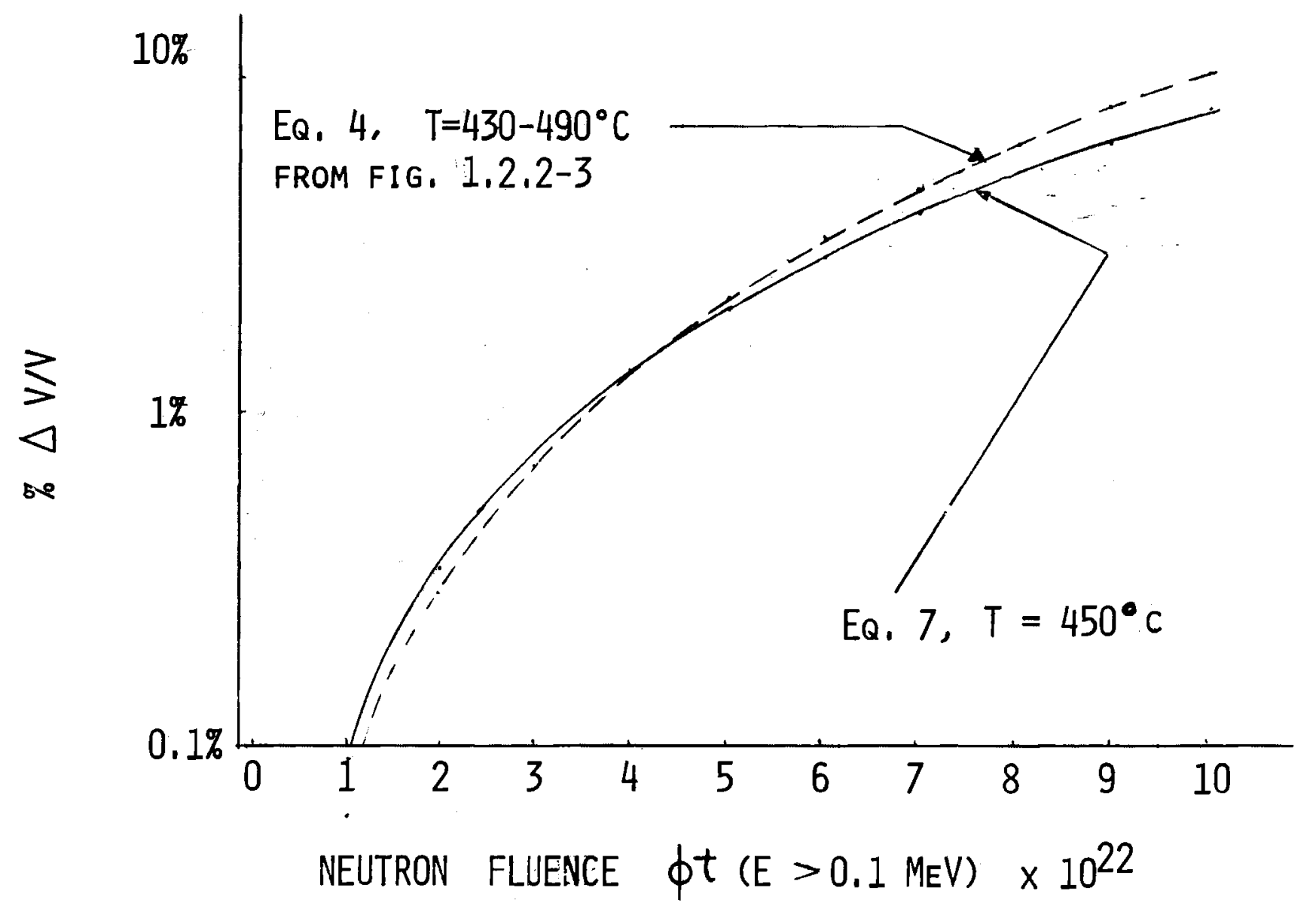

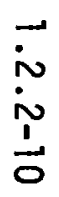

$\frac{N}{v}$

Figure 1.2.2-o Plot of Void Volume (Swelling) vs Neutron Fluence
for S.T. 316 , Equation (7) versus Equation (4) 


\subsection{2-11}

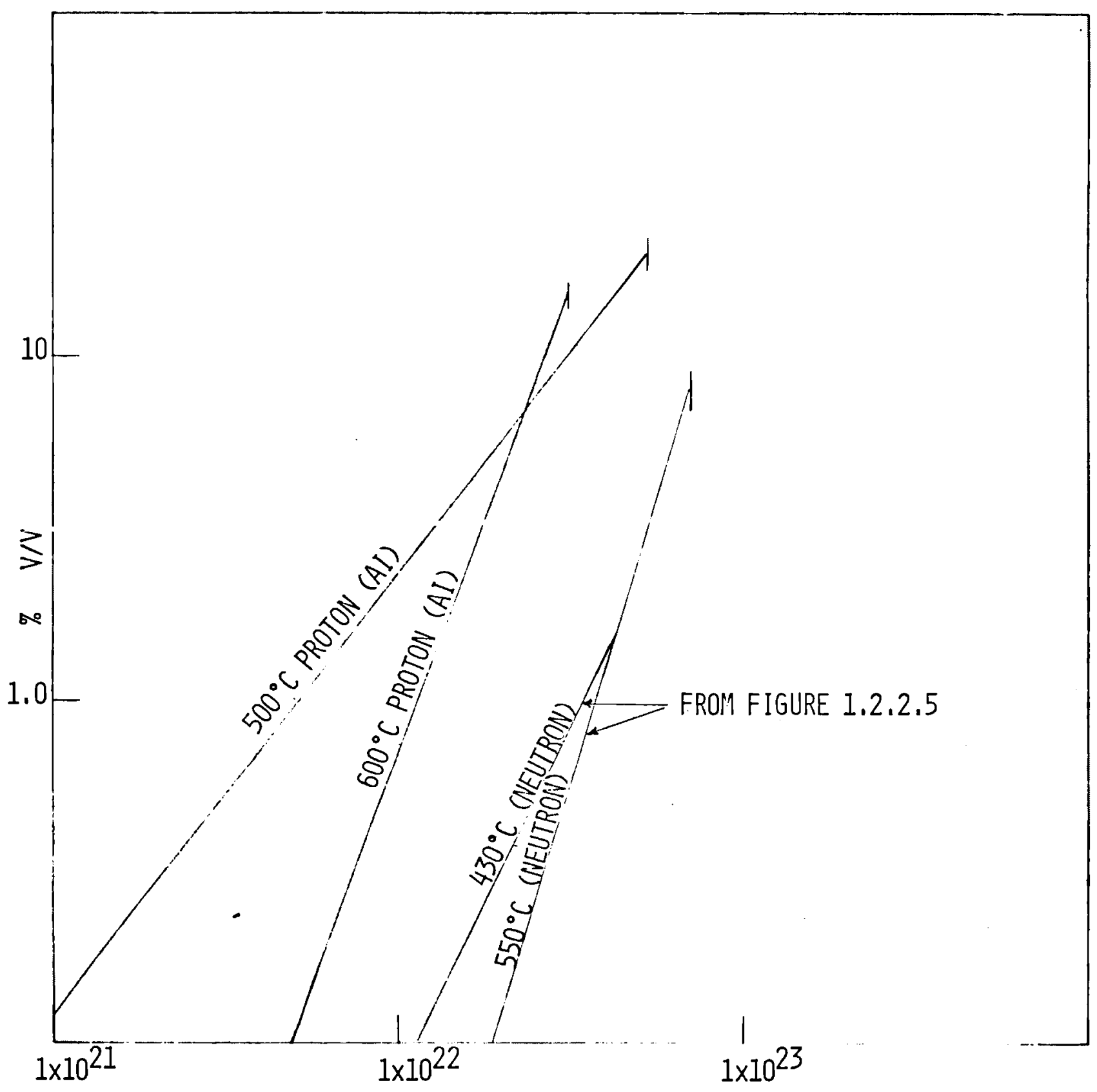

EQUIVALENT NEUTRON FLUENCE $\left(\mathrm{N} / \mathrm{CM}^{2}\right)$

Figure 1.2.2-7 Swelling vs Dose for 316 Stainless Stee1 Bombarded with Energetic Particles and Ions as Indicated. 


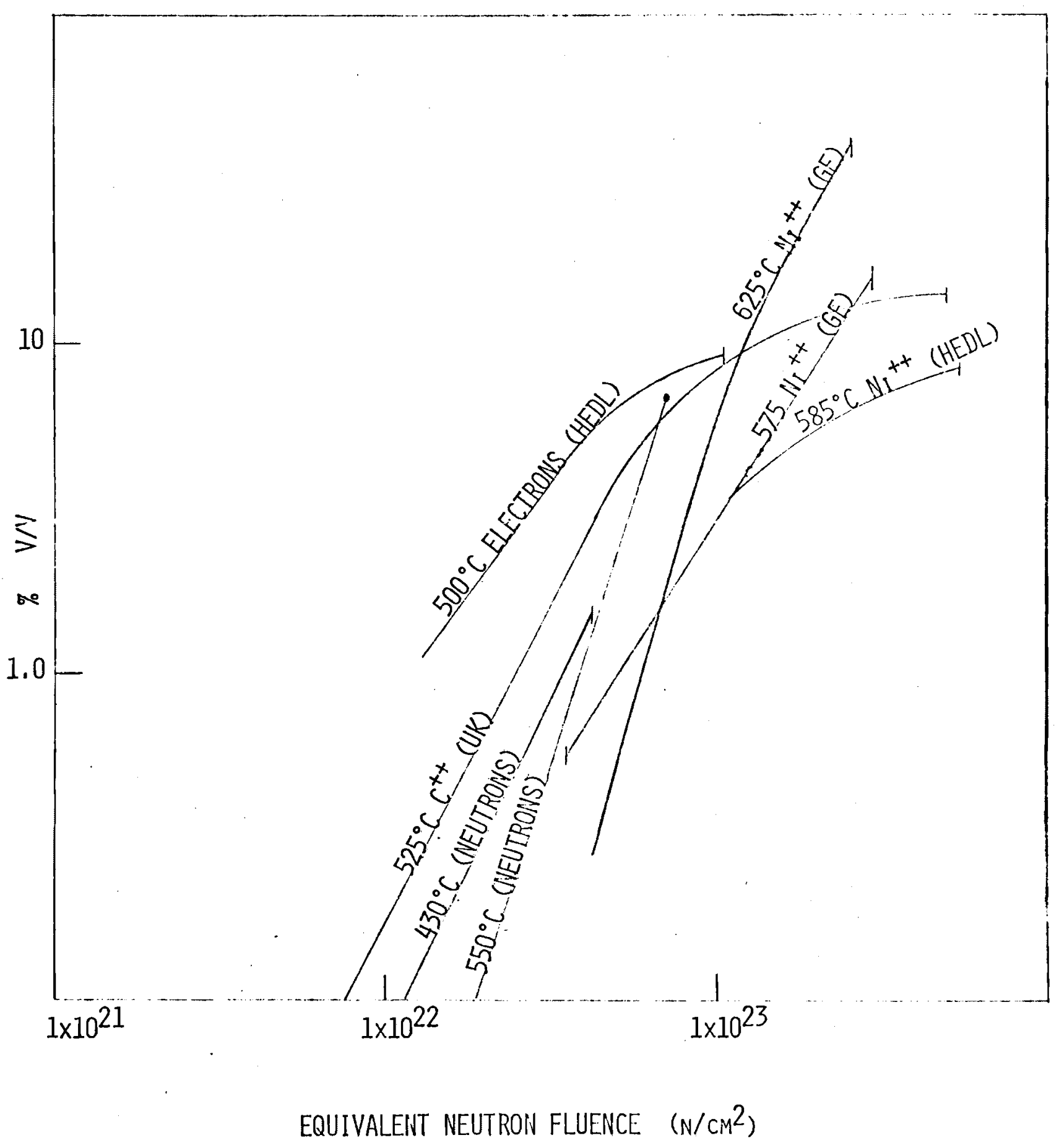

Figure 1.2.2-8 Swelling Vs Dose for 316 Stainless Steel Bombarded with Energetic Particles and Ions As Indicated. 


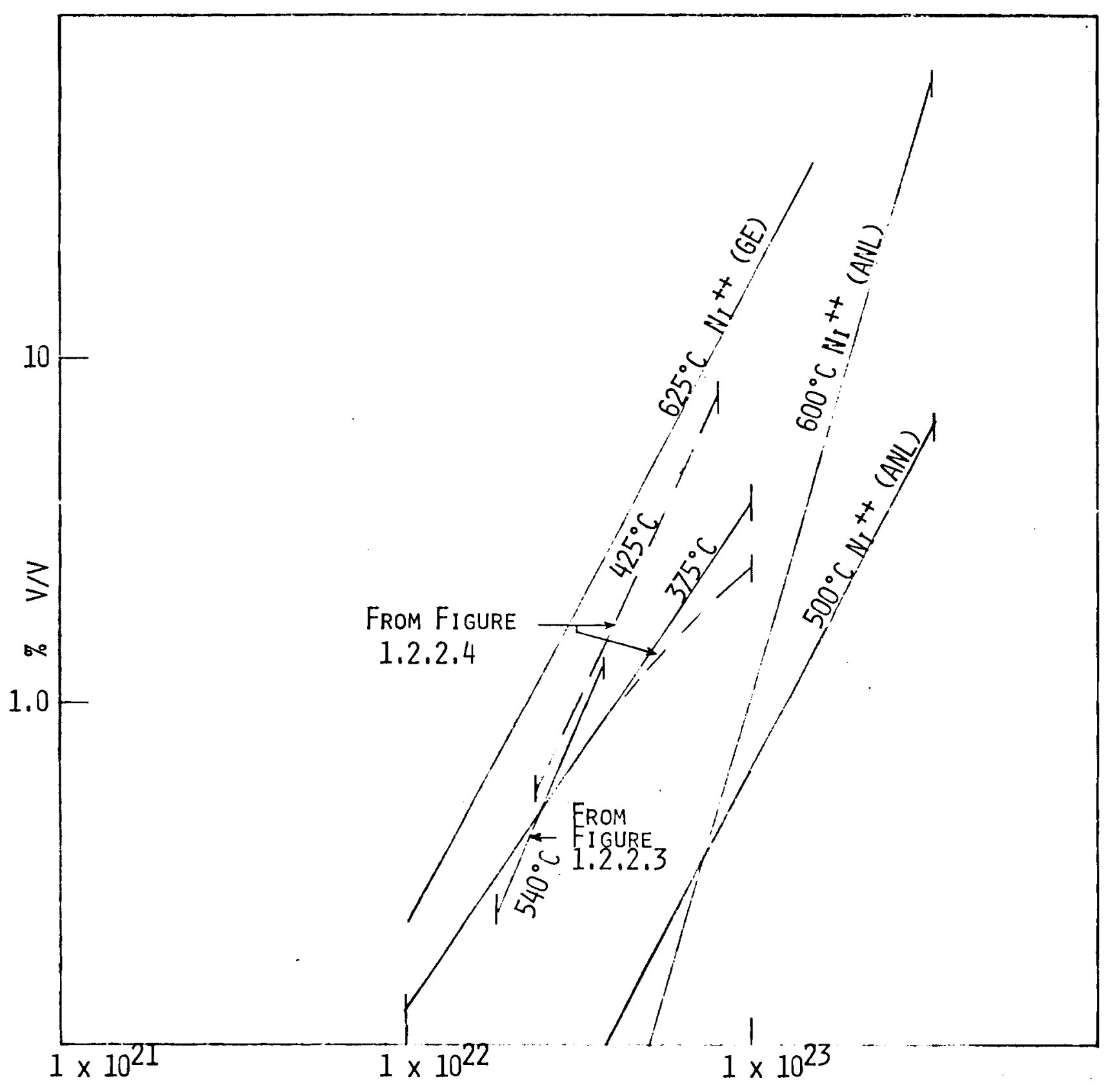

EQUIVALENT NEUTRON FLUEIICE N/CM ${ }^{2}$

Figure 1.2.2-9 Swelling vs Dose for 304 Stainless Stee1, Bombarded with Energetic Particles and Ions as Indicated. 
and 1.2.2-5 for neutron irradiation are also plotted for comparison. Ion and electron damage is generally expressed as atom displacements (dpa). In the figures, $80 \mathrm{dpa}$ is equivalent to about $1 \times 10^{23} \mathrm{n} / \mathrm{cm}^{2}$ ( $\mathrm{E}>0.1 \mathrm{MeV}$ ). It must also be noted that due to the very high dose rates in ion bombardment, there is a temperature shift and $525{ }^{\circ} \mathrm{C}$ i on bombardment is about equivalent to $400{ }^{\circ} \mathrm{C}$ neutron bombardment in EBR-II.

The results vary widely among the different investigations. The one important factor from a design standpoint is whether saturation is attained at very high fluences. There is some evidence that the swelling is saturating in S.T. 316 at damage levels corresponding to greater than $1 \times 10^{23} \mathrm{n} / \mathrm{cm}^{2}$. This has been observed by the British using $\mathrm{C}^{++}$ion and by HEDL using $\mathrm{Ni}^{++}$ions and electrons. However, workers at G.E.-Schenectady, A.I., and ANL did not see any trend towards saturation in 316 or 304 . Therefore, there is still some dispute as to whether saturation occurs. It is quite likely that the trend towards saturation is a low temperature phenomena. At temperatures at or above the maximum swelling, saturation may not occur. 


\section{REFERENCES}

1. J. F. Bates and J. L. Straalsund, "An Empirical Representation of Irradiation-Induced Swelling of Solution-Treated Type 304 Stainless Steel," Nuclear Technology, Vol. 14, 292-298 (1972).

2. "Quarterly Progress Report - Irradiation Effects on Reactor Structural Materials, Aug., Sept., 0ct., 1971," HEDL-TME-71-161, Nov. 1971, p. 1 of "Special Report."

3. R. C. Fish, J. L. Straalsund, C. W. Hunter, and J. J. Holmes, "Swelling and Tensile Property Evaluation of High Fluence EBR-II Thimbles," HEDL-SA-321.

4. K. Q. Bagley, J. I. Bramman, and C. Cawthorne, in Proc. of BNES Conf. on Voids Formed by Irradiation of Reactor Materials, pg. 1, pub. by AERE, Harwe11, 1971 .

5. J. F. Bates and J. L. Straalsund, "A Compilation of Data and Empirical Representation of Irradiation Induced Swelling of S.T. Types 314 and 316 Stainless Stee1s," HEDL-TME-71-139.

6. W. K. Appleby, "Evaluation of Cladding Alloy Swelling at High Fluences," G.E.-13737, February, 1972.

7. H. R. Brager and J. L. Straals und, "Defect Development in Neutron Irradiated Type 316 Stainless Stee1," HEDL-72-108. 


\subsubsection{Temperature}

There are some basic conclusions that have been established concerning the temperature dependence of swelling. There is a minimum and a maximum temperature outside of which voids are not observed and hence swelling does not occur. These minimum and maximum temperatures are dependent on the fluence, but bracket the temperature range between 0.3 and 0.55 of the absolute melting temperature. There is also a temperature at which the swelling attains a maximum. This maximum is very broad, and significant swelling can occur over a temperature range of approximately $150^{\circ} \mathrm{C}\left(270^{\circ} \mathrm{F}\right)$.

The parametric relationships between swelling, fluence and temeprature which were presented in section 1.2.2 can also be used to show the influence of temperature in swelling. Equations 1 and 4 in section 1.2.2 have been used to plot swelling as a function of temperature for a constant fluence. (1) Figure 1.2.3-1 shows the volume change as a function of temperature for S.T. 304 and S.T. 316 stainless steels for several different fluences. (1) The curves show that the temperature regime for void formation is somewhat higher in type 316 than in type 304 . The temperature of maximum swelling also shifts to slightly higher temperatures with increase in fluence particularly in the 304. These curves are no better than the parametric equation from which they are drawn; however, they do show the general temperature range over which swelling will be a significant problem. The temperature dependence of cold work type 304 and type 316 is discussed in a later section.

The vast majority of the data have been acquired from the temperature frange $370-470{ }^{\circ} \mathrm{C}$. There is a general lack of data above $550^{\circ} \mathrm{C}$. Workers at G.E. have irradiated S.T. 304 to high temperatures and the effect of temperature on swelling is shown in Figure 1.2.3-2. (2) The bel1-shaped curve is similar to Figure 1.2.3-1. A different equation was used to normalize the fluence values, therefore, the exact values cannot be equated with Figure 1.2.3-1. 


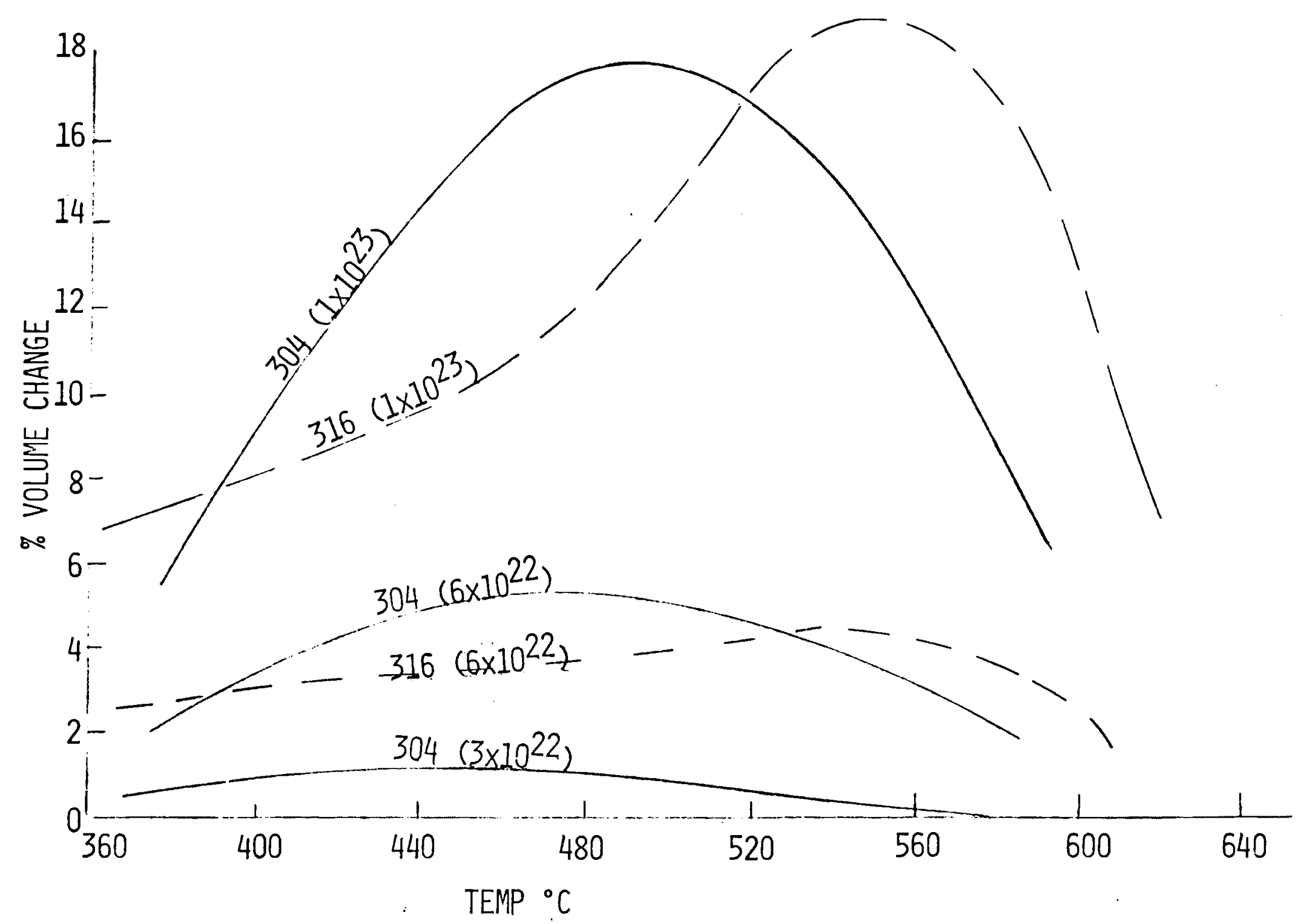

Figure 1.2.3-1 Temperature Dependence of Swelling Based on Equation (1) for 304 and Equation (4) for 316 in Section 1.2.2. 


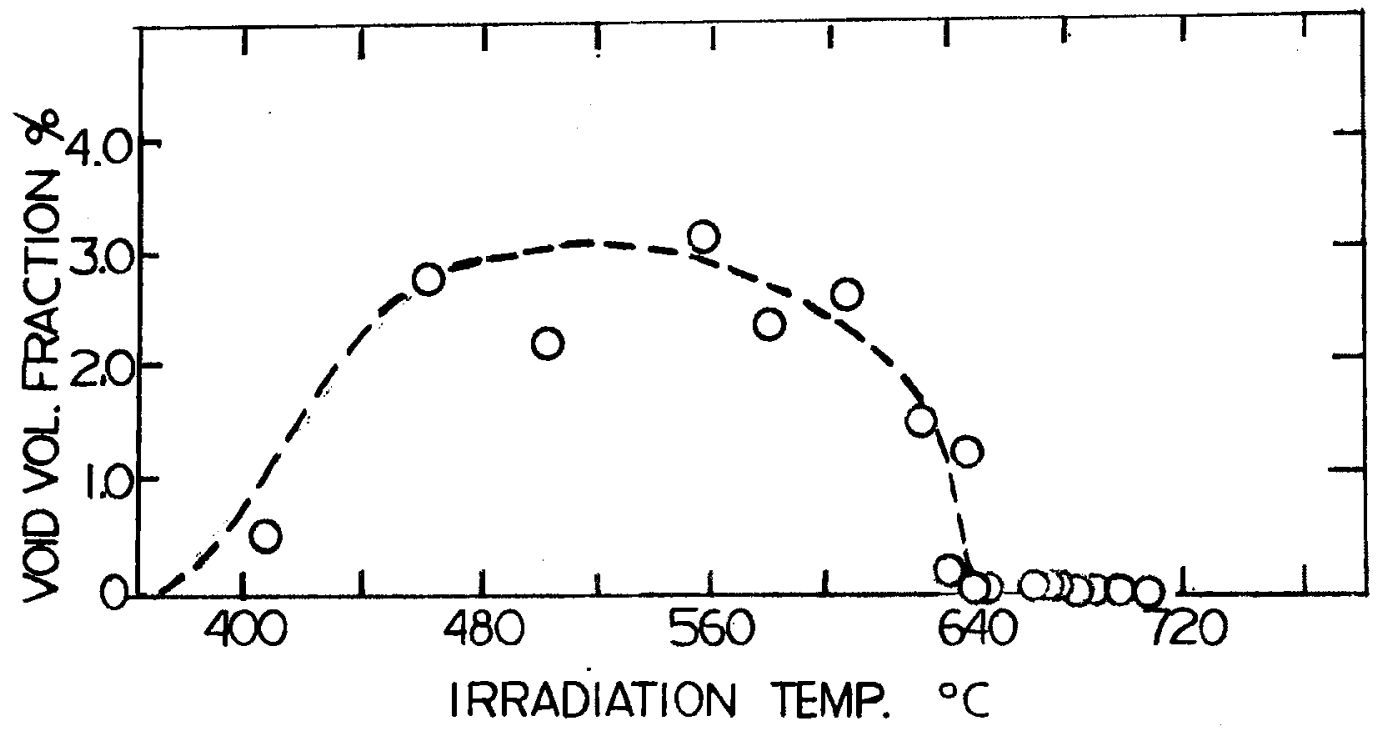

Figure 1.2.3-2 Relation between void volume fraction and temperature in irradiated type-304 stainless steel (normalized* to a neutron fluence of $5 \times 10^{22} \mathrm{n} / \mathrm{cm}^{2}, E>0.1 \mathrm{MeV}$ ). *Volume fraction has been normalized to a neutron fluence of $5 \times 10^{22}$ neutrons $/ \mathrm{cm}^{2}$, E $0.1 \mathrm{MeV}$ by multiplying each value by a factor of $(5.0 / F) 7.81$ where $F$ is fluence $\times 1 .-22$ neutrons $/ \mathrm{cm}^{2}, E$ o.1 MeV. The fluence exponent 1.81 is the result of fitting swelling data to an empirical equation which relates swelling to neutron fluence and irradiation temperature. 


\section{$1.2 .3-4$}

\section{REFERENCES}

1. J. F. Bates and J. L. Straals und, "A Compilation of Data and Empirical Representation of Irradiation Induced Swelling of Solution Treated Types 304 and 316 Stainless Stee1," Nucl. Tech., 14, 292298 (1972). HEDL-TME-71-139.

2. D. W. Sandusky, C. N. Spalaris, and U. E. Wolff, "Irradiation Temperature Dependence of Void Formation in Type 304 Stainless Stee 1," J. Nucl. Mat., 42, 133-141 (1972). 


\section{$1.3 .1-1$}

\subsection{OTHER FACTORS INFLUENCING SWELLING}

\subsubsection{Introduction}

The other factors influencing swelling can be broadly classified as those resulting from reactor variables and those resulting from material variables.

Reactor variables that have been observed to influence swelling (beyond those already discussed in section 1.2) are those associated with the production of neutrons: the flux (or dose rate, $\mathrm{n} / \mathrm{cm}^{2} / \mathrm{sec}$ ); the spectrum of neutron energies; and, as a by-product of nuclear bombardment, the amount of helium generated by nuclear transformations ( $\mathrm{n} / \mathrm{a}$ reactions).

Material variables that have been observed to influence swelling are alloy composition and microstructure. Since these are often intimately connnected (to produce precipitation, for example) they will be considered together. Those microstructural features that have been introduced during processing, such as cold work, will be considered separately. 


\section{$1.3 .2 .1-1$}

1.3.2 Effect of Reactor Variables

\subsubsection{Effect of Flux (Dose Rate)}

The rate at which a metal is bombarded by neutrons (i.e., the flux or dose rate) determines the rate of vacancy and interstitial production. In general, the higher the flux, the greater the void density ${ }^{(1)}$ with a shift in the peak of the swelling versus temperature curve to higher temperatures. (2) Some theoretical analyses have predicted an increase in void volume when the flux is changed from $2 \times 10^{14} \mathrm{n} / \mathrm{cm}^{2}-\mathrm{sec}$ to $2 \times 10^{15} \mathrm{n} / \mathrm{cm}^{2}-\mathrm{sec}$ at $600{ }^{\circ} \mathrm{C}$. (3) However, flux effects appear to be of primary concern only when one is attempting to correlate data between the various ion bombardment simulation experiments and neutron irradiation experiments. (Ion bombardment of metals is being studied because the high dose rates, $10^{3}$ greater than neutron fluxes, allow faster data generation.) Careful analysis has indicated that for representative fast reactors, such as EBR-II, DFR, and FFTF, no significant engineering differences are to be expected from flux effects. 


\section{$1.3 .2 .1-2$}

\section{REFERENCES}

1. D. W. Keefer, A. G. Pard, and D. Kramer in CONF-710601.

2. T. M. Williams, in Proc. of BNES Conf. on Voids in Reactor Materials, Reading University, March, 1971, p. 205.

3. Quarterly Progress Report, Irradiation Effects on Reactor Structural Materials, Nov., Dec., 1969 - January, 1970, BNWL-1318, p. 4-1. 


\subsubsection{Effect of Spectrum}

Neutrons generated from fuel burnup

have a spectrum of energies. The "damage" produced by a given neutron spectrum (i.e., the number of vacancies and interstitials) is proportional to the average energy of the neutron flux. The higher the average energy (i.e., the "harder" the spectrum), the greater is the damage, and, thus, the greater is the potential swelling. (1) There are significant spectrum differences between fast reactors, and these differences must be considered when extrapolating data. Various theoretical models indicate, for example, that the FFTF environment is only 50 to $68 \%$ as "damaging" for a given fluence as is that of EBR-II (from which most of the U.S. irradiation experiments come).

Workers at HEDL have developed damage functions which relate the energy of a neutron to $i$ ts effectiveness in causing a specific property change. (2) The damage function to produce $1 \%$ swelling in S.T. 304 irradiated at $450{ }^{\circ} \mathrm{C}$, is shown in Figure 1.3.2.2-1 as a function of neutron energy. ${ }^{(2)}$ Not only will the effectiveness of the spectra vary from EBR-II to FTR, but there will be differences within different parts of the reactor core. In the EBR-II core center $(\bar{E}$ of neutron $=0.82 \mathrm{MeV}) 2.9 \times 10^{22} \mathrm{n} / \mathrm{cm}^{2}$ wi 11 produce approximately $1 \%$ swelling whereas in the upper blanket ( $E$ of neutron $=$ $0.29 \mathrm{MeV})$, it takes $5 \times 10^{22} \mathrm{n} / \mathrm{cm}^{2}$ to produce this swelling. In the FTR, $4.1 \times 10^{22} \mathrm{n} / \mathrm{cm}^{2}$ at core center and $8 \times 10^{22} \mathrm{n} / \mathrm{cm}^{2}$ at core edge, respectively, are required to produce $1 \%$ swelling. 


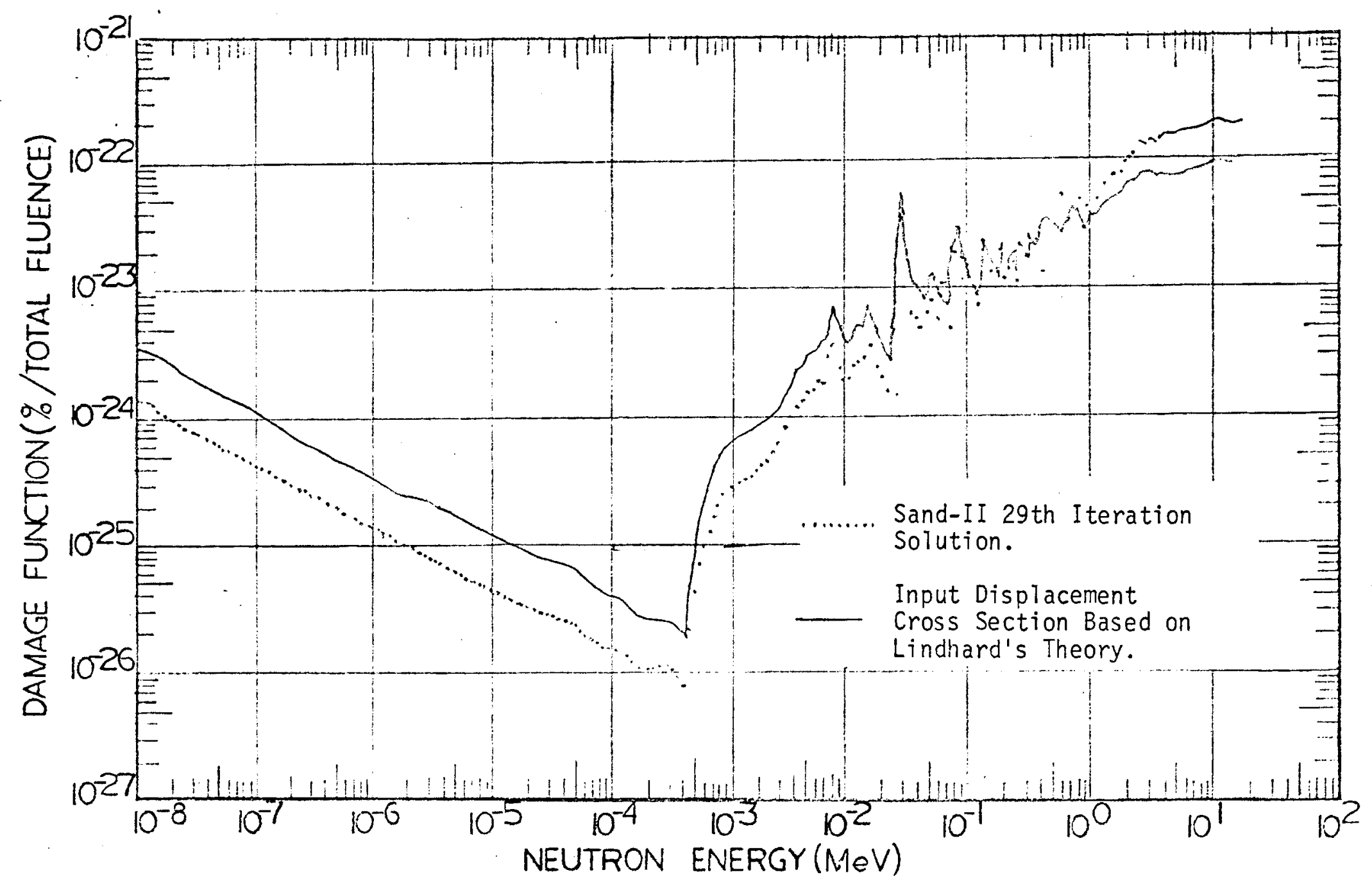

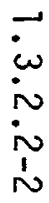

Figure 1.3.2.2-1 Damage Function for 1.0\% Swelling in Annealed SS 304 Irradiated at $450{ }^{\circ} \mathrm{C}$. 


\section{$1.3 .2 .2-3$}

\section{REFERENCES}

1. T. T. Clauds on, HEDL-TME-71-53, p. 4.3

2. W. D. McElroy, R. L. Simmons, D. G. Doran, and J. L. Straalsund, Trans. ANS, 15, 24a (1972). 


\section{$1.3 .2 \cdot 3-1$}

\subsubsection{Effect of Helium Production}

There is evidence that void nucleation

is influenced by the helium gas produced by nuclear transformations (e.g., ${ }^{59} \mathrm{Ni}+n \rightarrow{ }^{56} \mathrm{Fe}+{ }^{4} \mathrm{He}$ ). Hydrogen, which is also produced, diffuses out too rapidly to be of interest. The concept is that a few ppm of helium gas atoms may stabilize a nucleating void against collapse back into a vacancy loop. (1) The effect of helium, then, would be to increase void concentration.

Experiments on type 304 stainless stee 1 have compared material that was pre-injected with $20 \times 10^{-6}$ atom fraction of helium and subsequently irradiated $\left(390{ }^{\circ} \mathrm{C}\right.$ to $7.4 \times 10^{21} \mathrm{n} / \mathrm{cm}^{2} \mathrm{E}>0.1$ $\mathrm{MeV}$ ) with material irradiated without pre-injection. The pre-injected material contained a higher concentration of voids (by at least a factor of 2) and a smaller void size $(60 \AA$ versus $130 \AA$ ) than the non-injected material. (2) Other work has shown no correlation between overall swelling and helium content ${ }^{(3)}$ which $i m p l i e s$ that the increased void concentration due to helium is offset by the smaller void size.

The amount of helium produced in stainless steel irradiated in various fast reactor spectra is shown in Figure 1.3.2.3-1.4) Extrapolating to a maximum fluence of $1 \times 10^{24}$ $\mathrm{n} / \mathrm{cm}^{2}$, the EBR-II core would produce about $300 \mathrm{ppm} \mathrm{He}$ and the hardest spectrum in FTR would produce about $150 \mathrm{ppm} \mathrm{He.} \mathrm{It} \mathrm{is} \mathrm{expected} \mathrm{that} \mathrm{the}$ variation in the amount of helium due to different positions in the reactor will only have a small effect on the total swelling. At fluences where voids are expected, helium will be generated in excess of $1 \mathrm{ppm}$ He and this is all that is necessary to affect void nucleation. The effect of helium on swelling is therefore felt early in the irradiation and there will be no additional effects after long term irradiation. This is not to say that continued helium production will not have detrimental effects on other properties such as ductility. 


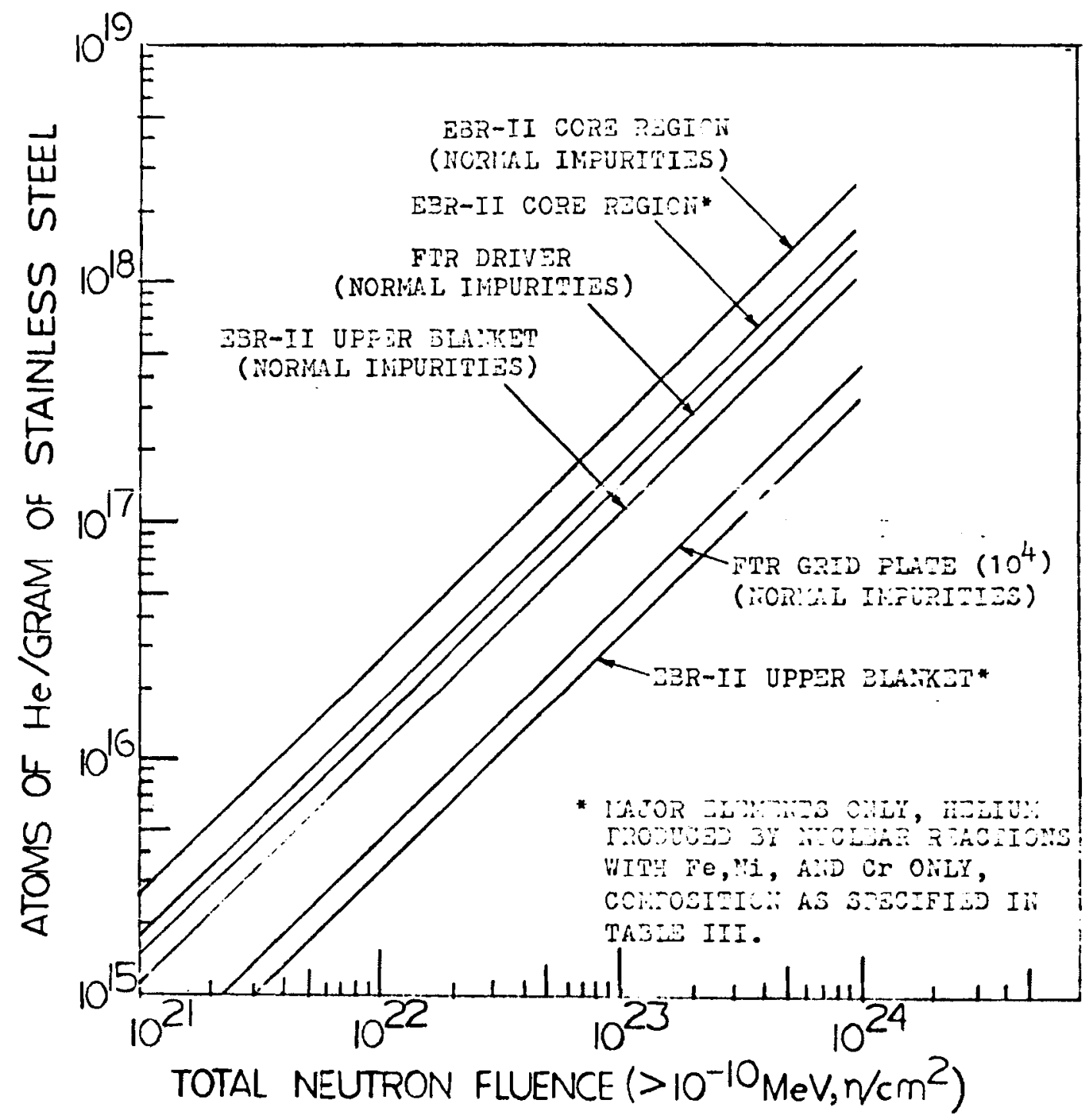

Figure 1.3.2.3-1 Helium Production in SS for Different Reactor Spectra 


\section{$1.3 \cdot 2.3-3$}

\section{REFERENCES}

1. R. Bullough and R. C. Perrin, Radiation Damage in Reactor Material, Vo1. 2, (Vienna I.A.E.A., 1969) p. 233.

2. E. E. Bloom, "An Investigation on Fast Neutron Radiation Damage in an Austenitic Stainless Steel," ORNL-4580, August, 1970, p. 109.

3. F. A. Compre11i, S. $01 \mathrm{dberg}$, D. Sandusky, "Empirical Analysis of Swe11ing in Austenitic Stainless Steel in Fast Reactors," GEAP-13517 (1969).

4. W. N. McElroy, H. Farrar IV, and H. H. Yoshikawa, Quarterly Progress Report, Irradiation Effects on Reactor Structural Materials, May, June, July, 1971, HEDL-TME-71-116, p. HEDL-110-124. 


\section{$1.3 .2 .4-1$}

\subsubsection{Effect of Stress}

Analys is of current data suggest that stress may enhance swelling. Theoretical treatments have shown that void growth will be enhanced by stress. In particular, work at Harwell predicts that 1) the greatest effect occurs in the temperature range beyond the temperature of maximum swelling, 2) the hydrostatic stress only affects voids that exceed a critical size, 3 ) the enhanced swelling effect decreases with increasing dislocation density, and 4) the magnitude of enhanced swelling is sensitive to flux, being greater at lower flux. (1)

\section{Circumstantial evidence for a stress}

effect has mainly come from U.K. fuel pin irradiations in which it was noted that cladding ( $20 \%$ cold worked M316 stainless stee 1 ) showed less tendency to swell opposite fuel-clad interface gaps than elsewhere in the fuel column. The implication is that fuel-swelling stressed the clad except at the gaps, where there was less swelling. (2)

A comparison of design equations, derived for the temperature dependence of swelling of solution-heated steels at a normalized fluence of $5 \times 10^{22} \mathrm{n} / \mathrm{cm}^{2}(E>0.1 \mathrm{MeV})$, with data from the U.K. fuel pin experiments showed that the cold-worked material swelled significantly less than that predicted for S.T. steels at low temperature. This would be expected from the effects on swelling of cold work (see the following section 1.3.3.2). However, at $T \geq 500{ }^{\circ} \mathrm{C}$, swelling in the coldworked material was substantially greater than in the S.T. material. Moreover, at $T \simeq 500{ }^{\circ} \mathrm{C}$, there appeared to be a substantial acceleration in the rate of void growth in the cold worked fuel pin material compared to that for S.T. stainless steels. (3) These data indicate that stressenhanced swelling is an elevated-temperature phenomenon related to accelerated void growth.

Further confirmation of stress-increased swelling appears to be forthcoming. Swelling data was obtained from capsule material (type 304) that was subjected to high internal pressurization, resulting in a large (approximately $12 \%$ ) increase in diameter. This data was compared with a correlation of swelling versus temperature obtained from over 150 data points for S.T. type 304 obtained from 


\section{$1.3 .2 \cdot 4-2$}

unstressed specimens. The analysis showed that while the swelling values of capsule material irradiated at $<500{ }^{\circ} \mathrm{C}$ was within the $95 \%$ confidence band for the unstressed specimens, the swelling of capsule material irradiated at $>500{ }^{\circ} \mathrm{C}$ was substantially greater by a factor of 3 - 4 than the $95 \%$ confidence band. ${ }^{(4)}$

Theoretical calculations indicate that void growth will spontaneously occur in fuel pins even in the absence of vacancy supersaturation, under easily attainable conditions of stress $(17,000 \mathrm{ps} i)$ and initial void size $(1000 \AA) .(5)$ Therefore, void growth should occur at even lower stresses in the presence of an irradiation induced vacancy supersaturation and should increase very markedly with irradiation temperature as discussed above.

Recent analysis of swelling in control rod thimbles from EBR-II suggests a possible large stress effect. ${ }^{(6)}$ Significant bowing of the ducts was expected due to differential swelling across the thimble which in turn is a result of the fluence difference across the thimble. Much less bowing was actually observed than expected. It is possible that as the duct began to swell, the restraint on the duct caused a compressive stress on the high swelling side and a tensile stress on the low swelling side. This stress gradient could produce approximately similar swelling for both sides of the duct. This means that the stress effect would be large over the whole temperature range not just at high temperatures, since these ducts were irradiated in the range $370-450{ }^{\circ} \mathrm{C}$.

At this point in time, it is not possible to make quantitative conclusions as to the effect of stress. The application of a tensile stress does appear to accelerate the swelling particularly at high temperatures. However the relationships between stress, temperature, void size, cold work, etc., are not at all defined. There has yet to be well defined experiments to test the effect of stress on swelling. 


\section{REFERENCES}

1. R. G. Anderson, R. Bullough, and A. J. E. Foreman, "Significance of Applied Stress on the Swelling of Irradiated Metals," AERE-R-6891, 1971.

2. K. Q. Bagley, J. I. Bramman, and C. Cawthorne, "Fast Neutron Induced Voidage in Non-Fissile Metals and Alloys," Conference on Voids Formed by Irradiation of Reactor Materials, Reading, U.K., March, 24-25, 1971, British Nuclear Society, p. 13.

3. T. T. Claudson, Ed., "Material Considerations in Support of the FFTF Preliminary Safety Analyses, Report - RM9, Vol. I," HEDL-TME-71-53, Apri 1, 1971, p. 4.3.2.

4. "Sodi um-Cooled Reactors, Fast Ceramics Reactor Development Program 38th Quarterly Report, February-Apri1, 1971," GEAP-10028-38, June, 1971, p. 11.5.

5. F. A. Compre11i, S. $01 \mathrm{dberg}$ and D. Sandusky, GEAP-13517, 1969, p. 4.35 .

6. R. C. Fish, J. L. Straalsund, C. W. Hunter, and J. J. Holmes, "Swelling and Tensile Property Evaluation of High Fluence EBR-II Thimbles," HEDL-SA-321. 
1.3.3 Effect of Material Variables

1.3.3.1 Effects of Alloy Composition

Sufficient irradiation data has been

obtained to indicate that there exists a marked effect of alloy composition on the magnitude and temperature dependence of swelling even amongst similar alloys such as the aus tenitic stainless steels and nickel-base alloys.

One example of the effect of alloy composition on some austenitic alloys is presented in Figure 1.3.1.1-1. (1) Compared to S.T. type 304 stainless steel, swelling may be greater for essentially all temperatures as in Inconel 800; or the temperature regime for void formation may only shift to higher temperatures as in type 316 and 347 stainless steels. Electron microscopy has indicated that the difference between 304,316 , and 347 stainless steels is that the amount of irradiation-produced intragranular precipitation (probably sigma phase) increases from 304 to 316 to 347; and with this, a corresponding increase in void concentration is observed. The voids are usually associated with the precipitate particles.

In contrast to the above observations, the presence of a high density of very fine, stable precipitates will, in general, reduce swelling. The British alloy Nimonic PE-16 which contains a fine dispersion of $\left(\mathrm{Ni}_{3}{ }^{\mathrm{TiA}} \mathrm{A}\right)$ shows much less swelling than 316 stainless stee1. (2) A comparison of the swelling in these materials induced by ion bombardment is shown in Figure 1.3.3.1-2. (2) Another example is the complete lack of voids in irradiated Inconel 625 . The microstructure of this alloy shows a high desntiy of very fine $\mathrm{Ni}_{3} 3^{\mathrm{Nb}}$ precipitates. ${ }^{\text {( } 3)}$ Therefore, the effect of a precipitate can either reduce or enhance void formation depending on size, type, morphology, and nature of the precipitate-matrix interface.

Much reduced swelling is characteristic of high nickel alloys. Early work showed no swelling in Incone 1-600 compared to pure nicke1, Figure 1.3.3.1-3, ${ }^{(4)}$ although this was at a very low fluence range. The data have been extended to a fluence of 


\subsubsection{1-2}

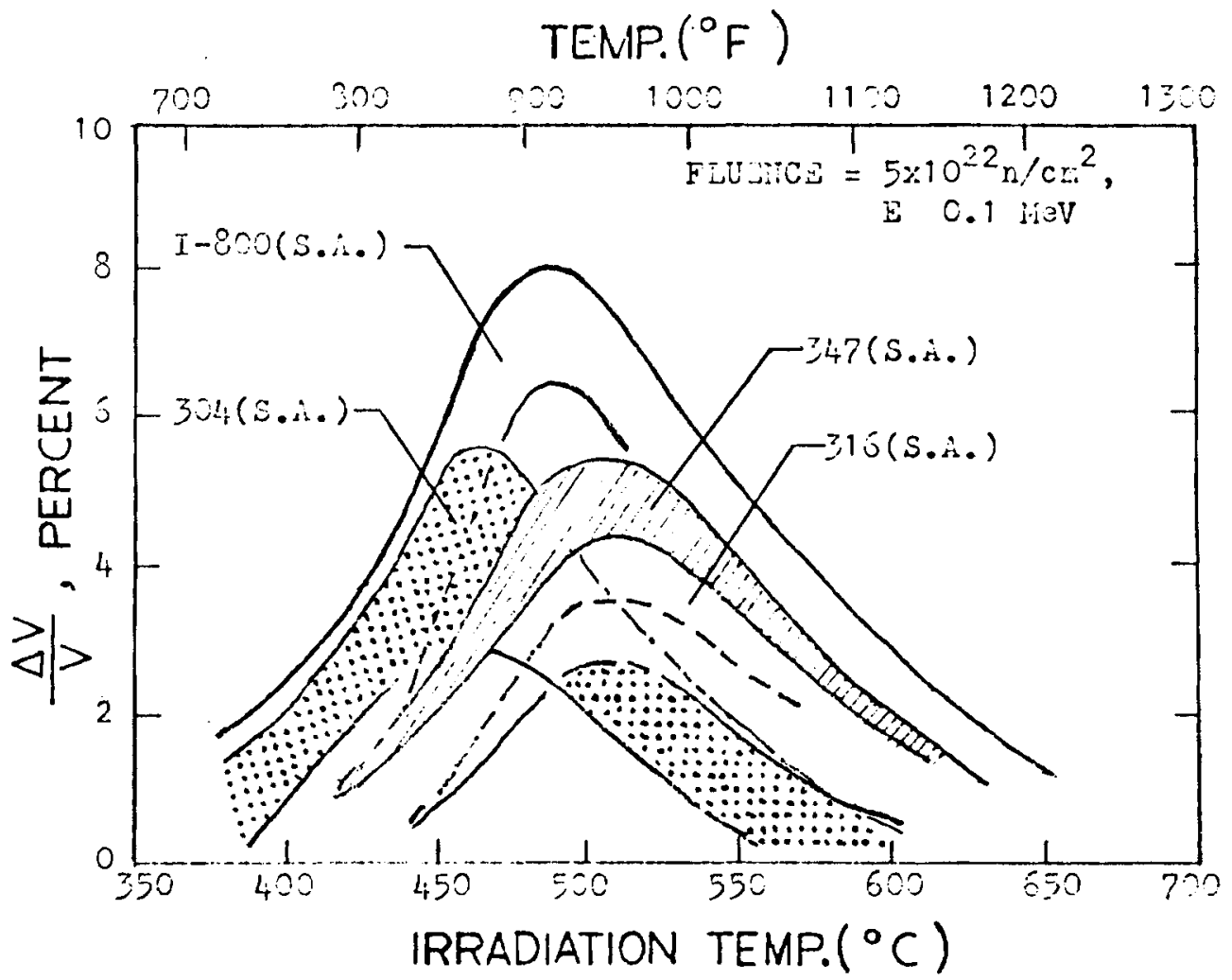

Figure 1.3.3.1-1 Swelling of Various Austenitic Alloys 
TOTAL INTEGRATED FLUX (nvt) IN P.F.R. PITCH I

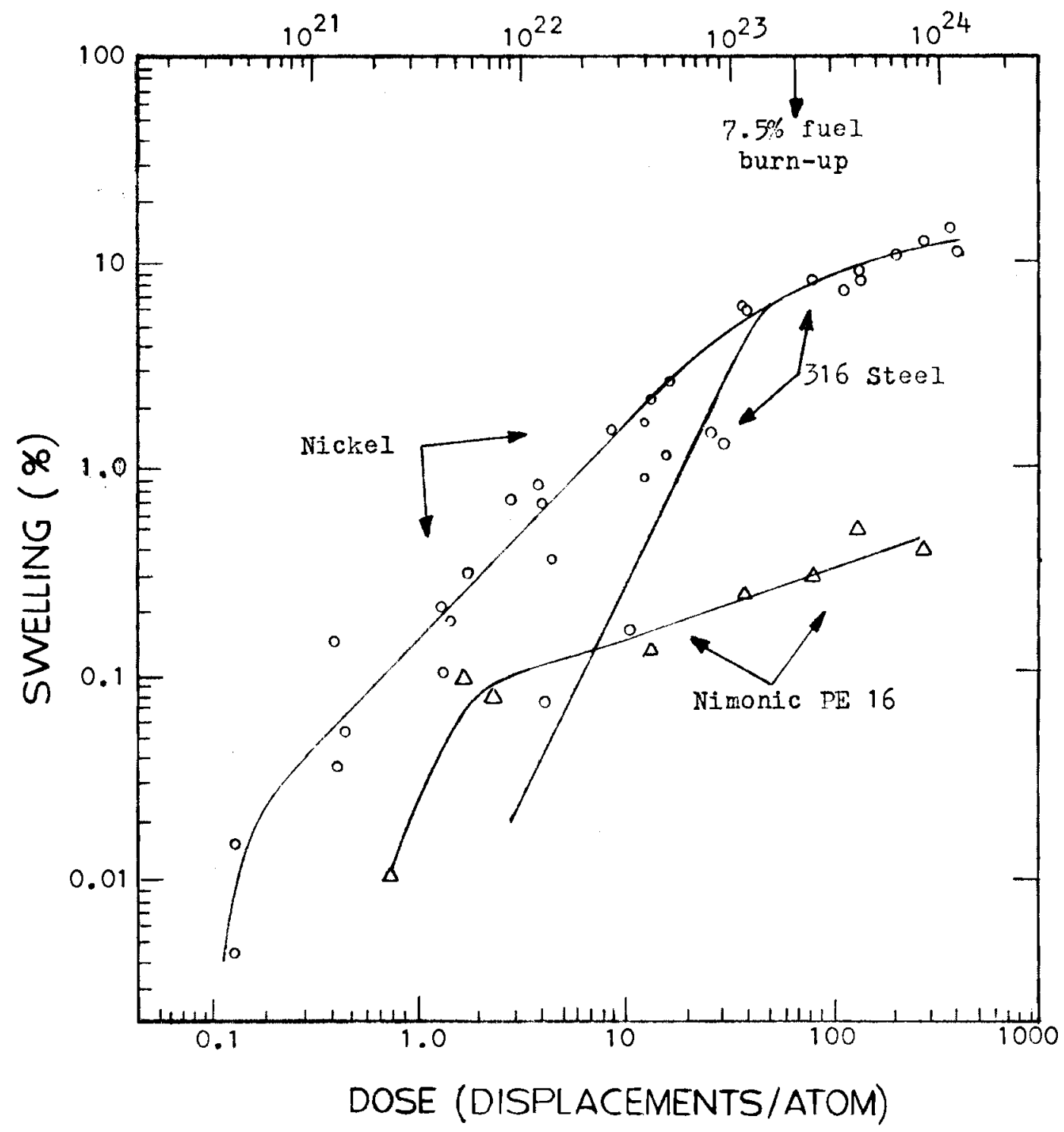

Figure 1.3.3.1-2 Swelling Versus Dose in Nicke1, 316 Stainless Steel+ and Nimonic PE16 at $525^{\circ} \mathrm{C}$ Bombarded with $20 \mathrm{MeV} \mathrm{C}$ Ions at $525{ }^{\circ} \mathrm{C}$ 
$1.3 .3 .1-4$

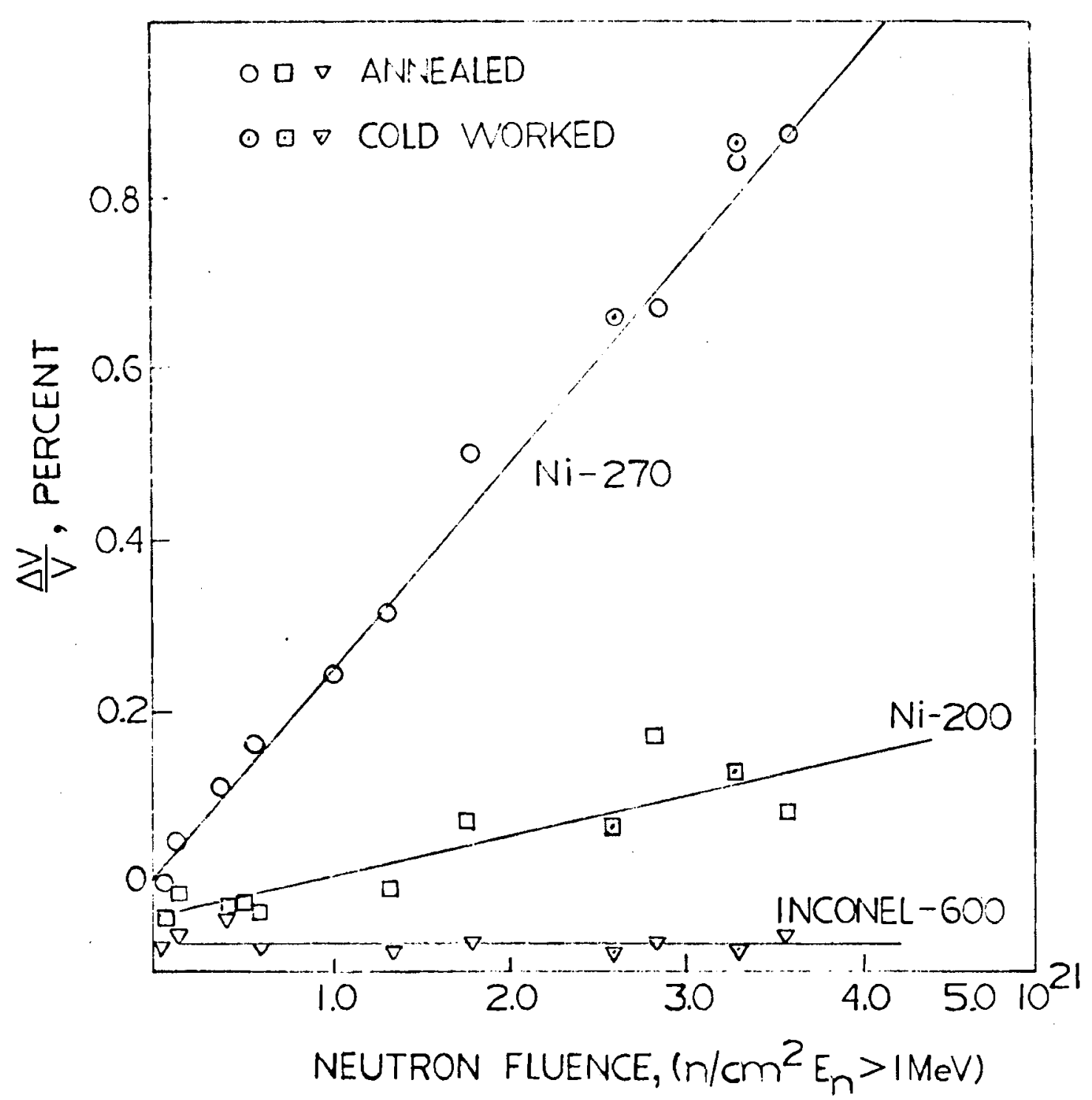

Figure 1.3.3.1-3 Swelling Versus Fluence in Nickel-Base Alloys 


\section{$1.3 .3 .1-5$}

$5 \times 10^{22} \mathrm{n} / \mathrm{cm}^{2}$ and still show much less swelling than in either pure nicke 1 or S.T. 316 stainless stee1. ${ }^{(5)}$ Application of $50 \%$ cold worked reduced swelling to negligible amounts. There are no fine precipitates in this alloy so the swelling resistance must arise from alloying elements in solution.

Minor modifications to common stainless steels can alter the swelling behavior. Results from the U.K. indicate that reducing the carbon content reduces the swelling. M316L, a low carbon 316, swells much less than regular M316. (6) The temperature of maximum swelling is also less. Addition of carbide formers such as titanium to stabilize the stainless steels also improves the swelling resistance. Data from ORNL on Ti modified 304 and $316,{ }^{(7)}$ G.E. data on $321^{(8)}$ and U.K. data on EN58B ${ }^{(9)}$ all show that an optimum addition of titanium will reduce swelling.

The work on effects of alloy composition has many inconsistences so that few concrete conclusions can be made at this time. Much more work is expected in this area in the future. It is believed that variations in the minor alloying elements in stainless steel, i.e., carbon, phosphorus, manganese, etc., have a significant effect on the swelling. Control of these elements is therefore very important. The swelling may be detrimental but will at least be predictable if compositional control is maintained. 


\section{REFERENCES}

1. "Sodi um Cooled Reactors, Fast Ceramic Reactor Development Program, 38th Quarterly Report, Feb.-Apri1, 1971," GEAP-10028-38, June, 1971, pg. 11.8 - 11.9.

2. J. A. Hudson, D. J. Mazey, and R. S. Nels on in Proc. of Conference on Voids Formed by Irradiation of Reactor Materials, Reading University, March, 1971, pg. 215, ed. by S. F. Pugh, M. H. Loretto, and D. I. R. Norris, A.E.R.E. Harwell.

3. D. W. Sandusky, P. J. Ring, R. T. Penrose, "Fast Neutron Damage in Type 304 Stainless Steel and High Nickel Alloys," GEAP-13738, 1971, p. 42.

4. J. J. Holmes, Trans, ANS. 12, p. 117-118 (1969).

5. H. R. Brager and J. L. Straalsund, in 6th Int1. Week1y On Radiation Effects on Structural Materials, ASTM, Los Angeles, June, 1972.

6. C. Cawthorne, E. J. Fulton, J. I. Bramman, G. A. B. Linekar, and R. M. Sharpe in ref. $2, p .35$.

7. E. E. Bloom, "Nucleation and Growth of Voids in Stainless Steels During Fast Neutron Irradiation," ORNL-TM-3492, Oct., 1971.

8. W. K. Appleby, GEAP-13737, Feb., 1972.

9. J. I. Bramman, C. Cawthorne, E. J. Fulton, and W. D. J. Sinclair, in ref. 2, p. 27. 


\subsubsection{Effect of Cold Work}

"Cold work" denotes the effect of a

fabrication process in which a material is deformed, usually at ambient temperature. Normally, the degree of cold work is given by the percent reduction in area. Cold-working introduces dislocations into the material, the higher the level of cold work, the greater the dislocation density.

In general, cold work reduces the resultant swelling in both 304 and 316 stainless steel. Work at ORNL and HEDL indicate that cold working up to $25 \%$ greatly reduces the swelling in 304 and 316 by as much as a factor of $10 .(1,2)$ An equation similar to equation (4) in Section 1.2.2 has been developed by HEDL to relate swelling in cold worked 316 stainless steel to fluence and temperature. $(3)$

$$
\begin{gathered}
\% \Delta V / V=F(T)\left(\frac{\phi t}{10^{22}}\right)^{N(t)} \\
N(t)=[2+3 \exp [.05(T-475)]] / 1+\exp [.05(-475)] \\
F(t)=\frac{\exp [.09(T-340)]}{1+\exp [.09(T-340)]}\left\{\left[\frac{0.002}{1+\exp [.05(T-600)]}\right]+\right. \\
\left.\left[\frac{.006}{1+\exp [.06(T-460)]}\right]\right\} \\
\text { where } \phi t=n / \mathrm{cm}^{2}(E>0.1 \mathrm{MeV}) \\
T={ }^{\circ} \mathrm{C}
\end{gathered}
$$

This equation will produce swelling values equal to $1 / 10$ those for S.T. 316 as determined by equation (4) in Section 1.2.2.

This equation is based on the fact that the number density of voids in C.W. 316 is only 1/10 that of S.T. 316. The actual swelling values were too low to measure since only relatively low fluence specimens were available. Data from the U.K. showed much different behavior in their C.W. 316 stainless steel and were therefore 
not used in the analysis of the data leading to equation (1). However, since it is possible that some FTR material may behave like U.K. material an equation for the maximum swelling does consider this U.K. data.

The equation for maximum swelling is

$$
\begin{gathered}
\% \Delta V / V=1.5 \times 10^{-34}(\phi t)^{1.5}\left[4.028-3.712 \times 10^{-2} \mathrm{~T}\right. \\
\left.+1.0145 \times 10^{-4} \mathrm{~T}^{2}-7.879 \times 10^{-8} \mathrm{~T}^{3}\right] \\
\phi t=\mathrm{n} / \mathrm{cm}^{2}(\mathrm{E}>0.1 \mathrm{MeV}) \\
T=\text { temperature }{ }^{\circ} \mathrm{C}
\end{gathered}
$$

Data from the U.K. does show a reduction in the swelling of C.W. 316 over that of S.T. 316, but the reduction is only by a factor of about 2 rather than a factor of 10 in the U.S. data. The U.K. data was mostly from fuel clad and the effect of stress in the clad could have been the cause of some of the differences in the U.K. and U.S. results.

An equation relating amount of cold work to swelling for constant fluence has been developed by HEDL for 316 stainless steel. ${ }^{(4)}$

$$
\begin{gathered}
\Delta V / V(X)=\Delta V / V(0) e^{-0.115 X} \\
X=\text { amount of cold work } \\
\Delta V / V(0)=\text { swelling at } 0 \% \text { cold work }
\end{gathered}
$$

This equation is restricted to low temperature $\left(425{ }^{\circ} \mathrm{C}\right)$ and low fluences $\left(<3 \times 10^{22}\right)$. A plot of swelling versus cold work is shown in Figure 1.3.3.2-1. (4)

The temperature dependence of swelling in cold work stainless steel is more complex than in S.T. material. In C.W. 304, there are two maxima in the swelling versus temperature curve as shown in Figure 1.3.3.2-2. ${ }^{(5)}$ The second maxima is a result of 


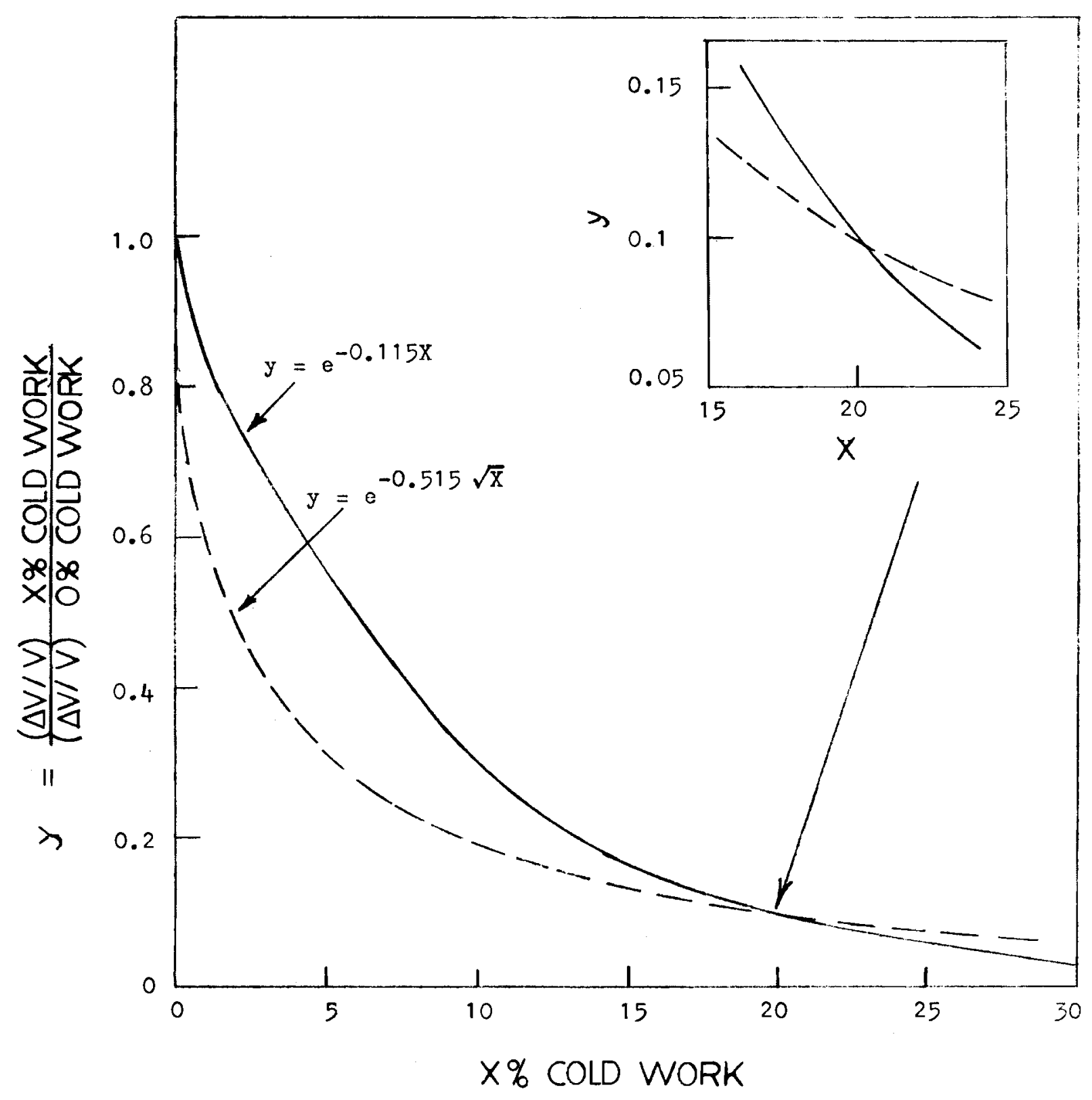

Figure 1.3.3.2-1 Graphic Relationship Between Swelling and Cold Work Level for 316 Stainless Steel 


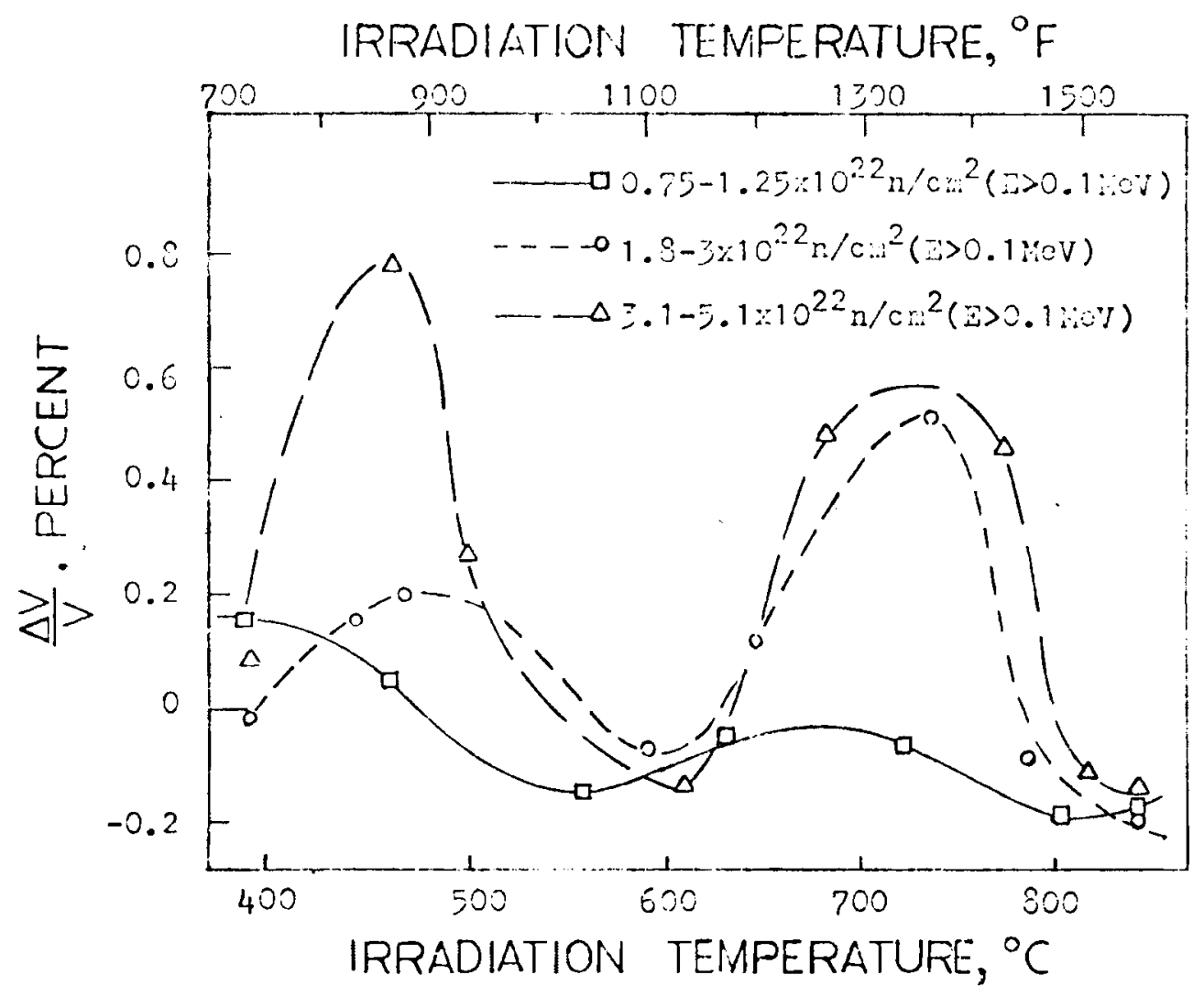

Figure 1.3.3.2-2 Swelling of 50\% C.W. 304 SS as a Function of Irradiation Temperature 
recrystallization of the cold work structure. There is copious void formation in the recrystallized area. Recent work has also shown a double peak when plotting the void number density versus temperature for $27 \%$ cold work 316 stainless steel, Figure $1.3 \cdot 3.2-3 .{ }^{(6)}$ It is therefore suspected that a similar double peak may exist between swelling and temperature. If this is found to be true, equation (1) above may have to be modified to account for this temperature anomaly.

If the cold work material is given a recovery anneal, e.g., 100 hours at $675{ }^{\circ} \mathrm{C}$ prior to irradiation then the swelling is similar to S.T. or in some cases even greater. $(1,7)$ Material irradiated in reactor at elevated temperatures, however, does not recover as rapidly as that annealed ex-reactor. For example, $27 \% \mathrm{C} . W$. 316 recrystallized at $1200^{\circ} \mathrm{F}\left(650^{\circ} \mathrm{C}\right)$ out of the reactor, but did not recrystallize in reactor during irradiation at that temperature. Recovery did occur, however. In spite of the reduced recovery and recrystallization in-reactor, cold work must be viewed as metastable at these elevated temperatures.

Overall, there is a definite lack of data on swelling of cold worked material. There is essentially no U.S. data above approximately $5 \times 10^{22}$ for C.W. 316 stainless steel. The swelling is exceptionally low in the cold worked material which has been examined but there is still some concern that there may be accelerated swelling at the higher fluences. Ion bombardment studies have generally shown that the swelling in cold worked material is lower than that in S.T. initially, but that at very high doses, the swelling values are about the same. The British have concluded from their experiments that at maximum fuel burnup, the swelling in cold worked 316 will be about one-half that of S.T. 316. (8) Much additional work is anticipated in the area of effects of cold work on swelling. 


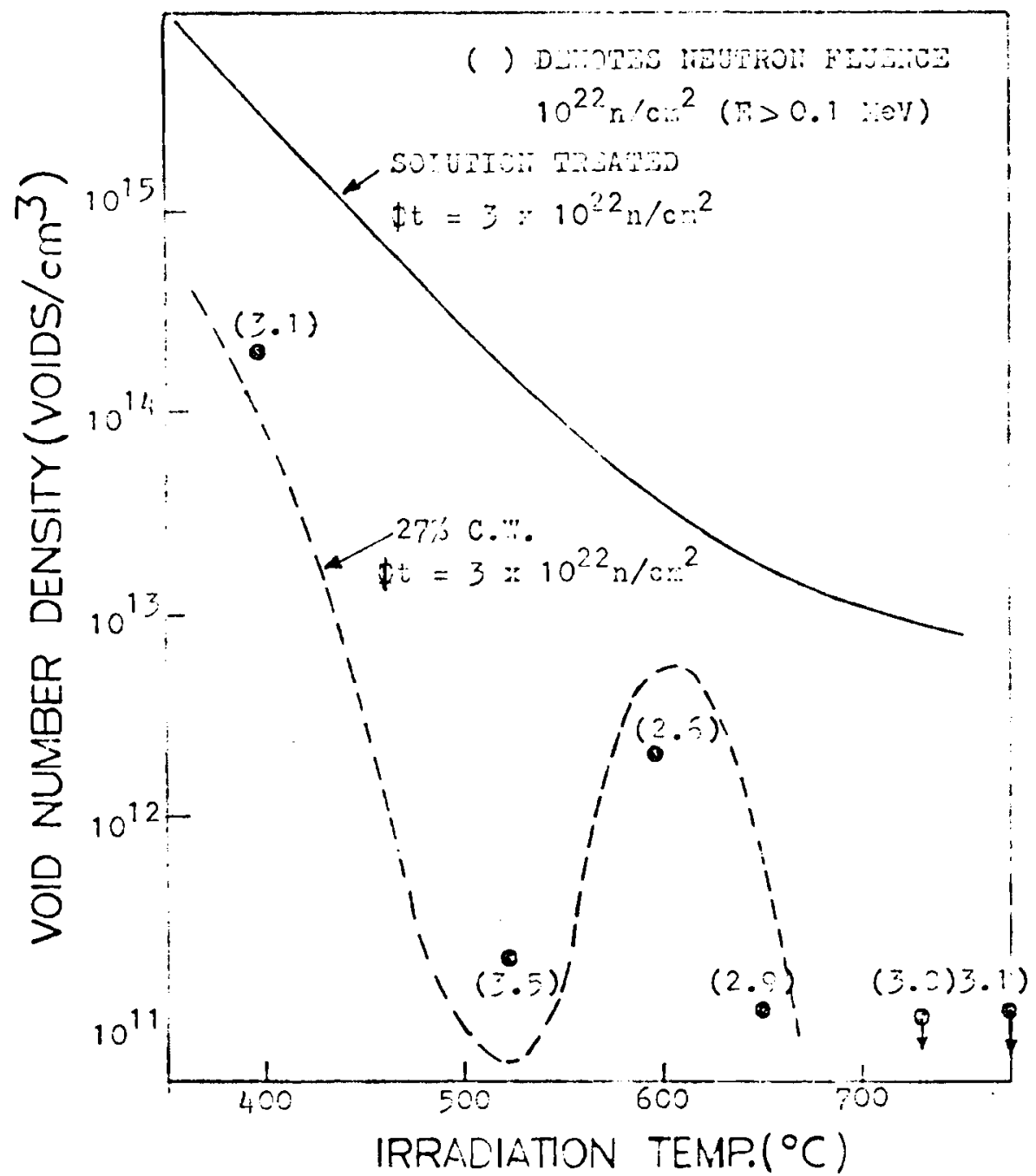

Figure 1.3.3.2-3 Void Number Density Data of $27 \%$ Cold Worked 316 SS Irradiated to a Nominal Neutron Fluence of $3 \times 10^{22}$ $\mathrm{n} / \mathrm{cm}^{2}$, Shown as a Function of Irradiation Temperature. The dashed curve, which was fit to this cold worked data, exhibits a markedly different temperature dependence than that for the same steel irradiated in the S.T. condition as shown by the solid line. 


\section{REFERENCES}

1. E. E. Bloom, "Nucleation and Growth of Voids in Stainless Steels During Fast Neutron Irradiation," ORNL-TM 3492, October, 1971, p. 29.

2. H. R. Brager and J. L. Straals und, Trans. ANS, 15, 251, 1972.

3. J. L. Straals und, E. R. Gi libert, R. J. Jackson, and T. T. Claudson, "Interim Analysis of Irradiation Induced Creep and Swelling of 20\% Cold Worked Type 316 Stainless Stee1," HEDL-TME-71-111, July, 1971.

4. Quarterly Prog. Rpt., "Irradiation Effects of Reactor Structural Materials, Feb., Mar., April, 1971,"ed. by T. T. Clauds on, HEDL-TME-72-64, June, 1972, p. HEDL-52.

5. Ibid, Aug., Sept., Oct., 1971, HEDL-TME-71-161, p. HEDL-34.

6. H. R. Brager and J. L. Straalsund, "Irradiation Temperature Dependence of Void Formation in Cold Worked 316 Stainless Steel, HEDL-72-121.

7. Quarterly Progress Report, "Irradiation Effects of Reactor Structural Materials, Feb., Mar., April, 1971, ed. by T. T. Claudson, HEDL-TME-71-66, p. ORNL-4.

8. J. A. Huds on, D. S. Mazey, and R. S. Nelson, "Void Formation in 316 Steel, Nickel and Nimonic PE-16 with $20 \mathrm{MeV} \mathrm{C} \mathrm{C}^{++}$Irradiation," Conf. on Voids Formed by Irradiation of Reactor Materials, BNES, p. 213, A.E.R.E., Harwe11, 1971 . 


\subsection{GENERAL SIGNIFICANCE OF SWELLING TO LMFBR PERFORMANCE}

\subsubsection{Introduction}

Metal swelling will have a major effect on the

design of LMFBR reactors. As yet, data from irradiations at fluences and temperatures and upon materials representative of those in advanced LMFBR's is quite meager. Predictions of metal behavior in relevant regimes has required extrapolations based on continuously updated, empirically-derived equations and upon theoretical considerations supported by irradiation-simulation experiments (ion bombardment techniques).

These equations are being utilized to forecast the potential effects of swelling on the design and performance of LMFBR reactor components.

Since the major emphasis to date in the U.S. has been on the development of FFTF, many of the remarks in this section are specifically related to the FFTF as a reference LMFBR reactor, though they will be of general application to future commercial LMFBR's as well.

The role of swelling on component behavior is not discussed in great detail. Only the general problem areas are presented. The references in the following section discuss more fully these problem areas. 


\subsubsection{1-1}

1.4.2 General Implications of Swelling to LMFBR Component Behavior

\subsubsection{Fuel Element Cladding and Fuel Element Support}

The role of swelling in fuel elements and other core components operation is discussed in considerable detail in references 1 and 2 .

The stainless steel fuel cladding will swell during reactor operation, Figure 1.4.2.1-1 ${ }^{(1)}$ and closure of the fue 1 element gap will occur if appropriate measures are not taken. It is now recognized, however, that clad swelling can allow more fuel swelling and hence more burn up. Hence, the requi rement for greater clearance to allow for swelling is offset by the greater fuel burn up. At this time, clad swelling per se does not appear to be a limiting problem. There may still be significant problems associated with clad ductility after high exposures.

Problems associated with swelling of fue 1 element supports are still unresolved. A helical wire wrap is presently considered as the fuel element support system for the FFTF. The problems associated with the wire wrap are (1) there is no compliancy to accommodate differential swelling between fuel element bundle and wrapper tube, and (2) differential swelling between the cladding and wire could produce either breakage or slackness in the wire. In this ca.se, differential swelling can be accommodated by cold working the fuel element and wire wrap different amounts and relying on the cold work dependence of swelling to give similar swelling to both components. However, there are still large uncertainties in the prediction of swelling particularly with the effect of cold work and swelling. Also, cold work cannot be controlled to better than $\pm 5 \%$. At present, best estimate values have to be used. The trend is to use initial slackness in the wire so there will not be breakage due to tightening. There appears to be no assembly in the core that could experience slackness based on present knowledge. Other designs that offer more compliancy such as intermittent grids are being considered for future applications. 


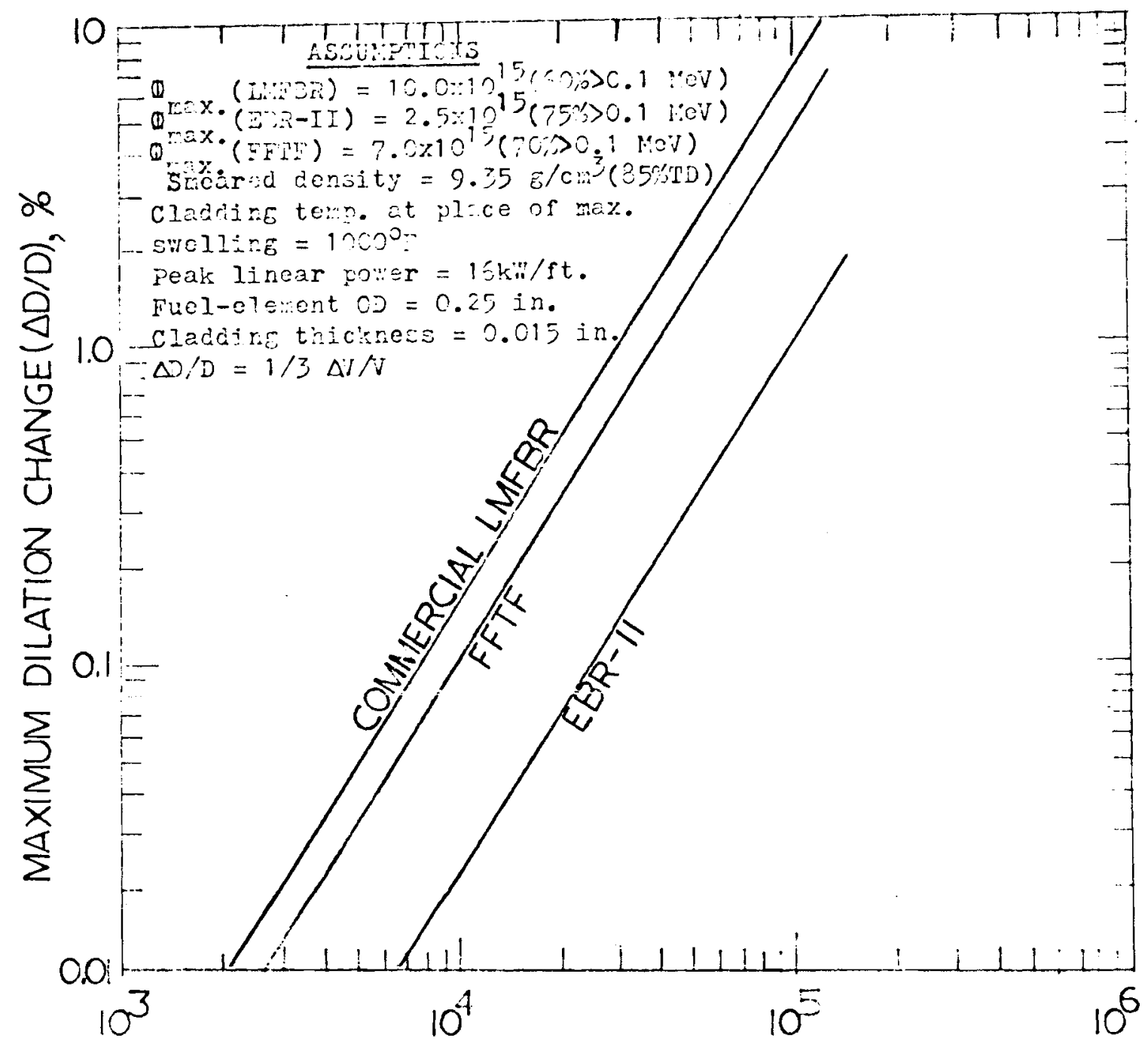

FEAK FUEL EURNUP, MWVA/METRIC TON

Figure 1.4.2.1-1 Cladding Dilation from Radiaton-Induced Swelling in Three Fast Reactors. 


\section{$1.4 .2 .1-3$}

Differential swelling between the pin bundle and the wrapper tube is a potential problem. The nominal gap between pin bundle and duct is found to close progressively throughout the period of irradiation. This pin bundle support system design must accommodate this differential growth. While at the same time, it must maintain the pin bundle to duct interface pressure within specified limits.

The present solution to these problems are admittedly not the best and in some instances burn up may be limited. However, these are only interim solutions which only serve the life time of a particular fuel loading and are not irreversible 20 year decisions. Additional modification can be made as more data is generated. 


\section{REFERENCES}

1. P. R. Heubotter and T. R. Bump, "Implications of Metal Swelling in Fast Reactor Design," International Conference on RadiationInduced Voids in Metals, CONF-710601-4, Albany, N.Y., June 9-11, 1971.

2. P. Murray, J. F. Pattersen and W. E. Penne11, "Design Ramifications of Irradiation Induced Swelling and Creep in Fast Reactors," TID-36147, 1972 . 


\section{$1.4 .2 .2-1$}

\subsubsection{Core Structural Components}

The principal effects of swelling on core structural components occur through elongation, dilation and bowing of the wrapper tubes and guide tubes.

Elongation is probably the least serious of the swelling problems. An example of the elongation that may occur in the wrapper tubes is shown in Figure 1.4.2.2-1.(1) Outer walls and inner walls will elongate different amounts and this will complicate the design of fuel handling procedures.

\section{Dilation of the wrapper and guide} tubes due to swelling is a more serious problem than elongation. Figure 1.4.2.2-2(1) ${ }^{(17 l u s t r a t e s}$ the possible magnitude of the dilation in the core region due to swelling. Possible consequences of unaccommodated dilation include (1) displacement of the in-core positions of control and safety rod guide tubes from their original positions, and (2) handling heads of all but the central core would move radially outward with time, consequently, fuel handling would be very difficult. The dilation can be accommodated by providing sufficient gaps between tubes. Fuel handling, particularly removal can still be a problem since bulged fuel elements will have to be pulled past spacer pads which will probably be located outside of the core. This will require careful surveillance to be sure the fuel can be removed.

Bowing results from differential swelling on opposite sides of a tube. The differential swelling is a result of the flux and/or temperature gradients in the region. An example of unrestrained bowing of assemblies which can occur due to differential swelling is shown in Figure 1.4.2.2-3! $(1)$ This bowing is accommodated by a core restraint system. There are various designs for core restraint. The residual bowing profiles produced by one such restraint system is shown in Figure 1.4.2.2-4. ${ }^{(1)}$ Core restraint systems place loads on the assemblies and these loads will result in creep of the assemblies. It is expected that this creep will at least partially compensate for the distortions produced by bowing. 
1.4.2.2-2

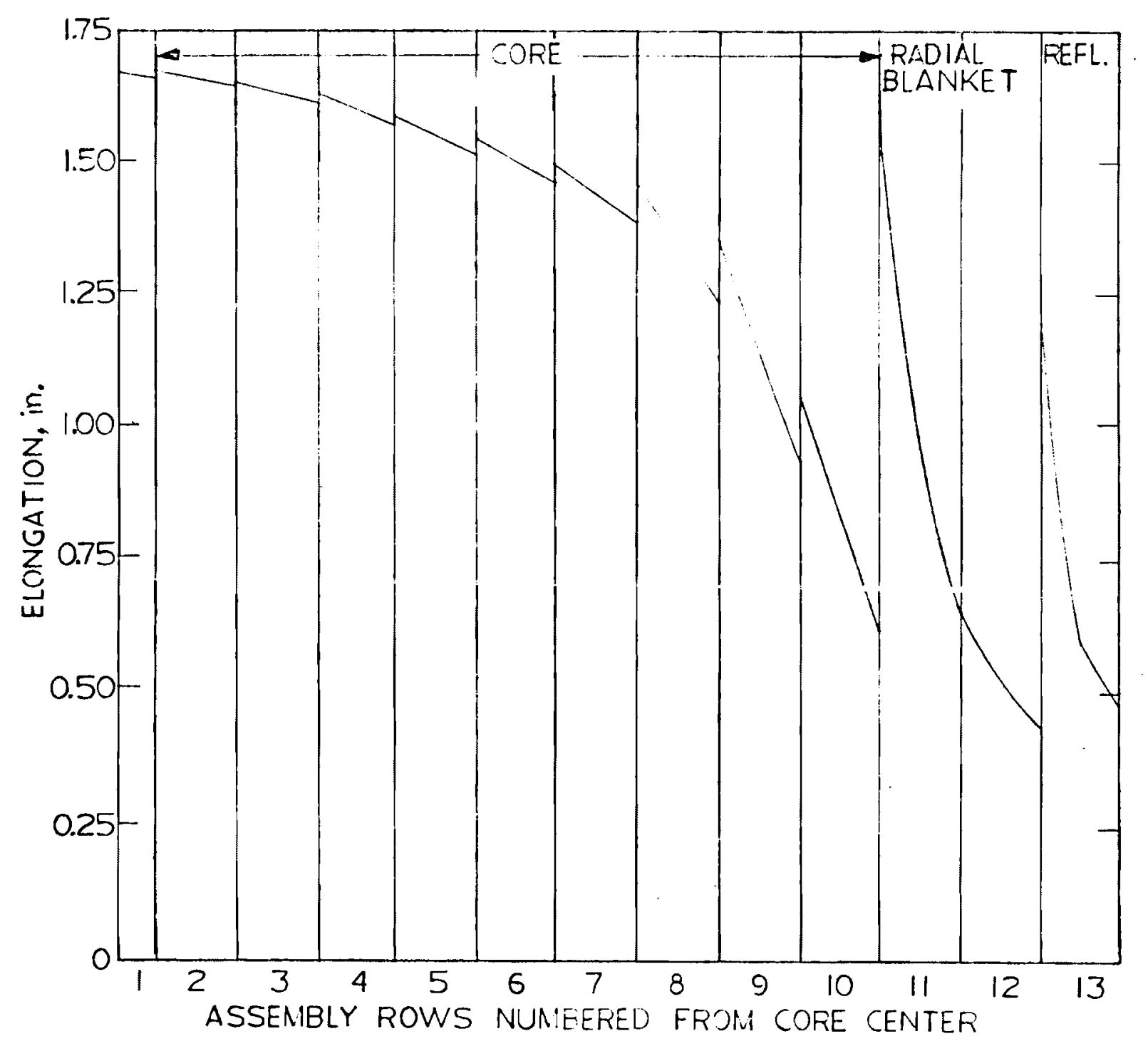

Figure 1.4.2.2-1 Elongation of Wrapper-tube Walls due to Swelling (End of Life) 


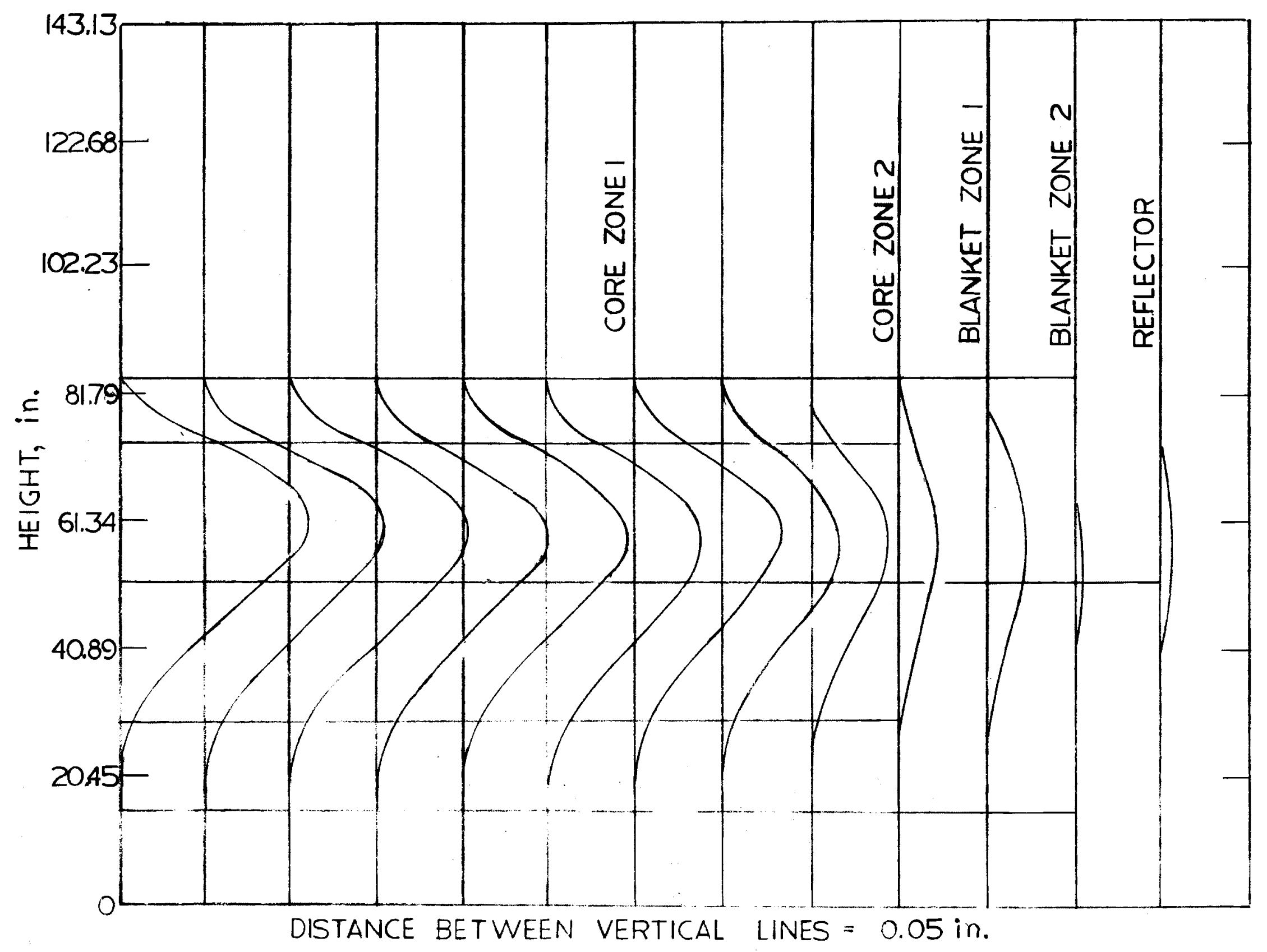

$\dot{+}$
$\dot{n}$
$i$
$\omega$

Figure 1.4.2.2-2 Dilation of Wrapper Tubes due to Swelling (End of Life) 


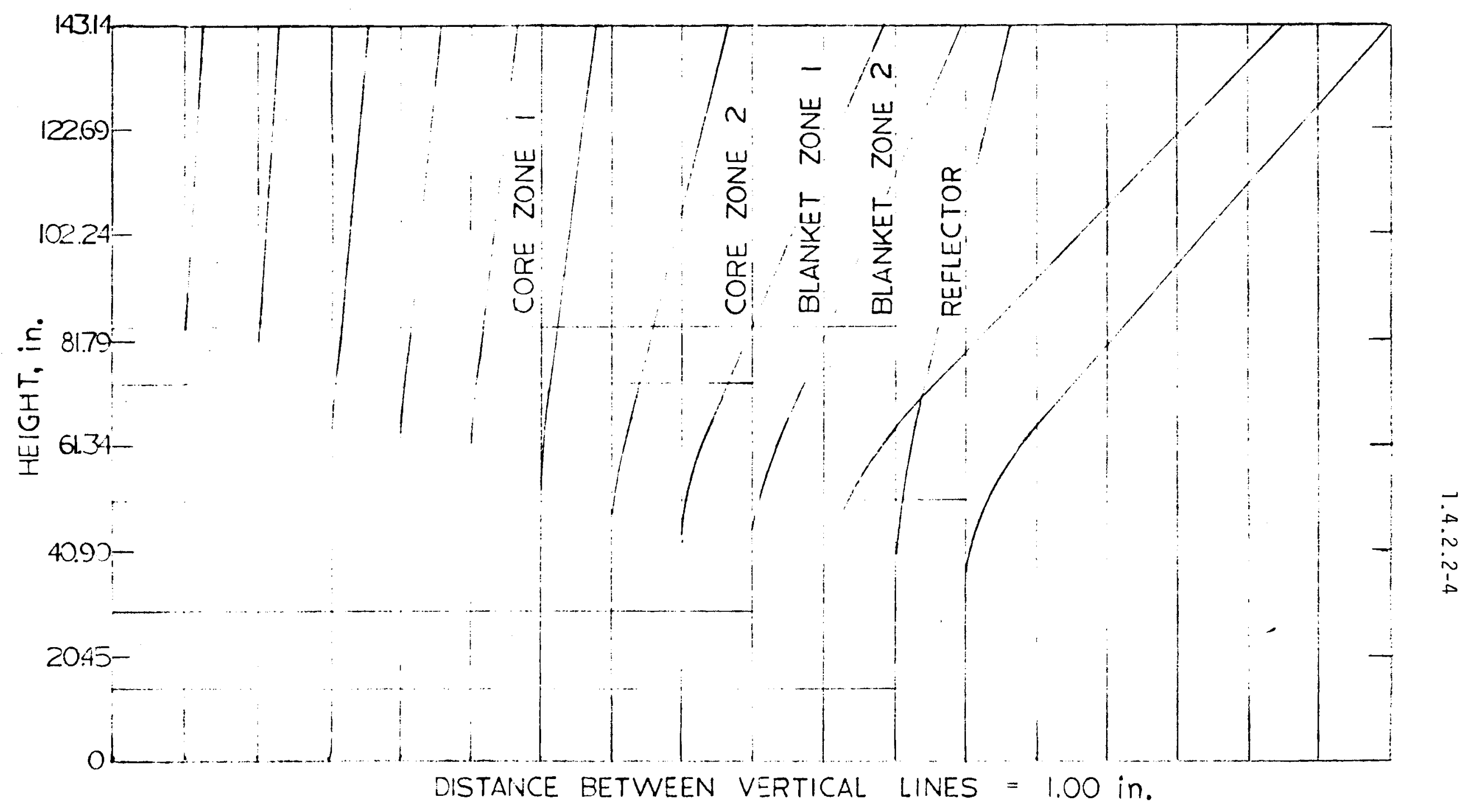

Figure 1.4.2.2-3 Free (Unrestrained) Bowing of Assemblies due to Differential Elongation (End of Life) 


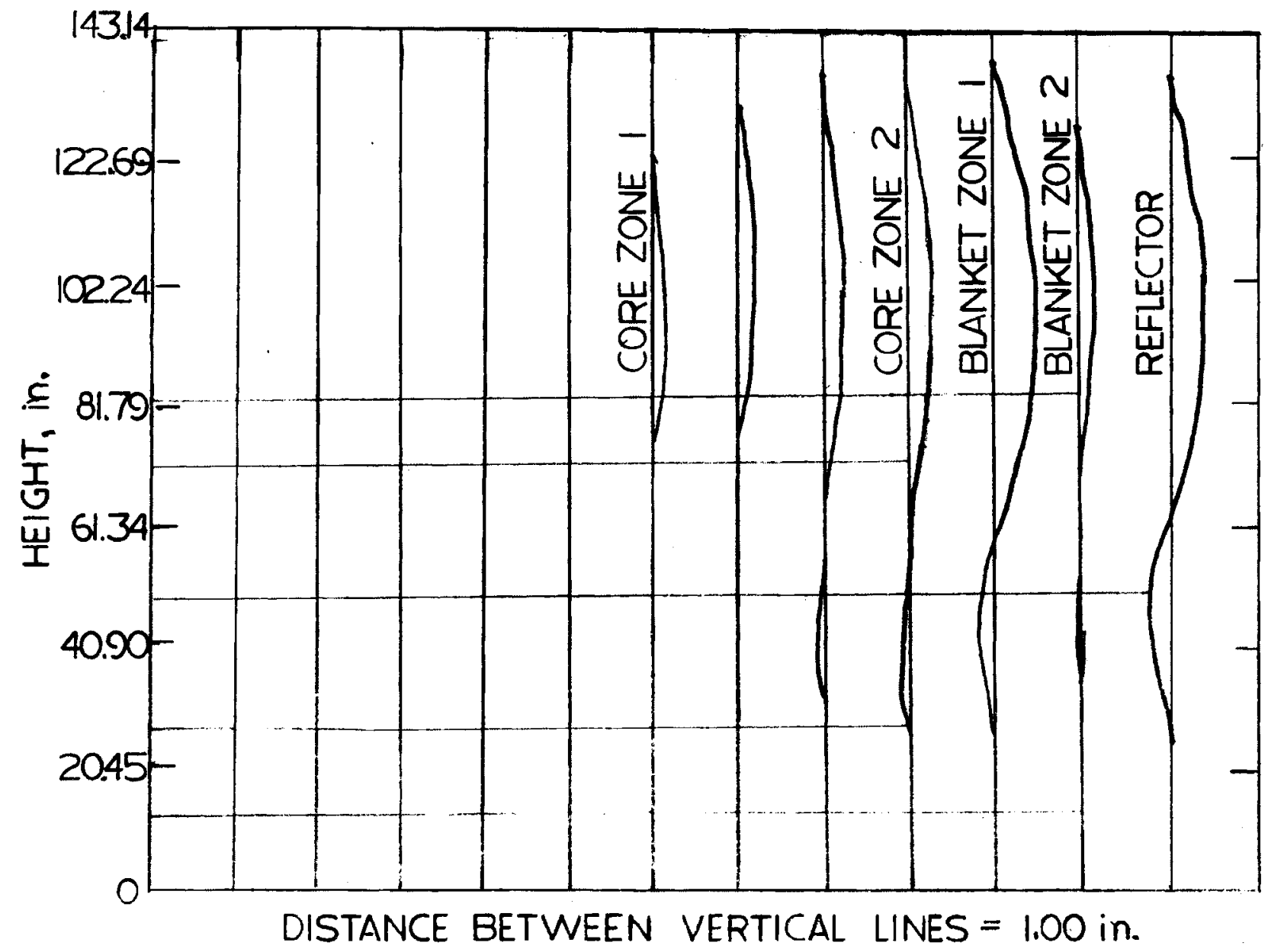

$\overrightarrow{0}$
$\vdots$
$i$
$i$

Figure 1.4.2.2-4 Bowing Profiles of Assemblies with Top-end Restraint and In-Core Spacer Pads (End of Life) 


\section{$1.4 .2 .2-6$}

Differential swelling between the top and bottom surfaces of the grid plates can produce appreciable bowing of the plates. The only protection against bowing in this instance is to keep the absolute magnitude of the swelling at a very low value.

In summary, swelling, and in particular differential sweliing, can produce distortions in the various components which can greatly hinder operations. Difficulties in control and safety rod maneuverability and fuel element handling are perhaps the most serious from a safety standpoint. Until better swelling data is available, designs will have to incorporate the worst possible cases for swelling. 


\section{$1.4 .2 .2-7$}

\section{REFERENCES}

1. P. R. Heubotter and T. R. Bump, "Implications of Metal Swelling in Fast Reactor Design," Intl. Conf. on Radiation Induced Voids in Meta1s, CONF-710601-4, A1bany, N.Y., June 9-11, 1971. 
1.4.2.3-1

\subsubsection{Pressure Vessel}

Since midplane fluences over the $20-30$

year reactor 1 ife are expected to be only about $5 \times 10^{19} \mathrm{n} / \mathrm{cm}^{2}$ (total neutrons), no swelling will occur. 


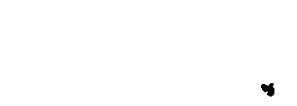

EFFECT OF IRRADIATION ON TENSILE PROPERTIES 


\section{IRRADIATION EFFECTS ON TENSILE PROPERTIES}

\section{TABLE OF CONTENTS}

2.1 INTRODUCTION . . . . . . . . . . . .

2.2 MAJOR FACTORS INFLUENCING IRRADIATION EFFECTS

ON TENSILE PROPERTIES. . . . . . . . . . 2.2.1-1

2.2.1 Introduction. . . . . . . . . 2.2.1-1

2.2.2 Irradiation Fluence and Temperature . . . . 2.2.2-1

2.2.3 Test Temperature. . . . . . . . . . 2.2.3-1

2.2.3.1 Low Irradiation Temperature--High

Test Temperature . . . . . . 2.2.3.1-1

2.2.3.2 High Irradiation Temperature--Low

Test Temperature ........ 2.2.3.2-1

2.3 OTHER FACTORS INFLUENCING IRRADIATION EFFECTS

ON TENSILE PROPERTIES .............. 2.3.1-1

2.3.1 Introduction. . . . . . . . . . . 2.3.1-1

2.3.2 Effect of Reactor Variable. . . . . . 2.3.2.1-1

2.3.2.1 Effect of Flux (Dose Rate) .... 2.3.2.1-1

2.3.2.2 Effect of Spectrum ....... 2.3.2.2-1

2.3.2.3 Effect of Helium Production. .... 2.3.2.3-1

2.3.2.4 Effect of Prior Stress ...... 2.3.2.4-1

2.3.3 Effect of Materials Variables. . . . . . 2.3.3.1-1

2.3.3.1 Effect of Alloy Composition. .... 2.3.3.1-1

2.3.3.1.1 Austenitic Steels . . . 2.3.3.1.1-1

2.3.3.1.2 Nickel-Base Alloys. . . 2.3.3.1.2-1

2.3.3.2 Effect of Cold Work. . . . . . . 2.3.3.2-1

2.3.3.2.1 Ductility ...... 2.3.3.2.1-1

2.3.3.2.2 Strength. ....... 2.3.3.2.2-1

2.4 GENERAL RELATIONSHIP OF IRRADIATED TENSILE PROPERTIES

TO LMFBR PERFORMANCE . . . . . . . . . . 2.4.1-1

2.4 .1 Introduction. .................. 2.4.1

2.4.2 Influence of LMFBR Variables. . . . . . 2.4.2.1-1

2.4.2.1 LMFBR Reactor Variables ..... 2. 2. . 2.1-1

2.4.2.2 LMFBR Material Variables ..... 2.4.2.2-1

2.4.3 General Implications of Irradiated Tensile

Properties on LMFBR Components. ....... 2.4.3.1-1

2.4.3.1 Pressure Vesse1. . . . . . . 2.4.3.1-1

2.4.3.2 Core Components. . . . . . . . 2.4.3.2-1 


\section{LIST OF FIGURES}

FIGURE

2.2.2-1(a)

$2.2 .2-1(b)$

$2.2 .2-1(c)$

$2.2 .2-1(d)$

$2.2 .2-7(e)$

$2.2 .2-1(f)$

$2.2 .2-2(a)$

$2.2 .2-2(b)$

$2.2 .2-2(c)$

$2.2 .2-2(d)$

$2.2 .2-2(e)$

$2.2 .2-2(f)$

$2.2 .2-3$

$2.2 .2-4$

$2.2 .3-1(a)$

$2.2 .3-1(b)$

$2.2 .3-1(c)$
Post-Irradiation Proportional Elastic Limit of Annealed 304 Stainless Steel. . . 2.2.2-2

Post-Irradiation Yield Strength of Annealed 304 Stainless Steel . . . . 2.2.2-3

Post-Irradiation Ultimate Tensile Strength of Annealed 304 Stainless

Steel

Post-Irradiation Uniform Elongation of Annealed 304 Stainless Steel. . . . . 2.2.2-5

Post-Irradiation Total Elongation of Annealed 304 Stainless Steel.

Post-Irradiation Reduction of Area of Annealed 304 Stainless Steel. . . . . 2.2.2-7

Post-Irradiation Proportional Elastic Limit of Annealed 316 Stainless Steel

Post-Irradiation Yield Strength of Annealed 316 Stainless Steel. . . . . 2.2.2-9

Post-Irradiation Ultimate Tensile Strength of Annealed 376 Stainless Steel

Post-Irradiation Uniform Elongation of Annealed 316 Stainless Steel. . . . 2.2.2-11

Post-Irradiation Total Elongation of Annealed 316 Stainless Steel. . . . . 2.2.2-12

Post-Irradiation Reduction of Area of Annealed 316 Stainless Steel. . . . . 2.2.2-13

Deformation Process Domains in Annealed 316 Stainless Steel .........

Ductilities for Deformation Process Domains in Irradiated Annealed 316 Stainless Steel. $0.2 \%$ Yield Stress Versus Test Temperature .......... 2.2.3.1-2

Ul timate Tensile Stress Versus Test Temperature ......... 2.2.3.1-3 Uniform Elongation Versus Test Temperature $2 \cdot 2 \cdot 3.7-4$ 


\section{LIST OF FIGURES (Continued)}

FIGURE

Page

2.2.3-1(d) Total Elongation Versus Test

Temperature . . . . . . . . . . 2.2.3.1-5

$2.2 .3 .2-1$

Effect of EBR-II Irradiation on the

Yield Strength of $20 \%$ CW Type

316 Stainless Steel . . . . . . 2.2.3.2-2

2.2.3.2-2 Effect of EBR-II Irradiation on the

Elongation of $20 \% \mathrm{CW}$ Type 316

Stainless Steel.......... 2.2.3.2-3

2.3.2.2-1 Yield Strength of 304 Stainless Stee 1

Versus Total Fluence for Different

Spectra (test and irradiation tempera-

ture of $\left.2450^{\circ} \mathrm{C}\right) . . . . . .2 .3 .2 .2-3$

2.3.2.3-1 Helium Production in Stainless Steel

for Different Reactor Spectra . . . . 2.3.2.3-2

2.3.2.4-1 Effect of Prior Creep Deformation on the $1000^{\circ} \mathrm{F}$ Tensile Stress-Strain

Curves of Annealed 316 Stainless

Steel ............. 2.3.2.4-2

2.3.3.1.2-1 The Effect of Test Temperature on the

Mechanical Properties of Incoloy-800

Strain Rate $0.02 \mathrm{~min}^{-1}$. . . . . 2.3.3.1.2-2

2.3.3.1.2-2 The Effect of Test Temperature on the

Mechanical Properties of Hastelloy- $X$

Strain Rate $0.02 \mathrm{~min}^{-1}$...... 2.3.3.1.2-3

2.3.3.1.2-3 The Effect of Test Temperature on the

Mechanical Properties of Inconel-625

Strain Rate $0.02 \mathrm{~min}^{-1}$. . . . . 2.3.3.1.2-4

2.3.3.2.1-1 Strength and Ductility of Annealed and CW 316 Stainless Steel Irradiated

in the EBR II to a Fluence of

$7 \times 10^{21} \mathrm{n} / \mathrm{cm}^{2}(\mathrm{E}>0.1 \mathrm{MeV})$ at $1100^{\circ} \mathrm{F}$. 2.3.3.2.1-2

2.4.2.2-1 FFTF Core and Vesse1 . . . . . . 2.4.2.2-2 


\section{LIST OF TABLES}

TABLE

2.3.3.1.1-1

Comparative Postirradiation Tensile Properties of Annealed 316 Stainless

Steel and Annealed $316+0.23 \%$ Ti

Stainless Stee1......... 2. . 3.3.1.1-2

$2 \cdot 4 \cdot 2 \cdot 2-1$

A: Fluence Limits for Type 304 Stainless Steel Base Metal..... 2.4.2.2-3

B: Fluence Limits for TIG Welds with Type 308 Stainless Steel Filler. . 2.4.2.2-3

2.4.3.2-1 Estimated Fluence of In-Vessel Components ......... 2. 2. . 2.3.2-2

2.4.3.2-2 Estimated Total Neutron Fluence on Radial Shield. . . . . . . . . 2.4.3.2-3

2.4.3.2-3 Reactor System Fluence Limits . . . . 2.4.3.2-4 


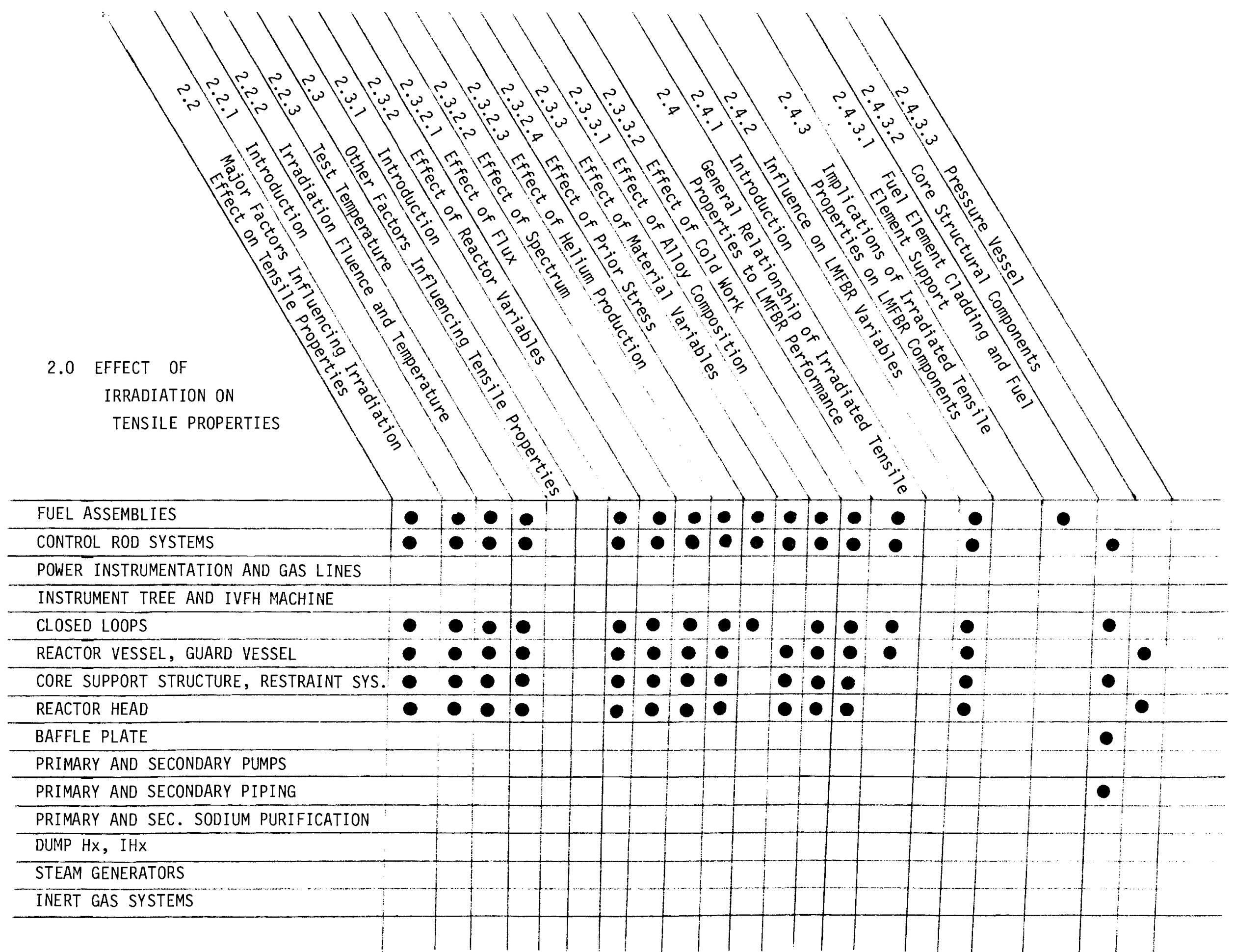





\section{IRRADIATION EFFECTS ON TENSILE PROPERTIES}

\section{$2.1 \quad$ INTRODUCTION}

The effect of irradiation on the tensile properties of metals has been extensively studied since the late 1950's. However, investigations relevant to the elevated-temperature, fast neutron environment of liquid metal fast breeder reactors did not commence until the latter 1960's; and today, intensive studies are still underway to characterize the high-fluence tensile behavior of candidate LMFBR alloys.

Qualitatively, the effects of irradiation can now be explained in some detail. Bombardment by neutrons during irradiation causes two important effects: the displacement of atoms from their atomic positions to produce interstitials and vacancies (see Paragraph 1.1 for more detail); and the transmutation of atoms, resulting in helium as an important by-product.

The interstitials cluster to form loops; the vacancies cluster to produce voids. Both of these defects contribute to hardening and embrittlement. However, each defect has a different recovery rate with temperature; and recovery of strength is not complete even at normal recovery temperatures in high-fluence irradiated material.

The helium produced by transmutation reactions has its major effect on grain boundaries where it accumulates to form bubbles, either as a result of nearby transmutation reactions or under the influence of service stress-induced motion. At temperatures near the equicohesive temperature of an alloy (above which the grain boundaries are weaker than the grains), these bubbles aid the initiation and propagation of grain boundary cracks and promote intergranular failure. In this way, ductility is reduced even at elevated temperatures where substantial recovery of the other irradiationproduced defects (with their contribution to embrittlement) has occurred. 


\section{1-2}

The quantitative description of this high-fluence "irradiation damage," i.e., the relationships between temperature, fluence and resultant tensile properties, are not completely defined for relevant alloys. It will be the purpose of this section of the report to discuss the generally accepted conclusions about high-fluence, fast neutron irradiation damage to tensile properties; to point out the current unresolved problem areas; and to discuss, in a general way, the significance of irradiated tensile properties to LMFBR performance. 


\subsection{1-1}

\subsection{MAJOR FACTORS INFLUENCING IRRADIATION EFFECTS ON TENS ILE PROPERTIES}

\subsubsection{INTRODUCTION}

The two major factors influencing irradiation effects on tensile properties have been elucidated as being the fast neutron fluence and temperature of the irradiation. Since their intimate relationship has been abundantly proven, these two factors will be discussed together (i.e., the effect of fast neutron irradiation fluence at a specified irradiation temperature).

A third major factor influencing tensile properties has also been elucidated. This is the temperature at which the tensile tests are conducted. Because of the effects that thermal history can have on defects and precipitate concentrations and morphologies, properties measured at tes t temperatures other than the irradiation temperature may not be, and in most instances are not, representative of those existing at the irradiation temperature. (This effect of a test temperature different from the irradiation temperature could have real and profound consequences in terms, for example, of properties of components during shut-down; or during fuel management involving fuel movement from low-to high-power regions of a core, and vice versa; or during transients.) Thus, a second section will discuss the effect of test temperatures different than irradiation temperatures. 


\subsubsection{IRRADIATION FLUENCE AND TEMPERATURE}

The degree of irradiation damage (i.e., hardening and embrittlement) increases with fluence in a manner that is a complex function of the combined effects of fast neutron irradiation fluence and irradiation temperature. At the highest fluences so far reported for a stainless steel $\left(1.07 \times 10^{23} \mathrm{n} / \mathrm{cm}^{2}>0.1 \mathrm{MeV}\right.$ for annealed 304 stainless steel ${ }^{(1)}$ ), it is not possible to determine that irradiation damage has yet saturated at a 11 temperatures.

Figures 2.2.2-1 (a-f) present data for annealed 304 stainless steel ${ }^{(2)}$ that indicate the changes occurring in mechanical properties with irradiation fluence for a range of irradiation temperatures. These figures include the highest fluence data generated to data for any stainless steel, $1.07 \times 10^{23} \mathrm{n} / \mathrm{cm}^{2}$ ( $\mathrm{E}>0.1 \mathrm{MeV}$ ) at $700^{\circ} \mathrm{F}$, which were generated from specimens obtained from an EBR-II thimble (control rod guide tube).

Figures 2.2.2-2 (a-f) present similar data for annealed 316 stainless steel. (2) The highest fluence data exhibited here $\left(\sim 2.5 \times 10^{22} \mathrm{n} / \mathrm{cm}^{2}\right)$ is at much lower fluence levels than the data for 304 stainless steel because of the availability for the latter material of specimens from EBR-II components.

From both of these two sets of these figures, it can be seen that high-fluence, fast-neutron irradiation results in significant increases in yield strength, even at irradiation temperatures $>T_{m / 2}$ $\left(\sim 1020^{\circ} \mathrm{F}\right)$ where low fluence irradiation $\left(<1 \times 10^{21} \mathrm{n} / \mathrm{cm}^{2}\right)$ had not such effect.

The greatest irradiation damage occurs at the lower temperatures $\left(700-900^{\circ} \mathrm{F}\right)$. In this low temperature range, there is an indication that at the very highest fluence, saturation of damage to strength and ductility may be occurring in annealed 304 stainless steel. However, the data indicates that at the higher irradiation temperatures, ductility is still decreasing with fluence, with no saturation observed at $2 \times 10^{22} \mathrm{n} / \mathrm{cm}^{2}$ in either alloy. 


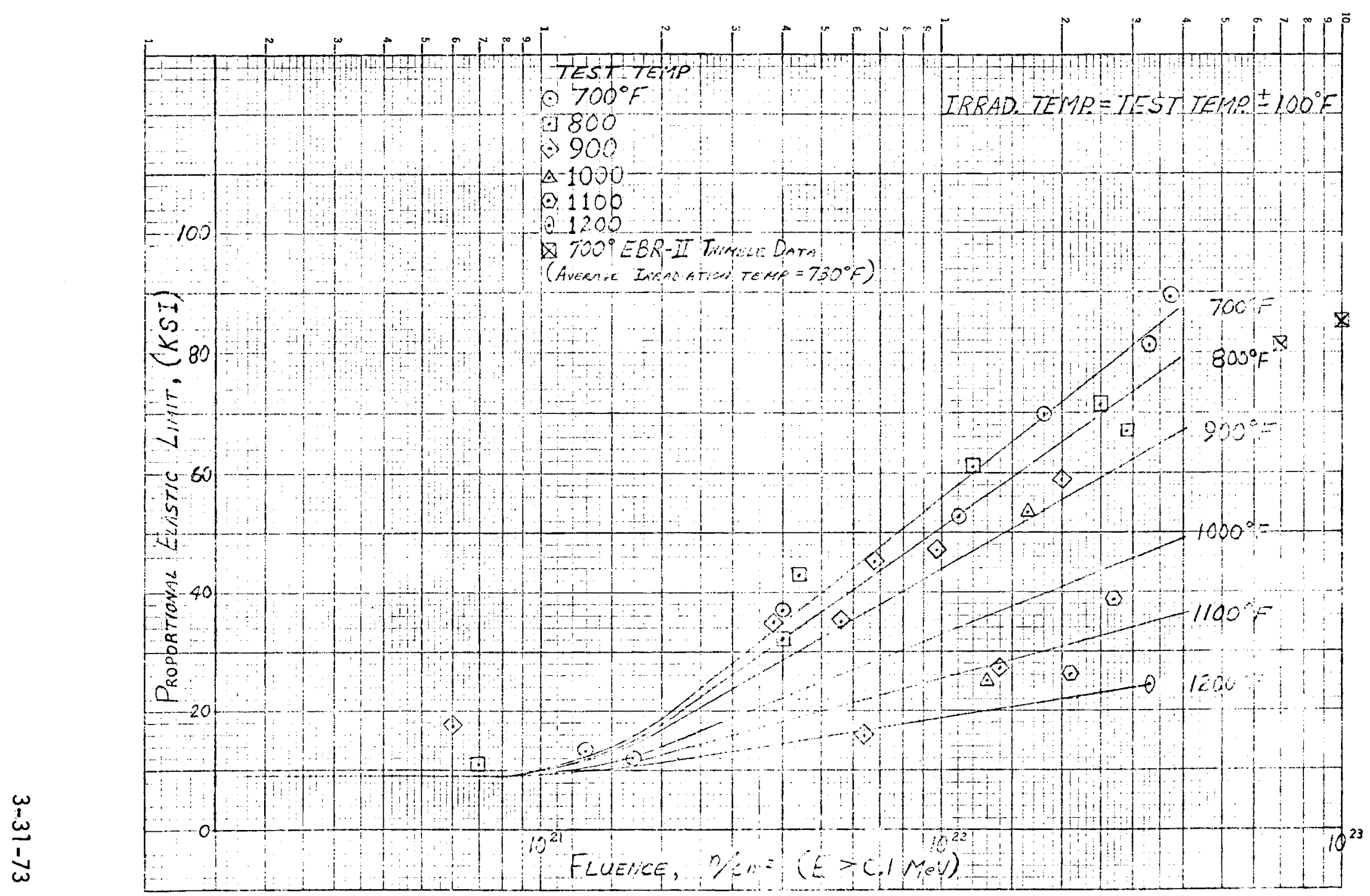




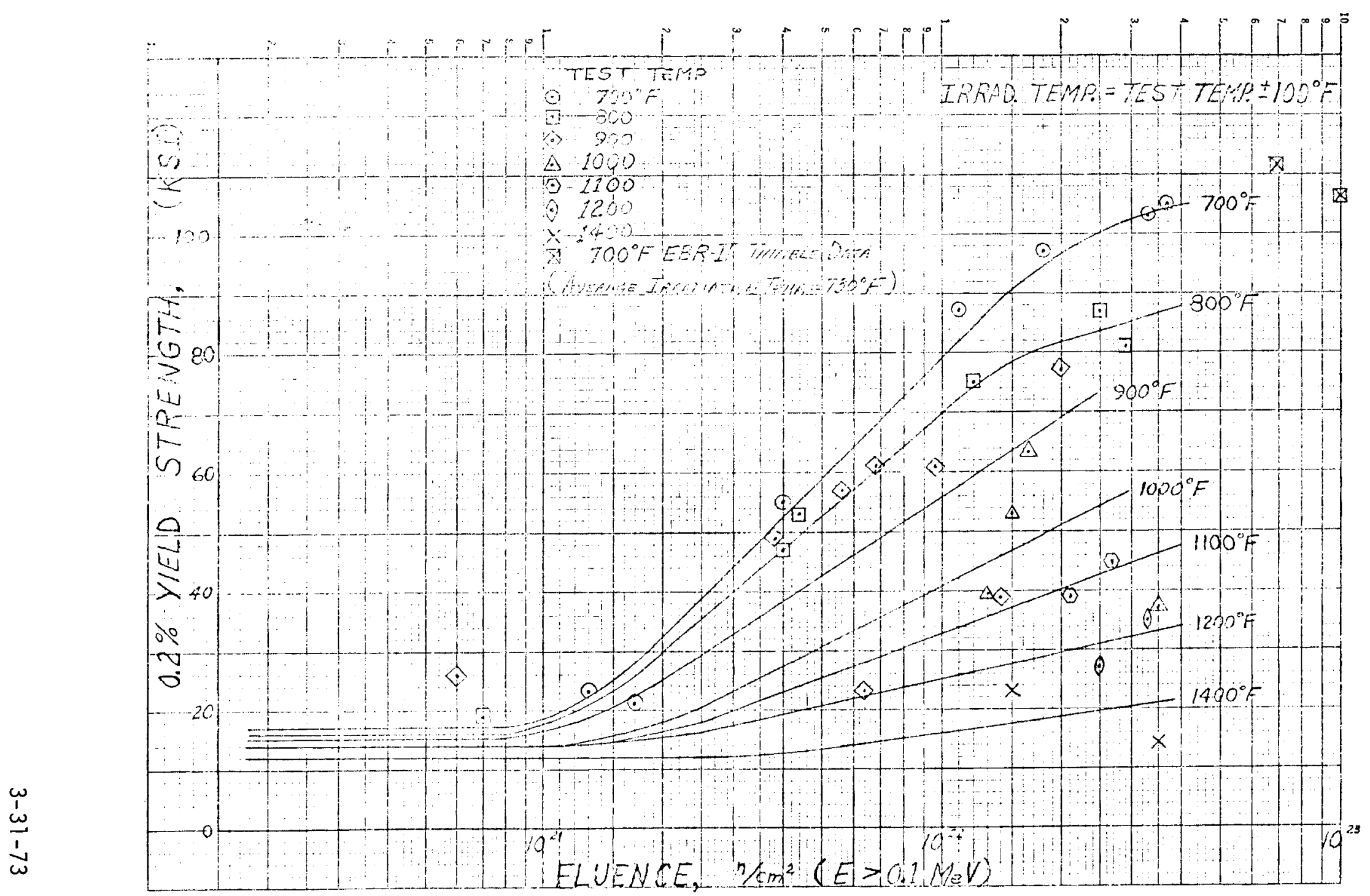

$\stackrel{\sim}{\sim}$

FIGURE 2.2.2-1(b) Post-Irradiation Yield Strength of Annealed 304 Stainless Steel 


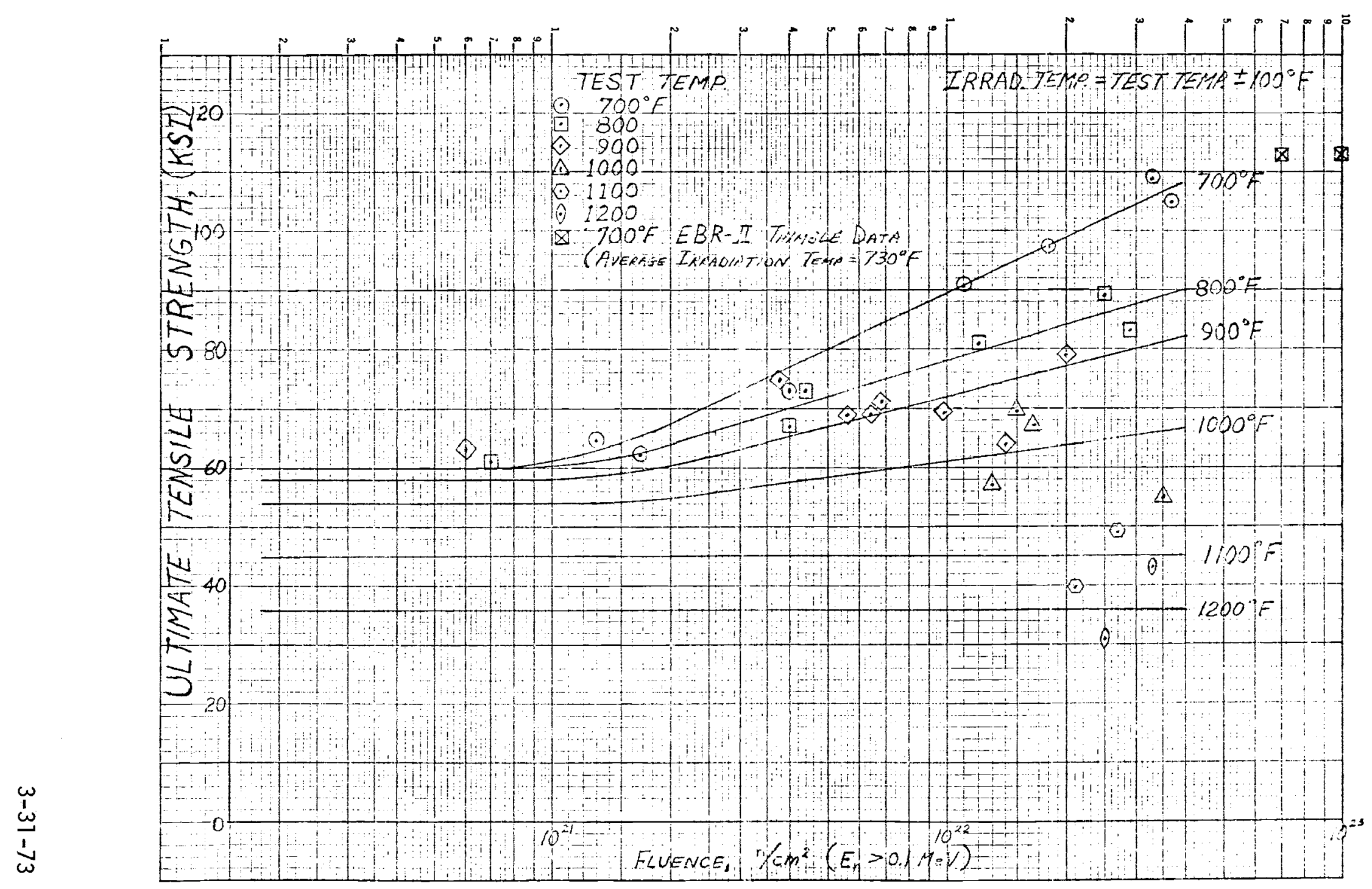

FIGURE 2.2.2-1(c) Post-Irradiation U1timate Tensile Strength of Annealed 304 Stainless Steel 


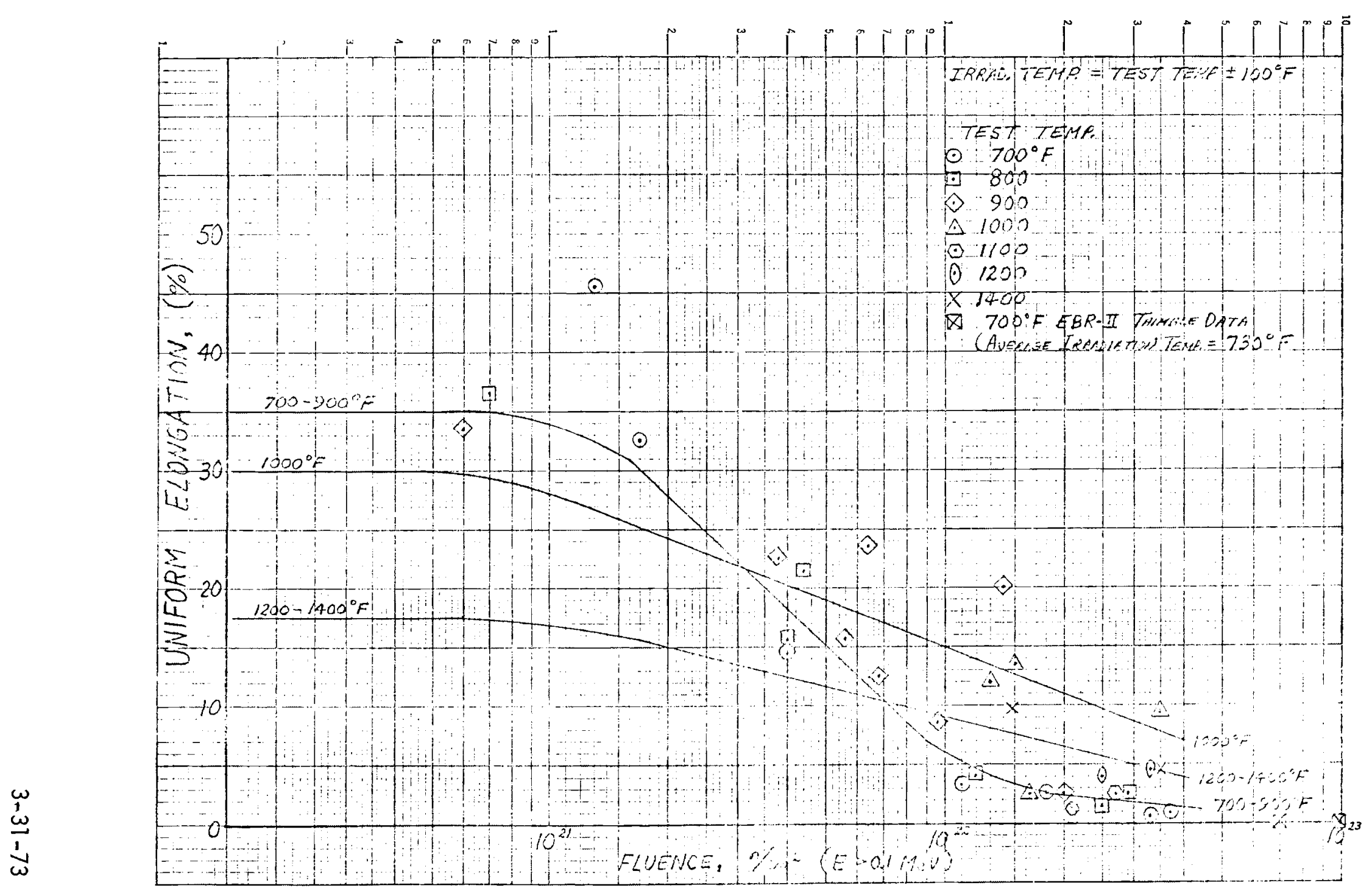

FIGURE 2.2.2-1(d) Post-Irradiation Uniform Elongation of Annealed 304 Stainless Steel 


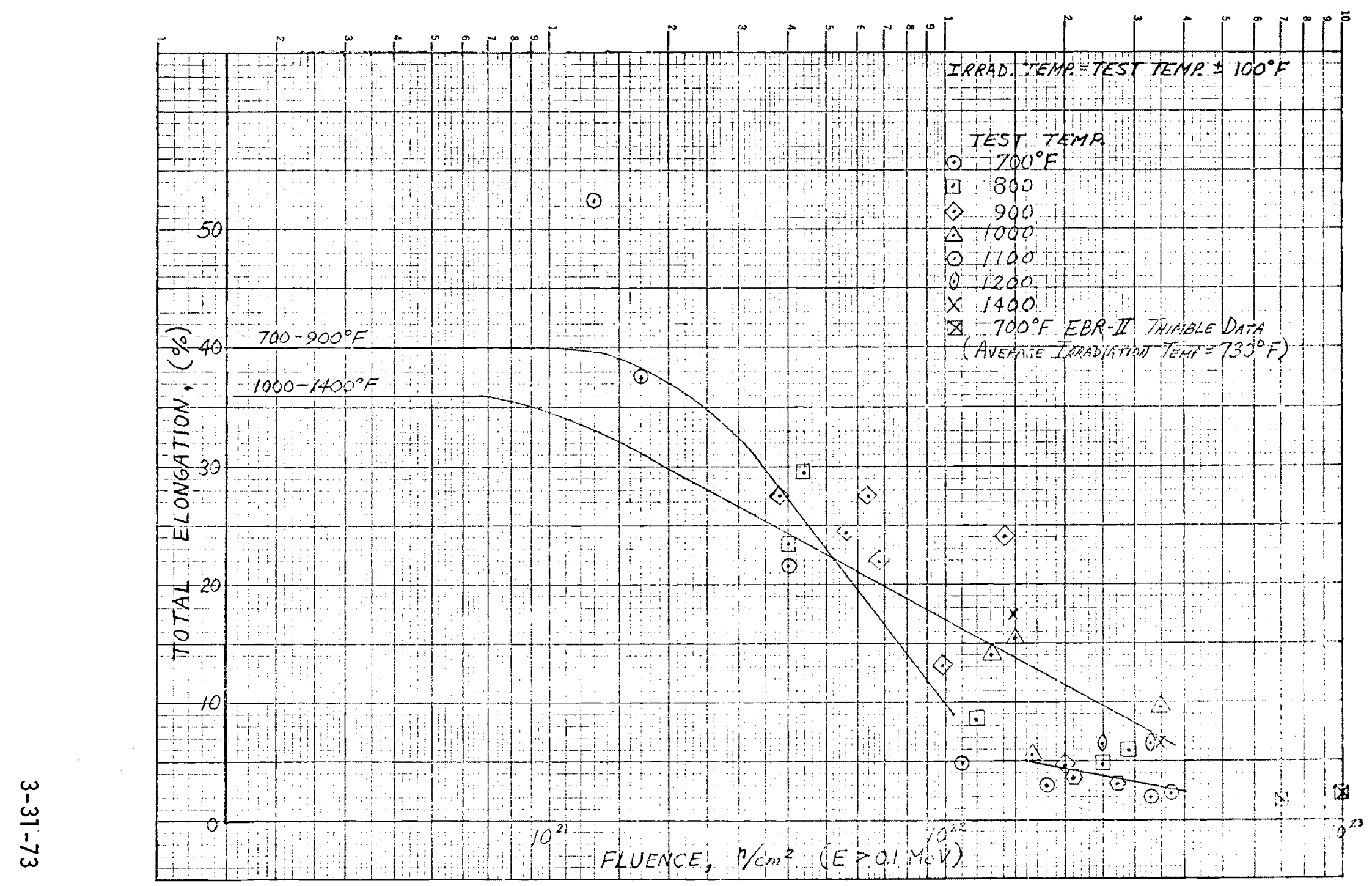




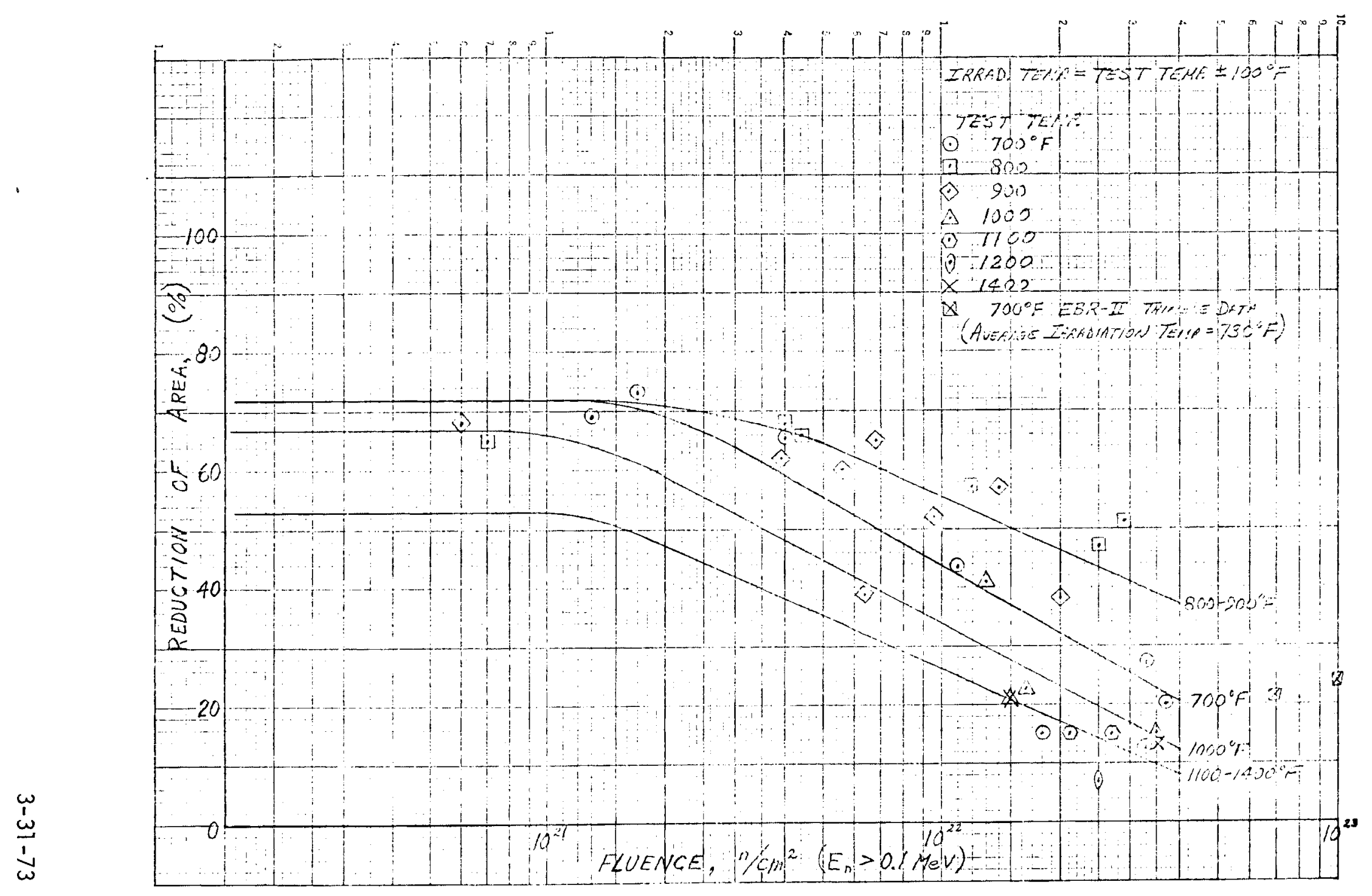

$\stackrel{\sim}{\sim}$
$\stackrel{\nu}{\nu}$

FIGURE 2.2.2-1(f) Post-Irradiation Reduction of Area of Annealed 304 Stainless Steel 


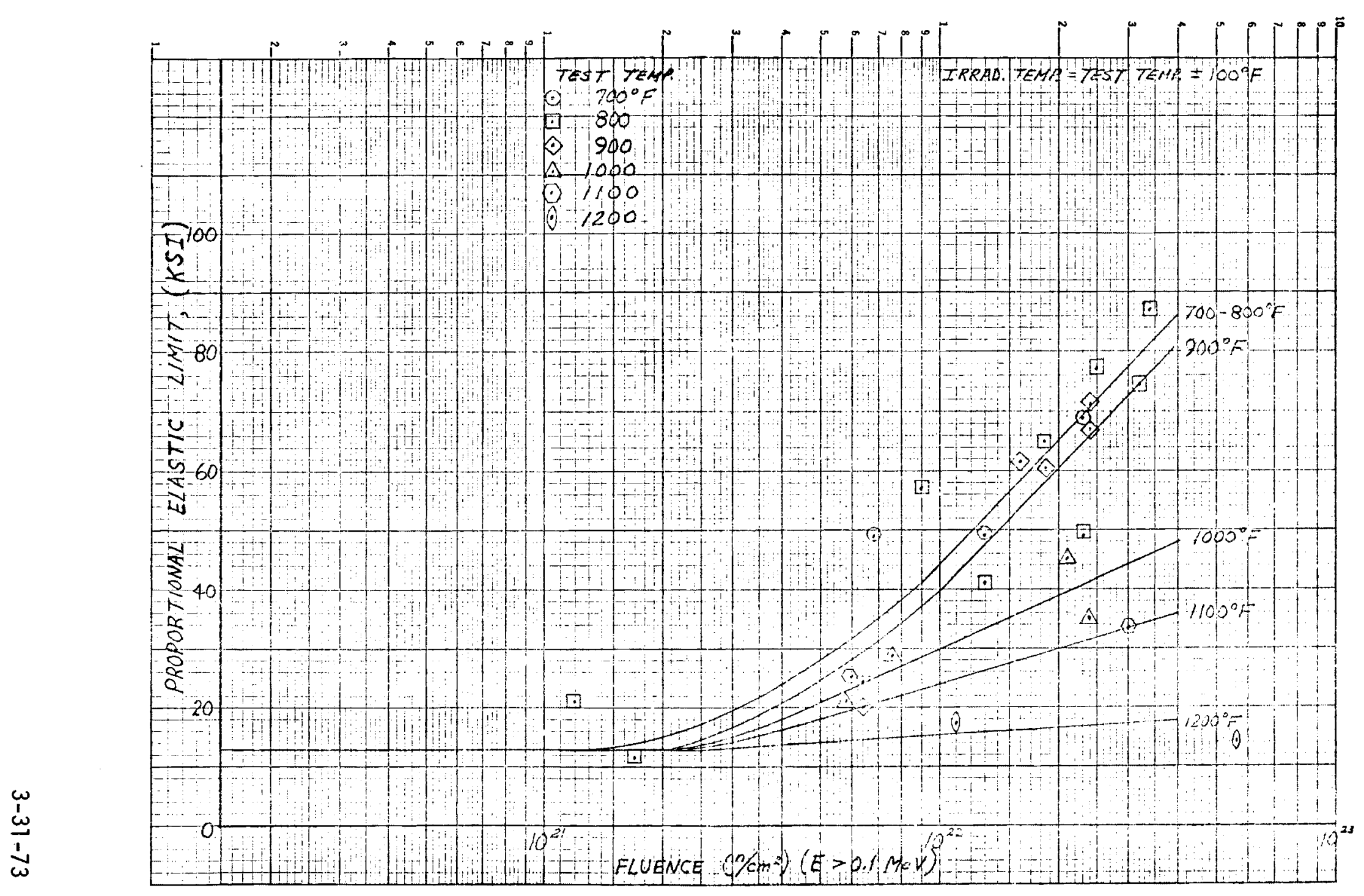

$N$
$\vdots$
1
1

FIGURE 2.2.2-2(a) Post-Irradiation Proportional Elastic Limit of Annealed 316 Stainless Steel 


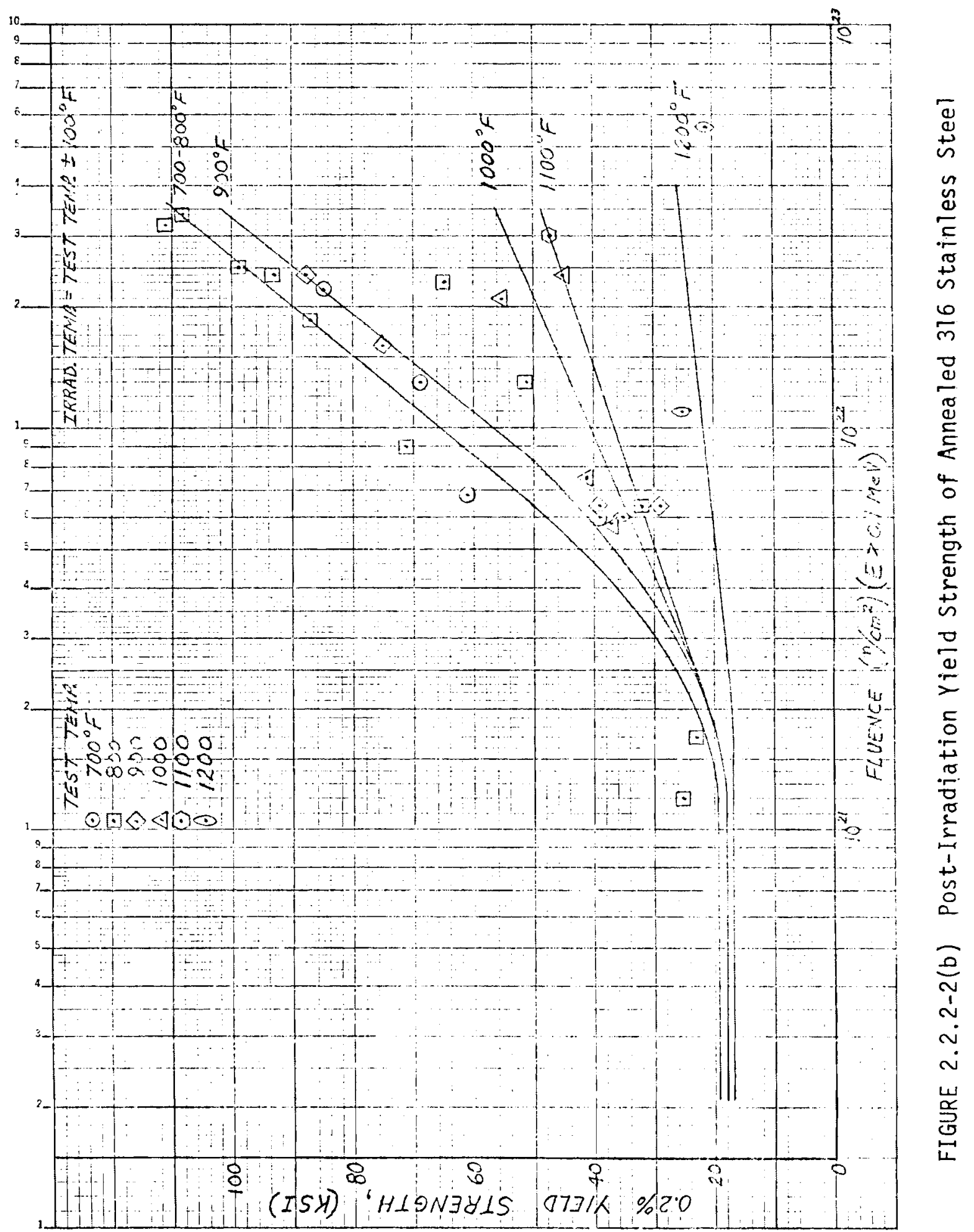




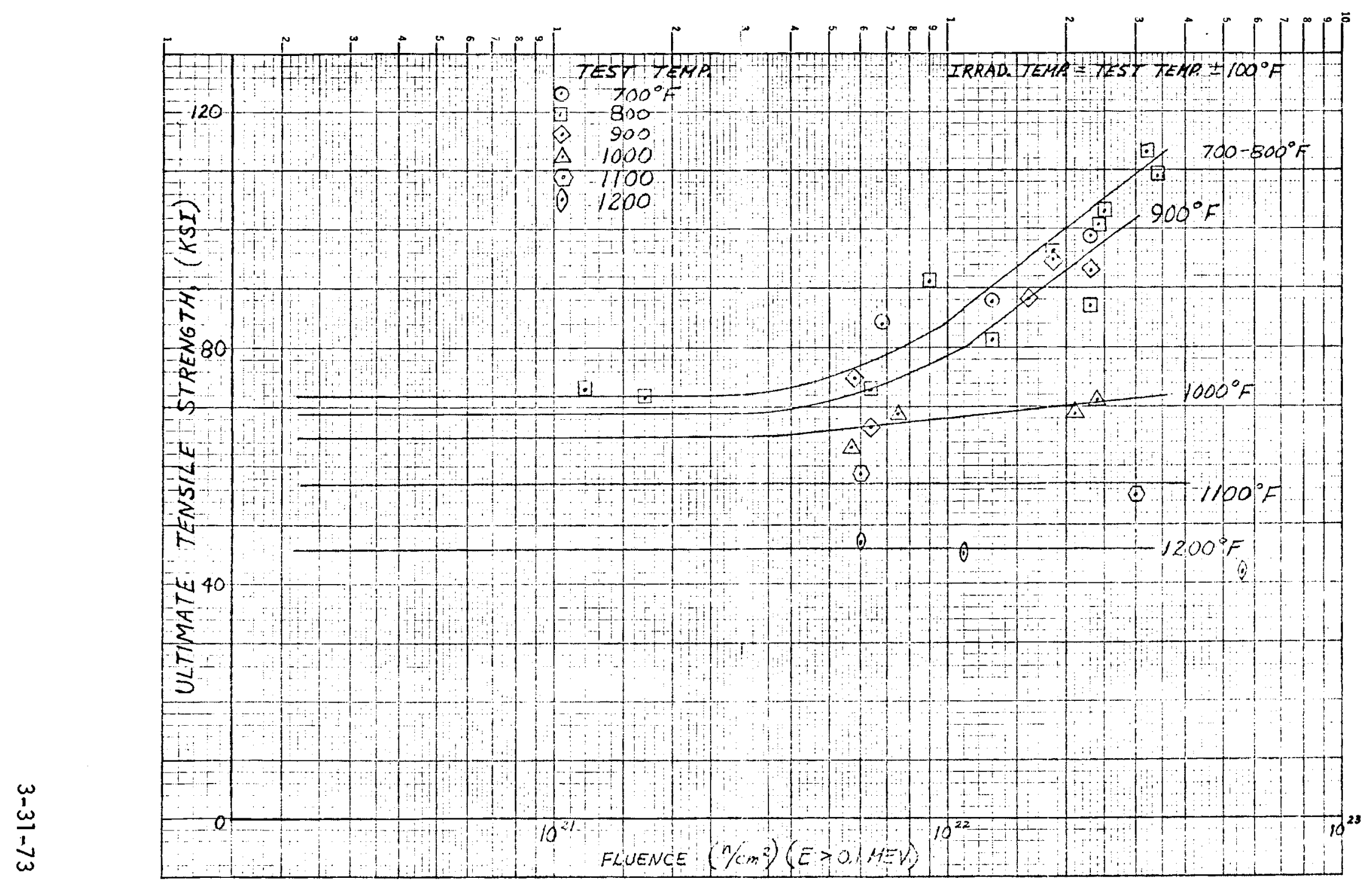

FIGURE 2.2.2-2(c) Post-Irradiation Ultimate Tensile Strength of Annealed 316 Stainless Steel 


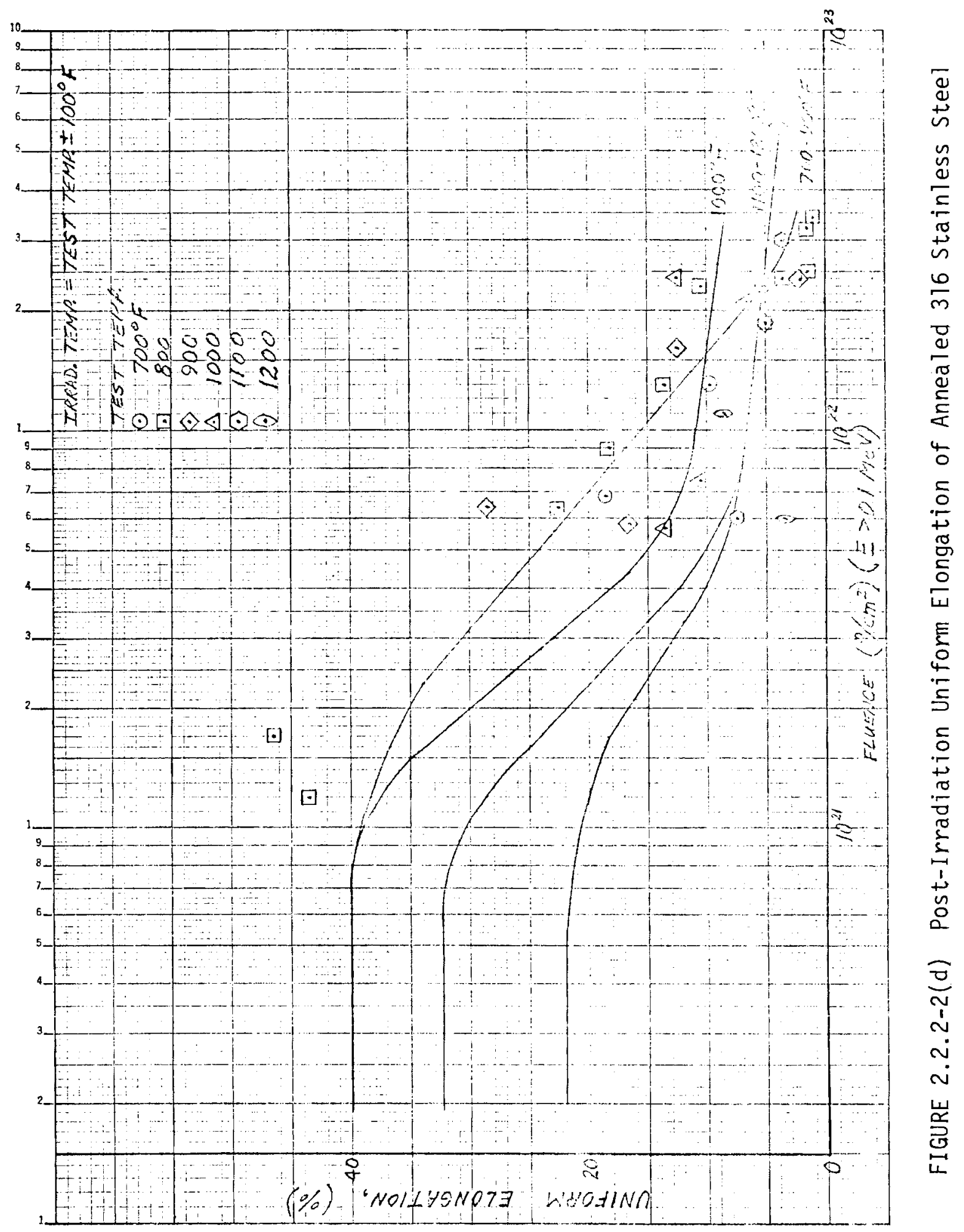




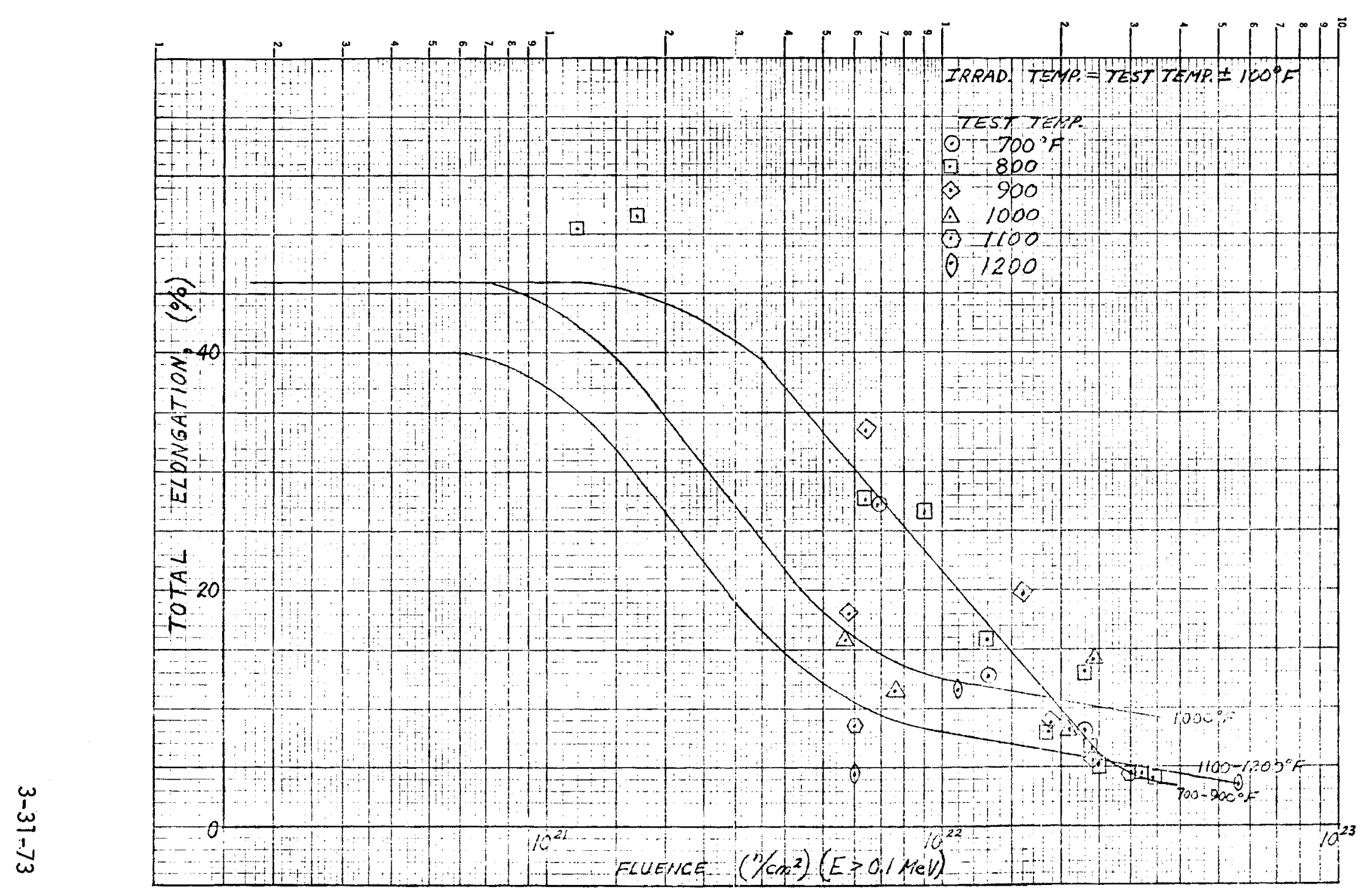

$n$
$\stackrel{N}{N}$
$\frac{1}{N}$

FIGURE 2.2.2-2(e) Post-Irradiation Total Elongation of Annealed 316 Stainless Steel 


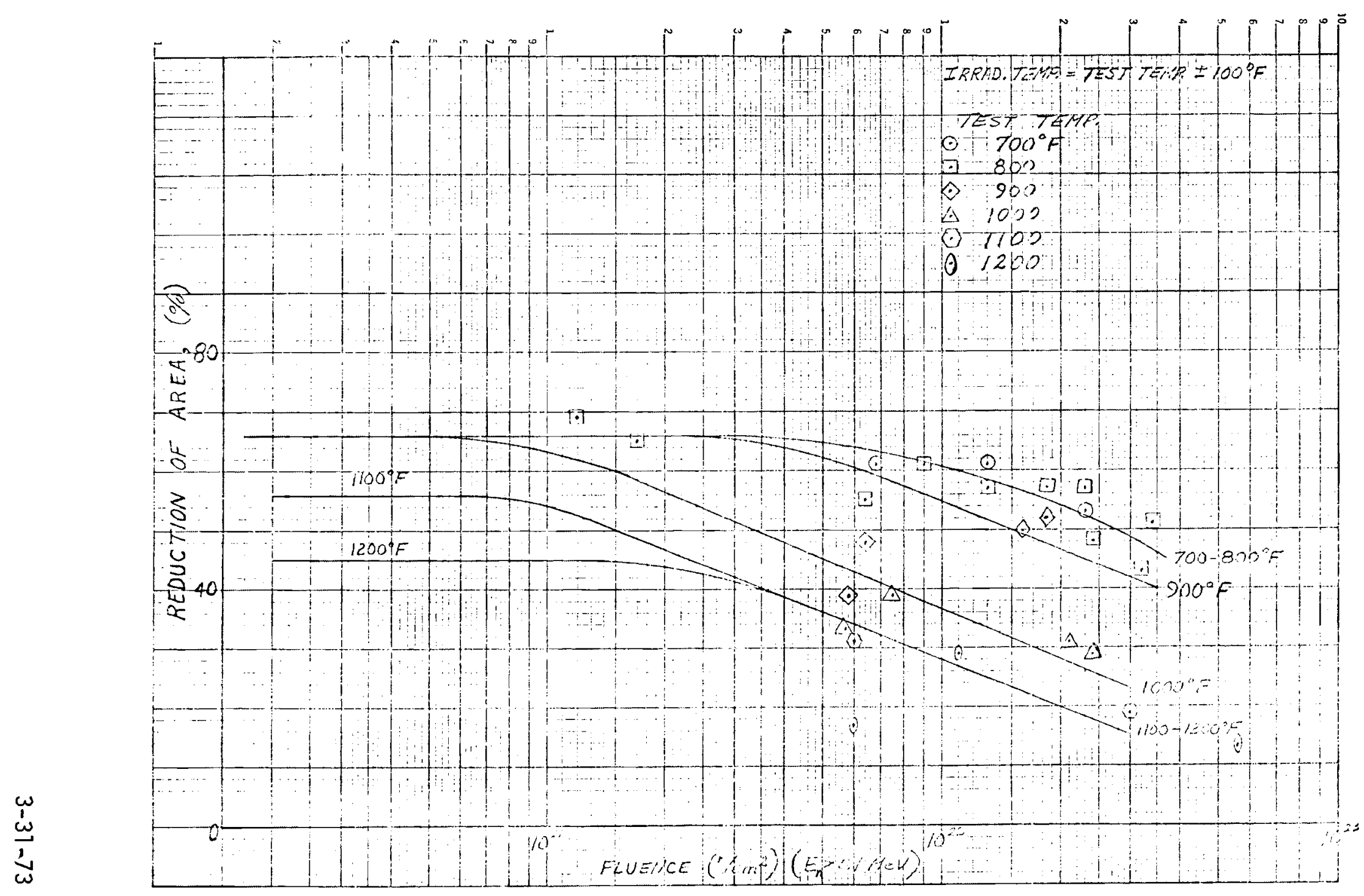

FIGURE 2.2.2-2(f) Post-Irradiation Reduction of Area of Annealed 316 Stainless Steel 


\subsection{2-14}

The ductility (uniform elongation) of annealed 316 stainless stee 1 has recently been analyzed in terms of temperature, strain-rate and fluence. ${ }^{(3)}$ In this analysis, the deformation behavior relative to temperature and strain-rate is described by three domains, as shown in Figure 2.2.2-3. Observed and extrapolated variations of ductility with fluence and temperature are given in Figure 2.2.2-4. 


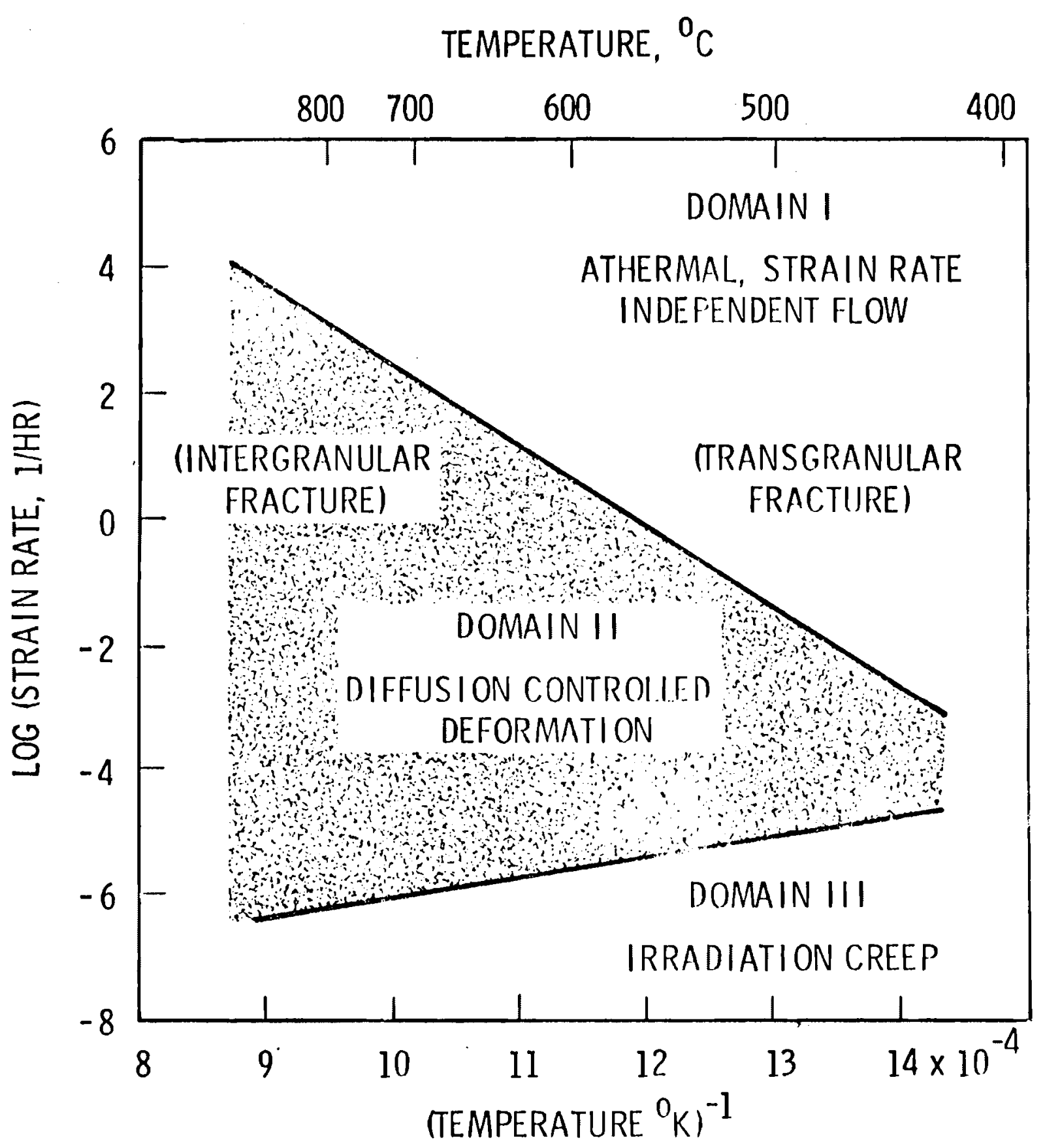

FIGURE 2.2.2-3 Deformation Process Domains in Annealed 316 Stainless Steel 


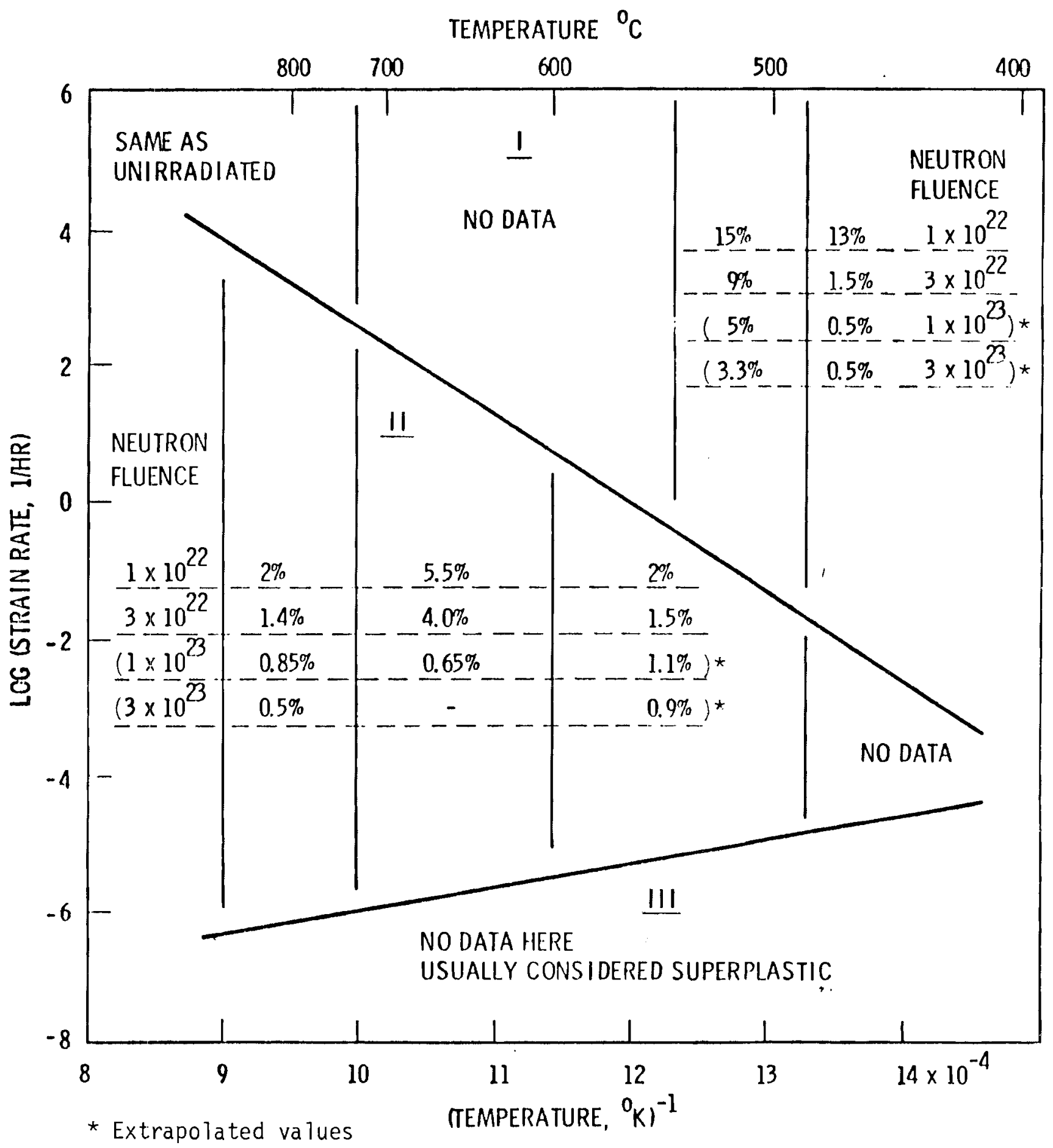

FIGURE 2.2.2-4 Ductilities for Deformation Process Domains in Irradiated Annealed 316 Stainless Steel 


\section{REFERENCES}

1. R. L. Fish, J. L. Straalsund, C. W. Hunter, and J. J. Holmes, "Swelling and Tensile Property Evaluations of High Fluence EBR-II Thimbles," HEDL-SA 321, presented at the ASTM 1972 Annual Meeting, Los Angeles, CA, June 25-28, 1972.

2. "Material Considerations in Support of the FFTF Preliminary Safety Analysis, Report-RM9, Vol 1," HEDL-TME 71-53, Apri1 1971.

3. J. J. Holmes, A. J. Lovell, and R. L. Fish, "Ductility of Irradiated Type 316 Stainless Steel," HEDL-SA 310, presented at the ASTM 1972 Annual Meeting, Los Angeles, CA, June 2528,1972 . 


\subsubsection{TEST TEMPERATURE}

Mechanical properties measured at a test temperature dissimilar to the temperature of irradiation are a function of the interaction of the irradiation-induced microstructure (reflecting the combined effects of irradiation fluence and temperature), the added thermal history imposed by the temperature and duration of the test and the mode of deformation and failure representative of that test temperature.

Because of the variability of radiation-induced microstructure with irradiation temperature, significant differences in properties can be observed between tests at the irradiation temperature and those within only $200^{\circ} \mathrm{F}$ or less of the irradiation temperature.

Two examples of this variation between expected mechanical properties and actual properties due to test temperature are offered. 


\subsubsection{Low Irradiation Temperature--High Test Temperature}

During the specimen pre-heat prior to a hightemperature tensile test, most irradiation defects produced by lowtemperature irradiation will be annealed out. Therefore, yield strength would not be expected to differ greatly from that of unirradiated material. However, ductility does not return to unirradiated values since, with fracture being of an intergranular mode at high temperature, helium bubbles, which do not anneal out, embrittle the grain boundaries.

Figures 2.2.3.1-1 (a,b,c,d) ${ }^{(1)}$ exemplify the low irradiation temperature-high test temperature behavior of annealed 304 stainless steel that was irradiated to a fluence of $2.0 \times 10^{22}$ at $380^{\circ} \mathrm{C}$ (designated by the symbol $\left.\otimes\right)$ ). The high irradiationinduced increase in yield strength observed at low temperatures is completely annealed at about $1300^{\circ} \mathrm{F}$ (Figure 2.2.3.1-1a). Annealing of ultimate strength also occurs; however, ultimate strength drops below unirradiated values (Figure 2.2.3.1-1b) due to the effects on ductility of helium embrittlement, as shown in Figures 2.2.3.1-1c and $d$. The low postirradiation uniform and total elongation values observed at low temperature (due to irradiation-induced hardening) do not recover at high temperature due to helium embrittlement of the grain boundaries at high temperature. 
2.2.3.1-2

\begin{tabular}{|c|c|c|c|c|c|}
\hline SYMBOL & MATERIAL & $\begin{array}{c}\text { TOTAL } \\
\text { FLUENCE } \\
(\times 1022)\end{array}$ & REFERENCE & $\begin{array}{c}\text { IRRADIATION } \\
\text { TEMPERATURE } \\
\left({ }^{\circ} \mathrm{C}\right)\end{array}$ & $\begin{array}{c}\text { STRAIN } \\
\text { RATE } \\
(\mathrm{min}-1)\end{array}$ \\
\hline$O$ & 304 & 2.0 & $(1)$ & 538 & 0.02 \\
0 & 304 & 1.7 & $(2)$ & $590 \pm 80$ & 0.002 \\
$\otimes$ & 304 & 2.0 & $(3)$ & 380 & 0.02 \\
$\nabla$ & 304 & 3.4 & $(4)$ & $590 \pm 80$ & 0.02 \\
$\Delta$ & 316 & 3.6 & $(7)$ & $250-350$ & 0.095 \\
$\Delta$ & $316 L$ & 3.4 & $(4)$ & $590 \pm 80$ & 0.02 \\
\hline ZIICD & 304 AND 316 UNIRRADIATED STANDARDS \\
\hline
\end{tabular}

TEST TEMPERATURE $\left({ }^{\circ} \mathrm{C}\right)$

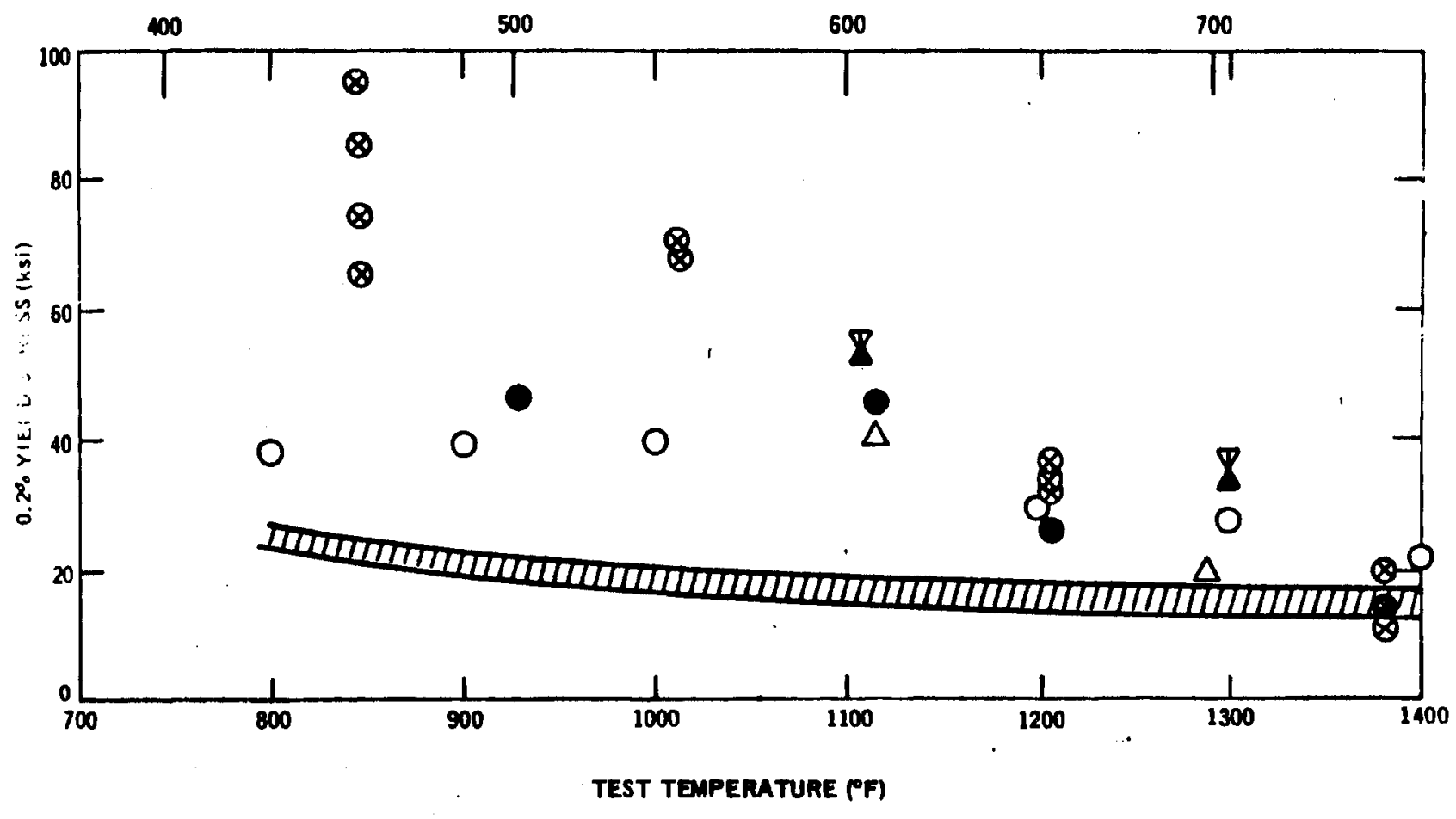

Figure 2.2.3.1-1(a) $0.2 \%$ Yield Stress Versus Test Temperature 


\section{$2.2 .3 .1-3$}

\begin{tabular}{|c|c|c|c|c|c|}
\hline SYMBOL & MATERIAL & $\begin{array}{l}\text { TOTAL } \\
\text { FLUENCE } \\
(\times 1022)\end{array}$ & REFERENCE & $\begin{array}{l}\text { TRAADIATION } \\
\text { TEMPERATURE } \\
\left.\text { ( }{ }^{\circ} \mathrm{C}\right)\end{array}$ & $\begin{array}{c}\text { STRANA } \\
\text { RATE } \\
(\min -1)\end{array}$ \\
\hline 0 & 304 & 2.0 & (1) & 538 & 0.02 \\
\hline & 304 & 1.7 & (2) & $590 \pm 80$ & 0.002 \\
\hline (2) & 304 & 2.0 & (3) & 380 & 0.02 \\
\hline $\boldsymbol{\nabla}$ & 304 & 3.4 & (4) & $590 \pm 80$ & 0.02 \\
\hline$\Delta$ & 316 & 3.6 & (7) & $250-350$ & 0.095 \\
\hline$\Delta$ & $316 L$ & 3.4 & (4) & $590 \pm 60$ & 0.02 \\
\hline Dinem & \multicolumn{3}{|c|}{304 AND 316 UNIRRADIATED STANDARDS } & & \\
\hline
\end{tabular}

TEST TEMPERATURE ${ }^{\circ} \mathrm{C}$

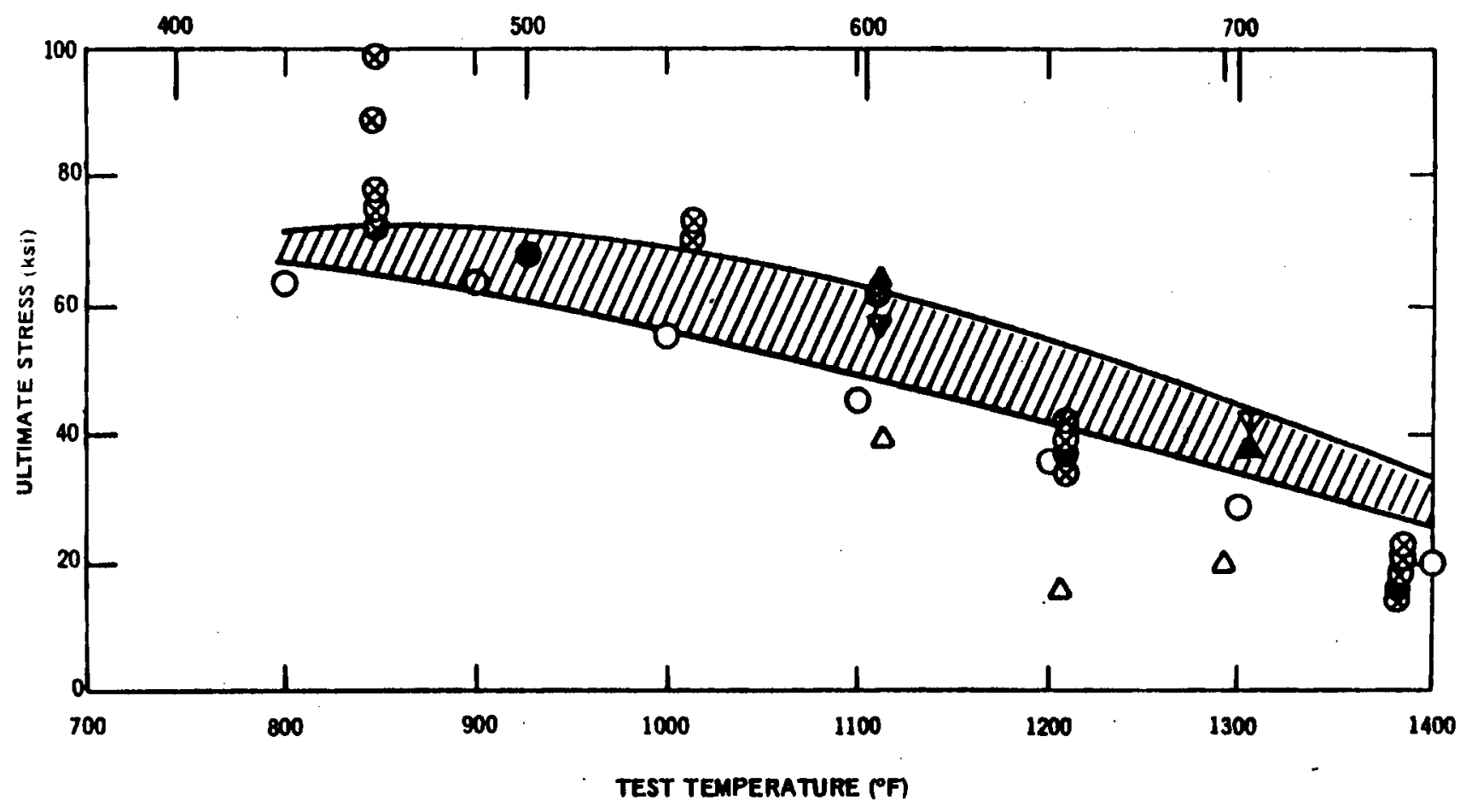

Figure 2.2.3.1-1(b) Ultimate Tensile Stress Versus Test Temperature 


\section{$2.2 .3 .1-4$}

\begin{tabular}{|c|c|c|c|c|c|}
\hline SYMBOL & MATERIAL & $\begin{array}{c}\text { TOTAL } \\
\text { FLUENCE } \\
(\times 1022)\end{array}$ & REFERENCE & $\begin{array}{c}\text { IRRADIATION } \\
\text { TEMPERATURE } \\
(\text { OC })\end{array}$ & $\begin{array}{c}\text { STRAIN } \\
\text { RATE } \\
(\text { min }-1)\end{array}$ \\
\hline 0 & 304 & 2.0 & $(1)$ & 538 & 0.02 \\
0 & 304 & 1.7 & $(2)$ & $590 \pm 80$ & 0.002 \\
$\otimes$ & 304 & 2.0 & $(3)$ & 380 & 0.02 \\
$\nabla$ & 304 & 3.4 & $(4)$ & $590 \pm 80$ & 0.02 \\
$\Delta$ & 316 & 3.6 & $(7)$ & $250-350$ & 0.095 \\
$\Delta$ & $316 L$ & 3.4 & $(4)$ & $590 \pm 80$ & 0.02 \\
\hline
\end{tabular}

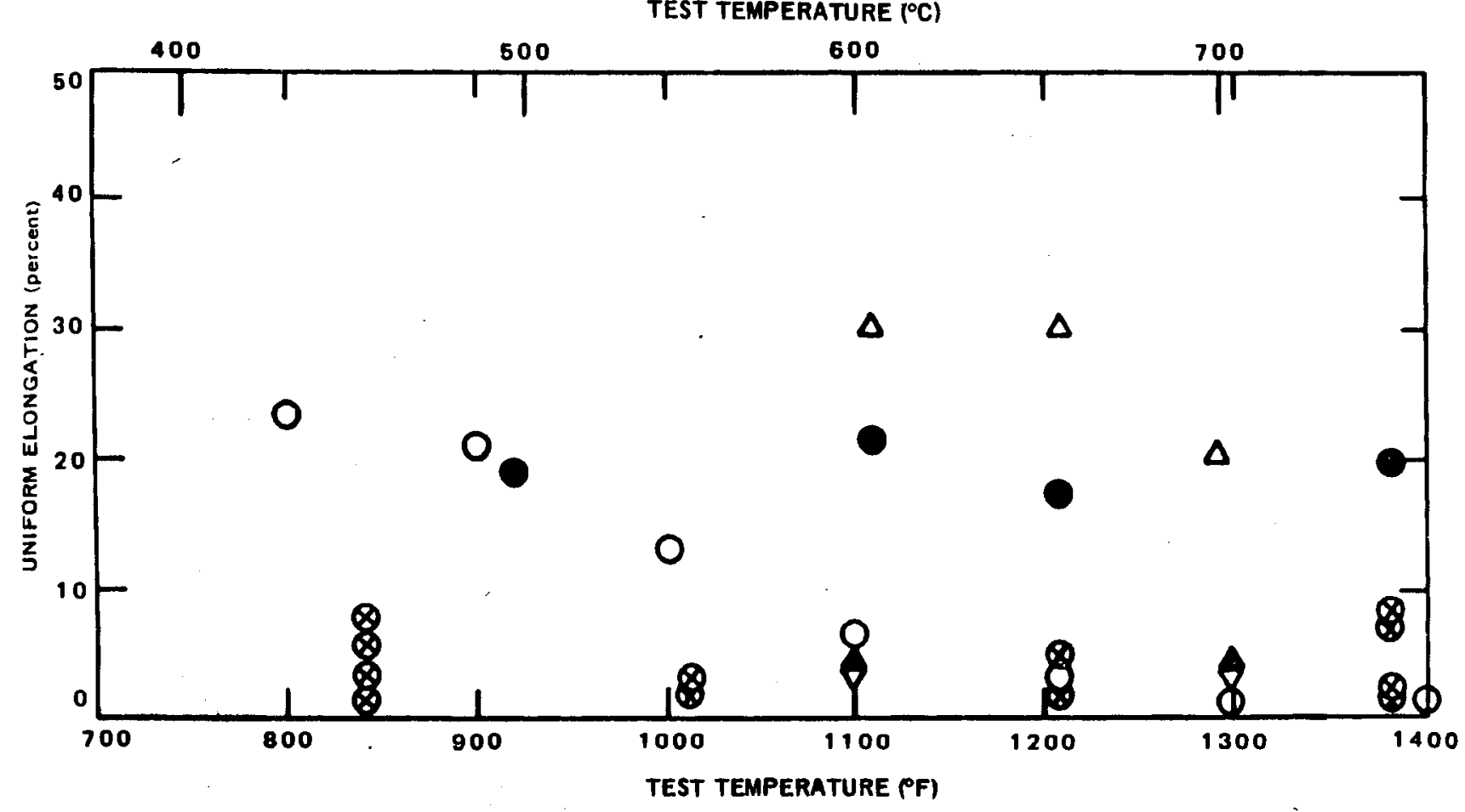

Figure 2.2.3.1-7(c) Uniform Elongation Versus Test Temperature 


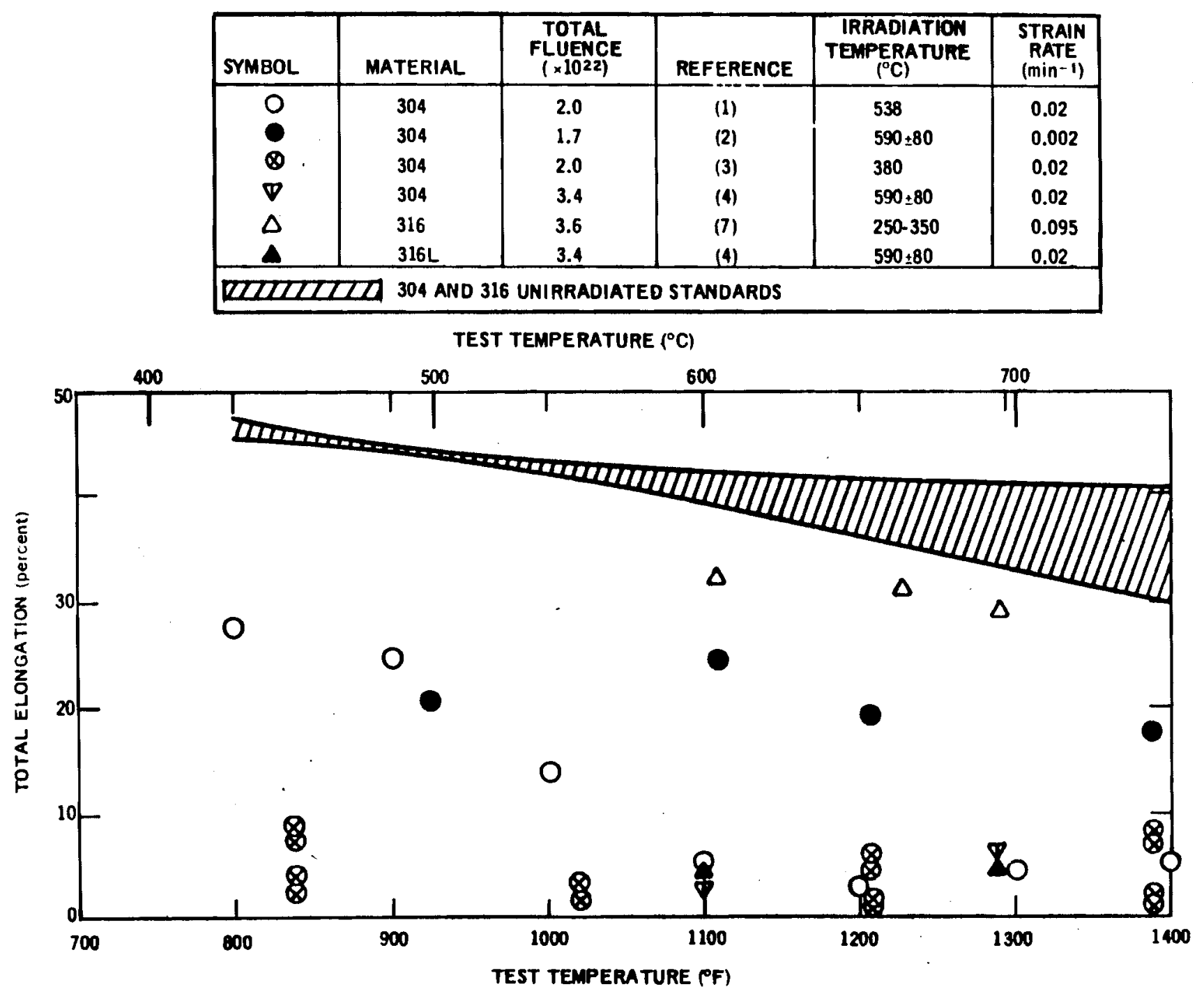

Figure 2.2.3.1-1(d) Total Elongation Versus Test Temperature 


\section{REFERENCES}

1. F.A. Camprelli, H. J. Busboom, and M. F. Gebhardt, "Mechanical Properties of Irradiated Type 304 and Type 316 Stainless Steel in Fast Reactors," GEAP-10062, General Electric Co., Sunnyvale, CA, June 1969 , p. 2-5. 


\subsubsection{High Irradiation Temperature--Low Test}

\section{Temperature}

During high-temperature irradiation (i.e., at

$\mathrm{T}>\mathrm{T}_{\mathrm{m} / 2} \approx 1020^{\circ} \mathrm{F}$ ), irradiation-produced defects are mobile. As a result, defects are more likely to annihilate one another by recombination or to be lost to sinks than they are to combine into stable defect clusters and loops. Thus, high-temperature irradiation does not produce as significant hardening as does low-temperature irradiation (of course, as fluence or flux goes to very high levels, higher irradiation temperatures are required to prevent hardeningl. Figure 2.2.3.1-1(a) showed that for 304 stainless steel irradiated at $2.0 \times 10^{22} \mathrm{n} / \mathrm{cm}^{2}$, specimens irradiated at $538^{\circ} \mathrm{C}\left(1000^{\circ} \mathrm{F}\right.$ ) (designated by the symbo1O) have a much lower yield strength at low-temperature than do specimens irradiated at on $1 y 380^{\circ} \mathrm{C}\left(716^{\circ} \mathrm{F}\right)$ (designated by the symbol $\otimes)$.

Moreover, a high-irradiation temperature wil1 tend to cause recovery of fabrication-produced dislocation structures, i.e., cold work. As a result, post-irradiation strength will be less than unirradiated strength when the cold-worked material is tested below normal recovery temperatures. Figure 2.2.3.2-1 (1) shows that when $20 \%$ cold-worked type 316 stainless steel is irradiated at fluence levels from 0.2 to $0.75 \times 10^{22} \mathrm{n} / \mathrm{cm}^{2}$ at temperatures from 865 to $1110^{\circ} \mathrm{F}$ post-irradiation yield strength values at $1000^{\circ} \mathrm{F}$ drop below unirradiated values at irradiation temperatures $\geq 960^{\circ} \mathrm{F}$.

However, ductility at $1000^{\circ} \mathrm{F}$ is not substantially altered by this elevated-temperature irradiation as shown in Figure 2.2.3.2-2. This is apparently due to two factors: 1) since transgranular fracture is the failure mode at $1000^{\circ} \mathrm{F}$, helium does not contribute to embrittlement; and 2) the combination of incomplete recovery plus some irradiation-hardening has prevented ductility from increasing to unirradiated annealed values. 


\section{$2 \cdot 2 \cdot 3 \cdot 2-2$}

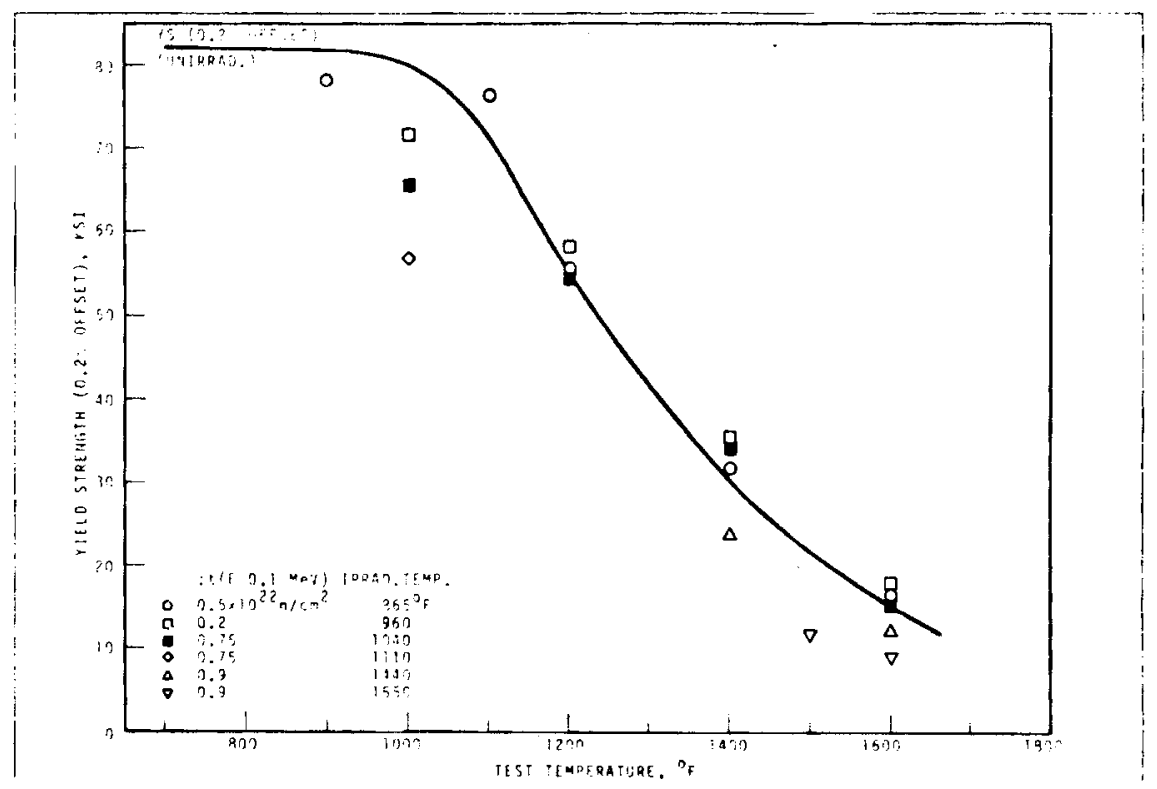

FIGURE 2.2.3.2-1 Effect of EBR-II Irradiation on the Yield Strength of $20 \%$ CW Type 316 Stainless Steel 


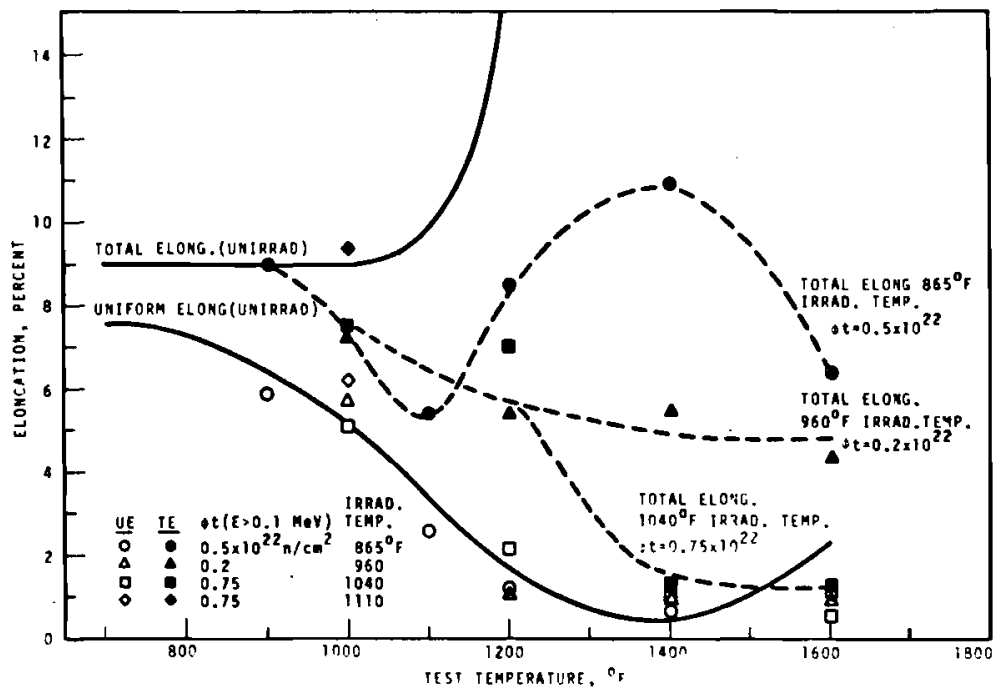

Figure 2.2.3.2-2 Effect of EBR-II Irradiation on the Elongation of $20 \% \mathrm{CW}$ Type 316 Stainless Steel 


\section{REFERENCES}

1. "Month7y Technical Progress Report, Hanford Engineering Development Laboratory," HEDL-TMT 72-8, August 1972, p. B32. 


\subsection{OTHER FACTORS INFLUENCING IRRADIATION EFFECTS}

ON TENSILE PROPERTIES

\subsubsection{INTRODUCTION}

The other factors influencing irradiation effects on tensile properties can be broadly classified as those resulting from reactor variables and those resulting from material variables.

Reactor variables that have been observed to influence tensile properties (beyond those already discussed in Section 1.2) are those associated with the production of neutrons: the flux (or dose rate, $\mathrm{n} / \mathrm{cm}^{2} / \mathrm{sec}$ ); the spectrum of neutron energies; the amount of helium generated by nuclear transformations ( $n / \alpha$ reactions); and the effect of prior stress.

Material variables that have been observed to influence irradiated tensile properties are alloy composition and microstructure. Since these are often intimately connected (to produce precipitation, for example), they will be considered together. Those microstructural features, however, that have been introduced during processing, such as cold work, will be considered separately. 


\subsubsection{EFFECT OF REACTOR VARIABLE}

\subsubsection{Effect of Flux (Dose Rate)}

The rate at which a metal is bombarded by neutrons

(i.e., the flux or dose rate) determines the rate of vacancy and interstitial production. The greater fast neutron flux in fast reactors than in thermal reactors $\left(\gtrsim 10^{2}\right)$ leads to irradiation strengthening at higher irradiation temperatures than observed in thermal reactors. This is due to higher damage accumulation as well as to defect agglomeration (i.e., loops and voids).

Careful analysis has indicated that between representative fast reactors, such as EBR-II, DFR and FFTF, however, no significant engineering differences are to be expected from flux effects. 


\subsubsection{Effect of Spectrum}

Neutrons generated from fuel burnup have a spectrum of energies. The "damage" produced by a given neutron spectrum (i.e., the number of vacancies and interstitial) is a function of the average energy of the neutron flux. The "harder" the spectrum (i.e., the higher the average energy), the greater is the damage and, thus, the greater the potential effect on tensile properties. There are significant spectrum differences between fast reactors and these differences must be considered when extrapolating data. Various theoretical models indicate, for example, that the FFTF environment is only $50-68 \%$ as "damaging" for a given fluence as is that of EBR-II. (1)

Procedures are being developed in an attempt to predict material performance under different neutron environment. $(2,3,4)$ These procedures involve the definition of the damage function or cross-section that relates the energy of a neutron to its effectiveness in causing a specific property change. This damage function, along with the neutron energy distribution, or spectrum, at the point of interest is used to define the fluence required to cause a given property change in a material for different reactors or different positions in the same reactor.

Figures 2.3.2.2-1 and -2 present, respectively, the variation of yield strength ${ }^{(3)}$ and total elongation ${ }^{(4)}$ with total neutron fluence for different spectra as calculated, to date, using these techniques for type 304 stainless steel. From these figures, one can predict the fluence required to produce, in different reactor positions or in different reactors, a given property value such as, a yield strength of $60 \mathrm{ksi}$ or a total elongation of $10 \%$ in 304 stainless steel. 


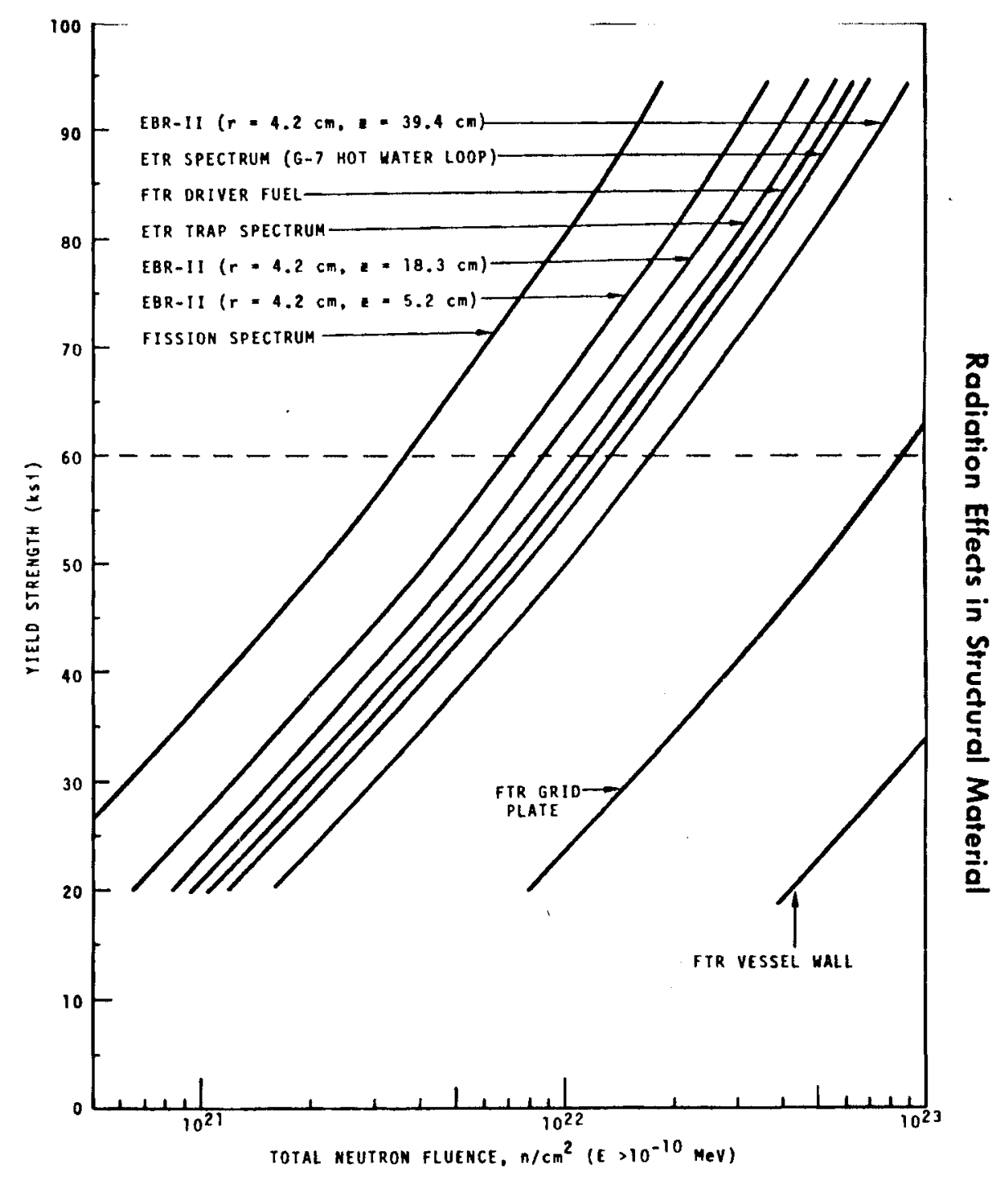

Figure 2.3.2.2-1 Yield Strength for 304 Stainless Stee 1 Versus Total Fluence for Different Spectra (test and irradiation temperature of $2.450^{\circ} \mathrm{C}$ ) 
2.3.2.2-3

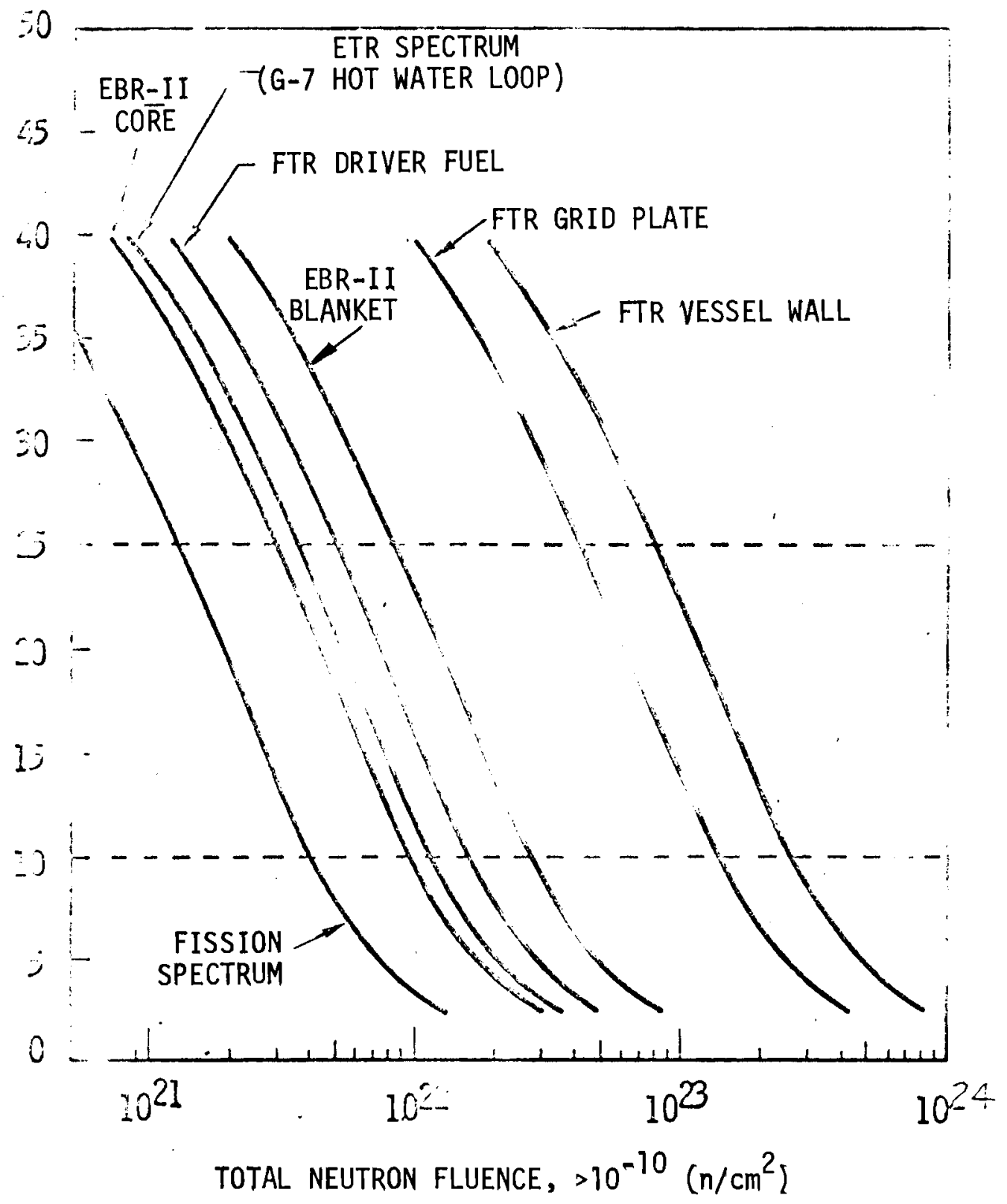

FFGURE 2.3.2.2-2 Total Elongation for 304 Stainless Steel Versus Total Fluence for Different Spectra (Test and Irradiation Temperature of $430^{\circ} \mathrm{C}$ to $540^{\circ} \mathrm{C}$ ) 


\section{REFERENCES}

1. "Material Considerations in Support of the FFTF Prel iminary Safety Analysis, Report-RM9, Vol 1," HEDL-TME 71-53, p. 4-3, April 1971.

2. W. N. McElroy, R. L. Simons, and L. D. Blackburn, Trans. ANS, 13, $144(1970)$.

3. W. N. McEl roy, R. L. Simons, and L. D. Blackburn, Trans. ANS, 13, $555(1970)$.

4. R. L. Simons, W. N. McElroy, and L. D. Blackburn, Nucl. Tech., October 1972, p. 14. 


\subsubsection{Effect of Helium Production}

There is much evidence that helium produced by nuclear transformations in stainless steel results in embrittlement and loss of ductility at test temperatures where intergranular fracture is the failure mode as indicated in Section 2.2.

Helium concentration varies with mean neutron energies and, thus, with different reactors or different positions in a given reactor. Variation in helium content between several ppm and several hundred ppm can have serious effects on ductility. Figure 2.3.2.3-1 (1) indicates the variation in helium production in stainless steel for different reactor spectra. 


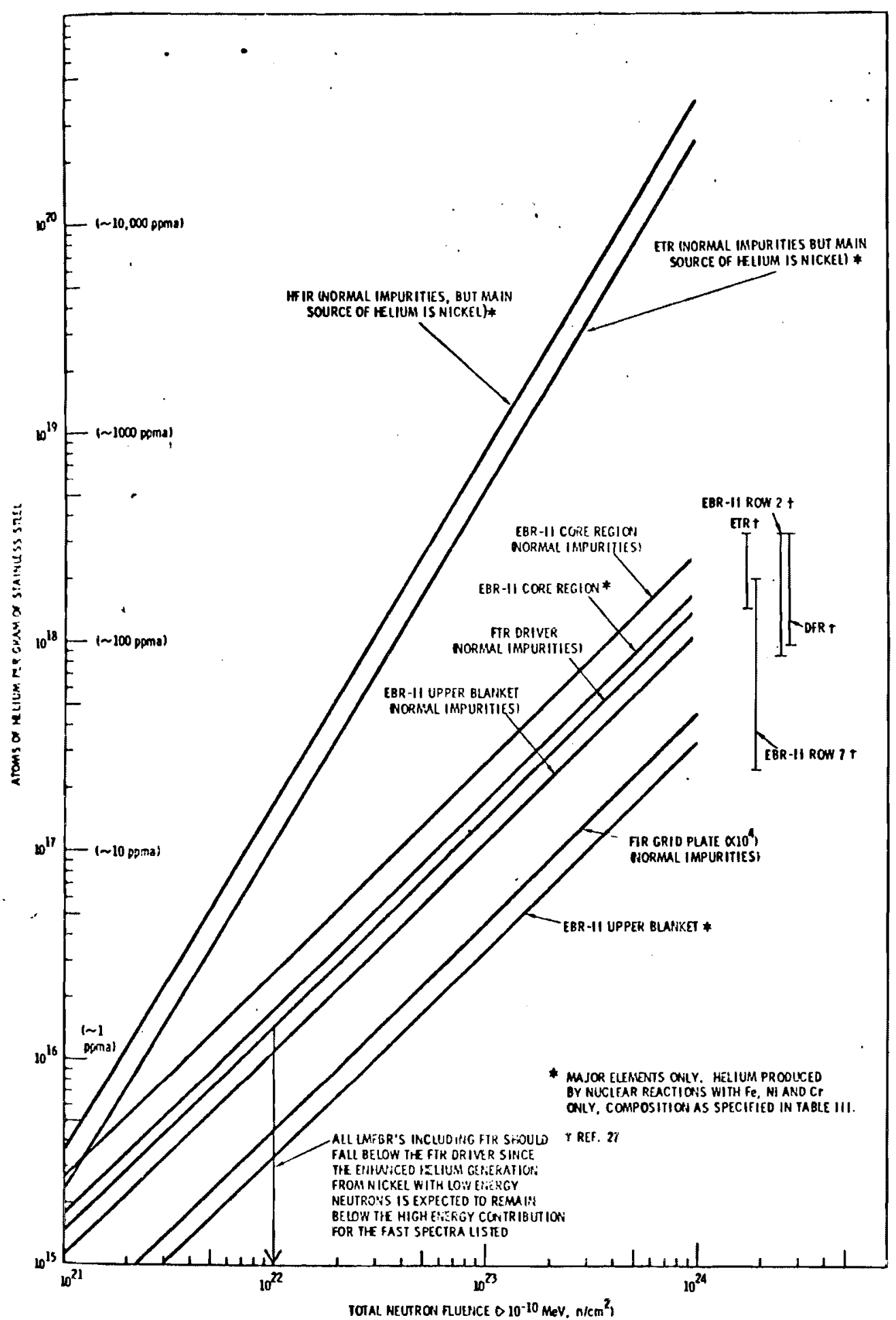

Figure 2.3.2.3-i Hei ium Production in SS for Different Reactor Spectra. 


\section{$2 \cdot 3 \cdot 2 \cdot 3-3$}

\section{REFERENCES}

1. "Quarterly Progress Report, Irradiation Effects on Reactor Structural Materials May, June, and July 1971,"

HEDL-TME $71-116$, p. HELD-123. 


\subsubsection{4-1}

\subsubsection{Effect of Prior Stress}

Core components will operate at elevated temperatures in liquid metal fast breeder reactors. With the sodium bulk outlet temperatures expected to be above $1000^{\circ} \mathrm{F}$, some heavy section components will operate above $1000^{\circ} \mathrm{F}$ and fuel elements and ducts will be operating at temperatures as high as $1400^{\circ} \mathrm{F}$. At these temperatures, stressed components will undergo creep deformation. Design criteria for core component operation specify ductility in terms of either the amount of ductility a component will use up during its lifetime (i.e., $\leq 0.7 \%$ strain on FFTF fuel cladding for a 1 steady-state operations plus anticipated faults plus transient operation ${ }^{(1)}$ ) or the amount of ductility required at end of life (i.e., 10\% residual tensile elongation for FFTF vessel, core barrel, and core support structures $\left.{ }^{(2)}\right)$. It is, therefore, important to determine if "creep damage" can occur, i.e., if prior creep can reduce residual ductility.

Limited studies have been conducted on unirradiated annealed 304 and 316 stainless steels to determine the effect of creep on residual tensile elongation. (3) Results of studies on annealed 316 stainless steel are exemplified by Figure 2.3.2.4-1. In this figure, stress-strain curves from $1000^{\circ} \mathrm{F}$ tensile tests are plotted for normal (A), aged (B) and specimens subjected to prior creep strain ( $C$ and $D)$. (Note, that the curves are not normalized to zero strain; for example, curve $D$ encompasses a total strain of only $12.6 \%$, not $19.8 \%$.

As can be seen, creep damage does occur. Curve $C$ indicates that a creep strain of only $0.6 \%$ at $1000^{\circ} \mathrm{F}$ can reduce ultimate strength by $10 \%$ and total tensile elongation by $25 \%$ at $1000^{\circ} \mathrm{F}$; curve $\mathrm{E}$ shows that a creep strain of $2.9 \%$ reduces UTS by $25 \%$ and total tensile elongation by $75 \%$ (residual value of only $12.6 \%$ ). (That this is an effect of creep and not just thermal aging can be seen by comparison of curves $B$ and $C$ ). 


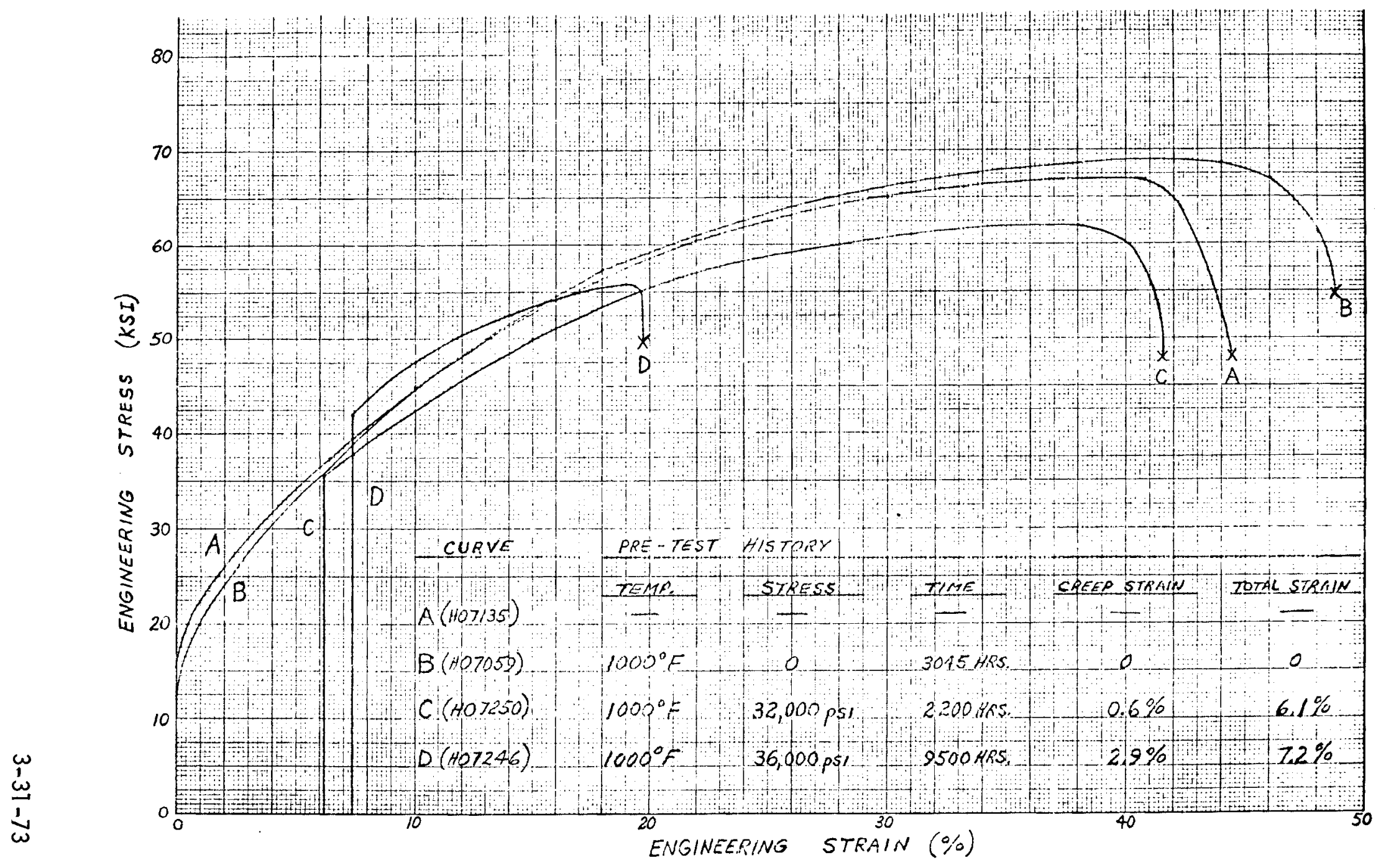

FIGURE 2.3.2.4-1 Effect of Prior Creep Deformation on the $1000^{\circ} \mathrm{F}$ Tensile Stress-Strain Curves of Annealed 316 Stainless Steel 
These reductions in properties due to prior creep are not only significant in themselves; they are also of concern when considered in the context of requirements for high residual ductility for components being concurrently subjected to the embrittiing effects of irradiation. For example, at a fluence of only $5 \times 10^{21} \mathrm{n} / \mathrm{cm}^{2}$, the $1000^{\circ} \mathrm{F}$ total elongation of annealed 316 stainless stee 1 is only about $15 \%$ and at $5 \times 10^{22} \mathrm{n} / \mathrm{cm}^{2}$, it is estimated to be on $1 y$ $8 \%$; these already low values may be further reduced by creep damage. 


\subsubsection{4-4}

\section{REFERENCES}

1. FOT-362: SDD-31, Rev. 5, "Reactor," Vol 1, p. 1.3.1.-7, January $19,1973$.

2. ibid, p. 1.2-8.

3. Material Considerations in Support of the FFTF Preliminary Safety Analys is, Report-RM9, Vol II, Appendix C," HELD-TME 71-53, 1971. 


\subsubsection{EFFECT OF MATERIALS VARIABLES}

\subsubsection{Effect of Alloy Composition}

There has been obtained to date sufficient highfluence irradiation data to indicate that there is a dependence, sometimes a marked one, of irradiation damage on alloy composition.

While steels, nickel-base alloys and some refractory metals and alloys have been investigated, only the steels and nickel alloys shall be discussed here since they are most usually considered in reference to LMFBR applications.

The variations in damage that can be observed within, and between, these two alloy systems appear to be related to the effects of alloy composition on one or more of the following factors: diffusivity, irradiation-defect trapping and precipitation reactions. 


\subsection{Austenitic Steels}

In the steels, annealed 304 and 316 stainless steels appear to respond to irradiation in generally the same way. That is, irradiation to $\sim 3 \times 10^{22} \mathrm{n} / \mathrm{cm}^{2}(\mathrm{E}>0.1 \mathrm{MeV})$ increases yield strengths for irradiation test temperatures bel ow $1400^{\circ} \mathrm{F}$ while above this temperature strengths similar to unirradiated values are obtained; postirradiation ultimate strengths are the same or slightly above unirradiated values at $T \leq 1100^{\circ} \mathrm{F}$, while above this temperature, they fall below unirradiated values due to lowered total elongation; and at all temperatures uniform and total elongation are well below unirradiated values.

Alloy modification to the basic 304 and 316 compositions have been examined to determine the potential of this approach towards reduction of irradiation damage. Additions of titanium to 316 stainless steel indicate significant benefits. (1)

As indicated in Table 2.3.3.1.1-1, irradiation to about $1 \times 10^{22} \mathrm{n} / \mathrm{cm}^{2}$ does not appreciably degrade properties of annealed type $316+0.23 \% \mathrm{Ti}$ stainless steel while those of the standard material are seriously affected. This comparison is particularly evident with reference to ductility. 
TABLE 2.3.3.1.1-1

COMPARATIVE POSTIRRADIATION TENSILE PROPERTIES OF ANNEALED 316 STAINLESS STEEL AND ANNEALED $316+0.23 \%$ Ti STAINLESS STEEL ${ }^{(1)}$

\begin{tabular}{|c|c|c|c|c|c|c|c|}
\hline $\begin{array}{c}\text { Irradiation } \\
\text { Temperature } \\
\left({ }^{\circ} \mathrm{F}\right)\end{array}$ & $\begin{array}{c}\text { Fluence } \\
\times 10^{22} \mathrm{n} / \mathrm{cm}^{2} \\
(\mathrm{E}>0.1 \mathrm{MeV})\end{array}$ & $\begin{array}{c}\text { Test } \\
\text { Tempera ture } \\
\left({ }^{\circ} \mathrm{F}\right)\end{array}$ & Alloy & $\begin{array}{l}0.2 \% \\
\text { YS } \\
\text { (ksi) } \\
\end{array}$ & $\begin{array}{c}\text { UTS } \\
\text { (ksi) }\end{array}$ & $\begin{array}{c}\text { Tota } 1 \\
\text { El ongation } \\
(\%)\end{array}$ & $\begin{array}{c}\text { Reduction } \\
\text { in Area } \\
(\%) \\
\end{array}$ \\
\hline-- & 0 & 932 & $316+\mathrm{Ti}$ & 21.2 & 84.5 & 47.8 & 58.8 \\
\hline 950 & 1.5 & 932 & $316+\mathrm{Ti}$ & 35.1 & 78.3 & 31.9 & 50.6 \\
\hline-- & 0 & 1000 & 316 & 18.0 & 65.0 & 46.0 & 66.0 \\
\hline 1000 & 1.5 & 1000 & 316 & 46.0 & 69.5 & 11.5 & 31.5 \\
\hline--- & 0 & 1112 & $316+\mathrm{Ti}$ & 19.7 & 80.4 & 34.7 & 42.8 \\
\hline 1165 & 1.2 & 1112 & $316+\mathrm{Ti}$ & 31.2 & 56.6 & 29.8 & 56.7 \\
\hline --- & 0 & 1100 & 316 & 18.0 & 57.5 & 40.0 & 56.0 \\
\hline 1112 & 1.2 & 1100 & 316 & 37.5 & 57.5 & 7.5 & 26.0 \\
\hline
\end{tabular}




\section{$2.3 \cdot 3 \cdot 1.1-3$}

\section{REFERENCES}

1. "Fuels and Materials Development Program Quarterly Progress, Report for Period Ending June 30, 1972," ORNL-TM-3969, p. 83. 


\subsection{Nickel-Base Alloys}

Data has recently been generated on the effect of irradiation at about $1150^{\circ} \mathrm{F}$ to a fluence of approximately $5 \times 10^{22} \mathrm{n} / \mathrm{cm}^{2}$ ( $\mathrm{E}>0.1 \mathrm{MeV}$ ) on three common nickel-base alloys: Incone $1800(35 \% \mathrm{Ni})$, Hastelloy-X (45\% Ni) and Inconel $625(65 \% \mathrm{Ni})$.

Properties were evaluated at three test temperatures (900, 1100 and $1300^{\circ} \mathrm{F}$ ) spanning the irradiation temperature by approximately $\pm 200^{\circ} \mathrm{F}$, with complementary tests being run on as-fabricated controls (i.e., specimens that received neither neutrons nor a thermal exposure similar to the irradiated specimens).

The data is presented in Figures 2.3.3.1.2-1, -2 and -3 . It is of interest to note that while all alloys show radiation embrittlement (decreased ductility relative to controls), only Incoloy 800 evidences no radiation hardening; Hastelloy $X$ and Inconel 625 show both higher yield and higher ultimate strengths. Both of these latter two alloys show extensive irradiation-induced precipitation, whereas Inconel 800 does not; this precipitation may play a role in the observed increases in strength. 
$2.3 \cdot 3 \cdot 1.2-2$

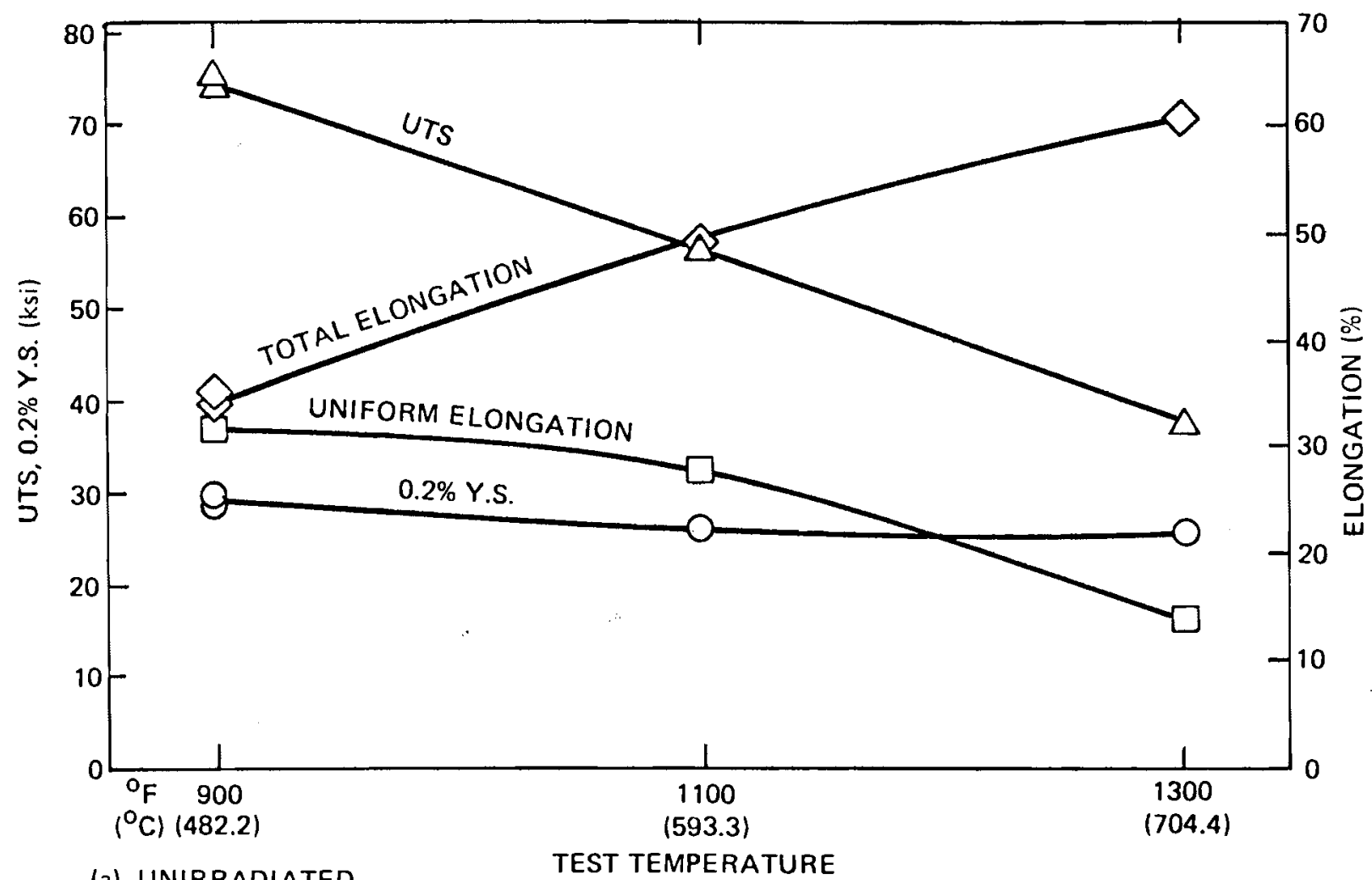

(a) UNIRRADIATED

TEST TEMPERATURE

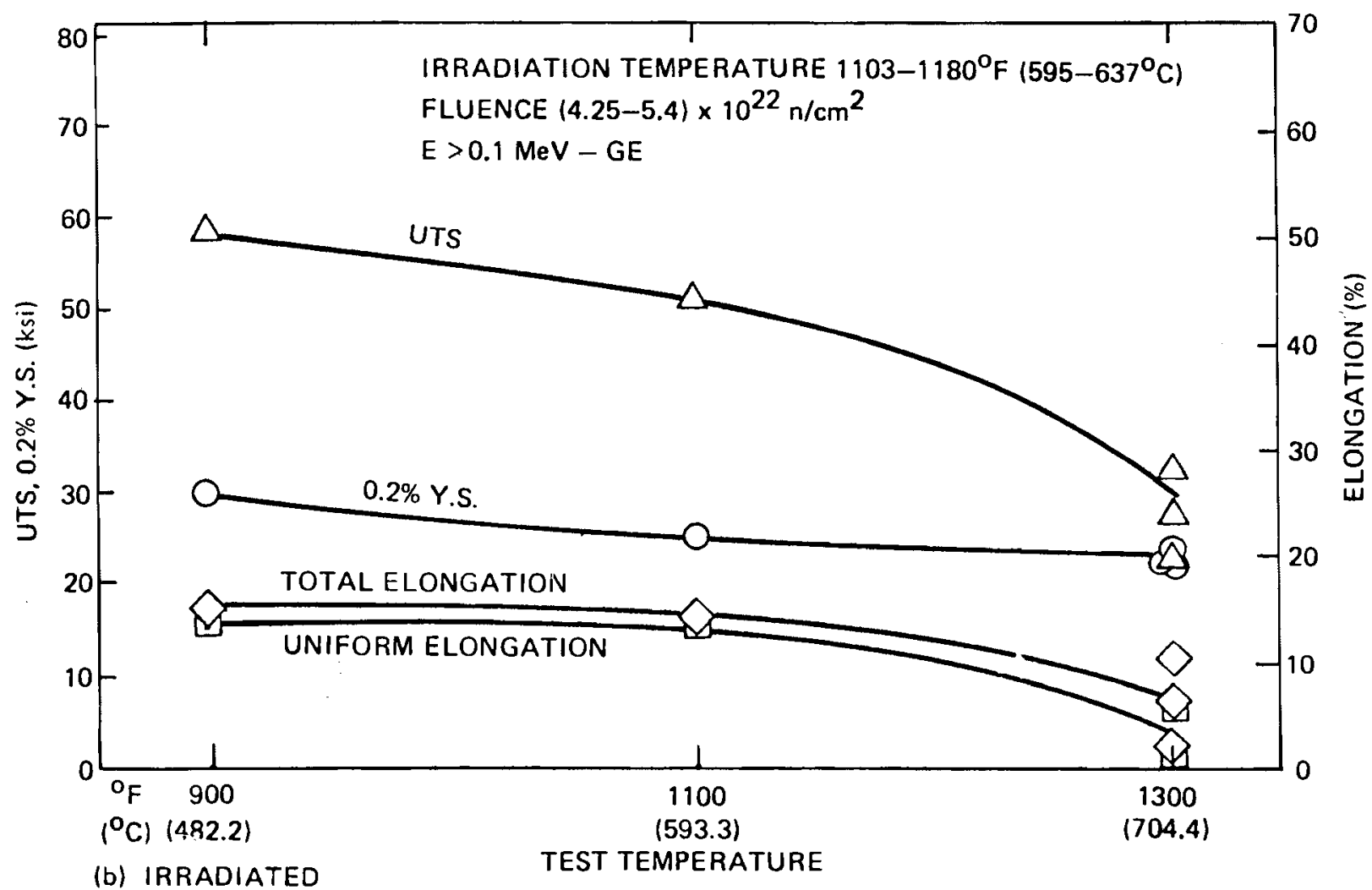

Figure 2.3.3.1.2-1 The Effect of Test Temperature on the Mechanical Properties of Incoloy-800 Strain Rate $0.02 \mathrm{~min}^{-1}$ 


\section{$2.3 \cdot 3 \cdot 1 \cdot 2-3$}

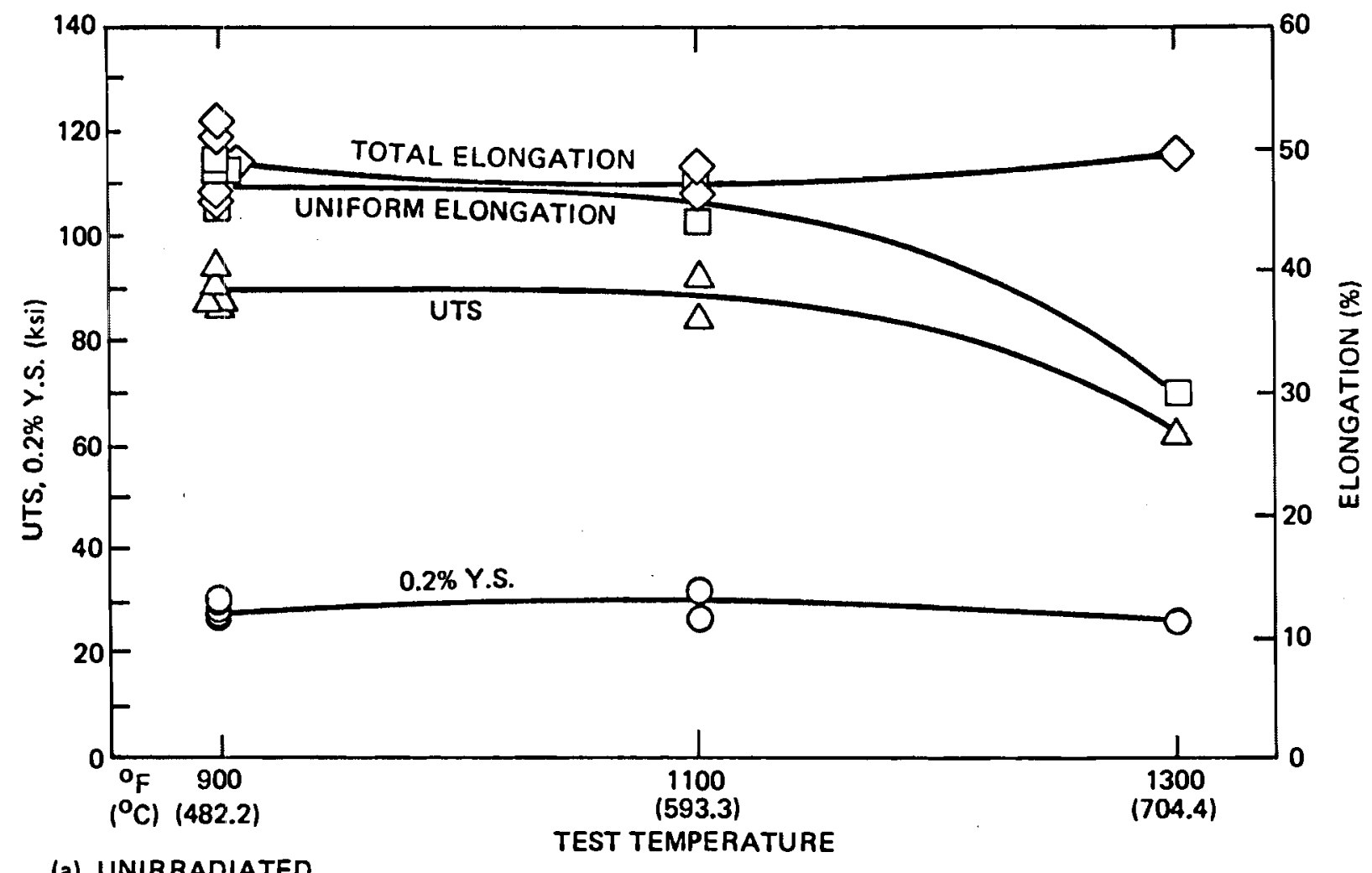

(a) UNIRRADIATED

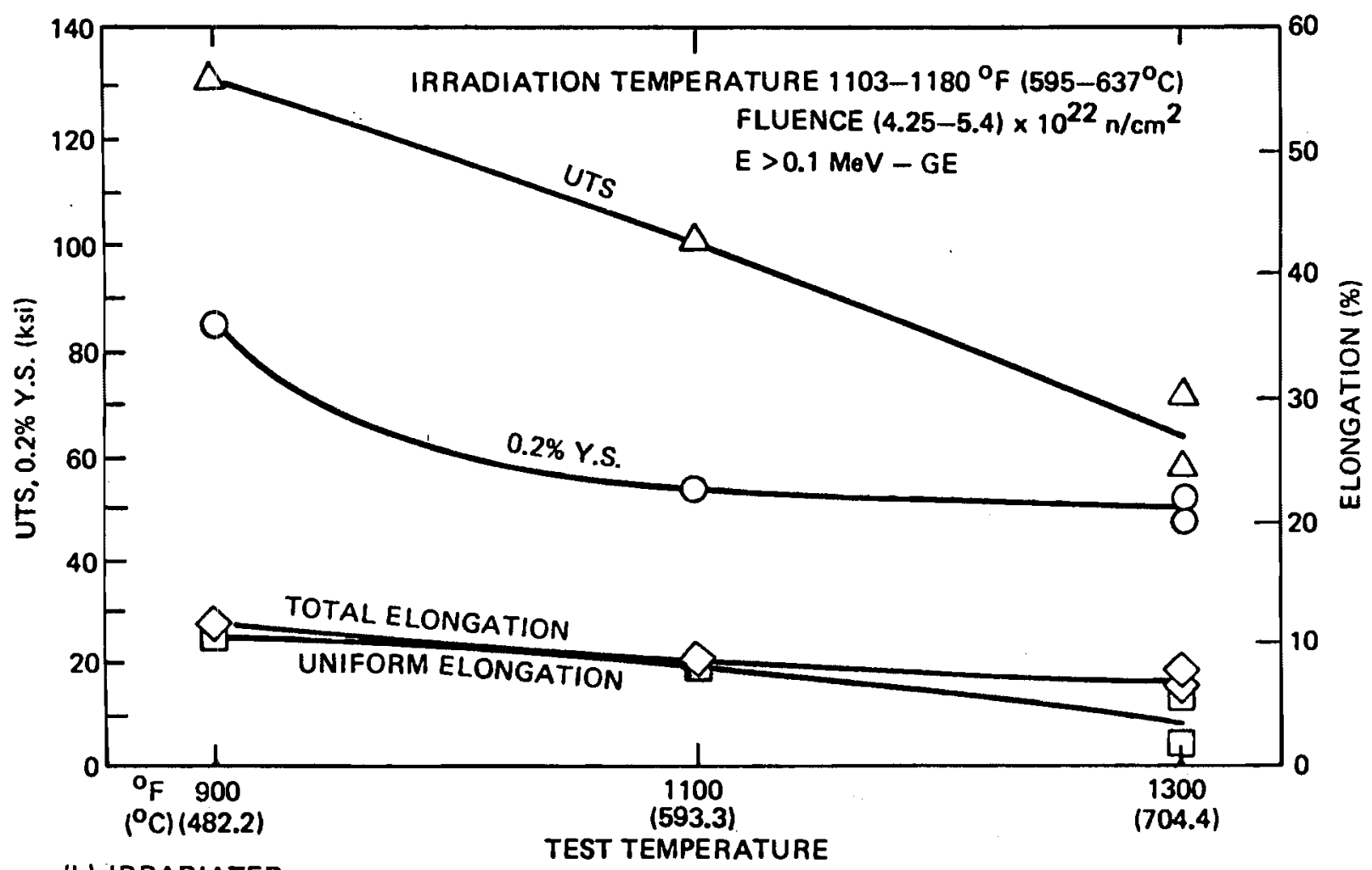

(b) IRRADIATED

Figure 2,3.3.1.2-2 The Effect of Test Temperature on the Mechanical Properties of Hastelloy-X Strain Rate $0.02 \mathrm{~min}^{-1}$ 
$2 \cdot 3 \cdot 3 \cdot 1 \cdot 2-4$

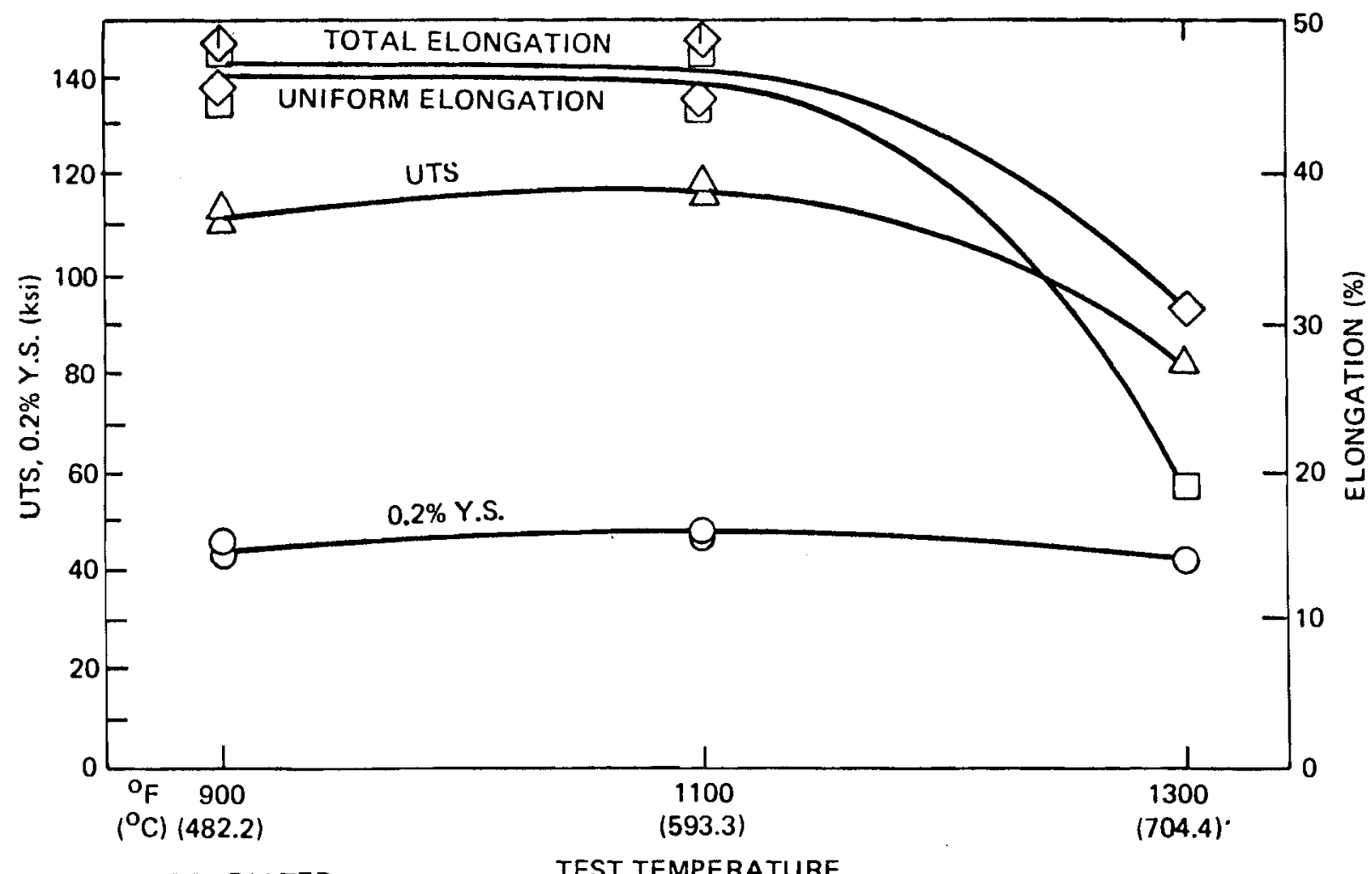

(a) UNIRRADIATED

TEST TEMPERATURE

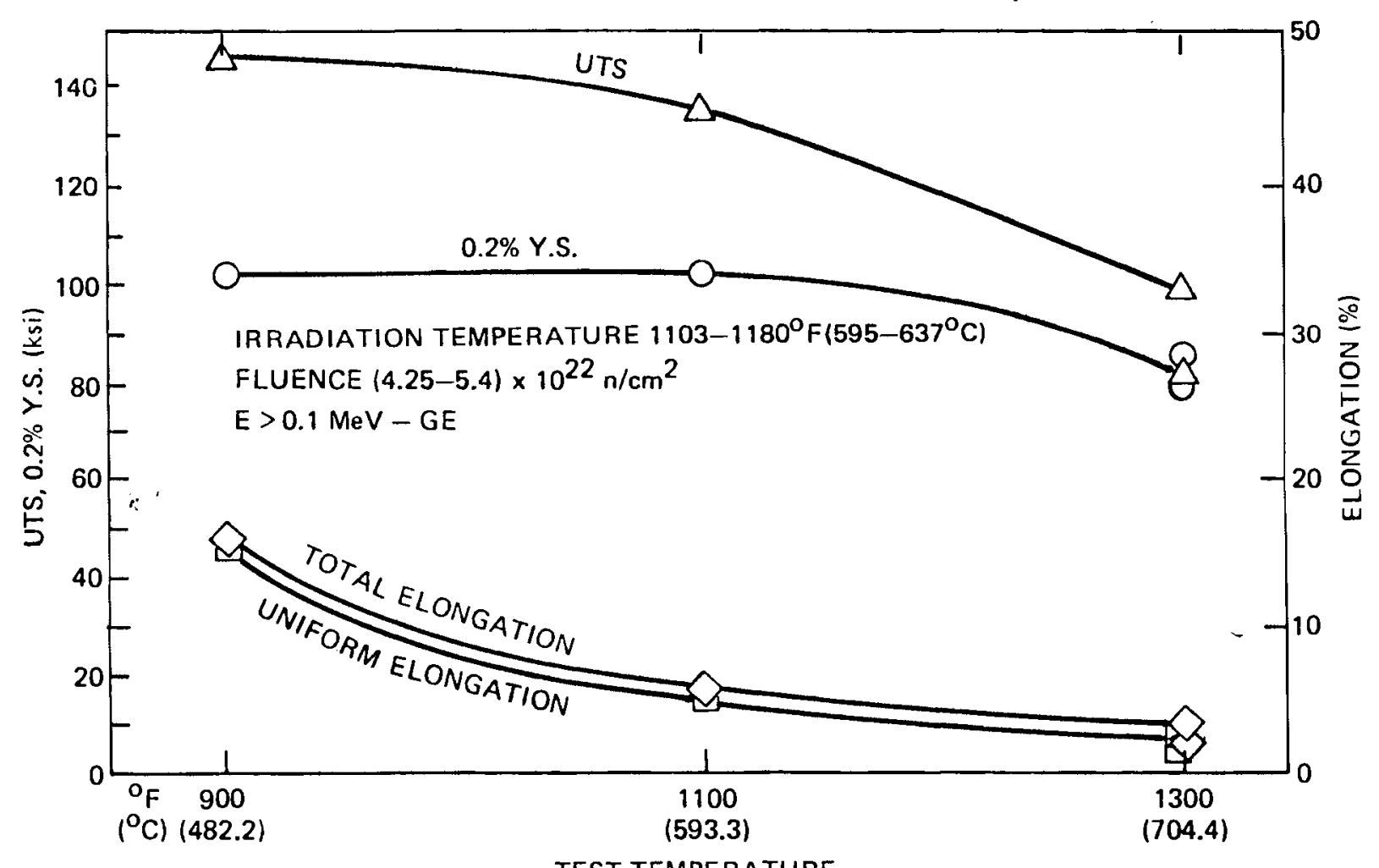

(b) IRRADIATED

TEST TEMPERATURE

Figure 2.3.3.1.2-3 The Effect of Test Temperature on the Mechanical Properties of Inconel-625 Strain Rate $0.02 \mathrm{~min}^{-1}$ 
2.3.3.1.2-5

\section{REFERENCES}

1. D. W. Sandusky, P. J. Ring and R. T. Penrose, "Fast Neutron Damage in Type-304 Stainless Steel and HighNickel Alloys," GEAP-13738, General Electric Co., Breeder Reactor Department, Sunnyvale, CA, December 1971. 


\subsubsection{2-1}

\subsubsection{Effect of Cold Work}

The effect of cold-work on the postirradiation properties of candidate LMFBR alloys is being extensively studied through the comparison of annealed and $20 \%$ cold-worked 316 stainless steels. High fluence $\left(\geq 1 \times 10^{22} \mathrm{n} / \mathrm{cm}^{2}\right)$ tensile data on (nonfueled) specimens of cold-worked 316 stainless steel is not yet available; but some moderate fluence $\left(0.7\right.$ to $\left.0.9 \times 10^{22} \mathrm{n} / \mathrm{cm}^{2}\right)$ data is available for comparison that are probably indicative of major features with regard to the effects of cold-work on ductility and strength that could be expected at relevant FTR fluences. These are considered below. 


\subsection{Ductility}

At moderate fluence $\left(0.7 \times 10^{22} \mathrm{n} / \mathrm{cm}^{2}\right)$, the higher ductility of unirradiated annealed 316 stainless steel already suffers some degradation at low temperature $\left(800^{\circ} \mathrm{F}\right)$ and extreme degradation at elevated temperature $\left(1200^{\circ} \mathrm{F}\right)$. Cold-worked material, on the other hand, suffers no degradation of its initially lower ductility at low temperature (i.e., the onset of low-temperature embrittlement is delayed dislocation-irradiation defect interactions). Twenty percent cold-worked 316 stainless steel also suffers less reduction percentage-wise at high temperature though, on an absolute basis, its high-temperature ductility is lower than is that for annealed material. These data are shown in Figure 2.3.3.2.1-1. (1)

The lower absolute ductility of cold-worked 316 stainless steel at elevated (irradiation/test) temperatures continue at fluence levels approaching $1 \times 10^{22} \mathrm{n} / \mathrm{cm}^{2}$. For example, at $1400^{\circ} \mathrm{F}$, annealed 316 stainless steel would have approximately $5 \%$ uniform elongation (2) while $20 \%$ cold-work 316 stainless steel has only about $0.9 \%$. (3) This lower uniform elongation of cold-worked material at elevated temperature is a direct result of the coldwork. (3) Total elongation is also lower than that of the annealed material due to the initially lower value from cold-working combined with the helium embrittlement mechanism, which is unimpeded since cold-work recovers at these temperatures.

At high fluence levels $\left(>5 \times 10^{22} \mathrm{n} / \mathrm{cm}^{2}\right.$ ), no significant distinction between annealed and cold-worked ductility would be expected. 


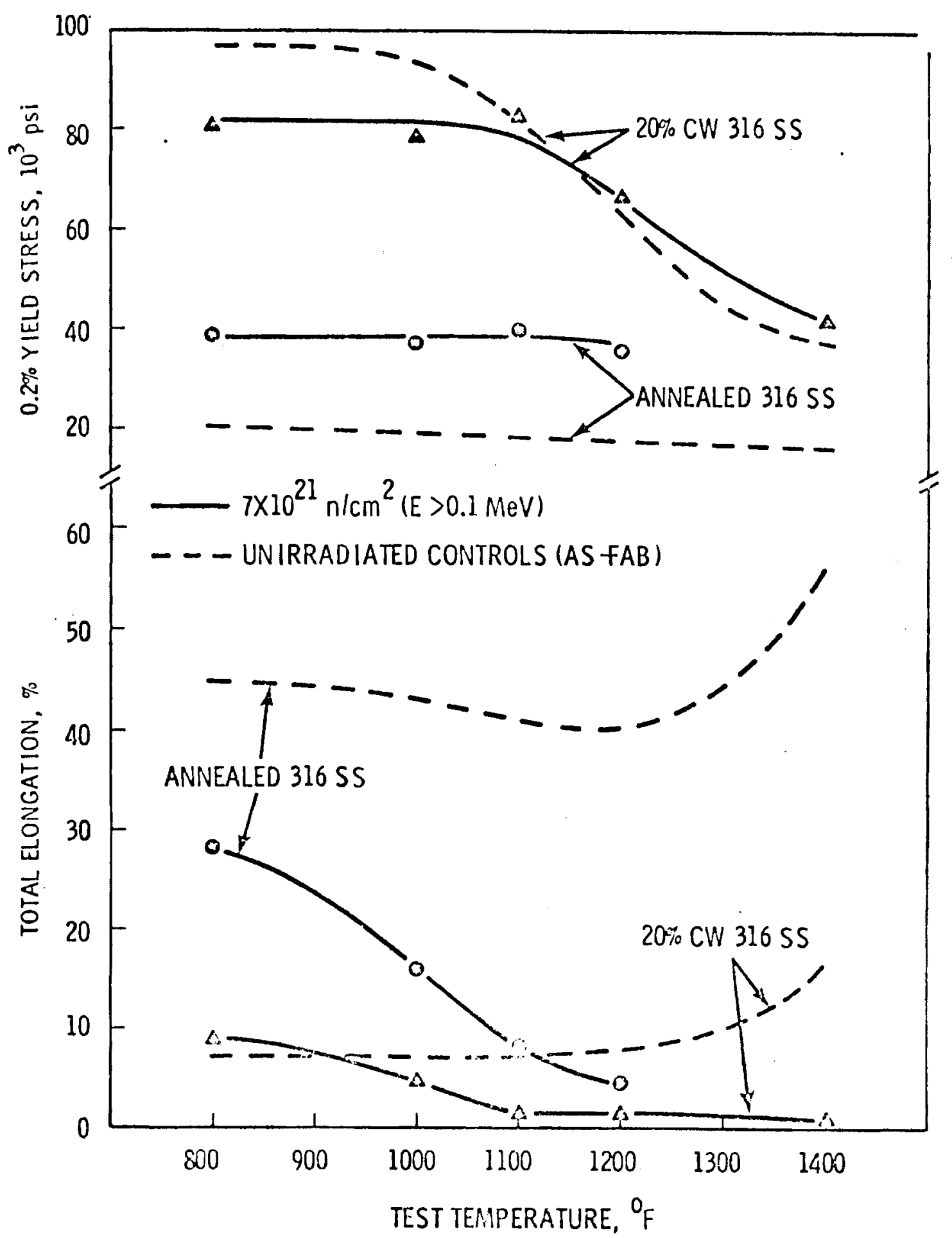

Figure 2.3.3.2.1-1 Strength and Ductility of Annealed and CW 316 SS Irradiated in the EBR II to a Fluence of $7 \times 10^{21} \mathrm{n} / \mathrm{cm}^{2}(\mathrm{E}>0.1 \mathrm{MeV})$ at $1100^{\circ} \mathrm{F}$ 


\subsubsection{1-3}

\section{REFERENCES}

1. "Material Considerations in Support of the FFTF Preliminary Safety Analysis," Report-RM9, Vol 1, HEDL-TME 71-53, p. 2-22, April 1971.

2. "Ductility of Fast Reactor Irradiated Annealed AISI

Type 316 Stainless Steel," Report RMT0, HEDL-TME 71-166, p. 24, October 1971 .

3. "Monthly Technical Progress Report," HEDL-TME 72-8, p. B-32, August 1972. 


\subsection{Strength}

Two factors influence the in-reactor yield strength of cold-worked 316 stainless steel, namely the effect of fabrication (cold-working) and the effect of irradiation. Irradiation-hardening of cold-worked material occurs. However, due to cold-work recovery, weaking occurs at $T \gtrsim 950^{\circ} \mathrm{F}$ apparently enhanced by irradiation (Figure 1 in Reference 1 of Section 2.3.3.2.2). At moderate fluences $\left(\gtrsim 0.2 \times 10^{22} \mathrm{n} / \mathrm{cm}^{2}\right)$, this recovery offsets irradiation-hardening at $\mathrm{T}>950^{\circ} \mathrm{F}$ so that strength levels are somewhat below those of unirradiated material. In annealed material, hardening is still observed at $1200^{\circ} \mathrm{F}$ (see Section 2.2.2).

Indications from United Kingdom data ${ }^{(2)}$ are that, for irradiation to level in excess of $1 \times 10^{22} \mathrm{n} / \mathrm{cm}^{2}$ at 800 to $1075^{\circ} \mathrm{F}$, irradiation-hardening starts to overcome cold-work recovery; the limited data available indicates, however, that strengths above those of unirradiated material may not have been achieved even at $2.9 \times 10^{22} \mathrm{n} / \mathrm{cm}^{2}$.

As noted in Section 2.2.2, annealed material shows continuous hardening out to the highest fluence values available $\left(\sim 1 \times 10^{23} \mathrm{n} / \mathrm{cm}^{2}\right)$, and it would be expected for this to occur in coldworked material also. Data is not currently available from which to determine if the strengths of annealed and cold-worked material became comparable at high fluence. 
2.3.3.2.2-2

\section{REFERENCES}

1. "Month1y Technical Progress Report," HEDL-TME 72-8, p. B-32 August 1972.

2. "Material Considerations in Support of the Preliminary Safety Analys is, Report-RM9, Vol I," HEDL-TME 71-53, pp 2-23 and 2-24, Apri1 1971. 


\subsection{GENERAL RELATIONSHIP OF IRRADIATED TENSILE PROPERTIES TO LMFBR PERFORMANCE}

\subsubsection{INTRODUCTION}

Irradiated tensile properties, whether normal strain-rate or high-strain rate (discussed in a Section 3.0), are specified as design criteria for certain core components. As yet, data from irradiations at fluences and temperature on materials representative of current and future LMFBR design is incomplete. Prediction of properties in relevant regimes will require extrapolative techniques until these gaps are filled.

Since the major emphases to date in the United States is upon the development of the FFTF, many of the remarks in this section are specifically related to it as the reference LMFBR reactor, though they will be of general application to future commercial LMFBR's as well. 


\subsubsection{INFLUENCE OF LMFBR VARIABLES}

\subsubsection{LMFBR Reactor Variables}

The major reactor variable that must be considered is the high fluences to which reactor materials will be subjected. Maximum values may be $1.5 \times 10^{23} \mathrm{n} / \mathrm{cm}^{2}$ for FFTF to $2-3 \times 10^{23} \mathrm{n} / \mathrm{cm}^{2}$ for commercial LMFBR. But, since even at an order of magnitude less fluence irradiation damage can still be severe, the matching of design criteria with a material's performance capability may still be difficult.

The second major reactor variable is temperature, which varies vertically and horizontally throughout the core; material properites are quite sensitive to irradiation temperature, as noted in Section 2.2.

Other variables that can influence tensile properties are flux, spectra, helium predictions rates and prior stress. These factors were considered in Section 2.3.2 with the general conclusions being: 1) that no significant engineering effects due to flux difference are expected between the EBR-II (where experimental data is currently being generated) and FFTF; 2) that, in terms of neutron spectrum, the FFTF shall be only 50 to $68 \%$ as "damaging" as that of EBR-II for a given fluence; 3 ) that helium concentration shall be less for a given fluence in FFTF than in EBR-II; and 4) that prior stress, if it produces creep, may significantly reduce residual tensile properties. 


\subsubsection{LMFBR Material Variables}

Current materials concepts for LMFBR (FFTF) call

for $20 \%$ cold-worked 316 stainless steel for fuel assemblies and control and safety rod guide tubes, solution annealed 304 for core support structures and the pressure vessel, and radial shields composed of 304 stainless steel, nickel and Inconel 718. (1) The expected temperature/fluence ranges for the FFTF is presented in Figure 2.4.2.2-1. (2)

The extremes of properties that are to be required in the FFTF appear to be exemplified by the design criteria for transient events for the $20 \%$ cold-worked 316 stainless steel fuel cladding ( $\leq 0.5 \%$ added strain) and that for end-of- 1 ife tensile ductility for major annealed 304 stainless steel core structures (10\% tota 1 elongation).

Fluences limits to achieve a minimum $10 \%$ total elongation for type 304 stainless steel base metal and welds, as enumerated by FFTF documentation, ${ }^{(3)}$ are presented in Table 2.4.2.2-1. These data, are not entirely consistent with raw property data presented with earlier documents and exhibited in Figure 2.2.2-7e; safety margins may be included in the former data.

For $20 \%$ cold-worked 316 stainless steel, $0.5 \%$ uniform elongation is observed at $1600^{\circ} \mathrm{F}$ test temperature (a relevant temperature for transients) after only moderate irradiation, i.e., at $7.5 \times 10^{21} \mathrm{n} / \mathrm{cm}^{2}$ at $T_{\text {irrad }}=1040^{\circ} \mathrm{F}$, and at $9.0 \times 10^{21} \mathrm{n} / \mathrm{cm}^{2}$ at $\mathrm{T}_{\text {irrad }}=1440^{\circ} \mathrm{F} .{ }^{(4)} \mathrm{Data}$ for uniform elongation, rather than total elongation, is cited here since it is considered to be the more relevant parameter for a failure criteria under transient conditions for highly embrittled material likely to contain notches. 


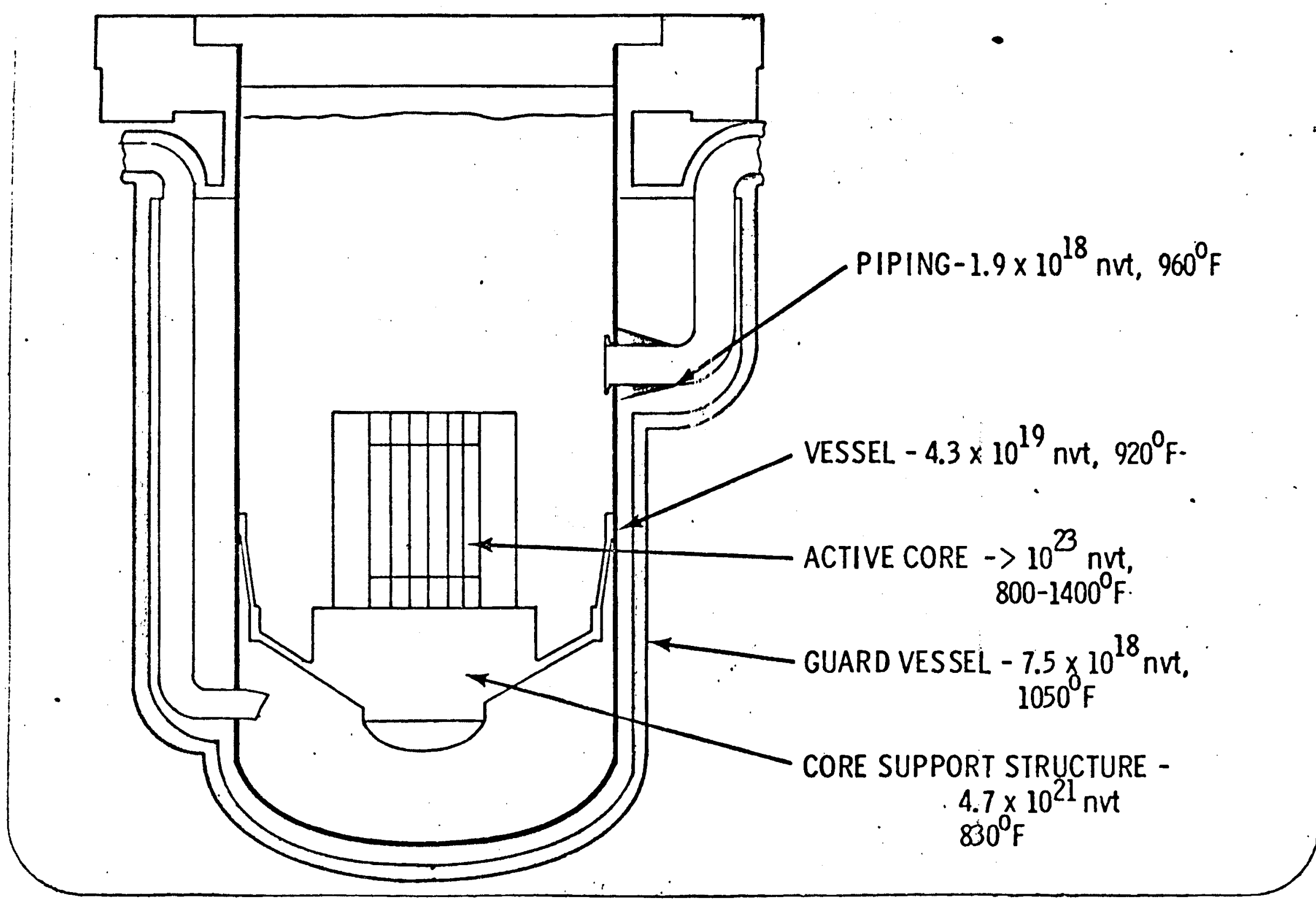


TABLE 2.4.2.2-1

A

FLUENCE LIMITS FOR TYPE 304 STAINLESS STEEL BASE METAL

\begin{tabular}{|c|c|c|c|}
\hline \multirow{2}{*}{$\begin{array}{l}\text { Temperature } \\
{ }_{\circ}^{\circ} \mathrm{F} \\
\end{array}$} & \multicolumn{3}{|c|}{$\begin{aligned} & \text { Total Fluence }\left(\mathrm{n} / \mathrm{cm}^{2}\right) \text { to Produce a Ductility } \\
& \text { of Not Less Than }\end{aligned}$} \\
\hline & $1 \%$ Elongation & $5 \%$ Elongation & $10 \%$ Elongation \\
\hline 600 & $1.45 \times 10^{22}$ & $1.2 \times 10^{22}$ & $9.5 \times 10^{21}$ \\
\hline 700 & $1.9 \times 10^{22}$ & $1.55 \times 10^{22}$ & $1.15 \times 10^{22}$ \\
\hline 800 & $1.9 \times 10^{22}$ & $1.55 \times 10^{22}$ & $1.2 \times 10^{22}$ \\
\hline 900 & $5.0 \times 10^{22}$ & $3.4 \times 10^{22}$ & $\times 10^{22}$ \\
\hline 1000 & $2.9 \times 10^{22}$ & $\times 10^{22}$ & $1.55 \times 10^{22}$ \\
\hline 1100 & $2.1 \times 10^{22}$ & $\times 10^{22}$ & $7.7 \times 10^{21}$ \\
\hline 1200 & $8.0 \times 10^{21}$ & $\times 10^{21}$ & $4.3 \times 10^{21}$ \\
\hline
\end{tabular}

B

FLUENCE LIMITS FOR TIG WELDS WITH TYPE 308 STAINLESS STEEL FILLER

\begin{tabular}{|c|c|c|c|}
\hline \multirow{2}{*}{$\begin{array}{c}\text { Temperature } \\
{ }^{\circ} \mathrm{F} \\
\end{array}$} & \multicolumn{3}{|c|}{$\begin{array}{c}\text { Total Fluence }\left(\mathrm{n} / \mathrm{cm}^{2}\right) \text { to Produce a Ductility } \\
\text { of Not Less Than }\end{array}$} \\
\hline & $1 \%$ Elongation & $5 \%$ Elongation & $10 \%$ Elongation \\
\hline 600 & $1.4 \times 10^{22}$ & $1.0 \times 10^{22}$ & $6.6 \times 10^{27}$ \\
\hline 700 & $1.9 \times 10^{22}$ & $\times 10^{22}$ & $\times 10^{21}$ \\
\hline 800 & $\times 10^{22}$ & $\times 10^{21}$ & $\times 10^{21}$ \\
\hline 900 & $1.25 \times 10^{22}$ & $\times 10^{21}$ & $3.7 \times 10^{21}$ \\
\hline
\end{tabular}




\section{$2 \cdot 4 \cdot 2 \cdot 2-4$}

\section{REFERENCES}

1. FOT-362: SDD-31, Rev. 5, "Reactor," Vol. 1 and 2, Janauary 19, 1973.

2. Presented by DRDT (HEDL) at the ACRS Subcommittee Meeting on FFTF Safety, September 29,1972.

3. FOT-362: SDD-31, Rev. 5, "Reactor," Vol 2, p. 2.3.7-32, January $19,1973$.

4. "Monthly Progress Report," HEDL-TME 72-8, p. B-32, August 1972. 
2.4.3 GENERAL IMPL ICATIONS OF IRRADIATED TENSILE PROPERT IES ON LMFBR COMPONENTS

\subsubsection{Pressure Vessel}

Since over a 20- to 30-year (CRBRP) reactor

design 1 ife, fluence levels at the pressure vessel are expected to be no greater than about $6 \times 10^{19} \mathrm{n} / \mathrm{cm}^{2}(\mathrm{E}>0.1 \mathrm{MeV})$, a $10 \%$ residual elongation (either total or uniform, the latter perhaps being a more suitable criteria for a high-strain rate accident) is readily expected for annealed Type 304 stainless steel base metal and welds. (See Section 2.4.2.2) 


\subsubsection{Core Components}

Core components will be subjected to a wide range of design requirements including fluence $\left(\sim 10^{21}\right.$ to $\left.>10^{23}\right)$, temperatures $\left(800\right.$ to $1400^{\circ} \mathrm{F}$ ) and design lifetime ( 1 to 20 years).

$$
\text { Tables 2.4.3.2-1 (1) and 2.4.3.2-2(2) presents }
$$

total design fluence for the large core structures and Table 2.4.3.2-3(3) present fluence levels to produce a minimum of $10 \%$ total elongation.

Table 2.4.3.2-1 is more conservative than is Table 2.4.3.2-3; i.e., more residual ductility is anticipated because less fluence wi11 be achieved than that required to reduce total elongation to $10 \%$. Ductility criteria for the radial shield is not available to correspond with fluence levels presented in Table 2.4.3.2-2. It is clear, however, that those components that will be subjected to $21.7 \times 10^{23}$ would not have $10 \%$ residual ductility (see Section 2.4.2.2). design limits: ${ }^{(4)}$

Fuel pin criteria for FFTF call for the following

$0.2 \%$ cladding strain for steady-state operation.

$0.3 \%$ cladding strain for steady-state plus anticipated upsets.

$0.7 \%$ cladding strain for steady-state, upsets and transients.

None of these three criteria are strictly tensile but are, rather, either creep or high strain-rate. Thus, fuel pins will not be considered in this section. 
TABLE $\quad 2 \cdot 4 \cdot 3 \cdot 2-1$

ESTIMATED FLUENCE OF IN-VESSEL COMPONENTS

Component

Core support structure

(surface)

(welds)

Core barrel

(surface)

(welds)

(Instrument Tree

Support Pad)

Radial Restraint Outer Module
Maximum estimated total fluence over 20 year Design Life at 400 MWt operation and $75 \%$ Plant Availability (Based on conservative nuclear calculation including uncertainty).

$$
\left(\mathrm{n} / \mathrm{cm}^{2}\right)
$$

$6.4 \times 10^{21}$

$4.1 \times 10^{21}$

$2.2 \times 10^{21}$

$2.2 \times 10^{21}$

$5.0 \times 10^{21}$

$2.2 \times 10^{21}$ 
TABLE $2 \cdot 4 \cdot 3 \cdot 2-2$

ESTIMATED TOTAL NEUTRON FLUENCE ON RADIAL SHIELD

Component

Outer Shield:

Inner surface

Lower welds

Core barrel connector welds

Holddown device

Inner Shield:

Inner surface

Lower welds

Outer shell connector welds

Holddown device
Design

life, years

20
$1.7 \times 10^{23}$
$1.3 \times 10^{22}$
$7.9 \times 10^{21}$
to be provided by ARD

10 ing uncertainty.)
Maximum estimated total

fluence over design life at 400 MWt operation and $75 \%$ plant availability, $n / \mathrm{cm}^{2}$ ? (Based on conservative nuclear calculations includ-
$1.8 \times 10^{23}$
$7.2 \times 10^{21}$
$1.2 \times 10^{22}$
to be provided by ARD 
TABLE 2.4.3.2-3

REACTOR SYSTEM FLUENCE LIMITS

Component and Location

Core Support Structure Welds

Core Support Structure Surface

Core Barrel Welds

Core Barrel Plate

Instrument Tree Support Pad

Core Basket Top Plate

Core Basket Welds

Core Restraint Outer Module

Core Restraint Outer Module Welds

Core Restraint Inner Module

Core Restraint Inner Module Welds

Low Level Flux Monitor
Fluence Limit ${ }^{(b)}$

Minimum (a)

(total fluence)

Ductility

$10 \%$

$10 \%$

$10 \%$

$10 \%$

$10 \%$

$10 \%(c)$

$10 \%$

$\mathrm{n} / \mathrm{cm}^{2}$

$4.1 \times 10^{21}$

$9.5 \times 10^{21}$

$4.1 \times 10^{21}$

$9.5 \times 10^{21}$

$9.5 \times 10^{21}$

$1.2 \times 10^{22}$

$10 \%$

$4.1 \times 10^{21}$

$10 \%$

$9.5 \times 10^{21}$

TBD

$4.1 \times 10^{21}$

TBD

TBD

TBD

TBD

TBD

(a) As measured by uniaxial tensile tests at the temperature of interest.

(b) Fluence limits are based on the lowest limit from Reference 37 in Appendix A for type 304 stainless steel over the operating temperature range for the noted components. Weld metal limits are based on submerged arc welds using type 308 stainless steel filler.

(c) Using energy-dependent damage function. 


\section{$2 \cdot 4 \cdot 3 \cdot 2-5$}

\section{REFERENCES}

1. FOT-362: SDD-31, Rev. 5, "Reactor," Vol. 2, p. 2.3.7-19, January 19, 1973.

2. ibid, p. 2,3.7-31.

3. ibjd, Vol. I, p. 1.2-8.

4. ibid, p. 1.2-24. 

3. EFFECT OF IRRADIATION ON HIGH STRAIN-RATE PROPERTIES

TABLE OF CONTENTS

3.1 INTRODUCTION ........................... $3.1-1$

3.2 EPPECT OF IRRADIATION FLUENCE, IRRADIATION TEMPERATURE, TEST TEMPERATURE AND STRAIN-RATE ............ 3.2.1-1

3.2 .1 Introduction ...................... 3.2.1

3.2.2 High Strain-Rate Tensile Tests ....... 3.2.2-1

3.2.3 Tube Burst Tests . . . . . . . . . . . 3.2.3-1

3.2.4 Simulated Transient Tests . . . . . . . . 3.2.4-1

3.3 OTHER FACTORS INFLUENCING IRRADIATION EFPECTS ON HIGH STRAIN-RATE PROPERTIES ............... 3.

3.4 GENERAL RELATIONSHIP OF IRRADIATED HIGH STRAIN-RATE PROPERTIES TO LMFBR PERFORMANCE .......... 3.4.1-1

3.4.1 Introduction .................... 3.4.1

3.4.2 Influence of LMFBR Variables ...... 3. . . . . . . . . .

3.4.2.1 LMFBR Reactor Variables ..... 3. . 3.2.1-1

3.4.2.2 LMFBR Material Variables . . . . . 3.4.2.2-1

3.4.3 General Implications of Irradiated High Strain-

Rate Properties on LMFBR Components...... 3.4.3.1-1

3.4.3.1 Pressure Vessel ........ 3. . . . . . . . . . . . . . 1-1

3.4.3.2 Core Components ......... 3.4.3.2-1 



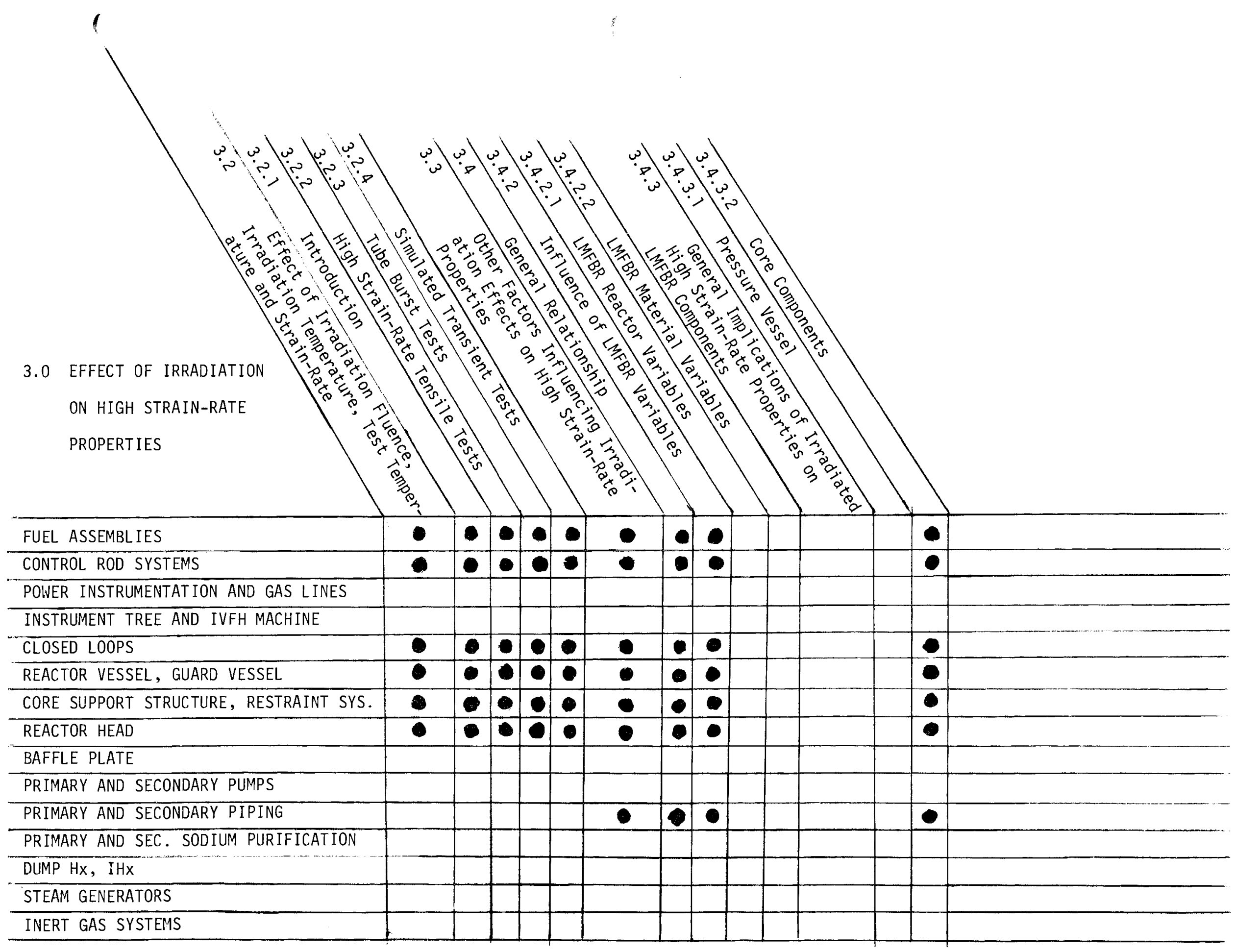



3. IRRADIATION EFFECTS ON HIGH STRAIN-RATE PROPERTIES

\subsection{INTRODUCTION}

Studies of the effects of high fluence irradiation on the high strain-rate properties of austenitic alloys are of relatively recent origin. Systematic research results are sparse due to the length of in-reactor residence time required and to the lesser priority of this area of investigation relative to swelling, tensile and creep studies. The studies had, until very recently, only involved either the standard strain-rate versus test temperature tensile-type test on solid specimens or the standard pressure ramp at constant temperature tube burst-type tests. However, the advent of safety-oriented concerns about cladding performance has led to the recent development of simulated transient tests on tubing. These tests were developed to evaluate fuel clad properties under accident situations such as loss-of-flow and transient overpower. These simulation tests, which involve temperature ramps at various initial pressures, are another type of high strainrate test.

The qualitative effects of irradiation on metals and alloys have been discussed in Section 2.1. These were matrix hardening, due to irradiation-produced loops, voids and dislocations, and alloy embrittlement resulting from this matrix hardening as well as from grain boundary weakening due to transmutation-produced helium and irradiation-induced precipitation reactions.

The quantitative description of the effect of "irradiation damage," i.e., the relationships between temperature, fluence and resultant high strain-rate properties, are as yet not fully defined for relevant alloys. It will be the purpose of this chapter to review the available data in terms of these relationships; to point out current unresolved problem area; and to discuss, in a general way, the significance of irradiated high strain-rate properties to LMFBR performance. 


\subsection{EFFECT OF IRRADIATION FLUENCE, IRRADIATION TEMPERATURE, TEST TEMPERATURE AND STRAIN-RATE}

\subsubsection{INTRODUCTION}

Pour major factors influencing irradiation effects on high strain-rate properties have been elucidated. The first three--fast neutron fluence, irradiation temperature and test temperature--also play important roles with regard to tensile properties (Chapter 2.0) and creep-rupture properties (Chapter 4.0). A fourth major factor is the effect of the high strain-rates.

These four factors wil1 be discussed in terms of properties observed for the three types of high strain-rate tests: high strainrate tensile tests, tube burst tests and simulated transient tests. 


\subsubsection{HIGH STRAIN-RATE TENSILE TESTS}

High strain-rate tensile tests have been performed to describe the effect of strain-rate on the postirradiation tensile properties of solid specimens. The available data is sparse; fluence levels are low for the stainless steel, and neither the irradiation temperatures, test temperatures nor strain-rates parameters are comprehensive.

The available data on type 304 stainless steel is presented in Pigures 3.2.2 -1 through 3.2.2 -7. (1) These data are for tests conducted at $800^{\circ} \mathrm{F}$ and $1000^{\circ} \mathrm{F}$ at strain-rates from $3 \times 10^{-5}$ to $1 \times 10^{1}$ $\mathrm{sec}^{-1}$ for specimens irradiated at $916-980^{\circ} \mathrm{F}$ from 0.18 to $0.75 \mathrm{x}$ $10^{22} \mathrm{n} / \mathrm{cm}^{2}(E>0.1 \mathrm{MeV})$. These data indicate the following:

- The ultimate and $0.2 \%$ yield strengths are not significantly influenced by increasing strain-rate (Figures 3.2 .2 -1 through 4).

- Ductility (uniform elongation, total elongation and reduction of area) are substantially decreased by irradiation; for uniform elongation and total elongation, this occurs throughout the range of strain-rate examined; for reduction of area, only the $1000^{\circ} \mathrm{F}$ tests show a decrease from controls and, then, only at the lower strain-rates. (Figures 3.1.2 -5 through -7.)

- At the highest fluence, ductility (uniform elongation, total elongation and reduction of area) increase with strain-rate except for the $800^{\circ} \mathrm{F}$ postirradiation reduction of area values, which coincide with the unirradiated values (Figures 3.2.2 -5 through -7.).

Metallography performed upon the fracture areas shows that, at $1000^{\circ} \mathrm{F}$, a transition from intergranular to transgranular failure occurs between $3 \times 10^{-6}$ and $3 \times 10^{-5} \mathrm{sec}^{-1}$ in unirradiated specimens. In irradiated specimens $\left(0.5 \times 10^{22} \mathrm{n} / \mathrm{cm}^{2}\right)$, this transition is delayed to a strain rate of approximately $3 \times 10^{-4} \mathrm{sec}^{-1}$ because of the increased propensity for intergranular failure at $1000^{\circ} \mathrm{F}$ due to grain boundary 


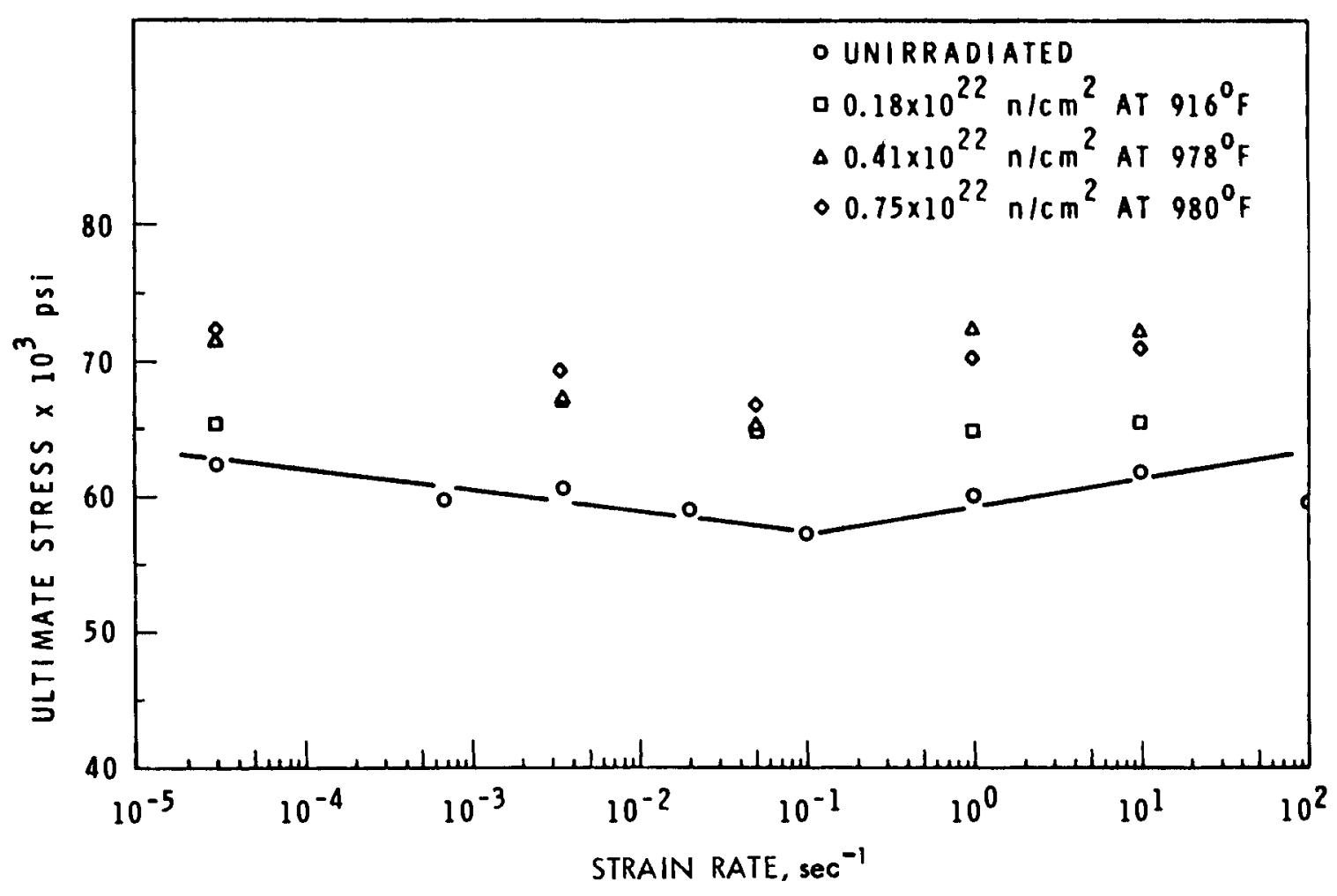

FIGURE 3.2.2-1 Effect of Strain Rate on the U1timate Stress of Irradiated Type 304 Stainless Stee1 at $800^{\circ} \mathrm{F}$. 


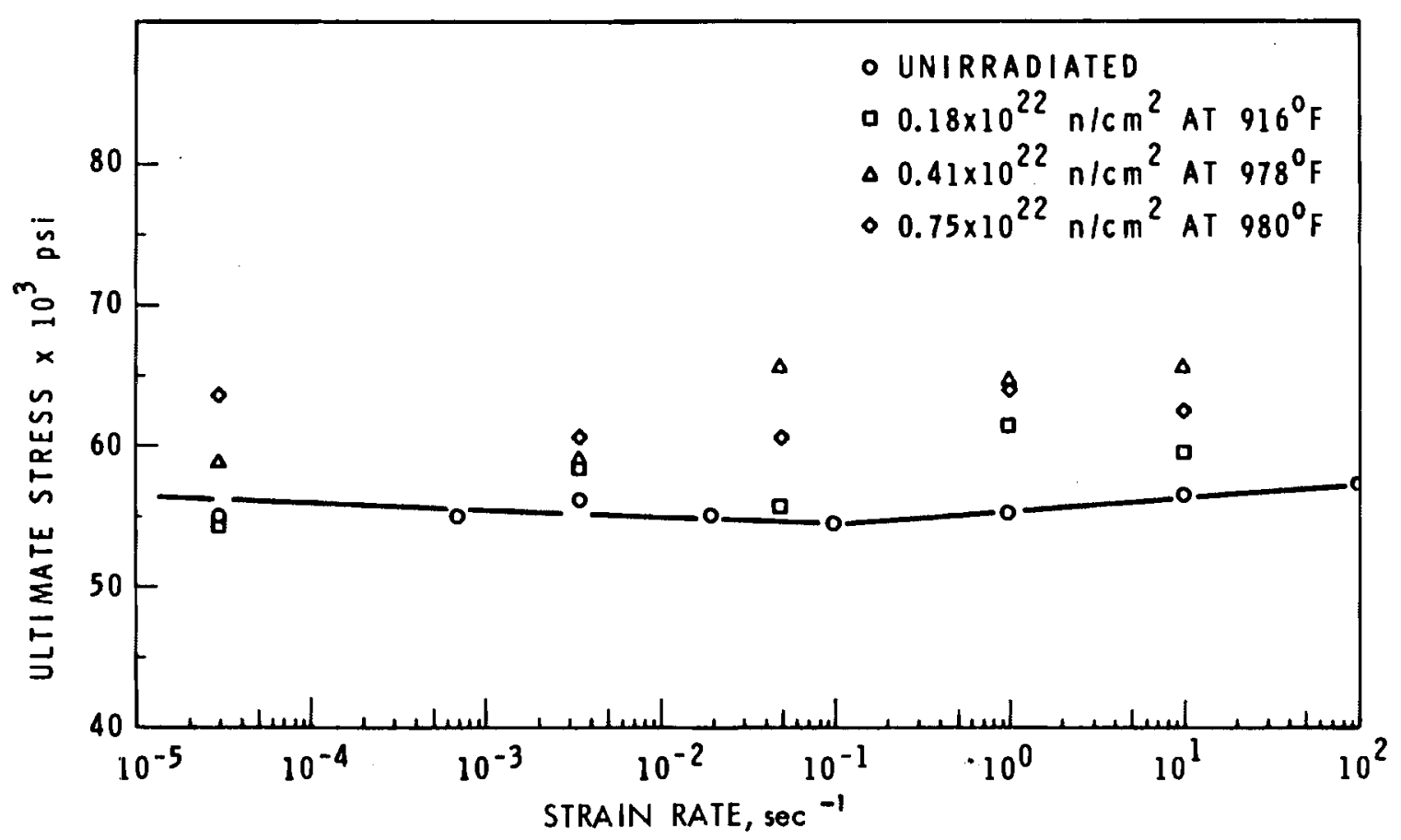

FIGURE 3.2.2-2 Effect of Strain Rate on the U1timate Stress of Irradiated Type 304 Stainless Steel at $1000^{\circ} \mathrm{F}$.

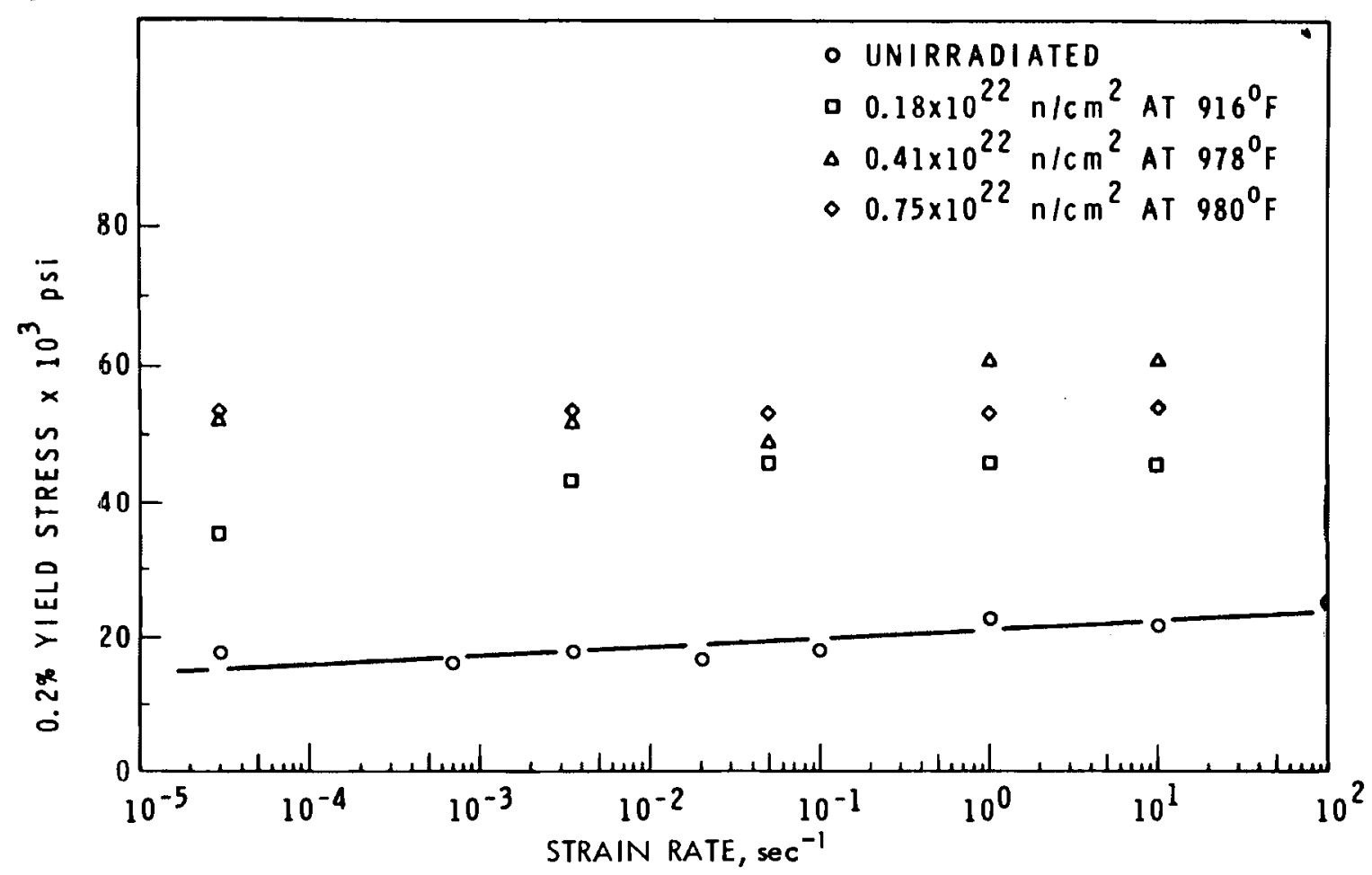

FIGURE 3.2.2-3 Effect of Strain Rate on the $0.2 \%$ Yield Stress of Irradiated Type 304 Stainless Steel at $800^{\circ} \mathrm{F}$. 


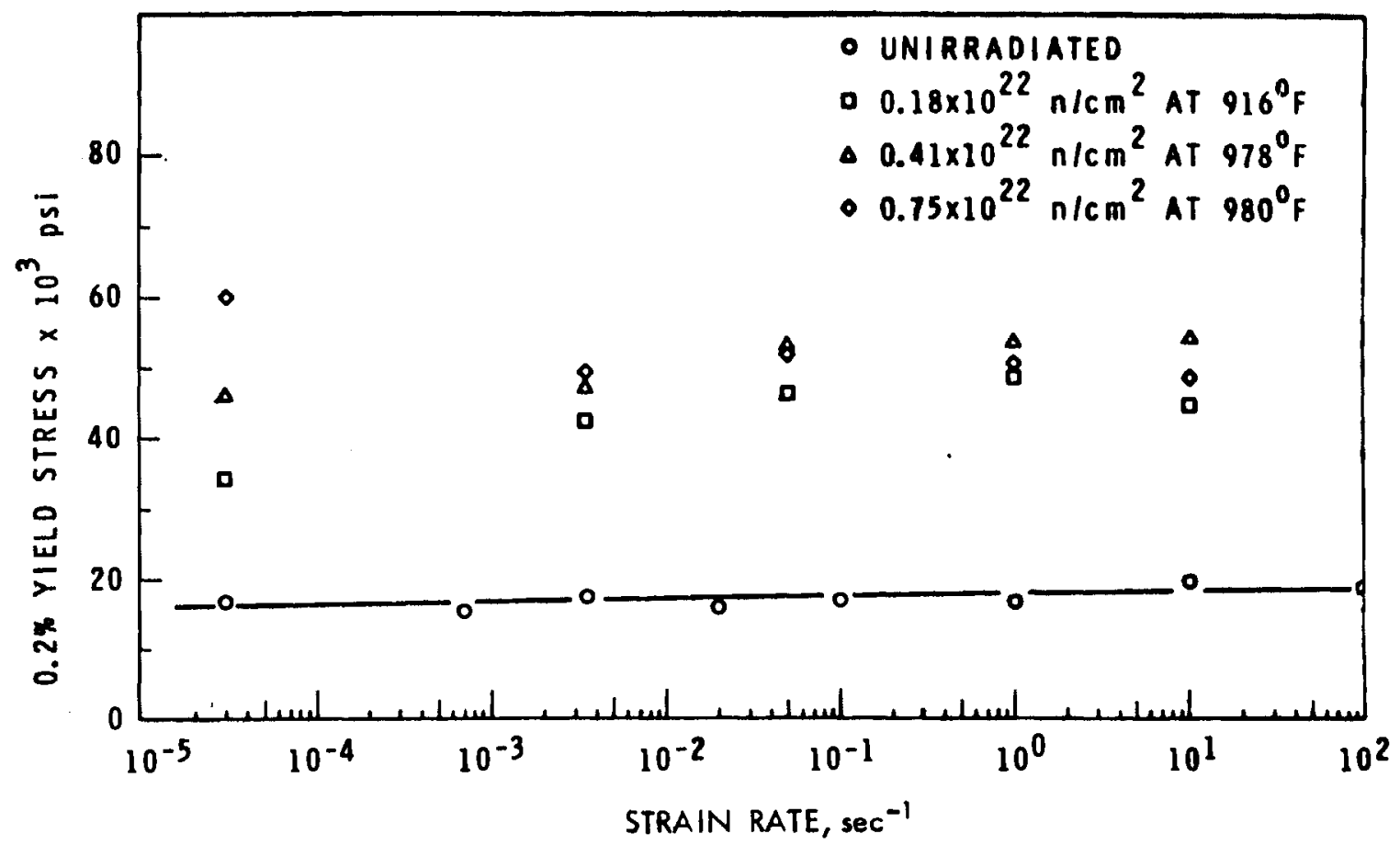

FIGURE 3.2.2-4 Effect of Strain Rate on the 0.2\% rield Stress of Irradiated Type 304 Stainless Steel at $1000^{\circ} \mathrm{F}$.

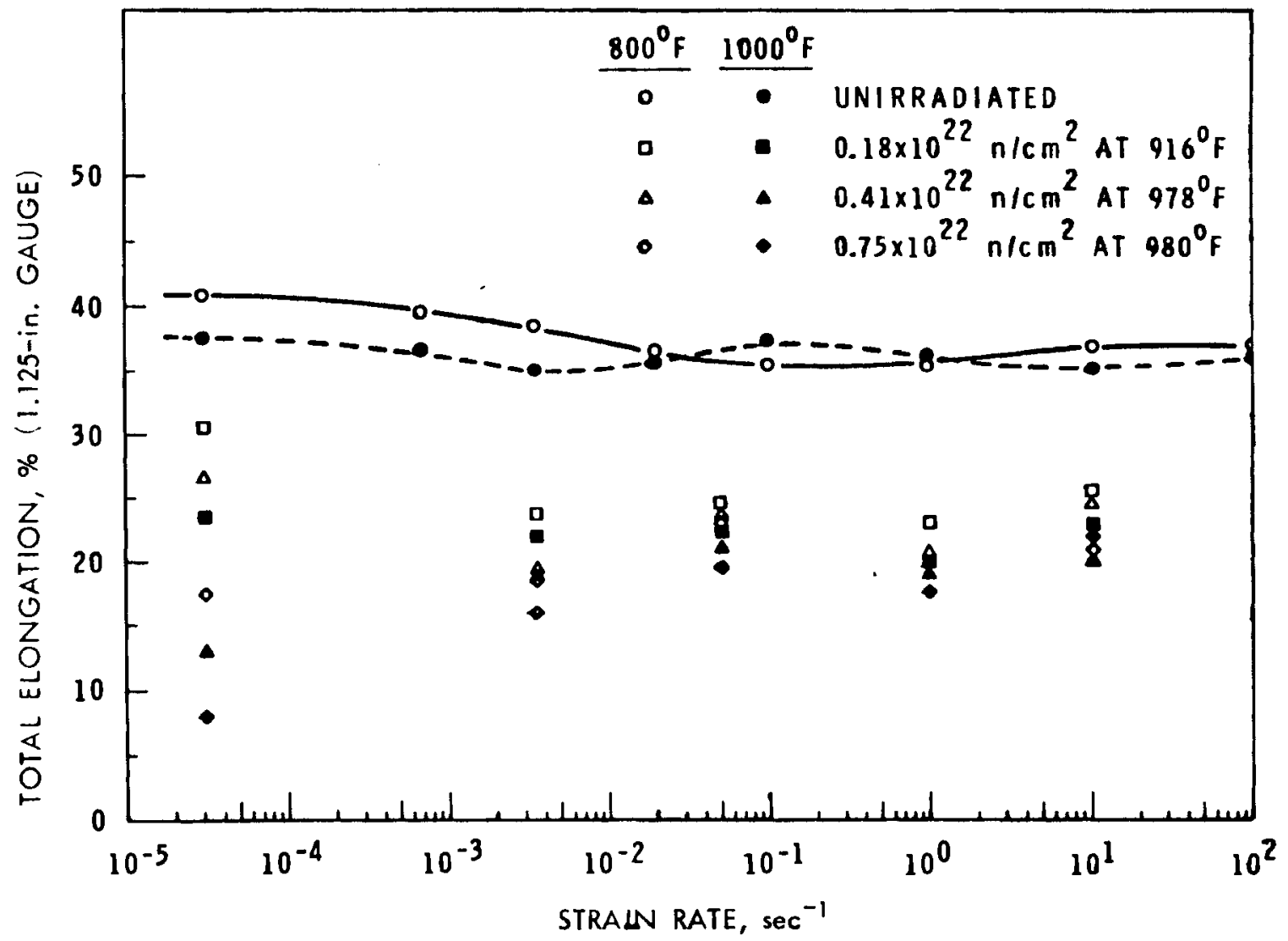

FIGURE 3.2.2-5 Effect of Strain Rate on the Total Elongation of Irradiated Type 304 StainTess Steel. 
$3.2 .2-5$

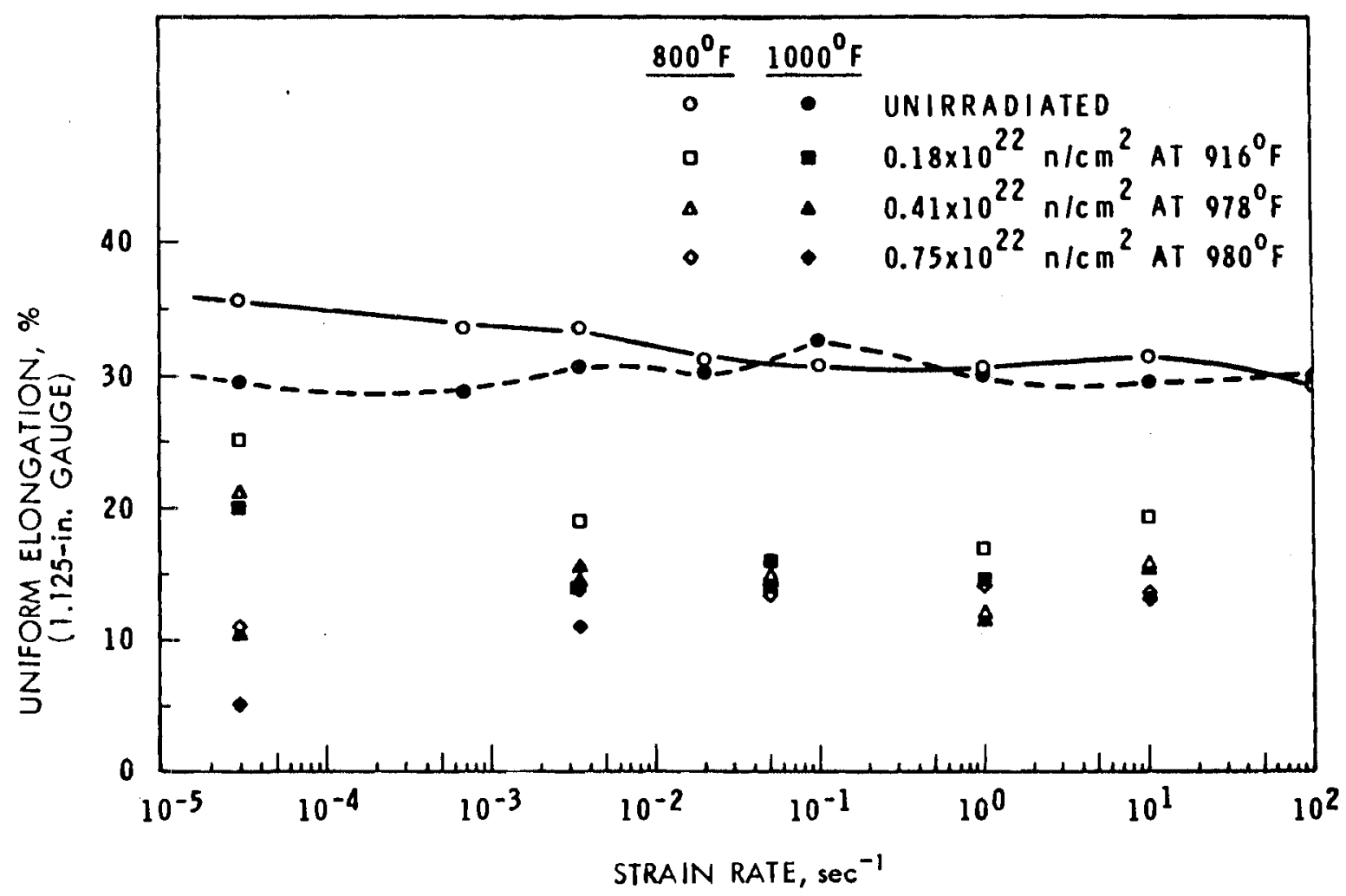

FIGURE 3.2.2-6 Effect of Strain Rate on the Uniform Elongation of Irradiated Type 304 Stainless Steel.

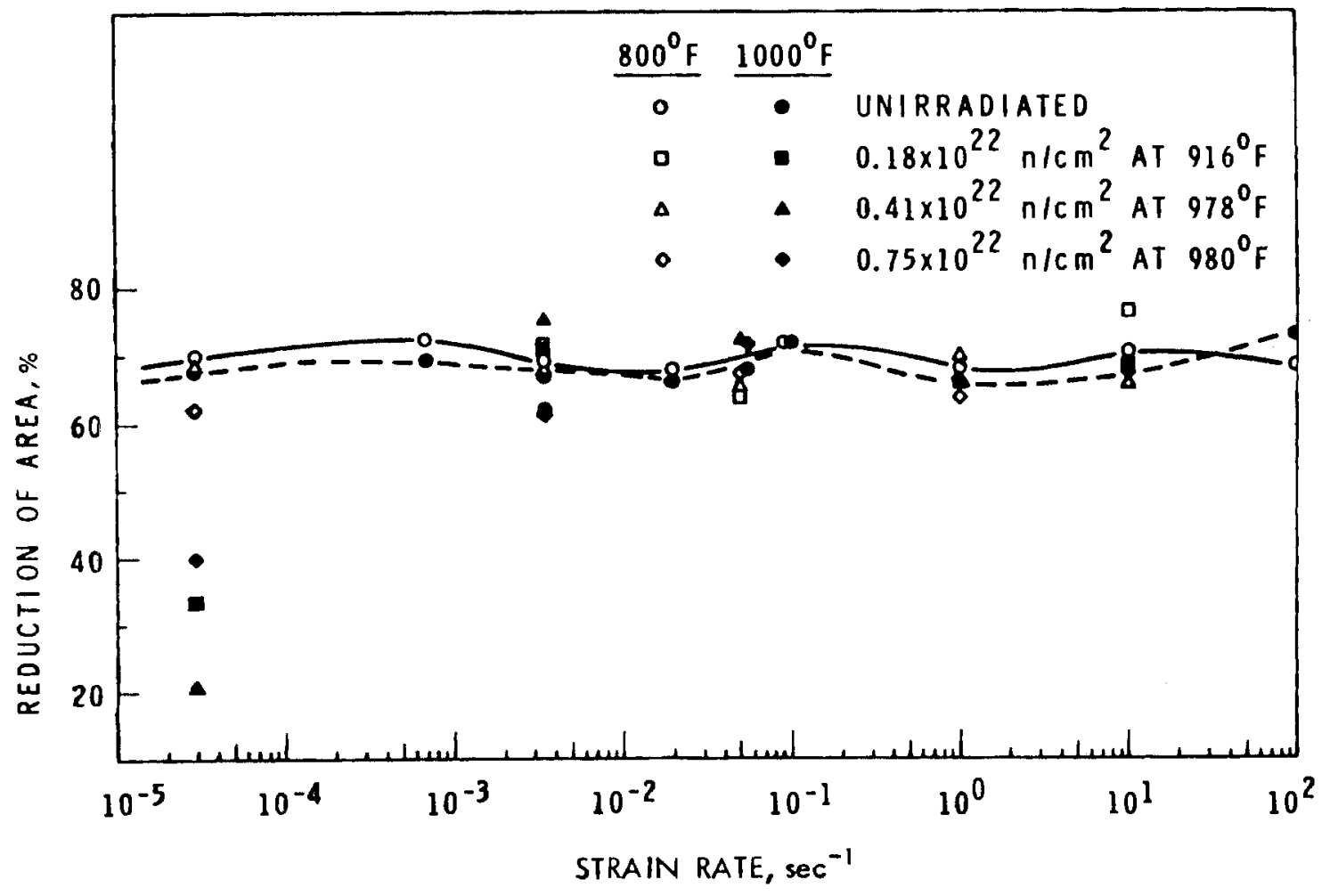

FIGURE 3.2.2-7 Effect of Strain Rate on the Reduction of Area of Irradiated Type 304 Stainless Steel. 
embrittlement. The increased ductility at high strain-rates noted in Figures 3.2.2-5 through 3.2.2-7 for highiy irradiated specimens can be associated, then, with this transition from intergranular to transgranular fracture, which in f.c.c. metals occurs by a shear process and requires more strain for fracture.

The effects of irradiation/test temperature and strain-rate on irradiated ductility is shown in Figure $3.2 .2-8$ for $20 \%$ C.w. 316 stainless steel irradiated at $0.2-0.9 \times 10^{22} \mathrm{n} / \mathrm{cm}^{2}$ ( $\mathrm{E}>0.1 \mathrm{MeV}$ ). For the lower strain-rate, ductility starts decreasing at $\mathrm{T} \gtrsim 1100^{\circ} \mathrm{F}$ as intergranular failure becomes the fracture mode. The higher ductility at the higher strain-rate is presumably the result of the retention of the transgranular fracture mode. For both strain-rates, comparison with unirradiated data ${ }^{(2)}$ shows that irradiation reduces total elongation values at $T \gtrsim 1000^{\circ} \mathrm{F}$, but has not significantly effected uniform elongation.

A study was made of the effect of strain-rate on the mechanical properties at $1300^{\circ} \mathrm{F}$ of three nickel alloys irradiated at a temperature of $1114-1190^{\circ} \mathrm{F}$ and a fluence of $4.25-5.4 \times 10^{22} \mathrm{n} / \mathrm{cm}^{2}$. (3) The data for both irradiated and unirradiated specimens is presented in Figures 3.2.2-9 through -11 . The most significant feature of these data is the generally similar increase in all property values with strain-rate for all the irradiated alloys, while the unirradiated alloys showed widely varying responses to changes in strain-rate. However, note that irradiation still results in ductility loss for all the alloys even at the highest strain-rates. 


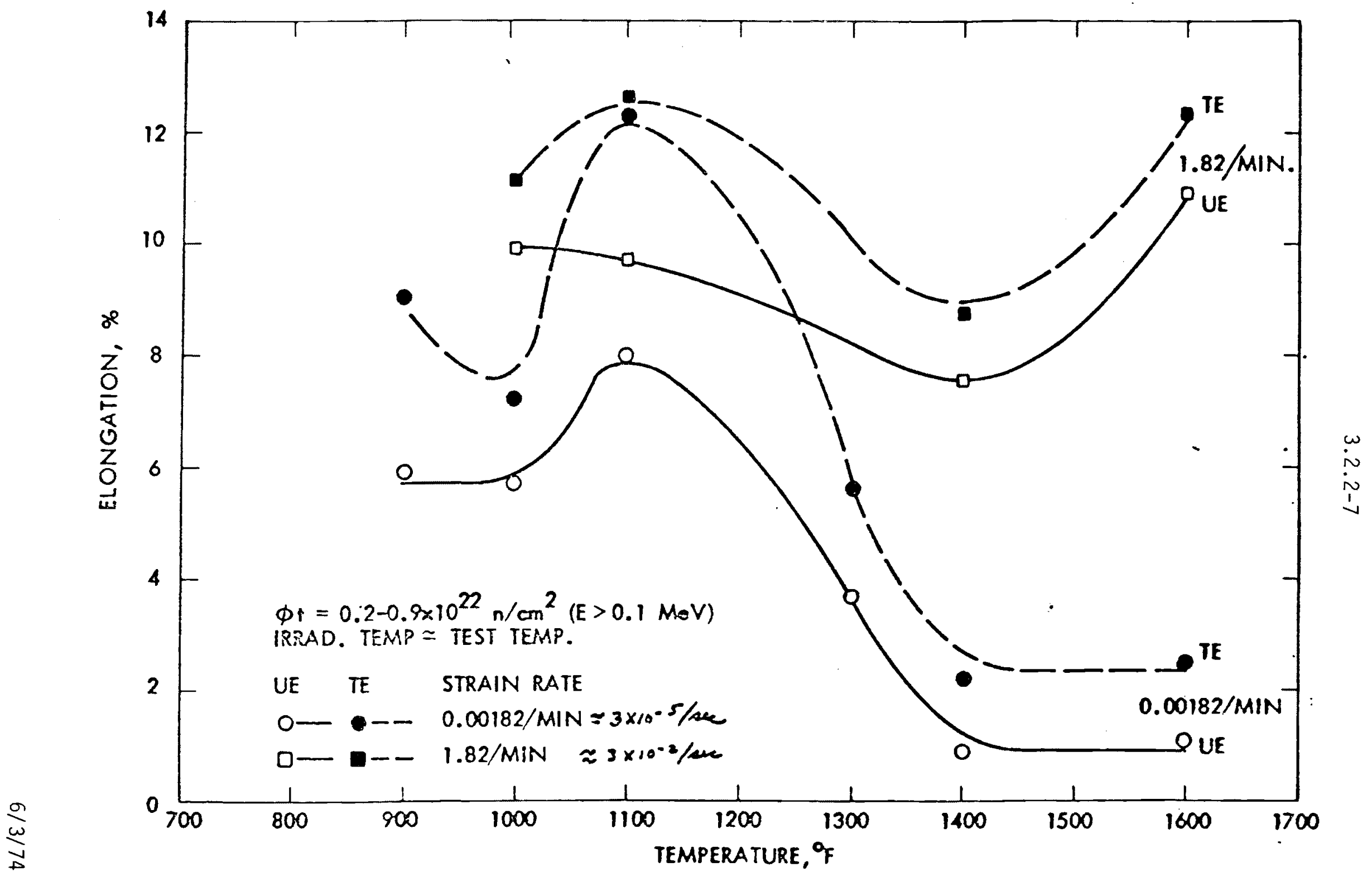

FIGURE 3.2.2-8 Effect of Temperature and Strain Rate on the Ductility of EBR-II Irradiated 20\% Cold Worked Type 316 Stainless Stee1 (S/A X-123). 
3.2.2-8
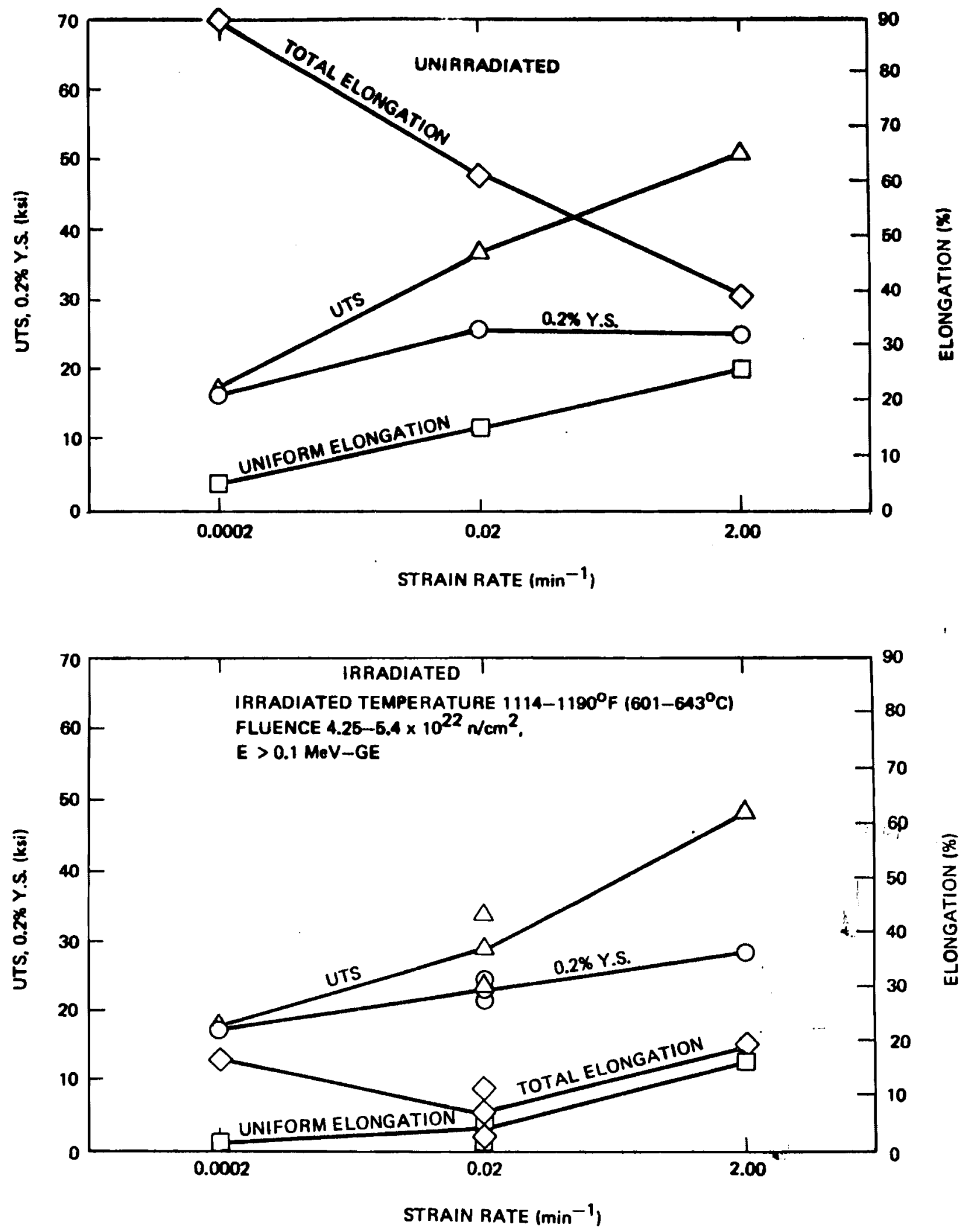

FIGURE 3.2.2-9 The Effect of Strain Rate on the Mechanical Properties of Incoloy 800 Tested at $1300^{\circ} \mathrm{F}\left(704.4^{\circ} \mathrm{C}\right)$. 
3.2.2-9
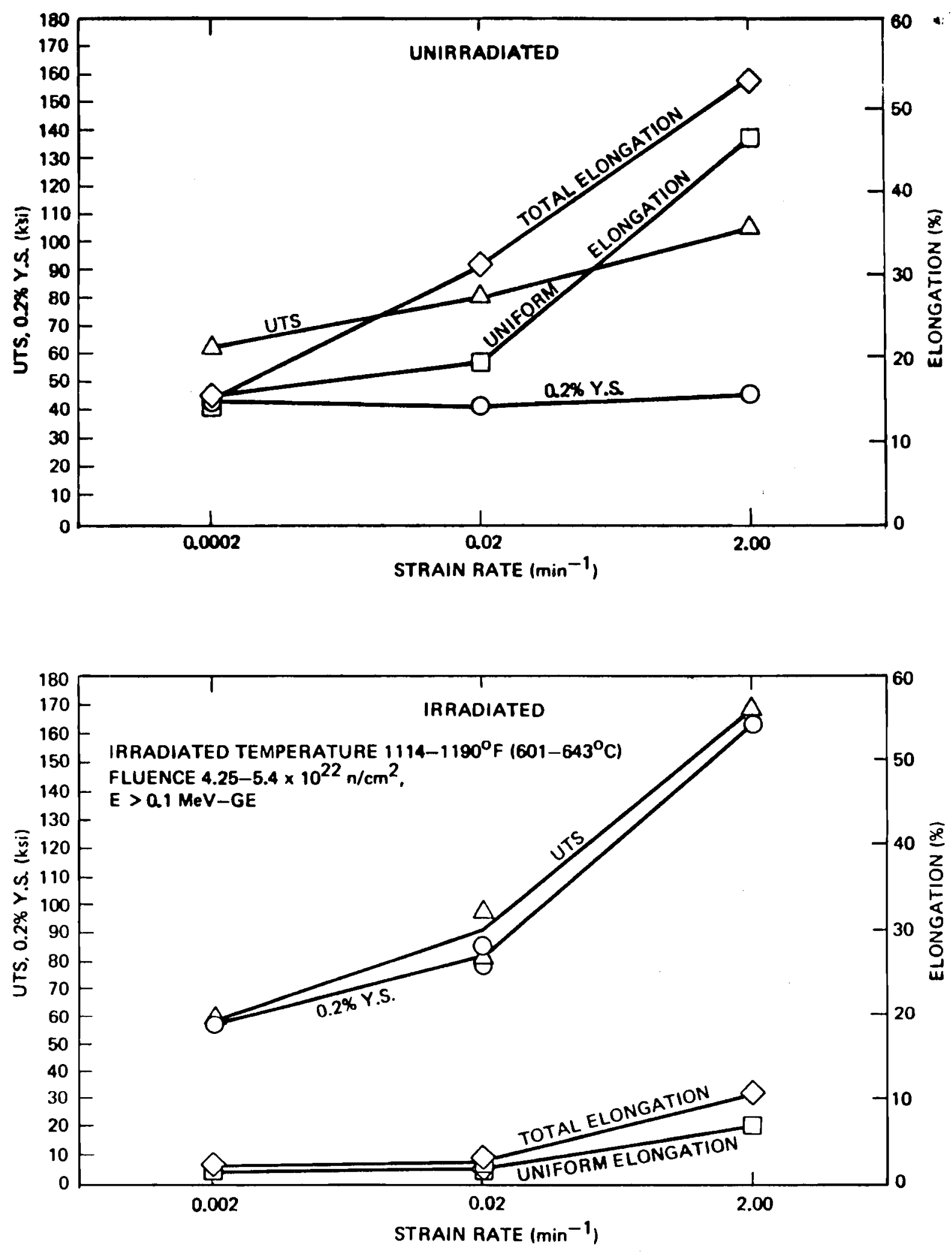

FIGURE 3.2.2-10 The Effect of Strain Rate on the Mechanical Properties of Inconel 625 Tested at $1300^{\circ} \mathrm{F}\left(704.4^{\circ} \mathrm{C}\right)$. 

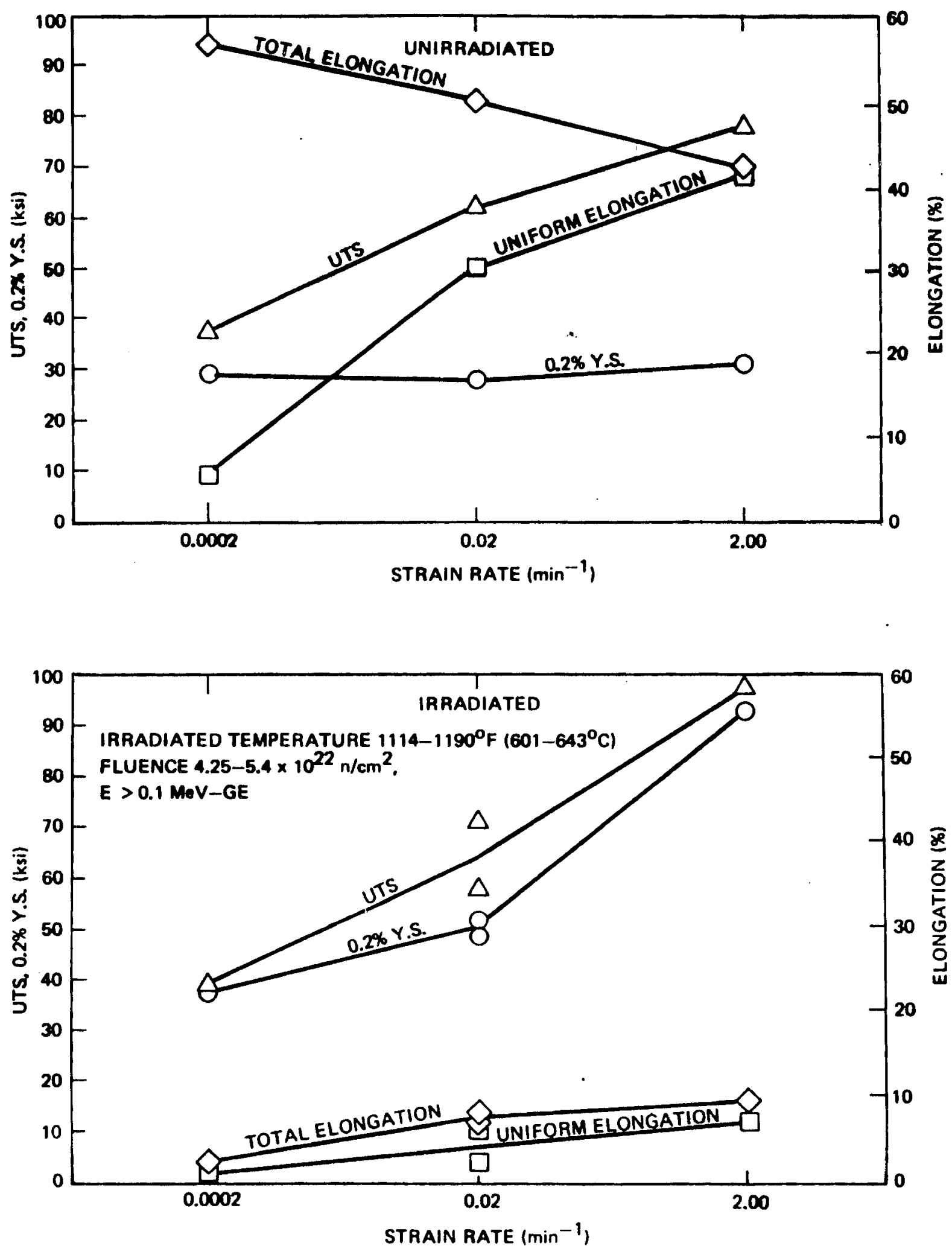

FIGURE 3.2.2-11 The Effect of Strain Rate on the Mechanical Properties of Hastelloy-X Tested at $1300^{\circ} \mathrm{F}\left(704.4^{\circ} \mathrm{C}\right)$. 


\section{REFERENCES}

1. J. M. Steichen, "Effect of Irradiation on the Strain-Rate Dependence of Type 304 Stainless-Steel Mechanical Properties," Nuclear Technology, Vol. 16, p. 308, October 1972.

2. J. M. Steichen, "Hìgh Strain Rate Mechanical Properties of Types 304 and 316 Stainless Steel," HEDL-TME 71-16Y, November 1971.

3. "Sodium-Cooled Reactors Fast Ceramic Reactor Development Program Portieth Quarterly Report," GEAP-10028-Y0, p. 10.15, November 1971. 


\subsubsection{TUBE BURST TESTS}

Tube burst tests have been performed to elucidate the effect of irradiation on hoop strength and rupture ductîlity of tubing. These tests are performed at a constant temperature under a constant pressure ramp of approximately $1000 \mathrm{psi} / \mathrm{min}$. Test data is limited by the fact that they usually represent tests on irradiated fuel pins, which are relatively scarce. In these tests, comparisons are made between fueled and unfueled sections of the pin. The low fluences usually involved make difficult attempts to draw distinctions between effects due only to irradiation fluence and temperature and those due to the combination of fluence, temperature and fuel chemical attack.

Until more definitive data is available, the current results from tube burst tests are adequately presented in Chapter 7.0: Effects of Fuel Clad Interactions on Mechanical Properties (see Section 7.3.2) and will not be further discussed here. 


\subsubsection{SIMULATED TRANSIENT TESTS}

To describe the deformation and faiture behavior of $20 \%$ coldworked 316 SS fuel cladding during postulated loss-of-flow or transient overpower accidents, simulated transient tests have been developed. (1-4) These tests, which are essentially constant pressure/ ramp temperature tests on short tubing sections, have as parameters temperature of irradiation, initial gas pressure, initial test temperature and tube heating rate. To date, strain measurements have only been made at the end of the test; where information on deformation prior to failure is desired, interrupted tests have been performed. Diametral strain away from the failure site and total hoop strain at the failure site have been determined using a combination of micrometer and metallographic means. (2)

The data for the first series of experiments are presented in Figures $3.2 .4-1,-2$ and -3 . In Figure $3.2 .4-1$, (2) the irradiation and test parameters relevant to al1 three figures are presented. Figures $3.2 .4-2^{(2)}$ and $-3^{(2)}$ summarize the effects of irradiation on ductility and strength. From these latter two figures, it is seen that irradiation, even to the relatively low fluences attained here $\left(7.4-9.0 \times 10^{21} \mathrm{n} / \mathrm{cm}^{2}\right)$, drastically reduces diametral strains and failure temperatures. Figure 3.2.4 -3 also indicates that the lower test temperature and, hence, lower irradiation temperature (see Figure $3.2 .4-1$ ) results in a lower failure temperature. This probably is a result of the increased embrittlement at $1050^{\circ} \mathrm{F}$ where two mechanisms, matrix-hardening and grain boundary embrittlement, are active; only the grain boundary embrittlement mechanism occurs at $1410^{\circ} \mathrm{F}$.

From earlier studies on recovery, recrystallization and annealing on cold-work in $316 \mathrm{SS},{ }^{(5)}$ annealing, with recovery of ductility, could be predicted from extrapolation of the data to occur in less than one second at $1900^{\circ} \mathrm{F}$. (2) The data in Figure 3.2.4 -2 show that significant annealing has not occurred in the irradiated material. Therefore, ballooning and resultant flow blockage would not be expected for irradiated cladding since the maximum total failure 


\section{$3.2 .4-2$}

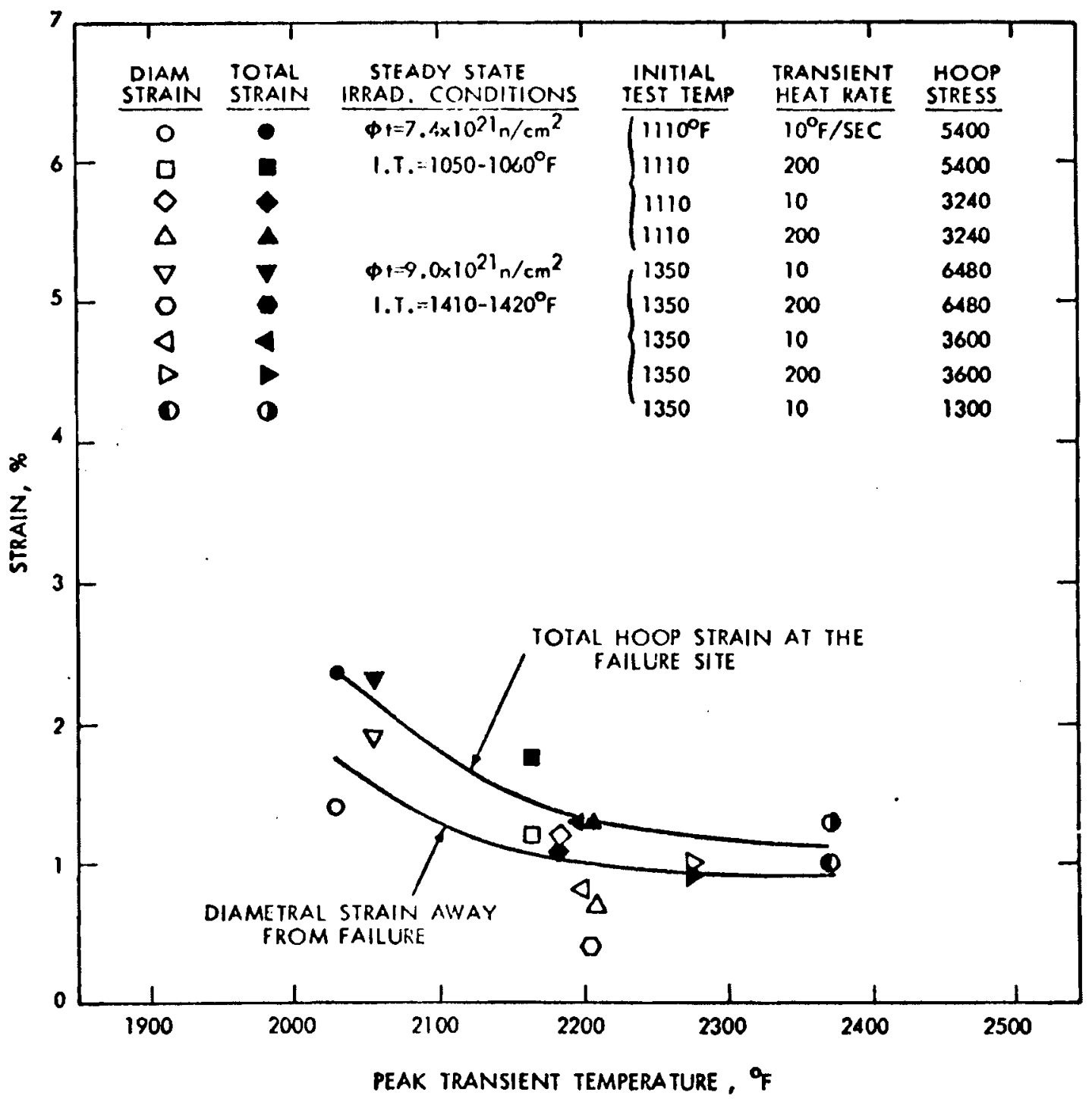

FIGURE 3.2.4-1 Failure Strain of Irradiated $20 \%$ Cold Worked Type 316 Stainless Steel Cladding During High Temperature Transients. 
$3.2 .4-3$

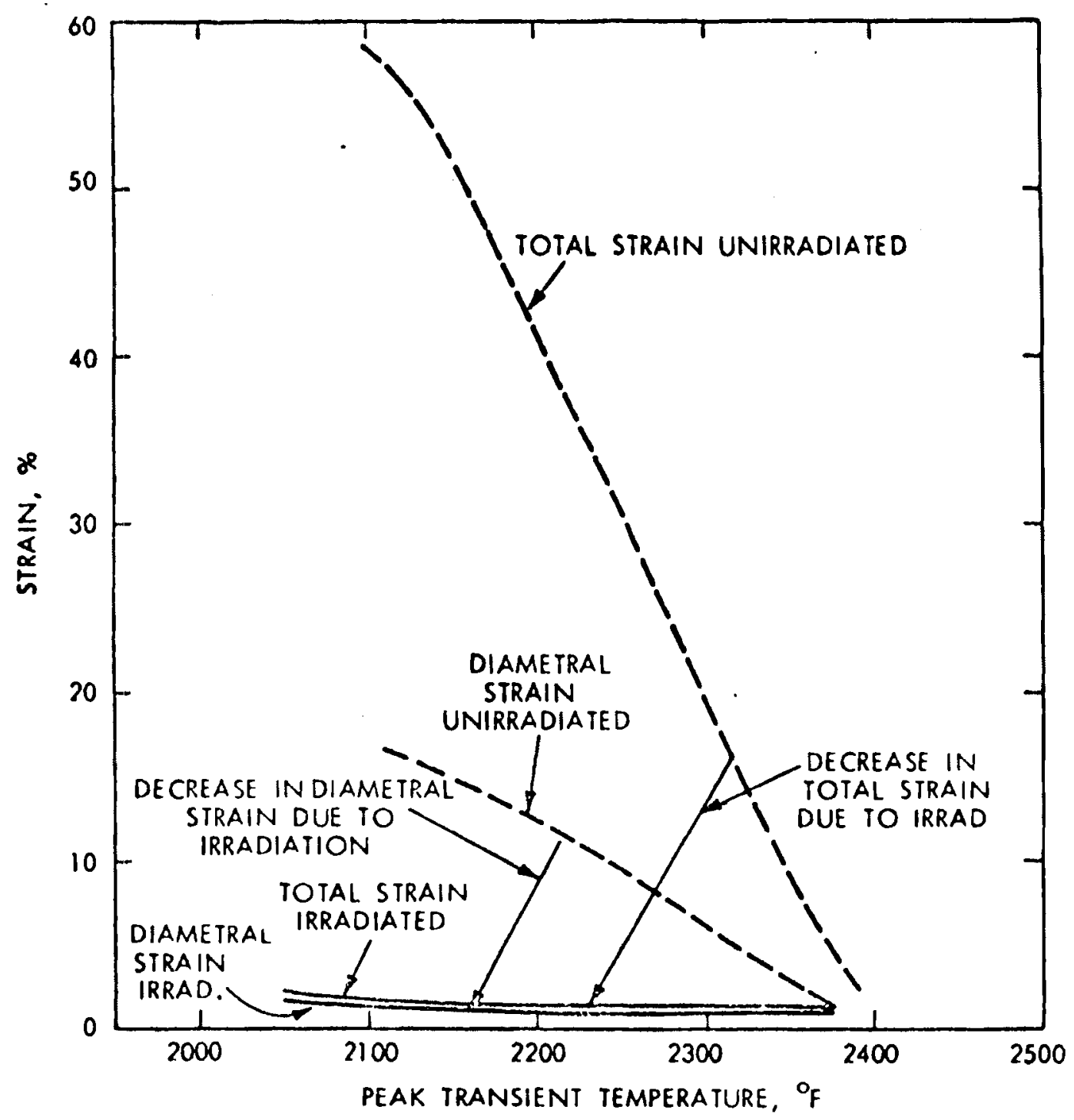

FIGURE 3.2.4-2 Effect of Irradiation on the Failure Strain of $20 \%$ Cold Worked Type 316 Stainless Steel Cladding During High Temperature Transients. 


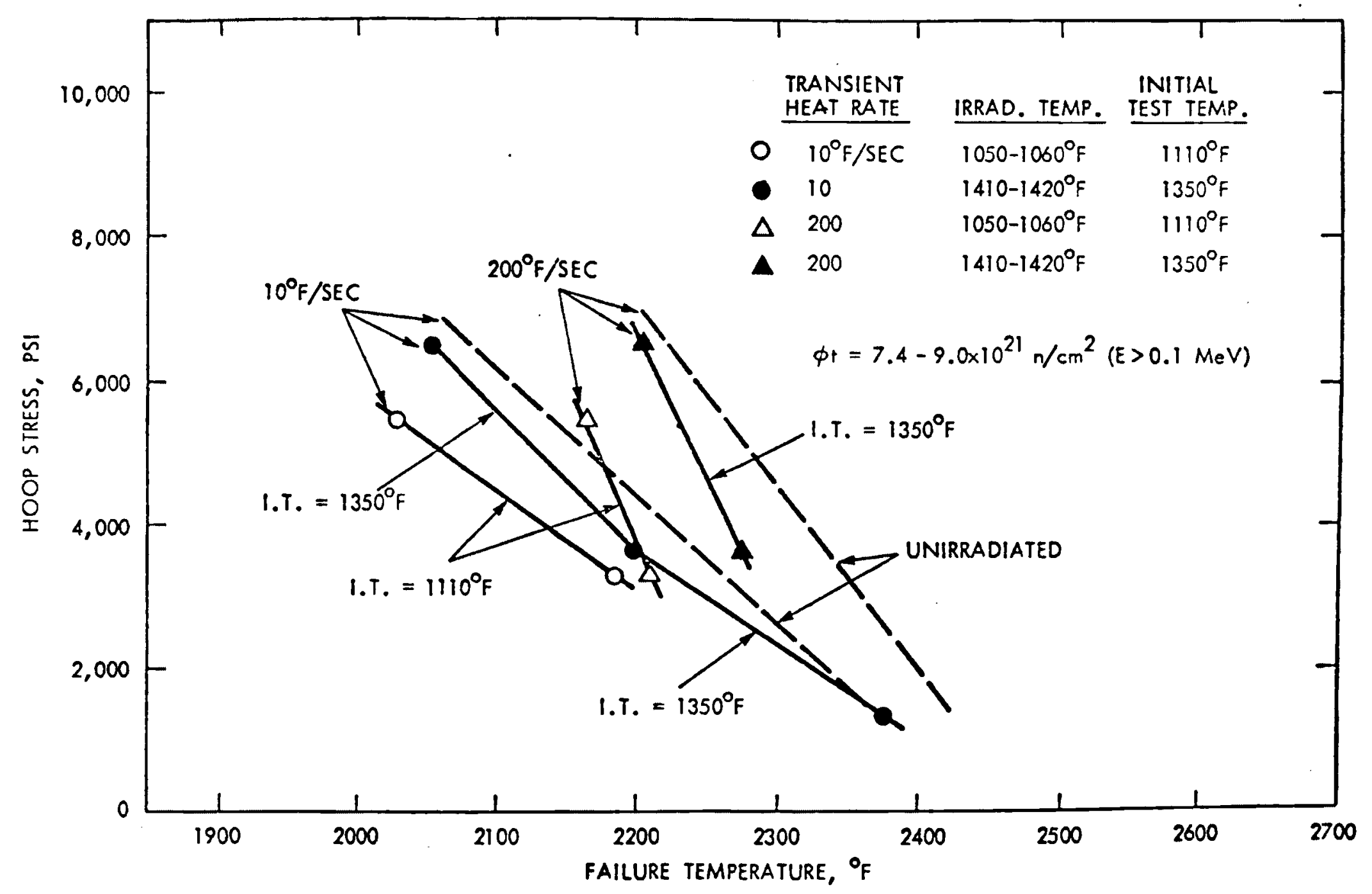

$w$
$\vdots$
$i$
$p$
$p$

$\frac{n}{D}$

FIGURE 3.4.2-3 Effect of Hoop Stress on the Failure Temperature of Irradiated 20\% Cold Worked Type 316 Stainless Steel Cladding During High Temperature Transients. 


\section{$3.2 .4-5$}

strain is only $2.5 \%$ (Figure $3.2 .4-1$ ). The higher failure temperatures, shown in Figure 3.2.4 -3 , for $200^{\circ} \mathrm{F} / \mathrm{sec}$ heating rate compared to the $10^{\circ} \mathrm{F} / \mathrm{sec}$ rate is probably the result of some annealing occurring during the slower rate; it should be noted, however, that, in irradiated material, this affect disappears at $2200-2300^{\circ} \mathrm{F}$, starting earlier with the more heavily damaged microstructure produced at the $1100^{\circ} \mathrm{F}$ irradiation temperature.

The second series of experiments $(3,4)$ were more comprehensive, covering higher fluence values and a wider range of irradiation temperatures. All tests were initiated at $700^{\circ} \mathrm{F}$, which was below the steady-state irradiation temperature of the specimens.

The effect of irradiation on diametral failure strain is presented in Figure 3.2.4 -4. Here, with data from irradiation fluences as high as $2.7 \times 10^{22} \mathrm{n} / \mathrm{cm}^{2}$, the effect of irradiation is seen to be a drastic reduction in ductility, with values less than approximately $0.2 \%$ being observed (for $10^{\circ} \mathrm{F} / \mathrm{sec}$ rate at failure temperatures from $1000-1500^{\circ} \mathrm{F}$ ).

As in the earlier series of transient tests, irradiation lowers the failure temperature, Figure 3.2.4-5. But in these series of tests, a correlation between diametral failure strain and decrease in failure temperature was established; as shown in Figure 3.2.4 -6, the lower the ductility is, the lower is the failure temperature. Moreover, the decrease in failure temperature was also related to the original temperature of irradiation, Figure 3.2.4 -7. These data show that the lower irradiation temperatures produce the greatest embrittlement, as discussed earlier; and that this, in turn, leads to earlier failure (i.e., lower failure temperatures). The lesser effect on failure temperature of the $200^{\circ} \mathrm{F}$ heating rate, seen in this figure, may be due to the tendency at high strain-rates for transgranular failure to be retained to higher temperatures, requiring greater strain to cause failure than would intergranular failure. ${ }^{(4)}$ This is borne out by the data in Figure 3.2.4 -4 that show that, below $1600^{\circ} \mathrm{F}$, the higher strain rate produces the greatest ductility. (Above $1600^{\circ} \mathrm{F}$, matrix 


\section{$3.2 .4-6$}

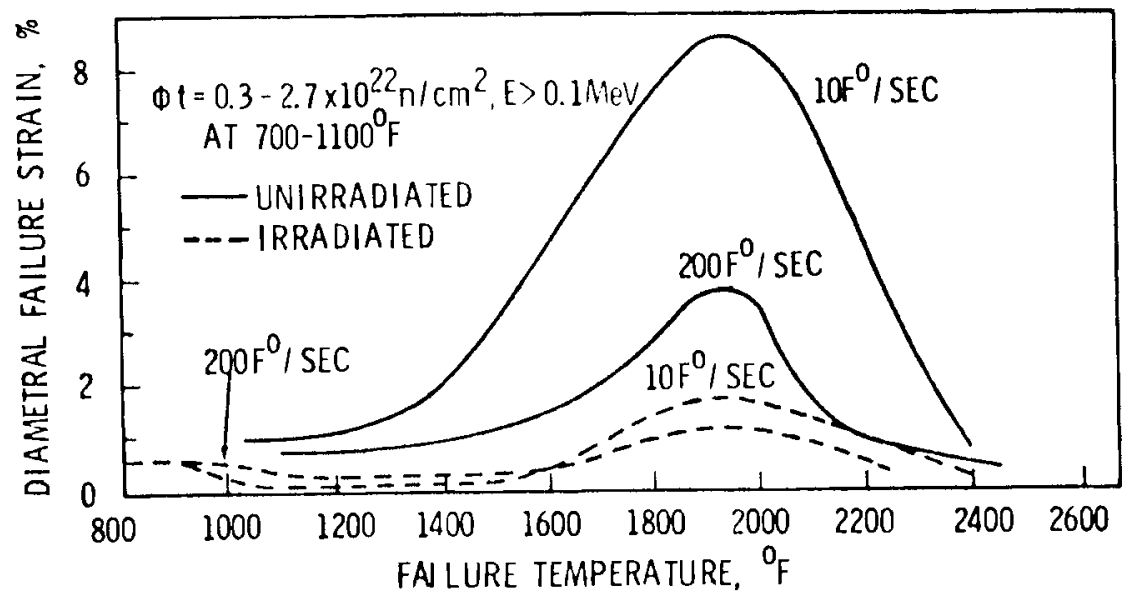

FIGURE 3.2.4-4 Effect of Irradiation on the Failure Ductility of Irradiated $20 \%$ Cold Worked Type 316 Stainless Steel Cladding.

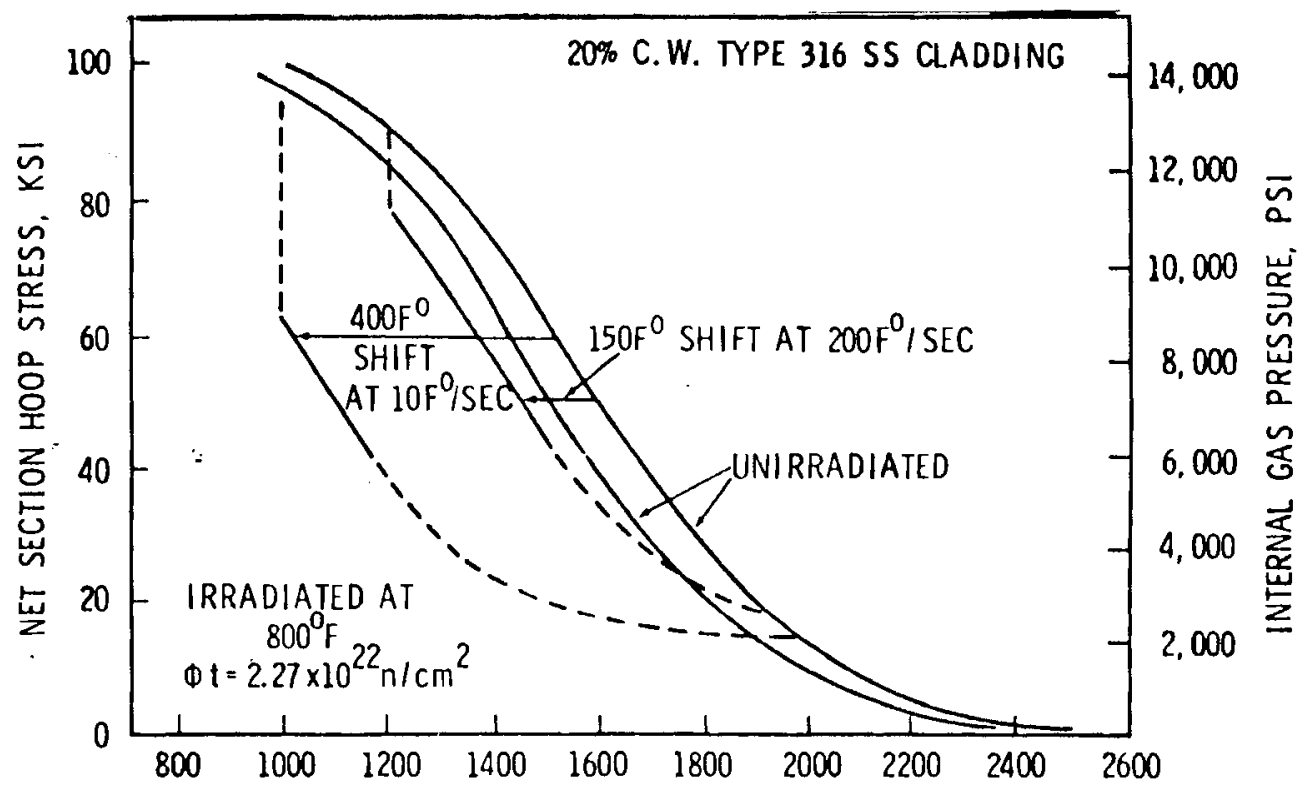

FIGURE 3.2.4-5 Effect of Irradiation on the Failure Strength 


\subsection{4-7}

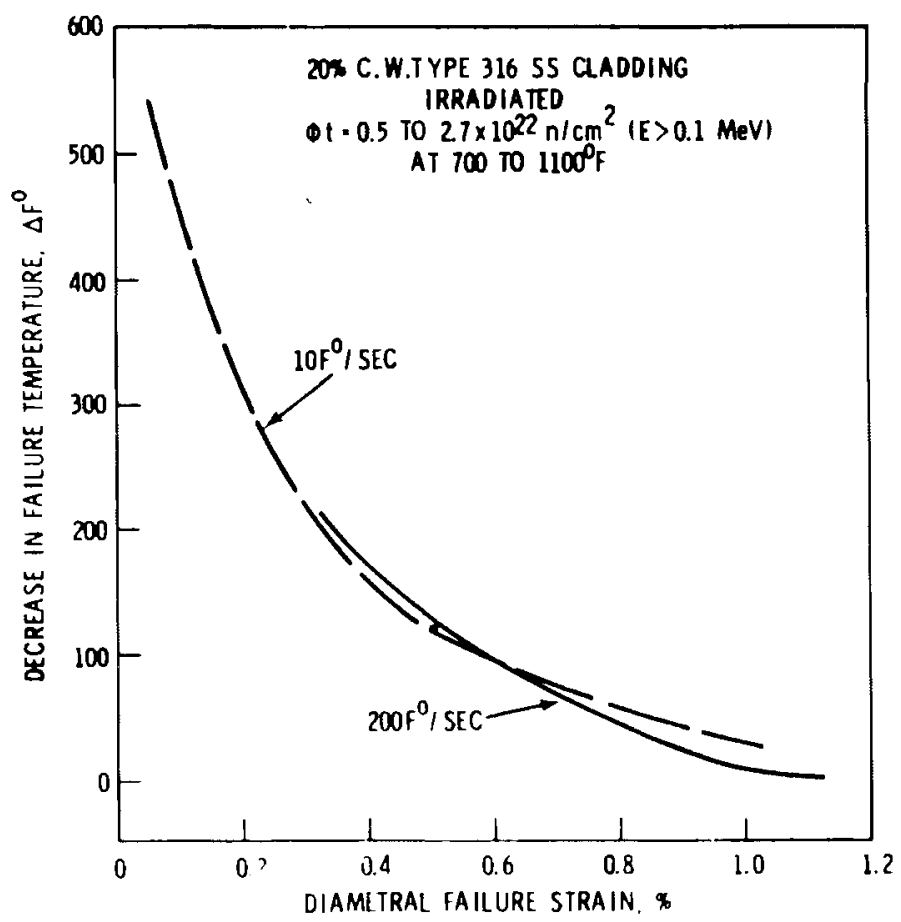

FIGURE 3.2.4-6 Relationship Between Decrease in Failure Temperature and Diametral Failure Strain.

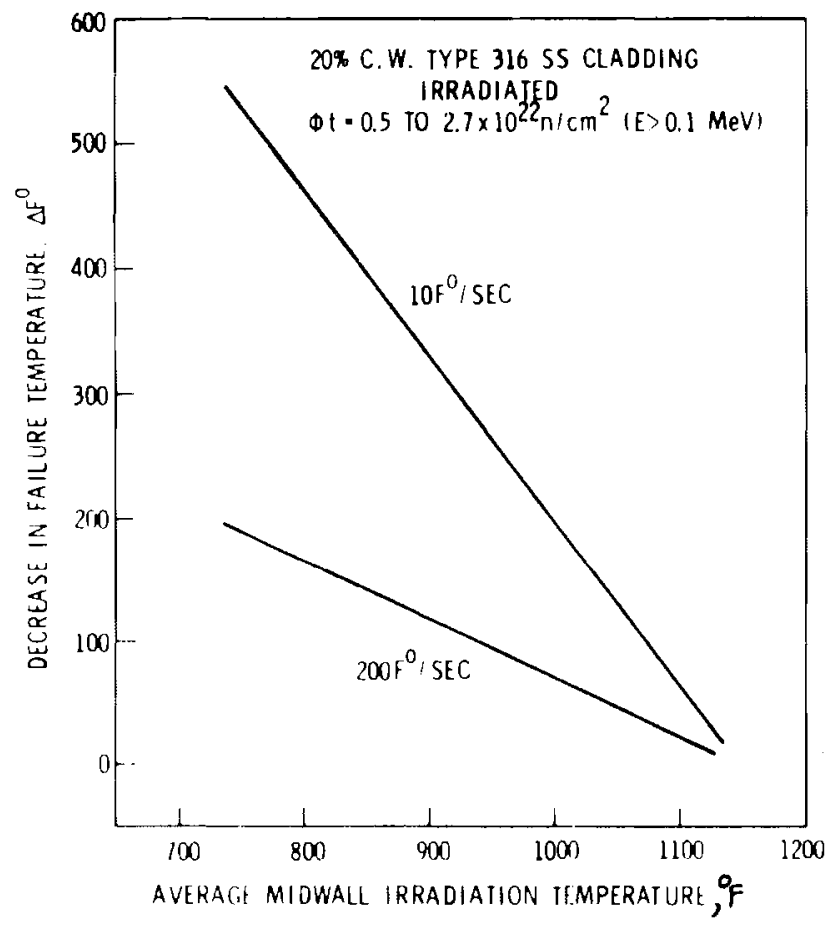

FIGURE 3.2.4-7 Effect of Irradiation Temperature on the Decrease in Failure Temperature During Temperature Transients. 
weakening, aided by some in-test annealing, leads to greater ductility even with intergranular failure the slower heating rate producing more annealing and greater ductility).

In no case, do diametral failure strains rìse above approximately $1.1 \%$; and they are below $0.5 \%$ at irradiation temperatures $\approx 900^{\circ} \mathrm{F}$ for the $200^{\circ} \mathrm{F} / \mathrm{sec}$ heating rate and $\lesssim 1050^{\circ} \mathrm{F}$ for the $10^{\circ} \mathrm{F} / \mathrm{sec}$ heating rate. 


\section{REFERENCES}

1. "Hanford Engineering Development Laboratory Monthly Technical Progress Report," HEDL-TME 72-12, December 1972, p. B-18-2. (Limited Distribution).

2. C. W. Hunter and R. L. Fish, "Deformation and Failure of Fast Reactor Cladding During Simulated Loss-of-Flow Type Transient," HEDL-SA-645, Apri 11974.

3. "Hanford Engineering Development Laboratory Quarterly Progress Report, Vol I-Materials," HEDL-TME 73-4 Vol I, August 1973, p. A23b (Appl. Tech.).

4. J. H. Scott, G. E. Culley, C. W. Hunter, and J. E. Hanson, "Microstructural Dependence of Failure in Mixed-0xide LMFBR Fuel Pins," HEDL-SA-701, Apri1 1974.

5. M. M. Paxton and J. J. Holmes, "Recovery and Recrystillization of Prototypic FTR Fuel Cladding - 20\% C.W. 316 Stainless Steel Tubing," HEDL-TME 71-126, September 1971. 


\subsection{OTHER FACTORS INFLUENCING IRRADIATION EFFECTS}

ON HIGH STRAIN-RATE PROPERTIES

The other factors influencing irradiation effects on high strainrate properties can, as was done in Section 2.3 for tensile properties, be broadly classified as those resulting from reactor variables and those resulting from material variables. However, the limitation of data on high strain-rate effects makes a detailed analysis impossible.

The reactor variables that can be expected to influence high strain-rate properties are the same as those described in Section 2.3.2. Recent data suggests that, as with tensile properties, there is an effect of prior creep on residual high-strain rate properties. Data from tests at $1200^{\circ} \mathrm{F}$ on unirradiated cold-worked 316 SS shows that tube burst strength is significantly reduced by prior creep exposure. $(1,2)$

The material variables that have been observed, or that can be, expected to influence high strain-rate properties are again similar to those detailed in Section 2.3.3. 


\section{REFERENCES}

1. M. M. Paxton, "Effect of Prior Creep Strain on Residual Mechanical Properties of 20\% Cold Worked Type 316 Stainless Stee1," HEDL-TME 72-153, January 1973.

2. "Hanford Engineering Development Laboratory Quarterly Progress Report, Vol. I-Materials," HEDL-TEM 73-6, Vol. I, January 1974, p. B-11. 


\subsection{GENERAL RELATIONSHIP OF IRRADIATED HIGH STRAIN-RATE PROPERTIES TO LMFBR PERFORMANCE}

\subsubsection{INTRODUCTION}

Irradiated high strain-rate properties are specified, or implied as part of tensile property criteria, for certain core components. As yet, data from irradiation at fluences and temperatures and at strain-rate representative of current and future LMFBR designs are incomplete. Prediction of properties in relevant regimes will require extrapolative techniques until these gaps are filled.

Since the major emphasis to date in the United States is upon the development of the FFTF, many of the remarks in this section are specifically related to it as the reference LMFBR reactor, though they will be of general application to future commercial LMFBRs as well. 


\section{$3.4 .2 \cdot 1-1$}

\subsubsection{INFLUENCE OF LMFBR VARIABLES}

\subsubsection{LMFBR Reactor Variables}

As noted in Section 2.4.2.1, with regard to tensile properties, the major reactor variables are high fluence levels (up to $2-3 \times 10^{23} \mathrm{n} / \mathrm{cm}^{2}$ in a commercial LMFBR) and temperature. other variables that can have an influence are as noted in that section. 


\subsubsection{LMFBR Materials Variables}

Current material concepts for LMFBR (FFTF) call for $20 \%$ cold-worked 316 stainless steel for fuel assemblies and control and safety rod guide tubes, solution annealed 304 for core support structure and the pressure vessel, and radial shields composed of 304 stainless steel, nickel and Inconel 718, as noted in Section 2.4.2.2. The expected temperature/fluence ranges for the FFTF were presented in Figure 2.4.2.2-1.

The extremes of properties that are to be required in the FFTF as noted in Section 2.4.2.2, appear to be exemplfied by the design criteria for transient events for the $20 \%$ cold-worked 316 stainless steel fuel cladding ( $\leq 0.5 \%$ added strain) and that for end-of-life tensile ductility for major annealed 304 stainless steel core structures ( $10 \%$ tota 1 elongation).

As noted in Section 2.4.2.2, uniform elongation, rather than total elongation, is considered the more relevant material parameter under transient conditions. The limited data available on high strain-rate tensile properties (Section 3.2.2) indicates that no significant increase in uniform elongation is obtained at high strain-rates on solid specimens. Therefore, ordinary tensile data can be used to approximate high strain-rate properties at high fluence. Based on the data in Figure 2.2.2-1(d), for postirradiation uniform elongation of annealed 304 stainless steel, a value of $10 \%$ is achieved, for $700-900^{\circ} \mathrm{F}$ and at $1200-1400^{\circ} \mathrm{F}$, at a fluence of $7 \times 10^{22}$ and, for $1000^{\circ} \mathrm{F}$, at $2.8 \times 10^{22} \mathrm{n} / \mathrm{cm}^{2}$ (E > $0.1 \mathrm{MeV}$ ).

For fuel cladding under transient conditions, available data (see Section 3.2.4) indicates that fuel cladding operating at steady state temperatures can be expected to exhibit failure strains of less than $0.5 \%$ from steady state temperatures of $\lesssim 1050^{\circ} \mathrm{F}$ for a heating rate of $10^{\circ} \mathrm{F} / \mathrm{sec}$ and from steady state temperatures of $\left\{900^{\circ} \mathrm{F}\right.$ for a heating rate of $200^{\circ} \mathrm{F} / \mathrm{sec}$. Since this data is for relatively low fluences (a maximum $2.7 \times 10^{22} \mathrm{n} / \mathrm{cm}^{2}$, 


\subsubsection{2-2}

$E>0.1 \mathrm{MeV}$ ), an increase in fluence would probably result in lower failure strains and/or an increase in the steady-state temperature that will produce the low failure strains. 
3.4.3 GENERAL IMPLICATION OF IRRADIATED HIGH STRAIN-RATE PROPERTIES ON LMFBR COMPONENTS

\subsubsection{Pressure Vessel}

Since over a 20 year reactor design life, fluence

levels at the pressure vessel are expected to be no greater than $3.8 \times 10^{19} \mathrm{n} / \mathrm{cm}^{2}(E>0.1 \mathrm{MeV}$ ) (see Section 2.4 .2 .2 ), $10 \%$ residual elongation (total or uniform) is readily expected for annealed Type 304 stainless steel base metal and welds. 


\subsubsection{Core Components}

Core components will be subjected to a wide range of design requirements including fluence $\left(210^{21}\right.$ to $\left.>10^{23}\right)$, temperatures $\left(800\right.$ to $1400^{\circ} \mathrm{F}$ ) and design lifetime ( 1 to 20 years).

Tables 2.4.3.2-1 and 2.4.3.2-2 have presented total design fluence for large core structures and Table 2.4.3.2-3 has presented fluence levels to produce a minimum $10 \%$ total elongation. Even under the constraints of considering high strain-rates and in utilizing uniform rather than total elongation, the discussion in Section 3.4.2.2 indicates that those components 1 isted in Table 2.4.3.2-2 as having a maximum fluence of 1.7 to $1.8 \times 10^{23} \mathrm{n} / \mathrm{cm}^{2}$ would definitely not have $10 \%$ residual elongation. The other components in these tables appear to be reasonably near to fluence limits, particularly if they should be subject to any steady-state creep deformation prior to the transient.

As noted in Section 2.4.3.2, fuel pin criteria for the FFTF call for an integrity 1 imit of $0.7 \%$ strain (i.e., $0.2 \%$ steady-state strain and $0.5 \%$ strain due to upsets and transients). As noted in Section 3.4.2.2, the data suggests that fuel pins, even when irradiated to a maximum of only $2.7 \times 10^{22} \mathrm{n} / \mathrm{cm}^{2}$, will exhibit failure strains of less than $0.5 \%$ under transient conditions. Thus, a $0.7 \%$ strain integrity limit appears not to be conservative. 

4. IRRADIATION EFFECTS ON CREEP-RUPTURE PROPERTIES

TABLE OF CONTENTS

4.1 INTRODUCTION . . . . . . . . . . . . . . 4.1-1

4.2 MAJOR FACTORS INFLUENCING IRRADIATION EFFECTS ON CREEP-

RUPTURE PROPERTIES . . . . . . . . . 4.2.1-1

4.2.1 Introduction ............ 4.2.1-1

4.2.2 Irradiation Fluence, Irradiation Temperature

and Test Temperature .......... 4.2.2-1

4.2.3 Irradiation Creep . . . . . . . . . 4.2.3-1

4.3 OTHER FACTORS INFLUENCING IRRADIATION EFFECTS

ON CREEP-RUPTURE PROPERTIES ............ . . 4.3-1

4.4 GENERAL RELATIONSHIP OF IRRADIATED CREEP-RUPTURE PROPERTIES TO LMFBR PERFORMANCE ......... 4. . 4.1-1

4.4.1 Introduction . . . . . . . . . . 4.4.1-1

4.4.2 Influence of LMFBR Variables ........ 4.4.2.1-1

4.4.2.1 LMFBR Reactor Variables ..... 4.4.2.1-1

4.4.2.2 LMFBR Material Variables . . . . . . 4.4.2.2-1

4.4.3 General Implications of Irradiated Creep-Rupture

Properties on LMFBR Components ....... 4.4.3.1-1

4.4.3.1 Pressure Vesse1 ........ 4.4.3.1-1

4.4.3.2 Core Components ........ 4. 4. . . . . . $2-1$ 



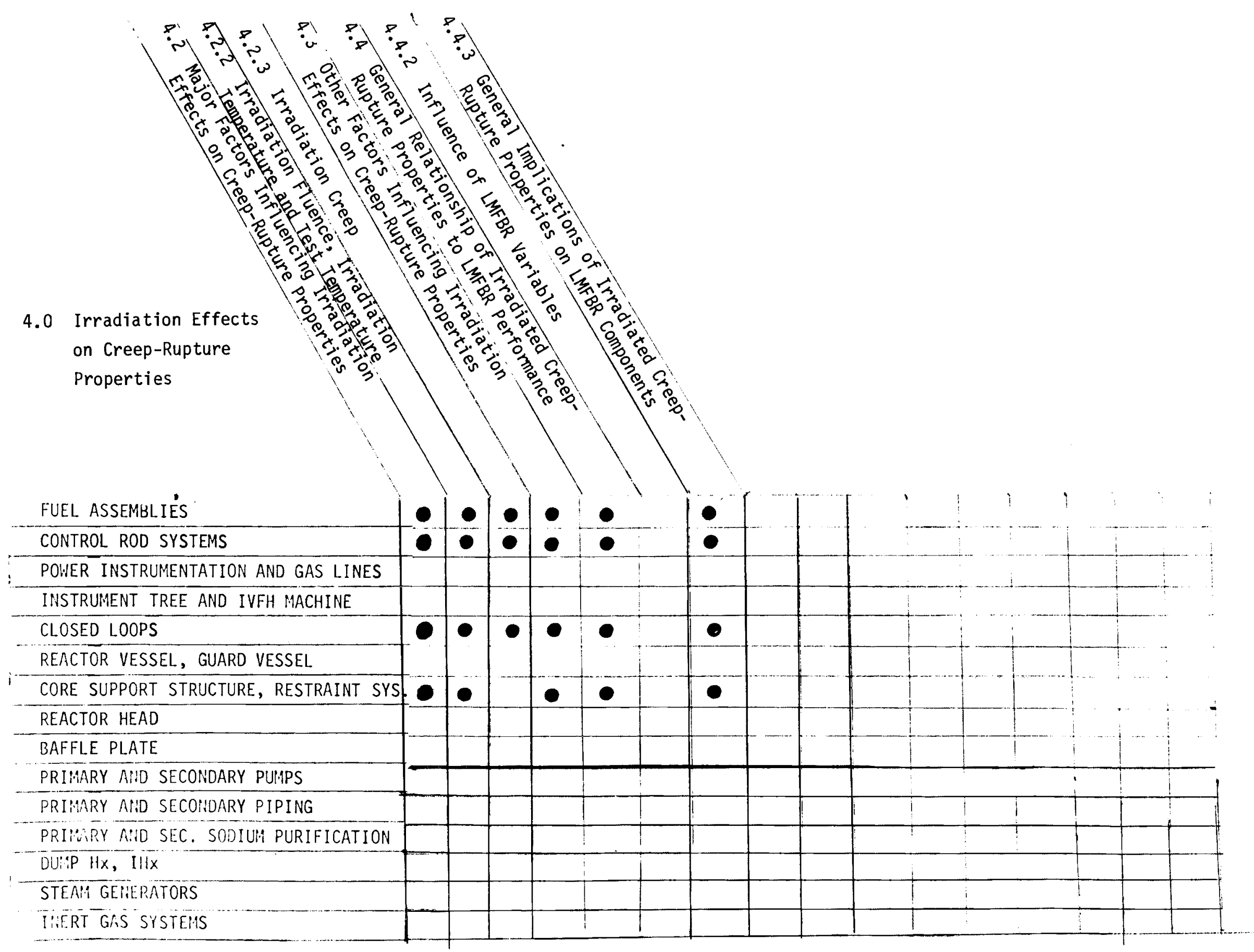





\section{IRRADIATION EFFECTS ON CREEP-RUPTURE PROPERTIES}

\subsection{INTRODUCTION}

Studies of the effects of irradiation on the creep-rupture (i.e., creep and stress-rupture) properties of metals did not commence as early as did those on tensile properties (see Section 3.1); significant work probably did not occur much before 1960. And investigations relevant to the elevated temperature, fast neutron environment of liquid metal fast breeder reactors did not commence until the latter 1960's. Intensive studies are still underway to characterize the high-fluence creep-rupture properties of candidate LMFBR alloys.

The qualitative effect of irradiation on metals and alloys have been discussed in Section 2.1. These were matrix hardening, due to irradiation-produced loops, voids and dislocations, and alloy embrittlement resulting from this matrix hardening as well as from grain boundary weakening due to transmutation-produced helium and irradiationinduced precipitation reactions. A further effect of irradiation is specifically manifested in creep-rupture behavior. It is known as "irradiation creep" and is an enhancement of creep-rate during irradiation.

The quantitative description of high-fluence "irradiationdamage," i.e. the relationships between temperature, fluence and resultant creep-rupture properties, are not completely defined for relevant alloys. It will be the purpose of this section of the report to discuss the generally accepted conclusions about high-fluence, fast neutron irradiation damage to creep-rupture properties; to point out the current unresolved problem areas; and to discuss, in a general way, the significance of irradiated creep-rupture properties to LMFBR performance. 


\section{$4.2 .1-1$}

\subsection{MAJOR FACTORS INFLUENCING IRRADIATION EFFECTS}

\section{ON CREEP-RUPTURE PROPERTIES}

\subsubsection{INTRODUCTION}

Four major factors influencing irradiation effects to creeprupture properties have been elucidated. The first two are the fast neutron fluence and the temperature of irradiation. Since their intimate relationship has been abundantly proven, these two factors will be discussed together (i.e., the effect of fast neutron irradiation at a specified irradiation temperature).

The third major factor influencing creep-rupture properties is the temperature at which the tests are conducted, a factor which was introduced in Section 2.2.1 with regard to its effects on tensile properties. An example of effects on creep-rupture properties of test temperatures different from the irradiation temperatures will also be discussed in the section dealing with irradiation fluence and temperature.

In a separate section, the fourth major factor influencing creep-rupture properties, namely irradiation creep, will be considered. 


\subsubsection{IRRADIATION FLUENCE, IRRADIATION TEMPERATURE AND TEST TEMPERATURE}

The extent of irradiation damage (i.e., hardening and embrittlement) increases with fluence in a manner that is a complex function of the combined effects of fast neutron irradiation fluence and irradiation temperature. Creep-rupture properties are likewise affected in a complex manner because of the interplay of irradiation hardening, tending to reduce creep-rate and, thereby, increase rupture life, with irradiation embrittlement, tending to reduce elongation to rupture and, thereby, decrease rupture life.

An example of this interplay between irradiation hardening and irradiation embrittlement is presented in Figure 4.2.2-1. (1) This figure shows the effect of irradiation on the creep of annealed 316 SS at $1200^{\circ} \mathrm{F} / 25,000 \mathrm{psi}$. While the irradiated material has been irradiation-hardened, as evidenced by its lower minimum creep-rate, it fails sooner because it has also been embrittled by irradiation. Other examples of the effects of irradiation on the creep of annealed 316 SS in various temperature and stress regimes are seen in Figure 4.2.2-2 $(a-c) .{ }^{(2)}$ Thus, relative to the unirradiated material, irradiated specimen creep-strengths (as indicated by the minimum creep rate) can be smaller (Figure 4.2.2-1), identical to (Figure 4.2.2-2 (b)), slightly larger (Figure 4.2.2-2 (a)) or much larger (Figure 4.2.2-2 (c)). Yet, in all cases rupture life is reduced by irradiation because of embrittlement.

Figures $4 \cdot 2 \cdot 2-3$ and $-4{ }^{(3)}$ present examples of the dramatic relationship between property degradation and neutron fluence for the creep elongation and rupture life of annealed 304 SS at two temperature/ stress conditions. A more generalized presentation of creep ductility versus fluence in terms of stable creep strain (i.e., the rupture strain minus the testing and loading strains) for uniaxial specimens of annealed $316 \mathrm{SS}$ from $1000^{\circ} \mathrm{F}$ is shown in Figures 4.2.2-5 through -8. (4) Band widths in these figures were set by using the extreme of the data points and drawing parallel lines to the least-square fit line. The 
EFFECT OF IRRADIATION ON THE $1200^{\circ} \mathrm{F}$ CREEP
CURVE AT $25,000 \mathrm{pSI}$

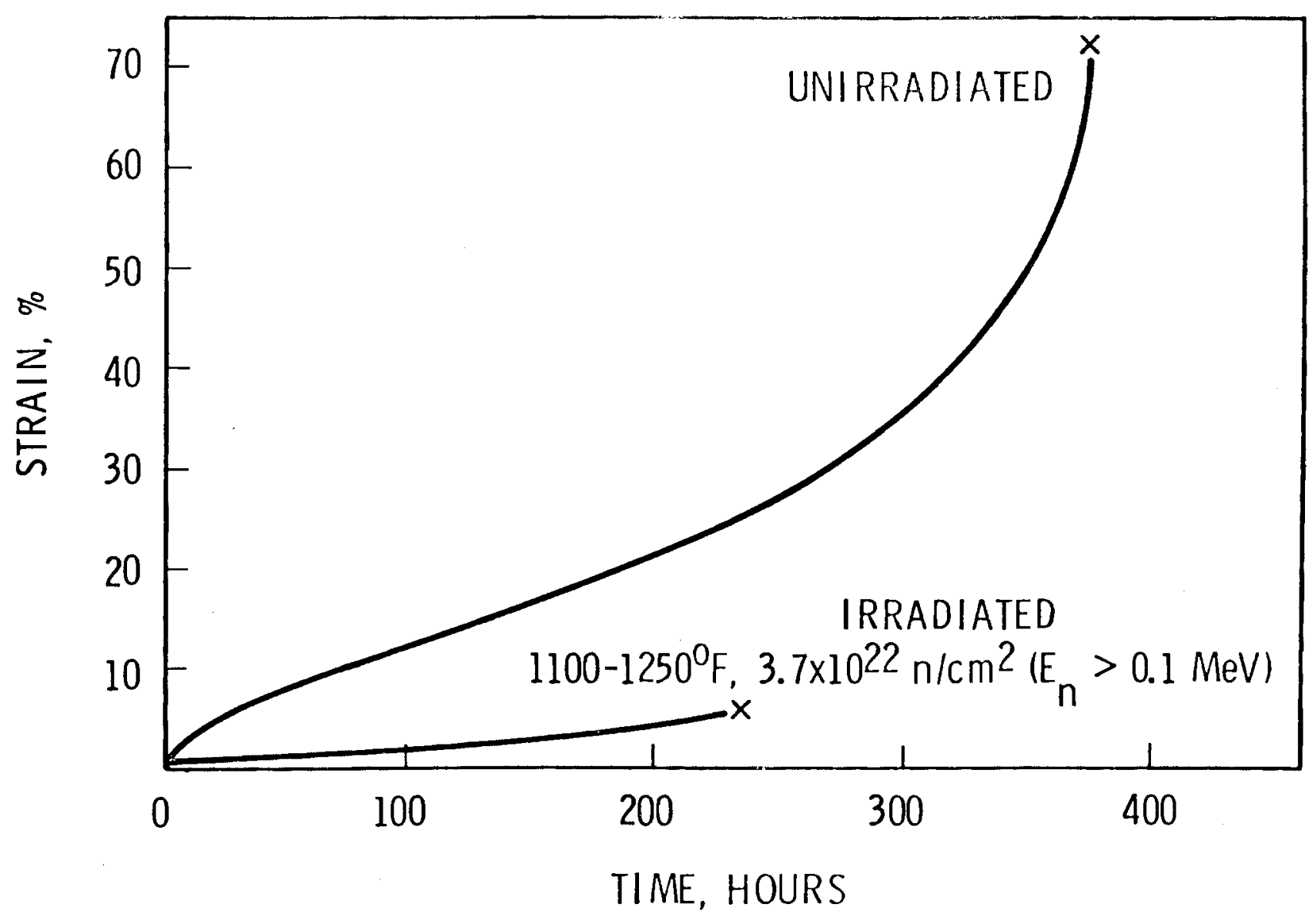

$n$
$i$
$i$ 


\section{$4.2 .2-3$}
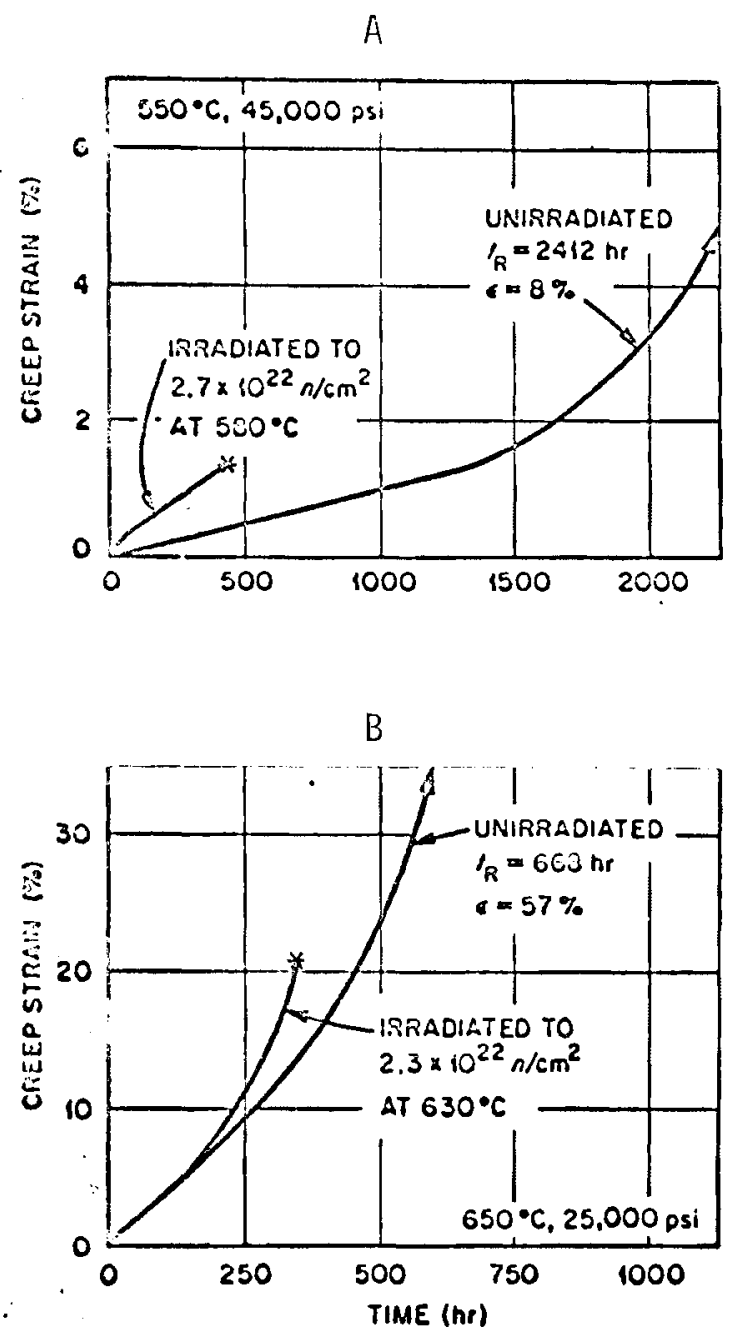

C

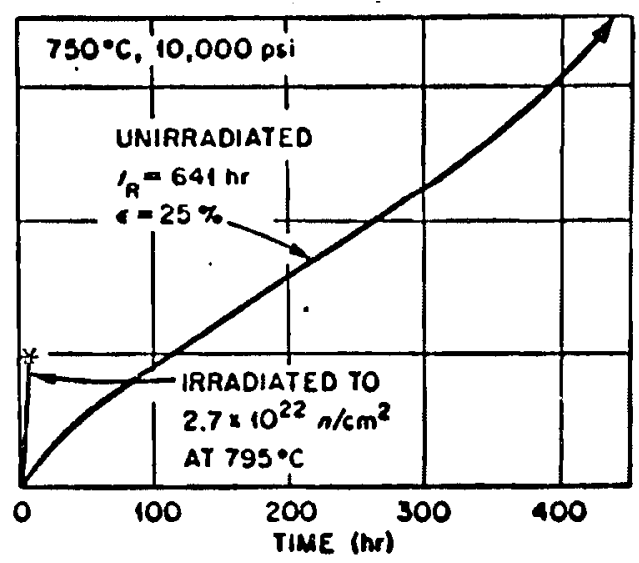

FIGURE 4.2.2-2 Effect of Fast Neutron Irradiation on the Creep-Rupture Behavior of Annealed Type 316 Stainless Steel. 


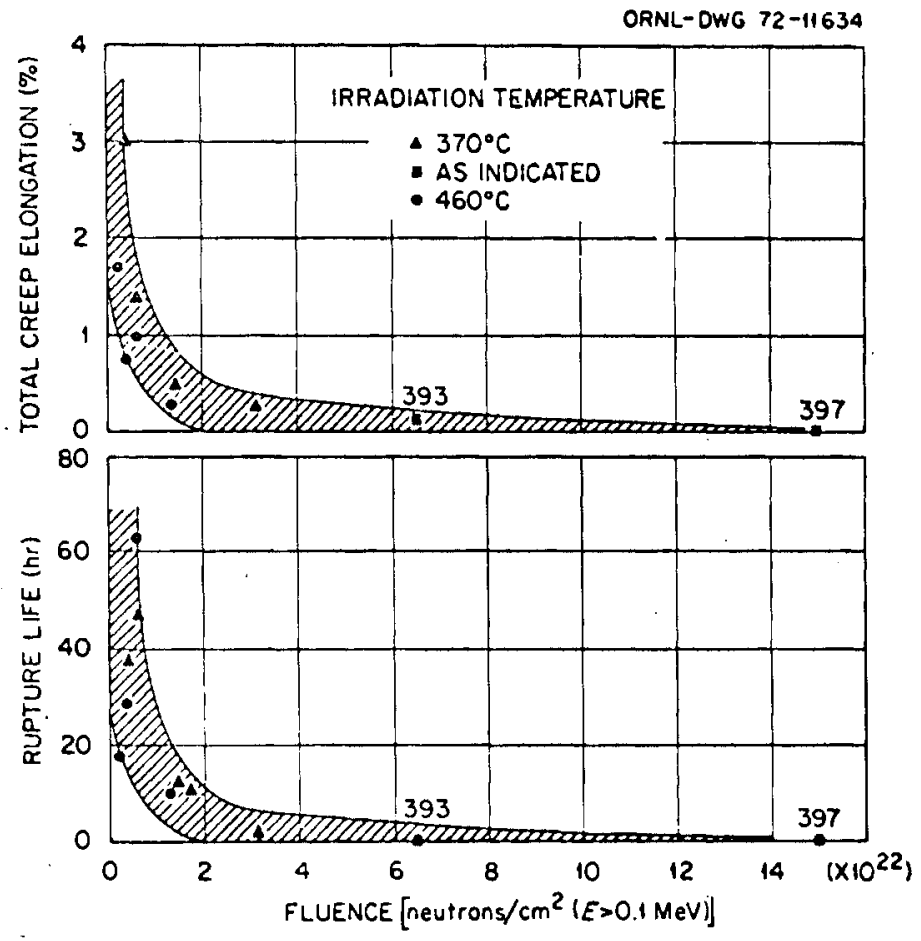

FIGURE 4.2.2-3 Rupture Life and Total Creep Elongation as a Function of Fast Neutron Fluence for Annealed Type 304 Stainless Steel Tested at $550^{\circ} \mathrm{C}$ and 35,000 psi. 


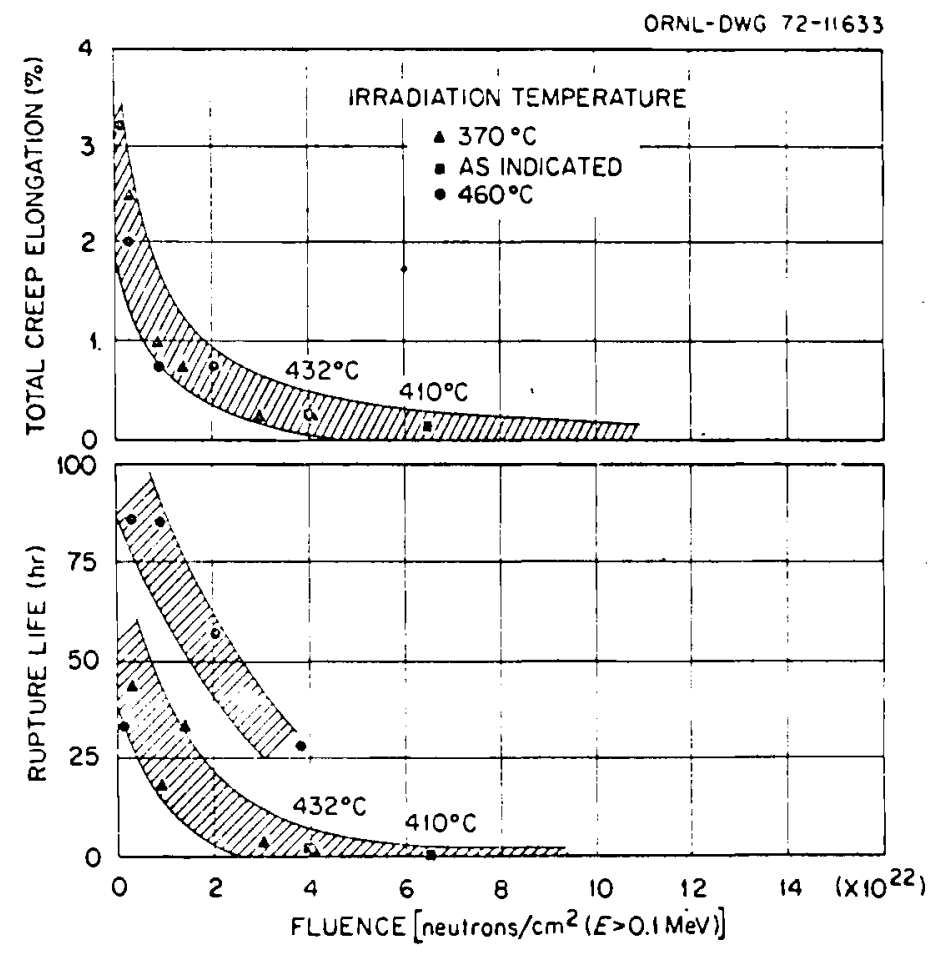

FIGURE 4.2.2-4 Rupture Life and Total Creep Elongation as a Function of Fast Neutron Fluence for Annelaed 304 Stainless Steel Tested at $600^{\circ} \mathrm{C}$ and 27,500 psi. 


\subsection{2-6}

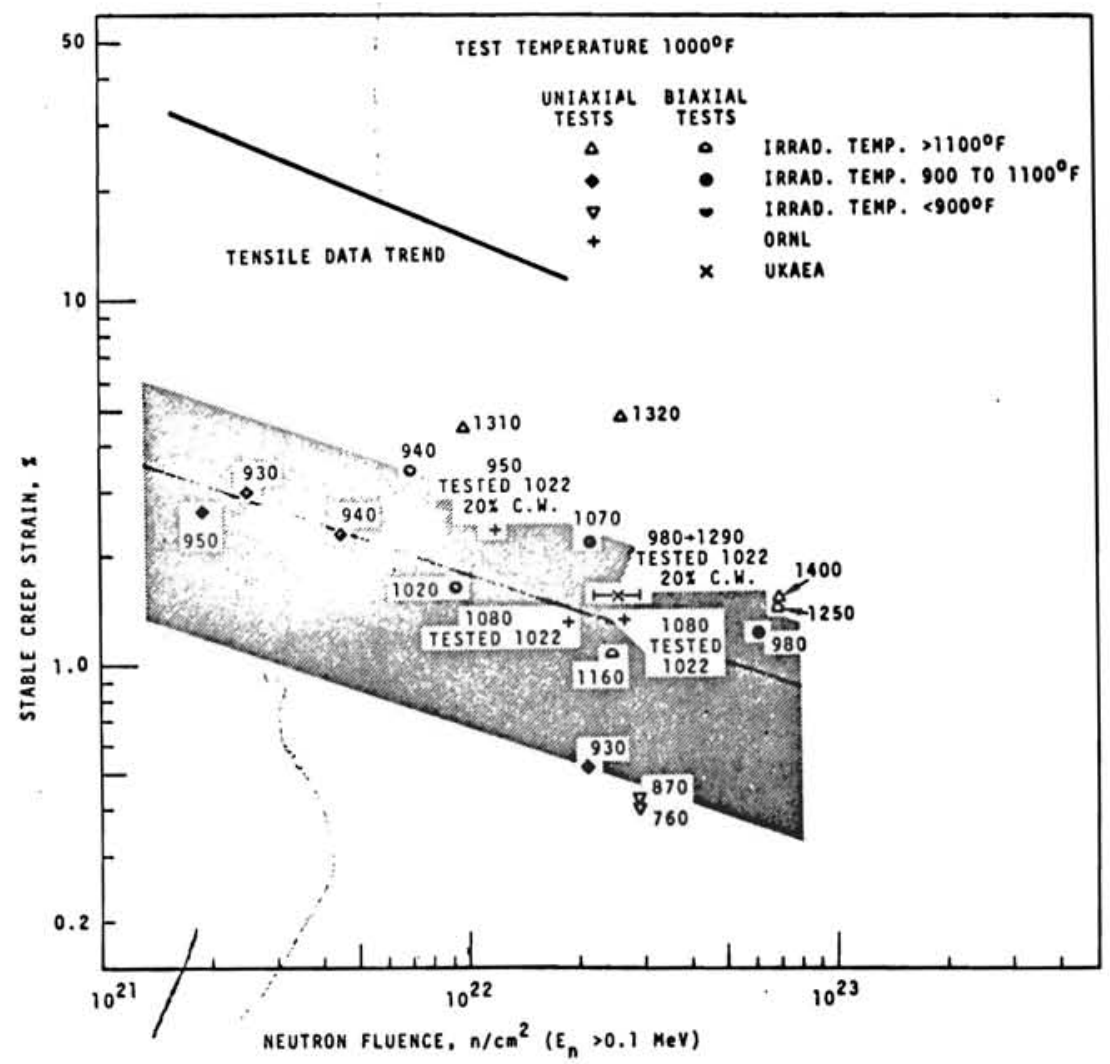

FIGURE 4.2.2-5 Post-Irradiation Ductility of Annealed 316 Stainless Steel at $1000^{\circ} \mathrm{P}$. 
4.2.2-7

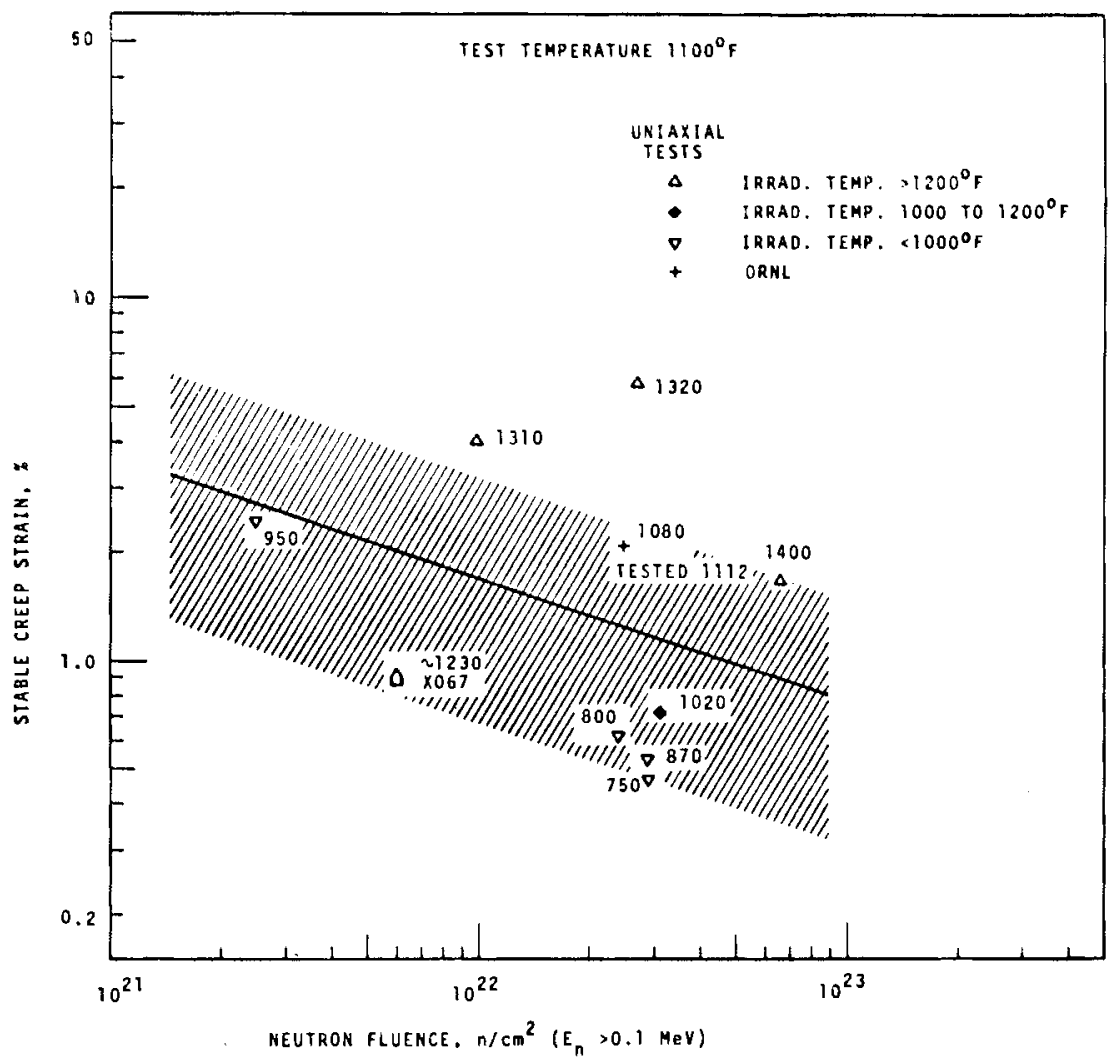

FIGURE 4.2.2-6 Post-Irradiation Ductility of Annealed 316 Stainless Steel at $1100^{\circ} \mathrm{F}$. 


\subsection{2-8}

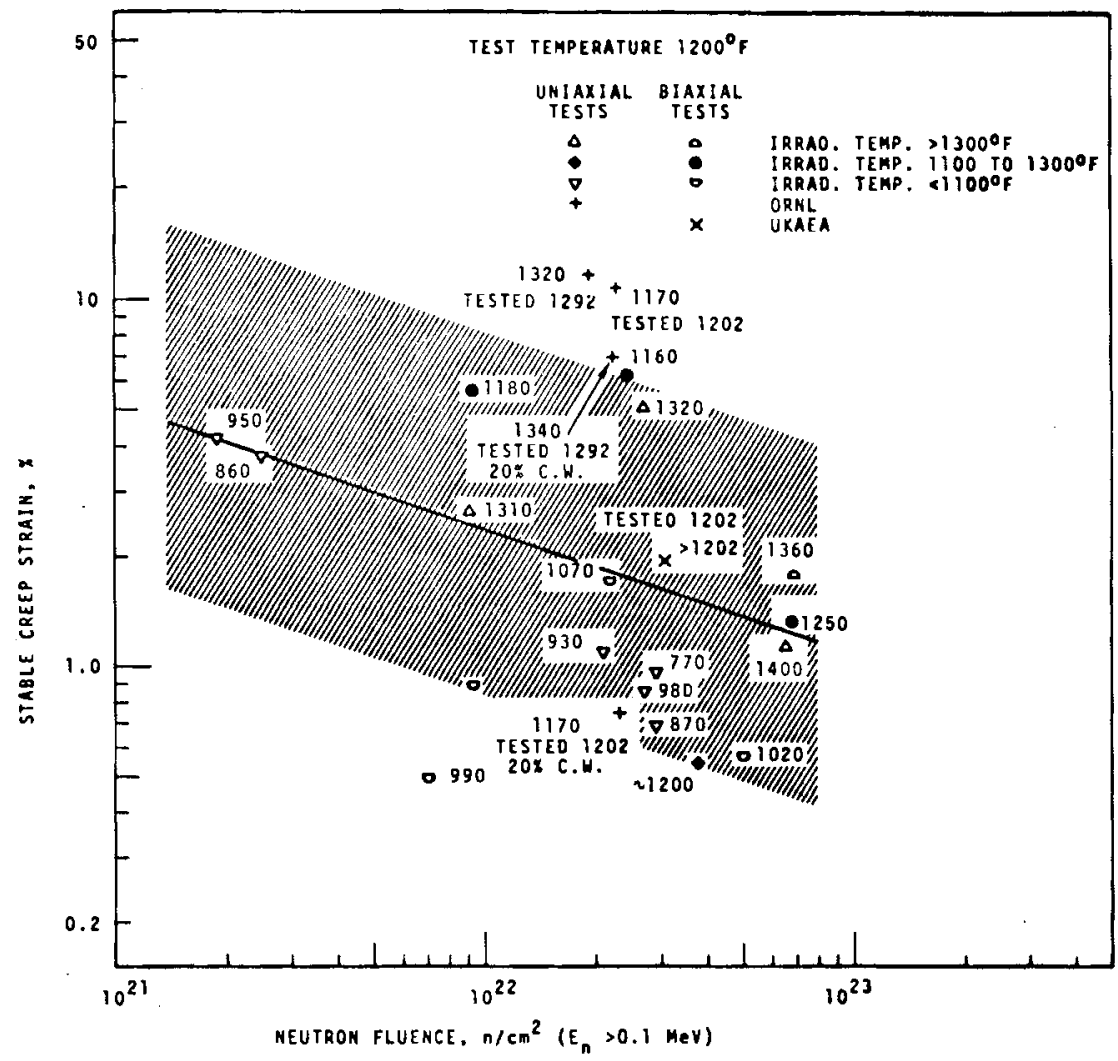

FIGURE 4.2.2-7 Post-Irradiation Ductility of Annealed 316 Stainless

Steel at $1200^{\circ} \mathrm{F}$. 
$4.2 .2-9$

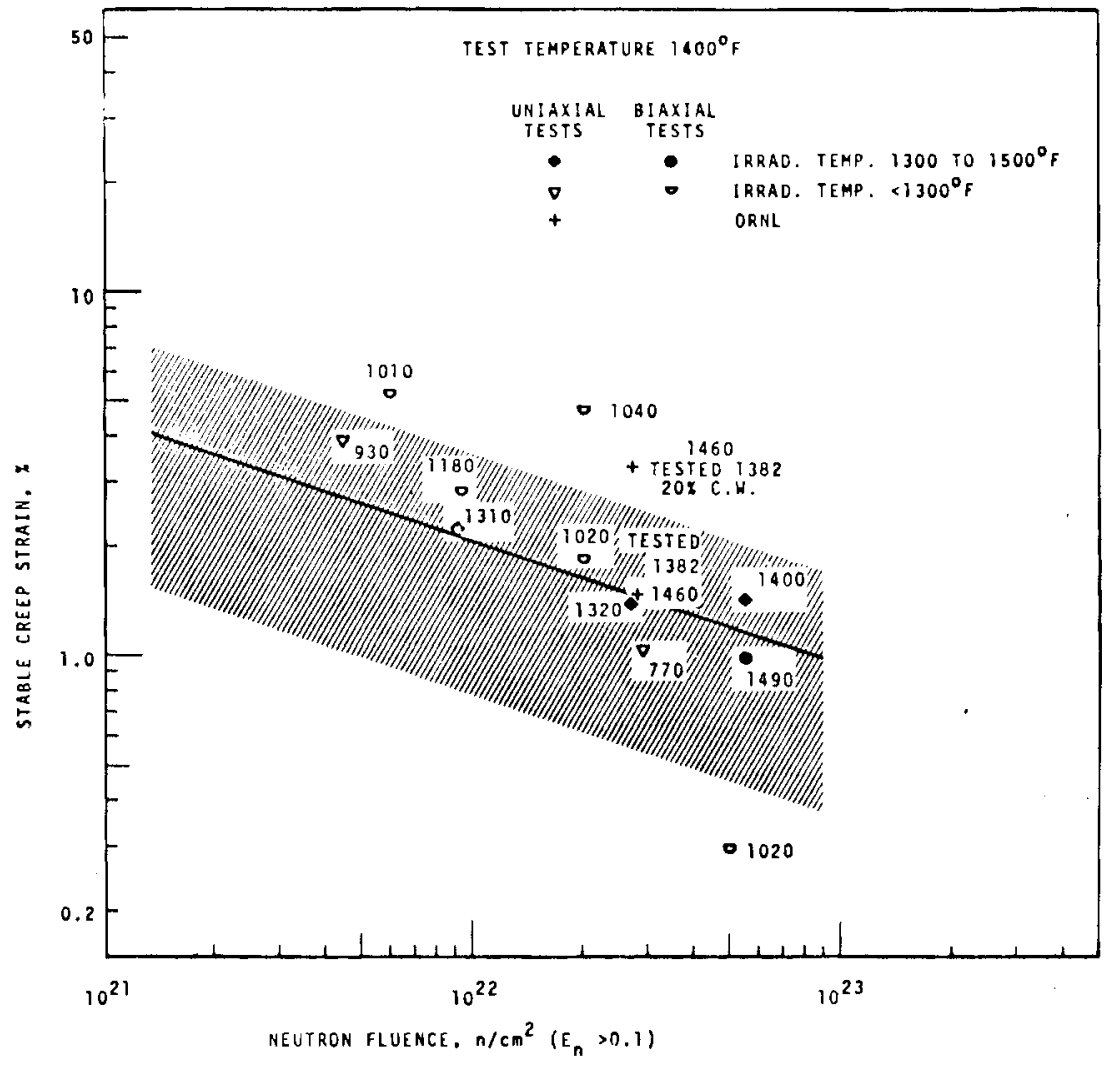

PIGURE 4.2.2-8 Post-Irradiation Ductility of Annealed 316 Stainless

Steel at $1400^{\circ} \mathrm{F}$. 
minimum ductility value at $1 \times 10^{23} \mathrm{n} / \mathrm{cm}^{2}\left(E_{n}>0.1 \mathrm{MeV}\right)$ would be $0.3 \%$ at $1000^{\circ} \mathrm{F}$ and $1100^{\circ} \mathrm{F}$ and $0.4 \%$ at $1200^{\circ} \mathrm{F}$ and $1400^{\circ} \mathrm{F}$, with average values at this fluence of $0.9 \%$ at $1000^{\circ} \mathrm{F}$ and $1100^{\circ} \mathrm{F}, 1.2 \%$ at $1200^{\circ} \mathrm{F}$ and $1.0 \%$ at $1400^{\circ} \mathrm{F}$.

For $20 \%$ cold-worked 316 SS tubing, biaxially-loaded at temperatures from $1000-1400^{\circ} \mathrm{F}$ after irradiation to the relatively low-fluences of from 0.2 to $0.9 \times 10^{22} \mathrm{n} / \mathrm{cm}^{2}$ ( $\mathrm{E}>0.1 \mathrm{MeV}$ ), large reductions in ductility (in terms of diameter change at rupture, $\Delta D / D$ ) was observed compared to unirradiated test values, as indicated in Table 4.2.2-1. Reductions of greater than a factor of 10 were observed; and at $1000^{\circ} \mathrm{F}$, for specimens irradiated to either 0.207 or $0.738 \times 10^{22} \mathrm{n} / \mathrm{cm}^{2}$, $\Delta D / D$ values $\leq 0.2 \%$ were observed. Compared to $1000^{\circ} \mathrm{F}$ test data for uniaxial specimens of annealed 316 SS (Figure 4.2.2-5), the $1000^{\circ} \mathrm{F}$ test data for biaxial 20\% cold-worked 316 SS represents approximately 5 - to 10 -fold reductions relative to the minimum or average uniaxial annealed 316 SS values, respectively.

As noted in the Introduction (Section 4.2.1), a test temperature different from that of the irradiation temperature will have an effect on creep-rupture properties. An example of this is annealed 316 SS uniaxial tests is shown in Figure 4.2.2-9.(6) All tests represented in this figure were performed at a stress of $20,000 \mathrm{psi}$ at a test temperature of $1200^{\circ} \mathrm{F}$ while specimens were irradiated at the same $\left(1100-1250^{\circ} \mathrm{F}\right)$, lower $\left(870^{\circ} \mathrm{F}\right)$ or higher $\left(1400^{\circ} \mathrm{F}\right)$ temperature. Differences in mechanisms of irradiation damage with irradiation temperature and in microstructural stability with test temperature, too complex to deal with here, account for these differences in creep behavior. It is only necessary to observe that variation between irradiation and test temperatures, which, for example, could be symbolized by a fuel management process in a reactor to maximize burnup, could lead to unexpected behavior. For example, initial irradiation at $1400^{\circ} \mathrm{F}$ followed by creep at $1200^{\circ} \mathrm{F}$ might lead to premature failure. 
TABLE 4.2.2.1-1

POSTIRRADIATION BIAXIALLY LOADED STRESS RUPTURE TESTS ON 20\% COLD WORKED TYPE 316 STAINLESS STEEL

\begin{tabular}{|c|c|c|c|c|c|c|c|c|c|}
\hline $\begin{array}{l}\text { Specimen } \\
\text { Number }\end{array}$ & $\frac{\text { Fluer }}{\text { Total }}$ & $\frac{\mathrm{E} \times 10^{22}}{\mathrm{E}>0.1 \mathrm{MeV}}$ & $\begin{array}{l}\text { Irrad. } \\
\text { Temp. } \\
{ }^{\circ} \mathrm{F} \\
\end{array}$ & $\begin{array}{l}\text { Test } \\
\text { Temp. } \\
\stackrel{\circ}{\circ} \\
\end{array}$ & $\begin{array}{c}\text { Hoop } \\
\text { Stress } \\
\text { (psi) }\end{array}$ & $\begin{array}{c}\text { Rupture } \\
\text { Life, } \\
\text { Hours }\end{array}$ & $\frac{\text { Post }}{\Delta \mathrm{D} / \mathrm{D} \%}$ & $\frac{\text { rradiation }}{\Delta D / D \text { Average }}$ & $\begin{array}{c}\text { Preirradiation } \\
\Delta D / D \text { Average }\end{array}$ \\
\hline $\begin{array}{l}\text { BB-42 } \\
\text { BB-43 } \\
\text { BB-44 } \\
\text { BB-46 }\end{array}$ & $\begin{array}{l}0.363 \\
0.363 \\
0.363 \\
0.363\end{array}$ & $\begin{array}{l}0.207 \\
0.207 \\
0.207 \\
0.207\end{array}$ & $\begin{array}{l}950 \\
950 \\
950 \\
950\end{array}$ & $\begin{array}{l}1000 \\
1000 \\
1000 \\
1000\end{array}$ & $\begin{array}{l}65,000 \\
60,000 \\
55,000 \\
45,000\end{array}$ & $\begin{array}{r}137 \\
200 \\
574 \\
>2600\end{array}$ & $\begin{array}{l}0.17 \\
0.17 \\
0.20 \\
-. .-\end{array}$ & 0.18 & 1.2 \\
\hline $\begin{array}{l}C-42 \\
C-43 \\
C-44\end{array}$ & $\begin{array}{l}0.894 \\
0.894 \\
0.894\end{array}$ & $\begin{array}{l}0.738 \\
0.738 \\
0.738\end{array}$ & $\begin{array}{l}1060 \\
1050 \\
1050\end{array}$ & $\begin{array}{l}1000 \\
1000 \\
1000\end{array}$ & $\begin{array}{l}65,000 \\
60,000 \\
55,000\end{array}$ & $\begin{array}{r}191 \\
446 \\
1816\end{array}$ & $\begin{array}{l}1.70 \\
0.80 \\
0.43\end{array}$ & 1.0 & 1.2 \\
\hline $\begin{array}{l}F-42 \\
F-44 \\
F-43 \\
F-46 \\
F-47 \\
F-48\end{array}$ & $\begin{array}{l}0.894 \\
0.894 \\
0.894 \\
0.894 \\
0.894 \\
0.894\end{array}$ & $\begin{array}{l}0.738 \\
0.738 \\
0.738 \\
0.738 \\
0.738 \\
0.738\end{array}$ & $\begin{array}{l}975 \\
970 \\
970 \\
970 \\
970 \\
975\end{array}$ & $\begin{array}{l}1000 \\
1000 \\
1000 \\
1000 \\
1000 \\
1000\end{array}$ & $\begin{array}{l}65,000 \\
54,600 \\
55,000 \\
50,000 \\
45,000 \\
35,000\end{array}$ & $\begin{array}{r}66 \\
243 \\
79 \\
215 \\
\sim 2200 \\
>1425\end{array}$ & $\begin{array}{r}0.52 \\
0.21 \\
0.22 \\
-0.20 \\
- \\
-\end{array}$ & 0.29 & 1.2 \\
\hline $\begin{array}{l}\text { BB-49 } \\
\text { BB-50 }\end{array}$ & $\begin{array}{l}0.363 \\
0.363\end{array}$ & $\begin{array}{l}0.207 \\
0.207\end{array}$ & $\begin{array}{l}950 \\
950\end{array}$ & $\begin{array}{l}1200 \\
1200\end{array}$ & $\begin{array}{l}34,000 \\
29,000\end{array}$ & $\begin{array}{r}345 \\
1776\end{array}$ & $\begin{array}{l}0.82 \\
1.34\end{array}$ & 1.09 & 4.2 \\
\hline$C-50$ & 0.894 & 0.738 & 1050 & 1200 & 29,000 & 955 & 0.60 & 0.60 & 4.2 \\
\hline $\begin{array}{l}E-42 \\
E-43 \\
E-44\end{array}$ & $\begin{array}{l}1.040 \\
1.040 \\
1.040\end{array}$ & $\begin{array}{l}0.900 \\
0.900 \\
0.900\end{array}$ & $\begin{array}{l}1330 \\
1320 \\
1320\end{array}$ & $\begin{array}{l}1400 \\
1400 \\
1400\end{array}$ & $\begin{array}{r}17,000 \\
12,000 \\
8,000\end{array}$ & $\begin{array}{r}31 \\
111 \\
835\end{array}$ & $\begin{array}{l}1.40 \\
1.10 \\
3.30\end{array}$ & 2.65 & 9.4 \\
\hline $\begin{array}{l}D-44 \\
D-42 \\
D-46\end{array}$ & $\begin{array}{l}1.040 \\
1.040 \\
1.040\end{array}$ & $\begin{array}{l}0.900 \\
0.900 \\
0.900\end{array}$ & $\begin{array}{l}1440 \\
1450 \\
1450\end{array}$ & $\begin{array}{l}1400 \\
1400 \\
1400\end{array}$ & $\begin{array}{l}8,000 \\
7,000 \\
6,000\end{array}$ & $\begin{array}{r}108 \\
73 \\
219 \\
\text { to } \\
332\end{array}$ & $\begin{array}{l}1.10 \\
0.34 \\
1.50\end{array}$ & 0.90 & 9.4 \\
\hline
\end{tabular}


EFFECT OF HIGH AND LOW IRRADIATION

TEMPERATURE ON THE $1200^{\circ} \mathrm{F}$ CREEP CURVES

AT 20,000 psi

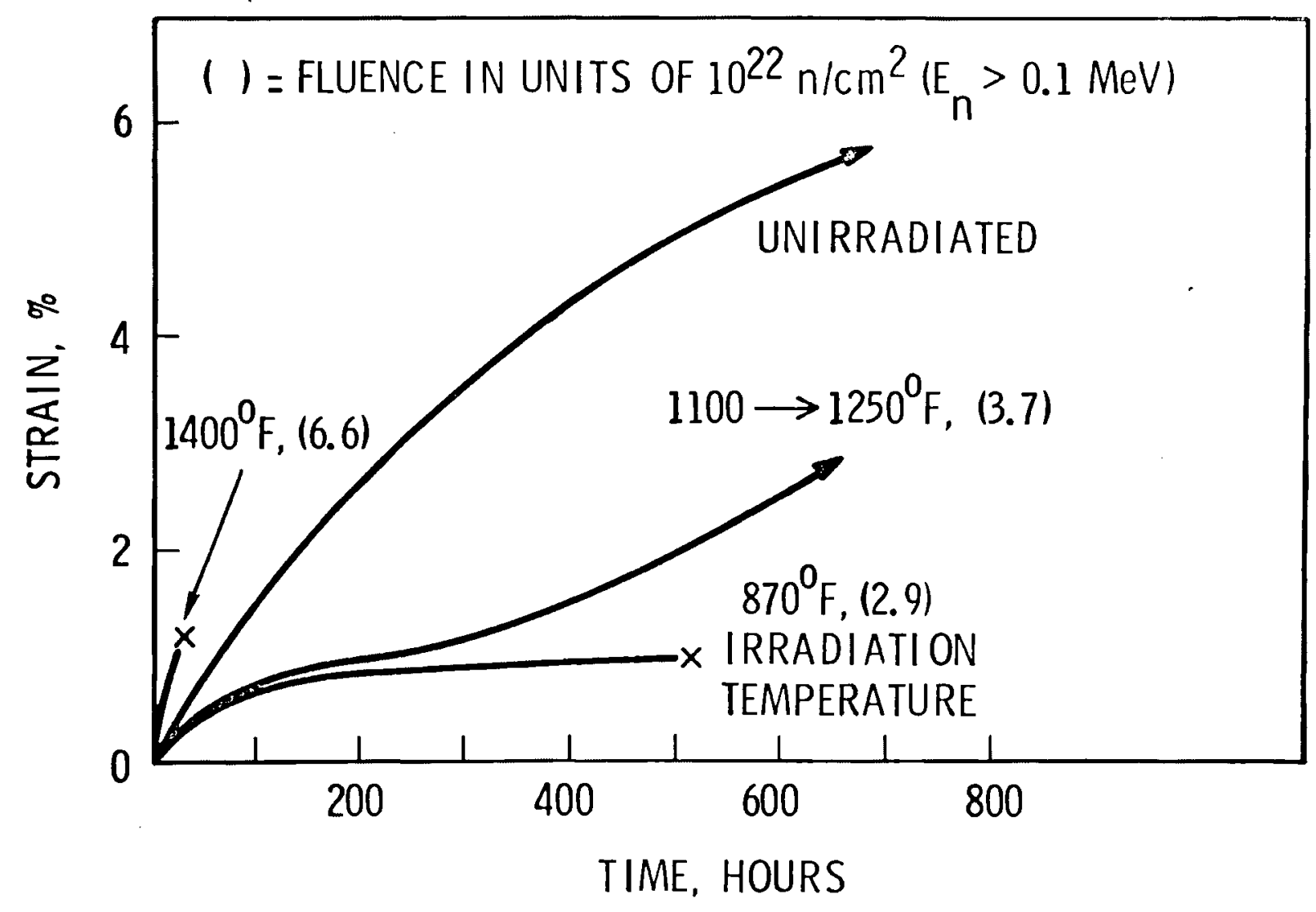

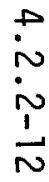

$\frac{\sigma}{b}$

FIGURE 4.2.2-9 


\section{$4.2 .2-13$}

\section{REFERENCES}

1. A. J. Love11, "Postirradiation Creep of Annealed Type 316 Stainless Steel," HEDL-SA-300, Apri 11972.

2. E. E. Bloom, "Correlation of Structure and Ductility of Irradiated Austenitic Stainless Steels," CONF-721115-1, 1972.

3. P. Patriarca, editor, "Fuels and Materials Development Program Quarterly Progress Report for Period Ending September, 1972," ORNL-TM-4055, p. 3.6. (Appl. Tech.).

4. T. T. Claudson, editor, "Quarterly Progress Report, Irradiation Effects on Reactor Structural Materials, November, December 1971, January 1972, HEDL-TME 72-27, pp. HEDL-67-68, (Uㅡ).

5. "Hanford Engineering Development Laboratory Quarterly Progress Report, Vol I - Materials," HEDL-TME 73-4 Vol I, August 1973, p. A-22 (App1. Tech). 


\subsubsection{IRRADIATION CREEP}

Irradiation creep is a flux-induced creep occurring during irradiation that is in excess of that creep that would have occurred without irradiation. This phenomenon cannot be observed by postirradiation creep tests and, as a result, several in-reactor experimental techniques, including instrumented creep tests, have been developed to evaluate its significance to FTR materials performance. Instrumented creep data shows that irradiation creep occurs at temperatures as high as $850^{\circ} \mathrm{F}^{(1)}$ but is not especially sensitive to temperature, at least for the current low-fluence data, see below. Figure 4.2.3-1 (1) gives an example of this phenomenon. Of particular importance is the fact that at this temperature and stress, coldworked 316 SS would not creep at all out-of-reactor.

Present creep measurements indicate a linear dependency on fluence; but since data is, so far, based on low-fluence measurements and since there appears to be a correlation between irradiation creep and swelling (i.e., materials with high swelling rates appear to have high irradiation creep rates), there may be substantial increases in creep rate at the high fluences where swelling (see Section 1) becomes significant. (2) And since swelling rates are temperature dependent, irradiation creep may also exhibit a temperature dependency at higher fluences. (2)

Irradiation creep not only requires the presence of a neutron flux; it also exhibits a rate that is higher during periods of steady reactor operation than an average rate calculated after a number of power on and off reactor cycles. (1) This lower rate averaged over a number of reactor cycles may be due to small amounts of strain recovery that occur during reactor outages. Thus, data from noninstrumented tests could lead to underestimation of the creep rate occuring during steady reactor operation by one-half or more.

Since irradiation creep strains in the range of $1 \%$ can be expected for high fluence levels, a determination as to whether or 


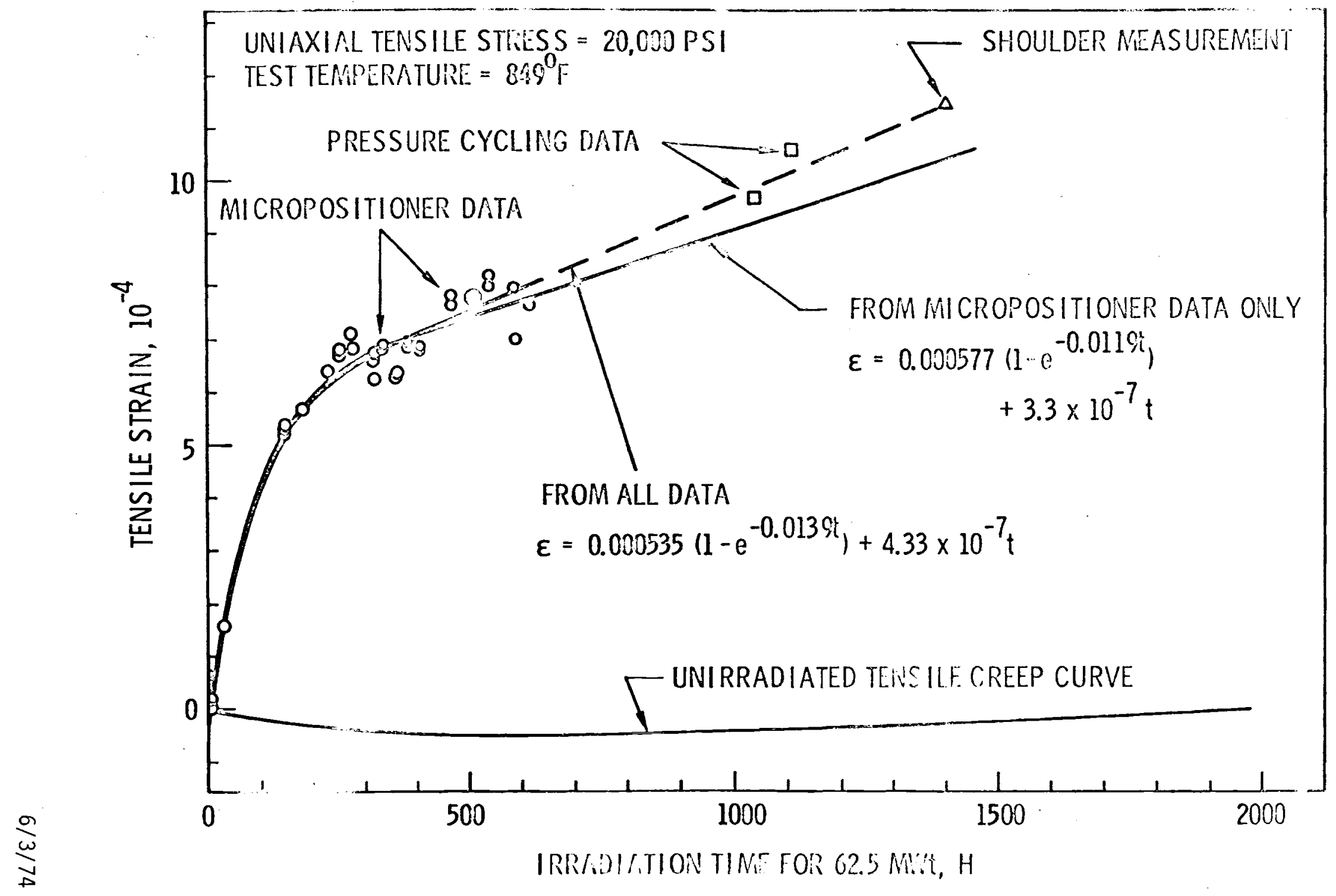

FIGURE 4.2.3-1 Comparison of In-Reactor Strain Data Points and Curves Generated by Computer Program "Creep." 
not this strain is damaging and should be included within the permissible strain limits becomes important. The true nature of irradiation creep is as yet unknown and, therefore, a positive answer is not possible. But if it were the result of irradiation-induced defect formation and growth, as is swelling, then the process would not be expected to be damaging and would not need to be included in allowable strain calculations. However, irradiation creep combined with swelling can lead to substantial component distortions and much of the work on core restraint systems, for example, has involved the implication of these effects on FTR core design. (4) 


\section{REFERENCES}

1. E. R. Gilbert and D. C. Kaulitz, "Fast Reactor Flux-Induced Creep in $20 \%$ Cold-Worked Type 316 Stainless Stee1," HEDLTME 72-98, July 1972.

2. P. J. Ring, "Irradiation-Induced Creep of $20 \%$ Cold-Worked Type 316 Stainless Stee1," GEAP-13961, May 1973, p. 25.

3. P. Murray, J. F. Patterson, W. E. Penne1, "Design Ramification of Irradiation-Induced Swelling and Creep in Fast Reactors," T1D-26147, Westinghouse Elective Corp., Advanced Reactors Division, 1971 . 


\subsection{OTHER FACTORS INFLUENCING IRRADIATION EFFECTS \\ ON CREEP-RUPTURE PROPERTIES}

The other factors influencing irradiation effects on creeprupture properties can, as was done in Section 2.3 for tensile properties, be broadly classified as those resulting from reactor variables and those resulting from material variables.

The reactor variables that have been observed, or can be expected, to influence creep-rupture properties are the same as those described in Section 2.3.2 except that an additional phenomenon, irradiation creep, occurs, as described above in Section 4.2.3. Recent data suggests that, as with tensile properties, there is an effect of prior creep on residual creep-rupture properties. Data from biaxial tests on cold-worked 316 SS at $1200^{\circ} \mathrm{F}$ indicates that rupture strength at high stress levels is significantly reduced by prior creep exposure. (1)

The material variables that have been observed, or can be expected, to influence creep-rupture properties are again similar to those described in Section 2.3, including the effect of cold-work, which has been briefly described above in Section 4.2.2. 


\section{REFERENCES}

1. "Hanford Engineering Development Laboratory Quarterly Progress Report - Materials," (Appl. Tech.), HEDL-TME 73-6, Vol. 1, January 1974, p. B-2 ff. 


\section{$4.4 .1-1$}

4.4 GENERAL RELATIONSHIP OF IRRADIATED CREEP-RUPTURE PROPERTIES TO LMFBR PERFORMANCE

\subsubsection{INTRODUCTION}

Irradiated creep-rupture properties are specified as design criteria only for the fuel elements. As yet, data from irradiations at fluences and temperatures representative of current and future LMFBR design is incomplete. Prediction of properties in relevant regimes will require extrapolative techniques until these gaps are filled.

Since the major emphasis to date in the United States is upon the development of the FFTF, many of the remarks in this section are specifically related to it as the reference LMFBR reactor, though they will be of general application to future commercial LMFBR's as well. 


\section{$4.4 .2 .1-1$}

\subsubsection{INFLUENCE OF LMFBR VARIABLES}

4.4.2.1 LMFBR Reactor Variables

The major reactor variable that must be considered is the high fluences to which reactor materials will be subjected. Maximum values may be $1.5 \times 10^{23} \mathrm{n} / \mathrm{cm}^{2}$ for FFTF to $2-3 \times 10^{23} \mathrm{n} / \mathrm{cm}^{2}$ for commercial LMFBR. Since even at one to two orders of magnitude less fluence irradiation damage can still be severe, the matching of design criteria with a material's performance capability may still be difficult. Also, the phenomenon of flux-induced irradiation creep is as yet not well defined as to either ultimate magnitude or mechanisms, though candidate materials do creep in temperature/stress regimes that they do not out-of-reactor.

The second major reactor variable is temperature, which varies vertically and horizontally throughout the core; material properties are quite sensitive to irradiation temperature, as noted in Section 4.2 .

Other variables that can influence creep-rupture properties are flux, spectra, helium productions rates and prior stress. These factors were considered in Section 4.3, referencing Section 2.3 where the general conclusions were: 1) that no significant engineering effects due to flux difference are expected between the EBR-II (where experimental data is currently being generated) and FFTF; 2) that, in terms of neutron spectrum, the FFTF shall be only 50 to $68 \%$ as "damaging" as that of EBR-II for a given fluence; 3) that helium concentration shall be less for a given fluence in FFTF than in EBR-II; and, from Section 4.3, that 4) prior creep stress, can significantly reduce residual creep-rupture properties. 


\subsubsection{LMFBR Material Variables}

Current materials concepts for LMFBR (FFTF) cal1

for $20 \%$ cold-worked 316 stainless steel for fuel assemblies and control and safety rod guide tubes, solution annealed 304 for core support structures and the pressure vessel, and radial shields composed of 304 stainless steel, nickel and Inconel 718. (1) The expected temperature/fluence ranges for the PPTP were presented in Figure 2.4.2.2-1.

The extremes of creep properties that may be required in the LMFBRs appear to be exemplified by the PFTF design criteria for the $20 \%$ cold-worked 316 stainless stee 1 fuel cladding: $\leq 0.2 \%$ creep strain for steady-s tate operation and $\leq 0.5 \%$ added creep and/or tensile strain for transient events. (See Reference 4, Section 2.4.3.2, p. 2.4.3.2-5.)

For $20 \%$ cold-worked 316 stainless steel, $0.5 \%$ uniform elongation is observed at a $1600^{\circ} \mathrm{F}$ test temperature (a relevant temperature for transients) after only moderate irradiation, i.e., at $7.5 \times 10^{21} \mathrm{n} / \mathrm{cm}^{2}$ at $T_{\text {irrad }}=1040^{\circ} \mathrm{F}$, and at $9.0 \times 10^{21} \mathrm{n} / \mathrm{cm}^{2}$ at $T_{\text {irrad }}=1440^{\circ} \mathrm{F}$, as noted in Section 2.4.2.2. Creep data on coldworked 316 SS for material irradiated at typical steady-state temperature and then tested at transient temperatures is not yet available. However, since at low fluence $\left(0.2-0.9 \times 10^{22} \mathrm{n} / \mathrm{cm}^{2}, E>0.1 \mathrm{MeV}\right)$ postirradiation ductilities are usualiy $\ll 1.0 \%$ for test temperatures that are $200^{\circ} \mathrm{F}$ higher than the irradiation temperature (see Table 4.2.2-1), higher ductility would not be expected at transient temperatures at reference fluences.

In terms of nominal steady-state creep strain, Table 4.2.2-1 indicates low postirradiation ductilities are produced Even after low fluences.

The possible ameliorating affects of irradiation creep are unknown at this time because both its relevancy to the ful1 
operating temperature range of cladding is unknown and its "nondamaging" character is yet to be fully proven. 


\section{$4 \cdot 4 \cdot 3 \cdot 1-1$}

4.4.3 GENERAL IMPLICATIONS OF IRRADIATED CREEP-RUPTURE PROPERTIES ON LMPBR COMPONENTS

\subsubsection{Pressure Vessel}

Since over a 20 year reactor design life, fluence

levels at the pressure vessel are expected to be no greater than $3.8 \times 10^{19} \mathrm{n} / \mathrm{cm}^{2}(\mathrm{E}>0.1 \mathrm{MeV})$ at a temperature of $920^{\circ} \mathrm{F}$, no creep criteria are applied (only a tensile criterion of $10 \%$ residual elongation, see Section 2.4.2.2). However, the implications of irradiation creep, which occurs at a higher rate in 304 SS than in cold-worked 316, have not been assessed, though presumably the flux is too low for significant creep to occur. 


\subsubsection{Core Components}

Core components wi 11 be subjected to a wide range of design requirements including fluence $\left(\sim 10^{21}\right.$ to $\left.>10^{23}\right)$, temperatures $\left(800\right.$ to $1400^{\circ} \mathrm{P}$ ) and design lifetime ( 1 to 20 years).

The only core components for which the design criteria involve creep are the fuel pins. Fuel pin criteria for FFTF cal1 for the following design limits, (see Reference 4, Section 2.4.3.2, p. 2.4.3.2-5):

(a) $\quad 0.2 \%$ cladding strain for steady-state operation.

(b) $\quad 0.3 \%$ cladding strain for steady-state plus anticipated upsets.

(c) $\quad 0.7 \%$ cladding strain for steady-state, upsets and transients.

of these three criteria, only the first is strictly creep. The latter two combine the steady-state creep criteria with added strain due to creep and/or high-strain rate deformation (see Section 3.0).

From postirradiation creep data, it is not clear that cold-worked 316 SS would have the required ductility to meet these criteria (see Section 4.4.2.2). There is the possibility that a non-damaging irradiation-creep can occur that would allow greater fuel pin strain to occur without failure during steady-state operation; this has to be substantiated. However, during power-off loss-of-flow accidents, where no neutron flux is being produced and, therefore, irradiation creep would not occur, it is not clear that the required transient clad strain would be available. (During overpower accidents, neutron flux is being produced, but the high strain-rates would overshadow potential irradiation creep effects.) 



\subsection{IRRADIATION EFFECTS ON FATIGUE}

5.1 THE NATURE OF FATIGUE DATA

5.1.1 Plastic Deformation and The Three Stages of Fatigue

5.1.2 Factors That Affect Fatigue Lifetime

5.1.2.1 Loading
5.1.2.1.1 Low Cycle Fatigue $\left(\Delta \varepsilon_{p}>\Delta \varepsilon_{E}\right)$
5.1.2.1.2 Transition-Life Fatigue $\left(\Delta \varepsilon_{P} \sim \Delta \varepsilon_{E}\right)$
5.1.2.1.3 High Cycle Fatigue $\left(\Delta \varepsilon_{E}>\Delta \varepsilon_{p}\right)$
5.1.2.1.4 Load Waveform, Frequency and Hold Time Effects

\subsubsection{Geometry}

5.1.2.2.1 Surface Effects

5.1.2.2.2 Notch Effects and Fatigue Crack Growth

5.1.2.2.3 Effect of Loading, Environmental and Metallurgical Condition on Fatigue Crack Growth in Austenitic Stainless Steels

\subsubsection{Environment}

\subsection{Temperature}

5.1.2.3.2 Aggressive Liquids and Gasses

5.1.2.3.3 Static Fatigue or Sustained Load Crack Growth

\subsection{CHARACTERIZATION OF FATIGUE DATA}

\subsubsection{High Cycle Fatigue}

\subsubsection{Low Cycle Fatigue}

\subsubsection{Fatigue Crack Growth}

5.3 EFFECT OF COMBINED TEMPERATURE AND FLUENCE ON FATIGUE IN CANDIDATE LMFBR ALLOYS

5.3.1 Unnotched Irradiated Fatigue

5.3.2 Irradiated Fatigue Crack Growth

5.4 THE SIGNIFICANCE OF ELEVATED TEMPERATURE IRRADIATED FATIGUE PROPERTIES TO LMFBR PERFORMANCE 



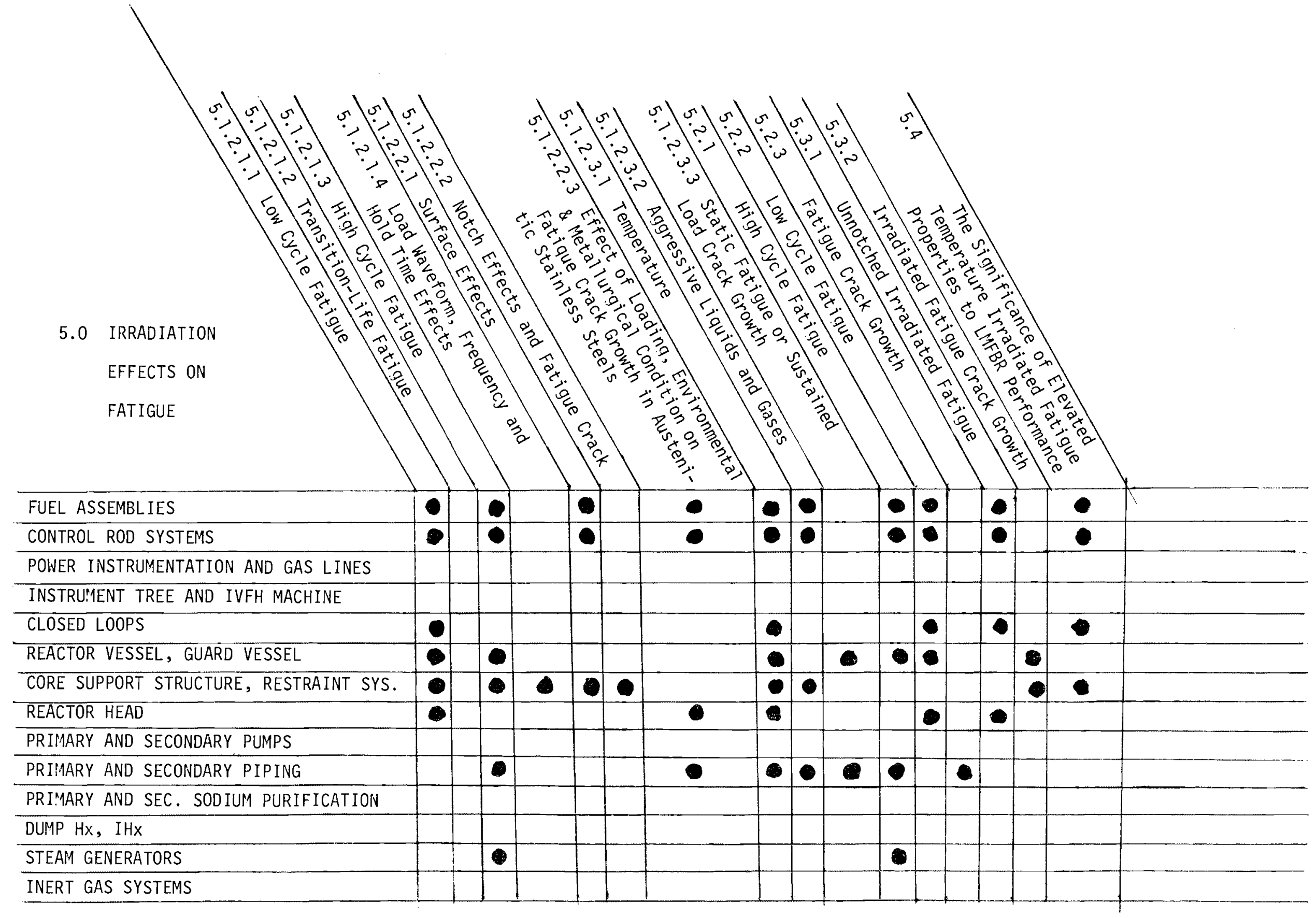





\section{$5.1-1$}

\subsection{IRRADIATION EFFECTS ON FATIGUE}

Fracture resulting from repetitive loading is known as fatigue. It is one of the commonest causes of structural and component service failures. Since it was first recognized over a century ago, fatigue has been investigated intensively. However, only recently have investigations begun on the fatigue behavior of candidate LMFBR alloys.

The study of the effect of irradiation on fatigue properties of metals was begun in the 1950's. Investigations relevant to elevated temperature liquid metal cooled fast breeder reactors began in the late 1960's. Today more intensive studies are underway to characterize the effect of loading, geometry, and environment (viz., temperature, sodium, and fluence) on the fatigue properties of candidate LMFBR alloys. The purpose of this section of the report is to 1) describe the nature and character of fatigue data; 2) discuss the effect of fluence and temperature on fatigue; 3 ) point out some of the currently unresolved problem areas; and 4) discuss in general manner the significance of irradiated fatigue properties to LMFBR performance.

\subsection{THE NATURE OF FATIGUE DATA}

This section presents a general engineering view of the factors that affect fatigue lifetime as a basis for relating elevated temperature irradiated fatigue data to LMFBR performance. Details are omitted for brevity and generalizations are made where possible. Because fatigue data are often influenced by a number of factors, examples in this section are illustrative only, and should not be construed as being typical of any given LMFBR material over the expected range of LMFBR environmental conditions. Creep and environmental effects will occur to varying degrees in an LMFBR. Their effects are discussed only in a general manner. Specific effects of each will be discussed in future sections of this document. 


\section{$5.1 .1-1$}

5.1.1 Plastic Deformation and the Three Stages of Fatigue

It is now recognized that fatigue occurs as the result of plastic deformation. Such deformation is often of an extremely localized nature preceding and accompanying the initiation and propagation of cracks in materials undergoing grossly plastic as well as grossly elastic loading.

Studies of the fatigue behavior of metals have indicated that it is convenient, from an engineering viewpoint, to subdivide the overall fatigue process into three stages:

- Crack initiation or nucleation,

- Stable crack propagation to a critical size, and

- Unstable rupture of the remaining section.

Depending on the nature of the loading, the geometry of the specimen and the test environment, fatigue tests predominantly measure the number of load cycles required to initiate and propagate cracks, which ultimately result in unstable fracture. 


\section{$5.1 .2-1$}

\subsubsection{Factors That Affect Fatigue Lifetime}

In general four factors affect fatigue lifetime:

- Loading (gross plastic to gross elastic, load waveform, including hold-time effects, frequency of loading....),

- Geometry and surface condition (smooth and unnotched, ranging through rough and sharply notched, size effect....),

- Environment ( temperature, aggressive gases, liquids, fluence.....),

- Material properties (strength, ductility, residual stress, cyclic softening, cyclic hardening, microstructure....).

Usually loading is the primary fatigue-controlling factor. Seldom however, is it the only factor. Geometry and environment can in some cases significantly bias both crack initiation and propagation behavior. Fractures toughness and ductility are important in that a decreased toughness reduces the critical or rupture crack size. The effect of load-cycling in an aggressive environment can be far greater than either conditions separately or the two alternately. Environments are of such variety and frequently so complex that they cannot be fully treated at this time. Often the requisite data are simply not available. The salient conclusion regarding environment is that its full effect can only be determined at present by fatigue testing candidate LMFBR alloys under simulated LMFBR environment and operating conditions. 


\section{$5.1 .2 .1-1$}

\subsubsection{Loading}

The most important factor affecting fatigue lifetime is the nature and magnitude of the applied mechanical or thermal loading. In high strain (low-cycle) fatigue the response of the metal to that loading is also important. Table 5.1 shows a breakdown of fatigue behavior based on strain level that is of general validity. For a number of reasons these cycle lifetimes should not be considered representative of materials to an extent suitable for quantitative design.

Assessment of the nature and magnitude of anticipated LMFBR loadings is beyond the scope of this work for several reasons. First, although there is a growing body of data on high temperature tensile, creep, and fatigue data, design for high temperature service of complex structures is far from perfect because subcritical* cracking behavior of materials in actual service environments are often not known. Second, reliable analytical methods have yet to be developed which characterize the effects of variable amplitude (real-1ife) loading on fatigue life. Despite these limitations fatigue testing under constant-amplitude loading in simulated service environments is still a valid means of rating fatigue sensitivity of LMFBR alloys and providing a base for bounding the limits of structural fatigue life. Fatigue data which are described below (see 5.3) are thus discussed in light of the response of candidate materials to constant-amplitude type loadings as opposed to their behavior under unknown LMFBR loadings.

Figure 5.1.2.1-1 indicates the usual appearance of a fatigue curve as a function of stress amplitude and strain amplitude loading. The designations "low-cycle" and "high-cycle" fatigue are arbitrary, but correspond roughiy to loadings that include primarily uniform plastic strains and primarily uniform elastic strains, respectively. Notches produce localized strains and in low strain fatigue bias fatigue lifetime significantly towards crack propagation. The two curves "a" and "b" differ in appearance in the low-cycle region because in the plastic range a small increment in stress is produced by a large increment in strain. Some early investigators arbitrarily separated high- and low-cycle fatigue based on number of cycles

* A term used to describe crack initiation and propagation brought about by processes such as fatigue and stress-corrosion. 
Table 5.1

\section{EFFECT OF LOADING ON FATIGUE PROPERTIES}

\section{Type of Test}

Low-cycle fatigue (a)so high strain fatigue

Low-high cycle

fatigue

(also transition

life fatigue)

High-cycle fatigue (a)so low strain

fatigue

High strain

Low strain
Geometry

Smooth

Strain Behavior

Primarily plastic strain $\left(\Delta \varepsilon_{p}>\right.$

$\left.\Delta \varepsilon_{E}\right)$

Smooth

Plastic \& elastic

strain $\left(\Delta \varepsilon_{P} \sim \Delta \varepsilon_{E}\right) \quad$ strain prop's

Primarily elastic strain $\left(\Delta \varepsilon_{E}>\Delta \varepsilon_{P}\right)$

Notched

Primarily gross plastic with complex local plastic distribution around $\operatorname{notch}(s)$

Notched properties
Primarily elastic with localized unknown plastic distribution ground $\operatorname{notch}(\mathrm{s})$
Primary Life-

controlling

Material Property

Tensile ductility $\left(\varepsilon_{f}^{\prime}\right)$

Tensile strength $\left(\sigma_{f}^{\prime}\right)$

Cracking Behavior

(Initiation-

Propagation Life)

Primarily crack propagation (usually $>75 \%$ )

Variable

Possibly cyclicstress-strain

Youngs modulus

(E) in the absence of environmental effects

Primarily crack "initiation" (up to $90 \%$ or more)

Primarily crack propagation due to strain concentrating effect of notch

Primarily crack propagation
Number of Load

Cycles

(Lifetime)

1 to $\sim 10^{4}$

10 to $10^{5}$

(highly dependent on cyclic stressstrain behavior)

$10^{4}$ to $10^{7}$ or more

1 or more (arbitrary range, limits not extablished)

Probably $10^{3}$ 104 and greater (size dependent)

$10-25-74$ 


\section{$5.1 .2 .7-3$}

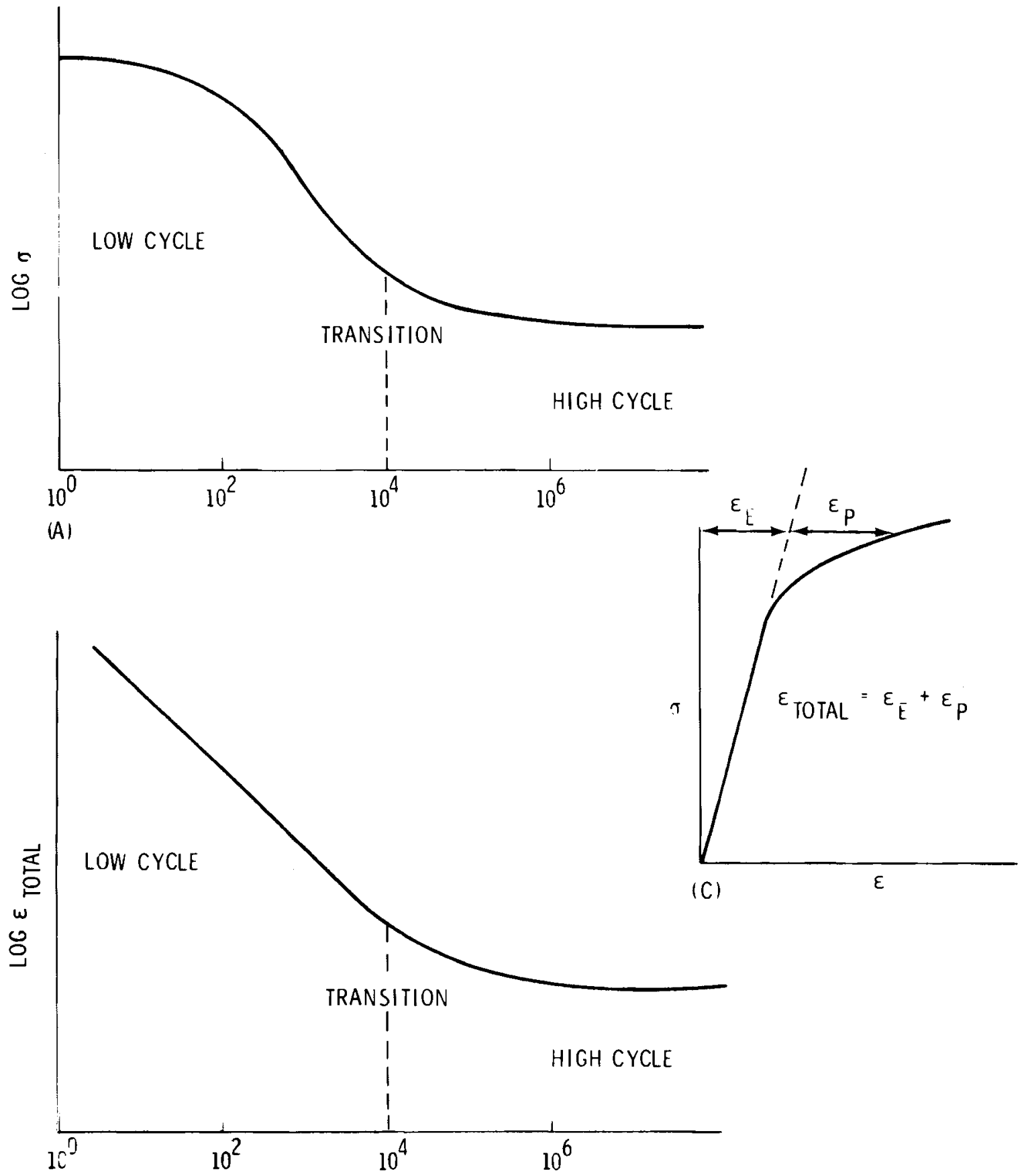

(B)

FIG. 5.1.2.1-1 STRESS-CYCLE (A), STRAIN-CYCLE (B), FATIGUE CURVES AND MONOTONIC STRESS-STRAIN CURVE (C) 


\section{$5.1 .2 .1-4$}

to failure: One to $10^{3}-10^{4}$ was low-cycle and $10^{4}$ or more designated high cycle. Because of improvements in testing equipment for recording and controlling complete stress/strain histories, later investigations have also identified a transition life region wherein plastic and elastic strains are about equal. 
5.1.2.1.1 Low Cycle Fatigue $\left(\Delta \varepsilon_{\beta}>\Delta \varepsilon_{E}\right)$

In low-cycle fatigue, maintaining specimen loading limits constant (i.e., constant load tests), the limit of strain will vary at least for some part of the test. Similary if the specimen limits of strain are maintained constant (i.e., constant strain tests), limits of load will also vary throughout some part of the fatigue life. For example under constant strain conditions a metal's deformation resistance may increase (cyclic hardening), decrease (cyclic softening) or remain unchanged (cyclic stability). Figure 5.1.2.1.1-1 shows the schematic effect of cyclic hardening and softening under completely reversed strain cycling. In general annealed metals (with high monotonic strain hardening exponents) exhibit cyclic hardening and heavily cold-worked metals (with low monotonic strain hardening exponents) cyclic softening. According to Landgraf $(1)$ the trends are not as clear for thermally strenghtened and thermomechanically produced alloys. Radiation hardened materials are also not well characterized. Because plasticity plays a significant role in low-cycle fatigue, the resistance of a material to high strain fatigue depends mainly on the material's ductility as determined by a corresponding tensile test.

Cyclic softening and biased loading can both give rise to mechanical instabilities resulting in failure modes unlike most fatigue failures. Cyclic softening during reversed stressing or loading as opposed to reversed straining can cause a "runaway process" (1) as strain limits continually increase to failure. Superimposition of a tensile mean stress can cause a large tensile mean strain to accumulate (hence cycledependent creep) leading to a ductile tension failure. A compressive mean strain would promote creep into compression probably leading to a buckling failure.

Alloys exhibiting yield strength differences between tension and compression states (viz., biased mechanical properties) can lead to failure 
CYCLIC HARDENING:
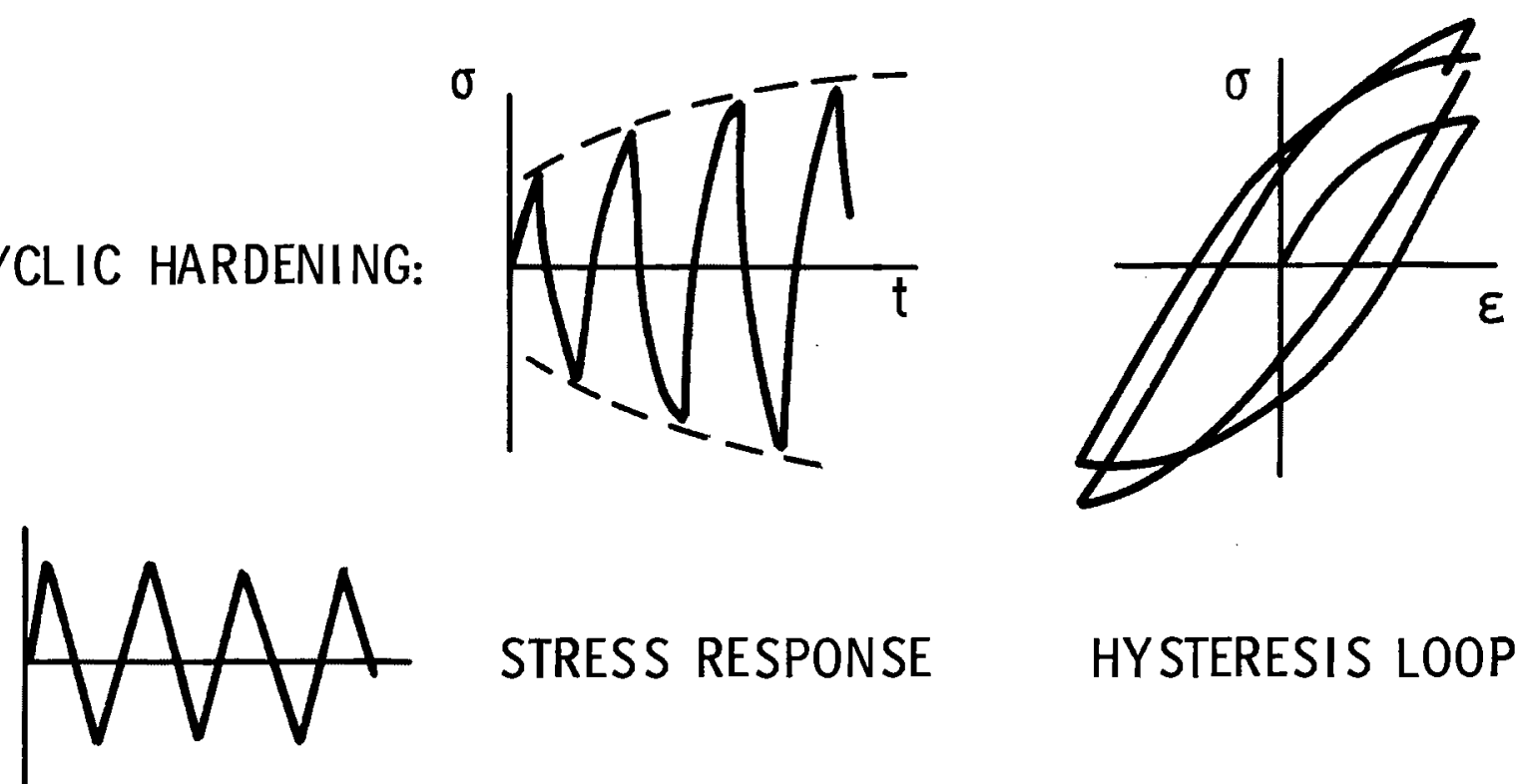

STRESS RESPONSE

HYSTERESIS LOOPS

STRAIN CONTROL

CYCLIC SOFTENING:
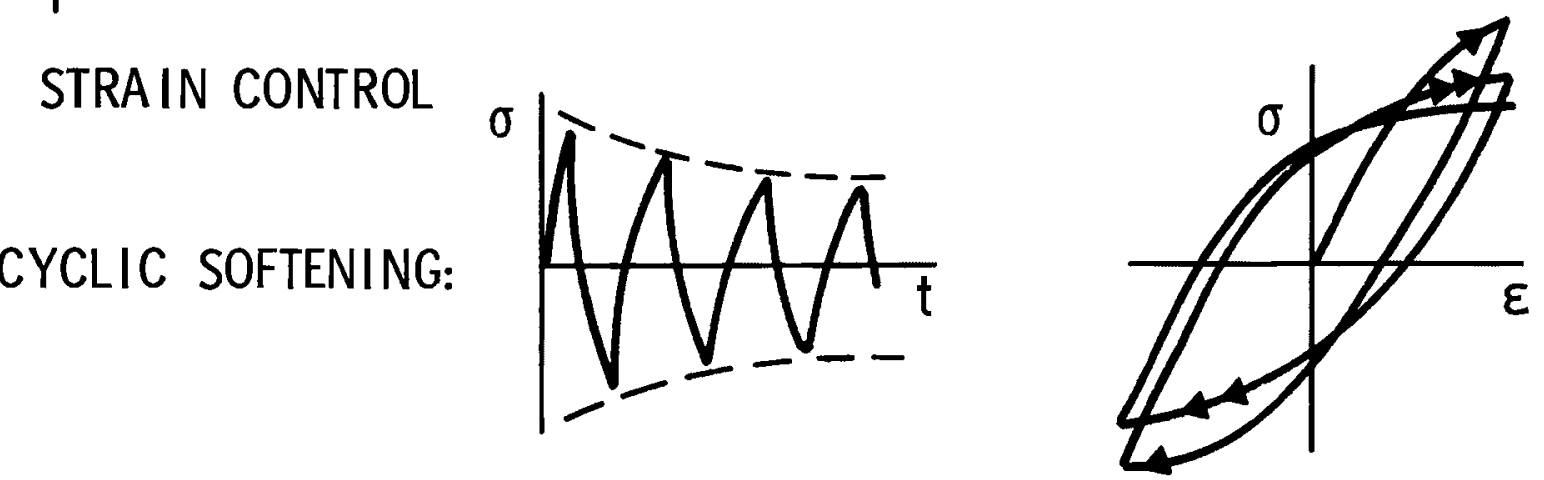

FIG. 5.1.2.1.1-1 SCHEMATIC REPRESENTATION OF THE RESPONSE OF METALS TO REVERSED

PLASTIC STRAINS (LOW-CYCLE FATIGUE) 


\section{$5.1 .2 .1 .1-3$}

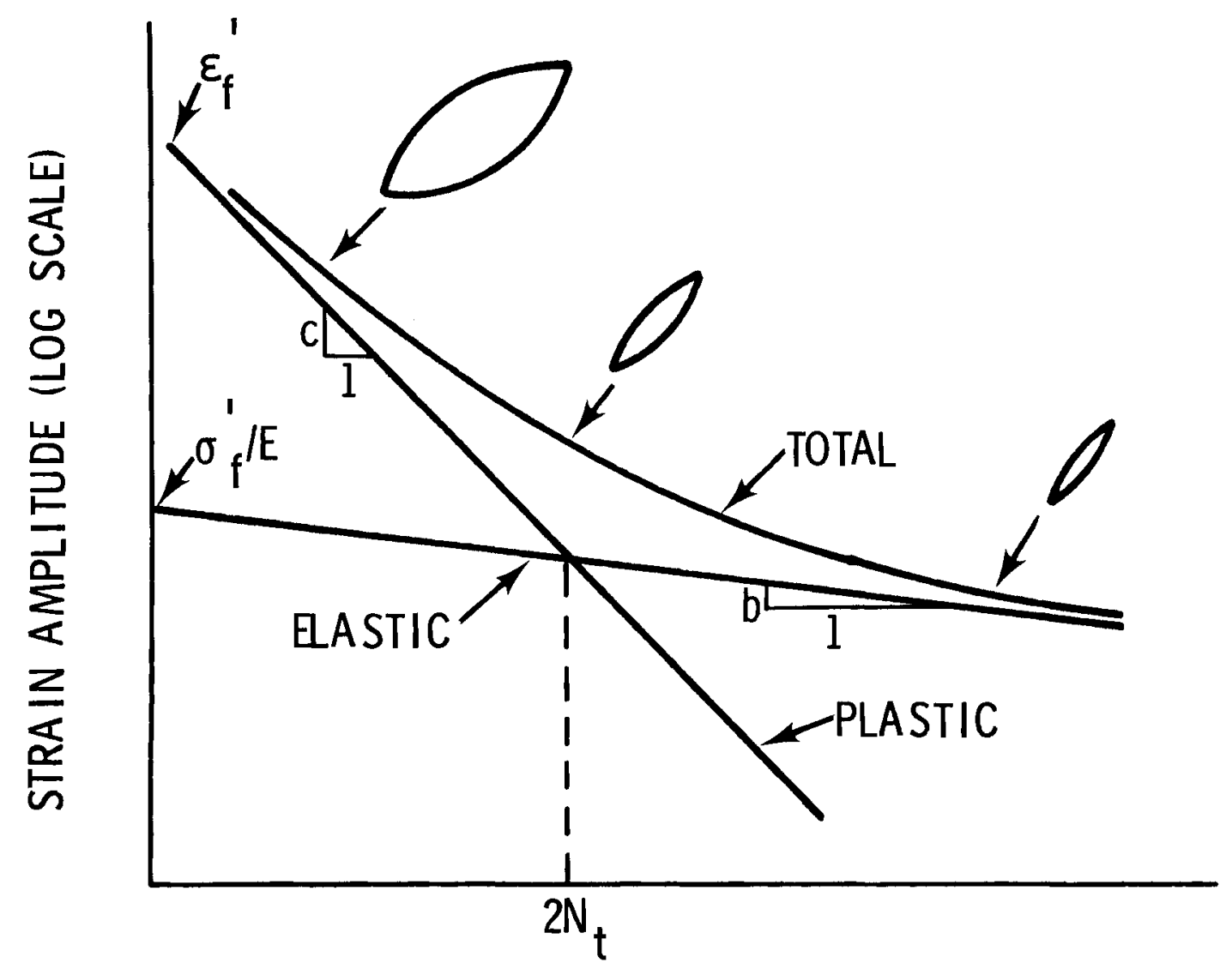

REVERSALS TO FAILURE (LOG SCALE)

FIG. 5.1.2.1.2-1 SCHEMATIC REPRESENTATION OF ELASTIC, PLASTIC AND TOTAL STRAIN AMPLITUDE FATIGUE LIFE RELATIONSHIPS 


\section{$5.1 \cdot 2 \cdot 1.1-4$}

modes like that due to biased applied loading. Thus, biased behavior could be very important where structural shakedown behavior may be involved in an engineering structure where thermal or mechanical fatigue may occur. In many structures or components the material at a critical location (e.g., the root of a notch or the surface of a loading member) would be subjected primarily to strain cycling within a gross elastic stress field. Changes in a components size or shape, however, might lead to a stress (or load) cycling condition where a "runaway" plastic failure could be possible. 


\section{$5.1 .2 .1 .1-5$}

\section{REFERENCES}

1. R. W. Landgraf, "The Resistance of Metals to Cyclic Deformation, ASTM STP 467, September, 1970. 


\section{$5 \cdot 1 \cdot 2 \cdot 1.2-1$}

\subsection{Transition Region Fatigue}

$\left(\Delta \varepsilon_{p} \sim \Delta \varepsilon_{E}\right)$

In low $\left(\Delta \varepsilon_{p}>\Delta \varepsilon_{E}\right)$ and high $\left(\Delta \varepsilon_{E}>\Delta \varepsilon_{p}\right)$ cycle fatigue the primary fatigue controlling material properties are tensile ductility $\left(\varepsilon_{f}\right)$ and tensile strength $\left(\sigma_{f}^{\prime}\right)$, respectively. Knowledge of cyclic stress-strain properties in the high- and low-cycle ranges are not necessary because in each type of fatigue test the fatigue life is dominated by $\Delta \varepsilon_{p}$ (low cycle) or $\Delta \varepsilon_{\mathrm{E}}$ (high cycle). In intermediate strain ranges (where $\Delta \varepsilon_{\mathrm{p}} \sim \Delta \varepsilon_{\mathrm{E}}$ ) fatigue lifetime $\left(2 \mathrm{~N}_{t}\right)$ may vary from 10 to $10^{5}$ cycles ${ }^{(2)}$ and depends strongly on the relative roles of both ductility and strength as determined from cyclic stress-strain properties.

Figure 5.1.2.1.2-1 is a schematic representation of the relative roles of ductility and strength. At short lives the plastic component becomes dominant emphasizing ductility $\left(\varepsilon_{f}^{\prime}\right)$; at long lives the elastic component becomes dominant emphasizing the role of strength $\left(\sigma_{f}^{\prime}\right)$. The change in transition fatigue 1 ife, $2 \mathrm{~N}_{t}$, varies for a variety of steels from about 10 reversals at high hardness to $10^{5}$ reversals at low hardness. Landgraf has also rated the idealized strain resistance of materials against the life range of interest, Figure 5.1.2.1.2-2. The "ductile" metal offers maximum strain resistance in the low-cycle region; the "strong" metal is superior at high cyclic life; good overall strain resistance is displayed by the "tough" metal. The curves also cross at a common point illustrating the "rule of thumb" that most metals, when subjected to a strain amplitude of 0.01 , fail in approximately 2,000 cycles. Some departures from this behavior have been observed in certain alloys and thus these general curves should not be considered suitable for quantitive design. 

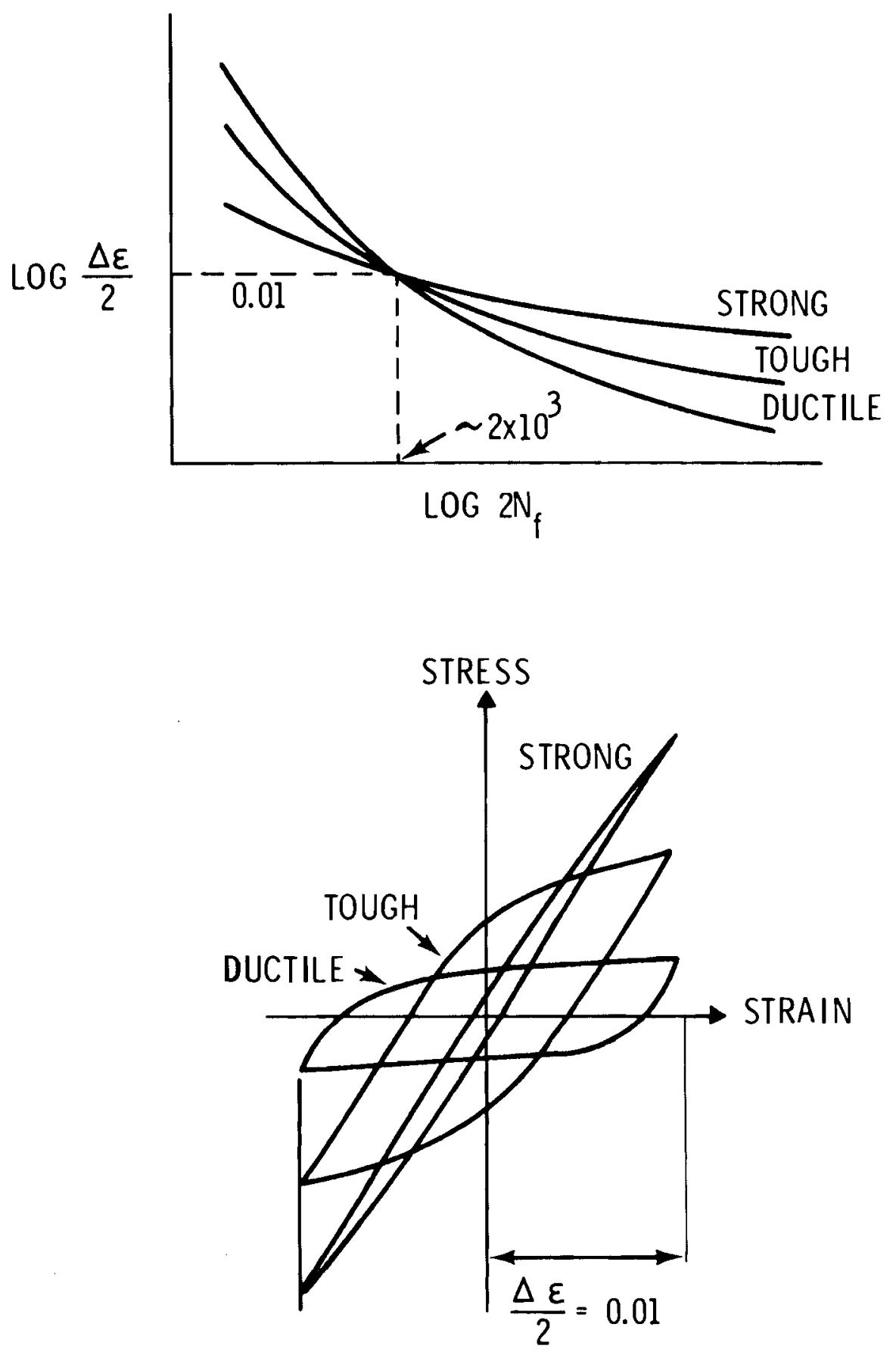

FIG. 5.1.2.1.2-2 SCHEMATIC REPRESENTATION OF THE CYCLIC STRAIN RESISTANCE OF IDEALIZED METALS ILOW-CYCLE FATIGUE) 


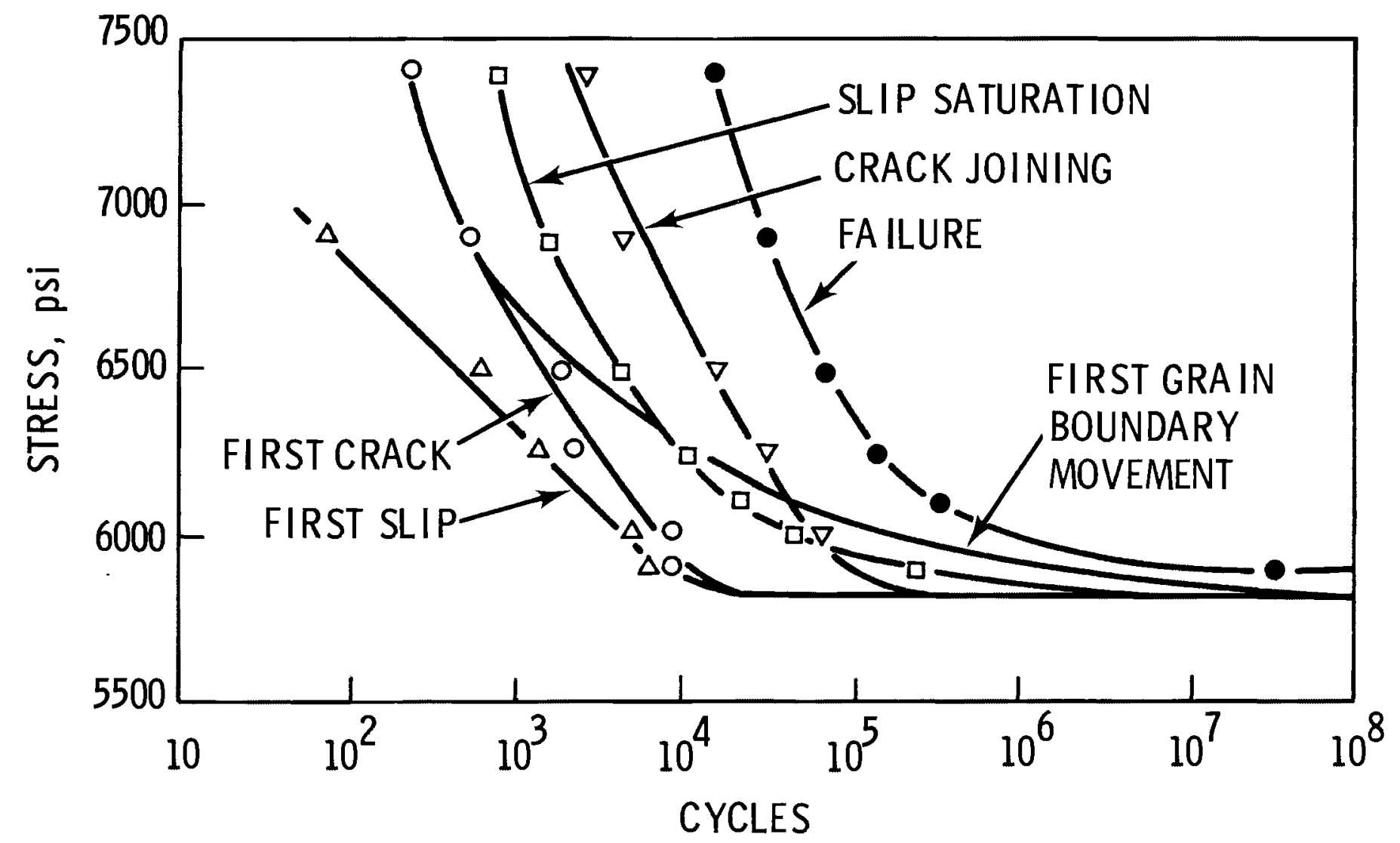

FIG. 5.1.2.1.3-1 RELATIONSHIP OF CRACK "INITIATION" AND "PROPAGATION" TO FAILURE IN $0.97 \% \mathrm{Mg}-\mathrm{AI}$ ALLOY 


\section{$5.1 \cdot 2 \cdot 1 \cdot 3-1$}

\subsection{High-Cycle Fatigue $\left(\Delta \varepsilon E>\Delta \varepsilon_{p}\right)$}

High-cycle fatigue failures occur in the range of $10^{4}$ to $10^{7}$ cycles or more and are controlled primarily by tensile strength. The largest portion of fatigue lifetime is spent in crack initiation.

Crack initiation at low homologous temperatures usually occurs in bands of localized slip. At higher temperatures crack initiation occurs primarily at grain boundaries. The separation of fatigue fracture into crack initiation, propagation, and fracture, is artificial, particularly with respect to the transition from initiation to propagation. Actually Stage I crack propagation occupies most (as much as 90\%) of the fatigue life, but only occupies a small portion of the fracture surface, and advances mainly in the plane and direction of maximum shear stress at rates on the order of Angstroms per cycle. Since Stage I* crack growth usually covers a small area and is difficult to observe, the "artificial" separation of crack initiation and propagation into distinct phases is both convenient and satisfactory. That fatigue starts on the first cycle and that crack propagation comprises (Stage I and II) the majority of the fatigue life, however, is scientifically more correct. Figure 5.1.2.1.3-1, al though representative of only one material ( $0.98 \% \mathrm{Mg}-\mathrm{Al}$ alloy), shows the relationship of crack "initiation" (i.e., first slip, first crack, first grain boundary movement, slip saturation) and "propagation" (crack joining and subsequent growth) to failure.

The effects of variations in mechanical properties, chemical composition, microstructure, and macrostructure have been studied extensively on steels and usually to lesser degrees in other alloy systems and are

*The mechanism of Stage I crack growth is not well known because of the fine scale of processes that are involved. Stage II occurs on a larger scale, is usually readily observable, is perpendicular to the maximum principal stress, and occurs in increments as large as $10^{-3}$ to $10^{-2}$ inch or more. 
$5 \cdot 1 \cdot 2 \cdot 1 \cdot 3-2$

covered extensively in the literature. These studies have shown, in general, that high-cycle fatigue 1 ife is proportional to tensile strength, can vary significantly from heat-to heat for the same metal (20\% variation in fatigue limit for some steels), that some metals display a fatigue limit while others do not, and biased loading usually increases life (see Figure 5.1.2.1.3-2) for a given maximum fatigue stress. Exceptions to fatigue life-increase with tensile strength have occurred. Metallurgical inhomogenieties (e.g., precipitate-free grain boundary zones) and instabilities (e.g., G.P. zones in aluminum alloys) can cause this behavior. 


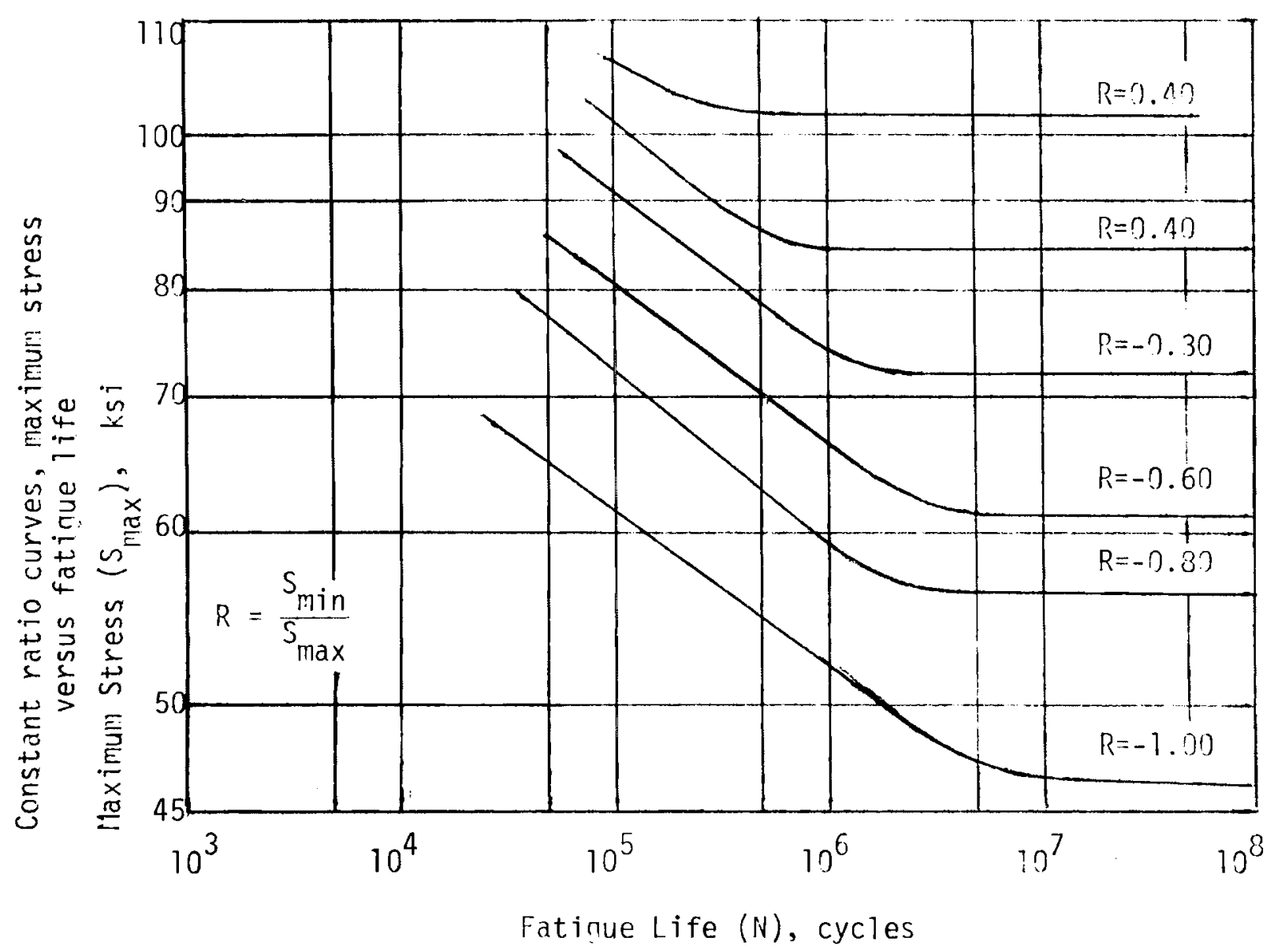

Fiqure 5.1.2.1.3-2 Effect of biased loztinn on fatinue life of un-notched sneciriens 


\section{$5.1 .2 .1 .4-1$}

\subsection{Load Waveform, Frequency and Hold-Time Effects}

Few encompassing generalizations can be made concerning the effects of load waveform, frequency and hold-time periods on fatigue life. The effects vary depending upon the type of fatigue test (high versus low strain), whether the specimen is smooth or notched, amount and type of residual stresses, microstructure (grain size) and directional characteristics, surfacing coatings, specimen size, and test environment. The latter is discussed in Section 5.1.2.3.

a. High Cycle Fatigue $\left(\Delta \varepsilon_{E}>\Delta \varepsilon_{p}\right)$

The effect of load waveform is usually obscured by the scatter of fatigue life and as such is non-significant.

The effect of frequency becomes significant at frequencies greater than 3000 cycles per minute and generally increases the endurance limit of the material, unless local heating due to high frequencies causes premature failure.

Hold-time and rest periods do not affect high cycle fatigue strength can be increased slightly due to changes in grain structure or local yielding at stress raisers.

b. Low Cycle Fatigue $\left(\Delta \varepsilon_{\mathrm{p}}>\Delta \varepsilon_{\mathrm{E}}\right)$

The effect of load waveform (see Figures 5.1.2.1.4-1 and -2) is associated with frequency and hold-time periods. In low cycle fatigue at elevated temperature, constant strain cycling is used, causing the load waveform to vary, depending on whether cyclic hardening or softening occurs. At faster strain rates, the total time to failure is shorter, and creep damage is negligible, the fatigue endurance becomes independent of time. 

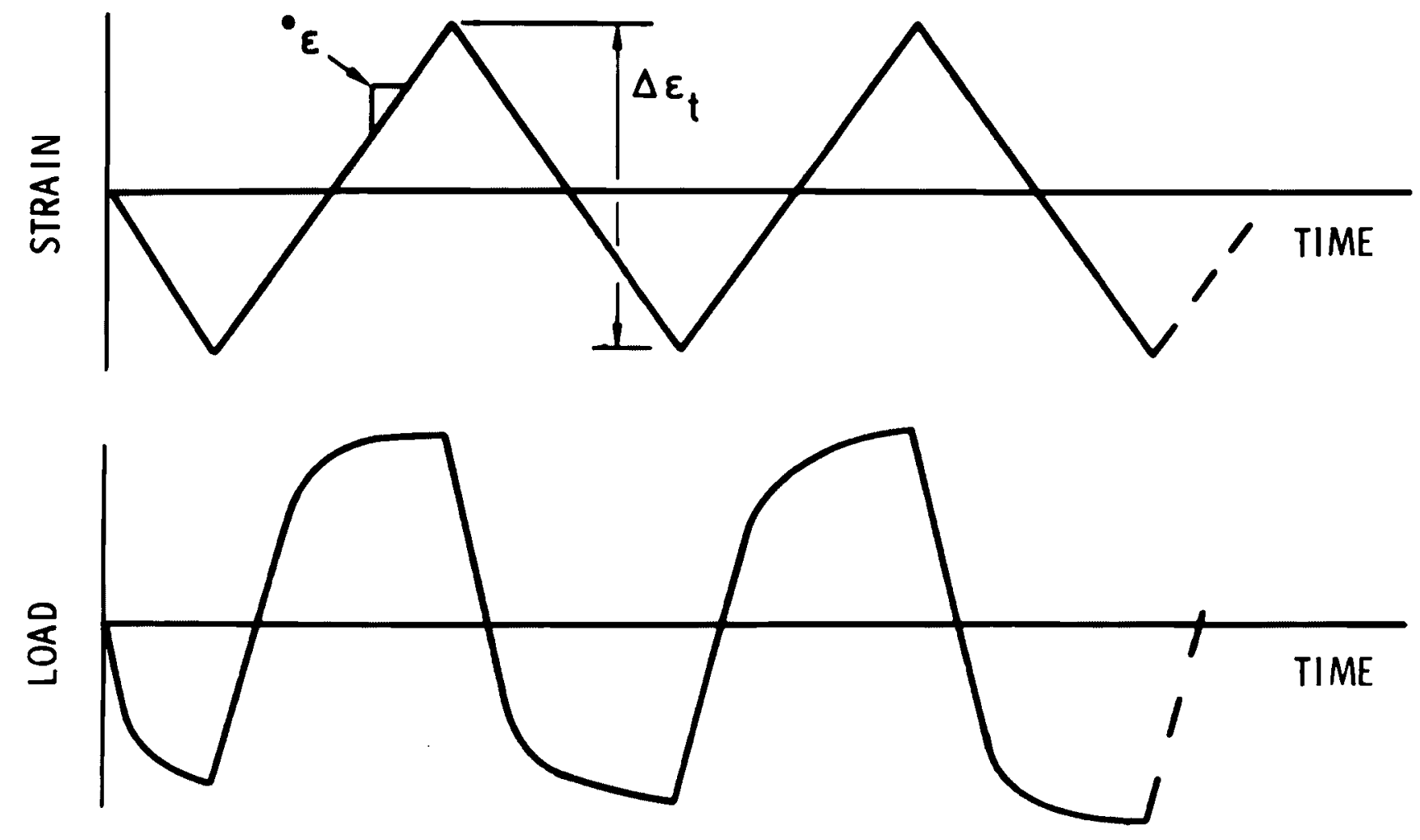

N

FIGURE 5. 1.2 1.4-1. SCHEMATIC OF PROGRAM WAVEFORM FOR FULLY REVERSED CONTINUOUS-CYCLING FATIGUE TEST. 


\section{1. 21.4-3}
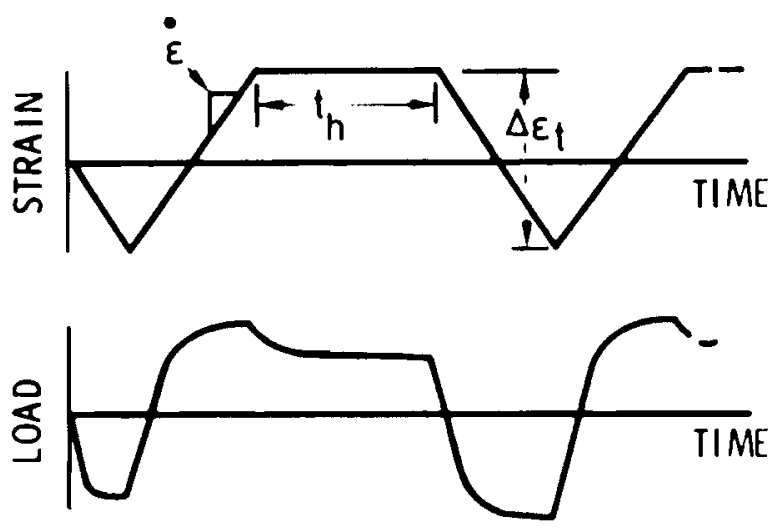

(a) TENSION HOLD TIME WITH NO COMPRESSION HOLD TIME
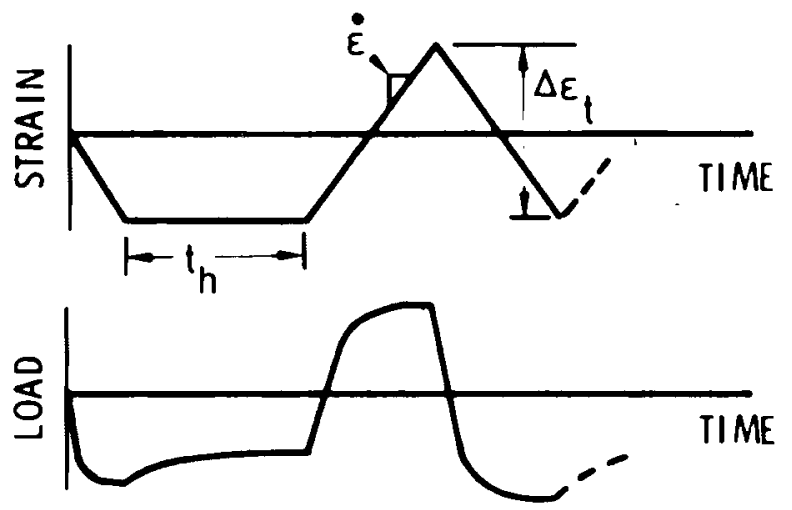

(b) COMPRESSION HOLD TIME WITH NO TENSION HOLD TIME
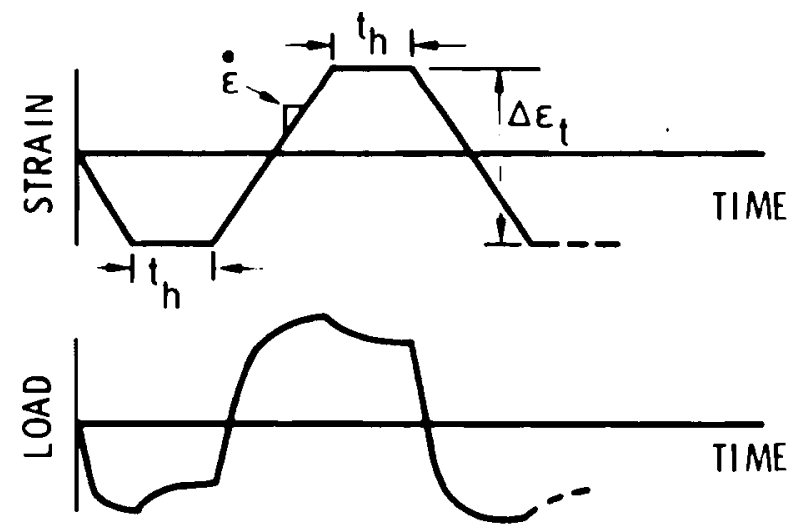

(C) BOTH TENSION AND COMPRESSION HOLD TIMES

FIGURE 5.1.2. 1.4-2 SCHEMATIC OF PROGRAM WAVEFORMS FOR FATIGUE TESTS WITH HOLD TIMES. 


\section{$5 \cdot 1 \cdot 2 \cdot 1 \cdot 4-4$}

At slower strain rates, a reduction in fatigue life occurs due to the creep damage accumulated during the relatively longer time spent near the peak stress of the cycle.

Hold periods causes even more pronounced time effects. During the hold period, the maximum strain is maintained constant, and the stress is allowed to relax. When the hold period is a tensile strain, a reduction of the fatigue life occurs, increasing with increasing hold periods. Compression hold periods have no significant effects; holds at both tensile and compression strains reduce the fatigue life only slightly. The decreasing life with increasing tension hold periods could be due to static crack growth during the hold period which could correlate with McEvily's ${ }^{1}$ observations that the majority of the life of a high-strain low cycle fatigue specimen life is spent in crack propagation. 


\section{$5 \cdot 1 \cdot 2 \cdot 1 \cdot 4-5$}

\section{REFERENCES}

(1) Boettner, R. C., C. Laird, and A.J. McEvily, Jr., "Crack Nucleution \& Growth in High Strain-Low Cycle Fatigue", Trans ASME, Vol. 233, 1965. 


$$
5.1 .2 .2 .1-1
$$

\subsubsection{Geometry}

\subsection{Surface Effects}

High-Cycle Fatigue

a. Surface Finish

Shallow grooves or notches that do not purposely define the shape in the design of a structural member, but are rather in the form of tool marks from the machining operations, corrosion pits, gouges, etc., may have a considerable effect on the fatique strength. Tool marks cannot always be completely removed; however, careful grinding and polishing operations may be used to reduce a coarser surface finish and greatly benefit its resistance to fatigue. Whenever possible, machining or turning operations should be made so that the resulting tool marks are in the direction of the loading of the member rather than normal to it. In general, the fatigue strength increases with decrease in RMS finish. The presence of defects bias fatigue behavior more towards crack propagation and is discussed further in Section 5.1.2.2.2.

b. Surface Hardness

Since the fatigue endurance limit of a metal increases with its ultimate strength, an increase in fatigue strength should be expected by such processes which harden the surface (providing no deletrious metallurgical or notch effects are included) as carburizing, nitriding, cyaniding and other forms of surface hardening. Cladding with a softer material than the core reduces the fatigue life, and so does decarburizing in steel; the latter can leave the soft case or rim in a state of tensile stress thus reducing fatigue life.

c. Residual Stress

Introduction of compressive residual stresses by mechanical means, such as cold working by surface rolling, tumbling and 
shot peening improves the fatigue life. Non-uniform or excessive application can be deleterious by leaving surface areas in a state of tensile stress or formation of cracks.

\section{Low-cycle Fatigue}

The effects of surface condition, hardness and residual stress appears to have a less significant effect on fatigue life in lowcycle fatigue than in high-cycle fatigue. High strain levels in lowcycle fatigue tests produce localized plastic flow which tends to reduce strain concentrations such as machine tool marks, scratches etc. The same high strain level could also cause the initiation of cracks in the compressively stressed brittle surface layer of a carburized or nitrided surface, or even virtually eliminate the compressive stresses produced by shot peening. Thus it may be possible that such treatments which improve fatigue life in high-cycle fatigue could be detrimental in low-cycle fatigue. One example is the premature cracking of a brittle surface layer at the first load cycle when loaded beyond a critical strain level. 


\section{$5.1 .2 \cdot 2 \cdot 2-1$}

\subsection{Notch Effects and Fatigue Crack Growth}

Notches (as well as any stress concentrations, such as abrupt changes in cross section, holes, grooves, keyways, threads etc) affect fatigue life to a variable degree, depending on notch geometry and material. Notch geometry, resulting in localized high stresses, is known as "stress concentration", a measure of which is the "stress concentration factor", defined as $K_{t}$ or the ratio of the maximum local stress versus the nominal stress, as defined by elementary formulas, such as P/A and Mc/I. $K_{t}$ is also known as the theoretical stress concentration factor.

The effect of notches on the high cycle fatigue strength varies also with the material and is usually less than the effect which would be predicted by $k_{t}$, but generally always reduces fatigue 1 ife. $1,2,3$ The fatigue notch sensitivity $q$ of the material is defined as a measure of the degree of agreement between $k_{f}$ and $k_{t}$, where $k_{f}$, the fatigue notch factor, is the ratio of the fatigue strengths determined for unnotched and notched fatigue specimens:

$$
q=\frac{K_{f}-1}{K_{t}-1}
$$

The subtraction of 1 from $k_{f}$ and $k_{t}$ provides a scale for $q$ ranging from zero (no notch effect, $k_{f}=1$ ), to unity (full theoretical effect, $k_{f}=K_{t}$ ). Stress concentration factors $k_{t}$ are obtained mathematically or experimentally by such means as photoelasticity, precision strain gage, membrane analogy or electrical analogy for torsion. Fatigue notch factors $k_{f}$ are usually somewhat less than $k_{t}$. In general it can be stated that for finergrained materials such as quenched and tempered steels, the value of $q$ is 


\section{$5 \cdot 1 \cdot 2 \cdot 2 \cdot 2-2$}

near unity $\left(K_{f}=k_{t}\right)$. For the coarser-grained materials, such as annealed or normalized steels or aluminum alloys, the value of q nears unity only for large members with notches of fairly large contour radii $\left(\frac{1}{4} i n\right.$. or larger).

The conventional S-N diagram (alternating stress versus cycles) is plotted by using the number of cycles to failure of the specimen. When notched specimens are used, the location of the fatigue crack is well defined, and plots of alternating stresses versus cycles to first detectable crack can be made, as shown in Figure 5.1.2.2.2-1.4

For low-cycle fatigue there are no well characterized relationshins for describing the effect of notches on the fatigue strength. The material itself, the environment and the method of loading (load control or strain control) exert an influence on low-cycle fatigue. Wandt ${ }^{5}$ found no significant change in the fatigue life in the low-cycle region. Yao and Munse ${ }^{6}$ have shown a slight increase in fatigue life up to the first 10 cycles.

The number of cycles required to propagate a detectable crack of a given size to failure can be estimated from fracture mechanics. From tests or a survey of available material-proterties data, the fatigue crack growth rate can often be put in the form $d a / d N=C \Delta K^{n}$. By integrating, the number of cycles required to grow a flaw of the minimum size detectable by a given NDT technique to the critical size can be determined from: ${ }^{2}$

$$
\begin{aligned}
& N=\frac{2}{(n-2) C M{ }^{n / 2} \Delta \sigma^{n}}\left[\frac{1}{a_{i}(n-2) / 2}-\frac{1}{a_{c r}(n-2) / 2}\right] \\
& N=\frac{1}{C M \Delta \sigma^{2}} \log _{e} \frac{a_{c r}}{a_{i}} \quad \text { for } n=2 \quad \text { or } \\
& N=\frac{1}{\operatorname{CH}^{2}(\Delta \sigma)^{4}} a_{i} \text { for } n=4 \text { and } a_{c r} \gg a_{i}
\end{aligned}
$$


Where:

$N=$ number of cycles to grow to critical crack size

$a_{i}=$ initial crack size

$n=$ slope of $\operatorname{lng} d a / d N$ vs, $\operatorname{lng} \Delta k$ curve, which have been reported to vary from as low as? to higher thar 8 , but trequently around 4 (in the absence of environmenta: influences!

$a_{c r}=$ critical rack size

$C=$ empirical intercept constant

$\Delta \sigma=$ applied cyclic stress range, psi

$M=$ component geometry and flaw shape parameter.

Thus the life of a component undergoing constant cyclic loading (for $n=4$ ) is inversely nroportional to both the minimum detectable size flaw $a_{j}$, and the stress range to the fourth nower $(\Delta \sigma)^{4}$. Note the importance here of minimizing initial defect size, shape and orientation in highly stressed regions to maximize fatigue crack nronagation life.

The equation per se may be conservative because seldom is the stress range constant and it does not take into consideration the number of cycles to initiate a crack from a built-in-flaw. Periodic overloads (s $\mathrm{Kcr}$ ) can cause the crack to temporarily arrest its growth, thus increasing the number of cycles to reach $a_{c r}$. On the other hand there are little data available on the effect of variable amplitude loading on fatigue crack propagation life and thus the effect of periodic overloading should be viewed cautiously. By plotting II versus initial crack size for several stress ranges, it is possible to establish quantitative material acceptance and inspection requirements as well as realistic safety factors for various practical situations where a given life and safety factor is desired. 


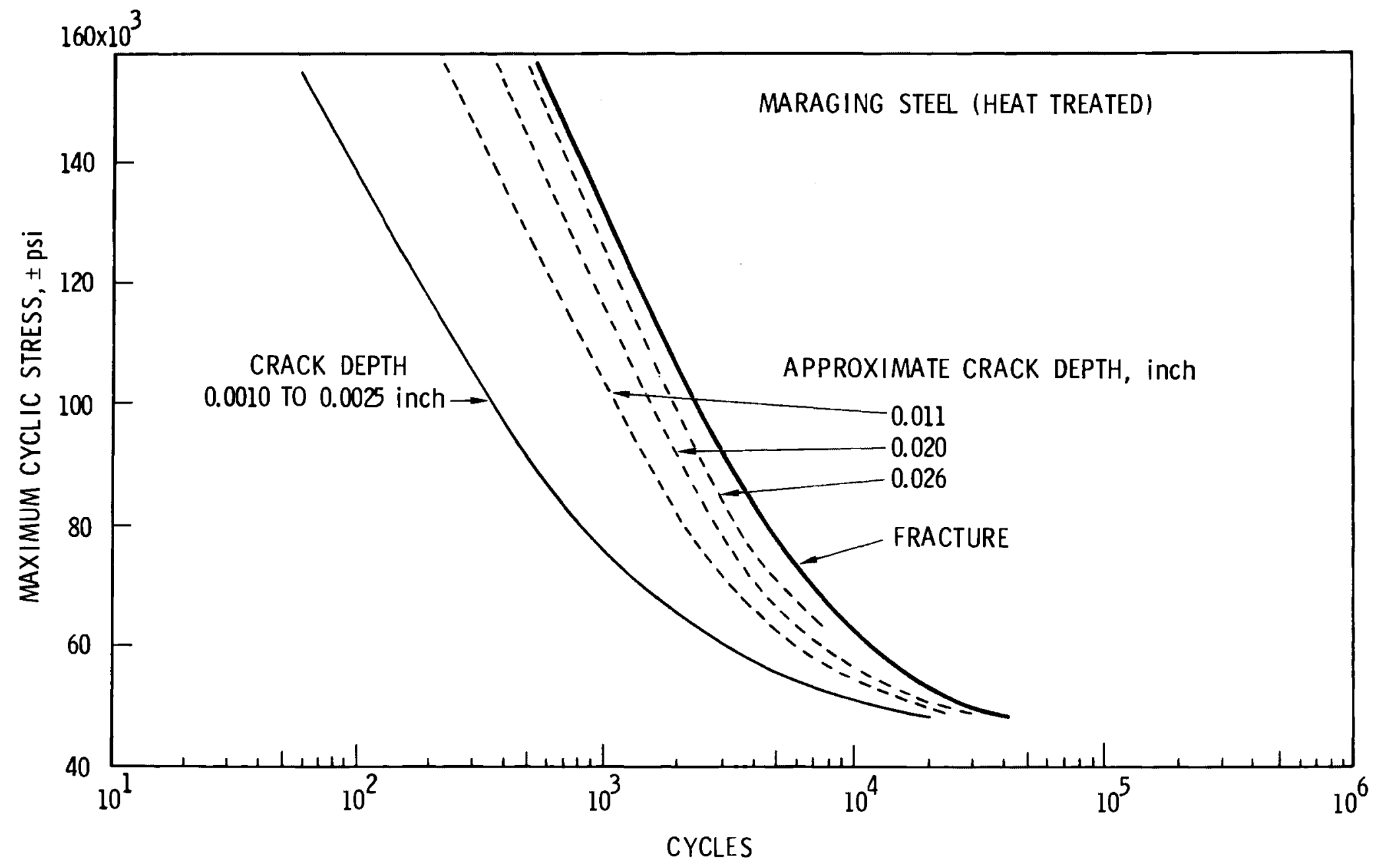

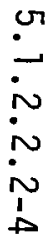

FIG. 5.1.2.2.2-1 FATIGUE CURVES SHOWING CYCLES TO FIRST DETECTABLE CRACKS AND CYCLES TO FRACTURE FOR CYLINDRICAL NOTCHED SPECIMENS SUBJECTED TO REVERSED LOADING. THEORETICAL STRESS CONCENTRATION, 3.65 


\section{$5 \cdot 1 \cdot 2 \cdot 2 \cdot 3-1$}

\subsection{Effect of Loading, Environmental and Metallurgical Conditions on Fatigue Crack Growth in Austenitic Stainless Steels}

Linear elastic fracture mechanics principles have been used to characterize fatigue crack growth behavior of austenitic stainless steels. Many conditions are known to effect crack growth behavior: temperature, environment $18,19,22$ cyclic frequency, 1,13 load waveform including hold times $\frac{14,15}{4}$ cyclic stress ratio ${ }^{16}$ cold work, ${ }^{10,11,18}$ thermal aging, ${ }^{17}$ crack orientation, ${ }^{11}$ alloy type, ${ }^{10,12}$ weldments 20,21 and neutron irradiation (see section 5.3 for latter). Environmental and metallurgical variables have been included in this section since the majority of the loading variables have been tested in conjunction with environmental and metallurgical variables.

Key figures and salient comments describing the above effects are presented below and also provide a basis for comparison with future irradiated data covering the same test parameters. One point should be emphasized at this time. Very recent work on fatigue crack growth in liquid sodium ${ }^{22}$ indicate that many of the factors noted above that effect $\frac{d a}{d N}$ in air may be eliminated when tested in "clean" sodium. Thus application of such crack growth data to high temperature LMFBR systems should be considered in light of the dominant environment, namely, air or sodium.

\subsection{Effect of Frequency and Hold Times on}

\section{Fatigue Crack Growth}

In type $304 S S$ at $1,000^{\circ} \mathrm{F}$ in air, James ${ }^{13}$ has found that $\frac{\mathrm{da}}{\mathrm{dN}}$ can be both frequency-dependent and frequency-independent, as shown in figure 5.1.2.2.3.1-1. In general the effect of decreasing frequency--in the frequency dependent region--is to increase $\frac{d a}{d N}$ at a given $\Delta K-$ level, about a 
factor of $7-8$; frequences varied from a high of $4000 \mathrm{cpm}$ to $0.083 \mathrm{cpm}$

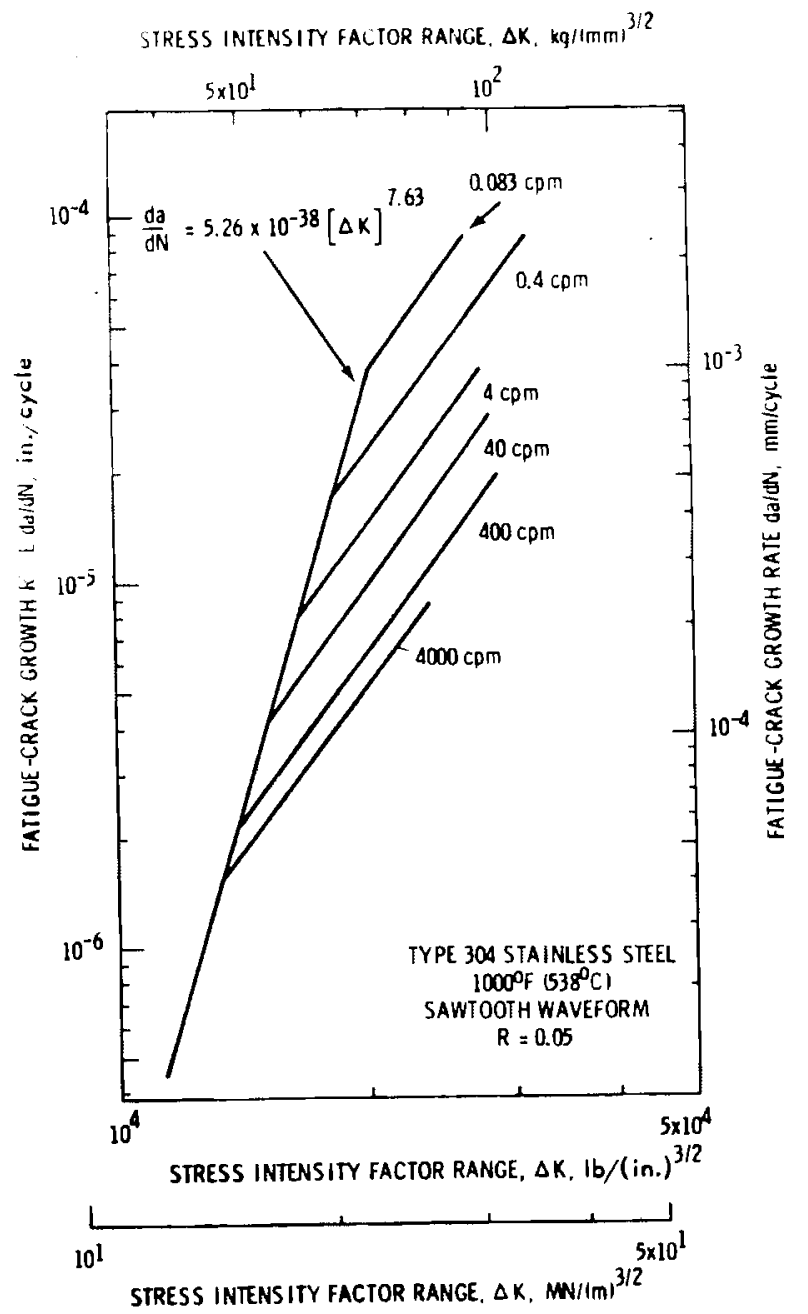

Figure $5 \cdot 1 \cdot 2 \cdot 2 \cdot 3 \cdot 1-1$

The Effect of Cyclic Frequency on the Fatigue Crack Propagation Behavior of Annealed Type 304 at $1000^{\circ} \mathrm{F}$. Sawtooth Waveform Utilized.

The effect of load waveform--which may inherently contain some effect of hold time--does not appear significant at frequencies of $0.333 \mathrm{cpm}$ and higher; James ${ }^{14}$ shows that there is little difference between sawtooth and trapezoidal wave load waveforms at $1000^{\circ} \mathrm{F}$ in air above $0.333 \mathrm{cpm}$ (Figure $5.1 \cdot 2 \cdot 2 \cdot 3 \cdot 1-2$ ). Below $0.333 \mathrm{cpm}$, viz, $0.083 \mathrm{cpm}, \frac{\mathrm{da}}{\mathrm{dN}}$ is higher for the 


\section{$5.1 .2 .2 .3 .1-2$}

sawtooth wave than the trapezoidal wave (Figure 5.1.2.2.3.1-3). However, a change in crack path was noted: the sawtooth wave produced primarily transgranular cracking while the trapezoidal wave produced primarily intergranular cracking.

The effect of hold time for se, in fatigue crack growth tests is less clear because of the possible frequency effect that can exist simultaneously. For example James ${ }^{14}$ has shown, as discussed above, that for equal test

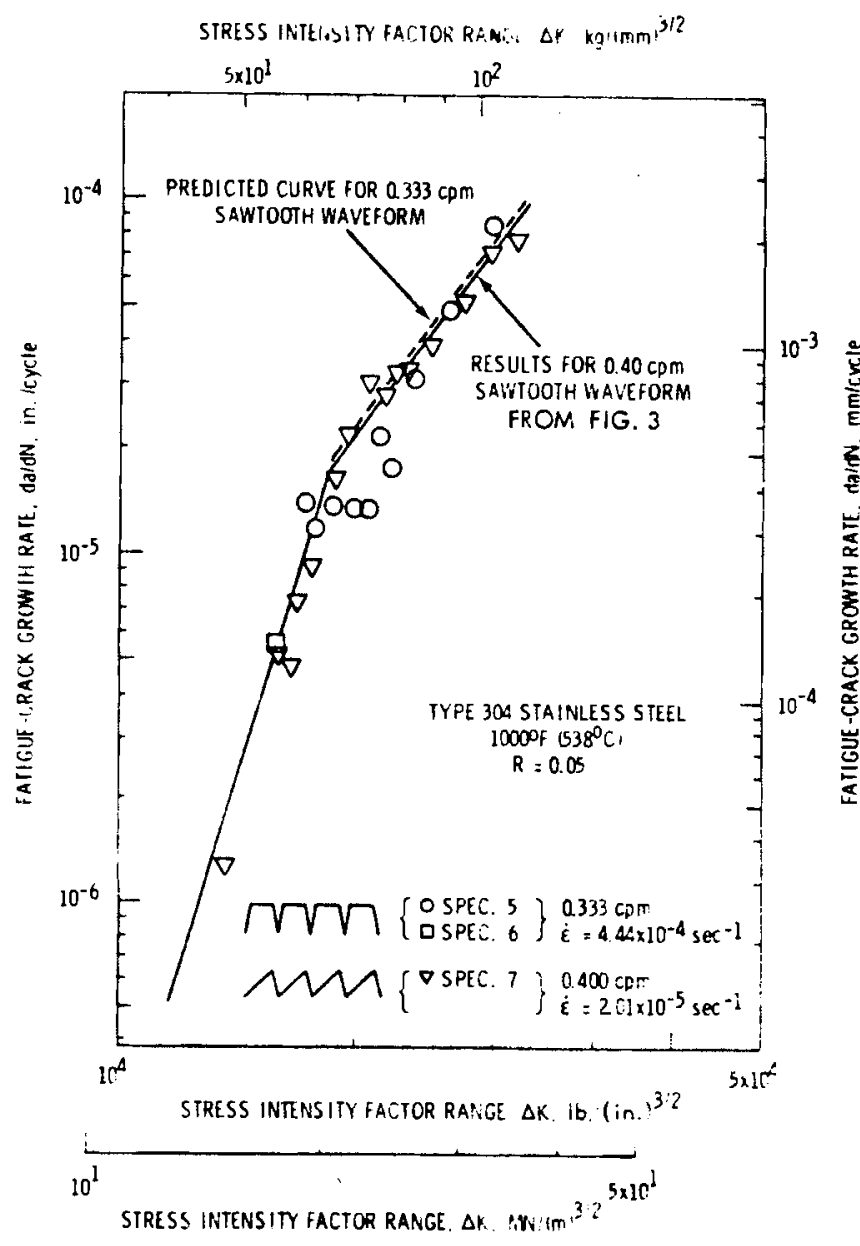

Figure 5.1.2.2.3.1-2

The Effect of Loading Waveform on the Fatigue-Crack Propagation Behavior of Annealed Type 304 at $1000^{\circ} \mathrm{F}$. Frequency $=0.4$ and 0.333 $\mathrm{cpm}$.

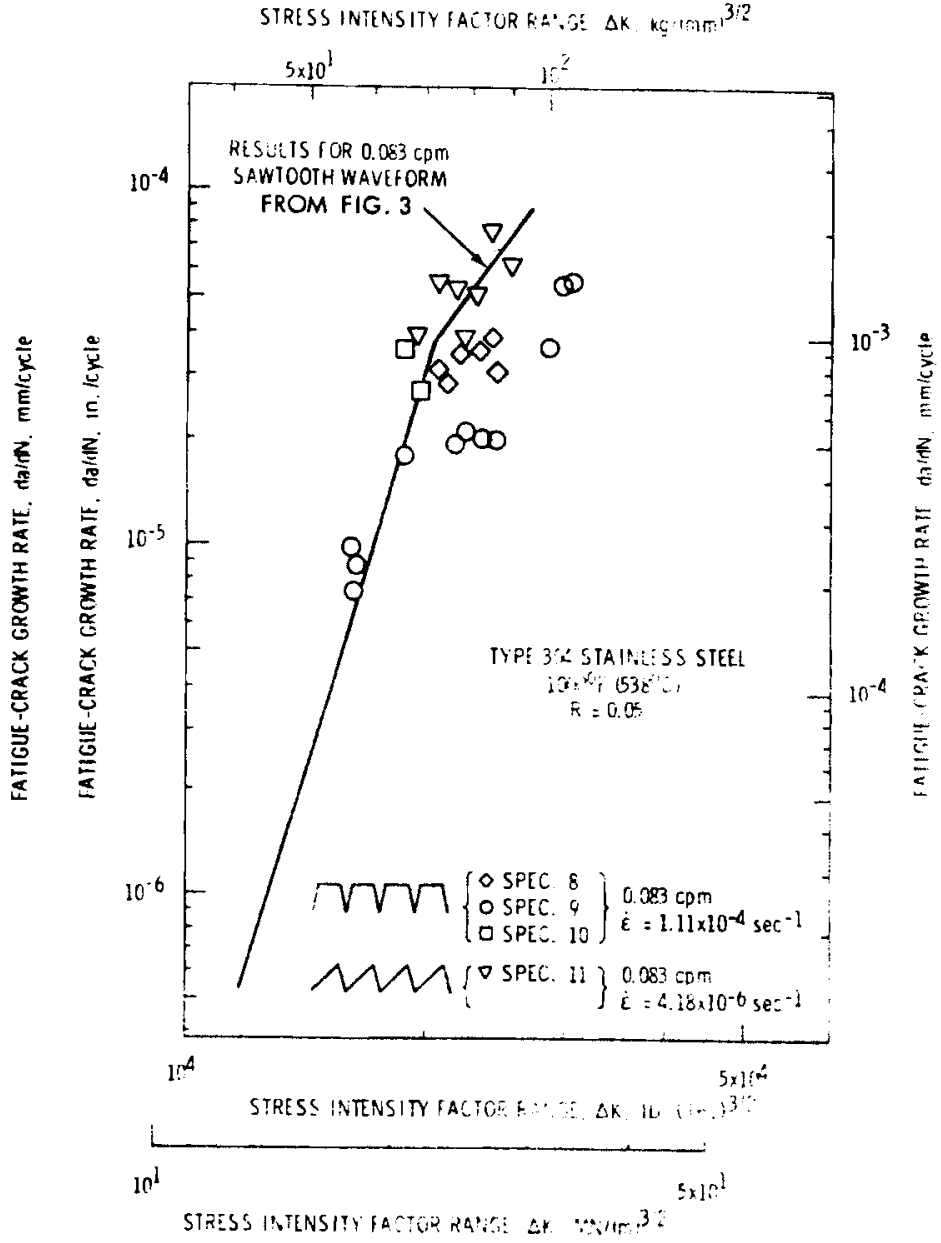

Figure 5.1.2.2.3.1-3

The Effect of Loading Waveform on the Fatigue-Crack Propagation Behavior of Annealed Type 304 at $1000^{\circ} \mathrm{F}$. Frequency $=0.083 \mathrm{cpm}$. 
frequencies there is no significant difference between sawtooth and trapezoidal loading wave forms. Shahinian, Smith and Watson ${ }^{15}$ show for $25 \% \mathrm{cW}$ 304 (Figure 5.1.2.2.3.1-4) and annealed 304 SS (Figure 5.1.2.2.3.1-5) a holdtime effect at $1100^{\circ} \mathrm{F}$ trapezoidal wave loading (.1 \& $1.0 \mathrm{~min}$ hold time), but only compare the data to $10 \mathrm{cpm}$ sawtooth and do not indicate if they may be in a frequency dependent region in their work. Other factors that may effect the difference are the $100^{\circ} \mathrm{F}$ test temperature difference, and the cold working and aging effects. These effects are discussed below.

Increasing the stress ratio $R$ (ratio of minimum stress in fatigue cycle to maximum stress in the same cycle) generally, decreases $\frac{d a}{d N}$ for a given value of $\mathrm{K}_{\max }$. The most common method used to characterize the relationship between fatigue crack growth rate, $\frac{\mathrm{da}}{\mathrm{dN}}$, and the stress intensity factor range $\Delta K$ is

$$
\frac{d a}{d N}=C(\Delta K)^{n}
$$$$
\text { where } c, n=\begin{aligned}
& \text { constants for a given material/environmental } \\
& \text { combination }
\end{aligned}
$$

James ${ }^{16}$ found that characterizing $\frac{\mathrm{da}}{\mathrm{dN}}$ in terms of an "effective stress intensity factor" provided the best correlation of data for stress ratios ranging from -0.15 to +0.75 .

$$
\begin{aligned}
& \frac{d a}{d N}=B\left\{K_{\max }(1-R)^{m}\right\}^{p} \\
& \text { where } K_{\max }(1-R)=\Delta K
\end{aligned}
$$

and $B, m$ and $p=$ constants for a given material/envi ronmental combination.

Should this equation hold for the many possible combinations of material and environments it could reduce the number of tests needed to characterize fatigue crack growth data. 


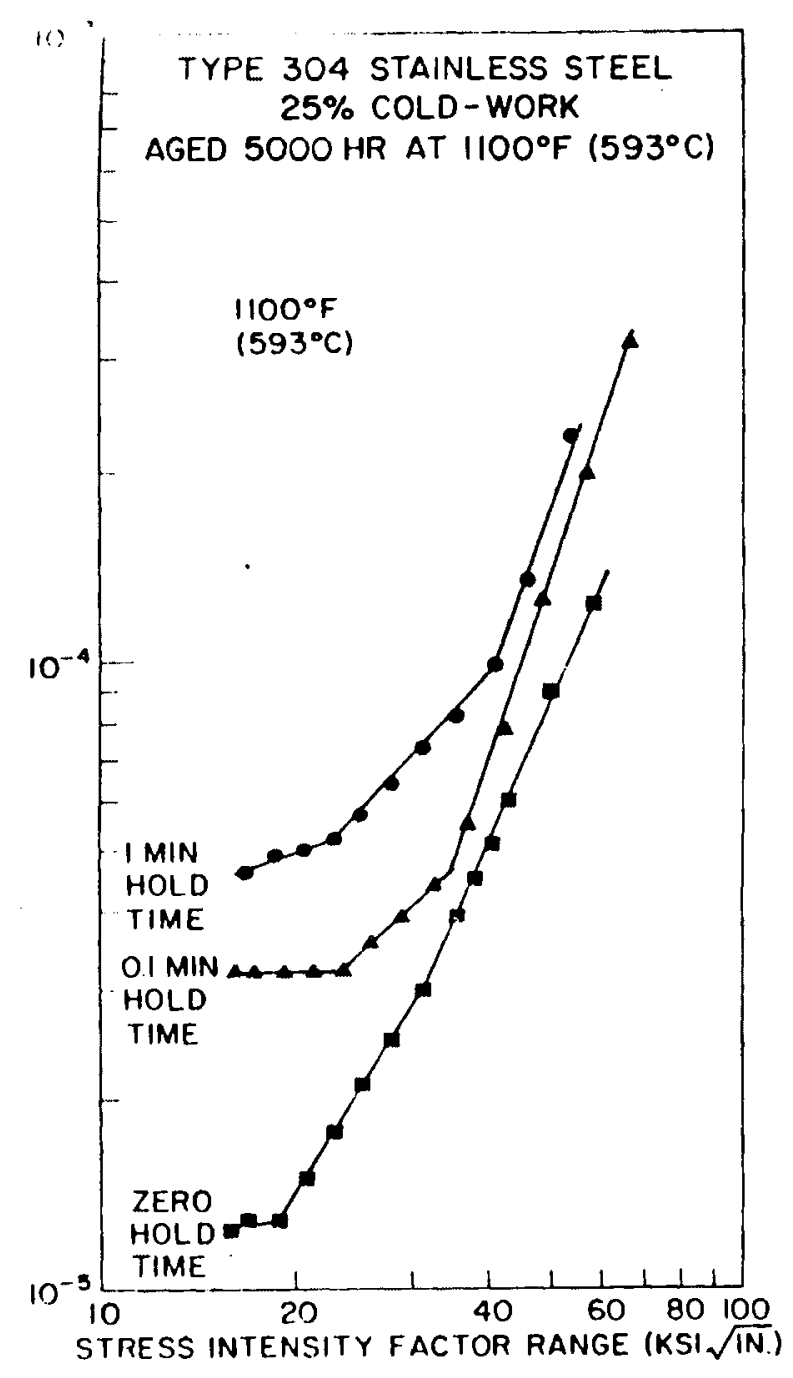

Figure $5.1 \cdot 2 \cdot 2 \cdot 3 \cdot 1-4$

Effect of Hold-Time on Fatigue Crack Growth Rates in 25\% CW and Thermally Aged 304 SS as a Function of the Stress Intensity Factor Range.

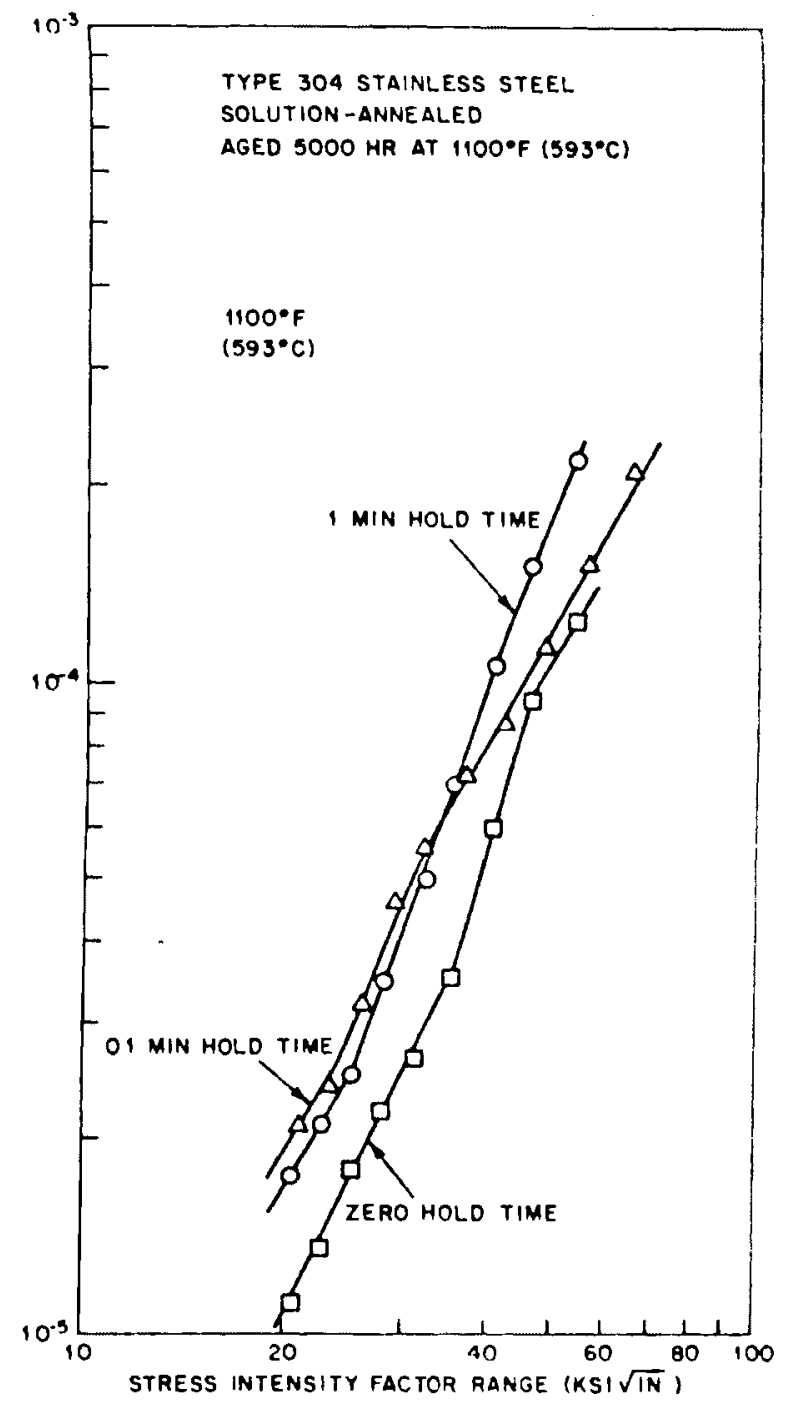

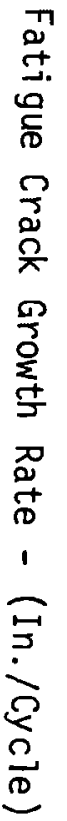

Effect of Hold-Time on Fatigue Crack Growth Rates in Solution Annealed and Thermally Aged 304 SS as a Function of the Stress Intensity Factor Range. 


\subsection{Environmental Effects}

The effect of elevated temperature on fatigue crack growth of stainless steels in air is shown in figures $5.1 \cdot 2 \cdot 2 \cdot 3 \cdot 2-1^{7}$ and $5 \cdot 1 \cdot 2 \cdot 2 \cdot 3.2-2^{8}$ for type 304 and 316. In general, crack growth rates increase as much as a factor of $10-30$ between $75^{\circ} \mathrm{F}$ and $1100^{\circ}$ to $1200^{\circ} \mathrm{F}$ at low $\Delta \mathrm{K}$ - levels, decreasing somewhat at higher $\Delta K$ levels. Figure $5 \cdot 1 \cdot 2 \cdot 2 \cdot 3 \cdot 2-3^{9}$ shows a normalization method for $\frac{\mathrm{da}}{\mathrm{dN}}$ in 316 SS based on $1 / E^{2}$ ( $E=$ Youngs Modulus); other parameters such as stress ratio and frequency would have to be examined in a similar manner to establish if such a Youngs Modulus normalization could be used.

The effect of temperature on $\frac{\mathrm{da}}{\mathrm{dN}}$ in vacuo and the effect of temperature on $\frac{\mathrm{da}}{\mathrm{dN}}$ in relatively clean sodium are shown in figures $5 \cdot 1 \cdot 2 \cdot 2 \cdot 3 \cdot 2-4$ and 5.1.2.2.3.2-5.22 These data are unique. The absence of an aggressive envi ronment--apparently oxygen--reduces crack growth rates at $1000^{\circ} \mathrm{F}$ in both cases back to the same levels experienced at $75^{\circ} \mathrm{F}$ in air. Wi thin the range of test variables examined, viz vacuum about $6 \times 10^{-6}$ torr, sodium with $<2$ and 20-40 ppm oxygen and frequencies around 180-400 cpm, the data indicate that thermal activation plays no role in the cracking process.

It should be noted that the MSAR data ${ }^{23}$ in effect of highly contaminated sodium do produce a significant reduction in fatigue life. Figure 5.1.2.3.2-1 below shows a significant part of that work. The contaminants that decreased fatigue life were carbon and oxygen, ranging as high as $300 \mathrm{ppm}$.

These data are useful in their demonstration of how serious relatively large amounts of contaminants can affect mechanical properties as well as low-cycle fatigue. Since contaminant levels in operating LMFBR systems will generally be maintained much lower than those of the MSAR work ${ }^{23}$ no further discussion of that work will be presented herein. 
$5.1 \cdot 2 \cdot 2 \cdot 3.2-2$

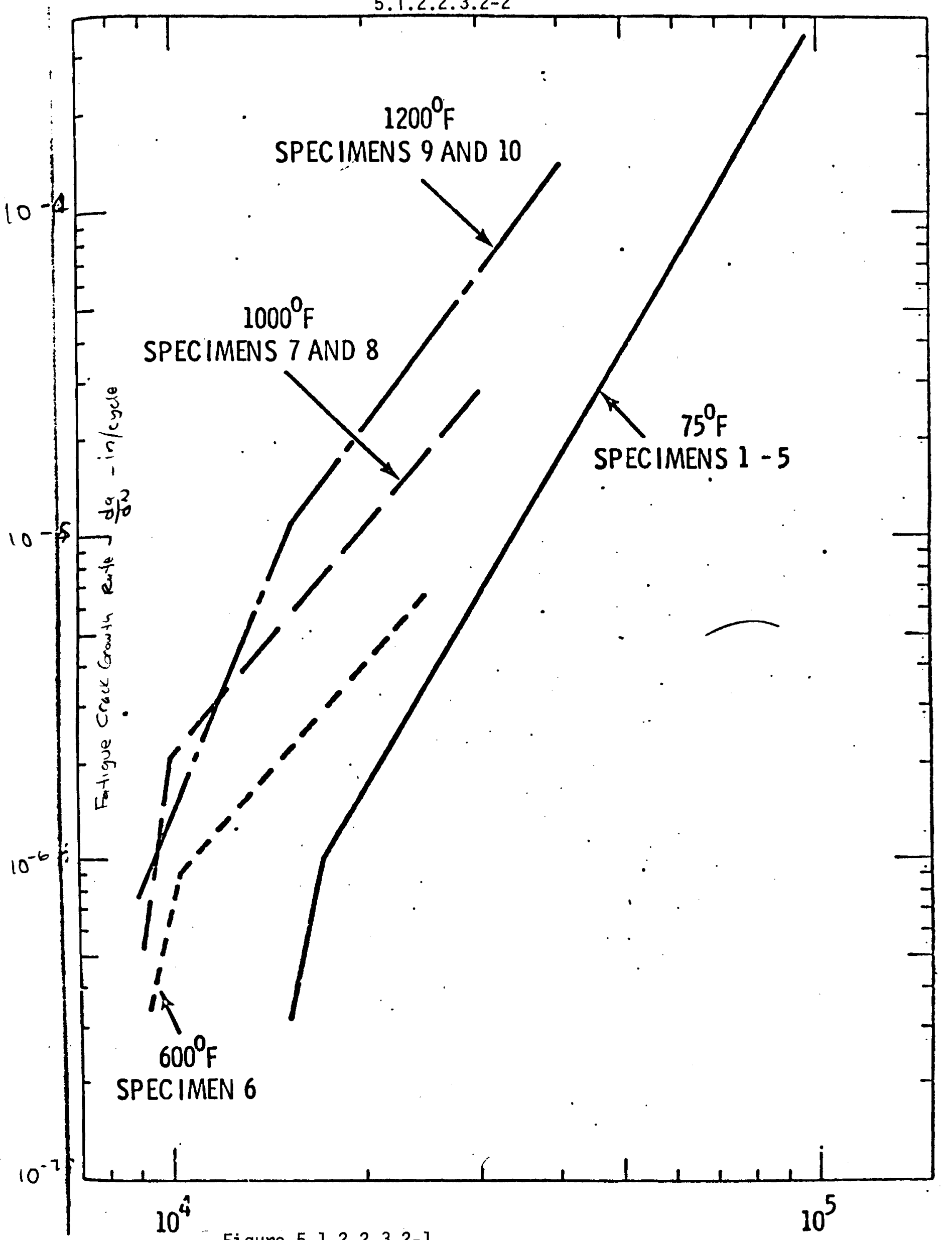

Figure 5.1.2.2.3.2-1

' STRESS INTENSITY FACTOR RANGE $\triangle K$, psi $\sqrt{I N}$. 


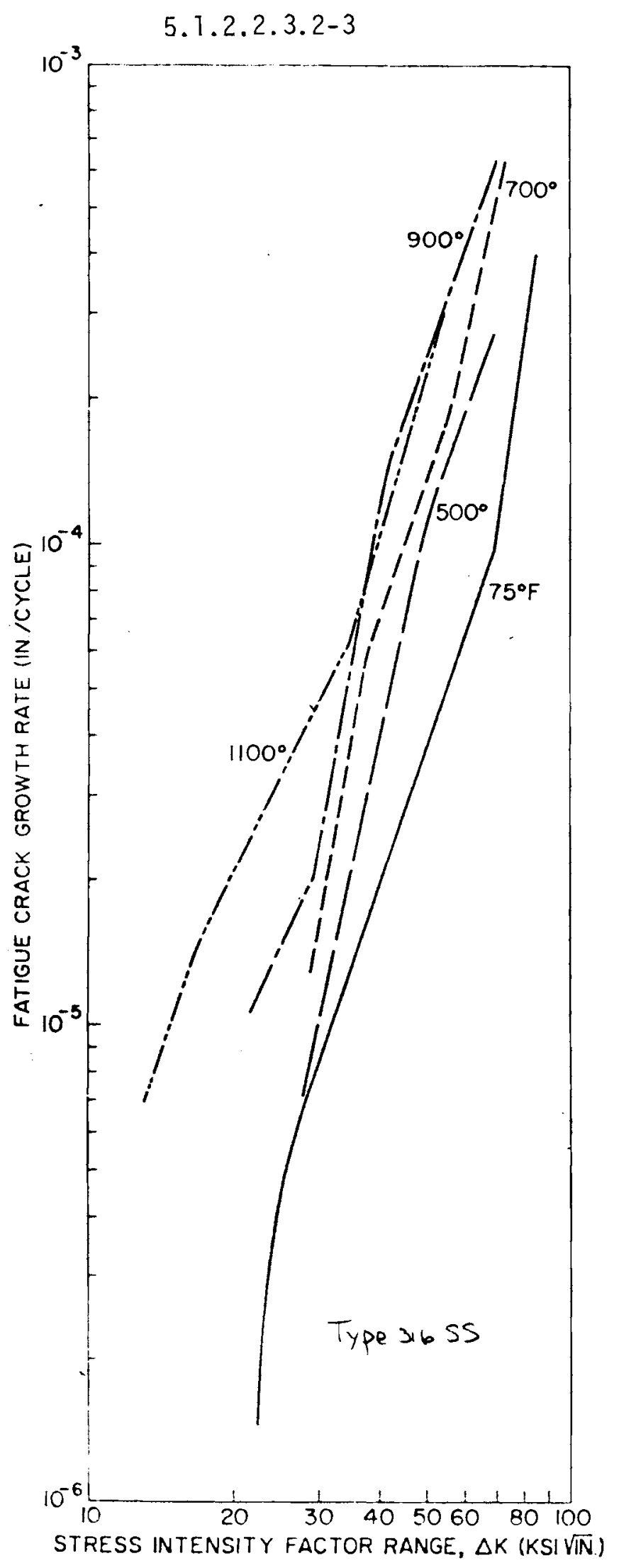

Figure 5,1,2.2.3.2-2

Summary of Fatigue Crack Growth Rate Correlation Curves at $75,500,700,900$, and 1100 deg $F$. 
$5 \cdot 1 \cdot 2 \cdot 2 \cdot 3 \cdot 2-4$

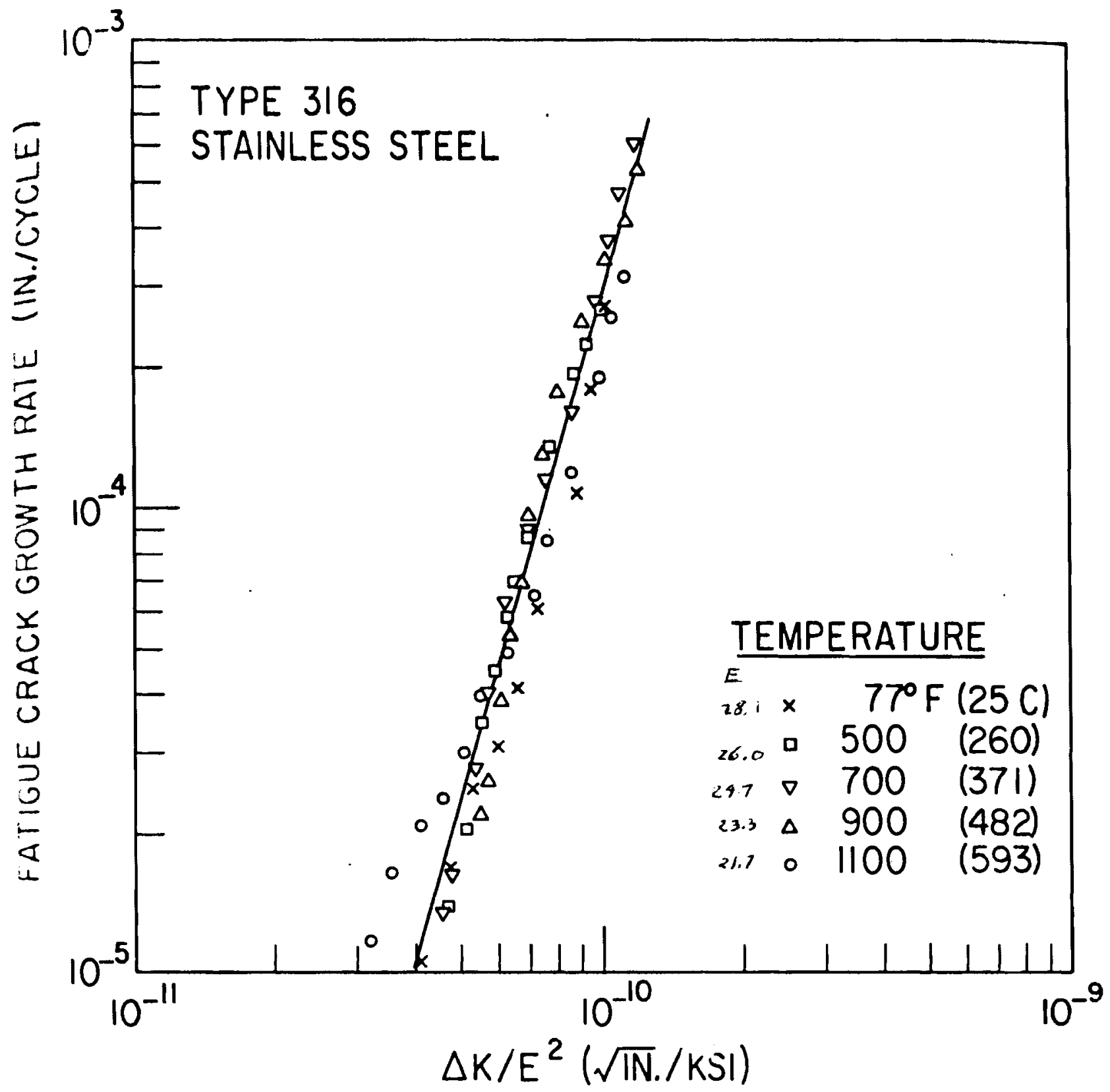

Figure $5 \cdot 1 \cdot 2 \cdot 2 \cdot 3 \cdot 2 .-3$

Dependence of fatigue crack growth rates in Type 316 stainless steel at high temperatures on ratio of stress intensity factor range to square of elastic modulus. 


\section{$5 \cdot 1 \cdot 2 \cdot 2 \cdot 3 \cdot 2-5$}

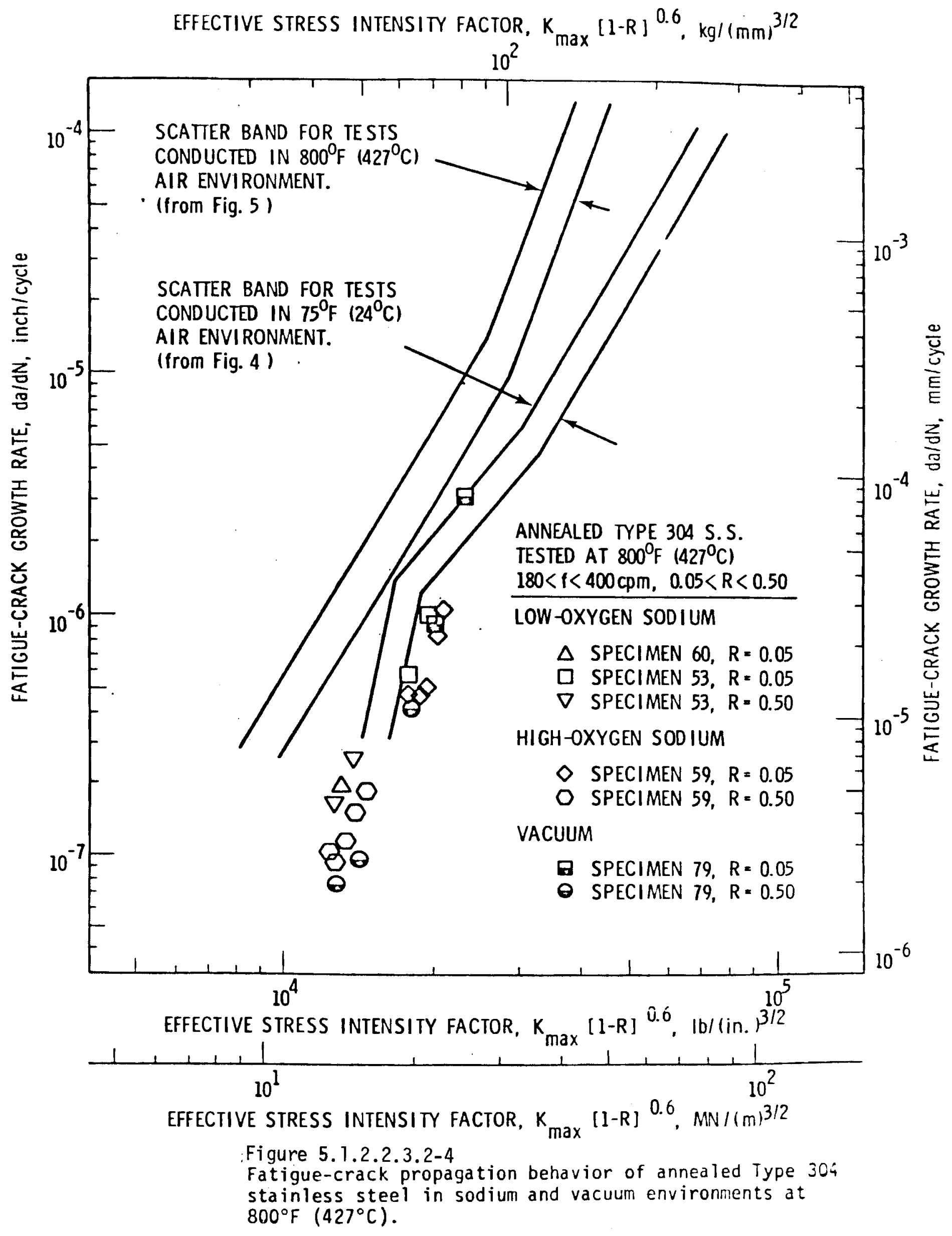




\section{$5.1 .2 \cdot 2 \cdot 3 \cdot 2-6$}

EFFECTIVE STRESS INTENSITY FACTOR, $k_{\text {max }}[1-R]^{0.5} \cdot \mathrm{kg} /(\mathrm{mm})^{3 / 2}$

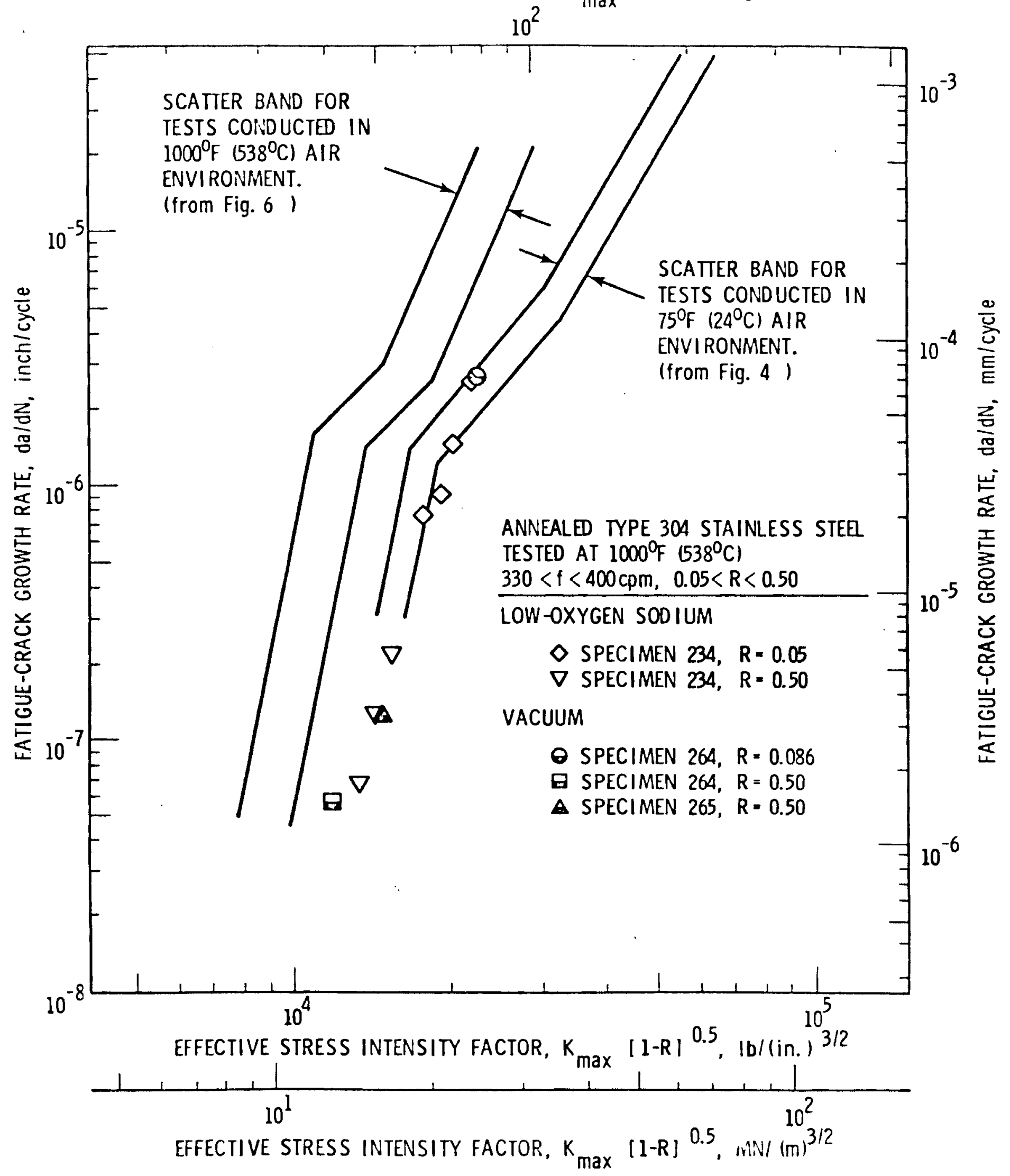

Figure 5.1.2.2.3.2-5

Fatigue-crack propagation behavior of annealed Type 304 stainless steel in sodium and vacuum environichts at $1000^{\circ} \mathrm{F}\left(538^{\circ} \mathrm{C}\right)$. 


\subsection{Metallurgical Effects}

The effect of thermal aging, cold work, weldments and crack orientation are presented. These data indicate thus far, that environmental influences override metallurgical effects. In general, thermal aging of stainless steels types $304,304 \mathrm{~L}$ and 316 at $1000^{\circ} \mathrm{F}$ and $1200^{\circ} \mathrm{F}$ for aging times of 1500,3000 , and 6000 hours over the range of $\Delta K$ and frequency values produced beneficial results, ${ }^{17}$ crack growth rates at $1000^{\circ} \mathrm{F}$ were reduced slightly in comparison to unaged material. The effect of $20 \%$ cold work on $\frac{\mathrm{da}}{\mathrm{dN}}$ in $316 \mathrm{SS}$ at $1000^{\circ} \mathrm{F}$ showed mixed results (Figure 5.1.2.2.3.3-1).11 At high $\Delta K$ values $(>15,000$ psi $\sqrt{7 n}$ ) crack growth rate ratios were less for the cold worked material. For $\Delta K<\sim 15,000 \mathrm{psi} \sqrt{\mathrm{in}}$, $\frac{\mathrm{da}}{\mathrm{dN}}$ was higher. The increased $\frac{\mathrm{da}}{\mathrm{dN}}$ values at law $\Delta K$ ratios are not significant for a structure undergoing a limited number of loading cycles during its lifetime. For a large number of loading cycles, however, the cold work effect--by itself--would not be as beneficial because the majority of the structure fatigue life could be spent in the low $\Delta K$ region where cracking would be faster. Thus, in terms of total cycles to reach a given crack length, the beneficial cold work effect at high $\Delta K$ values could be of little significance.

Weldments in type $304 \mathrm{SS}$, using 308 filler metal, made by the gastungsten-arc (GTA),20,21 submerged $\operatorname{arc}(S A)^{21}$ and the shielded metal arc $(\text { SMA })^{21}$ were studied for a variety of crack orientations. In general, the welds did not produce significant changes in $\frac{d a}{d N}$ when cracks were oriented either perpendicular or parallel to the welds. Residual stresses appear responsible for slight increases and decreases in $\frac{\mathrm{da}}{\mathrm{dN}}$ depending on the location of the crack with respect to the weld. The inherent variability of welding processes and natural operator dependence should also be considered. Variation in weld 
$5.1 .2 .2 \cdot 3 \cdot 3-2$

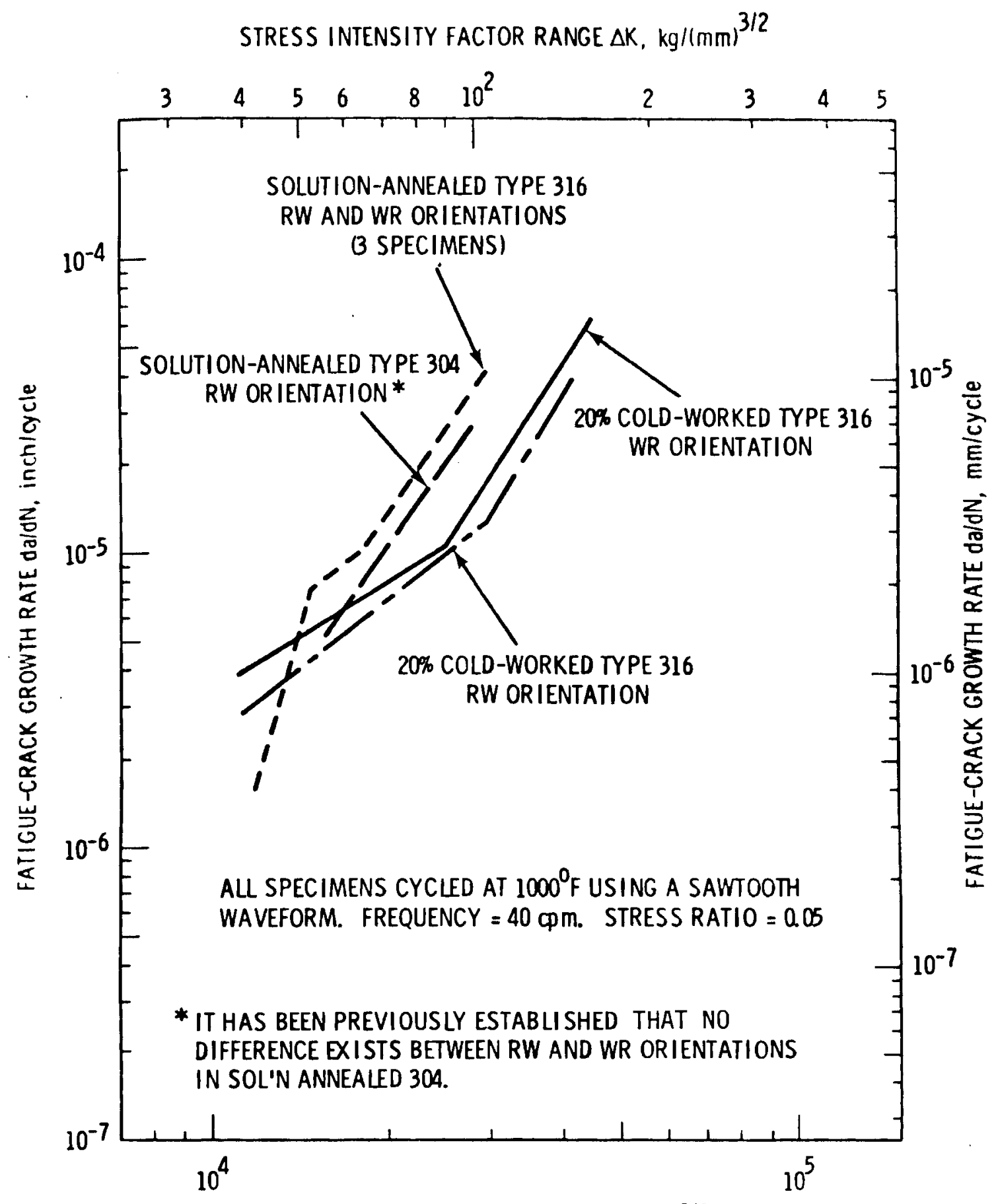

STRESS INTENSITY FACTOR RANGE $\Delta K, \mathrm{lb} /(\mathrm{in})^{3 / 2}$ OR pSi in

Figure $5 \cdot 1 \cdot 2 \cdot 2 \cdot 3 \cdot 3 .-1$

Fatigue Crack Growth of 316 and 304 Stainless Steels 


\section{$5 \cdot 1 \cdot 2 \cdot 2 \cdot 3 \cdot 3-3$}

procedure, weld wire quality, cover gas quality, etc. could possible have a significant effect on crack growth behavior.

Crack orientation effects in general do not appear significant in both base metal7,11 and weldments.21 Again the latter must be considered circumspect in welds of questionable quality. 


$$
5.1 .2 \cdot 2 \cdot 3 \cdot 3-4
$$

\section{REFERENCES}

1. Peterson, R. E., "Stress Concentration Design Factors", John Wiley and Sons, Inc., 1953.

2. Whaley, R. E., "Fatigue and Static Strength of Notched and Unnotched Aluminum-alloy and Steel Specimens", Experimental Mechanics, Vol. 2 No. 11, p. 329-334, 1962.

3. Peterson, R. E., "Notch Sensitivity", Metal Fatigue, G. Sines and J. L. Waisman, eds., McGraw-Hi11, New York, 1959.

4. Klima, S. J. and Freche, J. C., "Ultrasonic Detection and Measurement of Fatigue Cracks in Notched Specimens", Experimental Mechanics Vor. 9, No. 5, p. 198, 1969.

5. Wundt, B. M., "Effect of Notches on Low-Cyçle Fatigue", ASTM STP 490, 1972.

6. Yao, J. T. P. and Munse, W. H., "Low-Cycle Fatigue of Notches - Literature Review", SCC-137, Dept. of Navy, Bureau of Ships, Contract Nobs72046 .

7. L. A. James and E. B. Schwenk, "Fatigue-Crack Propagation Behavior of Type 304 Stainless Steel at Elevated Temperatures", Metallurgical Transactions, Vo1. 2, No. 2, pp. 491-496, 1971.

8. P. Shahinian, H. H. Smith and H. E. Watson, "Fatigue Crack Growth in Type 316 Stainless Steel at High Temperature", Journal of Engineering for Industry, Trans. ASME, Series B, Vol. 93, No. 4, pp. 976-980, 1971. 


\section{$5 \cdot 1 \cdot 2 \cdot 2 \cdot 3 \cdot 3-5$}

9. P. Shahinian, H. H. Smith and H. E. Watson, "Fatigue Crack Growth in Type 316 Stainless Stee 1 at High Temperatures", (0U0), HEDL-TME 71-66, Special Distribution, PPNRL-11 to NRL-19, Hanford Engineering Development Laboratory, May, 1971.

10. L. A. James, "The Effect of Elevated Temperature Upon the FatigueCrack Propagation Behavior of Two Aus tenitic Stainless Steels", Mechanical Behavior of Materials, Vol. III, pp. 341-352, The Society of Materials Science, Japan, 1972.

11. L. A. James, "Fatigue-Crack Growth in 20\% Cold Worked Type 316 Stainless Steel at Elevated Temperatures", Nuclear Technology Vol. 16, No. 1, pp. $316-322,1972$.

12. P. Shahinian, H. H. Smith and H. E. Watson, "Fatigue Crack Growth Characteristics of Several Austenitic Stainless Steels at High Temperatures", Fatigue at Elevated Temperatures, ASTM STP-520, in press.

13. L. A. James, "The Effect of Frequency upon the Fatigue-Crack Growth of Type 304 Stainless Steel at $1000^{\circ} \mathrm{F}$ ", Stress Analysis and Growth of Cracks, Part I, pp. 218-229, ASTM STP-513, 1972.

14. L. A. James, "Hold-Time Effects on the Elevated Temperature FatigueCrack Propagation of Type 304 Stainless Stee1", Nuclear Technology, Vol. 16, No. 3, pp. , 1972.

15. P. Shahinian, H. E. Watson, and H. H. Smith, "Effect of Hold-Time on Fatigue Crack Propagation in 20\% Cold Worked Stainless Stee1", 0u0 HEDL-TME-73-47, Hanford Engineering Development Laboratory, June 1973.

16. L. A. James, "The Effect of Stress Ratio on the Elevated Temperature Fatigue-Crack Propagation of Type 304 Stainless Stee1", Nuclear Technology, Vol. 14, No 2, pp. 163-170, 1972. 


\section{$5 \cdot 1 \cdot 2 \cdot 2 \cdot 3 \cdot 3-6$}

17. L. A. James, "Effect of Therma1 Aging Upon the Fatigue-Crack Propagation of Aus tenitic Stainless Steels", Metallurgical Transactions, Vol. 5, pp. 831-838, Apri1 1974.

18. P. Shahinian, H. E. Watson and H. H. Smith, "Fatigue Crack Growth in Selected Alloys for Reactor Applications", Testing for Prediction of Material Performance, ASTM STP 515,

19. L. A. James, R. L. Knecht, "Subcritical Crack Growth", (Effect of Sodium), OUO, HEDL-TME 73-4, Vol 1, UC-79 a-b-c, pp A-46 to A-4, Hanford Engineering Development Laboratory, June, 1973.

20. L. A. James, "fatigue Crack Growth in Type 304 Stainless Steel Weldments at Elemented Temperature", presented at ASTM Symposium on Fatigue at Elevated Temporatures, June 18-22, 1972, Storrs, Connecticutt.

21. L. A. James, "Crack Propagation Behavior in Type 304 Stainless Steel We1dments at Elevated Temperature, Welding Journal Research Supplement, 1973.

22. L. A. James and R. C. Knecht, "Fatigue Crack Propagation Behavior of Type 304 Stainless Stee1 in a Liquid Sodium Environment", (OUO), HEDL-SA-711, also submitted for publication.

23. R. C. Andrews, et. al, "Effect of High Temperature Sodium on the Mechanical Properties of Candidate Alloys for the LMFBR Program", Quarterly Reports for Years 1959 to 1968. 


\subsubsection{Environment}

The fatigue properties of a metal can be greatly influenced by the nature of the environment. This is particularly so in long duration tests at low alternating stresses and low loading frequencies. The general effect of fatigue loading in an environment is to decrease the life of a structure, relative to a vacuum-environment.

According to Tetelman and McEvily ${ }^{1}$, the main effect of a normal atmosphere on fatigue 1 ife is to affect crack propagation much more than crack initiation. In more corrosive environments, both crack initiation and crack propaqation can be adversely affected.

\subsection{Temperature}

Assuming that no permanent metallurgical changes, such as precipitation, phase changes, etc., occur as a result of exposure to temperature and stress, one effect of elevated temperature is that the fatigue strength has a continuous downward trend beyond $10^{8}$ cycles. There is also a marked effect of cycling test frequency, at al ternating stresses above the fatigue limit, failure at a given stress range occurs in a smaller number of cycles at lower cyclic speeds than at higher cyclic speeds. However, the fatigue strength depends on the time to failure, calculated as $N_{f} / d$, where $N_{f}$ is the value of cycles to failure, and $f$ is the cycling frequency. This holds true for al ternating stresses with zero mean stress (continuous-cycle loading; see Figure 5.1.2.3.1-1 and -2) so that no appreciable creep deformation can occur. When hold periods are introduced in the tests, using $t-n$ diagrams (time to failure versus cycles to failure); see Figure 5.1.2.3.1-3 and $-4^{2}$ a relationship for fatique cycles $\mathrm{n}$ can be used 


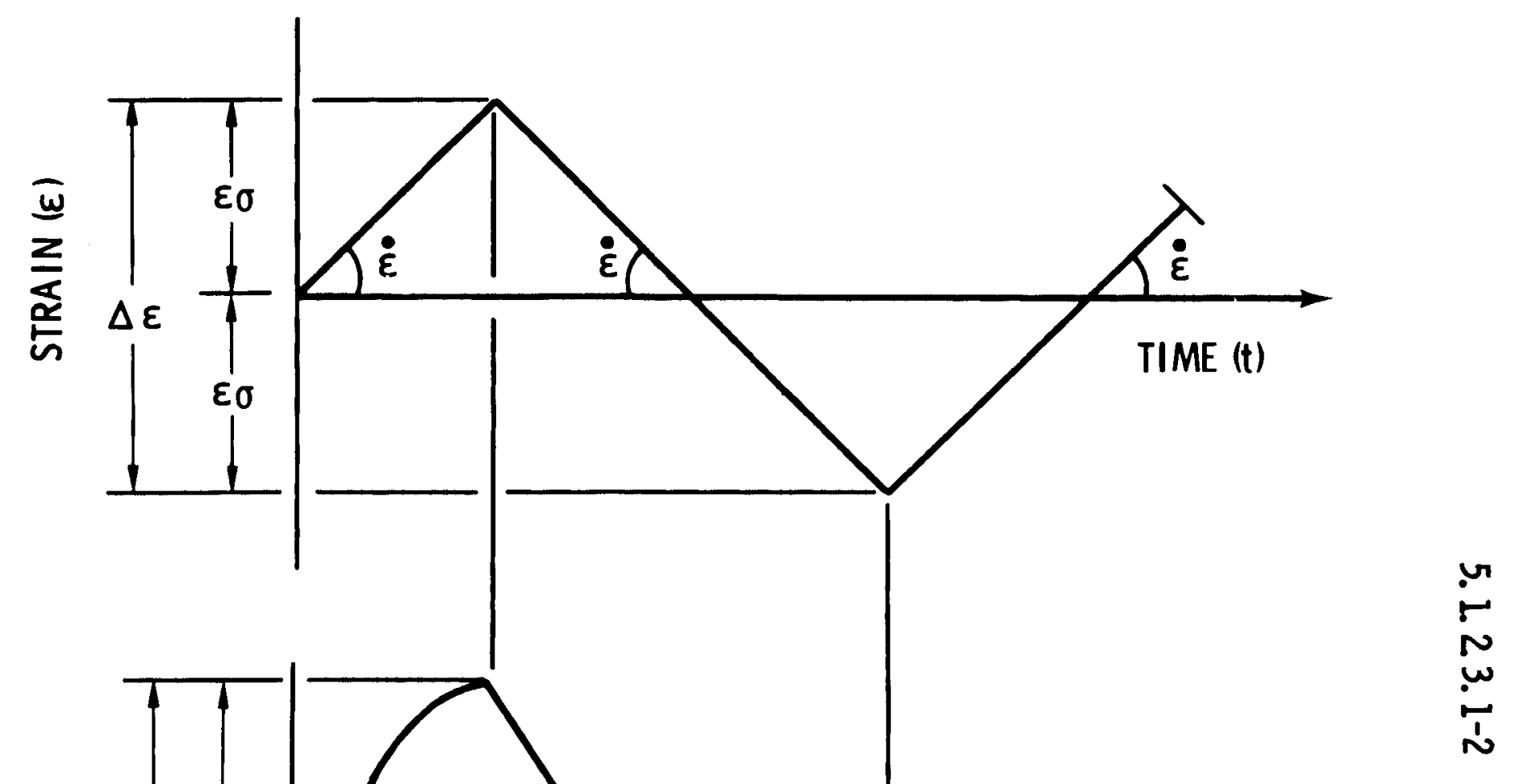

$$
\begin{aligned}
\varepsilon \sigma & =\text { STRAIN AMPLITUDE } & & \Delta \sigma=\text { STRESS RANGE } \\
\Delta \varepsilon & =\text { STRAIN RANGE } & & \sigma_{h}=\text { MAXIMUM TENSIL } \\
\dot{\varepsilon} & =\text { STRAIN RATE } & &
\end{aligned}
$$

FIGURE 5. 1.23.1-1. CONTINUOUS-CYCLE LOADING. 


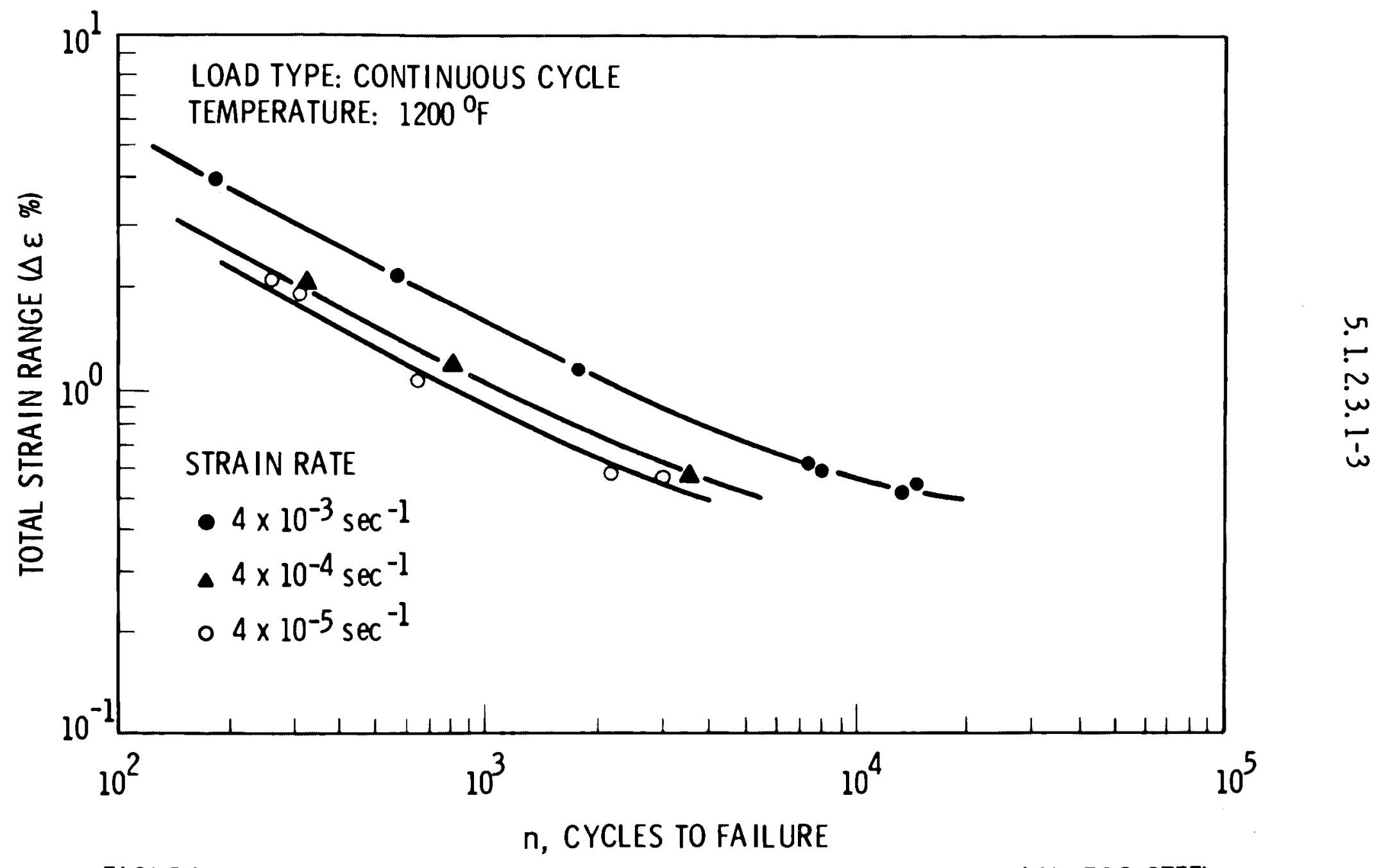

FIGURE 5. 1. 2.3.1-2. CONTINUOUS-CYCLE FATIGUE DATA FOR 304 STAINLESS STEEL AT $1200^{\circ} \mathrm{F}$. 
5.1.23.1-4

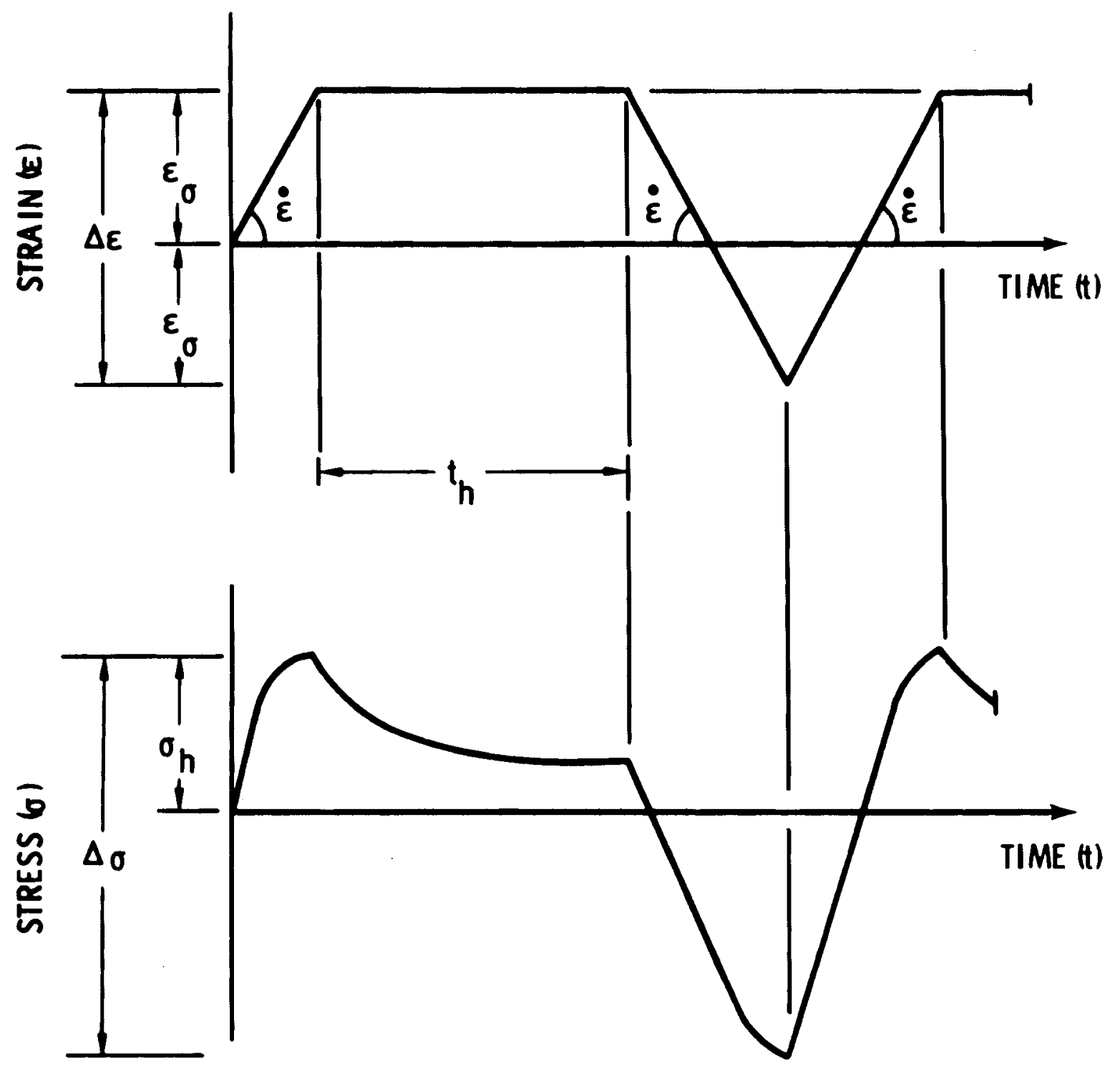

$\triangle E$ - TOTAL STRA IN RANGE

$\pm \varepsilon_{\sigma}=$ CONTROLLED STRAIN AMPLITUDE $=\frac{\Delta \varepsilon}{2}$

$\stackrel{\bullet}{E}$ STRAIN RATE

$\sigma_{h}=$ MAXIMUM TENSILE STRESS

$t_{h}=$ HOLD-PERIOD

$\Delta_{\sigma}=$ STRESS RANGE

FIGURE 5. 2.2.3.1-3. CYCLIC-REAXATION LOADING. 


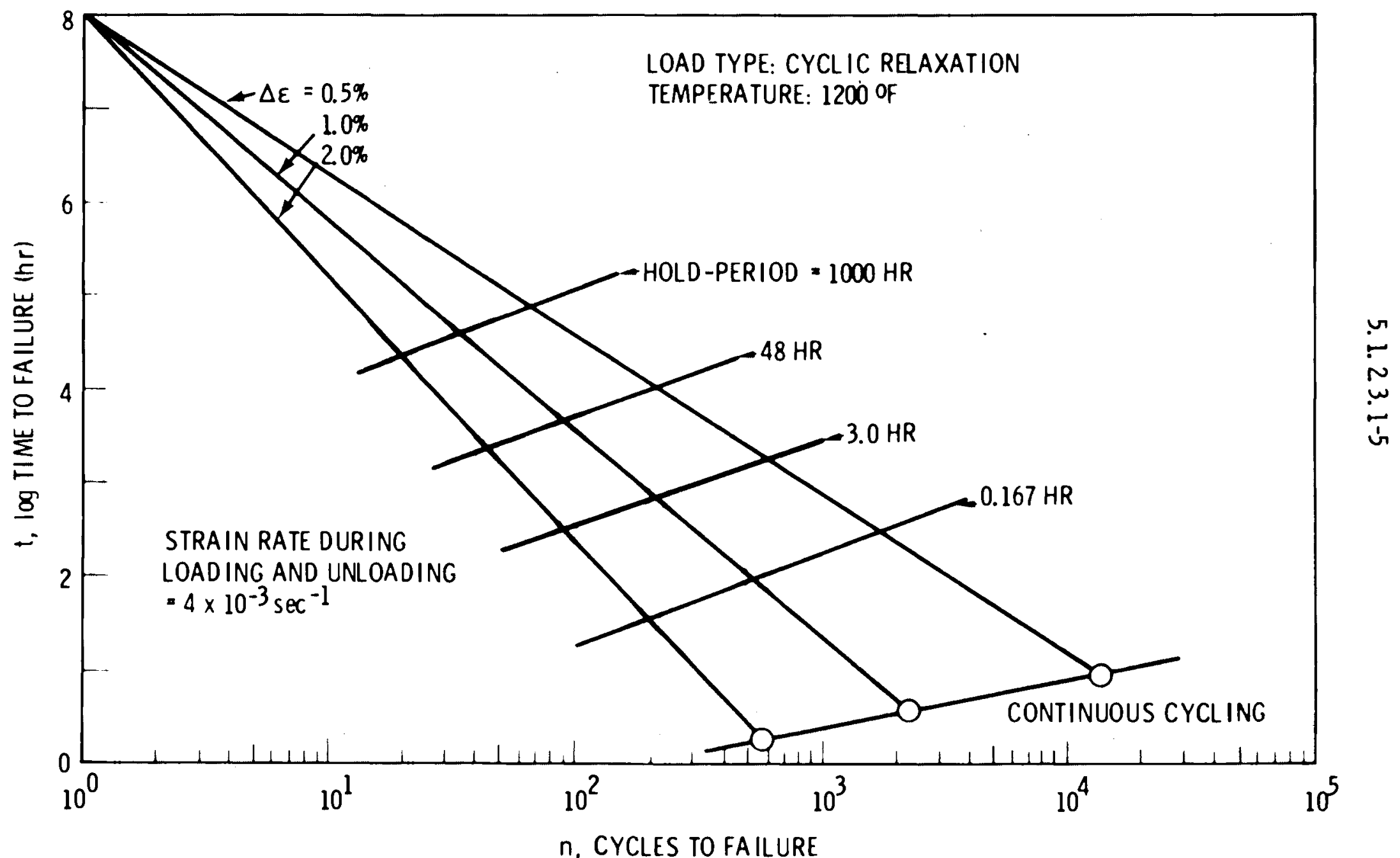

FIGURE 5. 1.2.3.1-4. CONSTANT HOLD -PERIOD CURVES FOR 304 STAINLESS STEE. 
5.1.23.1-6

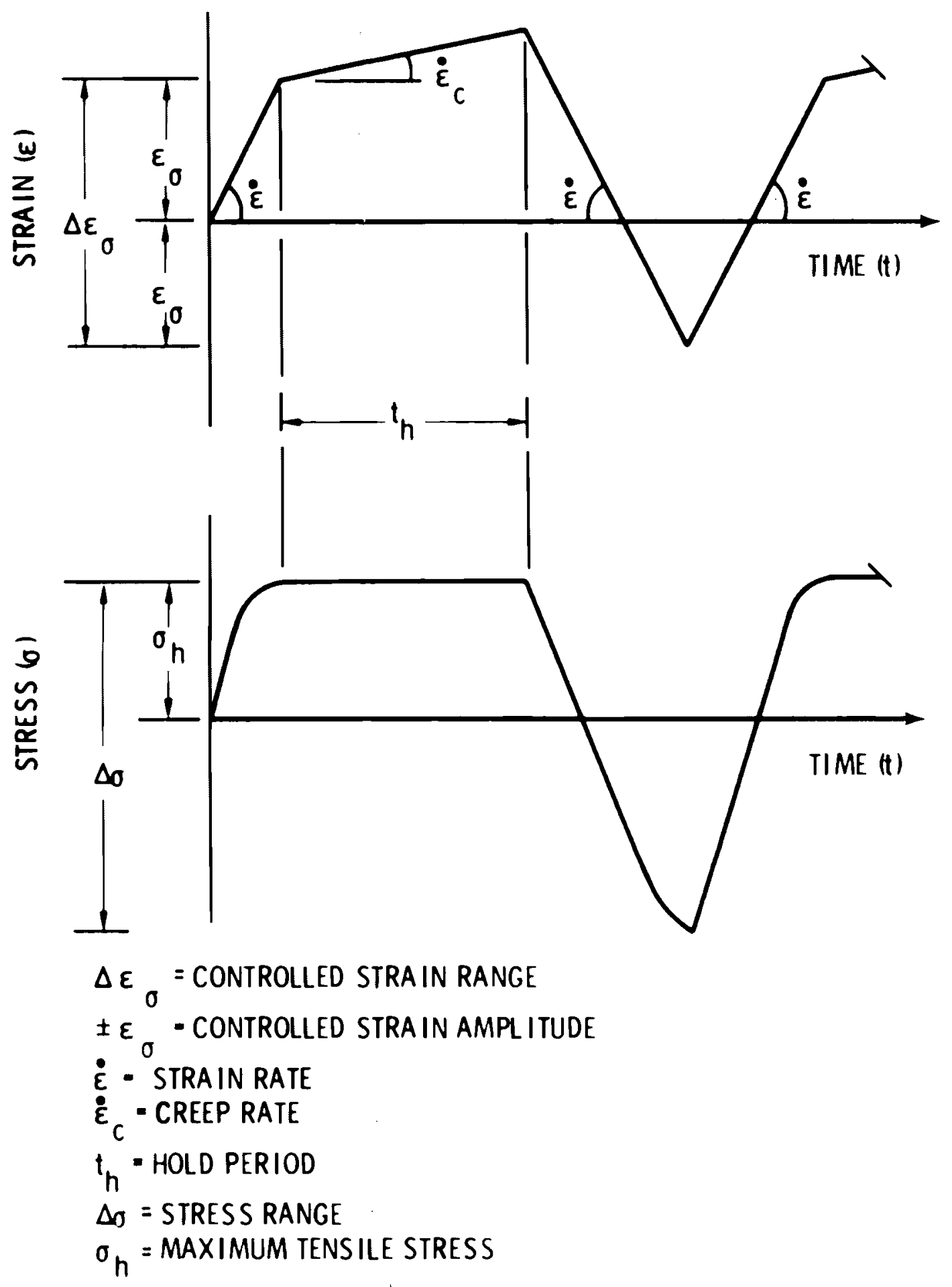

FIGURE 5. 1. 2.3.1-5. CYCLIC CREEP LOADING. 


\subsubsection{1-7}

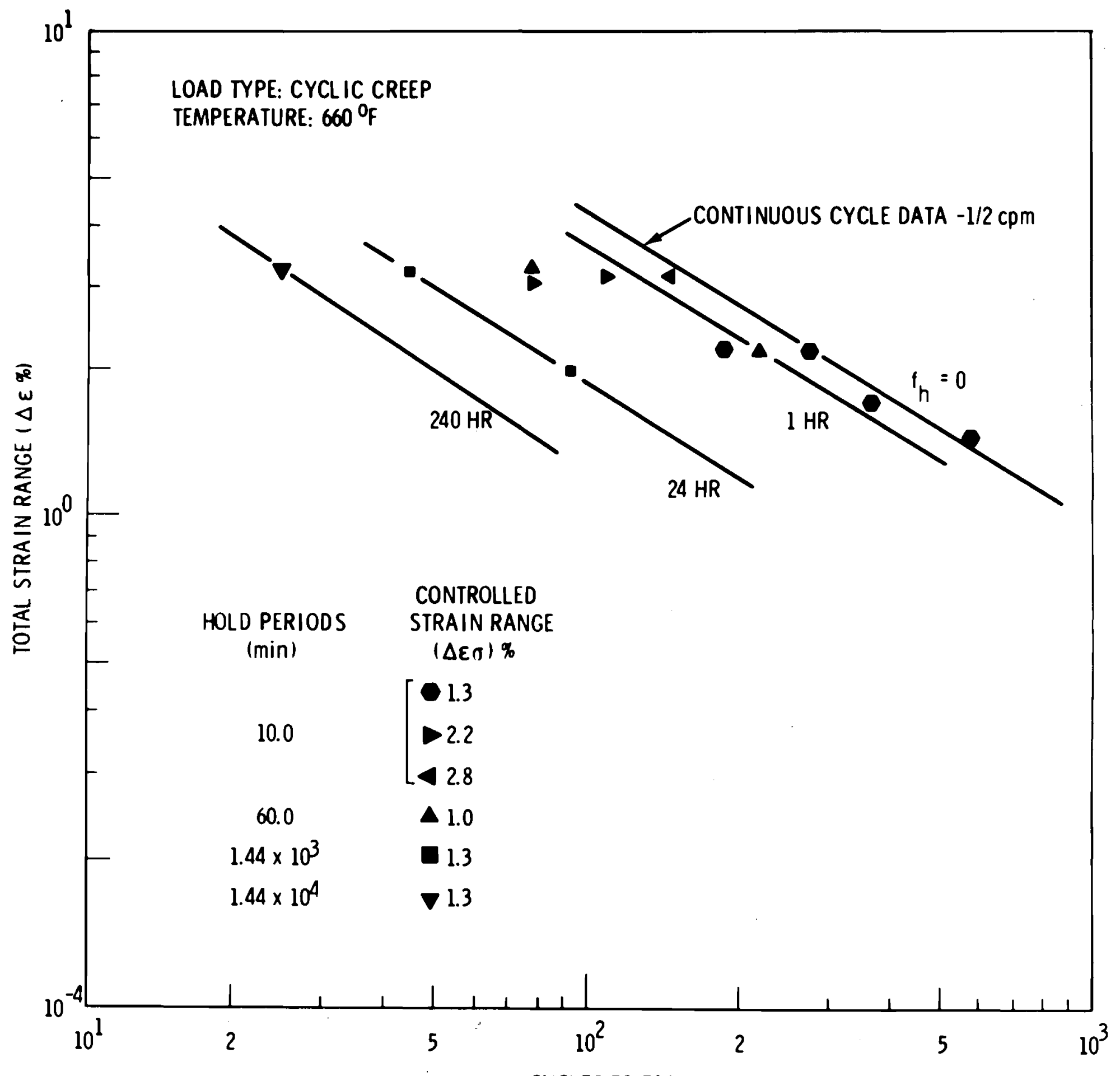

n, CYCLES TO FAILURE

FIGURE 5. 1.2.3.1-6. CYCLIC-CREEP DATA FOR LOW-CARBON, HIGH-MANGANESE STEE. 


$$
\begin{gathered}
5.1 .2 \cdot 3 \cdot 1-8 \\
\mathbf{n}=\left[\frac{k}{2 \Delta \varepsilon / \varepsilon+t_{h}}\right]^{1 / 1+m}
\end{gathered}
$$

where $\Delta \varepsilon$ is the strain range, $\varepsilon$ is the strain rate, $t_{h}$ is the hold period, and $\mathrm{k}$ a $\mathrm{m}$ are curve fitting constants. This relationship is to be used for cyclic-relaxation type loading (Figure 5.1.2.3.1-3), where the tensile strain is held constant.

For cyclic creep loading (Figure 5.1.2.3.1-5 and -6 ), where tensile stress is held constant, creep-fatigue interaction is more pronounced. The following creep-fatigue interaction relationship can be used:

$$
\alpha\left(\frac{n}{n_{f}}\right) u+\beta\left(\frac{t_{c}}{t_{r}}\right)^{v}=1.0
$$

where $\alpha, \beta, u$ and $v$ are interaction constants, $n$ is the number of cycles at the strain range $\Delta \varepsilon, n_{f}$ is the number of cycles to failure for the strain range $\Delta \varepsilon, t_{c}$ is the time spent at the stress $\sigma$, and $t_{r}$ is the time corresponding to creep rupture at the stress $\sigma$. 
$5.1 .2 \cdot 3 \cdot 1-9$

\section{REFERENCES}

1. A. S. Tetleman \& A. J. McEvily, "Fracture of Structural Materials", John Wiley \& Sons, P. 385, 1967.

2. E. P. Esztergar, "Creep-Fatigue Interaction and Cumulative Damage Evaluations for Type 304 Stainless Steel", ORNL-4757, June, 1972. 


\section{$5.1 .2 \cdot 3 \cdot 2-1$}

\subsection{Aggressive Liquids and Gases}

Fatigue life is reduced under the influence of corrosion caused by certain liquids and gases. Impure sodium results in a severe reduction in low-cycle fatigue 1 ife of stainless steels (see Figure 5.1.2.3.2-1). ${ }^{1}$ Since the majority of the life of a high strain, low cycle fatigue specimen is spent in crack propagation (2) the impure sodium is increasing crack propagation rate.

However, environments such as air (see Figure 5.1.2.3.2-2 ${ }^{3}$ ) and water can have an effect on the fatigue life of metals. Variables such as moisture content of air, temperature, frequency and mean stress influence the fatigue life of metals to such a degree that it is very difficult to make specific statements as to the effect of any single variable. Testing at an environment and load history simulating the expected conditions is the best way to estimate the fatigue life of a given material. 


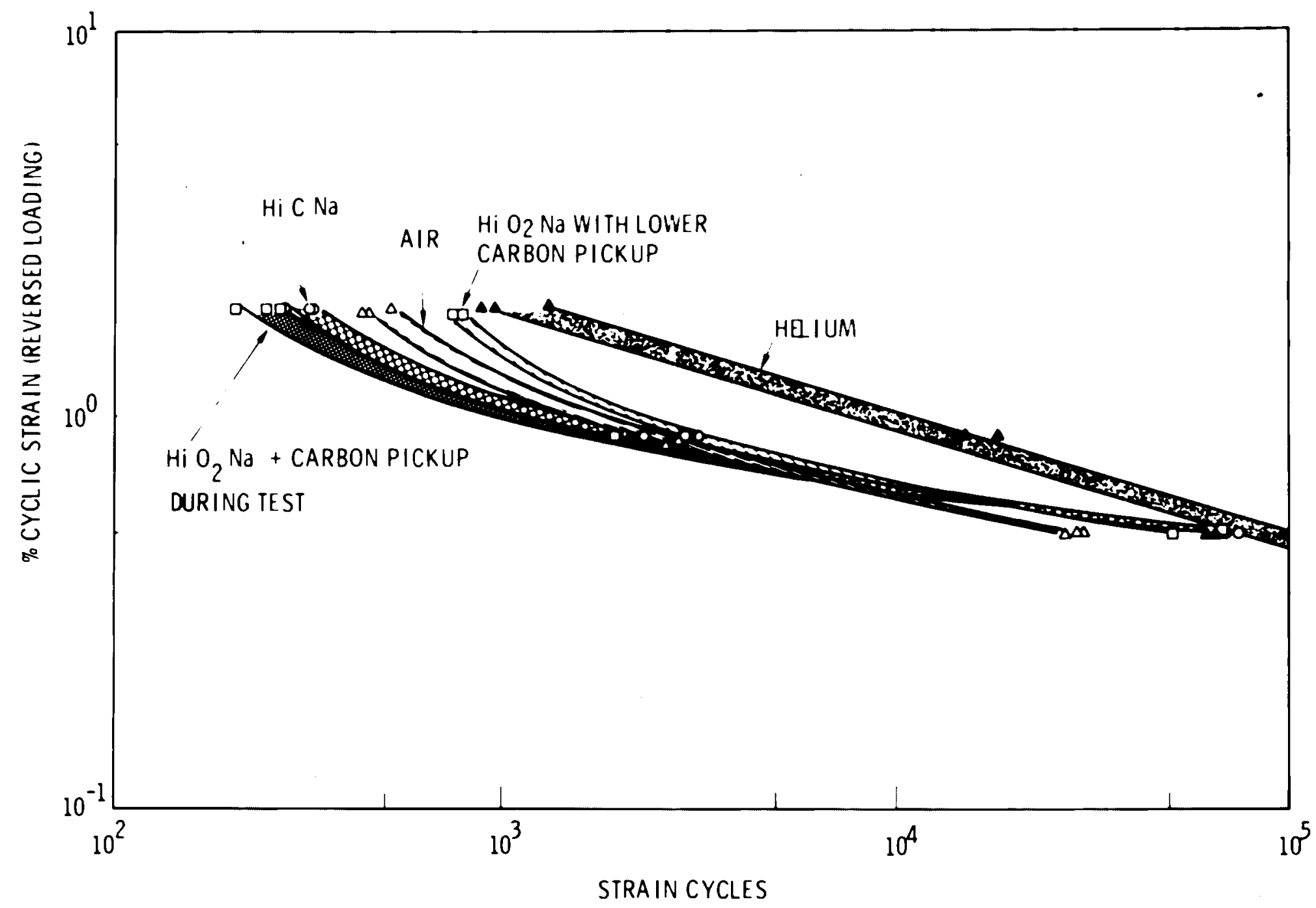

FIGURE 5. 1. 2.3.2-1. PERCENT CYCLIC STRAIN VERSUS STRAIN CYCLES AISI 304 SS at $1200^{\circ} \mathrm{F}^{\circ}$ 


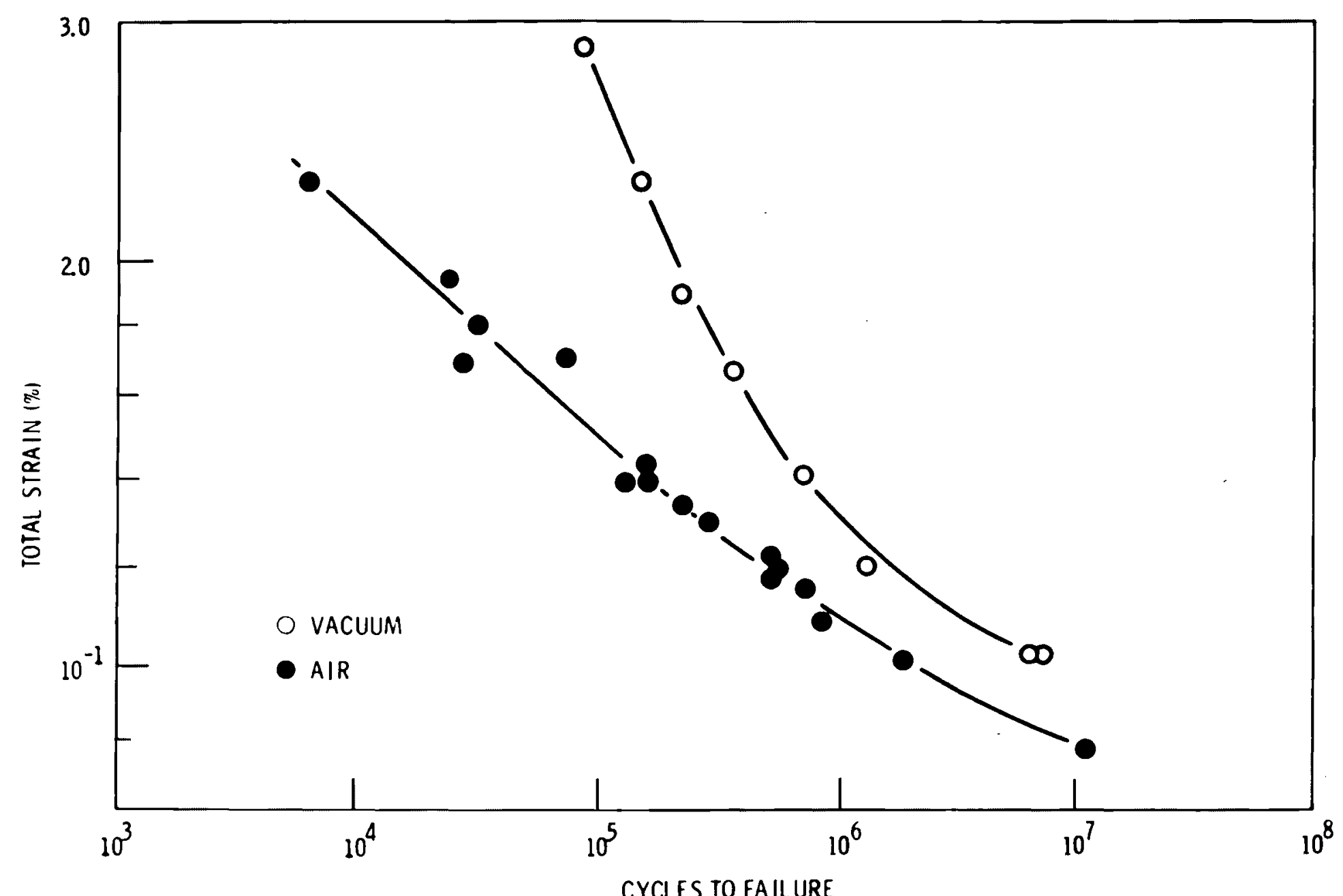

ñ

FIGURE 5. 1.2.3.2-2 FATIGUE OF TYPE 316 STAINLESS STEEL AT $1500^{\circ} \mathrm{F}\left(815^{\circ} \mathrm{C}\right)$ IN AIR AND IN VACUUM TESTED IN REVERSED BENDING 15 CPS). 


\section{$5.1 .2 \cdot 3 \cdot 2-4$}

\section{REFERENCES}

1. Estimate of the Fatigue Cracking Behavior of the Fast Test Reactor Primary Piping, BNWL-1035, Apri 1, 1969.

2. R. C. Buettner, C. Laird and A. J. McEvily, Jr., "Crack Nucleation and Growth in High Strain-Low Cycle Fatigue", Trans ASMT, Vo1. 223, 1965.

3. M. R. Archter, "Effects of Environment on Fatigue Cracks, ASTM STP 414, June, 1967. 


\subsection{Static Fatigue or Sustained Load Crack Growth}

Linear elastic fracture mechanics methods have been used to characterize the propagation of cracks at elevated temperature ${ }^{1}$, . Many structures, however, are subjected to long periods of static loading rather than cyclic loading at elevated temperature. Crack growth under sustained loading has been demonstrated ${ }^{3}$ and compared with fatigue crack growth data, as shown in Figure 5.1.2.3.3-1. The fatigue crack growth rate $d a / d N$ was converted to a time-base using

$$
\frac{d a}{d N}=\left(\frac{d a}{d t}\right) \cdot(\text { Cyclic frequency }),
$$

and the stress intensity factor range $\Delta K$ converted to $K_{\max }$ using

$$
K_{\max }=\frac{\Delta K}{T-R} \text {, where } R=\frac{K_{\min }}{K_{\max }} .
$$

The sustained load crack growth data suggest a possible lower bound for very low cyclic rate testing. 
$5.1 .2 \cdot 3 \cdot 3-2$

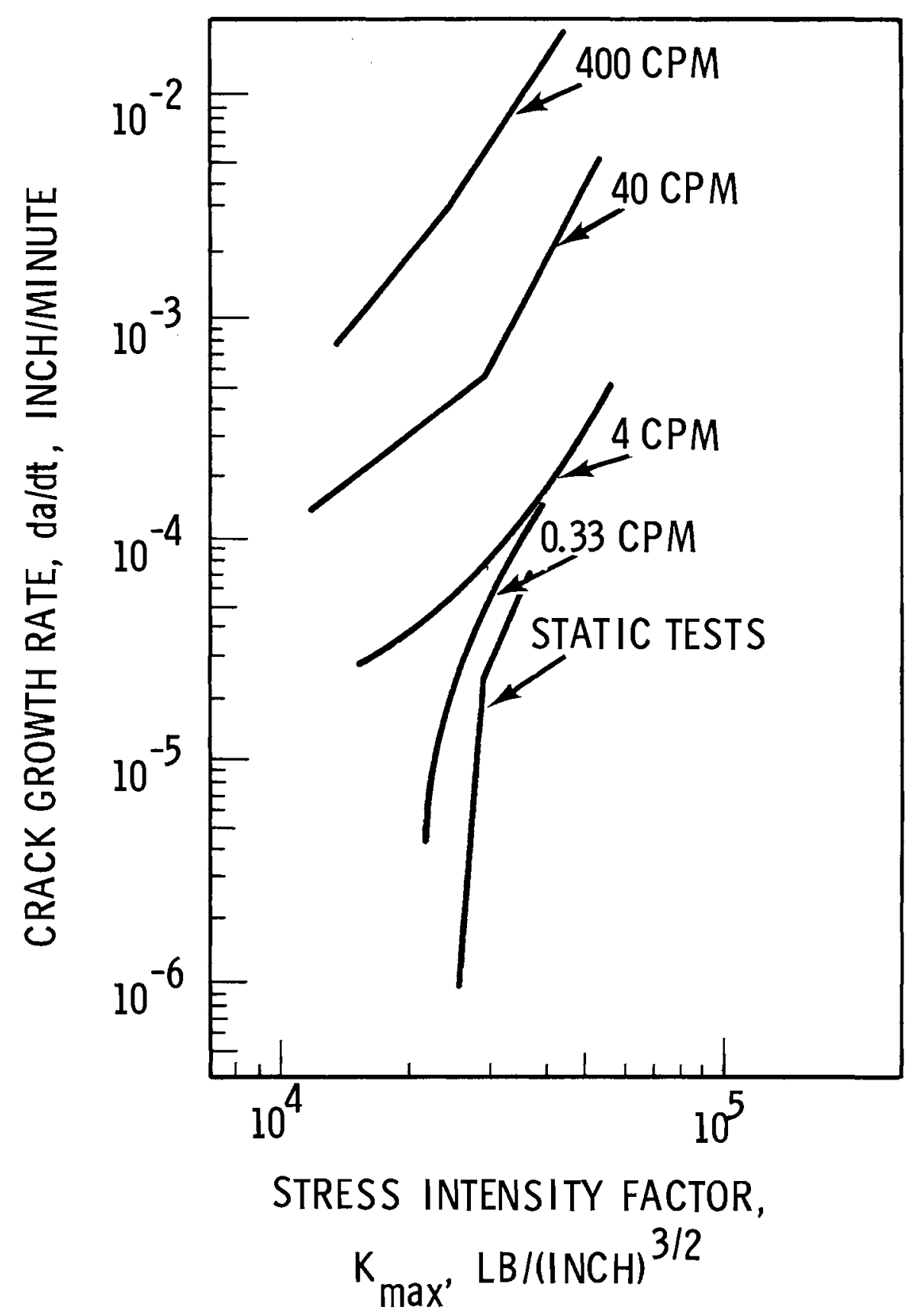

FIG. 5.1.2.3.3-1 CRACK PROPAGATION BEHAVIOR OF 20\% COLD-WORKED TYPE 316 STAINLESS STEEL AT $1000^{\circ} \mathrm{F}$ UNDER CYCLIC $(0.33,4$, 40 AND 400 CPM) AND STATIC LOADINGS 
5.1.2.3.3-3

\section{REFERENCES}

1. James, L. A. and E. B. Schwenk, Jr., "Fatique-Crack Propaqation Behavior of Type 304 Stainless Steel at Elevated Temperature", Metal1urgical Transactions, vo1. 2, pp. 491-496, Feb. 1971.

2. Shahinian, P., H. H. Smith and H. E. Watson, "Fatigue Crack Growth in Type 316 Stainless Steel at High Temperature", Journal of Engineering for Industry, pp. 976-980, Nov. 1971.

3. James, L. A., "Some Preliminary Observations on the Extension of Cracks under Statis Loadings at Elevated Temperatures", Int. Journal of Fracture Mechanics, 8, pp. 347-349, 1972. 


\section{$5.2-1$}

5.2 CHARACTERIZATION OF FATIGUE DATA

Fatigue data are usually plotted as S-N curves (stress or strain versus cycles) on semi-log or log-log graphs. Many attempts have been made to derive an equation of the $\mathrm{S}-\mathrm{N}$ curve. The equations can be divided in two groups: stress versus cycles to failure (or first detected crack), used for high-cycle fatigue only, and strain versus cycles to failure used for low-cycle fatigue, but easily extended to high cycle fatigue, except for correlation to the fatigue endurance limit. 


\section{$5.2 .1-1$}

\subsubsection{High-Cycle Fatigue}

An equation, used in the aircraft industry and particularly suited for aluminum alloys, for curves of maximum alternating stress versus cycles at a constant "R" ratio $\left(R=\sigma_{\min } / \sigma_{\max }\right)$ is:

$$
N=N_{0}\left[\operatorname{TAN}\left(\frac{S_{u}-S}{S_{u}-S_{E}}\right) \frac{\pi}{2}\right]^{h} \text { - see Figure 4.2.1-1 }
$$

where $N$ = number of cycles to failure

$$
\begin{aligned}
& N_{0}=\text { constant equal to } \frac{S_{u}+S_{E}}{2} \\
& S=\text { stress, psi } \\
& S_{u}=u l \text { timate tensile strength of the material, psi } \\
& S_{E}=\text { endurance limit stress, psi } \\
& h=\text { constant }
\end{aligned}
$$

The constant $h$ can be evaluated from the following equation:

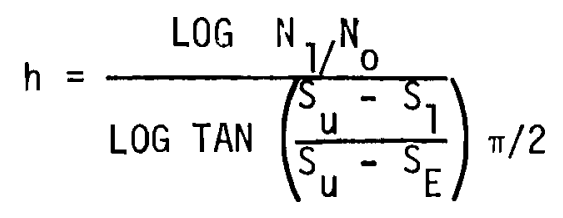

where $\mathrm{N}_{1}$ and $\mathrm{S}_{1}$ are coordinates of any points on the curve other than $\mathrm{N}_{0}$. Once the constants have been established, another useful form of the equation is:

$$
S=S_{U}-\left[\left(\frac{S_{U}-S_{E}}{\pi / 2}\right) \operatorname{TAN}^{-1}\left(\frac{N}{N_{0}}\right)^{1 / h}\right] .
$$




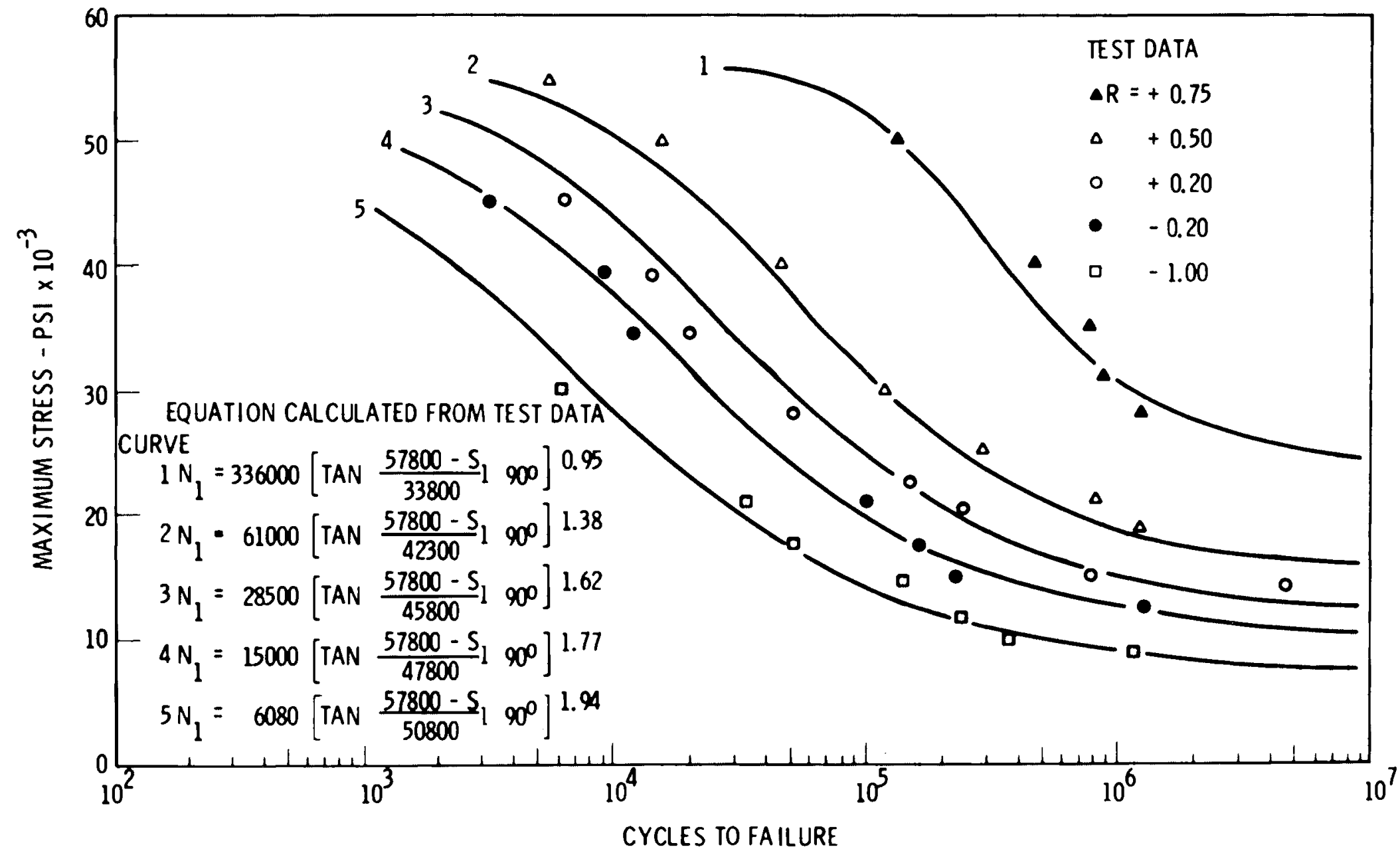

$\stackrel{\sim}{\sim}$

FIGURE 5. 2.1-1. SN DIAGRAMS FOR 24STAL 0.064 SHEET WITH NO. 33 DRILL DIAMETER HOLE CENTRALLY LOCATED. 
5.2.2 Low-Cycle Fatigue

1. Method of universal slopes (Manson) ${ }^{(1)}$ (see Figure 5.2.2-1)

$$
\Delta \varepsilon=3.5 \frac{\sigma_{u}}{E} N_{f}^{-0.12}+D^{0.6} N_{f}^{-0.6}
$$

where: $\Delta \varepsilon=$ total strain range

$$
\begin{aligned}
\sigma_{u} & =\text { ultimate tensile strength, psi } \\
D & =\text { ductility, expressed as } \log _{e} \frac{100}{100-R A} \\
R A & =\text { reduction in area, percent } \\
N_{f} & =\text { number of cycles to failure }
\end{aligned}
$$

2. Method of characteristic slopes (Berling-Conway) (2)

$$
\Delta \varepsilon_{t}=2 \varepsilon_{\text {ef }}\left(\frac{N_{f}}{10}\right)^{-\frac{m}{2}}+\frac{D^{2}}{\dot{\varepsilon}}\left(\frac{N_{f}}{f}\right)^{-1}
$$

where: $\Delta \varepsilon_{t}=$ total strain range

$$
\begin{aligned}
\varepsilon_{e f}= & \text { elastic strain at fracture }=\text { true fracture } \\
& \text { stress divided by Young's modulus } \\
N_{f}= & \text { cycles to failure } \\
D= & \text { fracture ductility }=\log _{e}[100 / 100-R A] \\
R A= & \text { reduction in area (percent) } \\
\varepsilon= & \text { strain rate }=2 \mathrm{f} \Delta \varepsilon_{t} \\
f= & \text { cyclic frequency } \\
m= & \text { constant }
\end{aligned}
$$

3. Exponential equations

$$
\text { a. } \begin{aligned}
\Delta \varepsilon_{p}=\frac{\varepsilon_{f}}{\dot{\varepsilon}}\left(\frac{N_{f}}{f}\right)^{-1} \quad \text { (Coffin-Manson) } \\
\text { where } \Delta \varepsilon_{p}=\text { plastic strain range } \\
\varepsilon_{f}=\text { tensile ductility }=\log _{e}[100 /(100-R A)] \\
R A=\text { reduction in area (percent) } \\
\dot{\varepsilon}_{t}=\text { strain rate } \\
N_{f}=\text { cycles to failure } \\
f=\text { frequency of failure }
\end{aligned}
$$




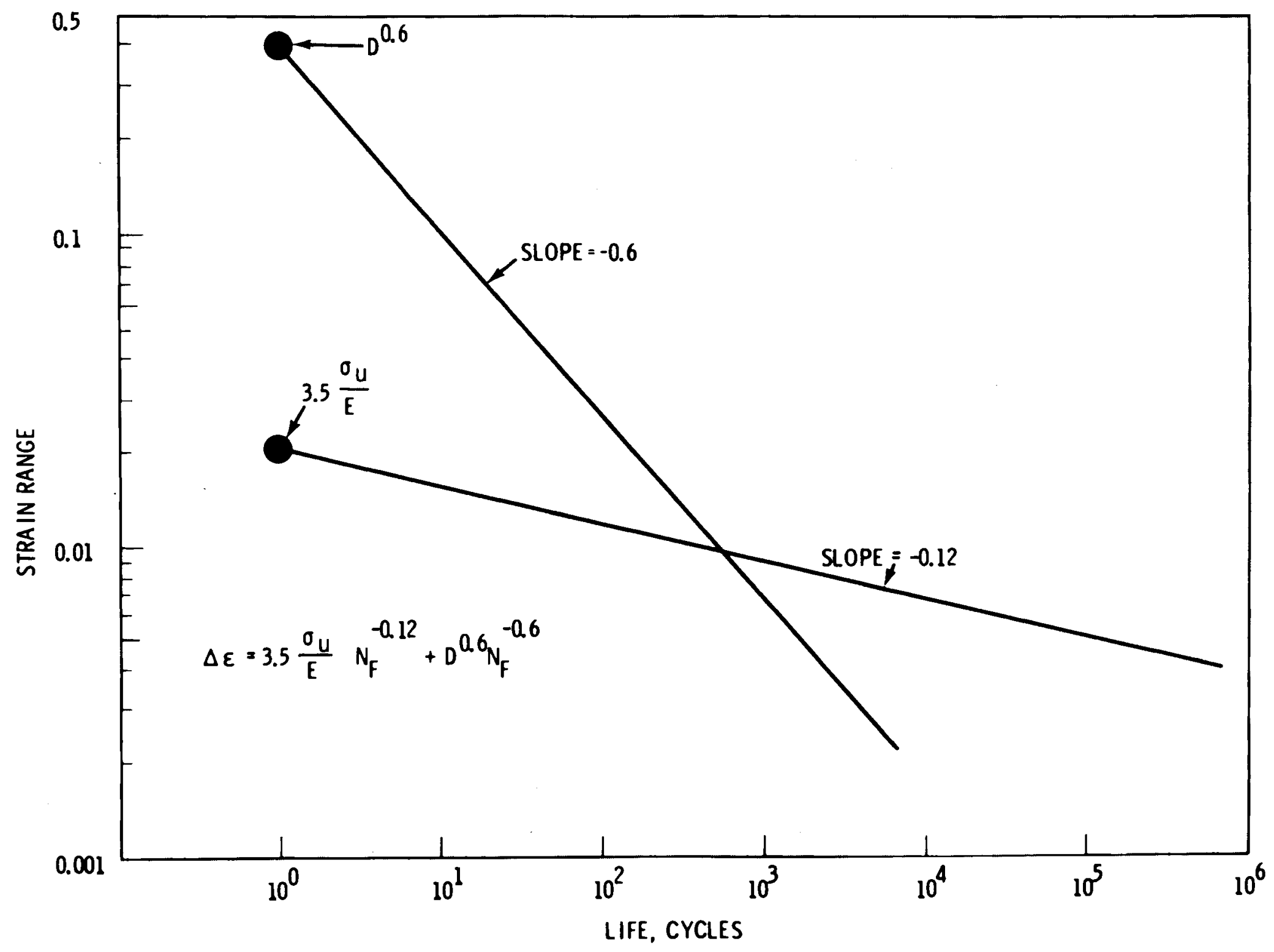

$\stackrel{n}{\sim}$

FIGURE 5.2.2-L. MODE FOR METHOD OF UNIVERSAL SLOPES. 


\section{$5.2 .2-3$}

b. $S_{\text {eq }}=\frac{A E}{\|_{f}^{c}}+S_{e}$ (Langer)

where $S_{e q}=$ equivalent fully reversed stress amplitude, $p s$ :

$E=$ Young's modulus, psi

$\mathrm{N}_{\mathrm{f}}=$ cycles to failure

$S_{e}=$ endurance limit, psi

$A$ and $c=$ constants

For $\mathrm{S}_{\text {eq }}$ use $\mathrm{S}_{\mathrm{a}}=$ alternating stress and $\mathrm{S}_{\mathrm{m}}=$ mean stress, where stress is actual stress when below proporational limit or the product of strain, $\varepsilon$, with Young's modulus, E. Then using Peterson's ${ }^{3}$. cubic equation

$$
S_{e q}=\frac{7 S_{a}}{8-\left[1+\frac{S_{\text {mean }}}{S_{u}}\right]^{3}}
$$

where $S_{u}=$ ultimate tensile strength, psi.

4. Inverse hyperbolic tangent equation

$\log N_{f}=A_{0}+A_{1} \tanh ^{-1}\left[\frac{\log \left(\varepsilon_{u} \varepsilon_{a} / \varepsilon_{e q}{ }^{2}\right)}{\log \left(\varepsilon_{u} / \varepsilon_{e}\right)}\right]$ (Rice-Jaske)

where $N_{f}=$ number of cycles to failure

$\varepsilon_{\text {eq }}=$ equivalent local strain $=\left(2 \varepsilon_{a}\right)^{m}\left(\sigma_{\max } / E\right)^{1-m}$

$\varepsilon_{\mathrm{a}}=$ local strain amplitude

$\sigma_{\max }=$ maximum local stress (ksi)

$m=$ Walker ${ }^{(4)}$ exponent

$\varepsilon_{u}=$ upper limit $=\varepsilon_{\mathrm{eq}} \mid \mathrm{N}_{\mathrm{f}}=10+0.0025$

$\varepsilon_{e}=$ lower limit $=\varepsilon_{e q} \mid N_{f}=108-0.0005$

$A_{0}$ and $A_{1}=$ constants 


\subsection{3-1}

\subsubsection{Fatigue Crack Growth}

Fatigue crack growth data are commonly reported as a $\log -\log$ plot of crack growth rates versus stress intensity range. Several empirical equations have been used to represent the relationship.

1. Paris equation 5

$$
\mathrm{da} / \mathrm{dN}=C(\Delta K)^{n}
$$

Where: $\mathrm{da}=$ incremental crack extention (mi cro-inches)

$$
\begin{aligned}
d N= & \text { discrete number of load cycles (usually one) } \\
C= & \text { growth rate intercept corresponding to a unity } \\
& \text { value of } \Delta K \\
\Delta K= & K{ }_{\text {max }}-K_{\text {min }}=\text { stress intensity range }(k s i \sqrt{i n c h}) \\
n= & \text { reciprocal slope of the function on log-log plot. }
\end{aligned}
$$

2. Forman equation 6

$$
d a / d N=c \Delta K^{n} /\left[(1-R) K_{c}-\Delta K\right]
$$

Where: $K_{C}=$ maximum stress intensity factor ( $k s i \sqrt{i n c h}$ )

$$
\begin{aligned}
& R=\text { ratio of minimum to maximum stress intensity } \\
& \text { factor }=K_{\text {max }} / K_{\text {min }}
\end{aligned}
$$

Note: $C, n$ in Forman's equation are similar to the Paris equation coefficients in origin, however, they are not numerically equivalent. 


\section{$5.2 .3-2$}

3. Collipriest equation ${ }^{7}$

$$
\begin{aligned}
& d a / d i N=c\left(K_{c} \Delta K_{0}\right)^{n / 2} \operatorname{EXP}\left[\ln \left(K_{c} / \Delta K_{0}\right)^{n / 2} .\right. \\
& \text { - arctanh } \left.\left\{\frac{\ln \left[\Delta K^{2} /\left((1-R) K_{c} \Delta K_{0}\right\}\right.}{\ln \left[(1-R) K_{c} / \Delta K_{0}\right]}\right\}\right]
\end{aligned}
$$

Where: $\quad C=$ Paris equation coefficient

$$
\begin{aligned}
& n=\text { Paris equation exponent } \\
& K_{C}=\text { Stress intensity for fracture } \\
& \Delta K_{0}=\text { Threshold stress intensity range for growth } \\
& \Delta K=\text { Cyclic stress intensity range } \\
& R=\text { load ratio }
\end{aligned}
$$

Examples of al1 three equations are shown on Figures 5.2.3-1, -2 and -3 . 


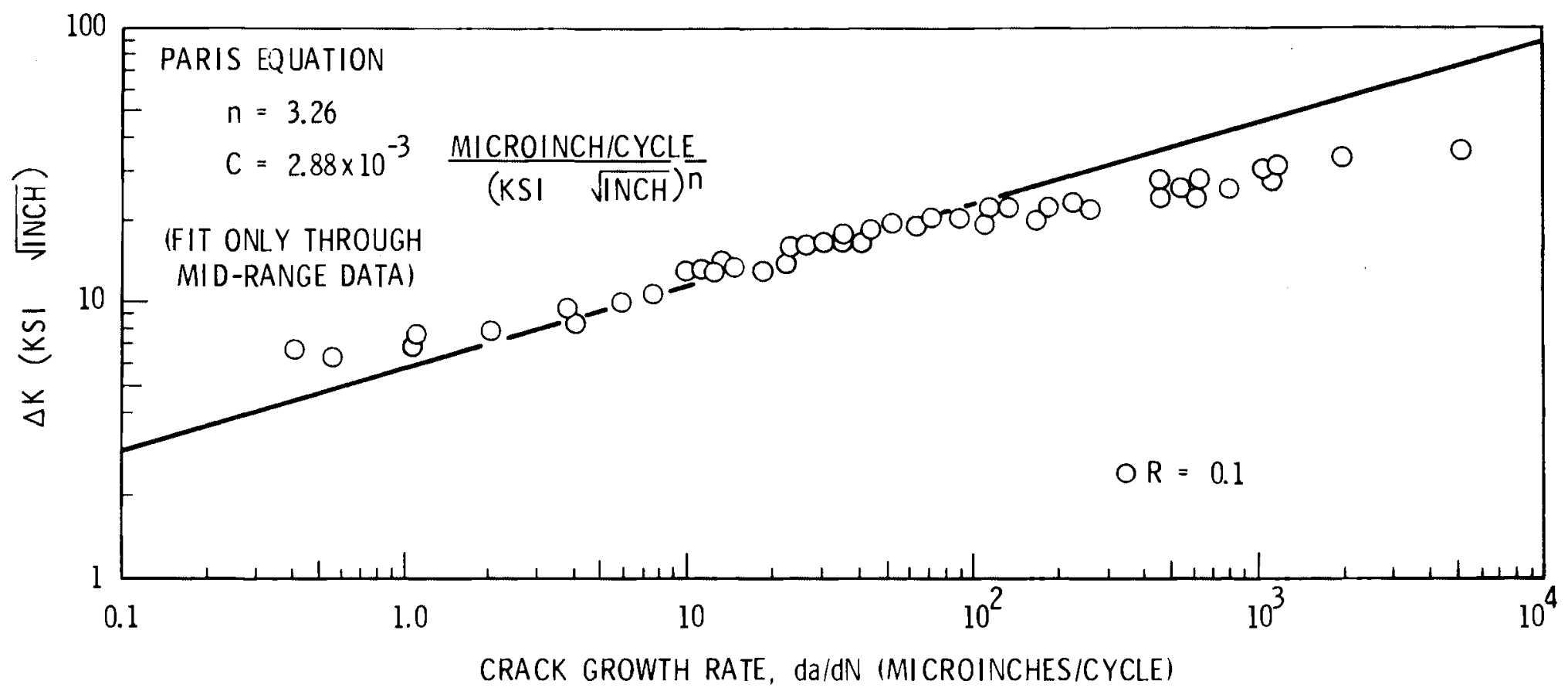

FIG. 5.2.3-1 ACCOMMODATION OF 2024-T851 ALUMINUM CRACK GROWTH RATE DATA BY GROWTH RATE EXPRESSIONS 


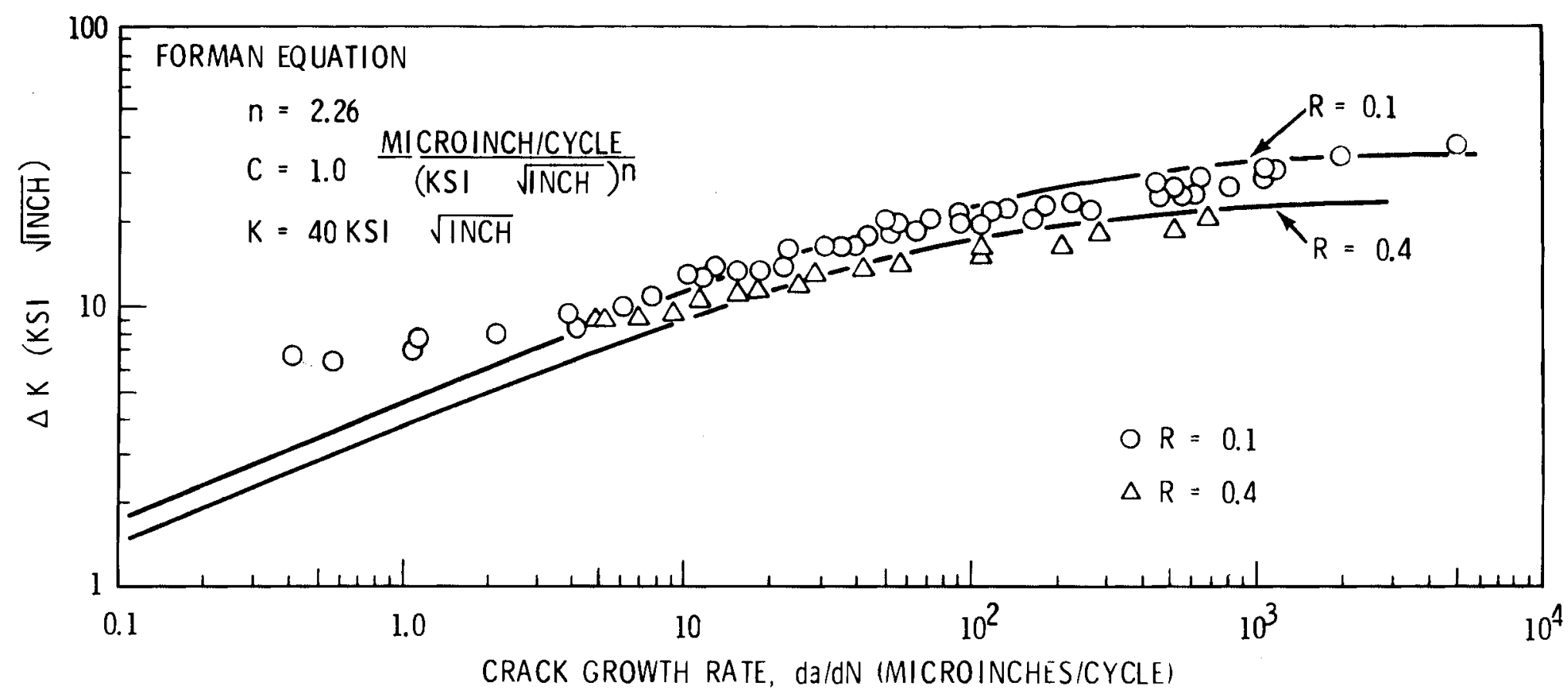

FIG. 5.2.3-2 ACCOMMODATION OF 2024-T85I ALUMINUM CRACK GROWTH RATE DATA BY GROWTH RATE EXPRESSIONS 


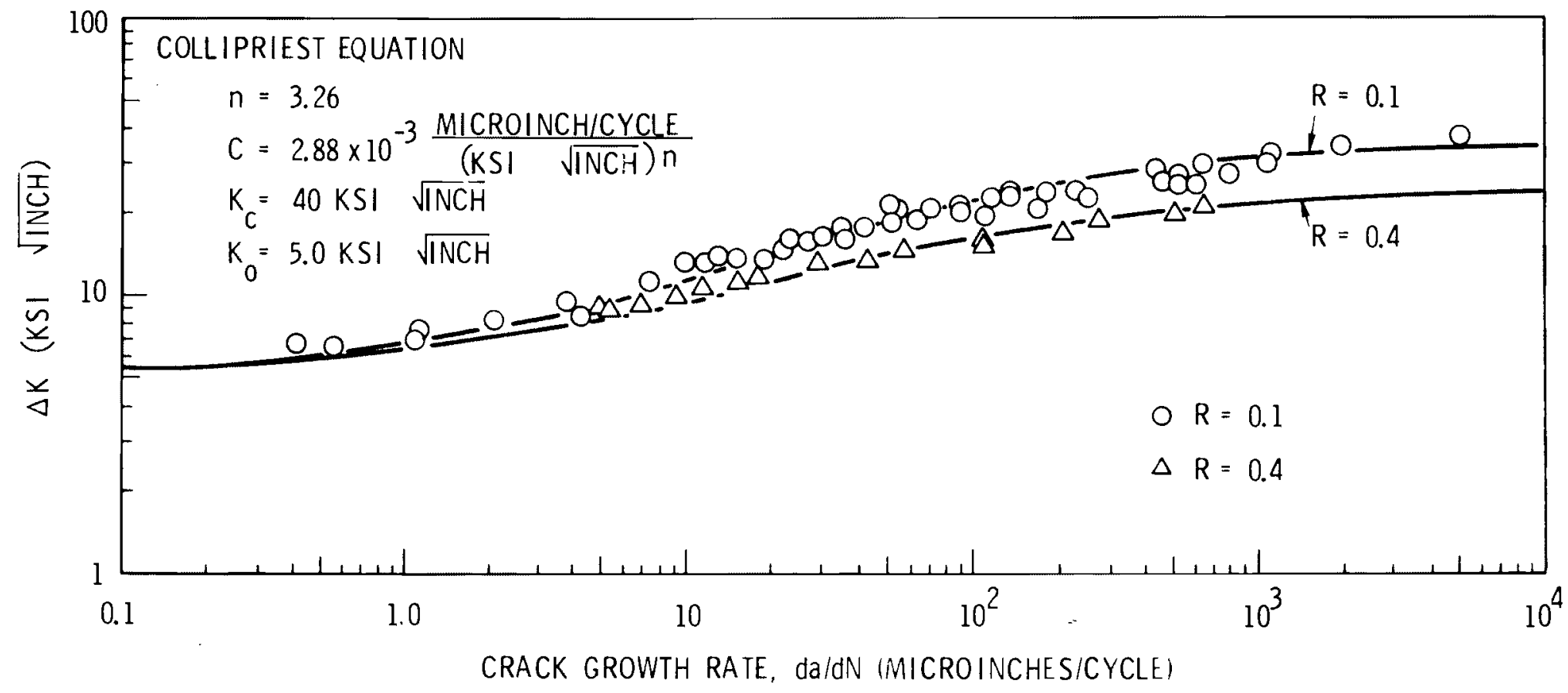

FIG. 5.2.3-3 ACCOMMODATION OF 2024-T85I ALUMINUM CRACK GROWTH RATE DATA BY GROWTH RATE EXPRESSIONS 


\subsection{3-6}

\section{REFERENCES}

1. S. S. Manson, "Fatigue: A Complex Subject - Some Simple Approximations," Experimental Mechanics, vol. 5, no. 7, p. 203, 1965.

2. J. B. Conway, "Evaluation of Plastic Fatigue Properties of HeatResistant Alloys," GEMP-740, Dec. 1969.

3. R. E. Peterson, "Brittle Fracture and Fatigue in Machinery," Fatigue and Fracture of Metals, John Wiley \& Sons, New York, N.Y., 1952.

4. K. Walker, "The Effect of Stress Ratio During Crack Propagation and Fatigue for 2024-T3 and 7075-T6 Aluminum," Spec. Tech. Pub1. 462, ASTM, 1970, pp. 1-14.

5. P. Paris and R. A. Erdogan, "A Critical Analysis of Crack Propaqation Laws" Journal of Basic Engineering, Transactions of ASME, Dec. 1963.

6. R. G. Forman, V. E. Kearney and R. M. Engle, "Numerical Analysis of Crack Propagation in Cyclic-Loaded Structures", Journal of Basic Engineering, Transactions of ASME, vo1. 89, Sept. 1967.

7. J. E. Collipriest Jr. and R. M. Ehret, "Computer Modeling of PartThrough-Crack Growth", Space Division, Rockwe11 International Corp., SD 72-CE-0015, 1972. 
- 5.3 Effect of Temperature and Fluence in

Fatigue in Austenitic Stainless Steel

Irradiation effects on the fatigue properties of austenitic stainless steels are described below. Comparisons are made, where possible, with unirradiated material tested under the same conditions. Data have been limited to temperature and environmental conditions that best simulate LMFBR core operating conditions with the result that most test temperature levels exceed $900^{\circ} \mathrm{F}$ except for some of the fatigue crack growth data.

The stainless steel data are also limited in scope when compared to the majors parameters which effect fatigue properties, viz loading, geometry, and environment as discussed in sections 5.1.2.1 through 5.1.2.3. As more irradiated data is obtained, comparison with these major parameters wil1 become possible and a more cogent framework for defining the effects of irradiation on structural life will become more feasible. The sparse data presented below, however, may not be a conservative representation for all possible loading and environmental conditions that would occur and thus should not be considered as design basis data. Most of the work to date on irradiation effects have been limited mainly to unnotched low cycle fatigue and fatigue crack growth in elastically loaded specimen although there are some exceptions. For brevity, data in this section are separated into the general categories unnotched irradiated fatigue and irradiated fatigue crack growth.

\subsubsection{Unnotched Irradiated Fatigue}

The limited data described below indicate that the major effect of fast reactor irradiation is to reduce low-cycle fatigue life of austenitic stainless steels. The reduction in life varies from little effect--generally at lower cyclic strains and higher test temperatures to decreases in life of 


\section{$5.3 .1-1$}

4 to 5 and more at higher plactic strain levels (1-5\%) and lower test temperatures. For a given test temperature, a lower irradiation temperature appears to decrease low-cycle fatigue life more than higher irradiation test temperatures. Introducing tensile hold times in the load cycle decreases creep fatigue resistance. Because the majority of the life of a high strain low cycle fatigue specimen is spent in crack propagation suggests that these parameters affect crack propagation more than crack initiation. Limited data in the next section--Irradiated Fatigue Crack Growth-indicate that fast reactor irradiation and testing at elevated temperature loads did increase crack growth rates in comparison to unirradiated material, over portions of the stress intensity factor range. Too little data exist, however, to consider the above statements as all encompassing generalization. Further work on the combined effects of irradiation and test environment (e.g., air, sodium, helium...), loading frequency, strain-rate, weldments and possible subtle variation in alloy chemistry and fabrication history is needed to clarify those factors that have the more significant effect on fatigue life.

Comparison of figures 5.3.1-1 and -2 show that irradiation of 304 SS in the range 0.3 to $17 \times 10^{20} \mathrm{n} / \mathrm{cm}^{2}\left(842^{\circ} \mathrm{F}\right)$ to 3.6 to $5.2 \times 10^{21} \mathrm{n} / \mathrm{cm}^{2}, \mathrm{E}>0.1$ $\mathrm{MeV}\left(1382^{\circ} \mathrm{F}\right)$ does decrease fatigue 1 ife at $932^{\circ} \mathrm{F}^{1}$ in comparison to unirradiated, thermally aged material. The greatest decrease in life was about a factor of 3 at high plastic strain levels and a lower irradiation temperature $\left(842^{\circ} \mathrm{F}\right)$, decreasing to nil difference with lower plastic strain levels. Few data points and differences in irradiation environmental conditions - static sodium, flowing sodium, and argon--however, suggest caution in deriving strong conclusions.

Figure 5.3.1-3 shows a lesser degradation of fatigue life caused by irradiation in comparison to thermally aged specimens when tested at a higher temperature leve $1,1292^{\circ} \mathrm{F}$. Again a trend in greater reduction of fatigue occurs at high plastic strain levels (2-3\%), decreasing to nil difference at less- 


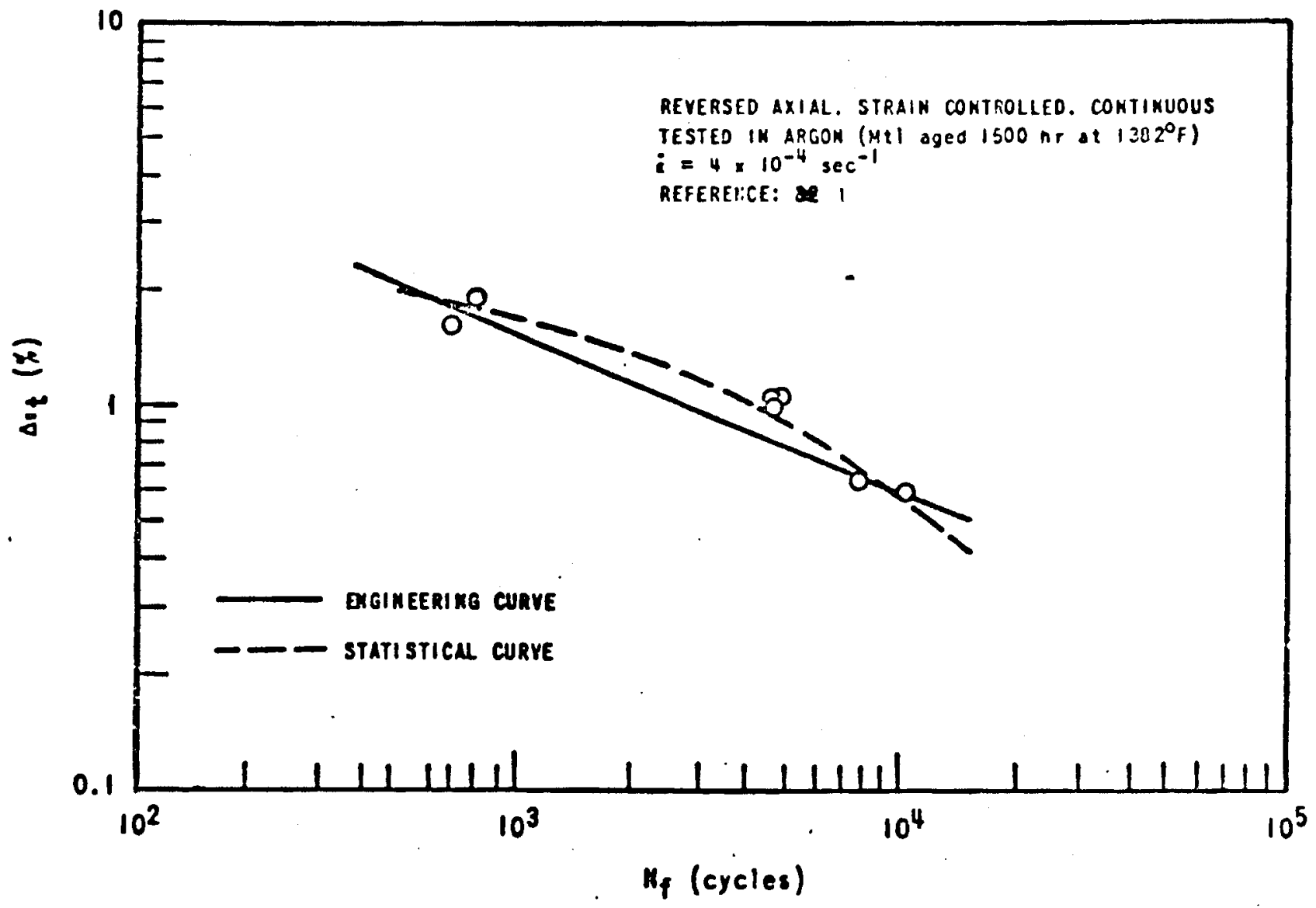

Figure 5.3.1-1

Axial Stralo Range Versus Cyclic Life for Unirradiated, Aged Type 304 Stainless Steel; Texts at $932^{\circ} \mathrm{F}$ 


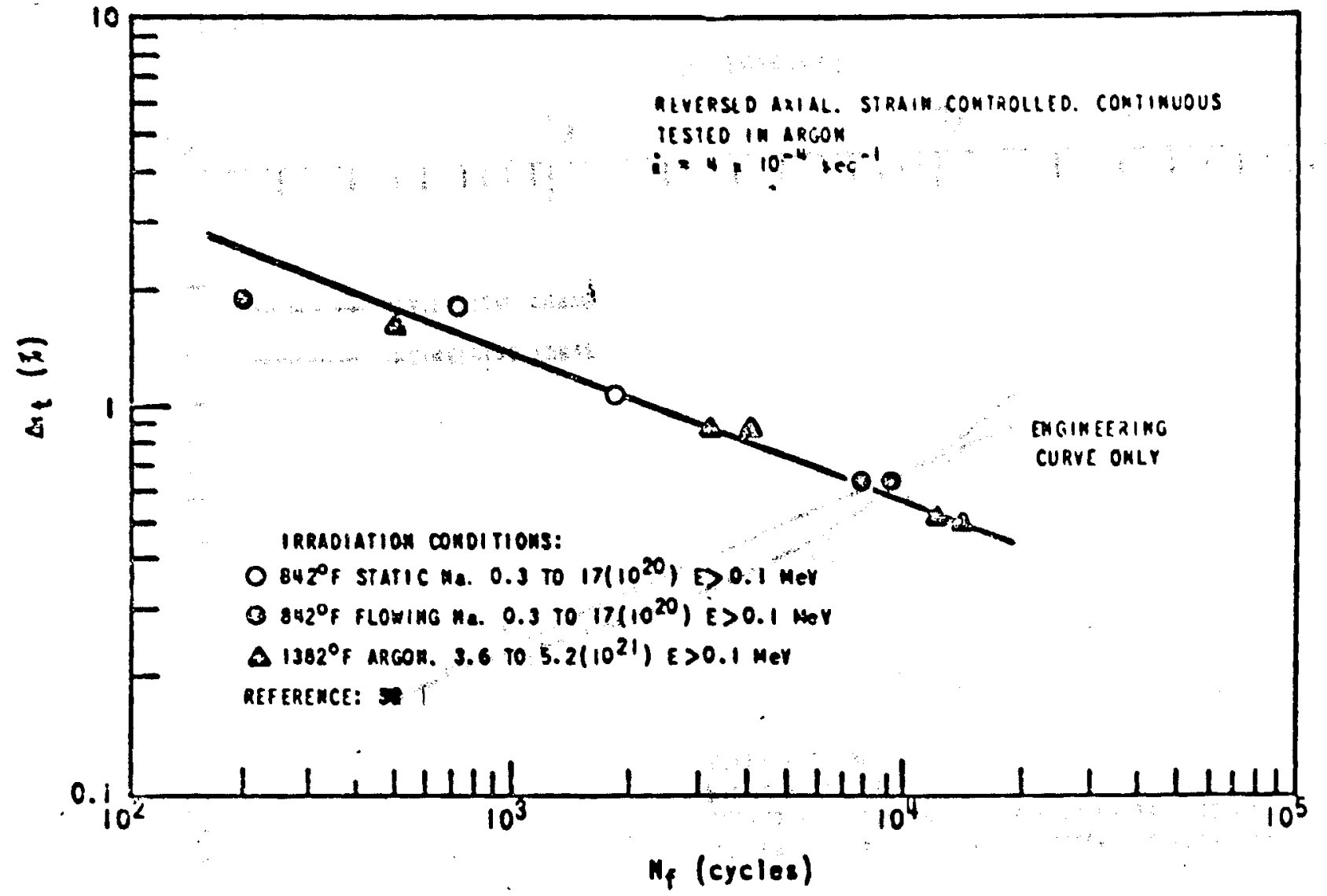

Figure 5.3.1-2

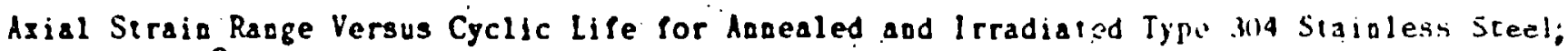
Tesis al $932^{\circ} \mathrm{F}$ 
er plastic strains. The more severe fluence level in comparison to figure $5.3 .1-2\left(1.3\right.$ to $3 \times 10^{22} \mathrm{n} / \mathrm{cm}^{2}$ vs $.3 \times 10^{20}$ to $5.2 \times 10^{21} \mathrm{n} / \mathrm{cm}^{2}$, both E> 0.1 $\mathrm{MeV}$ ) may have been compensated for by a higher irradiation test temperature $\left(1292^{\circ} \mathrm{F}\right.$ versus $842^{\circ} \mathrm{F}$ mainly) thus producing lesser differences between irradiated and thermally aged specimens in Figure 5.3.1-3.

The effect of irradiation on fatigue in 316 SS at elevated temperatures are shown in figures $5.3 .1-4$ through 6 . Figures $5.3 .1-4^{3}$ shows a larger reduction in fatigue life at $650^{\circ} \mathrm{C}\left(1202^{\circ} \mathrm{F}\right)$ possibly due to a low irradiation temperature: $70^{\circ} \mathrm{C}$ at a fast fluence of $4.8 \times 10^{18} \mathrm{n} / \mathrm{cm}^{2}, E>0.1 \mathrm{MeV}$. Irradiation reduced the fatigue 1 ife around a factor of 4 in comparison to unirradiated material at high plastic strains (2-3\%), decreasing slightly with decreasing plastic strain.

Figures $5 \cdot 3 \cdot 1-5^{1}$ and $5 \cdot 3 \cdot 1-6^{1,2}$ compare irradiated and unirradiated 316 SS at both higher fluence and irradiation temperature levels $\left(.6 \times 10^{20}\right.$ to $6.3 \times 10^{21} \mathrm{n} / \mathrm{cm}^{2}, E>0.1 \mathrm{MeV}, 842^{\circ}$ and $1382^{\circ} \mathrm{F}$ ) but at a lower test temperature $\left(1100-1112^{\circ} \mathrm{F}\right)$ than figure 5.3.1-4.3 In figure 5.3.1-5 the greatest reduction in fatigue life ( $\sim$ a factor of 2 ) occurs for the lower irradiation temperatures $\left(820^{\circ} \mathrm{F}\right)$ and high strain levels $(1-3 \%)$, decreasing with decreasing plastic strain.

The effect of irradiation on fatigue life in 308 SS weld metal at $1100^{\circ} \mathrm{F}$ is shown in figure 5.3.1-7.4 Again, in comparison to unirradiated control specimens, fatigue 1 ife at high strain levels $(1-2 \%)$ is reduced about $2-3$, decreasing to nil reduction in life at lower plastic strain levels.

Introduction of tensile hold times in a fatigue load cycles decreases creep/fatigue resistance of irradiated stainless steels as shown in figure 5.3.1-85. On figure 5.3.1-8 comparisons are made between the behavior of unirradiated thermally aged and irradiated 304 and 316 SS at a single strain 


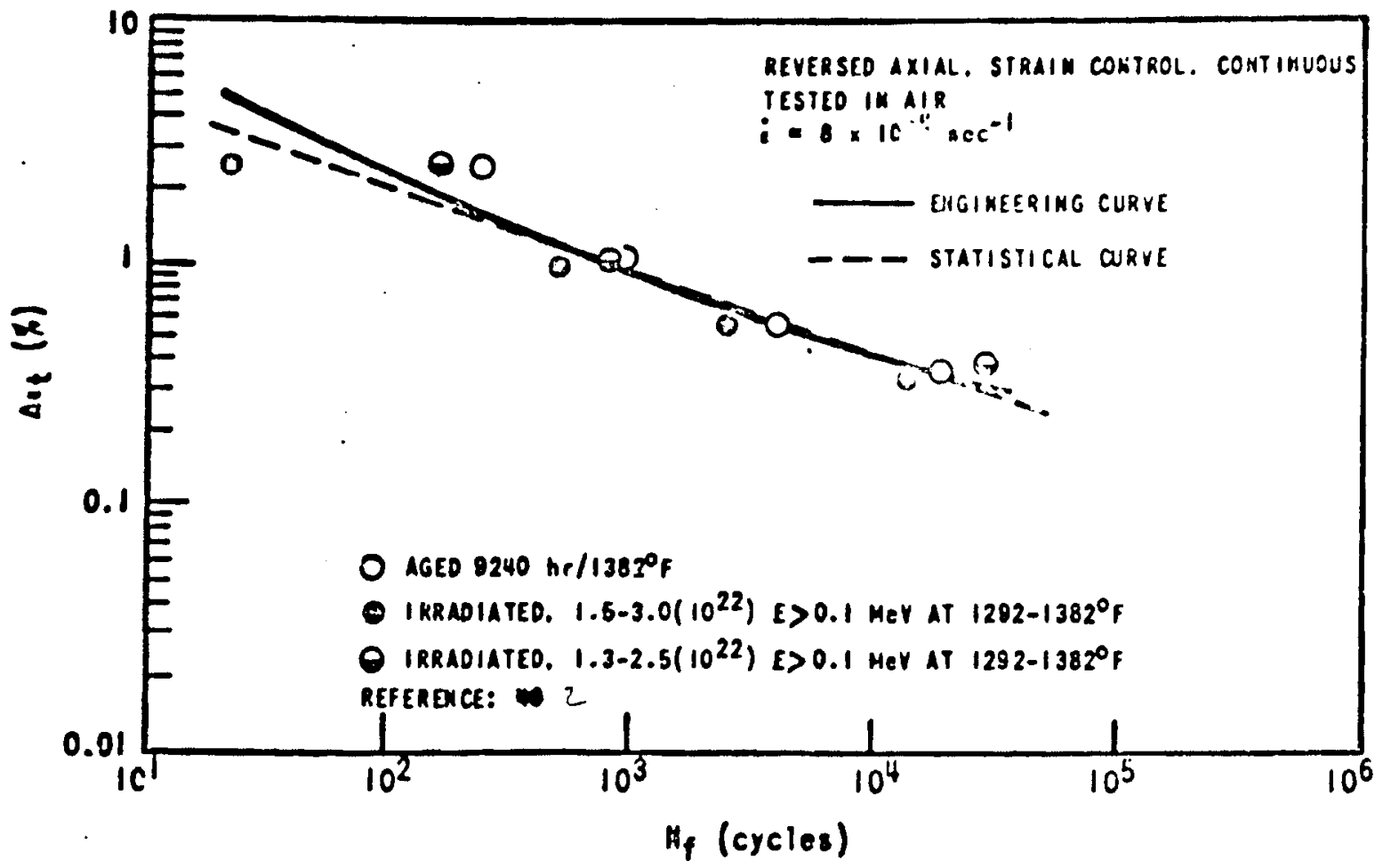

Figure 5.3.1-3

Axial Straio Rage Versus Cyclic Life for Aged or Irradiated Type 304 Sialolesg Steel; Tesis at $1292^{\circ} \mathrm{P}$ 


\section{5. $3.1-6$}

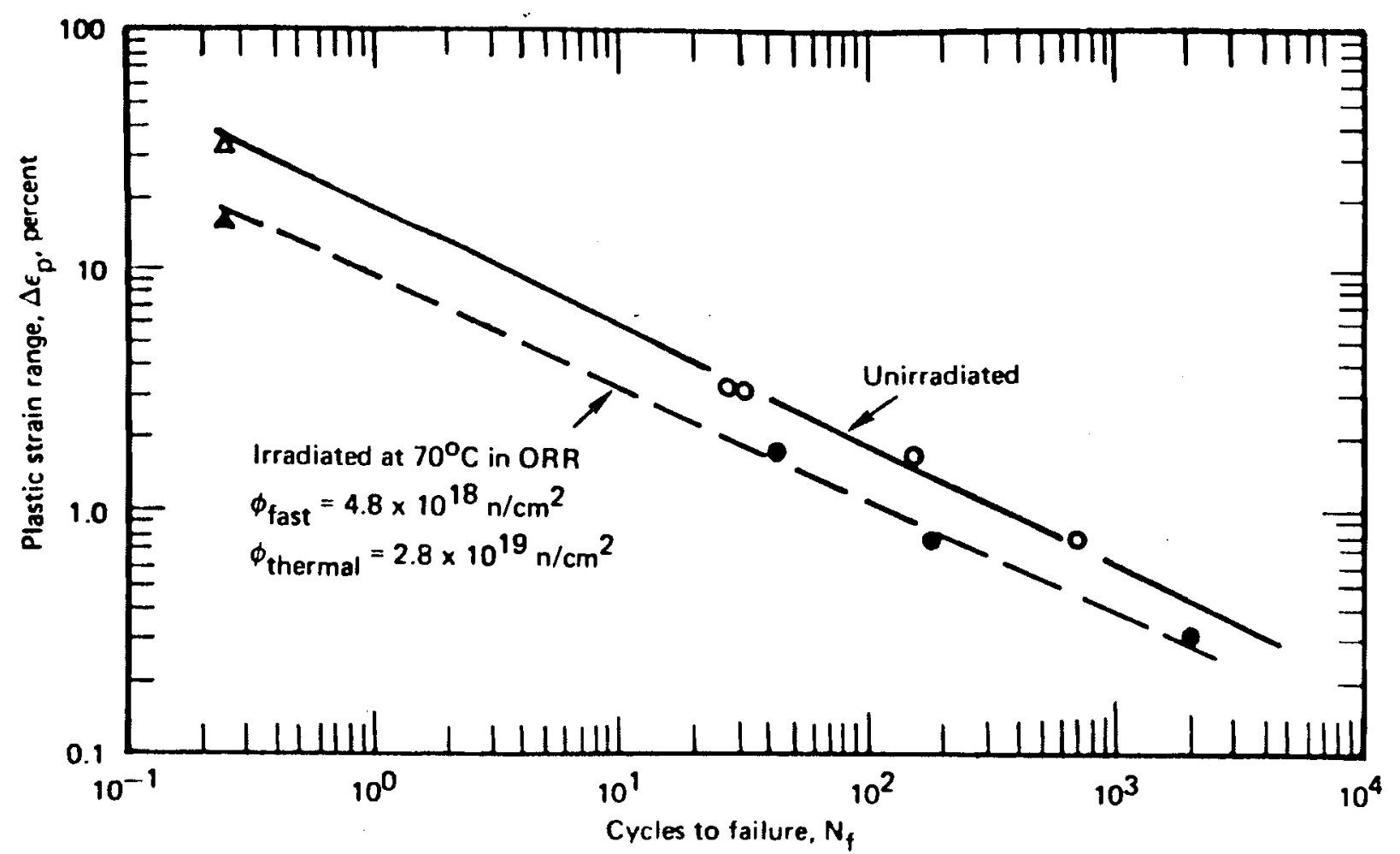

Figure 5.3.1-4

Cycles to failure, $\mathrm{N}_{f}$

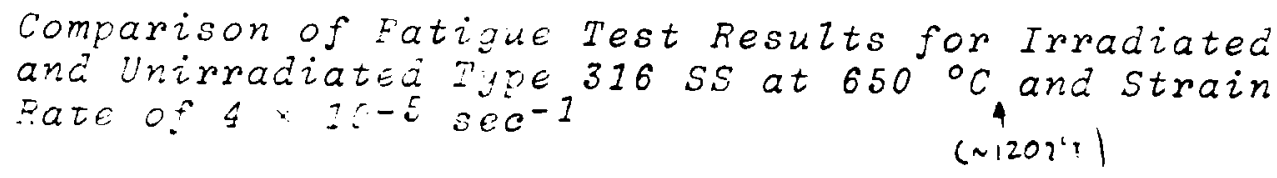

range of $1 \%$ and a test temperature of $1100^{\circ} \mathrm{F}$. For that strain range fatigue lines of the unirradiated 304 and 316 are nearly equal when no hold times are used. When hold-times exceed $0.1 h r$ - unirradiated 304 shows a superior creep/fatigue resistance to unirradiated 316 SS. After irradiation (.3 to $6 \times 10^{21} \mathrm{n} / \mathrm{cm}^{2} \mathrm{E}>0.1 \mathrm{MeV}$ ) both materials undergo a significant reduction in creep/fatigue resistance which is borne out by both a decreasing cycle to failure and decreasing time to failure. The effect of cold work (figure 5.3.1-9) on creep/fatigue resistance is not significant when comparing figures 5.3.1-9 and -8 . This is in contrast to data where cold work has shown to be beneficial in increasing both resistance to fatigue and creep. 


\section{$5.3 .1-7$}

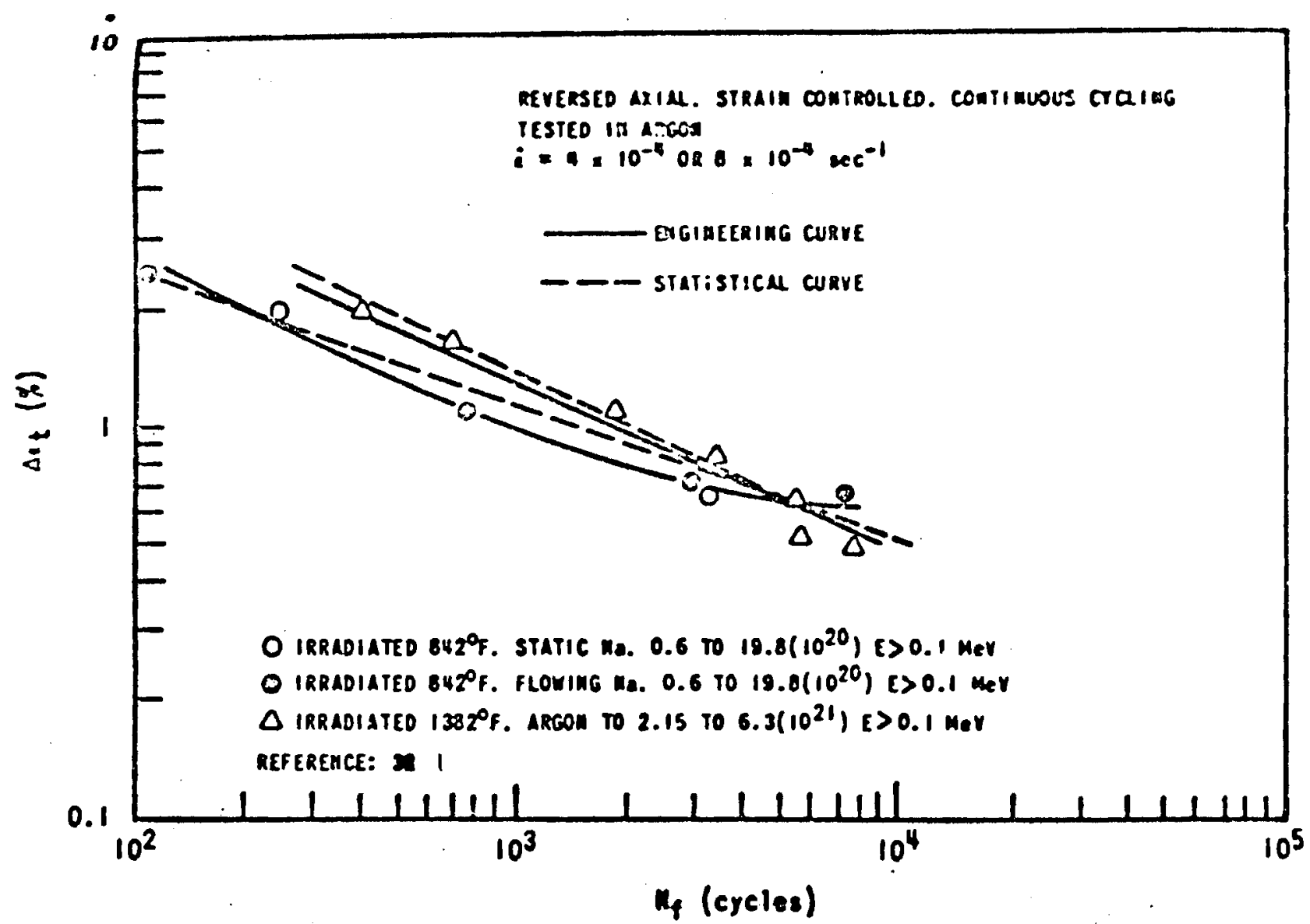

Figure 5.3.1-5

Axial Strain Range Versus Cyclic Life for Ansealed and Irradiated Type 316 Siaialess Steel; Tests at $1112^{\circ} \mathrm{F}$ 
$5.3 .1-8$

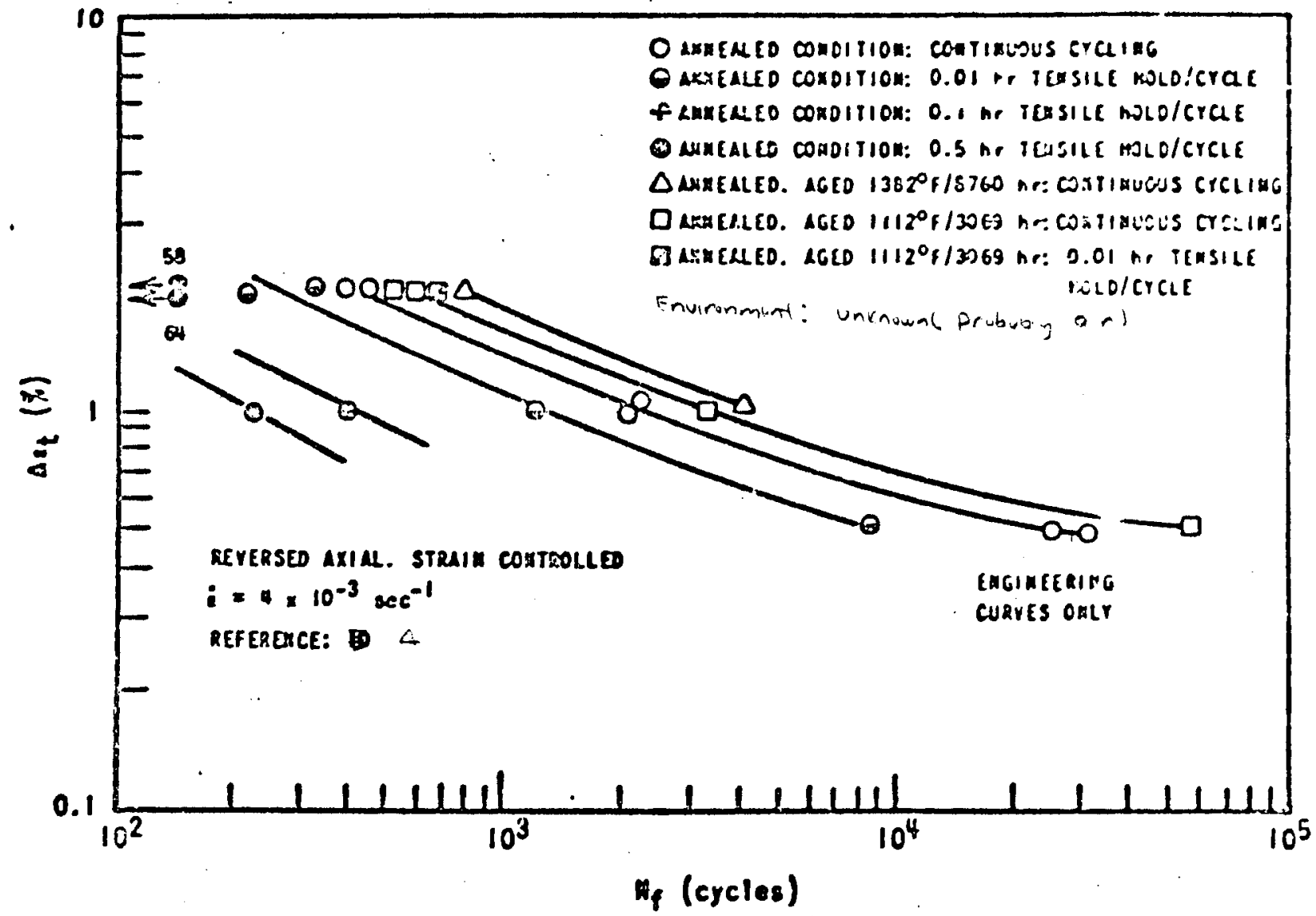

Figure 5.3.1-6

Axial Strain Range Yersus Cyclic life for Ranealed, ano Ranealed Plus Ages Type 316 Siainlees Steel, Uairradiated, With and Hithout Tension Hold Periods; Tests at $1100^{\circ} \mathrm{f}$ 


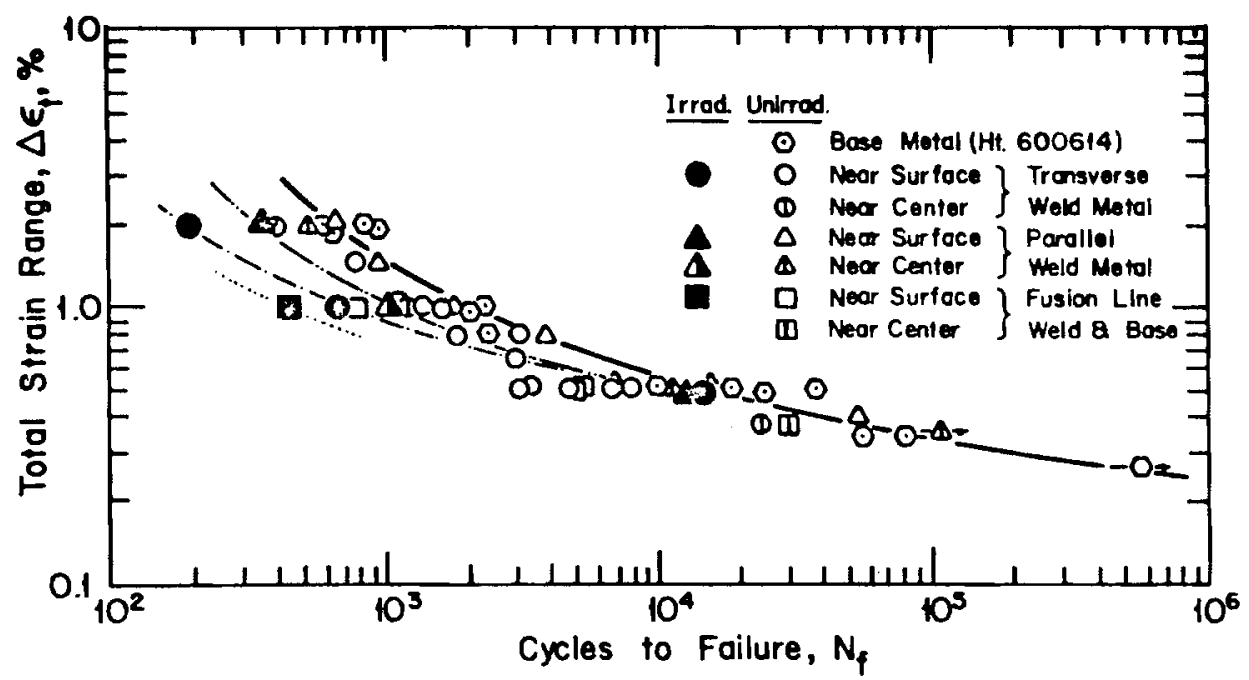

Figure $5.3,1-7$

Effects of Irradiation on the Strain Fatigue Behavior of 308 SS Weld Metal at $1100^{\circ} \mathrm{F}\left(593^{\circ} \mathrm{C}\right)$ at a Strain Rate of $4 \times 10^{-3} \mathrm{~s}-1$. Fluences are 0.5 to $1.0 \times 10^{22} \mathrm{n} / \mathrm{cm}^{2} \quad(E>0.1 \mathrm{MeV})$.

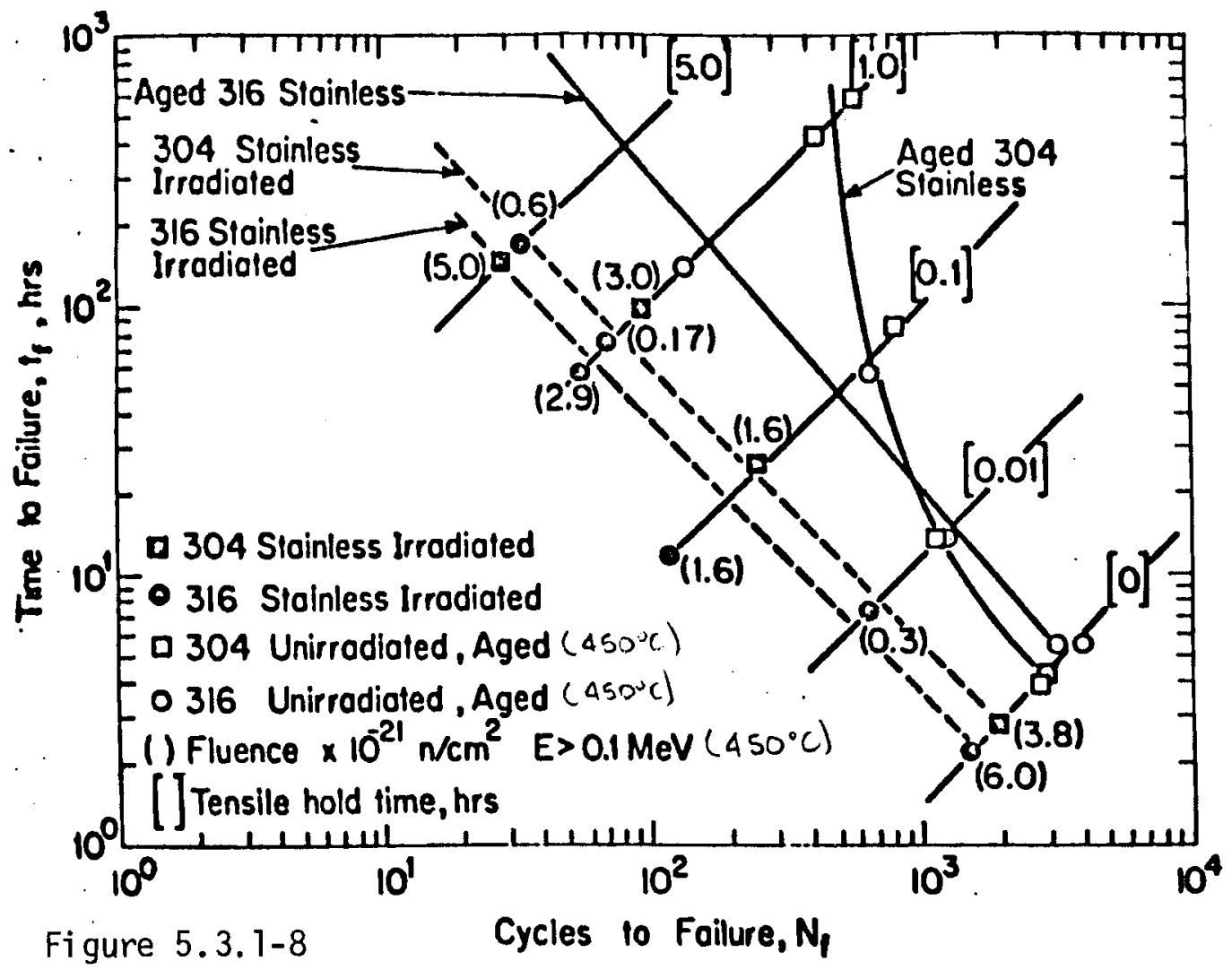

Total tirae to thilure veroun cycles to frilure for irradinted and unirradiated 304 and 316 steinjea teated at $593^{\circ} \mathrm{C}\left(1100^{\circ} \mathrm{F}\right), \Delta e_{1}=1.08$ with several tensile hold timea. 


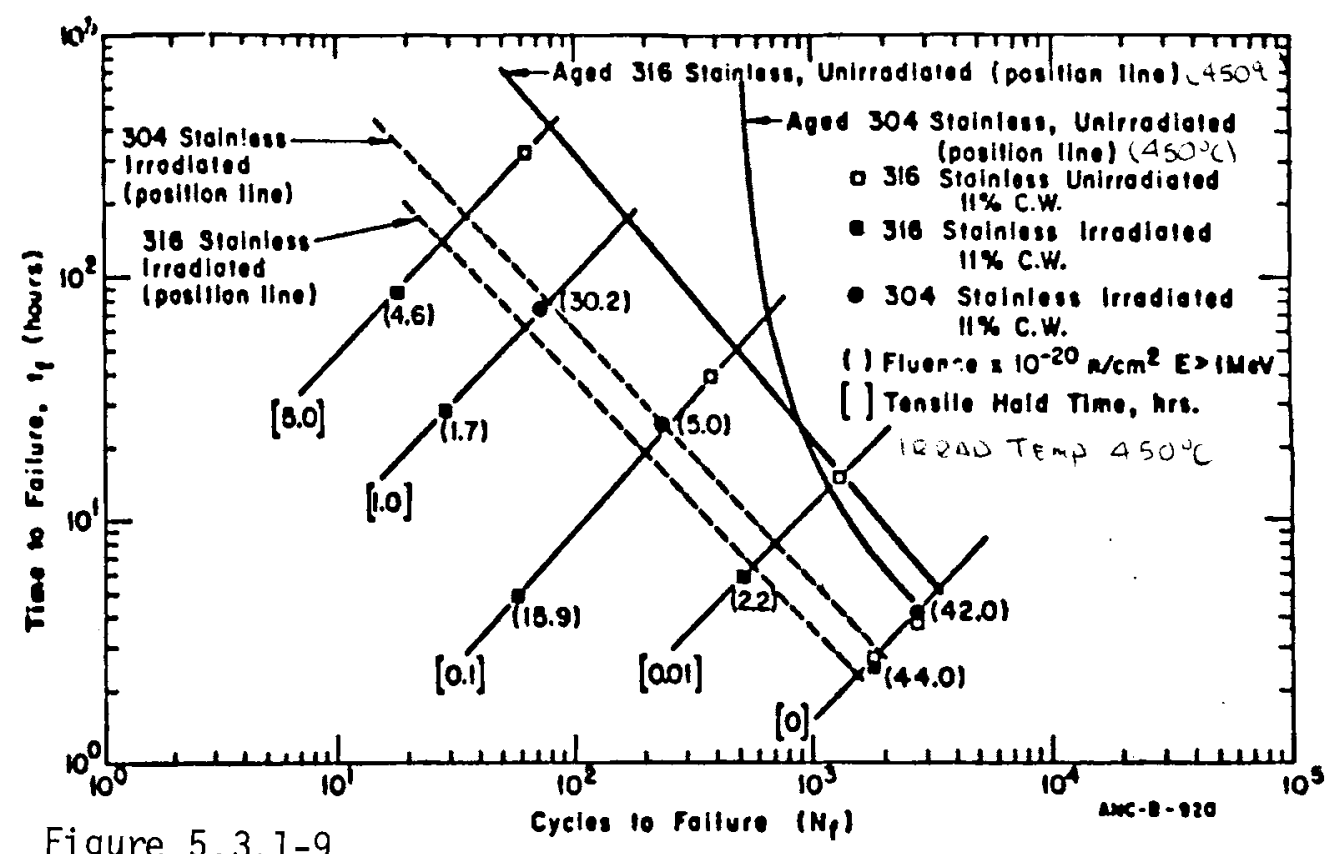

Figure 5.3.7-9

Time to failure versus cýcles to feilure ahowing the influence of cold-work (C. W.) on the creep-fattgue reabiance of irradiated 304 and 316 otainless steel at $593^{\circ} \mathrm{C}\left(1100^{\circ} \mathrm{F}\right)$. 


\section{REFERENCES}

1. J. M. Beeston, C. R. Brinkman, "Axial Fatigue of Irradiated Stainless Steels at Elevated Temperatures" in Irradiation Effects on Structural Alloys for Nuclear Reactor Application, ASTM STP 484, pp 419-450, 1971 and P. Soo and J. McAndrew, "Type 304 and Type 316 Stainless Steel Data for High Temperature Design", Topical Report WARD-3045T2C-3, UC-79h (OU0), Nov., 1972.

2. T. T. Claudson, "Quarterly Progress Report" Irradiation Effects on Reactor Structural Materials; Jan. 1971, HEDL-TME-71-43, (OUO), llarch 1971.

3. T. T. Claudson, "Quaterly Progress Report", Irradiation Effects on Reactor Structural Materia1s", BNWL 1091, p.10.9, June 1969.

4. T. T. Claudson, "Semi Annual Progress Report" Irradiation Effects on Reactor Structural Materials HEDL-TME-74-9 (OU0) March 1974.

5. C. R. Brinkman, G. E. Korth, J. M. Beeston, "Comparison of the Fatigue and Creep-Fatigue Properties of Irradiated and Unirradiated Type 304 and 316 Stainless Steel at $1100^{\circ} \mathrm{F} "$ Aero Jet Nuclear Company, ANCR-1078, UC25, August 1972.

OUO - Official Use Only 


\subsubsection{Irradiated Fatigue Crack Growth}

Irradiation ${ }^{1}$ and helium injection by cyclotron exposure ${ }^{2}, 3$ effect fatigue crack growth properties of post-irradiation tested stainless steels. The very small amount of data show both beneficial and detrimental effects on $\frac{d a}{d N}$ for both types of embrittlement producing conditions. No generalization is made, but interesting effects of irradiation environment and test temperature are described below.

Type 304 and 316 SS were irradiated in two different reactor environments (ATR and EBR II) and post-irradiation fatigue crack growth tests conducted at 800 and $1100^{\circ} \mathrm{F}$. The data are shown in figures 5.3.2.-1 through-4(ATR environment) and 5.3.2-5 and -6 (EBR II environment) as fatigue crack growth rate $(\mathrm{da} / \mathrm{dN})$ versus stress intensity factor range $(\Delta K)$.

In general, it appears that fatigue crack propagation 1 ife of 304 and 316 is improved by irradiation at $800^{\circ} \mathrm{F}$ (Figure 5.3.2-1 \& -2), but decreased at $1100^{\circ} \mathrm{F}$ (Figure $5.3 .2-3 \&-4$ ) for the ATR irradiation environment. The EBR II environment in general decreased fatigue crack propagation life at $1100^{\circ} \mathrm{F}$ (Figure 5.3.2-6), produced mixed results at $800^{\circ} \mathrm{F}$ (Figure 5.3.2-5) in that irradiation increased $\frac{d a}{d N}$ for $\Delta K<\sim 35 K s i \sqrt{i n}$, but decreased $\frac{d a}{d N}$ for $\Delta K>35 \mathrm{Ksi} \sqrt{i n}$ relative to unirradiated material. Figure 5.3.2-7 compares the effect of EBR II to ATR radiation on fatigue crack length versus cycles for 304 SS at $1100^{\circ} \mathrm{F}$. In general, the fatigue life was lowered by both irradiation environments, but the reductions in life was greatest for the lower ATR irradiation temperature $\left(550^{\circ}\right.$ vs $\left.760^{\circ} \mathrm{F}\right)$ and lower fluence ATR irradiated $\left(1.8 \times 10^{21}\right.$ vs $\left.\sim 1.2 \times 10^{22} \mathrm{n} / \mathrm{cm}^{2}, \mathrm{E}>0.1 \mathrm{MeV}\right)$.

Helium injection by cyclotron exposure increased fatigue crack propagation life at $650^{\circ} \mathrm{C}\left(1202^{\circ} \mathrm{F}\right)$ for both aged and cold worked 316 SS (Figure 5.3.2-8) but decreased fatigue crack propagation 7 ife at $816^{\circ} \mathrm{C}\left(1500^{\circ} \mathrm{F}\right)$. 


\section{$5.3 .2-2$}

Many factors, including the dispersion of helium bubbles throughout the sample and its relationship to fatigue damage acetmulation, remain to be examined. The technique is new, but appears promising as a means of evaluating simular test irradiation embrittlement on fatigue by ion bombardment rather than reactor exposure. 


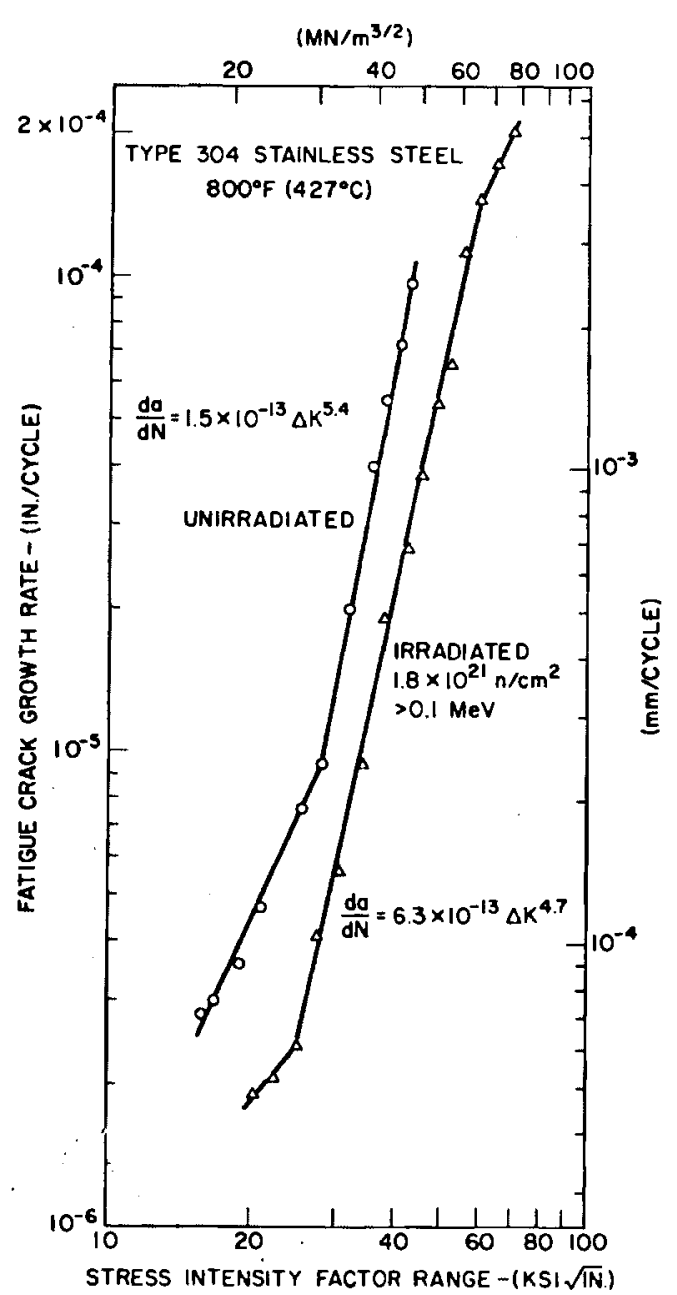

Figure 5.3.2-1

Influence of Irradiation (ATR) on Fatigue Crack Growth Rates in Type 304 Stainless Steel at $800^{\circ} \mathrm{F}\left(427^{\circ} \mathrm{C}\right)$.

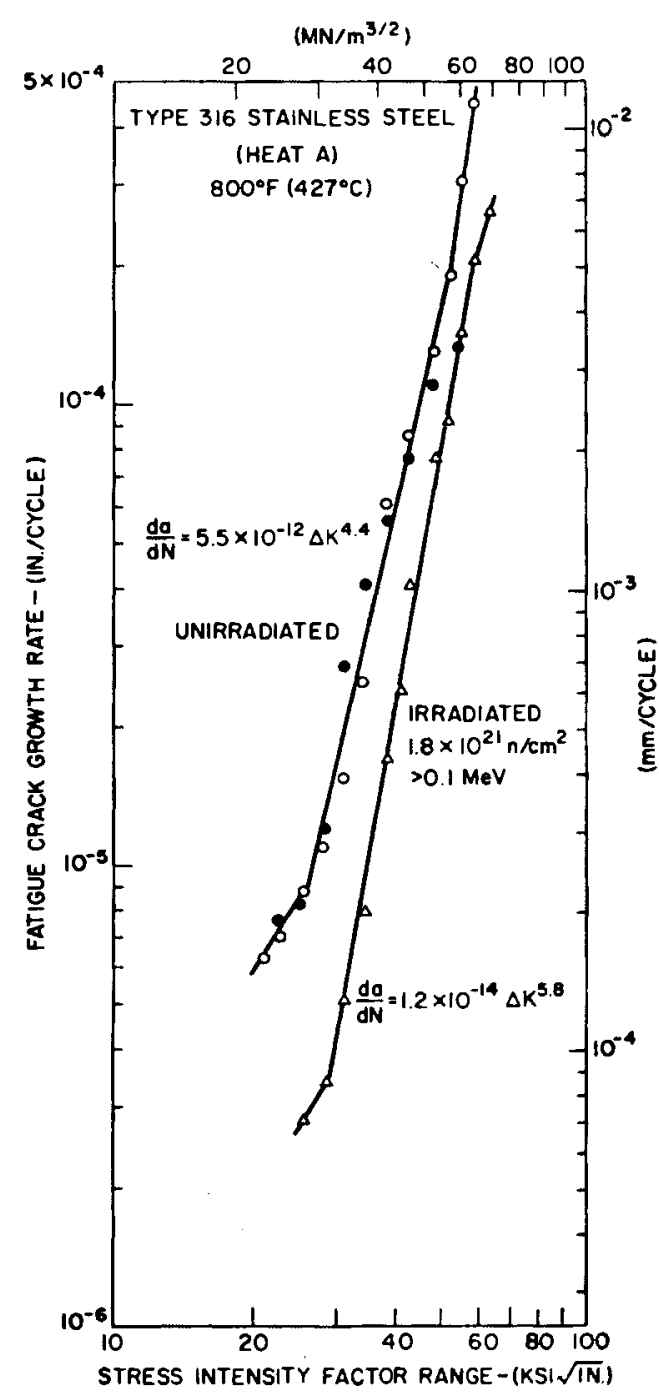

Figure 5.3.2-2

Influence of Irradiation (ATR) on Fatigue Crack Growth Rates in Type 316 Stainless Stee 7 at $800^{\circ} \mathrm{F}\left(427^{\circ} \mathrm{C}\right)$. 


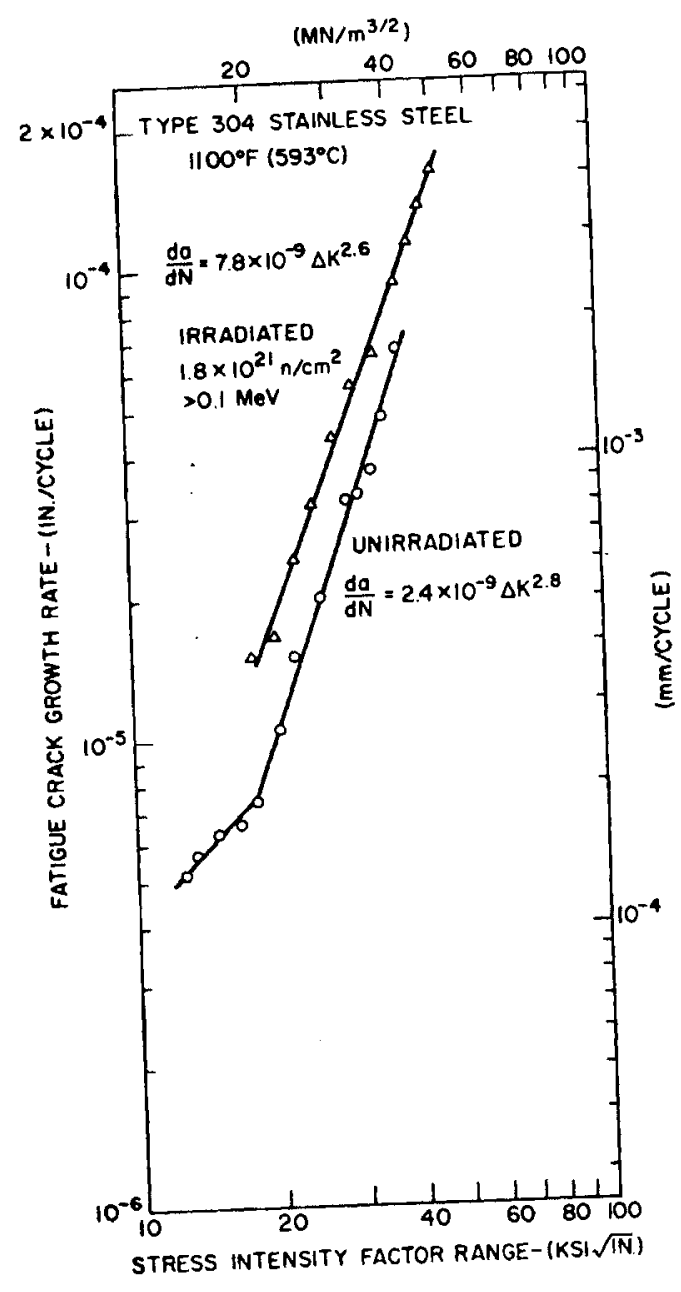

Figure 5.3.2-3

Influence of Irradiation (ATR) on Fatigue Crack Growth Rates in Type 304 Stainless Steel at $1100^{\circ} \mathrm{F}\left(593^{\circ} \mathrm{C}\right)$.

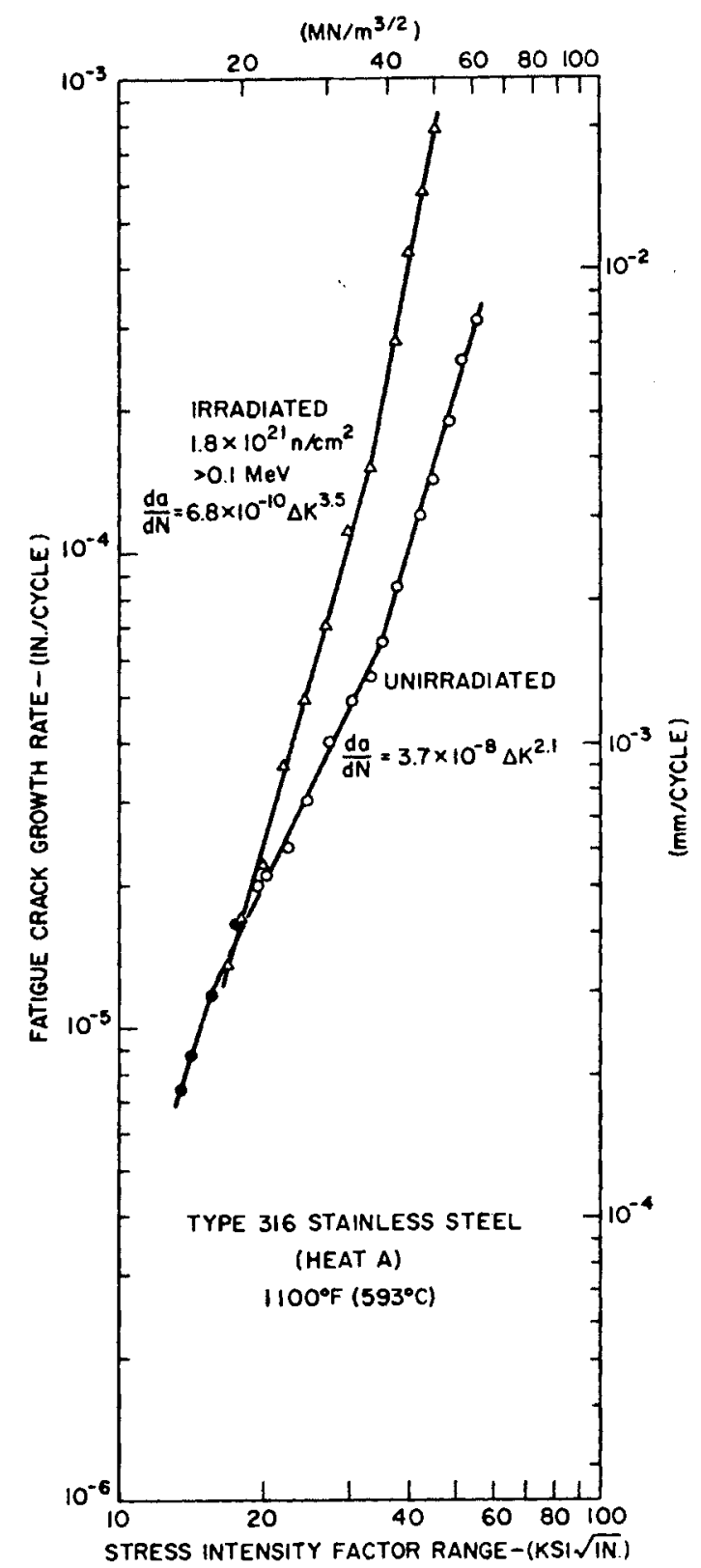

Figure 5.3.2-4

Influence of Irradiation (ATR) on Fatique Crack Growth Rates in Type 316 Stainless Stee 1 at $1100^{\circ} \mathrm{F}\left(533^{\circ} \mathrm{C}\right)$. 


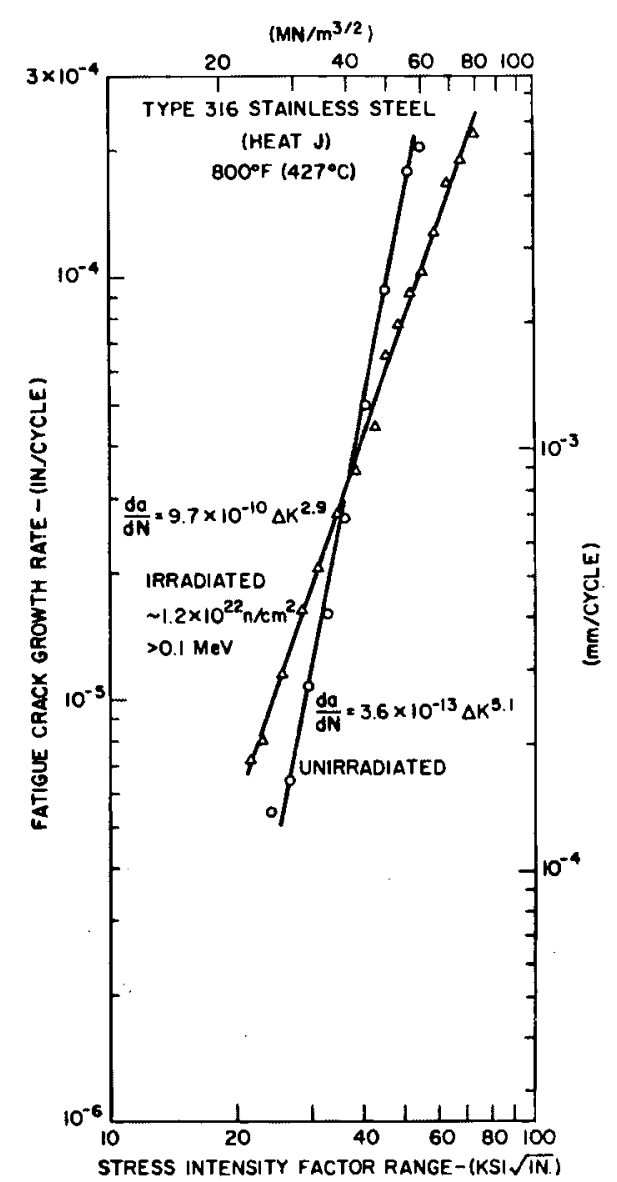

Figure 5.3.2-5

Effect of Irradiation (EBR-II) on Fatigue Crack Growth Rates in Type 316 Stainless Steel at $800^{\circ} \mathrm{F}\left(427^{\circ} \mathrm{C}\right)$.

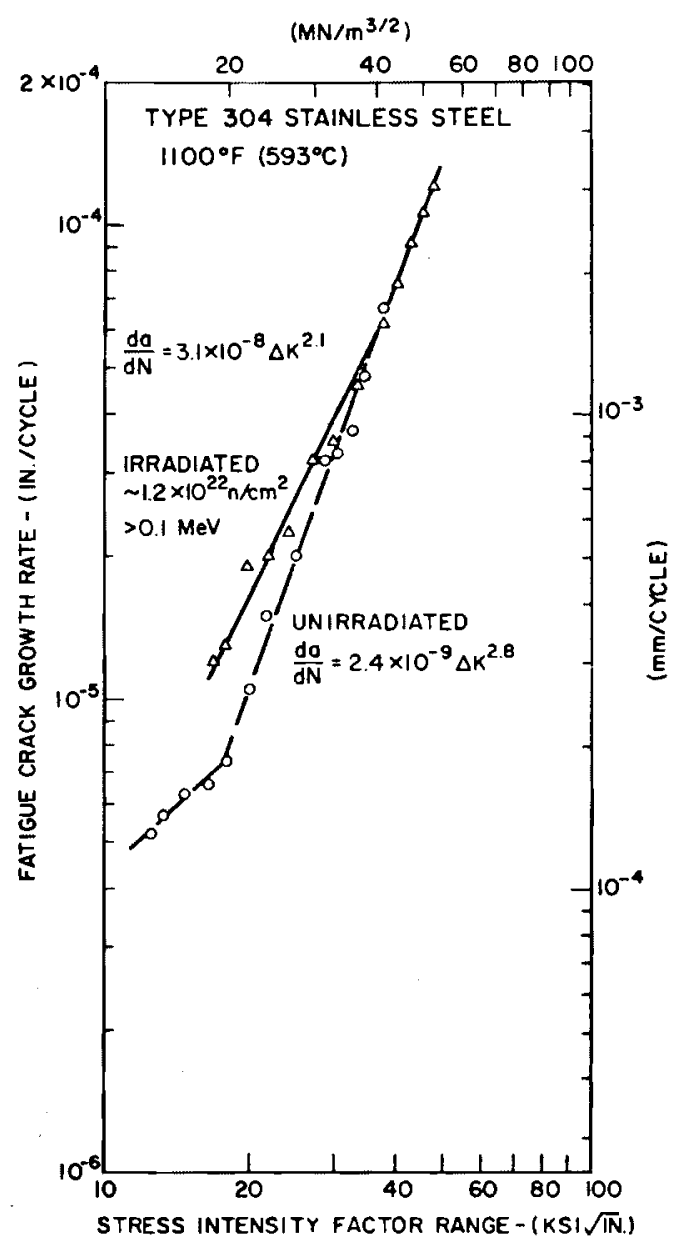

Figure 5.3.2-6

Effect of Irradiation (EBR-II) on Fatigue Crack Growth Rates in Type 304 Stainless Steel at $1100^{\circ} \mathrm{F}\left(593^{\circ} \mathrm{C}\right)$. 


\section{$5.3 .2-6$}

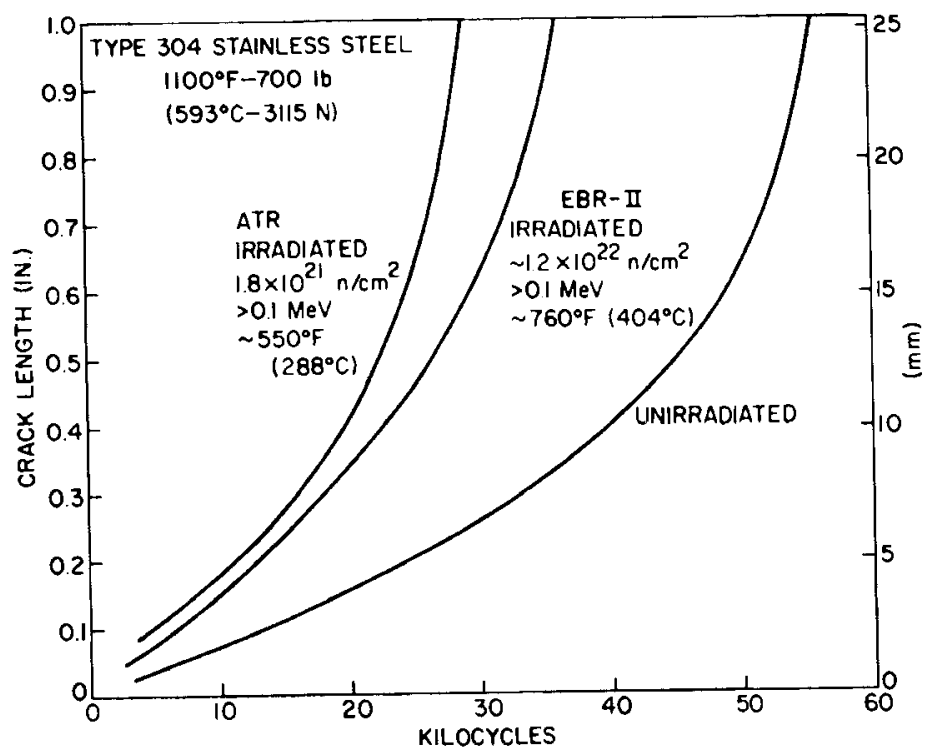

Figure 5.3.2-7

Comparison Between Effects of Irradiation in ATR and EBR-II on Fatigue Crack Growth in Type 304 Stainless Steel at $1100^{\circ} \mathrm{F}\left(593^{\circ} \mathrm{C}\right)$.

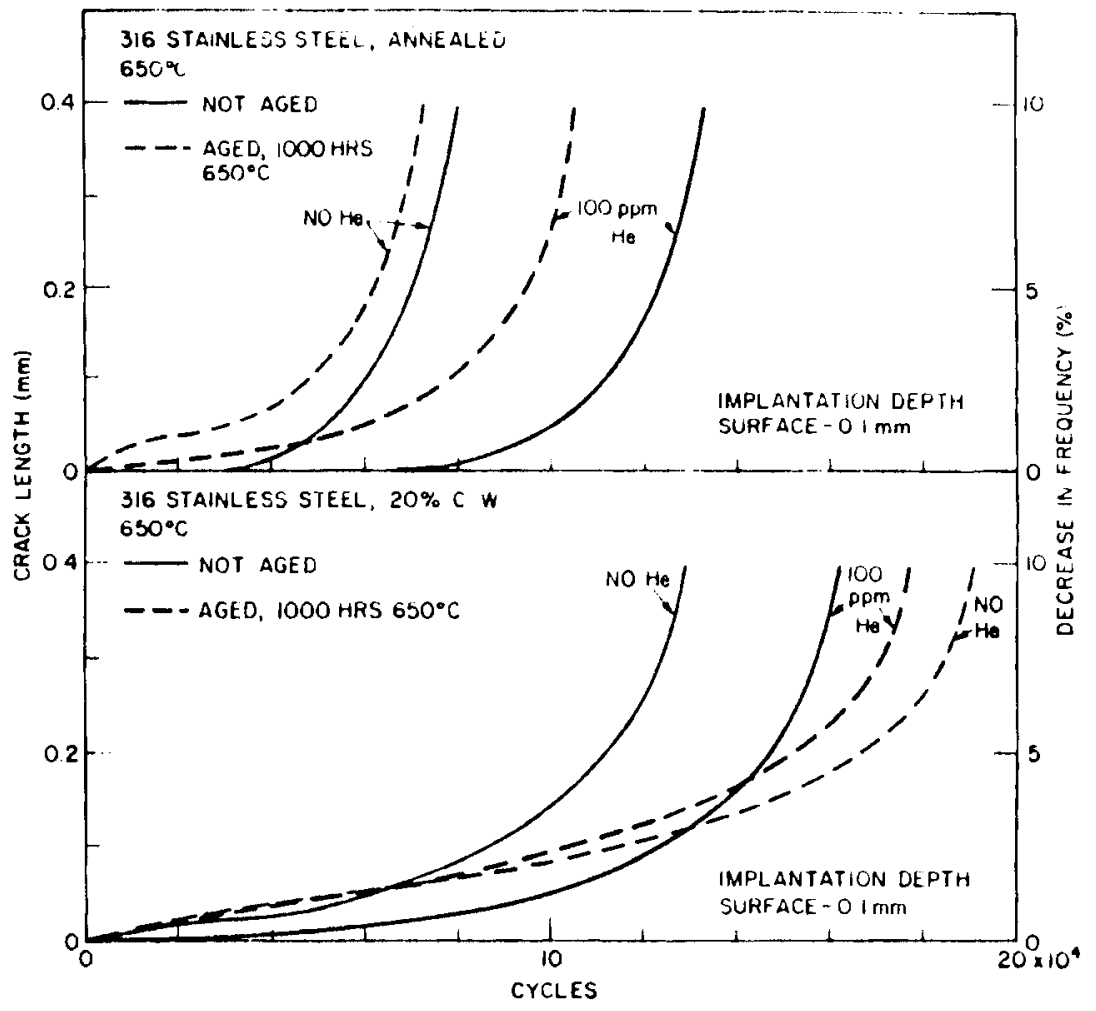

Fiqure $5.3 \cdot 2-8$

Crack Length as a Function of the Number of Cycles For Annealed and $20 \% \mathrm{CW}$ Thin-Section 316 SS at $650^{\circ} \mathrm{C}\left(1202^{\circ} \mathrm{F}\right)$. 
$5 \cdot 3 \cdot 2-7$

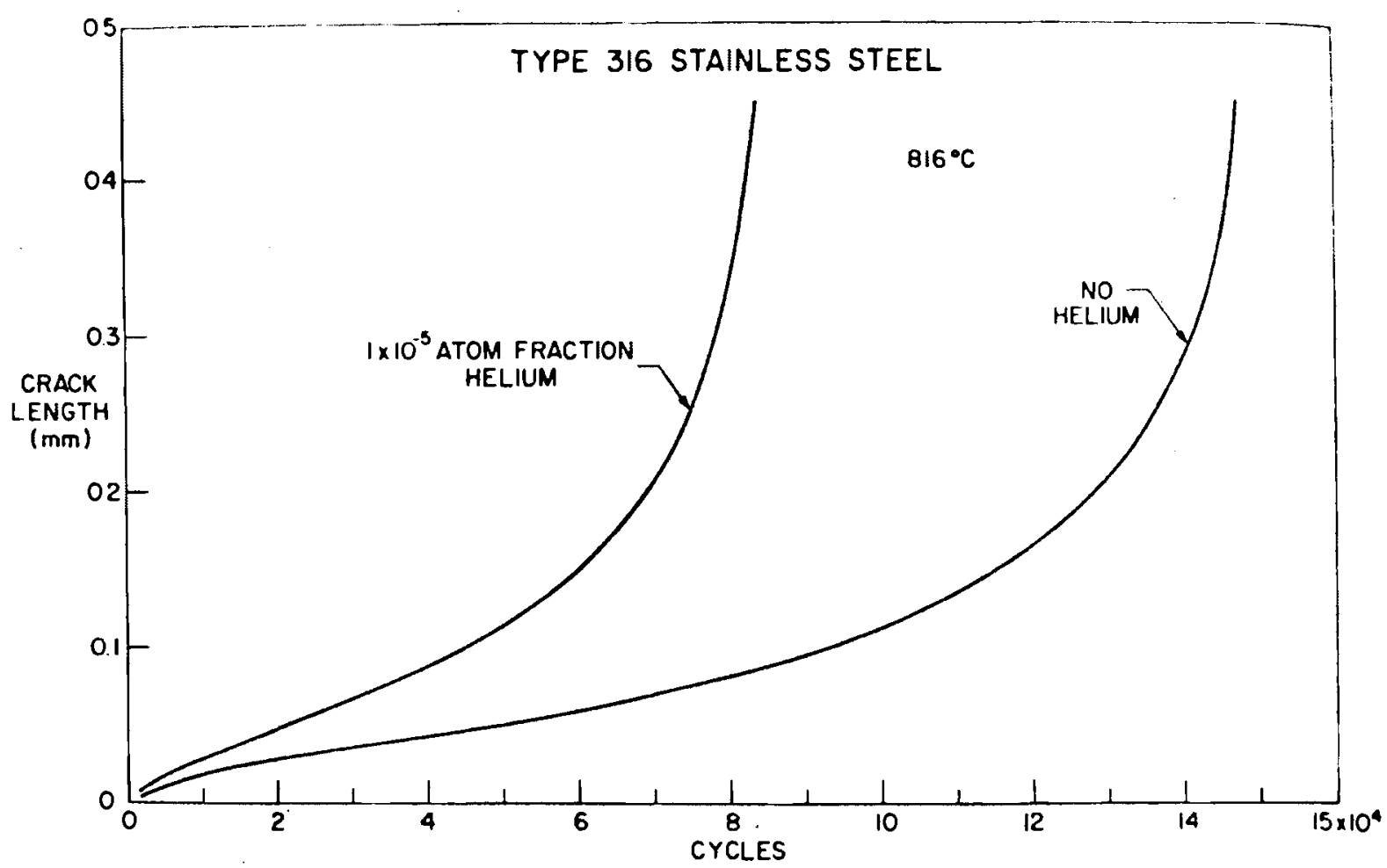

Figure 5.3.2-9

Crack Growth During Fatigue in 316 SS at $1500^{\circ} \mathrm{F}\left(816^{\circ} \mathrm{C}\right)$ for Unirradiated and Hel ium-Implanted (10 ppma, 0.004-in.) Specimens. 


\section{$5.3 .2-8$}

\section{REFERENCES}

1. P. Shahinan, H. E. Watson and H. H. Smith, "Effect of Neutron Irradiation on Fatigue Crack Propagation in Types 304 and 316 Stainless Steels at High Temperatures", in Effects of Radiation on Substructure and Mechanical Properties of Metals and Alloys, ASTM STP 519, 1973 pp. 493508.

2. T. T. Claudson, "Quarterly Progress Report", Irradiation Effects on Reactor Structural Materia1s, HEDL-TME-72-64, June 1972, p. NRL-20 (0U0).

3. T. T. Claudson, "Semi-Annual Progress Report", Irradiation Effects on Reactor Structural Materials, HEDL-TME 74-9, UL-79b, March 1974, (ㄴO) p. NRL-33.

OUo - Official Use Only 


\subsection{The Significance of Elevated Temperature Irradiation Fatigue Properties to LMFBR Performance}

\subsubsection{Introduction}

At this time fatigue data from irradiation at fluences and environmental conditions representative of current and future LMFBR design is incomplete. Data on the effect of irradiation under a limited set of environmental conditions are presently confined primarily to low-cycle fatigue including some fatigue-creep type loading. A very small amount of data exist on irradiated fatigue crack growth. This lack of data coupled with difficulties in relating structural to specimen behavior also hamper prediction of LMFBR component fatigue lives.

Crude estimation of the fatigue lives of LMFBR structural components is possible, although brought with several major limitations: structural or real-life fatigue loading consists generally of varying amplitudes in the presence of environmental fluctuations, such as temperature changes and the accumulation of radiation damage. Lastly complex stress (or strain) distribution in structural components are not readily relatable to the more simble stress (or strain) distribution in specimens. Subcritical crack growth under grossly elastic loading is an exception and reasonable success has been sho:!n in correlating specimen fatigue crack growth behavior with structural crack growth behavior based on linear elastic fracture mechanics.

\subsubsection{Genera1 Imp1ication of Elevated Temperature Irradiated Fatigue on LMFBR Components}

Caution is advised in drawing any relationship between design basis fatigue criteria from the statements that follow. The methods used to "rate" the importance of given parameters are less than accurate, and in some cases based on data from as few as two specimens (fatigue crack growth in EBR-II- 


\section{$5.4 .2-1$}

irradiated material). One more difficult-to-characterize situation should be noted: practical difficulties of testing in radiation hot cells, remote handling procedures, distance from the test observer to the specimen--often separated by four feet of oil-filled lead glass--nominal misalignment of testing fixtures and increased difficulties in remote measurement and control of loads, strain, temperatures, etc. all increase the likelihood of additional data scatter.

The four factors that affect factors that affect fatigue lifetime can be represented by a tetrahedron. ${ }^{2}$

\section{(4) MATERIAL}

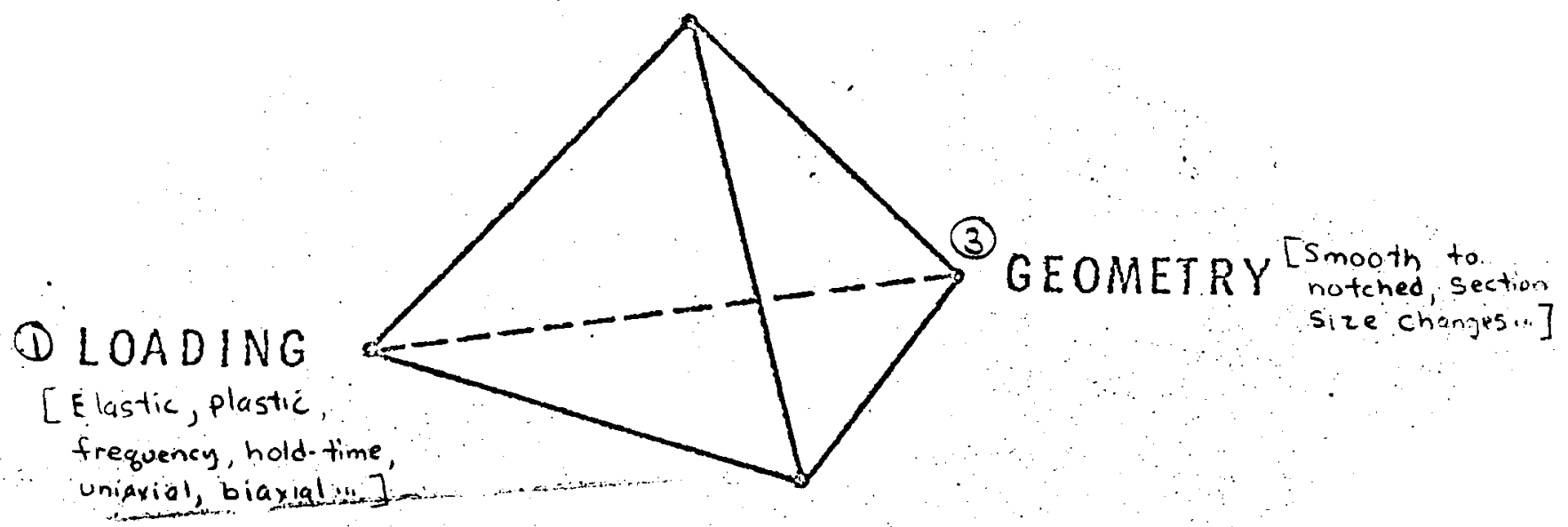

(2) ENVIRONMENT

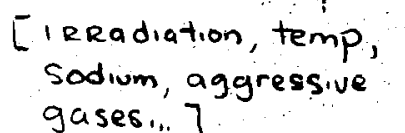

Fatigue data on "good quality" stainless steel suggest that the major parameters affecting 1 ifetime of LMFBR components proceed from (1) = most to (4) = least. obviously exceptions can be found, particularly if environmental influences are reduced (no irradiation, vacuum, low temperature) or severe changes in material properties (alloy composition variations, bad weldments, 


\section{$5.4 \cdot 2-2$}

bad thermal treatments, sharp notches) occur. No attempt wi11 be made to separate fatigue life effects based on component environmental conditions because of the weak data base.

Based on the data discussed earlier in the work, somewhat arbitrary separation of the four fatigue factors are presented:

a. Material Properties

By and large, "accentable variations"in metallurgical properties of 304 and 316 stainless steel do not produce significant variations in fatigue lifetime, both in high and low-cycle fatigue and fatigue crack growth.

b. Environment

Based on very recent, unique data, ${ }^{3}$ oxygen appears to $n$ lay a dominant role in affecting fatigue life.

1. Sodium

Tests in low oxygen clean sodium suggest that thermal activation and hence temperature level does not affect fatigue crack growth rate in comparison to room temperature, vacuum tests.

2. Air

Tests in air, including low-cycle and fatigue crack growth indicate that held-time, frequency, load waveform, etc. may be biased by a chemical interaction (oxygen) rather than the individual factors, per se. An implication of this is that fatigue of sodium contacting surfaces may be much less severe than air contacting surfaces, since fatigue in each generally initiate at a free surface. 


\section{$5.4 .2-3$}

\section{Irradiation}

A fast fluence environment, in general reduces low cycle fatigue life principally at high strain levels for an as sortment of environmental and metallurgical conditions. In fatigue crack growth, irradiation appears both beneficial and detrimental depending on the nature of the irradiation field (thermal versus fast), test temperature and probably irradiation temperature.

Further implication--al though subject to change when additional data becomes available--is that low temperature, thermal-type irradiation condition could possibly have a more severe affect in fatigue $1 \mathrm{ife}$ than high temperature fast irradiation. The latter observation effects are based on a very small amount of data and do not give any information on possible brittle fracture sensitivity of highly irradiated fuel cladding at relatively low temperatures. 


\section{$5.4 .2-4$}

\section{REFERENCES}

1. L. A. James, "Estimation of Crack Extension in a Piping Elbow Using Fracture Mechanics Techniques", ASME paper number 74-PVP-14, Trans ASME, Journal of Pressure Vesse1 Technology, 1974.

2. W. E. Anderson, Personal Communication, Battelle-Northwest, 1970.

3. L. A. James and R. C. Knecht, "Fatigue Crack Propagation Behavior in Type 304 Stainless Steel in a Liquid Sodium Environment", (OUO), HEDL-SA-711, also submitted for publication.

OUO - Official Use Onty 



\section{EFFECT OF IRRADIATION ON WELD PERFORMANCE}




\section{EFFECT OF IRRADIATION ON WELD PERFORMANCE}

\section{TABLE OF CONTENTS}

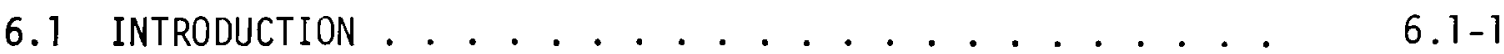

6.2 EFFECT OF IRRADIATION-, TEST-, AND MATERIAL CONDITIONS 6.2.1-1

6.2 .1 Introduction . . . . . . . . . . 6.2.1-1

6.2.2 Tensile Properties ........... 6.2.2.1-1

6.2.3 High Strain-Rate Properties ........ 6.2.3.1-1

6.3 OTHER FACTORS INFLUENCING IRRADIATION EFFECTS ON WELD

PERFORMANCE .................... 6.3-1

6.4 GENERAL RELATIONSHIPS OF IRRADIATED WELD PERFORMANCE

TO LMFBR PERFORMANCE . . . . . . . . . . . 6.4.1-1

6.4 .1 Introduction ............. 6.4.1-1

6.4.2 Influence on LMFBR Variables ........ 6.4.2.1-1

6.4.2.1 LMFBR Reactor Variables ...... 6.4.2.1-1

6.4.2.2 LMFBR Material Variables ...... 6. 6.4.2.2-1

6.4.3 General Implications on Irradiated High Strain

Rate Properties on LMFBR Components ...... 6.4.3.1-1

6.4.3.1 Pressure Vesse1 ........ 6.4.3.1-1

6.4.3.2 Core Components . . . . . . 6. 6.4.3.2-1 



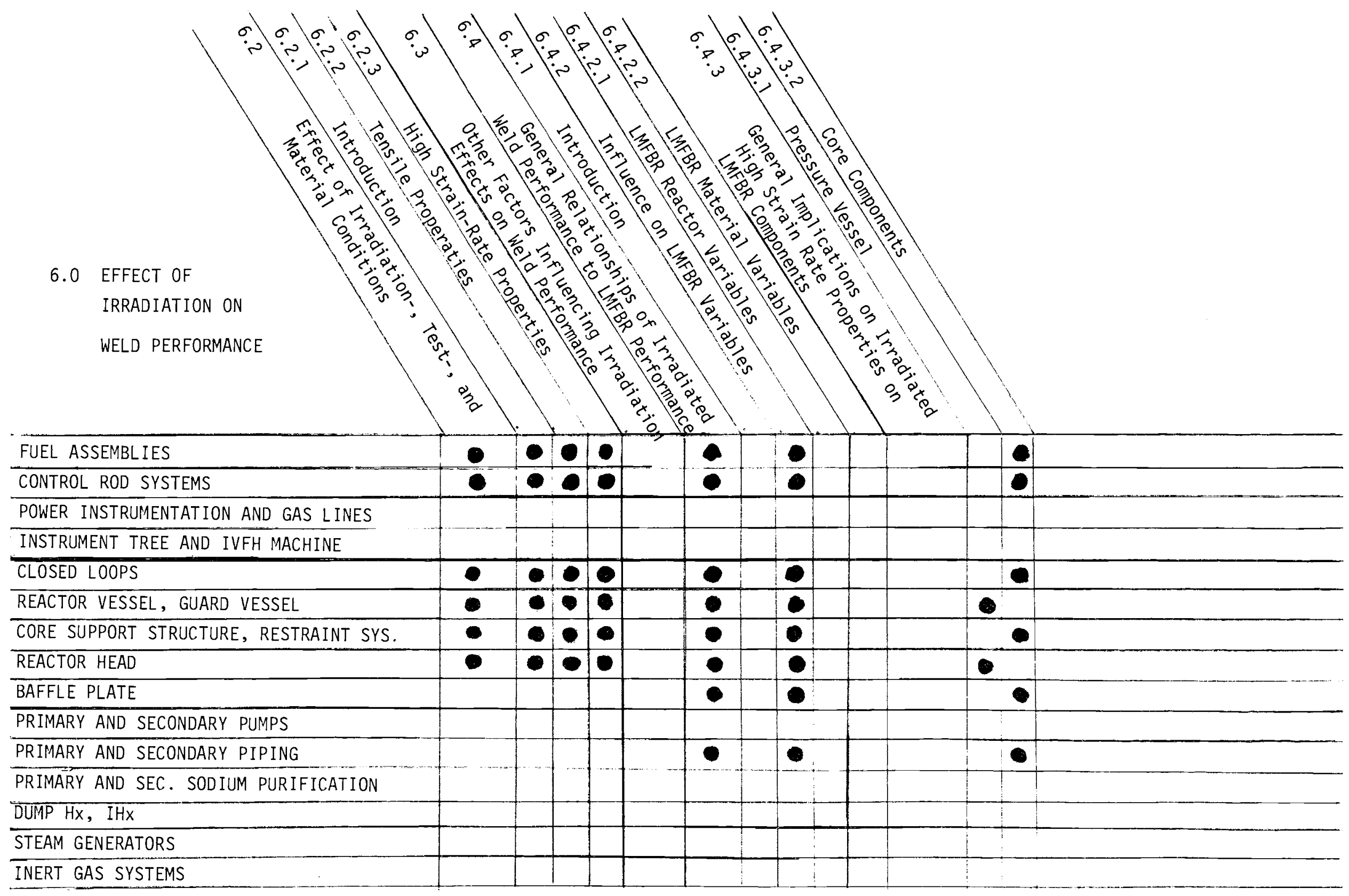





\section{IRRADIATION EFFECTS ON WELD PERFORMANCE}

\subsection{INTRODUCTION}

Studies of the effects of high fluence irradiation on the properties of welds in candidate fast breeder reactor materials is of recent origin. Through January, 1971, postirradiation mechanical property data included only that on tensile properties, and only at relatively low fluence levels $\left(0.5\right.$ to $3.5 \times 10^{21} \mathrm{n} / \mathrm{cm}^{2}, E>0.1$ $\mathrm{MeV})$. An active program is now underway to evaluate irradiation effects on the elevated temperature properties of pipe and vessel weldments. The data is incomplete, as yet.

The qualitative effects of irradiation on metals and alloys, namely matrix hardening and alloy embrittlement, were discussed in Section 2.1. Quantitative discussions of the effects of irradiation on base metal properties were presented for tensile properties (Chapter 2.0), high strain-rate properties (Chapter 3.0), and creeprupture properties (Chapter 4.0 ). It will be the purpose of this chapter to review the available data on weld performance in terms of the effects of "irradiation-damage," i.e., the relationships between temperature, fluence and mechanical properties; to point out currently unresolved problem areas; and to discuss, in a general way, the significance of the properties of irradiated weldments to LMFBR performance. 


\subsection{EFFECT OF IRRADIATION-, TEST-, AND MATERIAL CONDITIONS}

\section{2 .1 INTRODUCTION}

Several factors influencing the effect of irradiation on weld properties have been elucidated to date. The first group of factors are those associated with the irradiation and test conditions, as noted in Sections 2.2.1, 3.2.1 and 4.2.1, namely irradiation temperature, irradiation fluence, test temperature and strain-rate. The second group is "material conditions;" that is, those associated with the weld process itself, with the type of structure (pipe or vessel) and with the alloy being welded.

These factors will be discussed in terms of their effects on the tensile, high strain-rate properties of weldments (postirradiation creep-rupture data on weldments are, as yet, unavailable). 


\subsubsection{TENSILE PROPERTIES}

\subsubsection{Plate Weldments}

A variety of processes are being evaluated for welding 304 s.s. plate, particularly for FBR vessels. Table 6.2.2.1-1 ${ }^{(1)}$ and Figures $6 \cdot 2 \cdot 2.1-1^{(2)}$ and $-2^{(3)}$ show the effects of fast neutron irradiation on the strength and ductility of 304 s.s. base metal and weldments exemplifying four of these weld processes. For the maximum fluence levels obtained on the weldments $(26.5 \times$ $10^{21} \mathrm{n} / \mathrm{cm}^{2}, \mathrm{E}>0.1 \mathrm{MeV}$ in Table 6.2.2.1-1), the weldments are stronger and less ductile than the 304 base metal. The TIG process shows the highest strength (though the rate of increase of strength with fluence is greatest for the MIG process, Figure 6.2.2.1-1) and the lowest ductility.

For irradiation/test temperatures $\leq 900^{\circ} \mathrm{F}$, the minimum total elongation just does penetrate below the $10 \%$ value (TIG process, $\left.3.5 \times 10^{21} \mathrm{n} / \mathrm{cm}^{2} \mathrm{E}>0.1 \mathrm{MeV}\right)$. However, uni form elongation, at irradiation/test temperature $\leq 900^{\circ} \mathrm{F}$ at the maximum fluence of $3.5 \times 10^{21} \mathrm{n} / \mathrm{cm}^{2}$, and both uniform and total elongation at irradiation/test temperature $=1100^{\circ} \mathrm{F}$ at the maximum fluence of $6.0 \times 10^{21}$ $\mathrm{n} / \mathrm{cm}^{2}$, exhibit values that are substantially less than $10 \%$. A uniform elongation as low as $2.9 \%$ was recorded for the GTA (TIG) process at a fluence of only $3.5 \times 10^{21} \mathrm{n} / \mathrm{cm}^{2}\left(\mathrm{~T}_{\mathrm{imr}}^{2} 800^{\circ} \mathrm{F}\right.$, $\left.\mathrm{T}_{\text {test }}=900^{\circ} \mathrm{F}\right)$. Since uniform elongation, rather than total elongation, is probably the more relevant mechanical property when defining the $10 \%$ strain limit for transient events $(4)$, these low values are significant.

Another weld process for 304 stainless steel vessel material is a shielded metal arc process utilizing type 308 stainless steel (CRE) weld metal. (CRE, meaning Controlled Residual Elements, represents an ORNL development in which boron, phosphorous and ferrotitanium are added to increase weld ductility.) ${ }^{(5)}$ In Table 6.2.2.1-2(6), the postirradiation tensile properties are presented for 304 s.s. base material specimens, 308 s.s. weld specimens and 304/308 composite 
6.2.2.1-2

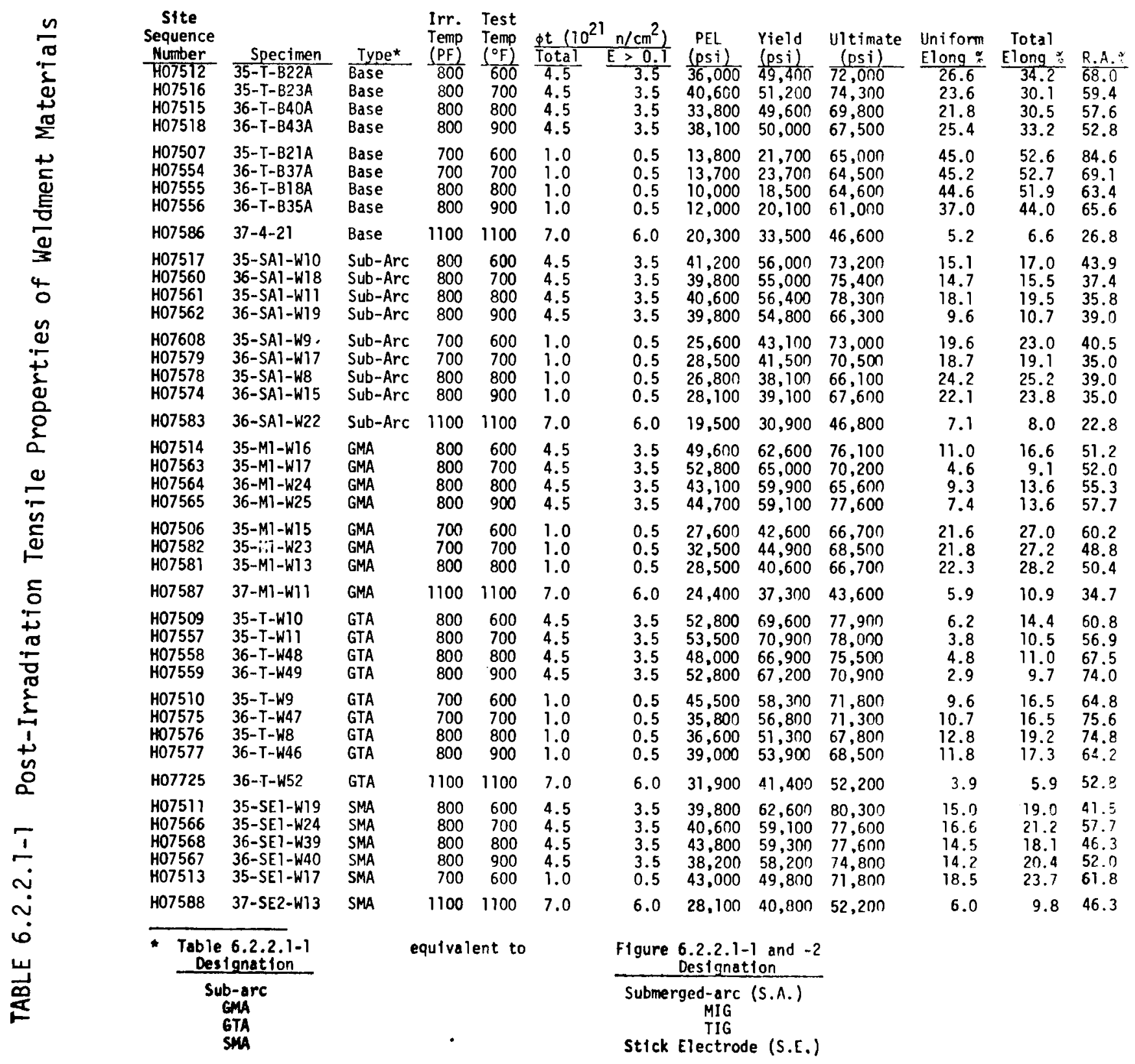




\section{$6.2 .2 .1-3$}

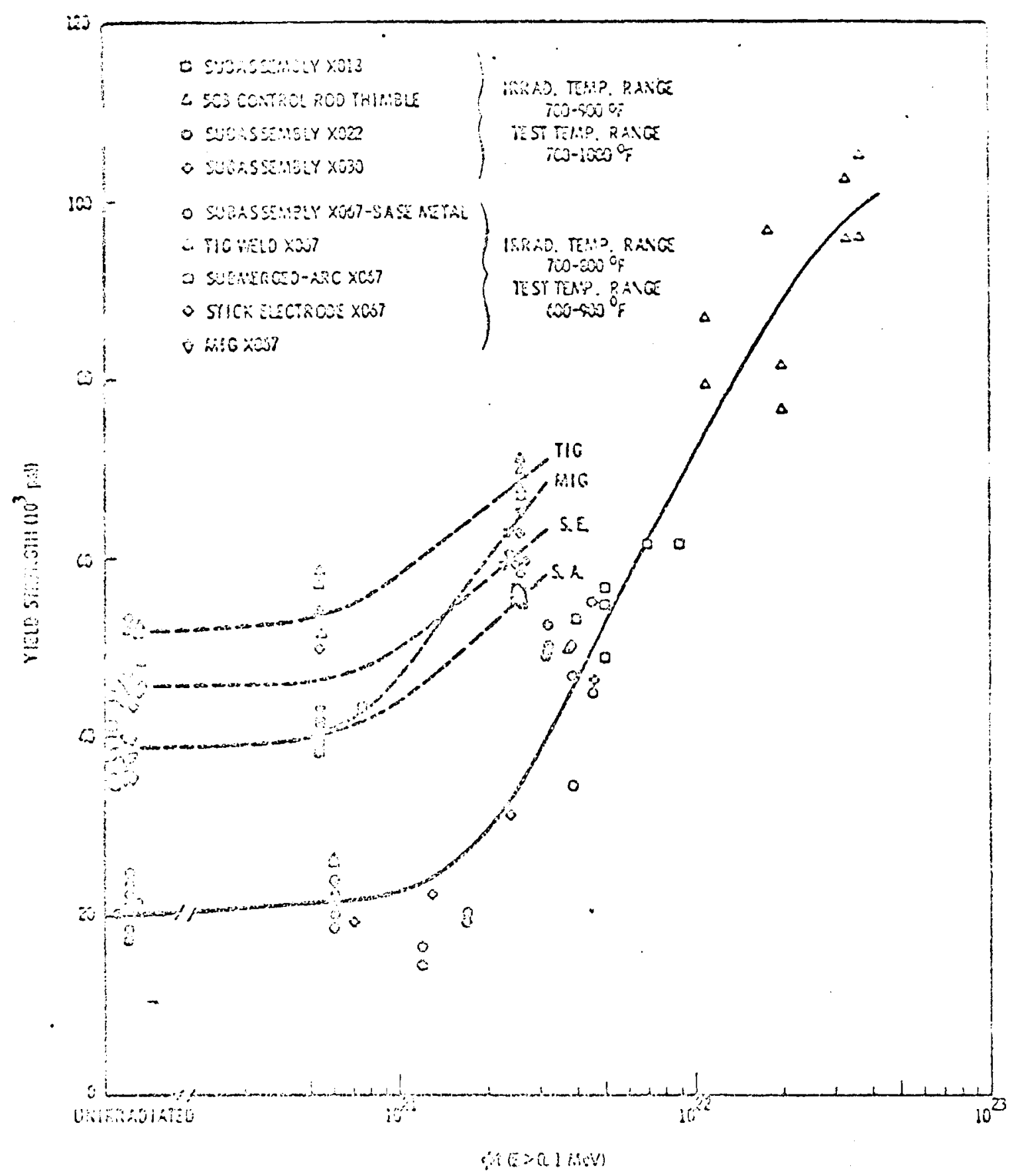

FIGURE 6.2.2.1-1 Yield Strength of Fast Reactor Irradiated AISI Type 304 Stainless Steel as a Function of Neutron Fluence (E>0.1 MeV). 
$6.2 \cdot 2.1-4$

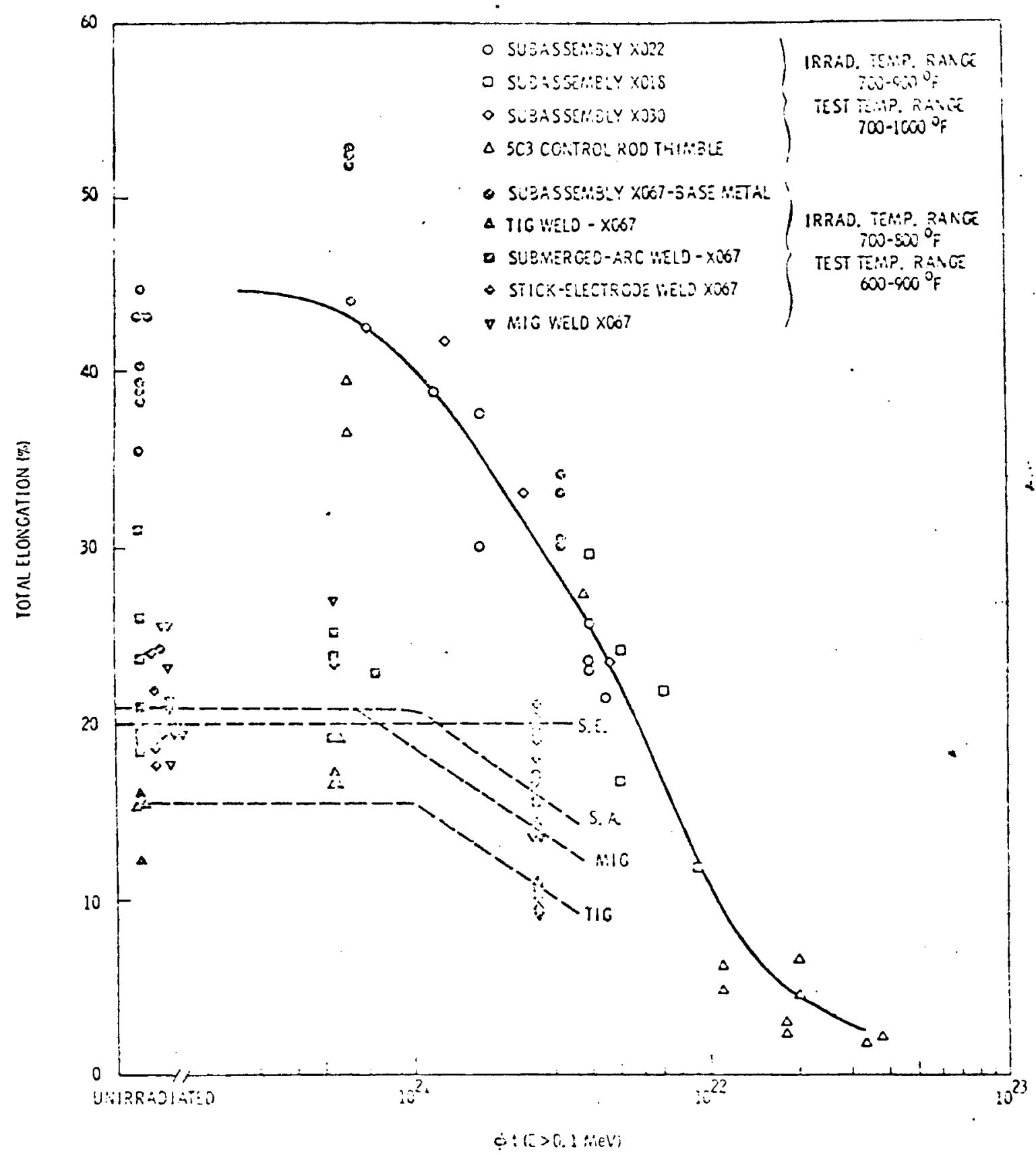

FIGURE 6.2.2.1-2 Tensile Ductility of Fast Reactor Irradiated AISI Type 304 Stainless Steel as a Function of Neutron Fluence (E>0.1 MeV). 
TABLE 6.2.2.1-2 Postirradiation Tensile Results from FTR Vessel Base and Weld Materials

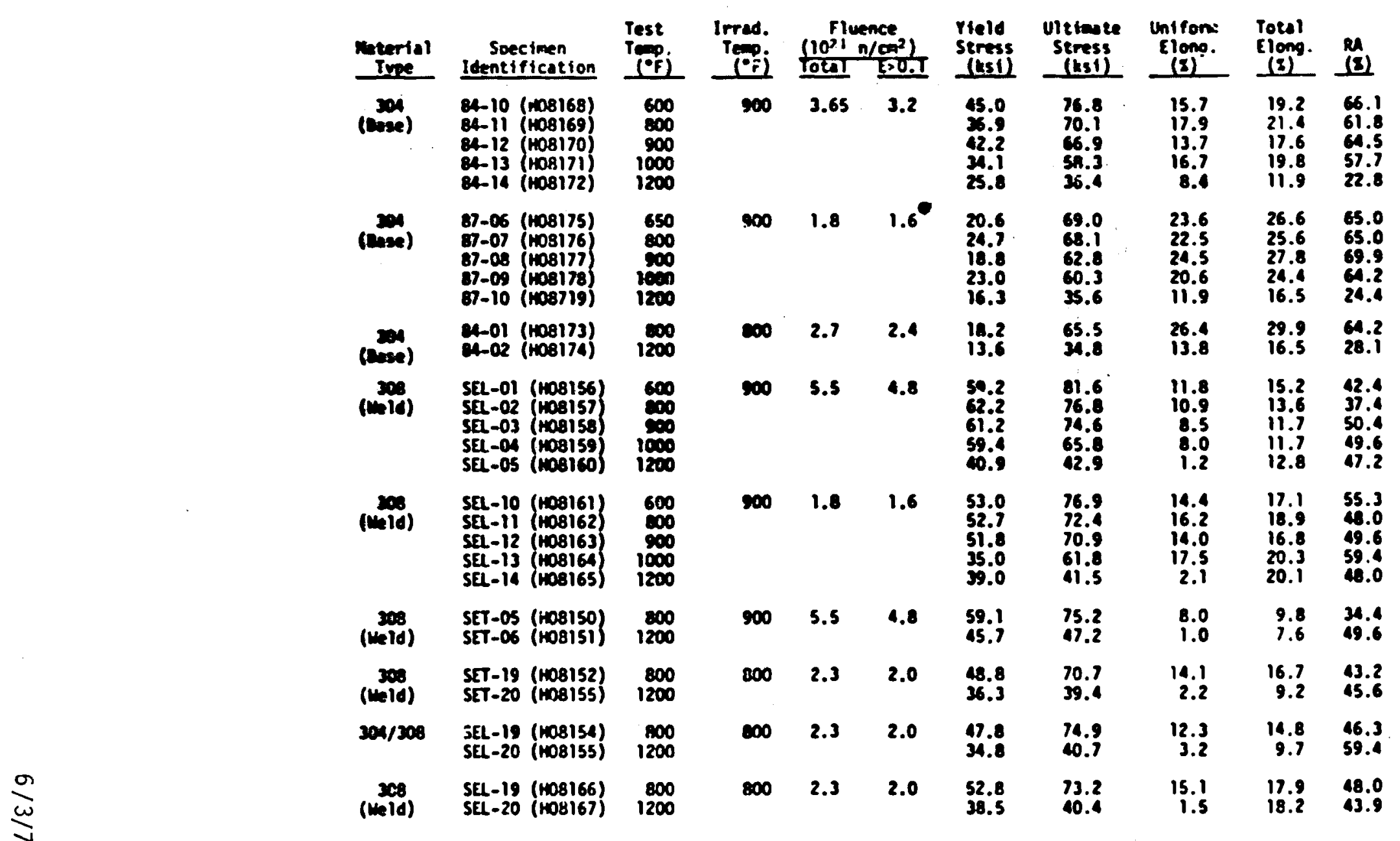


specimens (with fusion surface in the approximate center of the gage length). The designation SET represents weld specimens taken transverse to the weld axis; SEL represents weld specimens taken longitudinally to the weld axis. As the table indicates for the 308 weld specimens, for specimens irradiated at $800^{\circ} \mathrm{F}$ or $900^{\circ} \mathrm{F}$ to a fluence of $4.8 \times 10^{21} \mathrm{n} / \mathrm{cm}^{2}$ and tested at $\geq 900^{\circ} \mathrm{F}$, uniform elongations well below $10 \%$ are obtained. At lower fluences, similarly low uniform elongations also will occur in the 308 specimens at a test temperature of $1200^{\circ} \mathrm{F}$, which might suggest low available ductility during a transient temperature ramp from 800 or $900^{\circ} \mathrm{F}$ to $1200^{\circ} \mathrm{F}$. Even the total elongation values will, in some instances, penetrate the $10 \%$ level, the transverse ductilities usually being lower than the longitudinal. A graphical representation of the base metal and weld metal properties for Table 6.2.2.1-2 are presented in Figures 6.2.2.1-3 through -8 . (7) These values for 308 weld specimens are lower than for the corresponding 304 base metal specimens. 


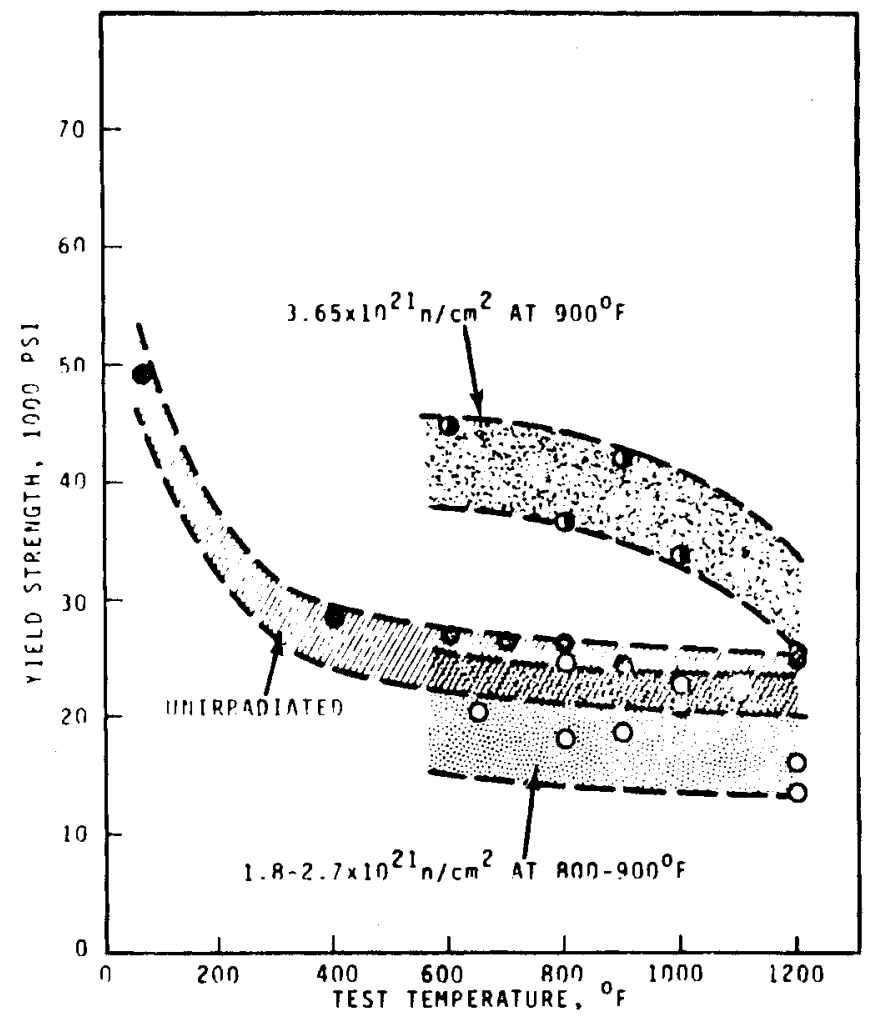

FIGURE 6.2.2.1-3 Pre- and Post-Irradiation Yield Strength of Prototypic FTR Vessel Type 304 Plate HT \#300188-1A. 
$6.2 .2 .1-8$

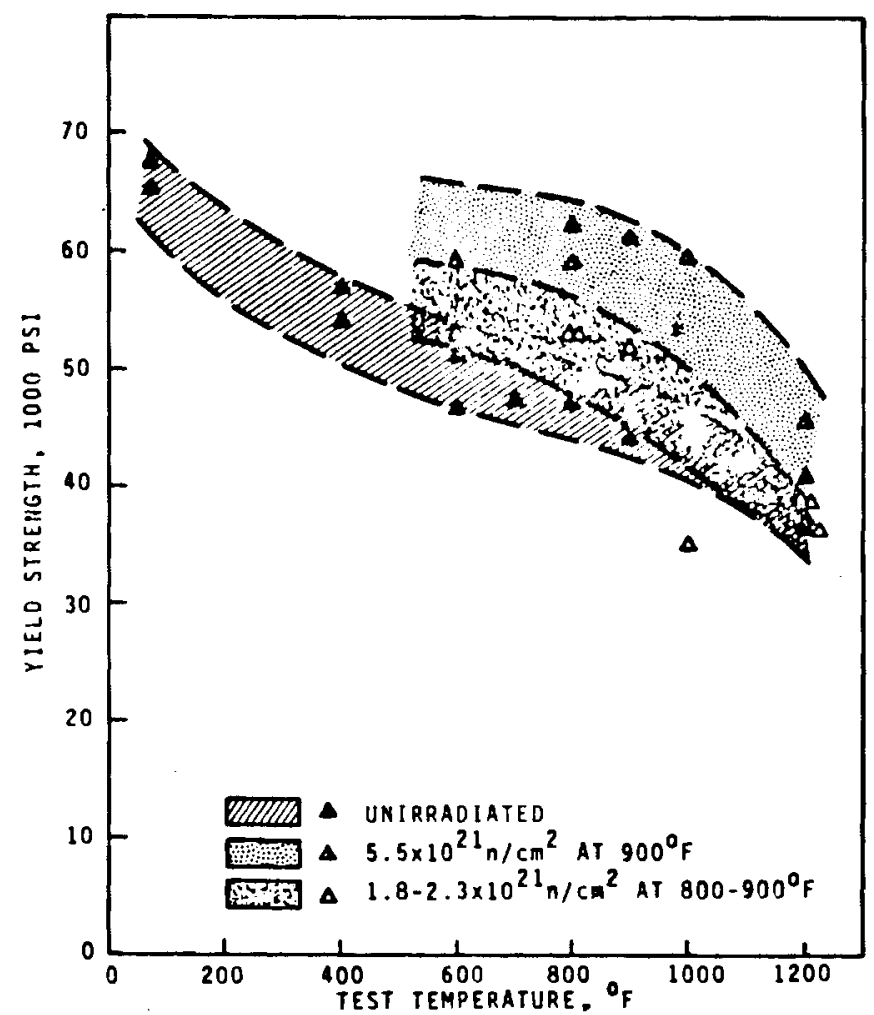

FIGURE 6.2.2.1-4 Pre- and Post-Irradiation Yield Strength of FTR Vesse 1 We1dment Material - Type 308 (CRE). 
6.2.2.1-9

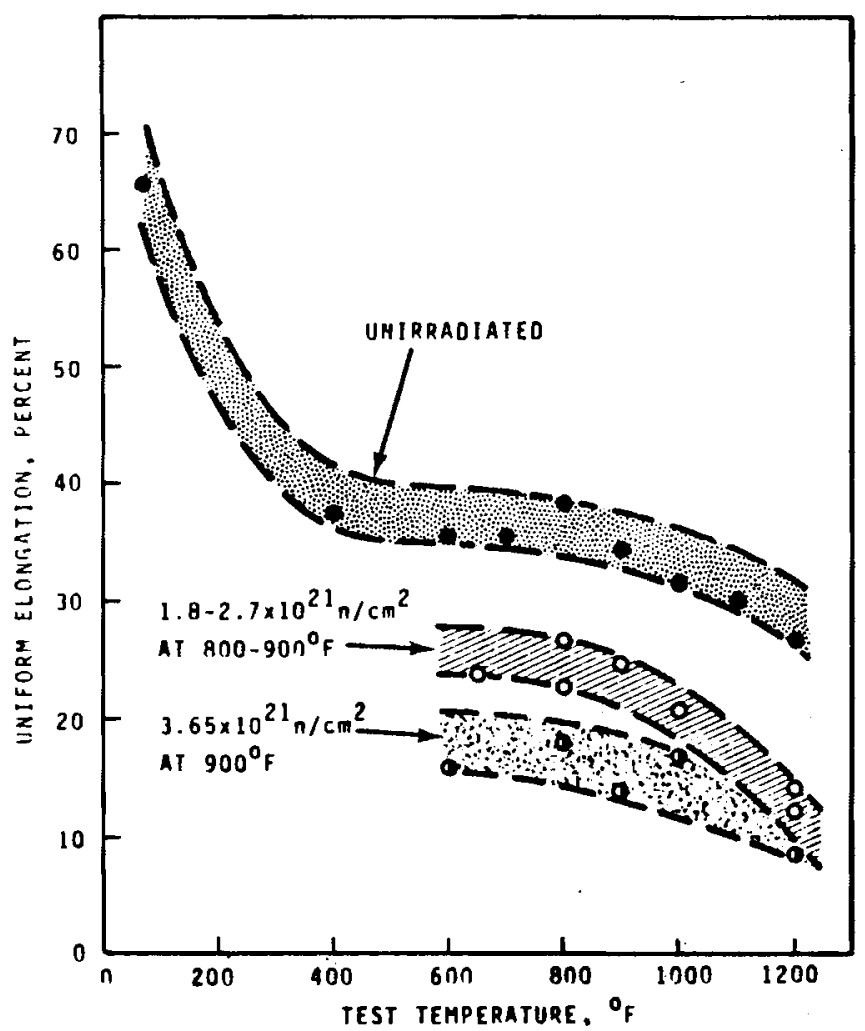

FIGURE 6.2.2.1-5 Pre- and Post-Irradiation Uniform Elongation of Prototypic FTR Vessel Type 304 Plate - HT \#300188-1A. 
$6.2 .2 .1-10$

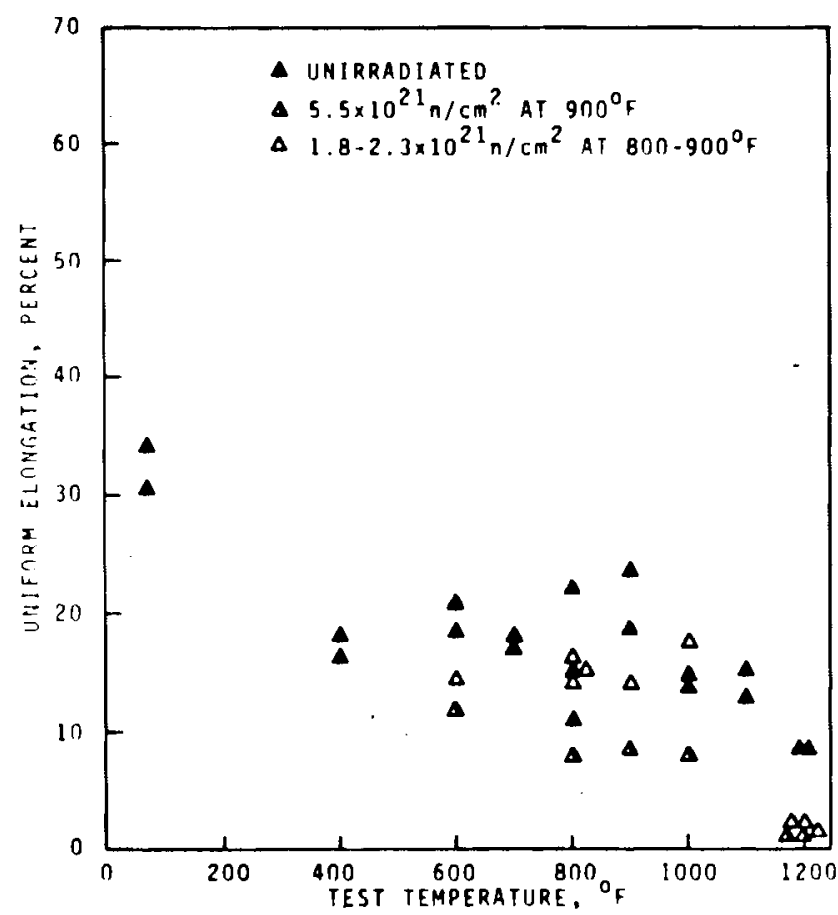

FIGURE 6.2.2.1-6 Pre- and Post-Irradiation Uniform Elongation of FTR Vessel Weldment Material - Type 308 (CRE)'. 


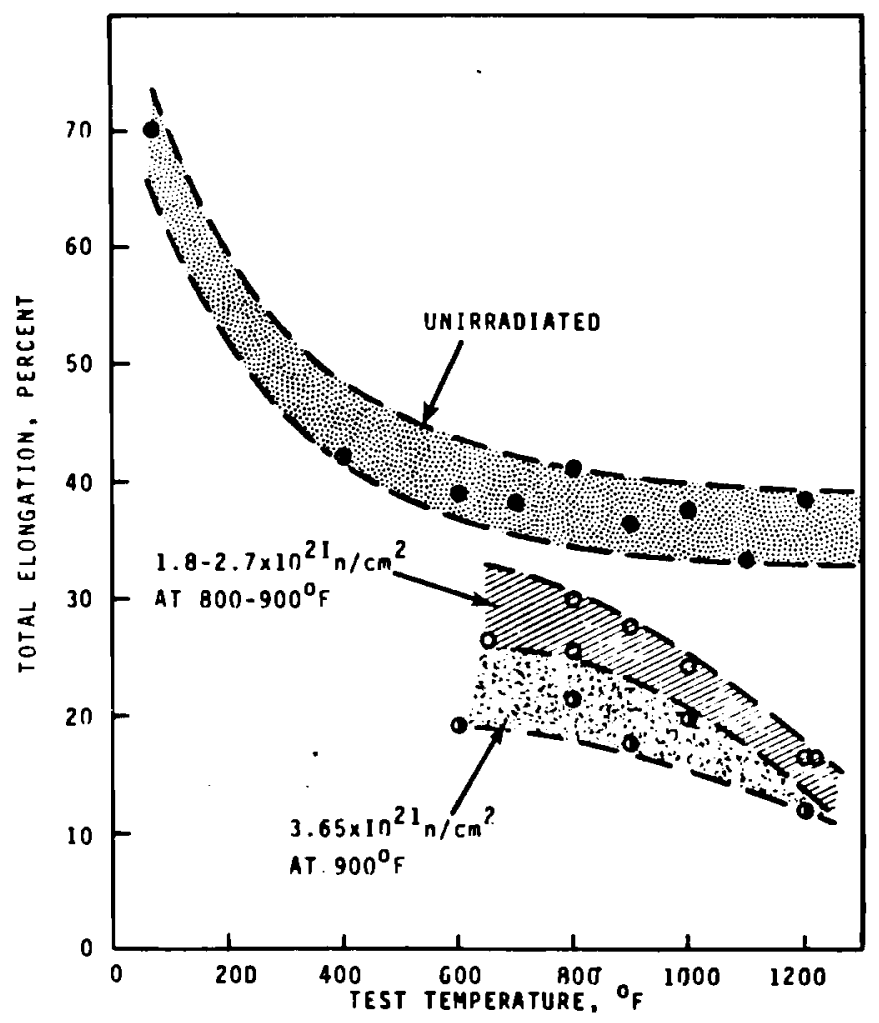

FIGURE 6.2.2.1-7 Pre- and Post-Irradiation Total Elongation of Prototypic FTR Vessel Type 304 Plate - HT \#300188-1A. 


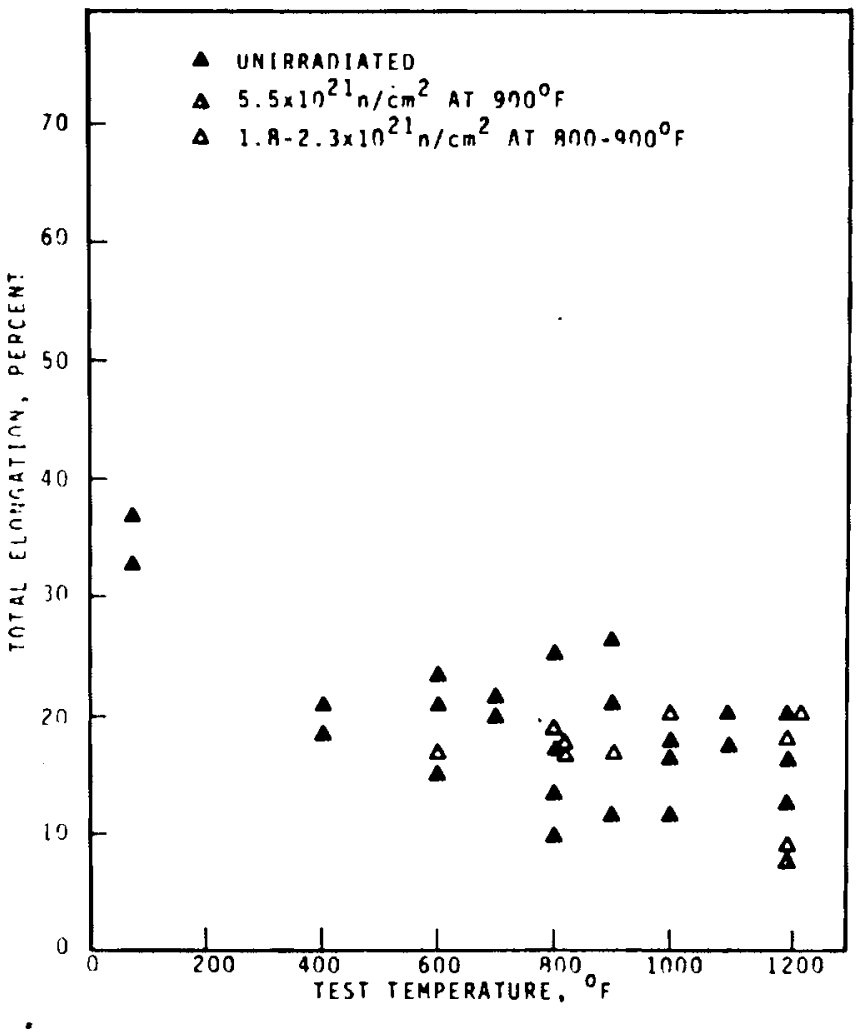

FIGURE 6.2.2.1-8 Pre- and Post-Irradiation Total Elongation of FTR Vessel Weldment Material - Type 308 (CRE). 


\section{REFERENCES}

1. "Material Considerations in Support of the FFTF Preliminary Safety Analys is, Report - RM 9, Vol I," HEDL-TME 71-53, April 1971, p. 2-70 (으).

2. "DRRD, HEDL, WARD, DOL, BPNL, "LMFBR Materials Test Information Meeting," March 15-16, 1973, Figure 42.

3. ibid, Figure 45.

4. H. D. Garkisch, "Preliminary LMFBR Core Structural Design Criteria," WARD-3045T2C-5, February 1973, p. 27.

5. P. Patriarca, "Fuels and Materials Development Program, Quarterly Progress Report for Period Ending June 30, 1972," ORNL-TM-3969, September 1972, p. 73.

6. "Monthly Technical Progress Report, Hanford Engineering Development Laboratory, November 1972," HEDL-TME 72-11, p. B-28.

7. ibid, pp. B-29 through B-32. 


\subsubsection{Pipe Weldments}

Postirradiation tensile properties have been reported for 316 stainless steel weld metal deposited by the gas tungsten-arc (GTA) process in $316 \mathrm{plate}$ as a result of a study of weld processes and materials potentially similar to those to be expected in FBR primary piping. Tables 6.2.2.2-1(1) and $-2(1)$ present the post- and pre-irradiation properties, respectively, of GTA-deposited 316 in the as-welded condition and in two post-weld annealed conditions. Irradiation conditions varied in fluence from 0.8 to $7.2 \times 10^{21} \mathrm{n} / \mathrm{cm}^{2}$ ( $\mathrm{E}>0.1 \mathrm{MeV}$ ) and from 900 to $1100^{\circ} \mathrm{F}$. The uniform elongation of the as-welded condition is uniformly less than $10 \%$, even at the lowest fluences, and decreases with increasing test temperature. For the $900^{\circ} \mathrm{F}$ temperature at $6.8 \times 10^{21} \mathrm{n} / \mathrm{cm}^{2}$, even total elongation is $<10 \%$. While post-weld annealing, particularly the $1950^{\circ} \mathrm{F} / 1 \mathrm{hr}$ anneal, improves ductility, penetration of the $10 \%$ level occurs in uniform elongation for all test temperatures after the $900^{\circ} \mathrm{F}, 6.8 \times 10^{21} \mathrm{n} / \mathrm{cm}^{2}$ irradiation. 
TABLE 6.2.2.2-1 Tensile Properties of Irradiated GTA-Deposited Type 316

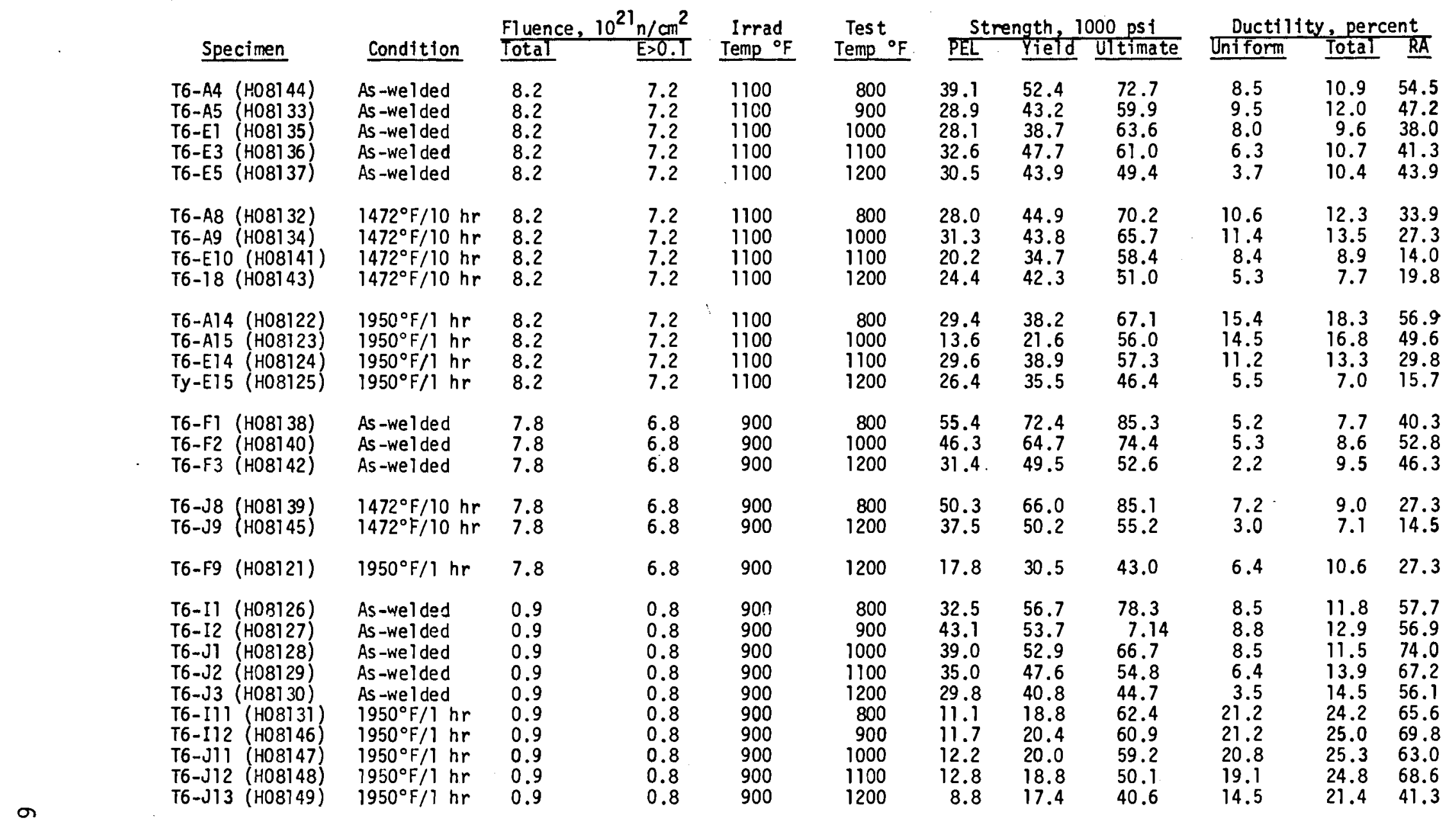


TABLE 6.2.2.2-2 Pre-Irradiation Tensile Properties of GTA-Deposited Type 316

\begin{tabular}{|c|c|c|c|c|c|c|c|c|}
\hline Specimen & Condition & $\begin{array}{l}\text { Test } \\
\text { Temp }{ }^{\circ} \mathrm{F} \\
\end{array}$ & PEL (psi) & $\begin{array}{c}0.2 \% \text { Yield } \\
\text { Stress (psi) }\end{array}$ & $\begin{array}{c}\text { Ultimate } \\
\text { Stress (psi) }\end{array}$ & $\begin{array}{l}\text { Uniform } \\
\text { Elong }(\%)\end{array}$ & $\begin{array}{l}\text { Total } \\
\text { Elong }(\%)\end{array}$ & $\mathrm{RA}(q)$ \\
\hline $\begin{array}{ll}\text { T6-E6 } & (\text { HO8050) } \\
\text { T6-I5 } & (\mathrm{H} 0805 \mathrm{i}) \\
\text { T6-B1 } & (\mathrm{H} 08052) \\
\text { T6-J5 } & (\mathrm{H} 08053) \\
\text { T6-F4 } & (\mathrm{H} 08054)\end{array}$ & $\begin{array}{l}\text { As-welded } \\
\text { As-welded } \\
\text { As-welded } \\
\text { As-welded } \\
\text { As-welded }\end{array}$ & $\begin{array}{r}800 \\
900 \\
1000 \\
1100 \\
1200\end{array}$ & $\begin{array}{l}52,100 \\
52,6 C \cdot 0 \\
45,900 \\
41,300 \\
38,000\end{array}$ & $\begin{array}{l}58,300 \\
57,400 \\
52,500 \\
47,300 \\
43,300\end{array}$ & $\begin{array}{l}67,600 \\
67,800 \\
63,400 \\
56,700 \\
50,500\end{array}$ & $\begin{array}{r}9.6 \\
12.8 \\
13.1 \\
14.2 \\
10.8\end{array}$ & $\begin{array}{l}15.0 \\
17.7 \\
17.8 \\
19.7 \\
21.7\end{array}$ & $\begin{array}{l}61.8 \\
67.5 \\
68.0 \\
70.2 \\
75.2\end{array}$ \\
\hline 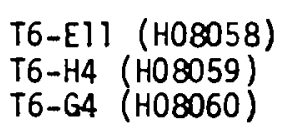 & $\begin{array}{l}1472^{\circ} \mathrm{F} / 10 \text { hours } \\
1472^{\circ} \mathrm{F} / 10 \text { hours } \\
1472^{\circ} \mathrm{F} / 10 \text { hours }\end{array}$ & $\begin{array}{r}800 \\
1000 \\
1200\end{array}$ & $\begin{array}{l}33,300 \\
32,100 \\
31,200\end{array}$ & $\begin{array}{l}37,700 \\
36,900 \\
35,700\end{array}$ & $\begin{array}{l}69,200 \\
70,600 \\
55,000\end{array}$ & $\begin{array}{l}15.0 \\
14.3 \\
14.2\end{array}$ & $\begin{array}{l}17.8 \\
18.2 \\
23.6\end{array}$ & $\begin{array}{l}50.0 \\
42.5 \\
55.0\end{array}$ \\
\hline $\begin{array}{l}\text { To-El7 (H08055) } \\
\text { T6-I16 (H08056) } \\
\text { T6-G5 (H08057) }\end{array}$ & $\begin{array}{l}1950^{\circ} \mathrm{F} / 1 \text { hour } \\
1950^{\circ} \mathrm{F} / 1 \text { hour } \\
1950^{\circ} \mathrm{F} / 1 \text { hour }\end{array}$ & $\begin{array}{r}800 \\
1000 \\
1200\end{array}$ & $\begin{array}{l}13,800 \\
13,200 \\
11,200\end{array}$ & $\begin{array}{l}18,100 \\
15,600 \\
13,500\end{array}$ & $\begin{array}{l}61,400 \\
56,900 \\
45,600\end{array}$ & $\begin{array}{l}28.7 \\
32.0 \\
31.9\end{array}$ & $\begin{array}{l}33.8 \\
37.3 \\
42.5\end{array}$ & $\begin{array}{l}69.2 \\
66.7 \\
59.5\end{array}$ \\
\hline
\end{tabular}


$6.2 .2 .2-4$

\section{REFERENCES}

1. "Monthly Technical Progress Report, Hanford Engineering Development Laboratory, HEDL-TME 72-7, July 1972, p. B-7. 


\section{$6.2 .3 .1-1$}

\subsubsection{HIGH STRAIN-RATE PROPERTIES}

\subsubsection{Plate Weldments}

Weldments, representative of LMFBR vessel fabrication welds in $23 / 8$ in. thick 304 stainless steel base plate containing 308 stainless steel welds produced by a manual shielded metal arc process were irradiated at $900^{\circ} \mathrm{F}$ and then subjected to high strain-rate tests at $900^{\circ} \mathrm{F}$ (1)

Figures 6.2.3.1-1 and 6.2.3.1-2 present data on the effect of irradiation on strength and ductility at several strain rates. Though both total and uniform elongation decrease with strain rate, they do not penetrate the $10 \%$ value of the highest fluence obtained, $4.8 \times 10^{21} \mathrm{n} / \mathrm{cm}^{2}(\mathrm{E}>0.1 \mathrm{MeV})$. 

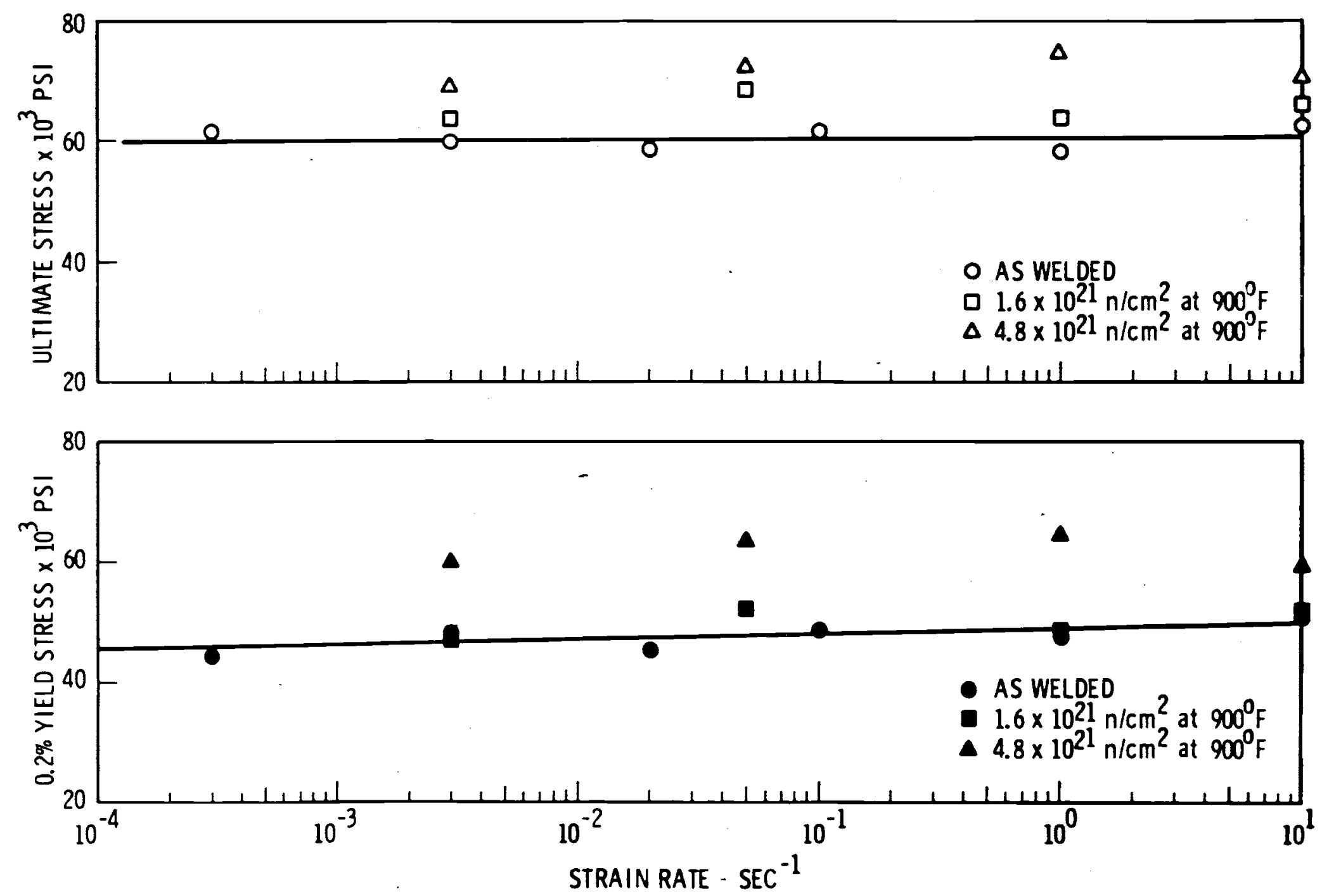

FIGURE 6.2.3.1-1 Effect of Irradiation on the Strength of Type 308 SMA Weld Metal at $900^{\circ} \mathrm{F}$ for Several Strain Rates. 

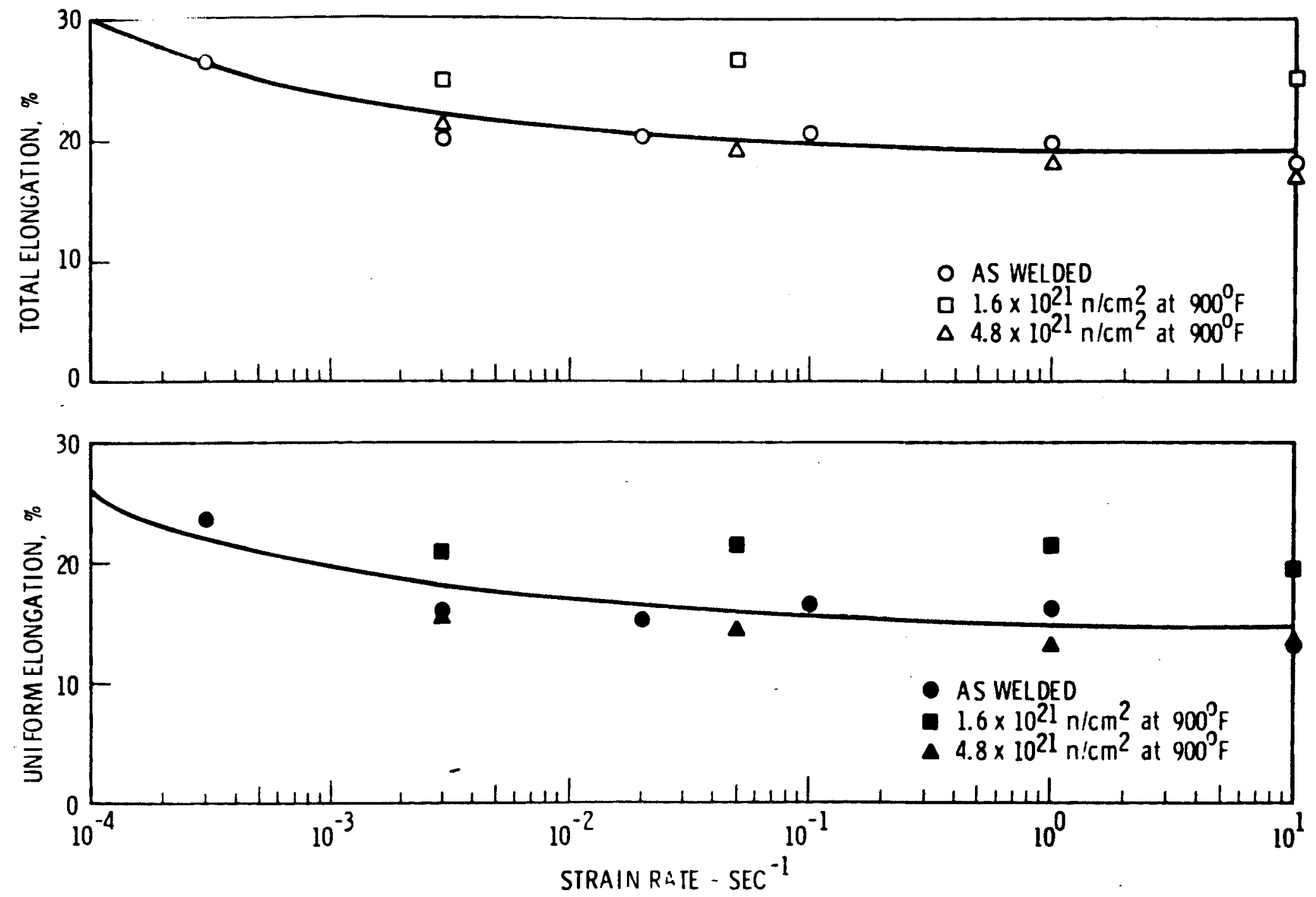

FIGURE 6.2.3.1-2 Effect of Irradiation on the Ductility of Type 308 SMA Weld Metal at $900^{\circ} \mathrm{F}$ for Several Strain Rates. 


\section{REFERENCES}

1. J. M. Steichen, "High Strain Rate Tensile Properties of Prototypic FTR Vessel Type 308 Weld Metal (RM-32)," HEDL-TME 73-16, January 1973. 


\subsection{OTHER FACTORS INFLUENCING IRRADIATION EFFECTS \\ ON WELD PERFORMANCE}

The other factors influencing irradiation effects on weld performance can be expected to generally be similar to those described in Sections 2.3.2 and 3.3.2, for tensile and high strain-rate properties, respectively. A more complete definition and analysis of these factors must await more data. 


\section{$6.4 .1-1$}

\subsection{GENERAL RELATIONSHIP OF IRRADIATED WELD PERFORMANCE TO LMFBR PERFORMANCE}

\subsubsection{INTRODUCTION}

Irradiated weld properties are specified as design criteria for vessel and core components. As yet, data from irradiations at fluences and temperatures and on all relevant weld processes and material parameters are incomplete. Prediction of properties in relevant regimes will require extrapolation until these gaps are filled.

Many of the remarks in this section are related to the FFTF but are of general application to future LMFBRs as wel1. 


\section{$6.4 .2 .1-1$}

\subsubsection{INFLUENCE OF LMFBR VARIABLES}

\subsubsection{LMFBR Reactor Variables}

As noted in Section 2.4.21, with regard to tensile

properties, the major variables are high fluence (up to $2-3 \times 10^{23}$ in a commercial LMFBR) and temperature. Other reactor variables that can have an influence are as noted in that section. 


\subsubsection{LMFBR Materials Variables}

Current material concepts for LMFBR (FFTF) call for $20 \%$ cold-worked 316 stainless steel for fuel assemblies and control and safety rod guide tubes, solution annealed 304 for core support structure and the pressure vesse1, and radial shields composed of 304 stainless stee1, nickel and Inconel 718, as noted in Section 2.4.2.2 of Chapter 2.0, "Effect of Irradiation on Tensile Properties." The expected temperature/fluence ranges for the FFTF were presented in Figure 2.4.2.2-1.

The criteria for weld performance is an end-offlie tensile ductility of $10 \%$, as noted in Section 2.4.2.2 and Table 2.4.3.2-3. The extremes of fluences that are to be imposed on welds, as noted in Section 2.4.2.2 (Figure 2.4.2.2-1) and Section 2.4.3.2 (Tables 2.4.3.2-1 through -3) are from $4.3 \times 10^{19} \mathrm{n} / \mathrm{cm}^{2}\left(\right.$ at $\left.920^{\circ} \mathrm{F}\right)$ for the vessel all the way to 0.7 to $1.3 \times 10^{22}$ (at 800 to $100^{\circ} \mathrm{F}$ ) for the radial shields.

Fluence limits for TIG welds of 308 in 304 base metal, as enumerated by FFTF documentation, were presented in Section 2.4.2.2, Table 2.4.2.2-1B. Total fluence to produce a ductility (total elongation) of not less than $10 \%$ elongation allowed up to $4.3 \times 10^{21} \mathrm{n} / \mathrm{cm}^{2}$ (total) in the $700-900^{\circ} \mathrm{F}$ temperature range. Data in Table 6.2.2.1-1 indicates this is only possible for total elongation, but not for uniform elongation. This may also be true at some temperatures for 308 welds produced by the shielded metal arc process, as indicated in Table 6.2.2.1-2 and Figures 6.2.2.1-6 and -8 . Moreover, if subjected to transients, where high strain-rates accompany an increase in temperature, uniform elongation will probably be reduced even more (see Figures $6.2 \cdot 2.1-6$ and -8 and 6.2.3.1-2). 


\section{$6.4 .3 .1-1$}

\subsubsection{GENERAL IMPLICATIONS OF IRRADIATED WELD PERFORMANCE ON LMFBR}

COMPONENTS

\subsubsection{Pressure Vessel}

Since over a 20 year reactor design life, fluence

levels at the pressure vessel are expected to be no greater than $3.8 \times 10^{19} \mathrm{n} / \mathrm{cm}^{2}$ ( $\mathrm{E}>0.1 \mathrm{MeV}$ ) (see Section 2.4.2.2), $10 \%$ residual elongation (total or uniform) is expected for welds in 304 stainless stee1 plate. 


\subsubsection{Core Components}

Core components will be subjected to a wide range of design fluence levels $\left(\sim 10^{21}\right.$ to $\left.>10^{23}\right)$, temperatures ( 800 to $1400^{\circ} \mathrm{F}$ ) and design lifetimes ( 1 to 20 years).

Tables 2.4.3.2-1 through 2.4.3.2-3 have presented total design fluence for large core structures. Table 2.4.3.2-1 which presents 304 stainless steel structures, indicates fluence requirements for welds of from 2.2 to $4.1 \times 10^{21} \mathrm{n} / \mathrm{cm}^{2}$ (total). As pointed out in Section 6.4.2.2, for the highest fluence levels required, uniform elongation values are below $10 \%$ for several weld processes and under transient conditions both uniform and total elongations would be further reduced. For the GTA process, even a total fluence of only $1 \times 10^{21} \mathrm{n} / \mathrm{cm}^{2}$ produces marginal uniform elongations. As to the requirement for a total fluence $2.2 \times 10^{21} \mathrm{n} / \mathrm{cm}^{2}$ for several components, data is insufficient to indicate where, between 1.0 and $4.5 \times 10^{21}$, the values below $10 \%$ begin.

In Table 2.4.3.2-2, total fluences are tested for the the radial shields. It is unclear how the welds, which are expected to experience from $7.2 \times 10^{21}$ to $1.3 \times 10^{22} \mathrm{n} / \mathrm{cm}^{2}$, can be expected to meet a $10 \%$ residual elongation criteria.

With regard to the welds tested in Table 2.4.3.2-3, for core restraints outer module, core basket, core barrel, and core support structure, which, in part, duplicates Table 2.4.3.2-1, similar comments apply as were made with regard to this latter Table in the second paragraph, above. 



\subsection{EFFECT OF FUEL CLAD INTERACTIONS ON MECHANICAL PROPERTIES}

\section{TABLE OF CONTENTS}

7.1 INTRODUCTION

7.2 MAJOR FACTORS INFLUENCING FUEL CLAD INTERACTION 7.2-1 7.2.1 Chemical Action 7.2.1-1

7.2.2 Mechanical Interaction 7.2.2-2

7.3 FUEL CLAD CHEMICAL ACTION AND CLAD MECHANICAL PROPERTIES EFFECTS

7.3.1 Characterization of Chemical Effects and Material \& Operating Variables 7.3.1-1

7.3.2 Chemical Effects on Strength and Ductility 7.3.2-1

7.3.3 Chemical Interaction Effects on Other Mechanical Properties

7.4 FUEL CLAD MECHANICAL ACTION AND CLAD MECHANICAL PROPERTIES EFFECTS

7.4.1 Characterization of Fuel Clad Mechanical Action Effects and Material Variables

7.4.2 Fuel Clad Interaction Effects on Clad Mechanical Properties

7.5 RELATIONSHIP OF FUEL CLAD INTERACTION EFFECTS TO FUEL DESIGN AND PERFORMANCE

7.5.1-1

7.5.1 Introduction

7.5.2 Effect of LMFBR Variables on Fuel Clad Interaction Processes

7.5.3 General Implications of Fuel Clad Interaction Processes on Fuel Operating and Safety Performance 


\section{LIST OF FIGURES}

Figure

Page

7. $2.1-1$

$\mathrm{MO}_{2}$ stainless steel (316 and 304 ) clad

pehetration versus clad temperature

$7.2 .1-2$

7.3.1-1 Summary of ANL results on depth of penetration

$7.3 .1-3$ of fission products in $304 \mathrm{~L}$ and 316 stainlesssteel cladding on EBR-II irradiated mixed-oxide fuel elements.

7.3.1-2 0xygen distribution in $U_{0.85} \mathrm{Pu}_{0.15^{0}}{ }_{2 \pm x}$ as

$7.3 .1-4$ computed by Rand and Markin.

7.3.1-3 Change in $\Delta \vec{G}_{0_{2}}$ with $0 / M$ ratio for natural-urania- 7.3.1-5 plutonia mixture at $2000^{\circ} \mathrm{K}$

7.3.2-1 Irradiation Temperature (Cladding Mean)

$7 \cdot 3 \cdot 2-5$

7.3.2-2 Effect of irradiation temperature on the rupture and 7.3.2-6 $0.2 \%$ yield strength of Type $304 \mathrm{~L}$ stainless-steel cladding tested at $11000 \mathrm{~F}\left(593^{\circ} \mathrm{C}\right.$ ) (burst tests using $1000 \mathrm{psi} / \mathrm{min}$ pressurization rate).

7.3.2-3 Irradiation Temperature (Cladding Mean) 7.3.2-7

7.3.2-4 Time to Rupture Hours 7.3.2-9

7.3.2-5 Cladding penetration in EBR-II subassemblies X040 7.3.2-11 and X040A-Normally calculated temperatures.

7.4.1-1 Total strain versus axial location FFTF hot pin. 7.4.1-2

7.4.1-2 Post irradiation gap between fuel and cladding 7.4.1-3

7.4.1-1 Compilation of fabrication, irradiation, and diametral 7.4.1-5 increase data for rods irradiated in EBR II

7.4.1-3 Effect of fission gas release model on fir fuel pin 7.4.1-6 cladding strain

7.4.1-7 Burnup when steady state clad strains (inelastic) in 7.4.1-7 the hot pin equal $0.2 \%$

7.4.1-5 Diametral increase as a function of burnup for $\quad$ 7.4.7-5 several sections of fuel rods irradiated in EBR-II 


\section{LIST OF FIGURES (continued)}

Figure

Page

7.4.1-6 Cladding plastic deformation as a function of burnup. 7.4.1-8

7.4.1-7 Plastic deformation as a function of smeared density. 7.4.1-9

7.4.2-1 Results of second order polynomial fit to stress- 7.4.2-2 rupture data on $20 \%$ cold worked 316 stainless steel tubing.

7.4.2-2 Creep damage and residual tensile ductility.

7.4.2-3 Total elongation of $20 \%$ C.W. type 316 .

$7.4 .2-5$

7.5.2-1 Effect of increase in temperature on cladding strain.

$7.5 .2-5$

7.5.2-2 The cladding outer surface plastic effective strain,

$7.5 .2-8$ the fuel pellet outer surface displacement, and the cladding inner surface displacement histories for the peak and average power FTR fuel pins at midplane during $3 \$ / \mathrm{sec}$ unterminated and secondary scram terminated with a nominal radial gap of $2.75 \mathrm{mils}-800^{\circ} \mathrm{F}$ inlet coolant

7.5.3-1 Uniaxial stress rupture - 316 SS

$7 \cdot 5 \cdot 3-2$

7.5.3-2 Biaxial stress rupture on $20 \%$ C.W. type 316 cladding

$7 \cdot 5 \cdot 3-3$

7.5.3-3 Effect of irradiation on FTR cladding strain during $10^{\circ} \mathrm{F} / \mathrm{sec}$ temperature transients (20\% CW type $316 \mathrm{SS}$ )

7.5.3-4 Effect of irradiation on FTR cladding strain during $2000 \mathrm{~F} / \mathrm{sec}$ temperature transients (20\% CW type $316 \mathrm{SS}$ )

$7 \cdot 5 \cdot 3-4$

$7 \cdot 5 \cdot 3-4$

7.5.3-5 Effect of irradiation on $10 \% \mathrm{CW} 316$ SS Cladding

$7 \cdot 5 \cdot 3-5$

$7.5 \cdot 3-7$ diated cladding

7.5.3-7 Effect of irradiation on the failure strength of irradiated $20 \%$ C.W. type 316 SS cladding 


\section{LIST OF TABLES}

Table

7.2-1

Behavior Regimes - Fuel Clad Interaction

$7.2-1$

7.2.2-1 Design Parameters Which Influence Fuel Clad Mechanical Interaction (Mixed Oxide Fuel) 7.2.2-2

7.3.2-1 PNL-1 Fuel Pin Burst Test Resu1ts-304L

7.3.2-2 Fuel Pin Parameters and Depth of Intergranular Attack

7.3.2-3 Biaxial Burst Behavior at $1200^{\circ} \mathrm{F}$ of PNL-17 Fuel Pin, Conduit, and Unirradiated Controls--20\% CW 316 SS

$7 \cdot 3 \cdot 2-10$

7.3.2-4 Biaxial Stress-Rupture Behavior at $1200^{\circ} \mathrm{F}$ of PNL-17 Fuel Pin, Conduit, and Unirradiated Controls- $-20 \%$ CW 316 SS

7.3.2-10

7.5.2-1 FFTF/LMFBR Fuel Performance Data

$7.5 .2-2$

7.5.2-2 Fuel Pin Cladding Strain Design Limits

$7.5 .2-3$

$7.5 .2-2$

"I

(continued)

$7.5 .2-4$

7.5.2-3 Summary-Mixed-0xide Fuel Pin Response to Overpower Transients

$7 \cdot 5 \cdot 2-7$ 


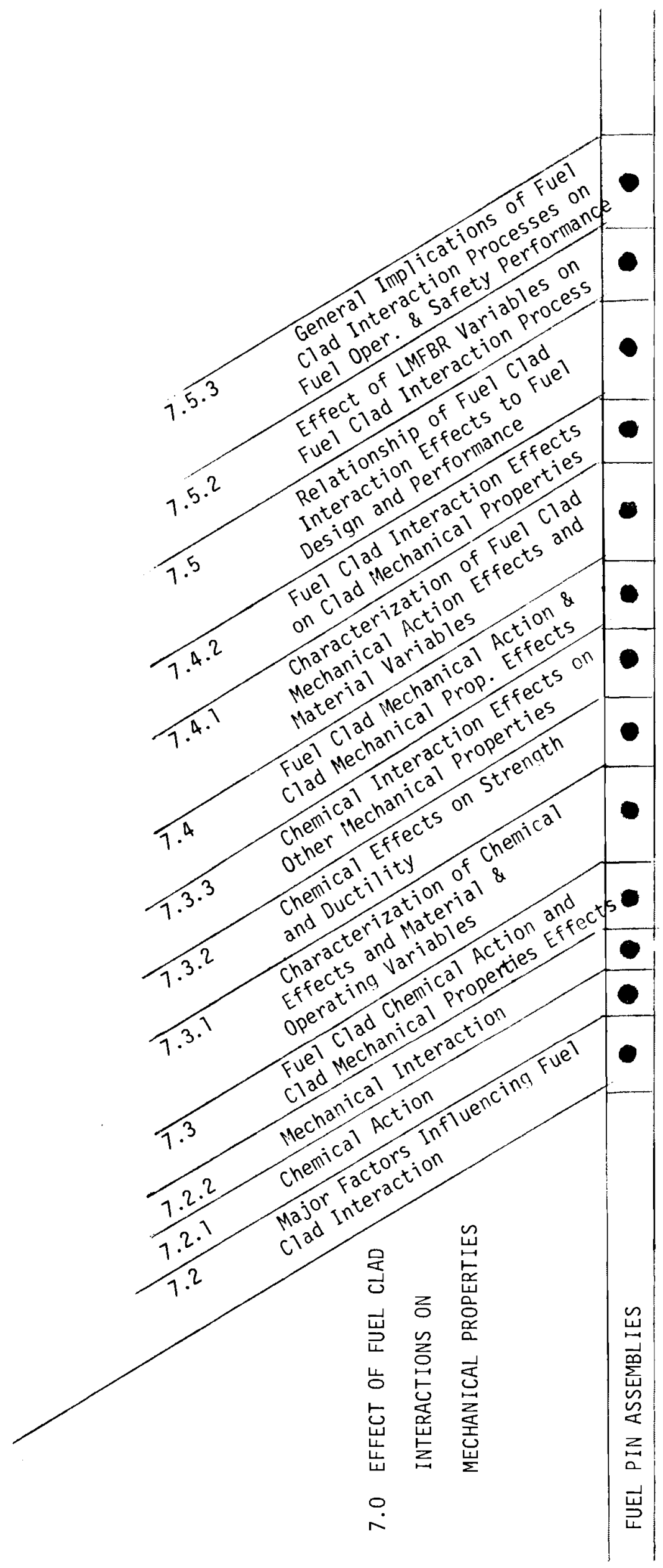





\section{$7.1-1$}

\subsection{Effect of Fuel Clad Interactions on Mechanical Properties}

\subsection{Introduction}

Interaction between the fuel and clad can affect the cladding mechanical properties due to both chemical and mechanical (stress, strain) action. Chemical action takes place through formation of reaction products between the fuel, gas gap, and clad constituents and diffusion of these products and/or other fuel and fission product constituents into the clad metal. These chemical changes modify the metallurgical structure of the clad and thus modify the clad mechanical behavior. Mechanical action may take the forms of 1) steady state fuel growth interaction with the clad and internal fission gas pressure, 2) cyclical (cool-down) short-term clad-fuel interaction, and 3) interaction induced by power transients. These interactions affect the mechanical properties through accumulated creep strain, short term strain, and stress level effects on clad growth (swelling).

Examination of the interaction effects must be made in light of highly irradiated cladding since the major interaction processes take place after burnups of $60,000+$ MWd/MTM, or about $1 / 2-3 / 4$ of design life. Fuel designs with interactions occurring late in the fuel's lifetime are currently the design basis for FFTF fuel ${ }^{(1)}$ and will most likely be the Breeder Demonstration plant design basis for the first oxide core loading. Current design practice calls for essentially zero clad strain caused by fuel pellet growth. This is accomplished by the combination of clad growth (swelling) and a low fuel rod smear density which keeps the clad "moving ahead" of the fuel pellet. This design approach does not elimate fuel clad contact and the possibility of clad-fuel chemical interaction, but it appears to reduce clad-pellet interfacial pressures to relatively low values, i.e., insufficient to cause much strain at steady state. However, the presence of increased fission gas pressure with burnup is sufficient to cause some thermal and irradiation induced creep. 


$$
7.1-2
$$

The design requirements of a commercially successful breeder fuel are somewhat different from FFTF fuel: the goal burnup most likely will be higher and the need for higher fertile-to-fissile ratios will tend to increase the optimum (for breeding) smear density. Thus fuel-clad interaction resulting in clad strain and chemical action will take place earlier in fuel life; the breeder fuel will have a residence time and burnup of perhaps twice that of current designs. Further, the possibie use of carbide and nitride fuels which are attractive due to their high metal densities, have less swelling resistances than the oxide; this will further aggravate fuel clad interaction. 
$7.1-3$

REFERENCES: $\quad 7.1$

1) USAEC-HEDL-BNW-WARD, LMFBR Materials Technology Information Meeting, Richland, WA, March 15-16, 1973 


\subsection{Major Factors Influencing Fuel Clad Interaction}

Fuel clad interaction may be divided into two major phases which may be roughly described as 1) intermittent and 2) continuous. The phenomena involved are listed in Table 7.2-1. The burnups at which these phenomena take place are highly dependent upon fuel design, operating temperature, linear power, etc.

Table 7.2-1

Behavior Regimes - Fuel Clad Interaction

\begin{tabular}{|c|c|c|c|c|}
\hline \multirow{2}{*}{$\begin{array}{l}\text { Phenomenon } \\
\text { Burnup }\end{array}$} & \multicolumn{2}{|r|}{ Intermittent } & \multicolumn{2}{|r|}{ Continuous } \\
\hline & $<n$ & $1 / 2$ goa 1 & $>n$ & $1 / 2$ goal \\
\hline \multirow[t]{2}{*}{$\begin{array}{l}\text { Pellet-clad } \\
\text { contact }\end{array}$} & 1) & $\begin{array}{l}\text { Incidental point contact } \\
\text { during steady state } \\
\text { operation. }\end{array}$ & 1) & $\begin{array}{l}\text { Full circumferential } \\
\text { interaction due to } \\
\text { pellet swelling }\end{array}$ \\
\hline & 2) & $\begin{array}{l}\text { Full contact during cool- } \\
\text { down at burnups near mid- } \\
\text { life. }\end{array}$ & 2) & Same \\
\hline $\begin{array}{l}\text { Fission Gas } \\
\text { pressure and } \\
\text { fission } \\
\text { products }\end{array}$ & & Builds up during fuel life. & & Same \\
\hline $\begin{array}{l}\text { Clad chemical } \\
\text { effects }\end{array}$ & & $\begin{array}{l}\text { Apparently minor due to } \\
\text { intermittent nature of } \\
\text { interfacial contact and lower } \\
\text { fission product availability. }\end{array}$ & & $\begin{array}{l}\text { May be significant } \\
\text { due to interfacial } \\
\text { contact and fission } \\
\text { product buildup. }\end{array}$ \\
\hline
\end{tabular}




\section{$7.2 .1-1$}

\subsubsection{Chemical Action}

Obviously the chemical condition of both the fuel and the cladding effect the chemical action between these two components. Less obvious is the fact that subtle changes in the chemistry of the fuel and clad lead to dramatic differences in the depth of penetration of fuel and fission product components into the cladding. Figure 7.2.1-1 provides evidence of the sensitivity of oxide fuel stoichiometry to clad penetration $(1)$. Current design practice calls for a green fuel $0 / M$ of about 1.97. The Stoichiometry of carbide and nitride fuels, selected to yield minimum clad penetration, can be estimated from data available for these fuels with various cladding and bonding combinations. However, the mixed oxide/304 and 316 stainless systems have been more thoroughly researched than the nitrides and carbides. This report section deals primarily with the oxide fuel/stainless clad system. The basic design practice for this system is to provide an I.D. wastage allowance, somewhat in excess of expected penetration, and use the reduced clad thickness (along with other wastage items) as the design basis. The major factors influencing fuel clad chemical interaction in the oxidestainless system are fuel stoichiometry, fissile species, clad sensitization state, oxygen potential due to thermal distribution, the interfacial pressure, and fuel residence time. (2) These are discussed in detail in Section 7.3.1. Current prototypic fabrication practice limits fuel and clad impurities to sufficiently low levels to exclude them from corrosion processes. (1)

The I.D. wastage for chemical interaction is usually larger than expected penetration and attempts to take into account uncertainties and notch effects; it is partially balanced by the attribute of assuming no strength in the penetrated region. From a degradation standpoint, for steady state and safety performance, the use of a wastage allowance is a sound design practice, providing the allowance effectively reflects material strength loss. 


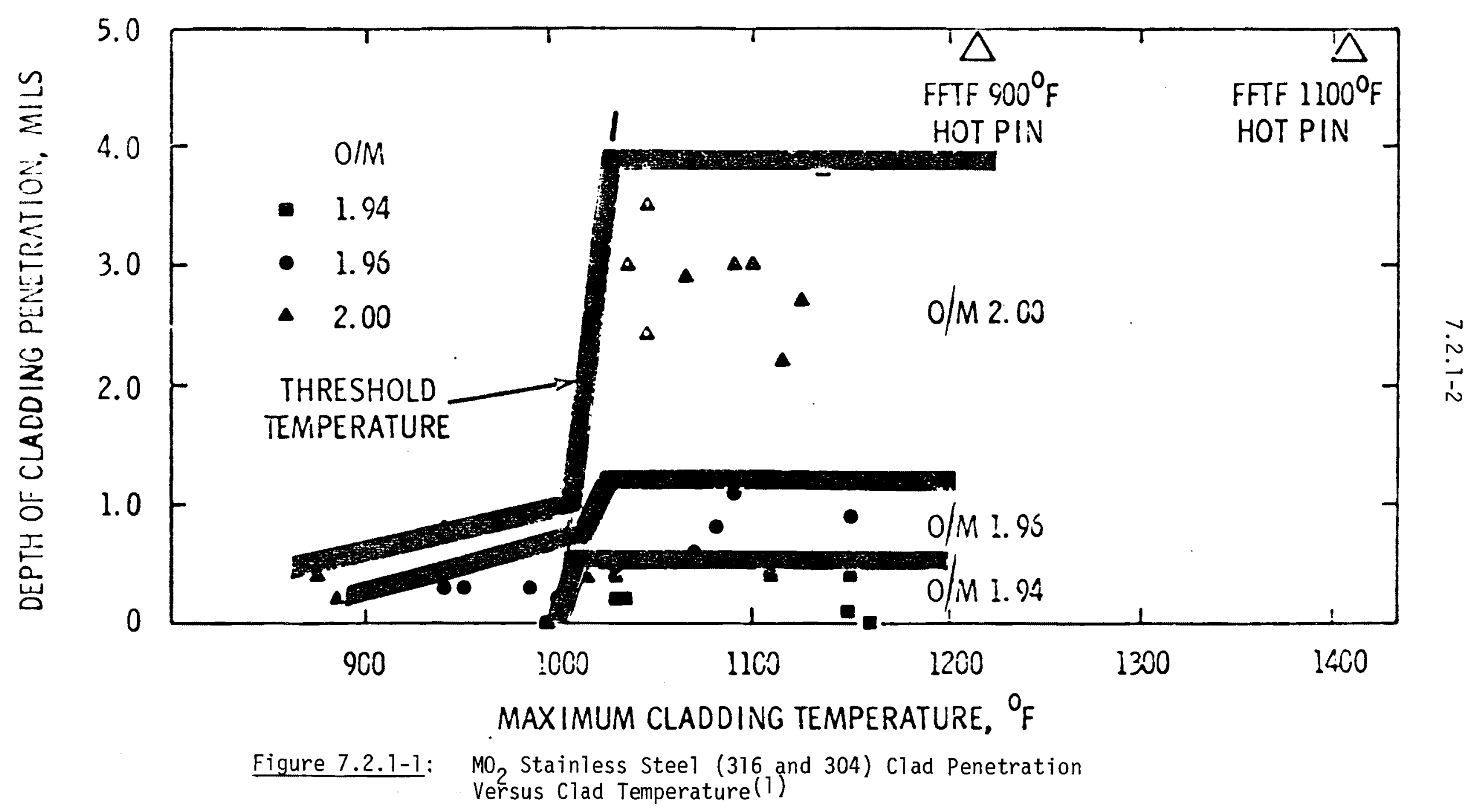




\subsection{1-3}

The design practice for carbide and nitride fuels may turn out to be significantly different from at least two standpoints: 1) fuel elements whichuse a bonding agent such as sodium in the clad-fuel gap are likely to require both a different stoichiometry and fuel clad alloy than gas bonded systems, and 2) wastage allowances may not be adequate to deal with carbide and nitride fuels. This latter item is due to the high mobility of carbon and nitrogen - as compared to oxygen. These attributes impose the potential for distribution of elemental carbon or nitrogen throughout the entire clad thickness; this results in changed clad mechanical properties; i.e., generally lower ductility and higher strength. Additionally carbon's high activity, coupled with its mobility, may result in a deeper (than oxygen) reaction layer if carbide formers are present. 


\section{$7.2 .1-4$}

REFERENCES: 7.2 .1

1) USAEC-HEDL-BNW-WARD, LMFBR Materials Technology Information Meeting, Richland, WA, March 15-16, 1973

2) C. E. Johnson, et. al, "Effects of Oxygen Concentration on Properties of Fast Reactor Mixed-0xide Fuel," Reactor Technology, Vol. 15, No. 4, Winter 1972-73. 


\section{$7.2 .2-1$}

\subsubsection{Mechanical Interaction}

Fuel clad mechanical interaction may be roughly categorized as shown in Table 7.2-1. It consists of actions which produce clad stress and resultant strain and/or creep due to physical contact of the fuel clad system and fission gas buildup. From the standpoints of degradation processes and safety performance: Mechanical interaction must be examined for the effects of prior strain, creep, and stress loading effects on other degradation processes such as swelling, radiation accelerated creep, and chemical action. Fission gas pressure buildup is controlled by the plenum size, burnup, fuel temperatures, and fuel gas retention. Fuel temperatures and gas retention vary throughout the fuel's lifetime, but are dependent upon the same variables which affect fuel-clad physical interaction. These include pellet density, gap size, linear heat rate, and, to a lesser extent, stoichiometry. Table 7.2.2-1 provides a list of design parameters which influence fuel-clad mechanical interactions for mixed oxide fuel. For nitride and carbide fuels, the influence of design parameters on mechanical interaction are similar to those shown for the oxide. However, in the case of thermally bonded carbide or nitride fuel the thermal influence of gap size is considerably lessened. 
Table 7.2.2-1

Design Parameters which Influence Fuel Clad Mechanical Interaction (Mixed 0xide Fuel)

Parameter

Pellet Density

Pellet-clad Gap

Linear Heat Rate

Stoichiometry $(0 / M)$
Influence

Porosity provides fission product swelling accommodation volume

Porosity reduces thermal conductivity and raises fuel temperatures

Gap provides swelling and thermal expansion accommodation

Larger gap raises fuel temperature and thus fuel swelling rate and fission gas release rate

Heat Rate determines fue 1 temperature which in turn affects $\mathrm{UO}_{2}$ swelling and gas release rate

$0 / M$ near 2.0 provides the highest fuel thermal conductivity, although the effect is much less than porosity or gap influences 


\section{$7.3-1$}

\subsection{Fuel Clad Chemical Action and Clad Mechanical}

\section{Properties Effects}

Chemical action in the oxide/stainless steel combination generally degrades clad mechanical properties through corrosion (thinning) and embrittlement actions. This report section deals with chemical action and mechanical property effects and focuses primarily on the mixed oxide ( $\left.\mathrm{MO}_{2}\right)$ stainless clad system. 


\section{$7.3 .1-1$}

\subsubsection{Characterization of Chemical Effects and Material}

and Operating Variables

Two types of cladding attack are observed at the fuel-clad interface: 1) a general reduction of the cladding thickness by uniform oxidation of the stainless steel at the fuel-clad interface (matrix attack), and 2) intergranular penetration by oxygen and fission products along grain boundaries in the cladding. Data from high-burnup fuel indicate that the matrix attack is generally limited to about $10 \%$ of the clad thickness; intergranular corrosion, when it occurs, can be considerably deeper.

Significant differences which exist in $\mathrm{MO}_{2}$ fast fission product yields as compared to thermal fission yields for $\mathrm{UO}_{2}$ lead to differences between cladding/fission product interaction behavior in the two systems. C. E. Johnson, et a ${ }^{(1)^{\star}}$ tabulated and compared fission yields. About $25 \%$ more oxide formers are produced by ${ }^{235} U$ thermal fission than ${ }^{239} \mathrm{Pu}$ fast fission. Thus the oxygen availability in $\mathrm{MO}_{2}$ fast fissioned fuel is significantly higher than thermal fissioned $\mathrm{UO}_{2}$ fuel. Further, the oxygen level influences the availability of potentially corrosive species of iodine, cesium, and other fission products in fast fissioned $\mathrm{MO}_{2}$ fuel.

Clad inner wall temperatures strongly affect clad attack. Various researchers have shown data which indicates a threshold at which little or no clad reaction takes place. These threshold temperatures range from about $500^{\circ} \mathrm{C}$ to $540^{\circ} \mathrm{C}^{(1)}$ upwards to $580^{\circ} \mathrm{C}(2)$ for 304 and 316 stainless steels. Current LMFBR (FFTF Design Basis) inner clad peak temperature range from about 640 to $760^{\circ} \mathrm{C}^{(3,4)}$ depending upon operating conditions; average fuel inner clad temperatures range from about 460 to $570^{\circ} \mathrm{C}$.

\#This article is one of the most comprehensive studies of chemical mechanisms in the field of fuel clad interactions. The reader is referred to this reference for background information relating to section 7.3 . 
Figure 7.3.1-1 (1) appears to demonstrate this temperature dependence. However, further examination of the data reveals a stronger dependence on $0 / M$ rather than temperature. These data can be segragated based on $0 / \mathrm{M}$ shown previously in Figure 7.2.1-1.

Sufficient research has been accomplished to conclude that stoichiometry is the most prominent factor influencing fuel clad chemical interaction in the mixed oxide stainless steel system. Initial $0 / M$ affects the oxygen potential adjacent to the cladding as may be seen in Figure 7.3.1-2 from Ref. 1. The thermal gradient generated by heat production drives the fuel oxide adjacent to the clad towards $0 / M=2.00$ depending upon the initial stoichiometry. The hypostoichiometric condition of the fuel at the clad fuel interface (for $\mathrm{MO}_{2}$ fuels with an initial $0 / \mathrm{M}<\sim 1.97$ ) leads to reduced chemical interaction through two related mechanisms, both of which are oxygen potential dependent. The first is reduced potential for oxidation of clad metal at the fuel clad interface. The second is reduced mobility of fission product oxides in the interface region.

A sensitized condition in the cladding, i.e., the depletion of $\mathrm{Cr}$ in the metal matrix, leads to corrosion by oxidation of the depleted regions. However, LMFBR stainless claddings operate at or above the temperature for sensitization $\left(550-650^{\circ} \mathrm{C}\right)$. Thus, this corrosion variable is not really controllable and the clad must perform adequately under sensitized conditions.

Burnup may contribute to chemical attack in the following manner: As stated previously, 0/M can be computed to increase in $\mathrm{MO}_{2}$ fast fission fuel as burnup progresses. Additionally, the fission product availability increases with burnup. 0/M may increase as much as +0.02 to 0.03 during irradiation to $10 \mathrm{a} / 0$ Burnup. This is accompanied by a significant increase in oxygen potential (and possible corrosion potential) as shown in Figure 7.3.1-3.(1) Thus a fuel pin with an overall green 0/M of 1.96 could increase to an overall of 1.99 at EOL. However, the $0 / M$ gradient, Figure 7.3.1-2, plus some clad oxidation $\sim 0.6 \mathrm{Mi} 1 \mathrm{~s}$, is sufficient to maintain the $0 / M$ at about 1.98 near the fuel surface. Thus the estimated increase of $0 / M$ with burnup does not appear to aggravate interfacial corrosion as long as it does not exceed 2.00 . 
$7.3 .1-3$

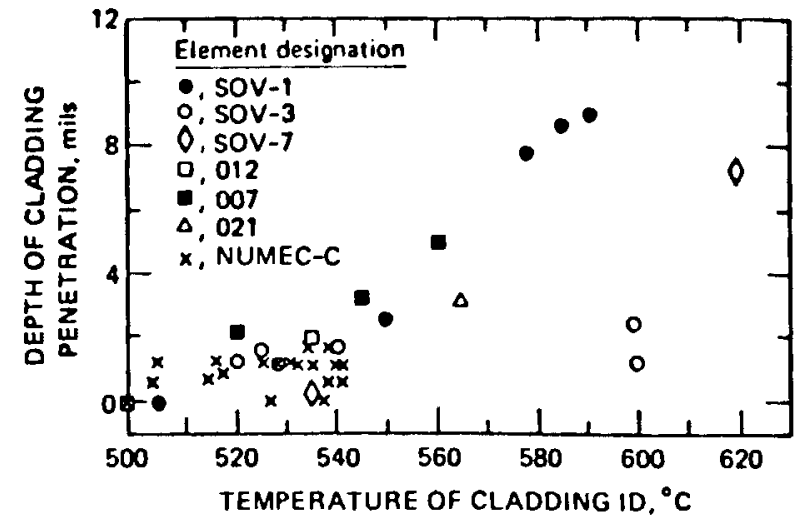

Summary of ANL results on depth of penetration of fission products in $304 \mathrm{~L}$ and 316 stainless-steel cladding on EBR-Il irradiated mixed-oxide fuel elements.

Fig. $7 \cdot 3 \cdot 1-1^{(1)}$ 


\subsection{1-4}

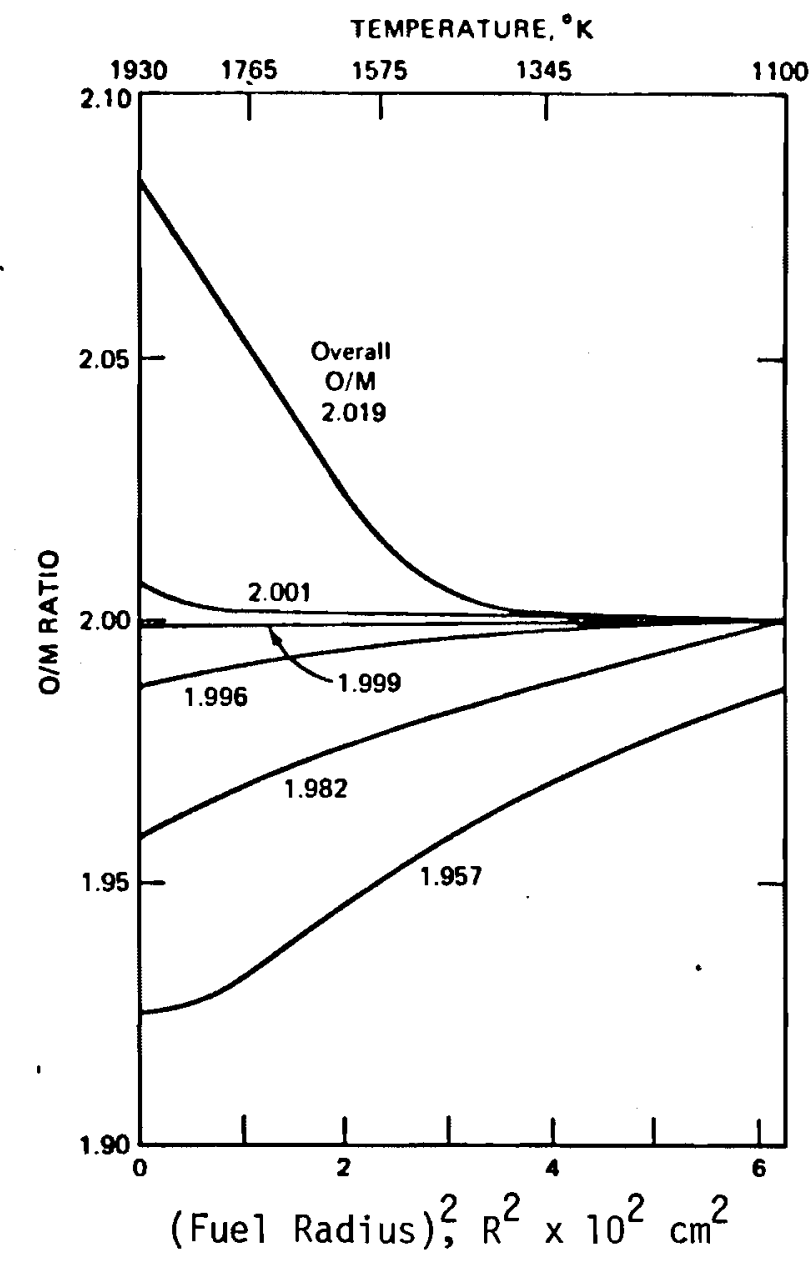

Oxygen distribution in $\mathrm{U}_{0.1}, \mathrm{Pu}_{0.1}, \mathrm{O}_{2 \pm x}$ as computed by Rand and Markin

Fig. $7 \cdot 3 \cdot 1-2^{(1)}$ 


\subsection{1-5}

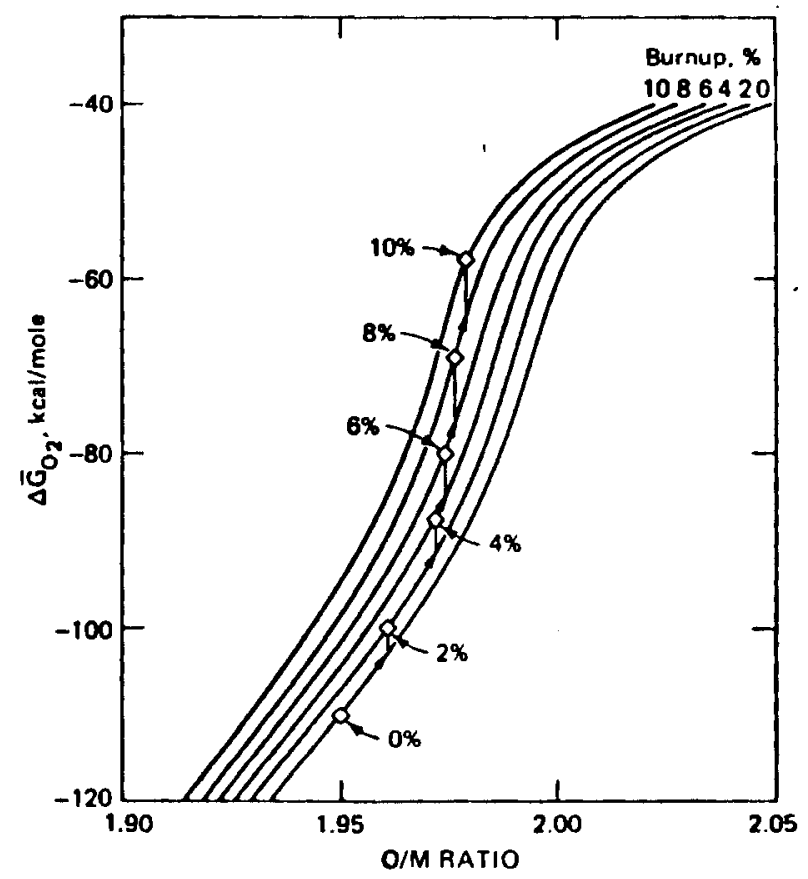

Change in $\Delta \bar{G}_{\mathrm{O}_{2}}$ with $\mathrm{O} / \mathrm{M}$ ratio for natural-urania plutonia mixture at $2000^{\circ} \mathrm{K}$.

Figure $7.3 \cdot 1-3^{(1)}$ 
Interfacial Pressure can aggravate corrosion, at least on a theoretical basis. Firstly, physical contact somewhat enhances the transport of solid species into the cladding. Secondly, intergranular attack, i.e., the transport of fission products and oxides into and along the grain boundaries is accelerated by tensile stress imposed on the cladding. Classically, this is a stress corrosion mechanism. However, the role of clad stress level due to fission gas pressure and fuel swelling is not yet determined. It may be assumed that clad stress level aggravates clad I.D. corrosion rates; quantitatively the extent of this contribution is unknown. 


\section{$7.3 .1-7$}

\section{REFERENCES:}

1) C. E. Johnson, et. a1., "Effects of 0xygen Concentration on Properties of Fast Reactor Mixed-0xide Fuel," Reactor Technology, Vol. 15, No. 4, Winter 1972-73.

2) K. J. Perry, et. al., "Fuel-Cladding Reactions Observed in Stainless Steel Clad Mixed-0xide Fuel Pin Irradiations," Proceedings of the Conference on Fast Reactor Fuel Element Technology, Apri1 13-15, 1971.

3)

P. D. Cohn, et. a1., "FFTF Fuel Pin and Subassembly Conceptual Design Methods and Data," BNWL-1064, June 1970, Battelle-Northwest

4) Fast Flux Test Facility System Design Description No. 31 , Rev. 5, Reactor, HEDL, Westinghouse Electric Corporation, Advance Reactors Division, Nov. 10, 1972, 0U0 


\subsection{2-1}

\subsubsection{Chemical Effects on Strength and Ductility}

The chemical effects on clad mechanical properties due to fuel clad interaction can be examined by comparing the behavior of fast reactor irradiated cladding with and without fuel present in the clad tubes. Additional insight can be obtained by comparing plenum clad samples with samples adjacent to the fuel. Caution must be exercised in this comparison because of the difference in flux level between the fueled and plenum regions and the extreme flux gradients experienced in the plenum. This latter item adds considerable uncertainty to the flux level determination. Also, the plenum is affected by chemical transport from the fuel via the fission and fill gas as well as the reactive fission gas components.

An attempt to isolate the chemical effects must also isolate the effects of stress loading on the cladding due to fission gas pressure, thermal stress, and fuel clad mechanical interaction. These effects can only be isolated qualitatively since the reactor environment imposes some or all of these effects during irradiation.

An extreme example of the effect of ID corrosion on mechanical properties may be seen in table 7.3.2-1 from reference 1 . The cladding "Above Fuel Midplane" exhibited both low ductility and burst strength when compared to specimens from other regions. This difference cannot be attributed to the temperature difference between the two fueled regions. The cladding in the "above" region was characterized by heavy precipitates and grain boundary separation. While this condition was not specifically identified as intergranular corrosion, the effect on strength and ductility is similar to that which would be brought about by ID intergranular corrosion.

The effect of more typical ID attack on mechanical properties is presented in the very comprehensive study by P. J. Ring, et. al. (2) 
TABLE 7.3.2-1 PNL-1 Fuel Pin Burst Test Results - 3.04L (1)

\begin{tabular}{|c|c|c|c|c|c|c|}
\hline $\begin{array}{c}\text { SPECIMEN } \\
\text { IDENTIFICATION }\end{array}$ & $\begin{array}{l}\text { OPERATII } \\
\text { TEMPERAT }\end{array}$ & $\begin{array}{l}\text { ING } \\
\text { TURE }\end{array}$ & $\begin{array}{c}\text { FLUENCE } \\
\mathrm{E}>0.1 \mathrm{MeV} \\
\mathrm{n} / \mathrm{cm}^{2} \\
\end{array}$ & $\begin{array}{c}\text { TEST } \\
\text { TEMPERATURE }\end{array}$ & $\begin{array}{c}\text { HOOP } \\
\text { STRESS } \\
\text { PSi } \\
\end{array}$ & $\begin{array}{l}\text { STRAIN } \\
\triangle D / D \% \\
\end{array}$ \\
\hline CONTROL & & ${ }^{\circ C}$ & & $900^{\circ} \mathrm{F}$ & 56,960 & 19.2 \\
\hline \multicolumn{7}{|l|}{ PLENUM REGION } \\
\hline PNL $1-6: H_{1}$ & $\sim 890^{\circ} \mathrm{F}$ & $F 490$ & $\sim 1.2 \times 10^{21}$ & 900 & 59,090 & 18.4 \\
\hline \multicolumn{7}{|l|}{ ABOVE FUEL MIDPLANE } \\
\hline PNL $1-6: G_{1}$ & $\sim 920$ & 495 & $\sim 4.2 \times 10^{21}$ & 900 & $22,020^{*}$ & 1.0 \\
\hline PNL $1-6: G_{2}$ & $\sim 920$ & & $\sim 3.0 \times 10^{21}$ & 900 & $27,160^{*}$ & 0.3 \\
\hline PNL $1-3: G_{4}$ & $\sim 945$ & 510 & $\sim 3.7 \times 10^{21}$ & 900 & $38,900^{*}$ & 0.2 \\
\hline \multicolumn{7}{|l|}{ BELOW FUEL MIDPLANE } \\
\hline PNL $1-6: C_{3}$ & $\sim 850$ & 455 & $-4.1 \times 10^{21}$ & 900 & 72,150 & 9.6 \\
\hline PNL $1-3: C_{2}$ & $\sim 860$ & 460 & $-4.3 \times 10^{21}$ & 1000 & 66,790 & 6.7 \\
\hline
\end{tabular}


This report presents data for rupture stress, yield stress, and ductility for 304 and $316 \mathrm{clad}$ samples with and without clad ID penetration up to $7.5 \mathrm{mils}$. Clad temperatures ranged from 375 to $550^{\circ} \mathrm{C}$ and fluences ranged from $\sim 1.5 \times 10^{22}$ in the plenum region to $3-4.6 \times 10^{22}$ in the mid fuel region. Table 7.3.2-2 from reference 2 provides the corrosion data; the mechanical properties data are presented in Figures $7.3 .2-1,2$, and 3 . The authors conclude that the penetration of about $1 / 3$ of the clad wall did not cause a commensurate decline in clad yield strength. The data plotted in Figure 7.3.2-1 for irradiated non-fueled clad sections (also supplied from reference 2) show about a $20 \%$ reduction in rupture stress using the midpoint of the reference 2 data for comparison. Based on the statistically varying quality of rupture stress data, even for alloys from the same heat, no real conclusions can be drawn from this comparison other than there appears to be some reduction in burst strength.

The authors also cite that the differences between the plenum (blanket) and fueled region mechanical properties are caused by clad ID penetration; they speculate that this penetration, which was lower or absent in the plenum regions, did not affect the clad strength but did reduce the ductility. However, a more reasonable explanation, based on the data presented in section 2.0 of this report, is that these strength and ductility differences can be attributed to the fluence differences between the fueled and plenum regions. These low ductilities shown in Figure $7.3 .2-3$ have also been seen in several other experiments $(3,4,5)$ with similar clad fluences, operational, and test temperatures with and without fuel present and without clad ID attack. These low ductilities are attributed mainly to fluence effects and are discussed below in light of fuel clad interaction.

The presence of fuel adjacent to the cladding, as long as clad ID attack has not occurred, does not lead to degradation of clad mechanical 
$7 \cdot 3 \cdot 2-4$

Fuel Pin Parameters and Deptl of Intergranular Attack - EBR-2 Irradiations

\begin{tabular}{|c|c|c|c|c|c|c|c|c|c|c|}
\hline \multirow{2}{*}{$\begin{array}{l}\text { Fucl } \\
\text { Iin }\end{array}$} & \multirow[b]{2}{*}{ Alloy } & \multirow{2}{*}{$\begin{array}{l}\text { Fucl } \\
\text { l'ellet } \\
\text { 'lype }\end{array}$} & \multirow{2}{*}{$\begin{array}{l}\mathrm{O} / \mathrm{M} \\
\text { IRatio }\end{array}$} & \multirow{2}{*}{$\begin{array}{c}\text { Fuel } \\
\text { Density } \\
\text { Averagre }\end{array}$} & \multirow{2}{*}{$\begin{array}{c}\text { Fucl } \\
\text { Density } \\
\text { Smeared }\end{array}$} & \multirow{2}{*}{$\begin{array}{l}\text { Fucl-Clad } \\
\text { Diametral } \\
\text { Gap (mils) }\end{array}$} & \multicolumn{2}{|c|}{$\begin{array}{l}\text { Peak Temp } \\
\text { Claddling i.d. } \\
\text { (C) }\end{array}$} & \multirow{2}{*}{$\begin{array}{l}\text { Dispo- } \\
\text { sition }^{c}\end{array}$} & \multirow{2}{*}{$\begin{array}{l}\text { Extent of } \\
\text { Intergranular } \\
\text { Penetration } \\
\text { Max Depth } \\
\text { (mils) }\end{array}$} \\
\hline & & & & & & & a & b & & \\
\hline F3B-1 & 316 & Annular & 1.98 & 94.92 & 88.35 & $4.0-5.7$ & 517 & 534 & M & 0.0 \\
\hline F3B-2 & 316 & Solid & 1.98 & 90.70 & 87.56 & $3.9-5.0$ & 568 & 593 & M & 7.5 \\
\hline F3B-3 & 316 & Annular & 2.00 & 93.49 & 87.54 & $3.7-4.6$ & 584 & 610 & M & 9.0 \\
\hline F3B-4 & 316 & Solid & 2.00 & 91.39 & 87.93 & $3.8-6.4$ & 561 & 584 & - & - \\
\hline F $3 B-5$ & 316 & Solid & 1.98 & 86.03 & 82.87 & $4.0-\overline{5} .5$ & 525 & 544 & M & 3.0 \\
\hline F3B-6 & 316 & Solid & 2.00 & 84.31 & 81.13 & $3.8-6.2$ & 521 & 541 & B & - \\
\hline F3B -7 & $304 \mathrm{~L}$ & Annular & 1.98 & 94.45 & 86.48 & $4.8-8.3$ & 510 & 527 & $\mathrm{M}$ & 3.5 \\
\hline F3B-8 & $304 \mathrm{~L}$ & Solid & 1.98 & 90.21 & 86.08 & $4.4-6.5$ & 561 & 585 & - & - \\
\hline F3B-9 & $304 \mathrm{~L}$ & Annular & 2.00 & 92.84 & 85.64 & $4.6-7.9$ & 577 & 602 & $M \& B$ & 7.5 \\
\hline F $3 B-10$ & $304 \mathrm{~L}$ & Solid & 2.00 & 90.21 & 85.19 & $4.3-7.9$ & 565 & 589 & M & 7.0 \\
\hline F $3 B-11$ & $304 \mathrm{~L}$ & Solid & 1.98 & 85.75 & 81.45 & $5.3-7.9$ & 523 & 542 & B & - \\
\hline F3B-12 & 316 & Annular & 1.98 & 94.43 & 87.88 & $4.0-5.7$ & 519 & 537 & B & - \\
\hline F $3 B-13$ & 316 & Solid & 1.98 & 90.22 & 87.26 & $3.6-4.6$ & 563 & 586 & - & - \\
\hline F3B-14 & 316 & Annular & 2.00 & 93.32 & 87.26 & $3.8-5.1$ & 518 & 527 & - & - \\
\hline F3B-15 & 316 & Solid & 2.00 & 89.42 & 86.25 & $3.9-5.4$ & 581 & 607 & $M \& B$ & 7.5 \\
\hline F3B-16 & 316 & Solid & 1.98 & 85.61 & 82.65 & $3.9-5.4$ & 525 & 544 & $M \& B$ & 4.8 \\
\hline F9C -31 & 316 & Solid & 1.97 & 88.40 & 84.30 & $3.8-6.0$ & 530 & 556 & $M \& B$ & $<0.5$ \\
\hline
\end{tabular}

a Temperature valucs derived from EBR-II calculated power values $\times 0.888$. 'This factor determined from GE fuel pin burnup history.

bemperatures based on EBR-II guide power values, Ref. 5 .

${ }^{\mathrm{c}} \mathrm{M}=$ Metallography only. $\quad \mathrm{B}=$ Burst test only. $\quad \mathrm{M} \& \mathrm{~B}=$ Metallography and burst tests.

Table $7.3 .2-2^{(2)}$ 

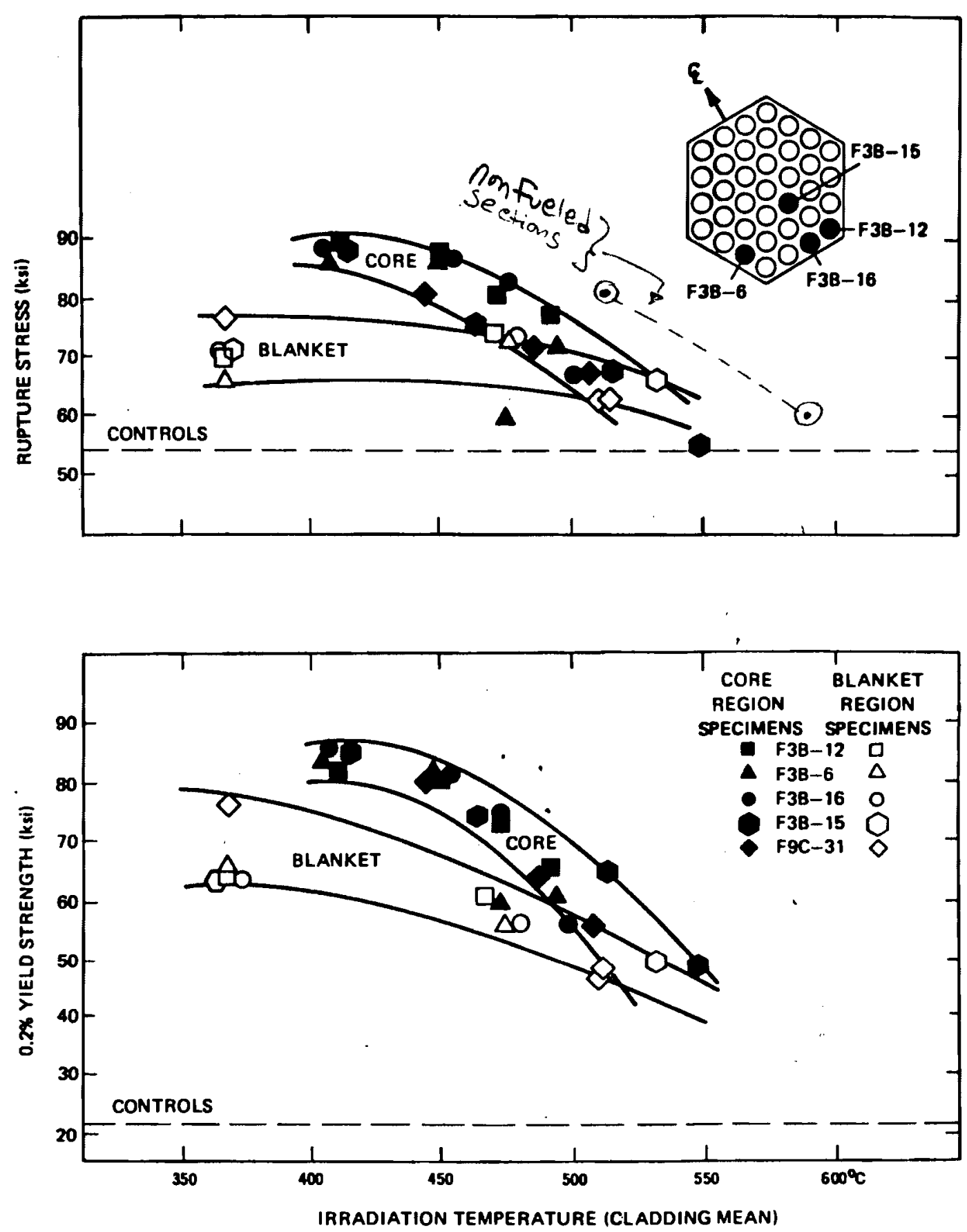

Effect of Irradiation temperature on the rupture and $0.2 \%$ yield strength of Type, 316 stainless-8teel cladding tested at $1100^{\circ} \mathrm{F}\left(593^{\circ} \mathrm{C}\right)$ (burst tests using $1000 \mathrm{psi} / \mathrm{min}$ pressurization rate). ( $(2)$

Figure 7.3.2-1 


\subsection{2-6}
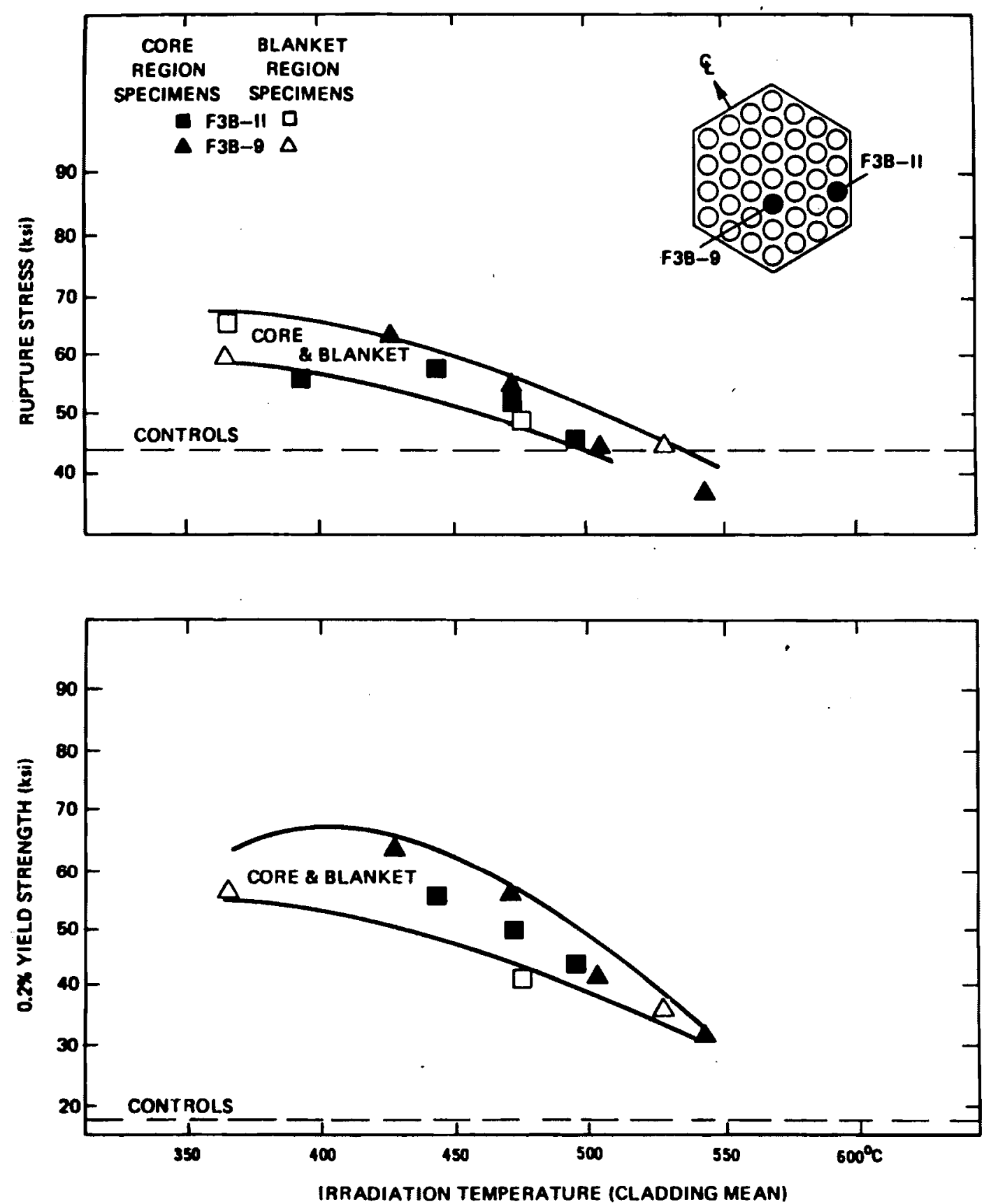

Effect of irradiation temperature on the rupture and $0.2 \%$ yield strength of Type $304 \mathrm{~L}$ stainless-steel cladding tested at $1100^{\circ} \mathrm{F}\left(593^{\circ} \mathrm{C}\right)$ (burst tests using $1000 \mathrm{psi} / \mathrm{min}$ pressurization rate). (2)

Figure $7.3 .2-2$ 


\section{$7.3 .2-7$}
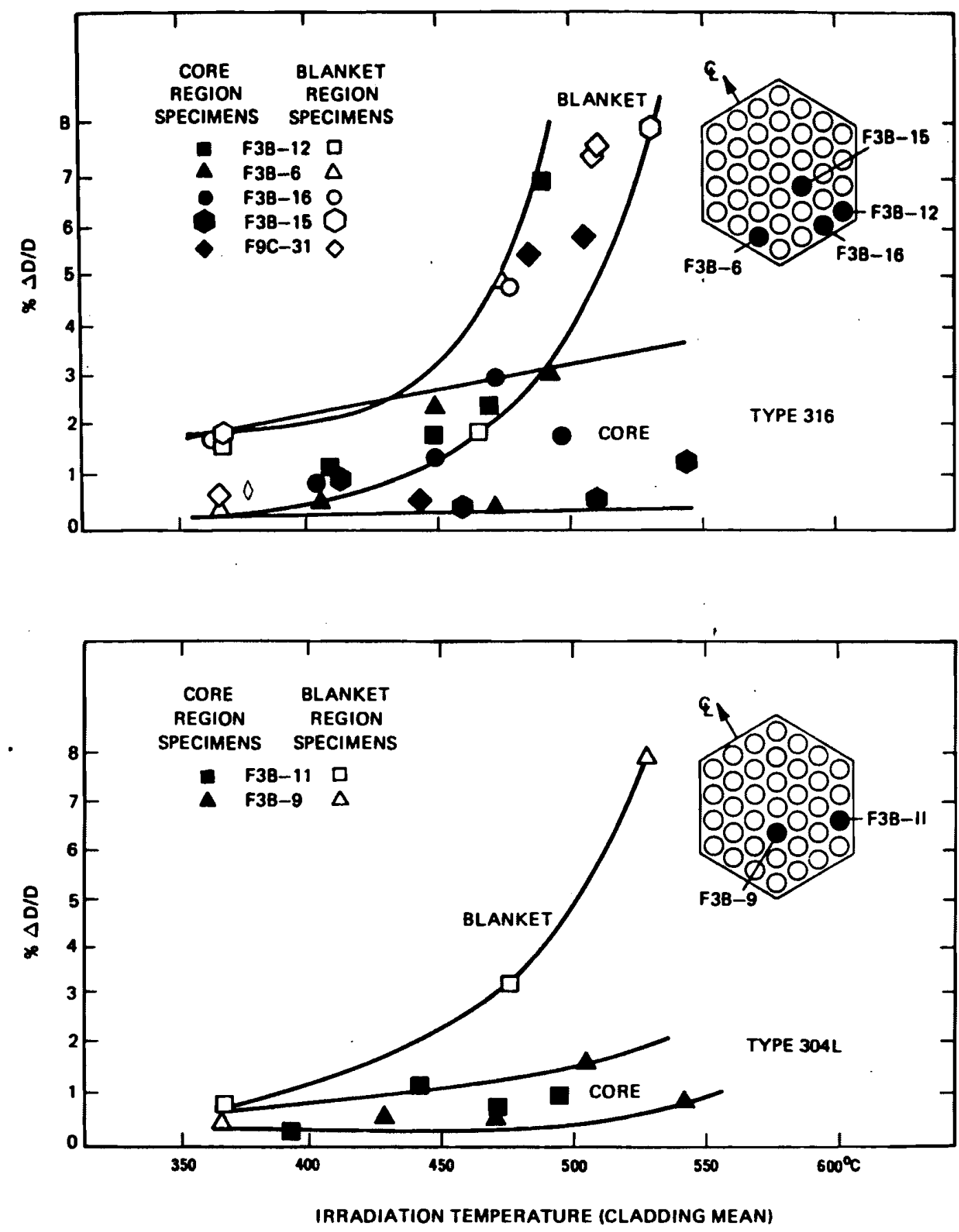

Effect of Irradiation temperature on the ductility of Types 304L and 316 stainless-steel cladding tested at $1100^{\circ} \mathrm{F}\left(593^{\circ} \mathrm{C}\right)$ (burst tests using $1000 \mathrm{psi} / \mathrm{min}$ pressurization rate). (2)

Fig. $7.3 \cdot 2-3$ 


\subsection{2-8}

properties. This is demonstrated in three separate reports cited below. Reference 3 presents detailed data on burst tests of the F9C-31 Fuel Pin (316 SS Clad, $~ 64,000$ MWd/MTM), which are also plotted in Figures 7.3.2-1 and 3. Cladding penetration was less than $0.5 \mathrm{mil}$. This fuel specimen experienced peak clad fluences of $4.6 \times 10^{22}$ as compared to the F3B series peak of about $3 \times 10^{22}$. The ductility results (Figure 7.3.2-3) tend to support the lack of fuel interaction. However, the rupture and yield test data (Figure 7.3.2-1) may support the contention of some interaction effects

Extensive data on 304L SS Mark $1 \mathrm{~A}$ clad at relatively low burnups and fluences, 0.7 to $1.8 \times 10^{22} \mathrm{n}>0.1 \mathrm{MeV}$, are presented in reference 4 . These data compare diametral strains resulting from burst tests conducted on fuel sections, plenum sections, and unfueled irradiated controls. The fuel section data show no effect of fuel presence on a statistically compared basis to unfueled and plenum samples. A similar trend is shown in Figure 7.3.2-4 from reference 5, which shows stress rupture data for fueled and unfueled irradiated and unirradiated $20 \%$ C.W. 316 SS. Tables 7.3.2-3 and -4 provide comparative data for the figure and for biaxial burst tests. (4) Examination of the data show no statistically significant trend among the data.

It should be emphasized that all of the cited data fall at least $25 \%$ short of the current goal peak burnup of 80,000 MWd/MTM for FFTF and are considerably less than the requirement of 100,000 + burnup for commercial fuel. Additionally the highest fast fluences are only $20 \%$ of those projected for FFTF at $2 \times 10^{23}$. Figure 7.3.2-5 ${ }^{(6)}$ provides a summary of ID penetration for the near prototype LMFBR fuel claddinq tabulated in table 7.3.2-2. The data, shown in Figures 7.3.1-1 and 7.3.2-5 and then replotted in Figure 7.2.1-1 to show 1) the differences due to $0 / M$ and 2) low ID penetration of $0 / M<1.98$, must be considered in light of the modest burnups and low fluences cited above for these data. There is a high likelihood that the low $0 / \mathrm{M}$ will adequately limit clad ID chemical 
7.3.2-9

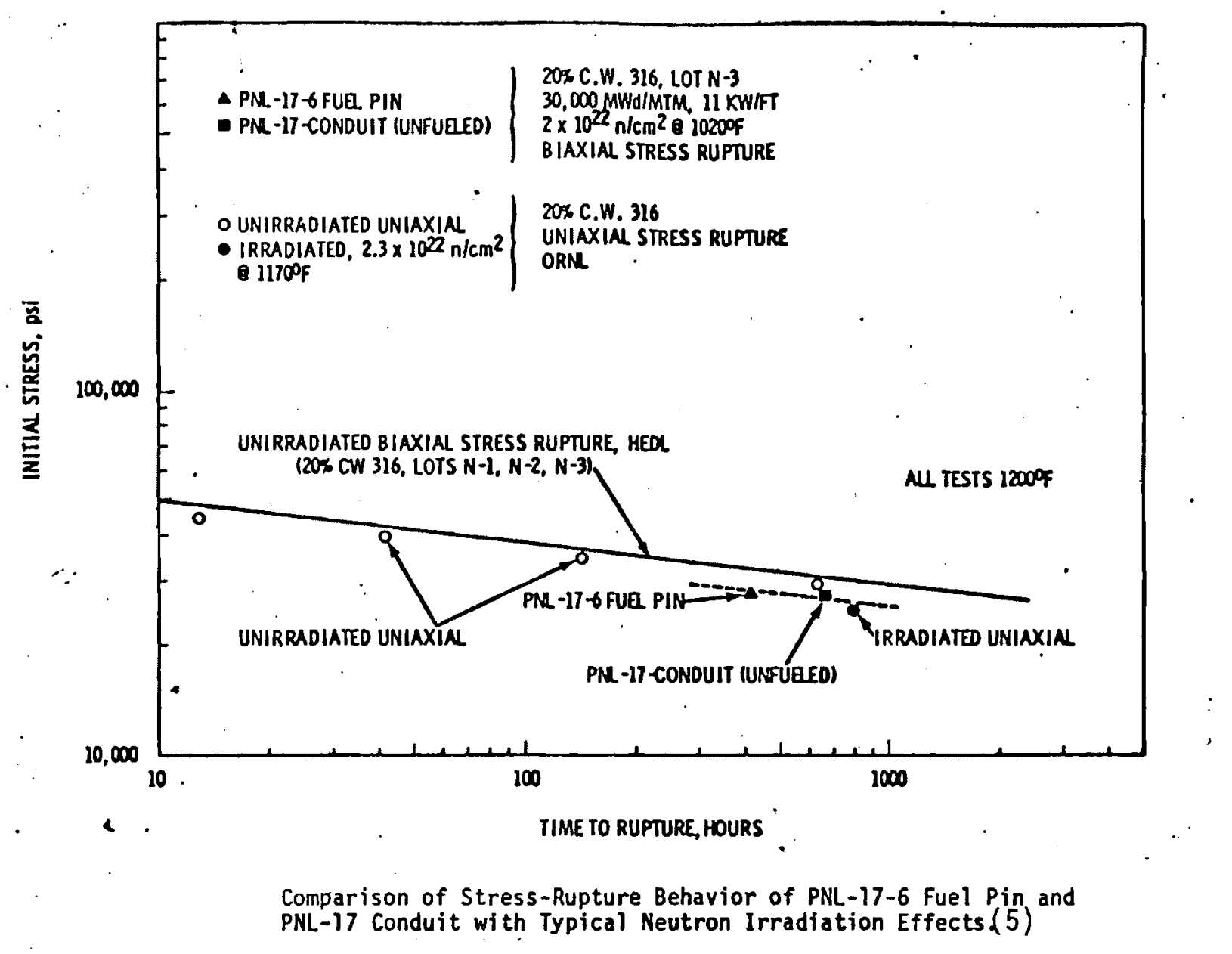

Fig. $7 \cdot 3 \cdot 2-4$ 


\subsection{2-10}

Table 7.3.2-3 ${ }^{(4)}$

BIAXIAL BURST BEHAVIOR AT $1200^{\circ} \mathrm{F}$ OF PNL-17 FUEL PIN, CONDUIT, AND UNIRRADIATED CONTROLS--20\% CW 316 SS

\begin{tabular}{|c|c|c|c|c|}
\hline \multirow{2}{*}{$\begin{array}{c}\text { Specimen } \\
\text { Identification }\end{array}$} & \multirow{2}{*}{$\begin{array}{l}\text { Position above } \\
\text { bottom of fuel } \\
\text { column (1n.)(a) }\end{array}$} & \multicolumn{2}{|c|}{ Burst Pressure } & \multirow{2}{*}{$\begin{array}{c}\text { Uniform } \\
\text { Fallure Strain } \\
(\Delta D / D \alpha)\end{array}$} \\
\hline & & $(p s+g)$ & Hoop o (ps1) : & \\
\hline 17-60 (fueled) & $2-3 / 4-5-1 / 2$ & 10,360 & $7.4,500$ & $0.87 \succ$ \\
\hline $\begin{array}{l}17 \text {-Conduit E } \\
\text { (unfueled) }\end{array}$ & $2-3 / 4 \cdot 5-1 / 2$ & 10,740 & 77,400 & 1.83 \\
\hline $\begin{array}{l}\text { Tube fots } N-1, N-2, \\
N-3(b) \\
\text { (unirradiated controls }\end{array}$ & & $\begin{array}{c}11,000 \\
(10,500-11,600)(c)\end{array}$ & $\begin{array}{c}79,200^{\circ} \\
(75,600-83,500)(c)\end{array}$ & $\frac{1.46}{(0.6-2.3)(c)}$ \\
\hline
\end{tabular}

(a) From cutting plan, Ref. 1.

(b) Unirradiated cladding characterization, Ref. 2.

(c) $95 \%$ confidence 1 imits, Ref. 2.

Table $7.3 .2-4^{(4)}$

BIAXIAL STRESS-RUPTURE BEHAVIOR AT $1200^{\circ} \mathrm{F}$ OF PNL-17 FUEL PIN, 1 CONDUIT, AND UNIRRADIATED CONTROLS - -20\% CW 316 SS

\begin{tabular}{|c|c|c|c|c|c|}
\hline $\begin{array}{c}\text { Specimen } \\
\text { Identification }\end{array}$ & $\begin{array}{l}\text { Position above } \\
\text { bottom of fuel } \\
\text { column (in.)(a) }\end{array}$ & $\begin{array}{l}\text { Burst } \\
\text { (psig) }\end{array}$ & $\begin{array}{l}\text { Pressure } \\
\text { Hoop } \sigma \text { (psi) }\end{array}$ & $\begin{array}{l}\text { Fallure } \\
\text { Time (hr) }\end{array}$ & $\begin{array}{c}\text { Uniform } \\
\text { Failure Strain } \\
(\Delta D / O \%)\end{array}$ \\
\hline $17-6 \mathrm{H}$ (fueled) & $8-103 / 4$ & 3820 & 27,500 & 410 & $1.43(d)$ \\
\hline $\begin{array}{l}\text { 17-Conduit G3 } \\
\text { (unfueled) } \\
T \\
\text { Tube Lots } N-1, N-2, \\
N-3(b) \\
\text { (unirradiated controls }\end{array}$ & $8-103 / 4$ & $\begin{array}{l}3820 \\
3820 \\
4400\end{array}$ & $\begin{array}{l}27,500 \\
27.500 \\
31,700\end{array}$ & $\begin{array}{r}657 \\
2000 \\
500\end{array}$ & $\begin{array}{c}1.35 \\
4.06 \\
4.16 \\
(2.4-5.8)(c)\end{array}$ \\
\hline
\end{tabular}

(a) From cutting plan, Ref. 1.

(b) Unirradiated cladding characterization, Ref. 2.

(c) Range of 16 tests at 25,000 to 32,000 ps 1 , Ref. 2 .

(d) Pressure maintained for $\sim 290 \mathrm{hr}$ following first fallure indication; therefore, actual failure strain was less than $1.48 \%$. 


\subsection{2-11}

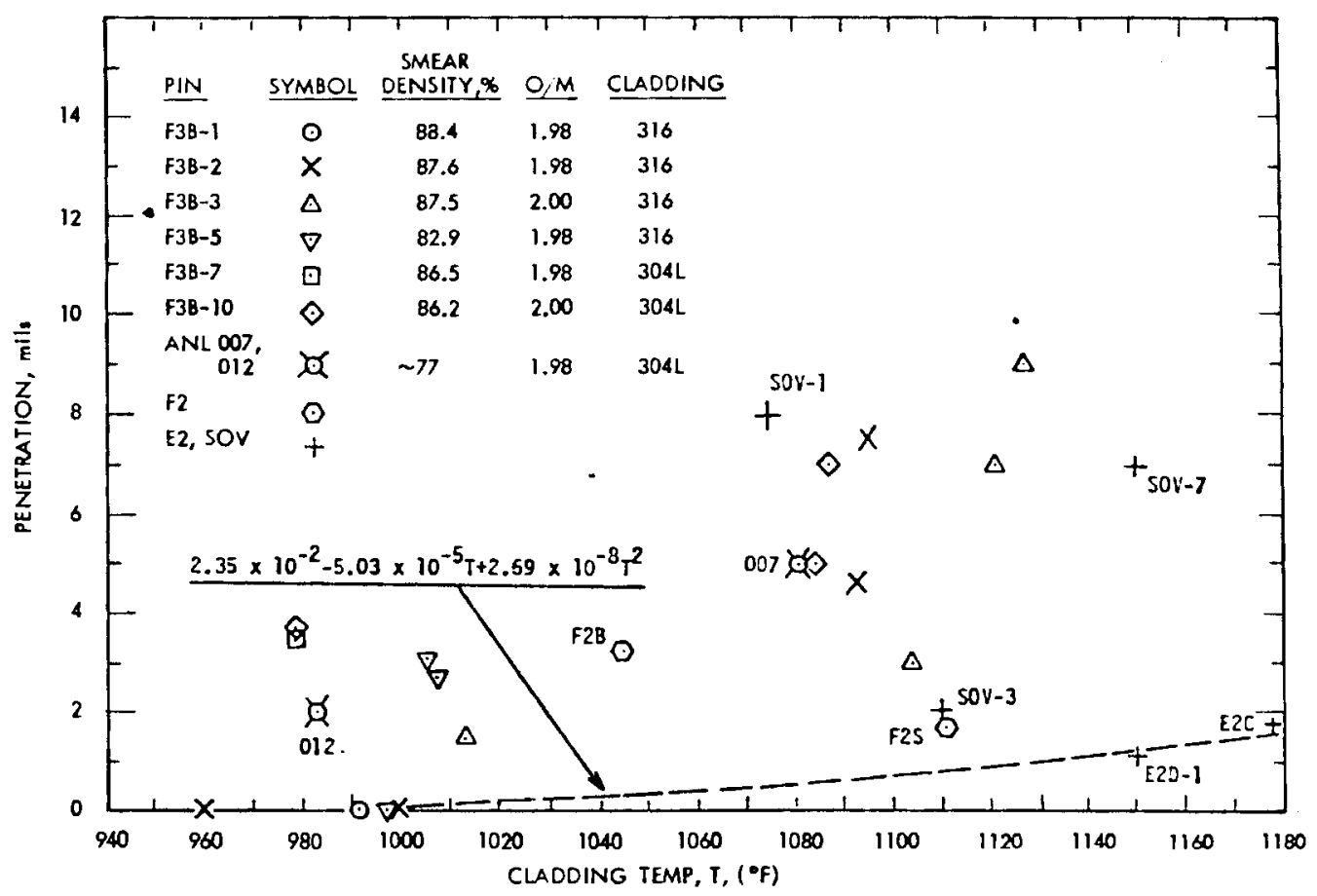

Cladding penetration in EBR-II subassemblies X040 and X040A-Normally calculated temperatures.

Fig. $7 \cdot 3 \cdot 2-5$ 


\section{$7.3 .2-12$}

attack for the high burnup and fluences for the FFTF and LMFBR; however, proof of this design approach will require demonstration through examination and analysis of the several fuel pins now under irradiation to reactor goal exposures in EBR-II as part of the US LMFBR program. The material parameters, manufacturing methods, and controls specified for these fuel pins (if successful) must be incorporated into commercial practice to insure the same success in LMFBR and FFTF use. 
REFERENCES: $\quad 7.3 .2$

1) R. L. Fish, J. J. Holmes and R. D. Leggett, "Interim Burst Test Results on EBR-11 Irradiated Fuel Pin Sections, BNWL-1323, Battelle-Northwest, April 1970

2) P. J. Ring, et. al., "An Evaluation of the Effect of Intergranular Attack on Fuel Pin Burst Properties," Nuclear Technology, Vol. 16, October 1972.

3) GEAP-10028-41, Sodium Cooled Reactor Development Program, 41st Quarterly Report, November 1971-January 1972; dated February 1972

4) HEDL-TME 72-27, HEDL Monthly Technical Progress Report, December 1972, ANL Section.

5) IBID, HEDL Section

6) W. H. McCarthy, et. a1., "Examination of F3A Series Unencapsulated Mixed-0xide Fuel Pins Irradiated in EBR-II, Nuclear Technology, Vo1. 16, October 1972. 


\subsection{3-1}

\subsubsection{Chemical Interaction Effects on Other Mechanical Properties.}

No relevant data could be found which compare clad with and without ID attack for specific mechanical properties other than those described in the preceding sections and other chapters in this report. Generally clad ID attack lowers lifetime expectancies.

The effect of ID attack on creep rupture life and fatigue 1ife can be estimated from data presented in sections 4.0 and 5.0 of this report. Although fatigue is not currently a safety or performance problem in LMFBR fuel design, generally it can be concluded ID attack will raise the equivalent clad stress for creep rupture or fatigue proportional to the ratio of the original clad thickness to the attacked clad thickness. Extensive creep rupture and lifetime studies are being conducted on nonfueled samples $(1)$ and may be extended to high burnup prototypic fuel samples when available. ID attack effects on long term creep and creep life are not currently available. However the test-to-failure irradiation on $\mathrm{MO}_{2}-316,20 \%$ C.W. stainless cladding currently underway at HEDL ${ }^{(1)}$ should ultimately provide insight into this behavior.

High strain rate properties are undoubtedly affected by ID attack. In pile and out of pile transient tests simulating accidents are being conducted as part of the LMFBR program $(2,3)$. These tests, using irradiated fueled and unfueled clad samples simulate most LMFBR major transient accidents. The data and program scopes are quite comprehensive. However, the radiation level of the samples is about $15 \%$ of peak burnup for the fueled samples ${ }^{(2)}$ and $1 / 3$ to $1 / 2$ of goal peak exposure for the unfueled samples. The irradiation level in the former samples is assumed to be insufficient to have ID attack (or continuous fuel-clad interaction) present and internal corrosion is not indicated for any of the samples. Thus the unavailability of comparative data, It can be assumed that ID attack, if present, would reduce high strain rate stress failure levels and ductilities-to-failure. High strain rate data for ID attacked cladding may become available as part of the TREAT and out-of-pile transient tests on high burnup pins ${ }^{(1)}$. 


\section{$7.3 \cdot 3-2$}

REFERENCES: $\quad 7.3 .3$

1) HEDL-TME-73-16, HEDL Quarterly Technica1 Report, October-December 1973, Pub. January 1974.

2) J. H. Scott, et. a1., "Microstructural Dependence of Failure in Mixed-0xide LMFBR Fuel Pins," HEDL-SA-701, Hanford Engineering Development Laboratory, undated.

3) C. W. Hunter and R. L. Fish, "Deformation and Failure of Fast Reactor Cladding During Simulated Loss-of-Flow Type Transients," HEDL-SA-645, Hanford Engineering Development Laboratory, undated. 


\section{$7.4 .1-1$}

7.4 Fuel Clad Mechanical Action and Clad Mechanical Properties Effects

7.4.1 Characterization of Fuel Clad Mechanical Action Effects and Material Variables

Fuel and material design aspects play an important role in fuel clad interaction during accidents as well as the normal fuel lifetime. Sections 7.1 and 7.2 .2 dealt with the behavior regimes and design parameters leading to fuel clad mechanical (and chemical) interaction. Examination of the specific variables leading to interaction is the subject of this section.

Current design practice provides a cladding that swells and stays "slightly ahead" of the fuel swelling during about 508 of the fuel peak lifetime. Fluence-and stress-induced swelling are not considered to "use up" the strain limit which is reserved for thermal (and irradiation accelerated)* creep. Continuous, solid-solid interaction takes place during the latter half of the fuel life. Fission gas buildup takes place continuously. Figure 7.4.1-1 (1) provides an end of life profile of the fuel clad interactions as well as clad swelling and other effects. An FFTF clad deformation model which "overestimates"(1) plastic strain was used for this estimate. The specifics of clad swelling, creep strain, and irradiation creep are detailed in chapters 1.0 and 4.0 of this document. The major point of interest for safety performance is: What effect does prior creep, short term strain, and prior stress level have on mechanical properties related to operational and safety behavior? The combined effects of mechanical ratcheting, thermal set, and fuel and pressure driven swelling must be considered in total to determine the lifetime and safety limiting influences of these creep inducing mechanisms.

\footnotetext{
*Current FFTF design practice is to consider irradiation accelerated creep excluded from the strain limit criteria. This phenomenon is discussed further in sections 4.2.3 and 4.4.2.2 of this report.
} 
F' FiE.7.4.1-1. TOTAL STRAIN VS. AXIAL LOCATION FFTF HOT PIN (1)

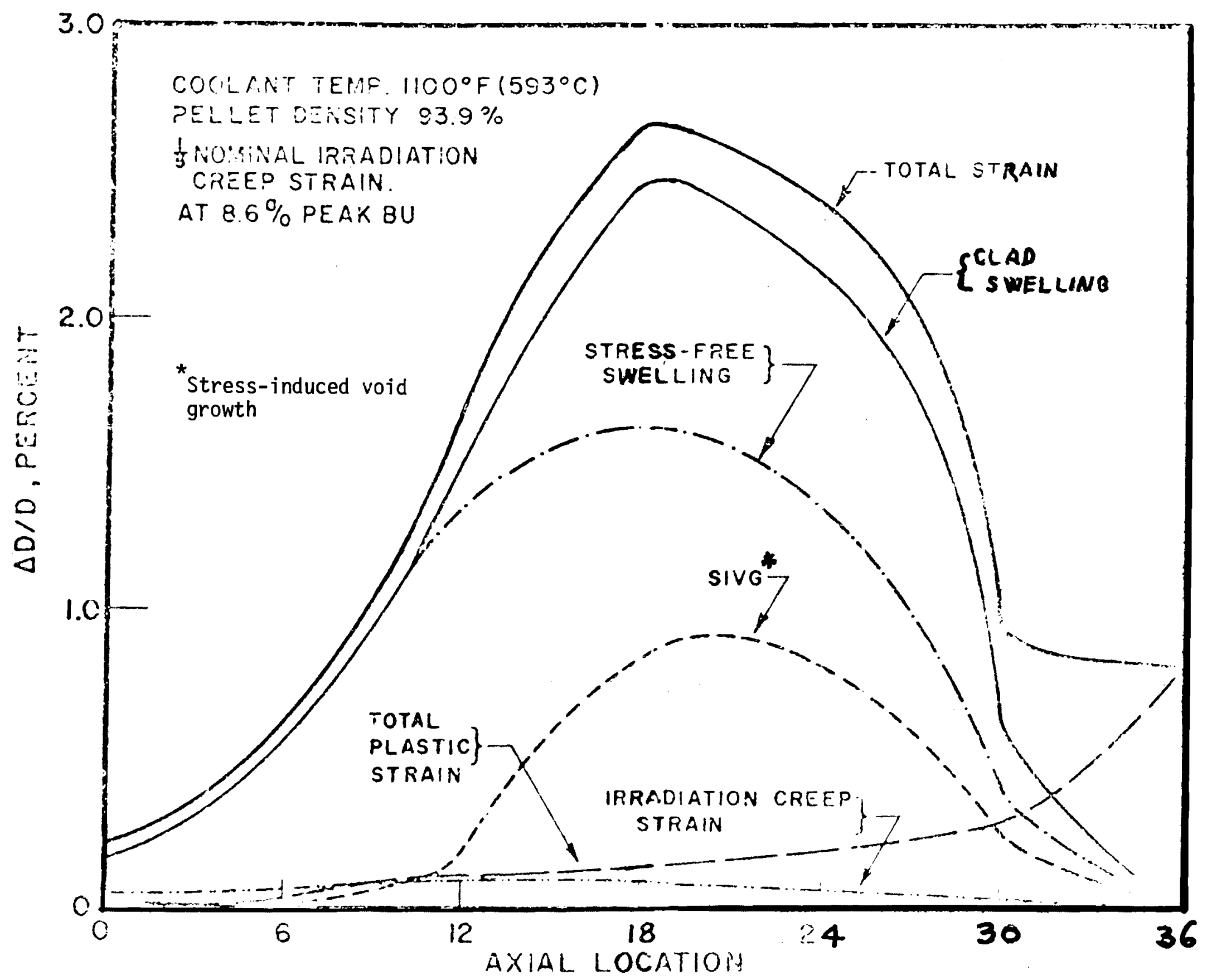


- EBR-II FUEL PIN TESTS -

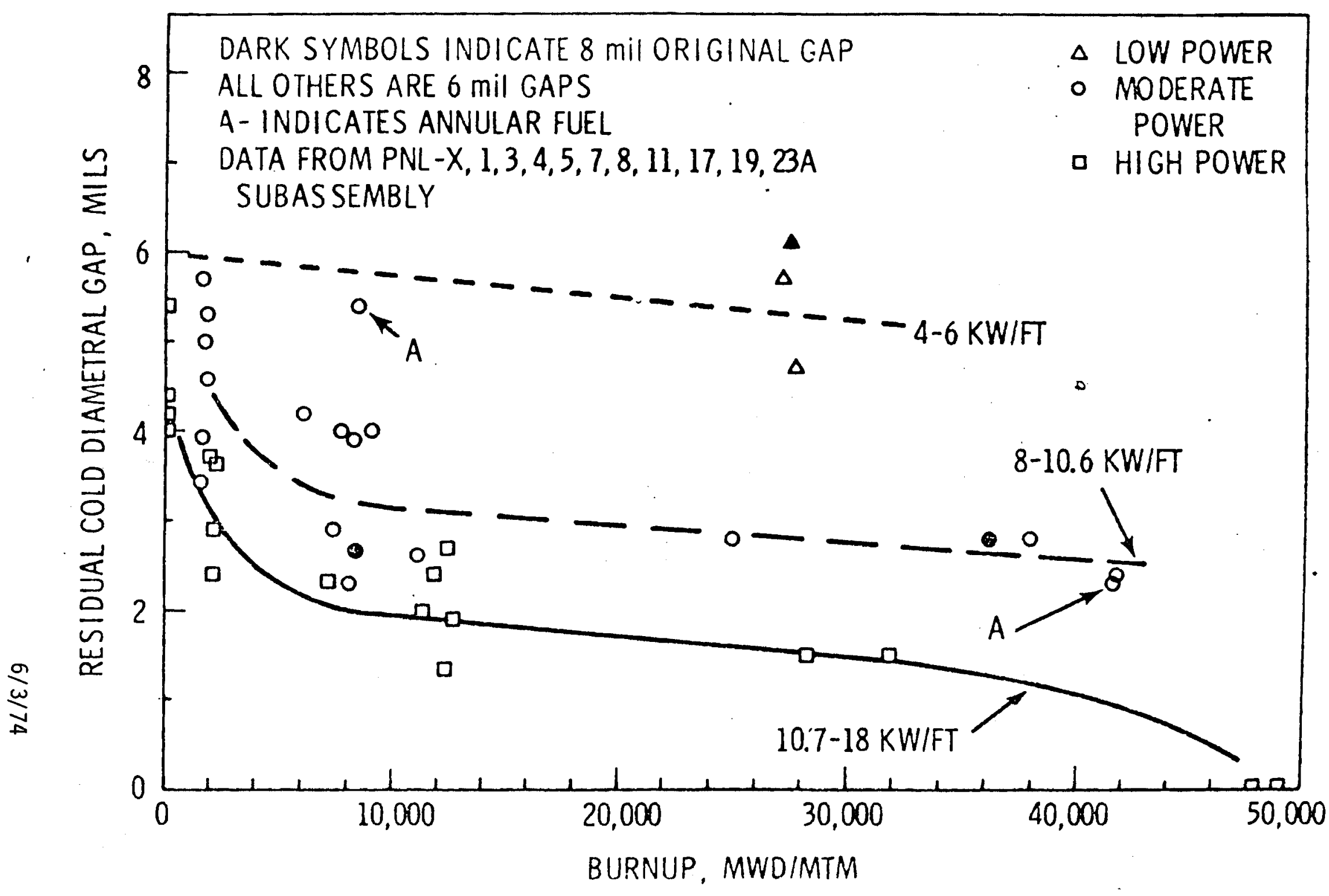




$$
7.4 \cdot 1-4
$$

Mechanical (thermal) Ratcheting. This mechanism is due to fuel interference at cool down and can be assumed to take place after about 50,000 MWd/MTM for high heat rate pins based upon data shown in Figure 7.4.1-2(1). Different designs and operating conditions will place the onset of this phenomenon at different burnups.

Fission Gas Pressure Buildup. This factor is dependent upon the parameters described in Section $7 .^{(2)}$ and 7.2 .2$, Clad stress level is controlled by plenum (storage) length. However venting schemes may be used in carbide and nitride systems. Figures 7.4.1-3 and 4 provide insight into the wide range of conclusions which can be drawn based upon fission gas release models and computational assumptions. (1)

Long Term Creep Strain and Stress. It is assumed that accumulated plastic strain is the main contributor to degradation of mechanical properties and lifetime limitations. (1) The following summary table and series of charts depict the level of creep strain expected for $\mathrm{MO}_{2}$ fuel under LMFBR operating conditions. Table 7.4.1-1 lists the design and performance parameters for the data presented in Figures 7.4.1-5,6, and 7.(2)

Figure 7.4.1-5 shows the relationship between clad swelling and total diametral strain. The difference, assumed to be predominately creep strain, is shown in Figure 7.4.1-6. Above a burnup of about 5.1 a/o the clad seems to be "moving ahead" of the fuel at a constant interval---perhaps the creep strain "saturates" at about $5.1 \%$ burnup for this fuel system. While a low smear density is often cited as a requirement to hold down plastic strain, Figure 7.4.1-7 appears to show no correlation of plastic strain with smear density. 
FIGURE $7.4 .1-1$

$(2)$

Compilation of Fabrication, Irradiation, and Dlametral Increase Data for Rods Irradiated in EBR $\Pi$

\begin{tabular}{|c|c|c|c|c|c|c|c|c|c|c|c|c|c|c|c|}
\hline Rod & Section & $\begin{array}{c}\text { Cladding } \\
\text { Type }\end{array}$ & $\begin{array}{c}\text { Fuel } \\
\text { Form }\end{array}$ & $\begin{array}{c}\text { PuO, } \\
\text { Content } \\
\text { (wt } 6)\end{array}$ & $\mathrm{O} / \mathrm{M}$ & $\begin{array}{c}\text { Pellet } \\
\text { Density } \\
\text { (\% TD) }\end{array}$ & $\begin{array}{l}\text { Smeared } \\
\text { Density } \\
(\%)\end{array}$ & $\underset{(\mathrm{mils})}{\text { Gap }}$ & $\begin{array}{c}\text { Calc } \\
\text { Peak } \\
\text { Powerb } \\
(\mathrm{kW} / \mathrm{ft})\end{array}$ & $\begin{array}{c}\text { Meas } \\
\text { Peak } \\
\text { Burnup } \\
\text { (at. \%) }\end{array}$ & $\begin{array}{c}\text { Calc Peak } \\
\text { Fluence } \\
\left(\times 10^{+84}-\mathrm{GE}\right) \\
(<0.1 \mathrm{MeV})\end{array}$ & $\begin{array}{c}\text { Calc } \\
\text { Peak } \\
\text { Cladding } \\
\text { Temp }\left(^{\circ} \mathrm{F}\right)\end{array}$ & $\begin{array}{l}\text { Total } \\
\Delta D / D \\
(\mathscr{\phi})\end{array}$ & $\begin{array}{c}\text { Cladding } \\
\text { Swelling } \\
\Delta D / D \\
(\mathscr{W})\end{array}$ & $\begin{array}{l}\text { Plastic } \\
\text { Deformation } \\
(\mathscr{q})\end{array}$ \\
\hline F 3B-15 & $\begin{array}{l}\mathbf{C} \\
\mathbf{F} \\
\mathbf{I}\end{array}$ & $\begin{array}{l}316 \\
316 \\
316\end{array}$ & $\begin{array}{l}\text { SP } \\
\text { SP } \\
\text { SP }\end{array}$ & $\begin{array}{l}24.9 \\
24.9 \\
24.9\end{array}$ & $\begin{array}{l}2.00 \\
1.99 \\
2.02\end{array}$ & $\begin{array}{l}88.9 \\
90.7 \\
97.2\end{array}$ & $\begin{array}{l}86.0 \\
87.0 \\
95.0\end{array}$ & $\begin{array}{l}4.0 \\
5.0 \\
2.2\end{array}$ & $\begin{array}{l}15.1 \\
13.4 \\
11.8\end{array}$ & $\begin{array}{l}4.6 \\
4.5 \\
3.7\end{array}$ & $\begin{array}{l}2.0 \\
1.8 \\
1.6\end{array}$ & $\begin{array}{r}\theta 30 \\
1180 \\
1160\end{array}$ & $\begin{array}{l}0.18 \\
0.20 \\
0.08\end{array}$ & $\begin{array}{l}0.18 \\
0.02 \\
--\end{array}$ & $\begin{array}{l}0.00 \\
0.18 \\
--\end{array}$ \\
\hline $\begin{array}{l}\text { E1H-21 } \\
\text { E1H-23 } \\
\text { E1H-26 }\end{array}$ & $\begin{array}{l}\mathrm{D} \\
\mathrm{H}\end{array}$ & $\begin{array}{l}316 \\
316 \\
316 \\
316\end{array}$ & $\begin{array}{l}\text { VC } \\
\text { AP } \\
\text { SP } \\
\text { SP }\end{array}$ & $\begin{array}{l}25.4 \\
24.7 \\
25.2 \\
25.2\end{array}$ & $\begin{array}{l}1.97 \\
1.97 \\
1.97 \\
1.97\end{array}$ & $\begin{array}{l}-.- \\
86.4 \\
89.9 \\
89.9\end{array}$ & $\begin{array}{l}82.3 \\
88.5 \\
87.0 \\
88.6\end{array}$ & $\begin{array}{l}2 .- \\
2.9-4.9 \\
3.0-3.8 \\
3.5\end{array}$ & $\begin{array}{l}14.2 \\
15.7 \\
14.1 \\
14.3\end{array}$ & $\begin{array}{l}8.1 \\
8.5 \\
7.9 \\
8.2\end{array}$ & $\begin{array}{l}6.1 \\
6.5 \\
4.5 \\
4.5\end{array}$ & $\begin{array}{r}980 \\
970 \\
940 \\
1010\end{array}$ & $\begin{array}{l}0.80 \\
1.30 \\
0.68 \\
1.30\end{array}$ & $\begin{array}{l}-- \\
0.65 \\
--\end{array}$ & $\begin{array}{l}-- \\
0.04 \\
--\end{array}$ \\
\hline F5F & $\begin{array}{l}\text { B } \\
E \\
\text { H }\end{array}$ & $\begin{array}{l}316 \\
316 \\
316\end{array}$ & $\begin{array}{l}\text { SP } \\
\text { SP } \\
\text { SP }\end{array}$ & $\begin{array}{l}24.3 \\
24.3 \\
24.3\end{array}$ & $\begin{array}{l}1.97 \\
-- \\
--\end{array}$ & $\begin{array}{l}92.2 \\
93.5 \\
94.0\end{array}$ & $\begin{array}{l}91.0 \\
90.0 \\
90.0\end{array}$ & $\begin{array}{l}3.5-3.8 \\
3.5-3.9 \\
3.0-3.5\end{array}$ & $\begin{array}{l}15.1 \\
15.2 \\
11.9\end{array}$ & $\begin{array}{l}4.7 \\
5.1 \\
4.0\end{array}$ & $\begin{array}{l}3.2 \\
3.3 \\
2.4\end{array}$ & $\begin{array}{r}980 \\
1100 \\
1160\end{array}$ & $\begin{array}{l}0.44 \\
0.36 \\
0.20\end{array}$ & $\begin{array}{l}0.13 \\
0.16 \\
0.08\end{array}$ & $\begin{array}{l}0.31 \\
0.20 \\
0.14\end{array}$ \\
\hline F5M & $\begin{array}{l}\text { B } \\
\text { F } \\
\text { J }\end{array}$ & $\begin{array}{l}321 \\
321 \\
321\end{array}$ & $\begin{array}{l}\text { SP } \\
\text { SP } \\
\text { SP }\end{array}$ & $\begin{array}{l}24.1 \\
24.1 \\
24.1\end{array}$ & $\begin{array}{l}1.97 \\
-- \\
--\end{array}$ & $\begin{array}{l}94.1 \\
94.1 \\
94.1\end{array}$ & $\begin{array}{l}89.9 \\
89.9 \\
89.9\end{array}$ & $\begin{array}{l}3.4-6.7 \\
3.4-6.7 \\
3.4-6.7\end{array}$ & $\begin{array}{l}15.0 \\
15.2 \\
12.2\end{array}$ & $\begin{array}{l}4.8 \\
4.9 \\
3.9\end{array}$ & $\begin{array}{l}3.1 \\
3.2 \\
2.3\end{array}$ & $\begin{array}{r}980 \\
1105 \\
1160\end{array}$ & $\begin{array}{l}0.52 \\
0.64 \\
0.30\end{array}$ & $\begin{array}{l}0.17 \\
0.33 \\
0.11\end{array}$ & $\begin{array}{l}0.35 \\
0.31 \\
0.18\end{array}$ \\
\hline F5Q & $\begin{array}{l}\mathbf{B} \\
\mathbf{E} \\
\mathbf{I}\end{array}$ & $\begin{array}{c}316- \\
50 \% \mathrm{CW}\end{array}$ & $\begin{array}{l}\text { SP } \\
\text { SP } \\
\text { SP }\end{array}$ & $\begin{array}{l}24.3 \\
24.3 \\
24.3\end{array}$ & $\begin{array}{l}1.97 \\
-- \\
--\end{array}$ & $\begin{array}{l}94.2 \\
94.6 \\
93.9\end{array}$ & $\begin{array}{l}81.0 \\
89.0 \\
91.0\end{array}$ & $\begin{array}{l}3.3-3.8 \\
3.2-6.8 \\
3.3-3.6\end{array}$ & $\begin{array}{l}14.4 \\
15.2 \\
12.0\end{array}$ & $\begin{array}{l}4.9 \\
5.3 \\
4.1\end{array}$ & $\begin{array}{l}3.1 \\
3.3 \\
2.4\end{array}$ & $\begin{array}{r}980 \\
1100 \\
1160\end{array}$ & $\begin{array}{l}0.44 \\
0.52 \\
0.24\end{array}$ & $\begin{array}{l}0.00 \\
0.00 \\
0.00\end{array}$ & $\begin{array}{l}0.44 \\
0.52 \\
0.24\end{array}$ \\
\hline$F 9 C-31$ & $\begin{array}{l}C \\
E \\
G \\
N\end{array}$ & $\begin{array}{l}316 \\
316 \\
316 \\
316\end{array}$ & $\begin{array}{l}\text { SP } \\
\text { SP } \\
\text { SP } \\
\text { SP }\end{array}$ & $\begin{array}{l}24.1 \\
24.1 \\
24.1 \\
24.1\end{array}$ & $\begin{array}{l}1.98 \\
1.98 \\
1.98 \\
1.97\end{array}$ & $\begin{array}{l}88.4 \\
87.5 \\
88.5 \\
88.0\end{array}$ & $\begin{array}{l}84.6 \\
84.6 \\
84.6 \\
84.6\end{array}$ & $\begin{array}{c}4.2-4.5 \\
4.1 \\
4.1-5.0 \\
4.6-4.7\end{array}$ & $\begin{array}{l}11.1 \\
12.1 \\
13.3 \\
10.7\end{array}$ & $\begin{array}{l}5.8 \\
6.3 \\
6.9 \\
5.6\end{array}$ & $\begin{array}{l}3.9 \\
4.3 \\
4.6 \\
3.7\end{array}$ & $\begin{array}{r}815 \\
870 \\
920 \\
1050\end{array}$ & $\begin{array}{l}0.52 \\
0.56 \\
0.60 \\
0.32\end{array}$ & $\begin{array}{l}0.11 \\
0.56 \\
0.29 \\
0.04\end{array}$ & $\begin{array}{l}0.41 \\
0.00 \\
0.31 \\
0.28\end{array}$ \\
\hline $\begin{array}{l}\text { FaH } \\
\text { (axially } \\
\text { restrained) }\end{array}$ & $\begin{array}{l}4 \\
7 \mathrm{~B} \\
7 \mathrm{~A}\end{array}$ & $\begin{array}{l}316 \\
316 \\
316\end{array}$ & $\begin{array}{l}\text { SP } \\
\text { SP } \\
\text { SP }\end{array}$ & $\begin{array}{l}20,1 \\
20.1 \\
20.1\end{array}$ & $\begin{array}{l}1.98 \\
1.98 \\
1.98\end{array}$ & $\begin{array}{l}95.9 \\
95.8 \\
95.6\end{array}$ & $\begin{array}{l}95.0 \\
82.0 \\
83.0\end{array}$ & $\begin{array}{l}1.0-2.5 \\
1.8-3.0 \\
1.3-3.2\end{array}$ & $\begin{array}{l}16.7 \\
16.9 \\
15.4\end{array}$ & $\begin{array}{l}5.6 \\
6.4 \\
6.1\end{array}$ & $\begin{array}{l}3.9 \\
3.9 \\
3.8\end{array}$ & $\begin{array}{r}955 \\
1000 \\
1000\end{array}$ & $\begin{array}{l}1.16 \\
1.19 \\
1.15\end{array}$ & $\begin{array}{l}0.69 \\
0.49 \\
0.45\end{array}$ & $\begin{array}{l}0.47 \\
0.70 \\
0.70\end{array}$ \\
\hline $\mathbf{F} 2 \mathrm{~V}$ & $\begin{array}{l}\mathbf{C} \\
\mathbf{E} \\
\mathbf{F} \\
\mathbf{J} \\
\mathbf{M} \\
\mathbf{P}\end{array}$ & $\begin{array}{l}316 \\
316 \\
316 \\
316 \\
316 \\
316\end{array}$ & $\begin{array}{l}\text { SP } \\
\text { SP } \\
\text { SP } \\
\text { SP } \\
\text { SP } \\
\text { SP }\end{array}$ & $\begin{array}{l}20.0 \\
20.0 \\
20.0 \\
20.0 \\
20.0 \\
20.0\end{array}$ & $\begin{array}{l}1.99 \\
1.99 \\
1.99 \\
1.99 \\
1.99 \\
1.99\end{array}$ & $\begin{array}{l}89.8 \\
90.1 \\
89.1 \\
89.6 \\
90.2 \\
89.9\end{array}$ & $\begin{array}{l}86.0 \\
86.0 \\
86.0 \\
86.5 \\
87.0 \\
87.0\end{array}$ & $\begin{array}{l}3.6-4.1 \\
2.8-4.2 \\
3.3-3.6 \\
3.5-4.0 \\
2.8-3.4 \\
3.2-3.6\end{array}$ & $\begin{array}{r}14.1 \\
15.4 \\
15.6 \\
15.9 \\
13.4 \\
9.5\end{array}$ & $\begin{array}{r}9.9 \\
10.9 \\
11.0 \\
11.1 \\
9.1 \\
8.3\end{array}$ & $\begin{array}{l}7.8 \\
8.5 \\
8.6 \\
8.3 \\
7.2 \\
6.5\end{array}$ & $\begin{array}{r}880 \\
925 \\
945 \\
975 \\
995 \\
1000\end{array}$ & $\begin{array}{l}1.61 \\
2.70 \\
3.30 \\
3.74 \\
2.78 \\
1.41\end{array}$ & $\begin{array}{l}1.32 \\
2.50 \\
2.59 \\
2.90 \\
2.00 \\
1.00\end{array}$ & $\begin{array}{l}0.29 \\
0.20 \\
0.71 \\
0.84 \\
0.78 \\
0.41\end{array}$ \\
\hline F $2 X$ & $\begin{array}{l}\mathbf{D} \\
\mathbf{J} \\
\mathbf{M} \\
\mathbf{R}\end{array}$ & $\begin{array}{l}316 \\
316 \\
316 \\
316\end{array}$ & $\begin{array}{l}\text { VC } \\
\text { VC } \\
\text { VC } \\
\text { VC }\end{array}$ & $\begin{array}{l}20.0 \\
20.0 \\
20.0 \\
20.0\end{array}$ & $\begin{array}{l}1.99 \\
1.99 \\
1.99 \\
1.99\end{array}$ & $\begin{array}{l}-- \\
-- \\
--\end{array}$ & $\begin{array}{l}83.9 \\
83.9 \\
83.9 \\
83.9\end{array}$ & $\begin{array}{l}-- \\
-- \\
--\end{array}$ & $\begin{array}{l}13.8 \\
15.5 \\
13.4 \\
99.3\end{array}$ & $\begin{array}{r}9.3 \\
10.2 \\
8.4 \\
7.2\end{array}$ & $\begin{array}{l}7.2 \\
7.8 \\
6.4 \\
5.1\end{array}$ & $\begin{array}{l}860 \\
940 \\
960 \\
---\end{array}$ & $\begin{array}{l}0.94 \\
2.12 \\
1.49 \\
0.15\end{array}$ & $\begin{array}{l}0.94 \\
1.95 \\
1.12 \\
0.15\end{array}$ & $\begin{array}{l}0.00 \\
0.17 \\
0.37 \\
0.00\end{array}$ \\
\hline F $2 Y$ & & 316 & vC & 20.0 & 1.99 & -- & 83.9 & -- & 13.3 & 3.7 & 0.18 & 995 & 0.40 & -- & -- \\
\hline
\end{tabular}

$\checkmark$

"SP refers to solid pellets; VC refers to vibro-compacted powder; AP refers to annular pellets.

bCalculations are based upon EBR-II guide values.

"Calculations based on a GE method described in "Quarterly Progress Report-Irradiation Effects on Reactor Structural Materials," Nov., Dec. 1070, Jan., 1971 HEDLTME-71-43, p. 37. 
FIGURE $7.4 .1-3$

EFFECT OF FISSION GAS RELEASE MODEL ON FTR FUEL PIN CLADDING STRAIN

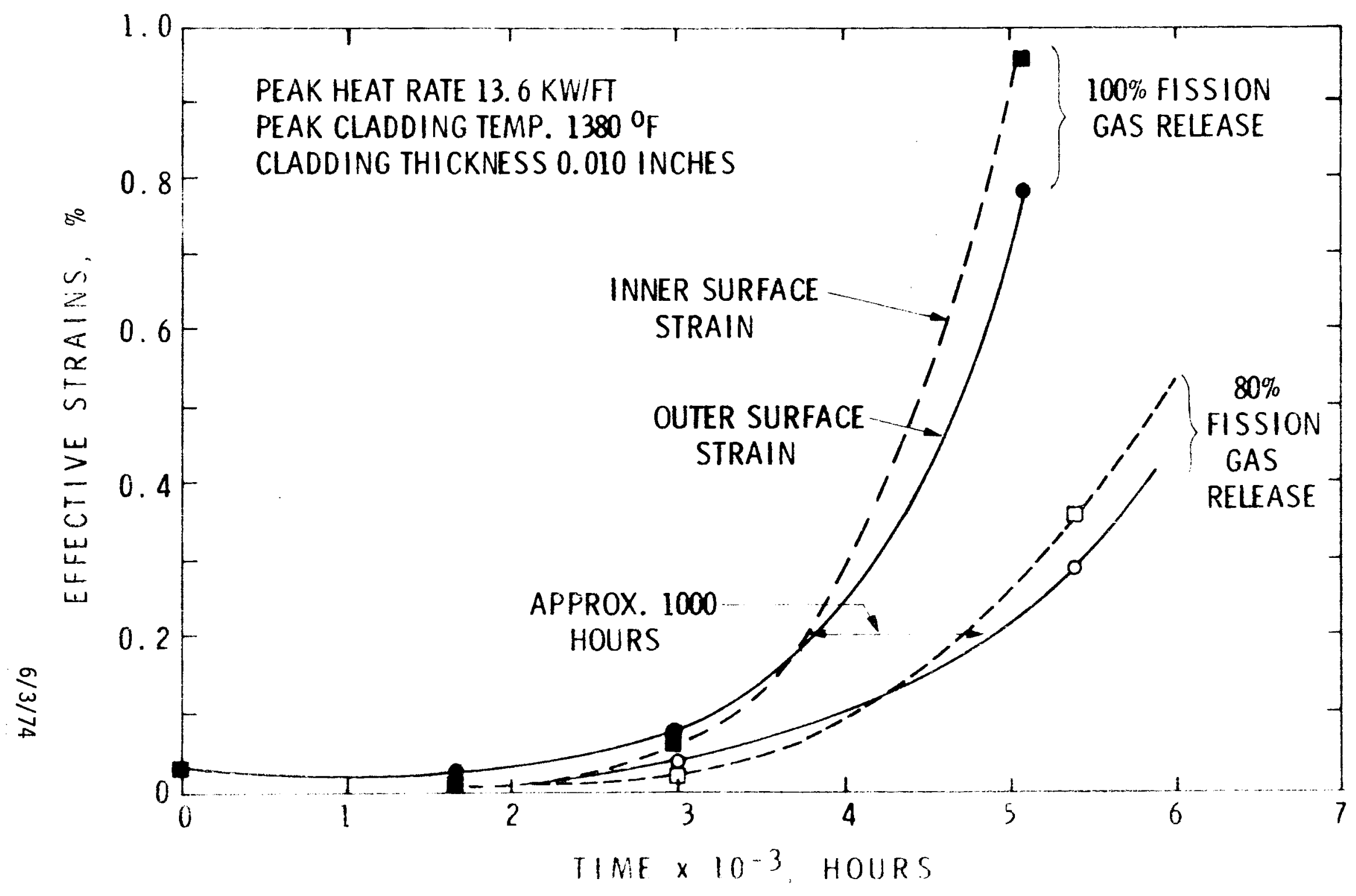




\subsection{1-7}

FIGURE $7.4 .1-4$

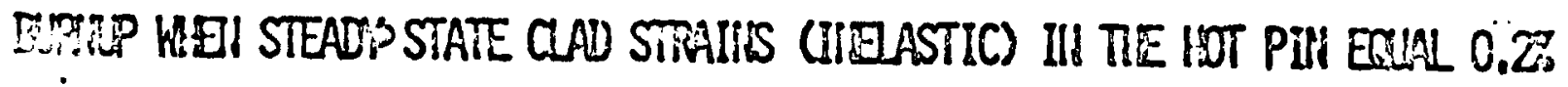

. (FFTF)

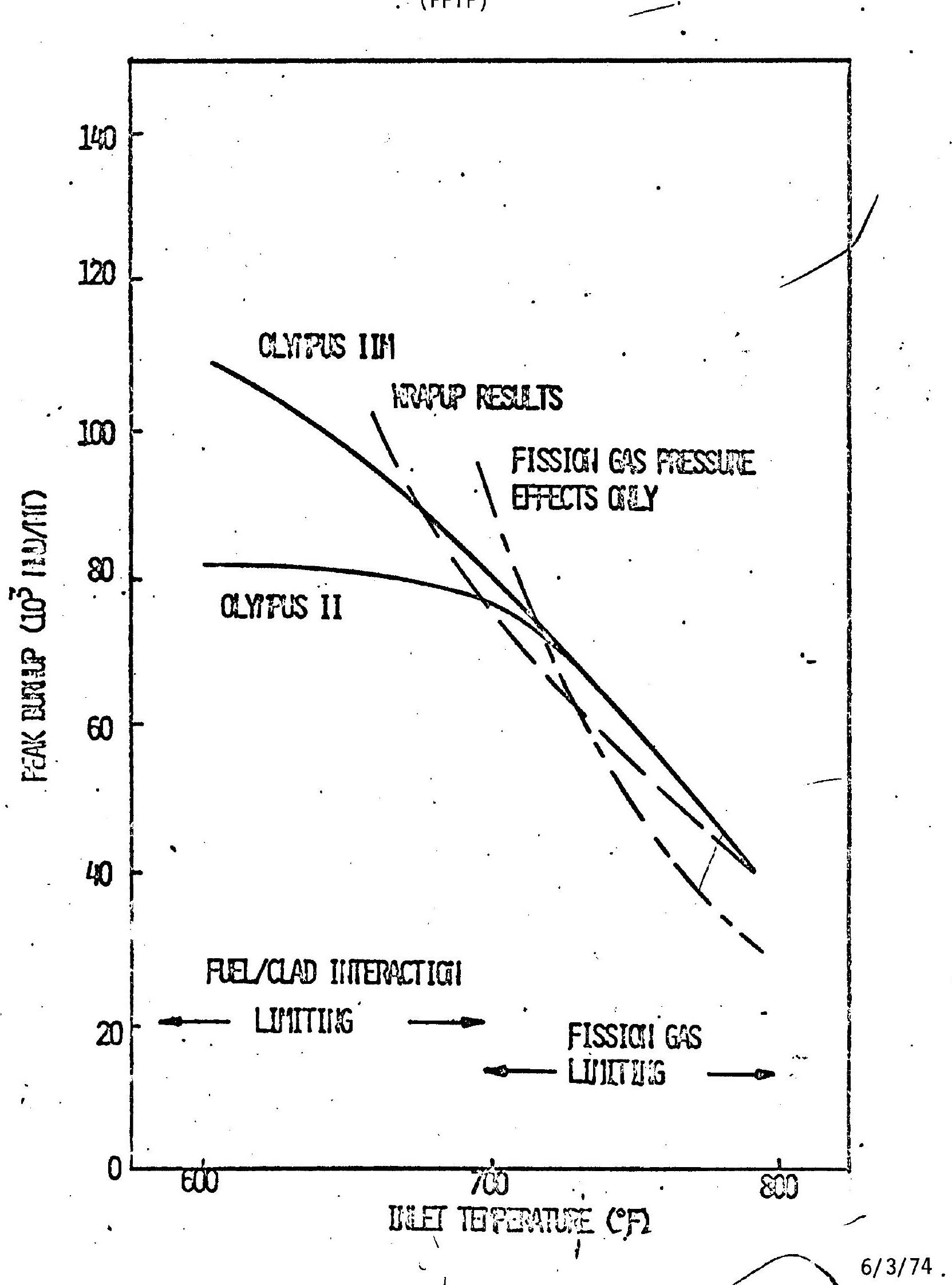


FLUENCE $\times 10^{-22},>0.1 \mathrm{MeV}$

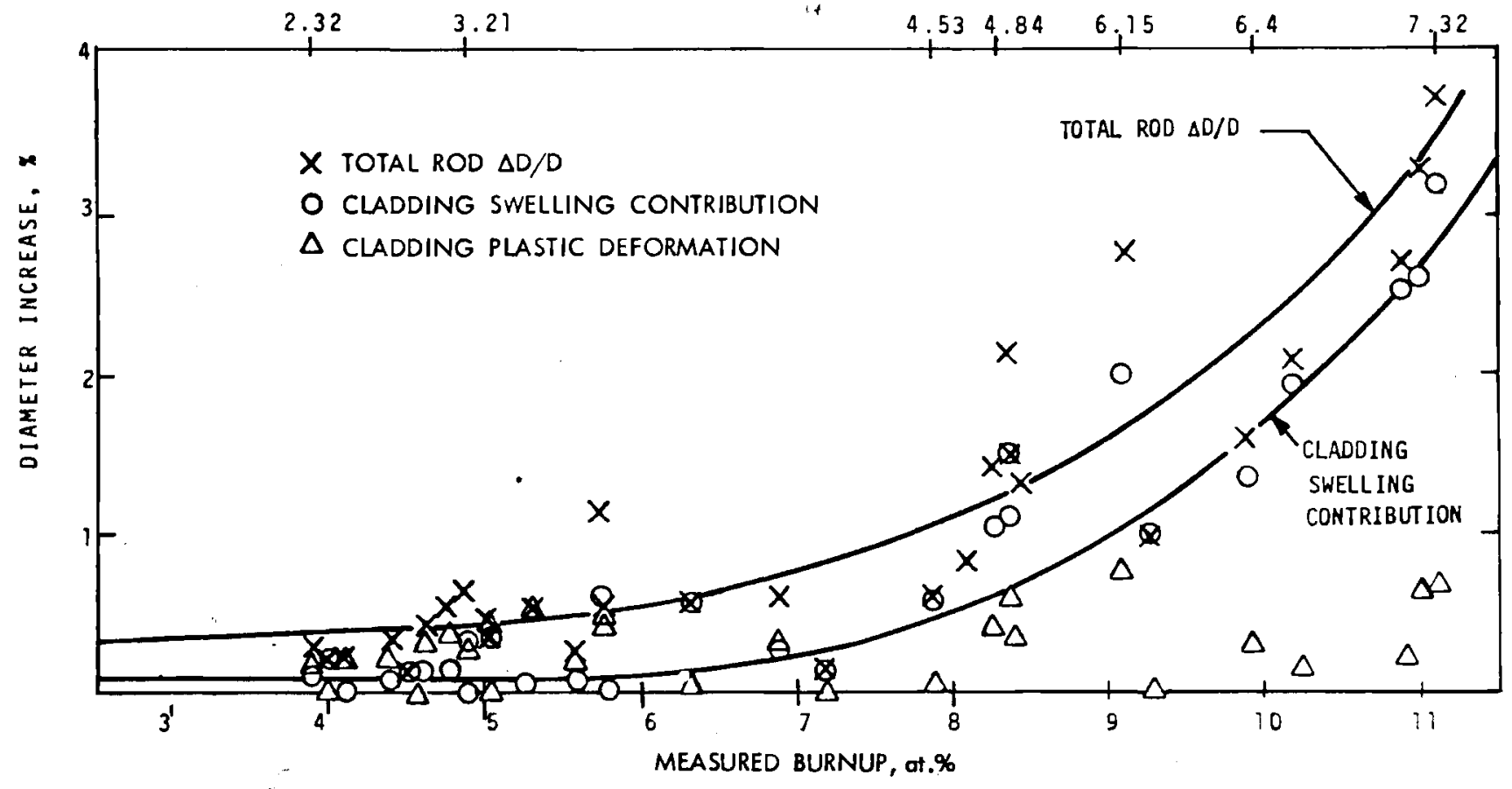

Diametral increase as a function of burnup for several sections of fuel rods irradiated in EBR-II.

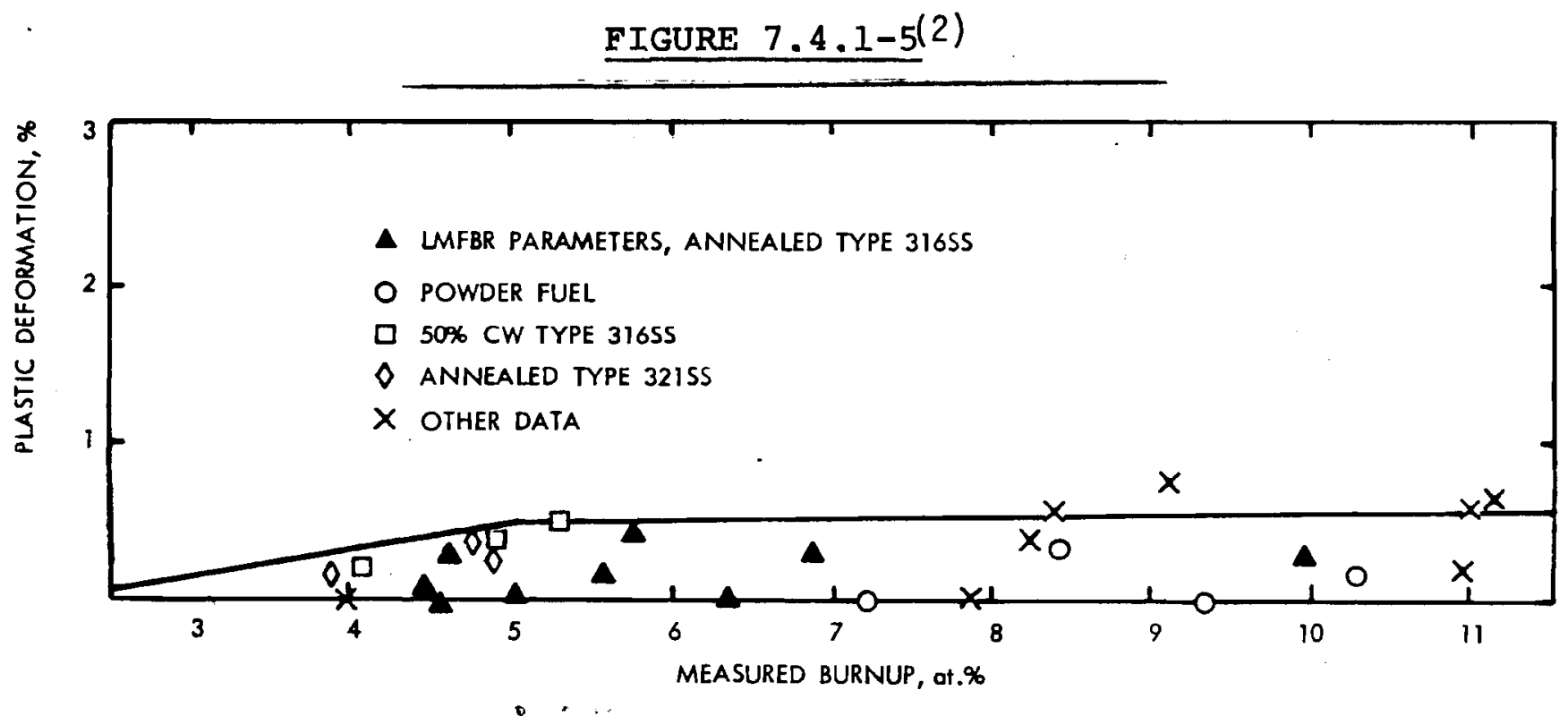

Cladding plastic deformation as a function of burnup.

FIGURE $7.4 .1-6^{(2)}$ 
7.4.1-9

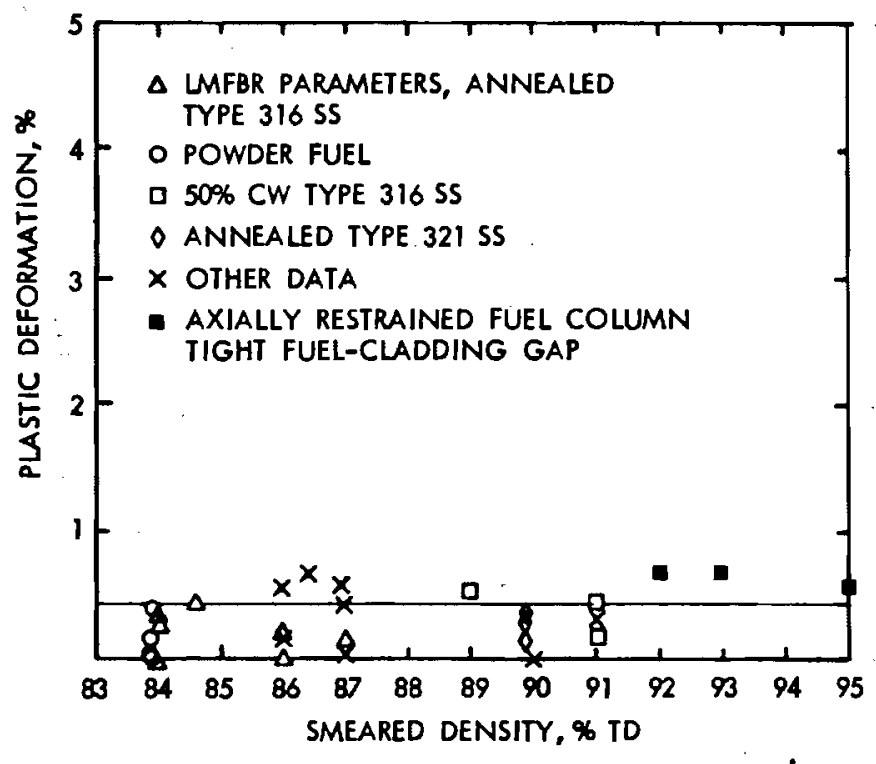

Plastic deformation as a function of smeared density.

FIGURE $7.4 \cdot 1-7^{(2)}$ 


$$
7.4 .1-10
$$

REFERENCES: 7.4 .1

1) USAEC-HEDL-BNW-WARD, LMFBR Materials Technology Information Meeting, Richland, WA, March 15-16, 1973

2) B. F. Rubin, et al,"Fuel-Cladding Mechanical Interaction in LMFBR Fuel Rods," Nuclear Technology, Vo1. 16, October 1972 . 


$$
7.4 \cdot 2-1
$$

\subsubsection{Fuel Clad Interaction Effects on Clad Mechanical Properties}

Fuel clad mechanical interaction is manifest in two ways: the predominant mode is clad creep; the less important mode is short term tensilestrain from power transients, initial thermal set, and cooldown ratcheting. From the standpoint of safety performance, the emphasis of "effect of prior creep" on mechanical properties should be the major focus. Reference 1 provides detailed experimental data on stress rupture, out-of-pile, unirradiated, tests on prestressed (and precreep) clad. These tests indicate some rather definite trends, but conclusions should be guarded since the important effects of irradiation exposure, in-reactor stress loading, and irradiation creep are missing from these data. Section 4.2 .3 of this document provides data on the irradiation creep phenomenon. Figure 7.4.2-1 (1) shows a 208 reduction in burst strength at $1200^{\circ} \mathrm{F}$ with prior creep, independent of prior stress level down to 29,000 psi. The reference (1) study does not indicate the amount of prior creep, so correlation with this parameter is not possible. However, Section 2.3.2.4 of this document demonstrates that prior creep significantly reduces both total elongation and UTS. These tests cited in section 2.3.2.4, conducted on annealed $316 \mathrm{SS}$, generally support the data depicted in Figure 7.4.2-1, the $\sim 20 \%$ reduction in burst strength.

The effect of prior creep coupled with irradiation for 304 annealed stainless is shown in Figure 7.4.2-2 ${ }^{(2)}$. It demonstrates that prior creep sirain of $\sim 1 \%$ causes a $\geq 50 \%$ reduction in irradiated materials tensile elongation. This compares with a 20 s reduction in the unirradiated material. In comparison, the current design criteria for FFTF clad is 0.2-0.3\% lifetime strain at normal conditions and a $0.7 \%$ failure strain. Fluences in Figure 7.4.2-2 are only $2 \%$ to $5 \%$ of peak FFTF clad fluences. 

FIG. 7.4.2-1 Results of Second Order Polynomial Fit to Stress-Rupture Data on 20\% Cold Worked 316
Stainless Steel Tubing

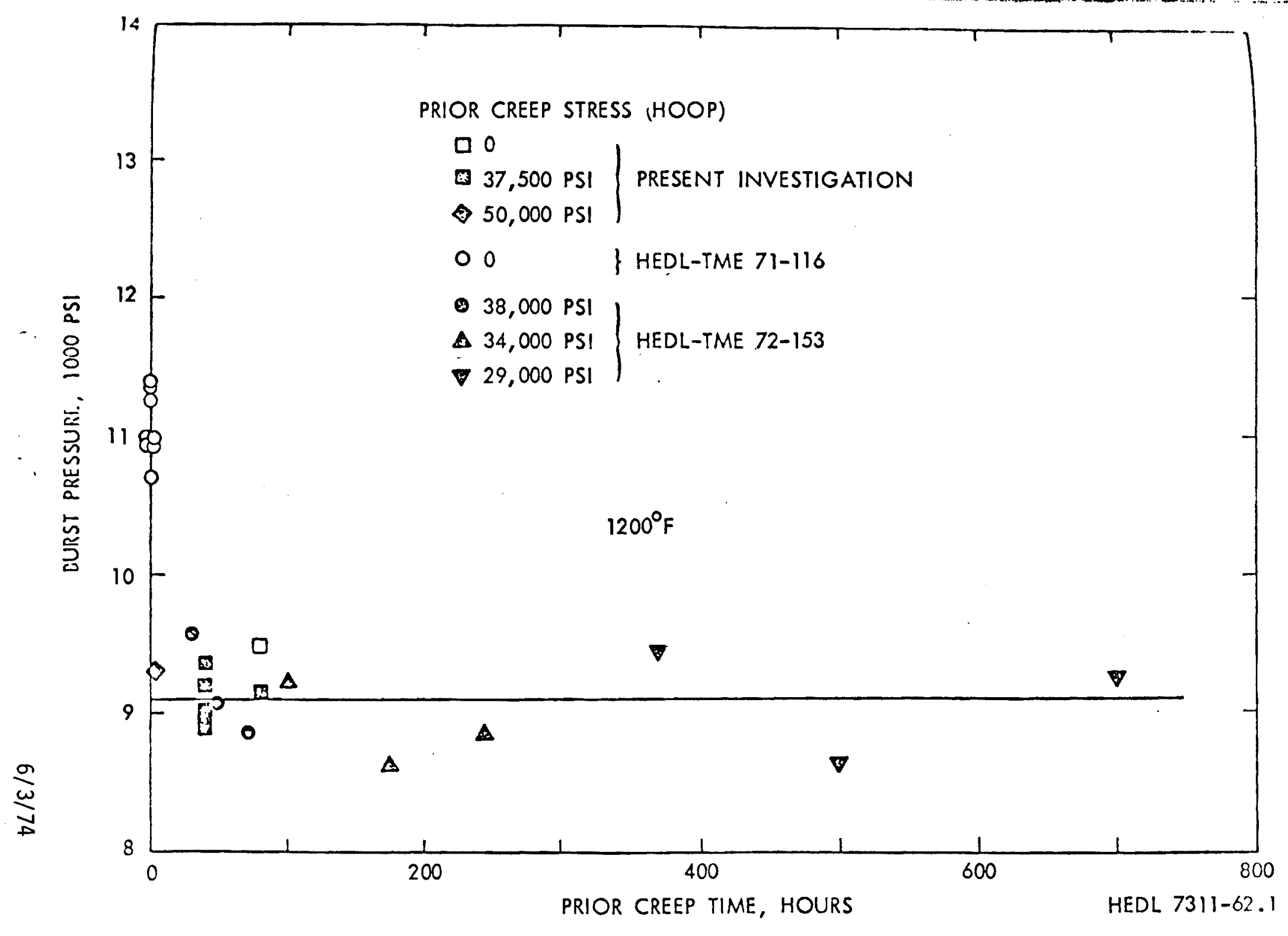


FIG. $7.4 .2 \div 2$

CREEP DAMAGE AND RESIDUAL TENSILE DUCTILITY

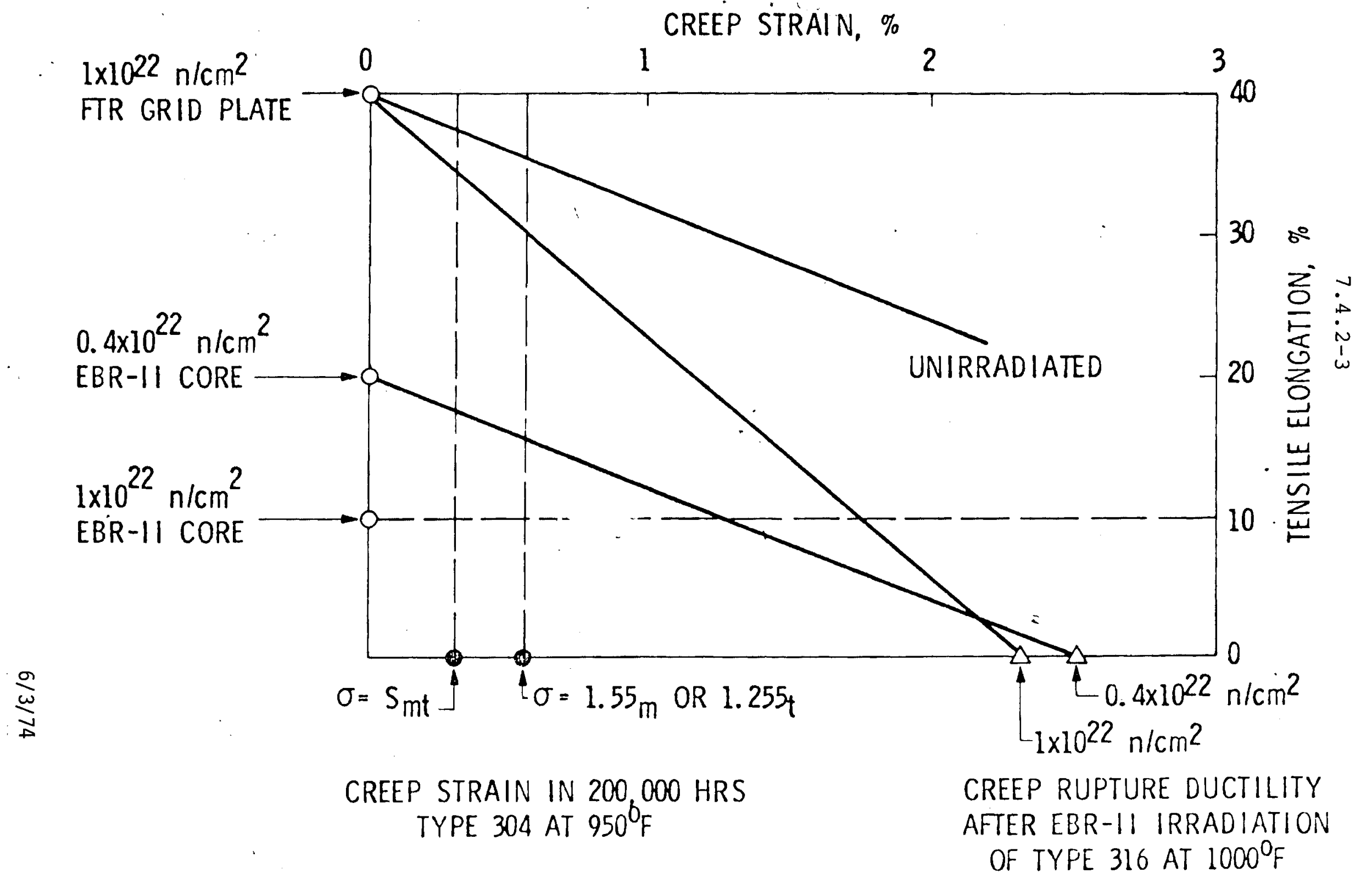




$$
7.4 .2-4
$$

Figure 7.4.2-3(2) is helpful in showing what ductility reduction might be expected for higher fluence (10\% of peak fluence) at a baseline of zero precreep for prototypic clad. A baseline (zero precreep) tensile elongation of from 1 to 108 might be expected. There is no statistically significant difference between the PNL-17, fueled and unfueled, sections shown in Figure 7.4.2-3. The true residual ductility and burst strength of precreep prototypic clad under LMFBR operating conditions will not be known until these data become available at goal fluences for the ongoing U. S. LMFBR fuels test program. 
FIG. $\quad 7.4 .2-3$

TOTAL ELONGATION OF $20 \%$ C.W. TYPE 316

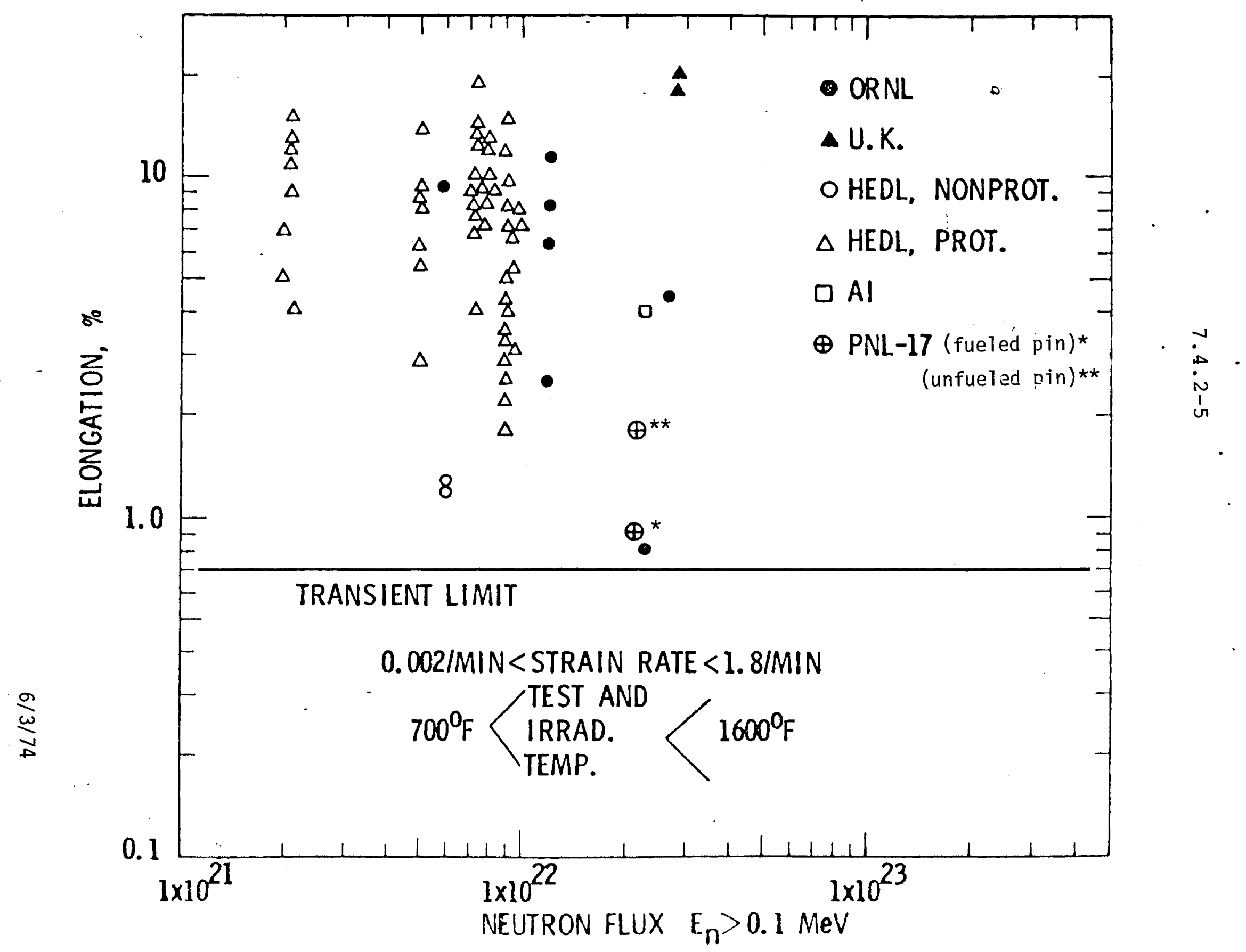




$$
7.4 .2-6
$$

REFERENCES: $\quad 7.4 .2$

1) HEDL-TME 73-16, HEDL Monthly Technical Progress Report, December 1974 .

2) USAEC-HEDL-BNW-WARD, LMFBR Materials Technology Information Meeting, Richland, WA, March 15-16, 1973. 


$$
7 \cdot 5 \cdot 1-1
$$

\subsection{Relationship of Fuel Clad Interaction Effects to Fuel Design and Performance}

\subsubsection{Introduction}

Fuel clad interaction has effects on two areas of design and performance as far as the fuel pin and assembly are concerned: normal operation and safety. The two are closely related since the materials effects and conditions which build into the fuel during normal operation influence the performance during accident conditions. The "degraded" condition of the clad does not necessarily represent a worst case condition for some accident situations. For instance, the $\$ 3 / \mathrm{sec}$ ramp incident (E-6 FFTF Classification (1)) which results, under some conditions, with fuel failure and fuel material expulsion into the coolant: The expulsion position and rate effect reactivity level, and thus accident consequences. A "degraded" condition in the cladding, i.e., lowered ductility and burst strength due to corrosion and/or mechanical effects result in earlier expulsion.* The application of the data contained in this volume for safety evaluation purposes must be considered in light of each accident since a materials condition may be an attribute to one accident consequence and a detriment to another.

* This consequence may reinforce or diminish the accident level depending upon the characteristics of the fuel expulsion process: early expulsion may shut down the accident quickly, on the other hand, low fission gas driving force and/or large fuel chunks may block the channel of delay further expulsion and shutdown. 


$$
7 \cdot 5 \cdot 1-2
$$

REFERENCES: $\quad 7.5 .1$

1) "Fast Flux Test Facility System Design Description No. 31," Reactor, Rev. 5, Hanford Engineering Development Laboratory, Westinghouse Electric Corporation, Advance Reactors Division, November 10, 1972 , ou0. 


\subsubsection{Effect of LMFBR Variables on Fuel Clad Interaction Processes}

The major developmental emphasis for LMFBR in the U.S. has focused on FFTF. Many of the comparative data in this report section are based upon FFTF design. These data are also applicable to commercial LMFBRs and the Demo. since the design and experimental data developed for FFTF are generally applied to the commercial program. Table 7.5.2-1 lists the FFTF fuel performance data appropriate to materials degradation from interaction processes. The intent of the clad strain limits listed in this table is to demonstrate design compliance with empirically determined materials limits. These limits have been discussed in the preceding parts of section 7 . The ID wastage is based upon a $95 \%$ probability leve ${ }^{(2)}$ of 1.04 mils at initial core conditions and $1.7 \mathrm{mils}$ at rated conditions.

The interaction processes for accident conditions, $\varepsilon>0.7 \%$, which result in, or approach to, clad breach arequite variable because of the spectrum of accidents. Generally clad strain in these accidents is due to short term thermal stress and relatively mild mechanical stresses from fission gas pressure at overpower or temperature excursion conditions. Table 7.5.2-2 (1) provides a brief description of these incidences. Specific strains computed for accumulated incidences E1, U3, E5, plus overtemperature operation transients during the fuels' three-year life result in a total strain of $0.005 \%(1)$ which is much below the differential strain margin allowed for operational and minor incidents. Figure 7.5.2-1 shows how large a safety margin appears to be available for operating transients. The figure shows several hundred hours or several hundred degrees ${ }^{\circ} \mathrm{F}$ available for transient times or temperature excursions prior to exceeding the $0.1 \%$ transient strain criterion.

A brief description of events which cause the fuel to exceed the established $0.7 \%$ strain failure 7 imit are also 1 isted in Table $7.5 .2-2$ ( $^{(3)}$ These accidents result in fuel clad failure due to 1) strain in excess of 
$7 \cdot 5 \cdot 2-2$

Table 7.5.2-1

FFTF/LMFBR Fuel Performance Data $(1,2)$

Parameter

Avg. Inlet Temp/outlet Temp, ${ }^{\circ} \mathrm{F}$

Avg. Disch. Burnup, MWD/kg

Peak Burnup,

Pin Linear Power KW/ft

Max. Clad ID Temp, ${ }^{0} \mathrm{~F}$

(Steady state, hot ch. factor)

Clad thickness, BOL, mils

$$
\text { " "EOL equiv., mils }
$$

ID Wastage Allowance, mi?s

Clad Material

Clad strain, design steady-state, end-of-life $\%$

Clad strain, design steady-state, plus anticipated transients \%

Clad strain, integrity limit \%

Maximum Fission Gas Pressure (100\% release) psi

$0 / \mathrm{M}$

BOL Cold Fuel/clad gap, mils

Smear Density, \%

Peak fluence $(E>0.1 \mathrm{MeV})$, nvt
FFTF

\begin{tabular}{|c|c|c|}
\hline$\frac{\text { Initial Core }}{600 / 900}$ & $\frac{\text { Rated Core }}{777 / 1077}$ & $\frac{\text { LMFBR GOALS }}{800 / 7100}$ \\
\hline 45 & $\sim 15$ & $>50$ \\
\hline 80 & 30 & $>100$ \\
\hline 7,13 & $\overline{7}, \hat{13}$ & $\sim \overline{7}, 13$ \\
\hline$\sim 1220$ & $\sim 1400$ & $\sim 1400$ \\
\hline 15 & 15 & $\sim 15$ \\
\hline 8 & 8 & $\sim 8$ \\
\hline 2.0 & 2.0 & same \\
\hline 316 SS, $20 \%$ CW & same & same \\
\hline 0.2 & 0.2 & $\sim 0.2$ \\
\hline 0.3 & 0.3 & $\sim 0.3$ \\
\hline 0.7 & 0.7 & $\sim 0.7$ \\
\hline 750 & Not available & unknown \\
\hline 1.97 & 1.97 & same \\
\hline 5.5 & 5.5 & ح same. \\
\hline 85.5 & same & $>85.5$ \\
\hline $2 \times 10^{23}$ & $\sim 7 \times 10^{22}$ & $\sim 2 \times 10^{23}$ \\
\hline
\end{tabular}


Table 7.5.2-2

FUEL PIN CLADDDING STRAIN DESIGN LIMITS

\begin{tabular}{|c|c|c|c|c|c|}
\hline \multirow[b]{2}{*}{$\begin{array}{l}\text { AJYE Vode Stcelon III } \\
\text { (A:t1c1e }: B-3112-3)\end{array}$} & \multirow[t]{2}{*}{ Condition Sumbarles } & \multirow[b]{2}{*}{ Severity Levols } & \multirow[b]{2}{*}{ Examples } & \multicolumn{2}{|c|}{ Design $L f=1$ tg } \\
\hline & & & & $\begin{array}{l}\text { Cladding } \\
\text { Strain } \\
\end{array}$ & $\begin{array}{l}\text { Fuc: Areal } \\
\text { Melt:sz, }\end{array}$ \\
\hline 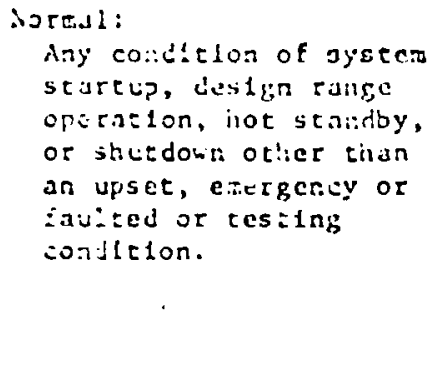 & 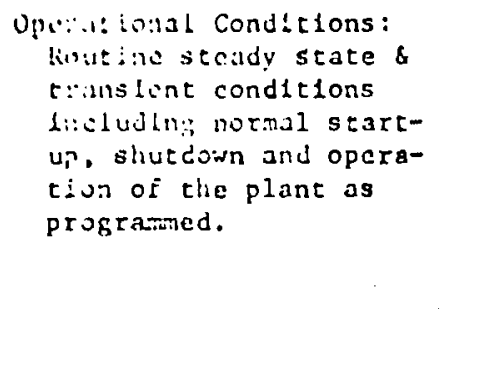 & $\begin{array}{l}\text { Steady Staze Operation: } \\
\text { The desinn range of } \\
\text { flow, temperature, } \\
\text { power, and flux. } \\
\text { parameters. } \\
\text { Operaticnal rransients: } \\
\text { Expccted chances In } \\
\text { parameters duc to } \\
\text { control or matrtenance } \\
\text { operation. }\end{array}$ & $\begin{array}{l}\text { Refueling } \\
\text { Hot Standby } \\
\text { Intefal Operation } \\
\text { Rated Operation } \\
\text { Advanced iperation } \\
\text { Normal Sirutdohn }:-4 \\
\text { Power Chang, } l-5 \\
\text { Terperature Change N-6 } \\
\text { Normal Temperature } \\
\text { fluctuations }:-7\end{array}$ & $.2 \pi$ & None \\
\hline 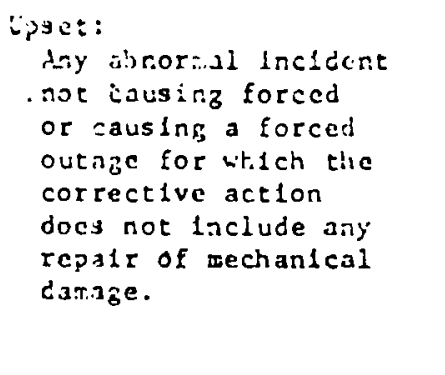 & $\begin{array}{l}\text { Anticlpated Faults: } \\
\text { N off nomal condition } \\
\text { which lndioldually may } \\
\text { be expected to occur } \\
\text { orce or more durlng } \\
\text { plane lifetime, }\end{array}$ & 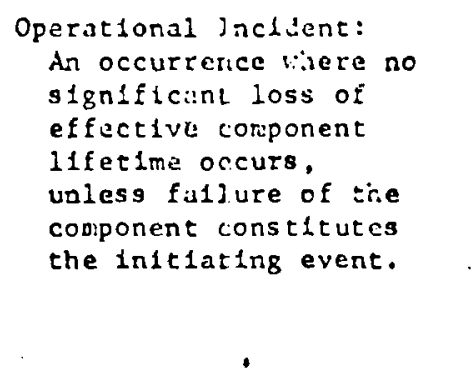 & $\begin{array}{l}\text { Reactor Scram U-? } \\
\text { Sa:cey Rod Drop U-2 } \\
\text { Loss of Power U-3, } 4 \\
\text { DHX Flow Loss U-6 } \\
\text { Pony Purp Loss U-8 } \\
\text { DHX Excess Dump U-9 } \\
<3 \text { c/sec } \\
\text { OB Earthquake U-11 } \\
\text { Closed Loop Test } \\
\text { Meltdown }\end{array}$ & .37 & $10 \%$ \\
\hline $\begin{array}{l}\text { Encrgency: } \\
\text { Infrequent Incldcnt } \\
\text { requizing shutdown for } \\
\text { correction of zhe } \\
\text { cordition or repalr of } \\
\text { damage in tile system. } \\
\text { io joss of structural } \\
\text { integrity. }\end{array}$ & 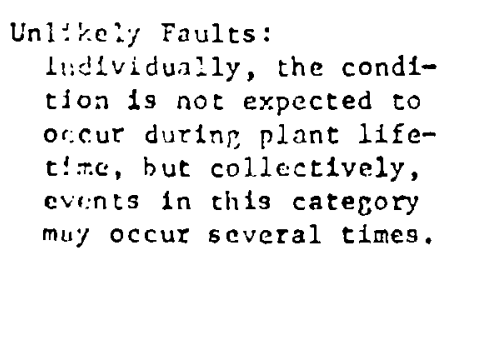 & $\begin{array}{l}\text { Minor Incidert: } \\
\text { An occurrerce where } \\
\text { component camage is } \\
\text { within speclfled loss } \\
\text { of effective lifet1me. } \\
\text { No lifet'me reduction } \\
\text { for pernancint or semi- } \\
\text { permanent components for } \\
\text { total nurber of occur- } \\
\text { rences in this class. }\end{array}$ & $\begin{array}{l}\text { Pup Fallures E-1, } 2 \\
\text { Ail DHX Fallure E-4 } \\
\text { All Power Loss E-5 } \\
\text { Mult1ple Fallure E-10 }\end{array}$ & $0.7 \pi$ & $20 z$ \\
\hline
\end{tabular}


TABLE 7.5.2-2 (continued)

FUEL PIN CLADDING STRAIN DESIGN LIMITS

\begin{tabular}{|c|c|c|c|c|}
\hline & Cond1tion Summarlas & & & Desfga Lialts \\
\hline 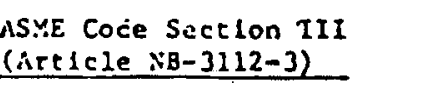 & RDT Standard & Sever1ty Leve1s & Examples & $\begin{array}{ll}\text { Cladding } & \text { Fucl Areal } \\
\text { Strain } & \text { Melting, } \\
\end{array}$ \\
\hline 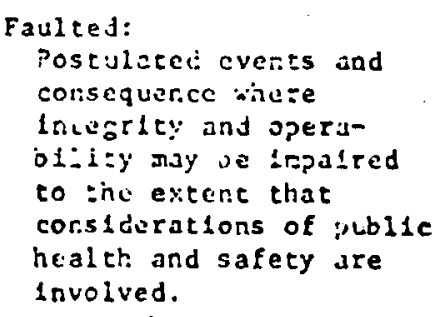 & 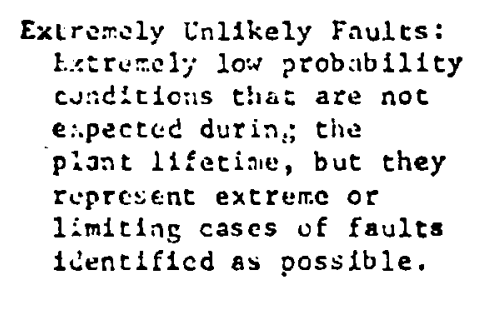 & $\begin{array}{l}\text { Major Incldent: } \\
\text { Damage that requires } \\
\text { repiacement or repait } \\
\text { of repiace.blc semi- } \\
\text { permanent components or } \\
\text { systers and replaccment, } \\
\text { repalr, or at least } \\
\text { extensive inspection of } \\
\text { perinanent components. }\end{array}$ & $\begin{array}{l}\text { Muleiple Fallures } \\
\text { 3\$/sec Ramp E-6 S( }) \\
\text { Driver Fuel Meitdown } \\
\text { P1pe Rupture }\end{array}$ & $\begin{array}{l}\text { Coolable } \\
\text { Geometry }\end{array}$ \\
\hline$\cdot$ & 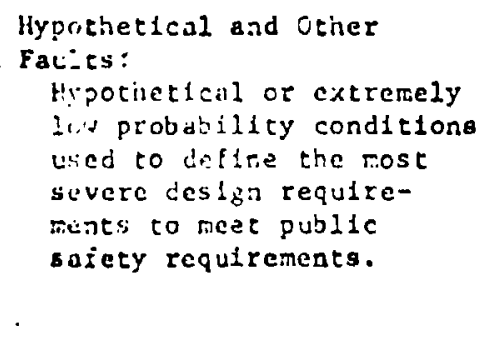 & 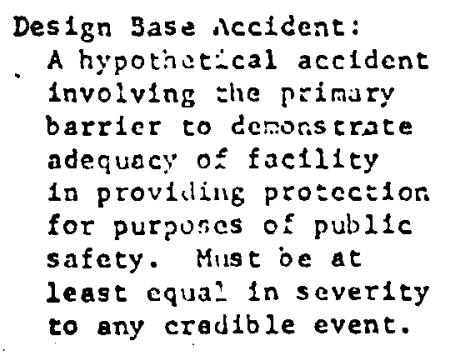 & $\begin{array}{l}\text { Core Disruptive } \\
\text { Aceldent } \\
\text { Dy Earthquake } \\
\text { Otherg }\end{array}$ & $\begin{array}{l}\text { Core debris } \\
\text { held coolable; } \\
\text { Public environs } \\
\text { shall not be } \\
\text { endangered: as } \\
\text { per loCrR-100. } \\
\text {. }\end{array}$ \\
\hline
\end{tabular}

(*) It shall be the objective of the prS to limit the results of these transients within the fuel pla 1ntegrity limit. 


\section{$7 \cdot 5 \cdot 2-5$}

Figure 7.5.2-1

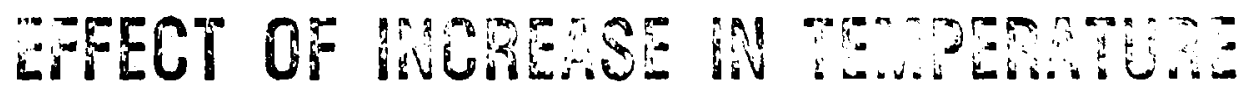

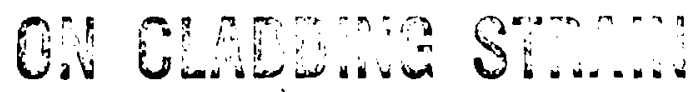

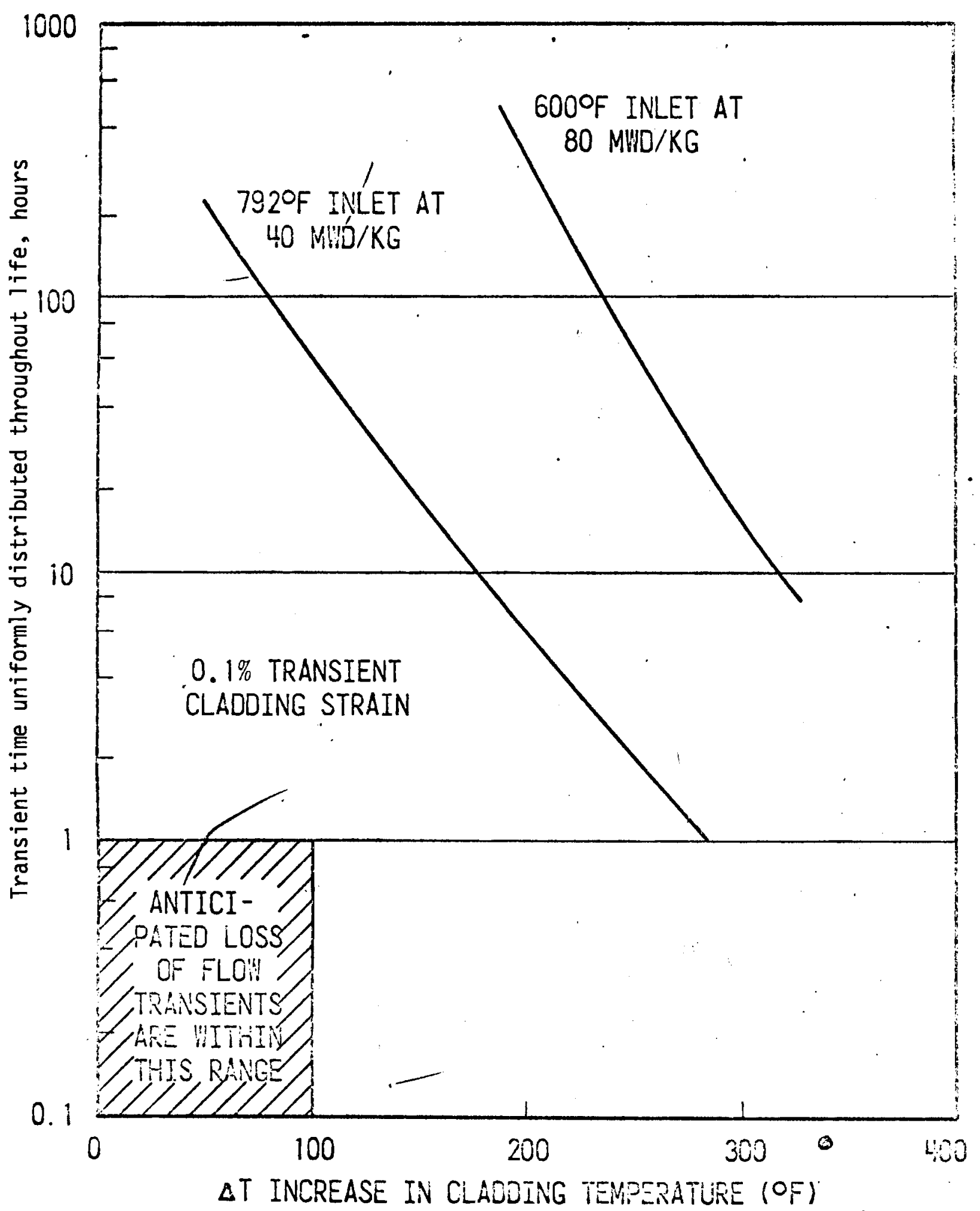




$$
7.5 .2-6
$$

$0.7 \%$ and/or 2) excessive fuel clad temperature, and/or 3) fuel clad meltthrough. In a 11 cases the combination of internal gas pressure, thermal, and physical ineraction stresses exceed burst strengths. A summary of some of these failure models is shown in Table 7.5.2-3(3). Figure 7.5.2-2 ${ }^{(2)}$ demonstrates clad displacements for a type E6 incident. It may be seen that short term tensile properties are probably controlling in this incident. A broad series of TREAT tests are planned on burned and green prototypic fuel to verify both the failure characteristics and thresholds. 


\begin{tabular}{|c|c|c|c|c|}
\hline PIN TYPE & $\begin{array}{l}\text { CONDITIONS } \\
\text { TFAIL }\end{array}$ & RELATIVE $\tau_{\text {FAIL }}$ & $\begin{array}{l}\text { FAILURE LOCATION } \\
\text { ANO TYPE }\end{array}$ & MOLTEN FUEL BEHAVIOR \\
\hline $\begin{array}{l}\text { FRESH } \\
\text { (TYPE A) }\end{array}$ & $\begin{array}{l}\text { - }-80 \% \text { MOLTEN FUEL } \\
\text { - } T_{\text {CLAD }}=T_{\text {MELT }} \\
\text { - } T_{\text {BULK Na }}=T_{B O I L}\end{array}$ & $\begin{array}{l}\text { - LAST PINS TO FAIL } \\
\text {. } \\
\vdots\end{array}$ & $\begin{array}{l}\text { ONEAR TOP } \\
\text { - MELTTHROUGH }\end{array}$ & $\begin{array}{l}\text { - HIGHLY MCBILE } \\
\text { - EXPULSION BY FILL GAS, } \\
\text { SORBED GASES AIIO FLEL } \\
\text { VAPOR }\end{array}$ \\
\hline $\begin{array}{l}\text { LOW POWER } \\
\text { (TYPE D) }\end{array}$ & $\begin{array}{l}\text { - } T_{\text {FUEL }} \leq T_{\text {MELT }} \\
\text { - NO MOLTEN FUEL } \\
\text { - THREE MECHANISIIS } \\
\text { OPERATING }\end{array}$ & $\begin{array}{l}\text { - SEQUENCE OF FAILURE } \\
\text { DEPENDENT UPON } \\
\text { RADIAL POLIER } \\
\text { PROFILE }\end{array}$ & $\begin{array}{l}\text { OBETHEEN CEIITER AYY } \\
\text { TOP } \\
\text { - CLADOING STRAIN }\end{array}$ & $\begin{array}{l}\text { - LIMITED QUUANTITY EXPELLED } \\
\text { AT } \tau_{F A I L} \\
\text { - } \tau>T F A I L, \text { FUEL-GAS MIX } \\
\text { EXPELLED }\end{array}$ \\
\hline $\begin{array}{l}\text { HIGH PONER } \\
\text { (TYPE B) }\end{array}$ & $\begin{array}{l}-T_{\text {FUEL }} \leq \mathrm{T}_{\text {MELT }} \text { IN } \\
\text { LON POWER } \\
\text { MICROSTRUCTURE } \\
0: 30 \% \text { HOLTEN FUEL } \\
\text { IN PIN AT AXIAL } \\
\text { MIDPLANE }\end{array}$. & & $\begin{array}{l}\text {-TOP OF CENTRAL VOID } \\
\text { OCLADOING STRAIN }\end{array}$ & $\begin{array}{l}\text { - RAPID EXPLLLSIOII BY FISSIOII } \\
\text { GAS O } \tau=\tau \text { FAIL } \\
\text { - CONTINUED EXPULSION OF } \\
\text { FUEL-GAS KIX }\end{array}$ \\
\hline
\end{tabular}

$T=$ TEMPERATURE

$\frac{\sigma}{\omega}$

TABLE 7.5.2-3 ${ }^{(3)}$ SUIMARY - IIIXED-OXIDE FUEL PIN RESPONSE-TO OVERPOWER TRANSIENTS 
THE CLADDING OUTER SURFACE PLASTIC EFFECTIVE STRAIN.

THE FUEL PELLET OUTER SURFACE DISPLACEMENT, AND THE CLADDING INNER SURFACE DISPLACEMENT HISTORIES FOR THE PEAK. AND AVERAGE POWER FTR FUEL PINS

AT MIDPLANE DURING 3\$ISEC UNTERMINATED AND SECONRARY SCRAM TERMINATED

WITH A NOMINAL RADIAL GAP OF 2.75 MILS - $800 \mathrm{~F}$ INLET COOLANT

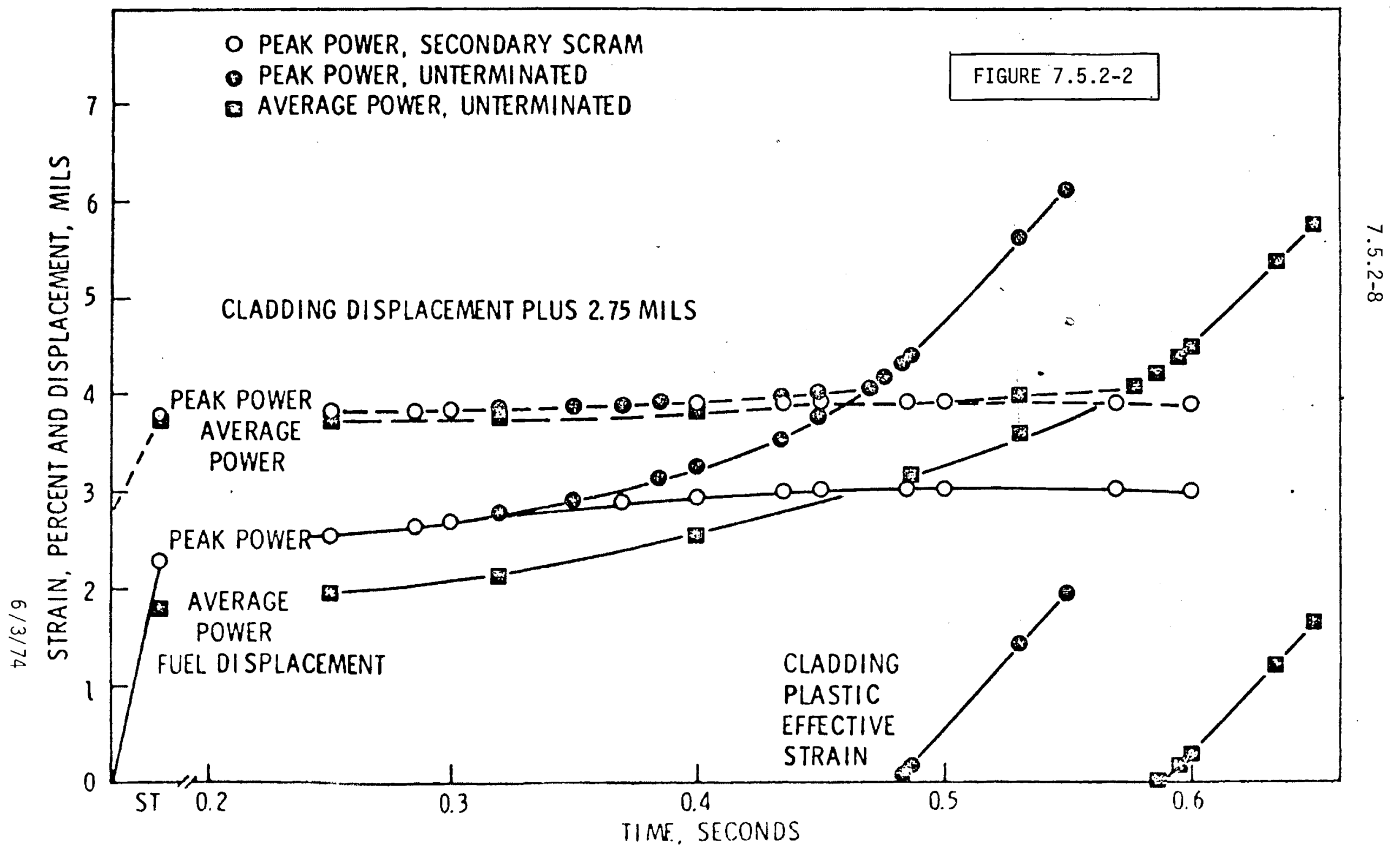




$$
\text { 7.5.2-9 }
$$

REFERENCES: $\quad 7.5 .2$

1) "Fast Flux Test Facility System Design Description No. 31," Reactor, Rev. 5, Hanford Engineering Development Laboratory, Westinghouse Electric Corporation, Advance Reactors Division, November 10, 1972, OUD

2) USAEC-HEDL-BNW-WARD, LMFBR Materials Technology Information Meeting, Richland, WA, March 15-16, 1973

3) W. L. Partain, et. al., "Effects of Molten Fuel Movement during a Fast Reactor Overpower Transient," HEDL-TME 72-109, August 4, 1972, 0U0 Rough Draft. 


\subsubsection{General Implications of Fuel Clad Interaction Processes} on Fuel Operating and Safety Performance.

The steady state requirement for fuel performance is basically an integral pin throughout its lifetime with strain not to exceed $0.3 \%$. Plastic strains (mostly creep). for irradiation conditions and claddings somewhat different than current LMFBR prototype, have exceeded this value, Figure 7.4.1-5 and -6 . Additionally, the strain capability of the prototype cladding at LMFBR conditions has not been demonstrated. Figure 7.5.3-1 seems to support the trend towards strain capability in excess of $0.3 \%(1)$. However, the unfueled clad data in this figure have experienced exposures of only 10\% goal FFTF fluence. Additionally, the single 304 SS datum shown in the figure indicates zero creep strain at about $75 \%$ of FFTF fluence. The biaxial clad data shown in Figure 7.5.3-2 do not appear to differ between fueled and unfueled sections. Again fluences are less than $10 \%$ of goal FFTF exposure. The three data points at $\sim 0.2 \%$ strain may be anomalies since the data shown in Figure 7.4.1-5 demonstrate a plastic deformation capability in excess of $0.2 \%$ at burnups near LMFBR goals but at $\sim 30 \%$ of the fluence. ${ }^{*}$ Except for the fluence level, these pins probably experienced the full extent of expected fuel clad interactions.

Transient clad failure characteristics of prototype cladding generally show lower strain-to-failure with increasing transient (strain) rate. Irradiation (up to $15 \%$ of goal fluence) shows about a factor of 4 reduction in stable strain at failure ${ }^{(2)}$, Figures $7.5 .3-3$ and -4 . Some irradiated samples did contain fuel; the presence of fuel may have affected ductility. Since the fueled and non-fueied tubes are not segregated in the reference, the effect of fuel cannot be assessed. Similar results for a different series of tests are shown in Figure 7.5.3-5. (3) A detailed analys is of transient clad failure characteristics are presented in Section 3.2.4 of this report.

* Because of the lower neutron flux in EBR-II as compared to FFTF or the LMFBR, fuel exposed in EBR-II experiences a fast fluenceto-burnup ratio considerably less than FFTF or LMFBR when test pin enrichment is increased to some later LMFBR 1 inear heat rates; see Table 7.4.1-1. 
Figure 7.5.3-1

UNIAXIAL STRESS RUPTURE - $316 \mathrm{SS}^{(1)}$

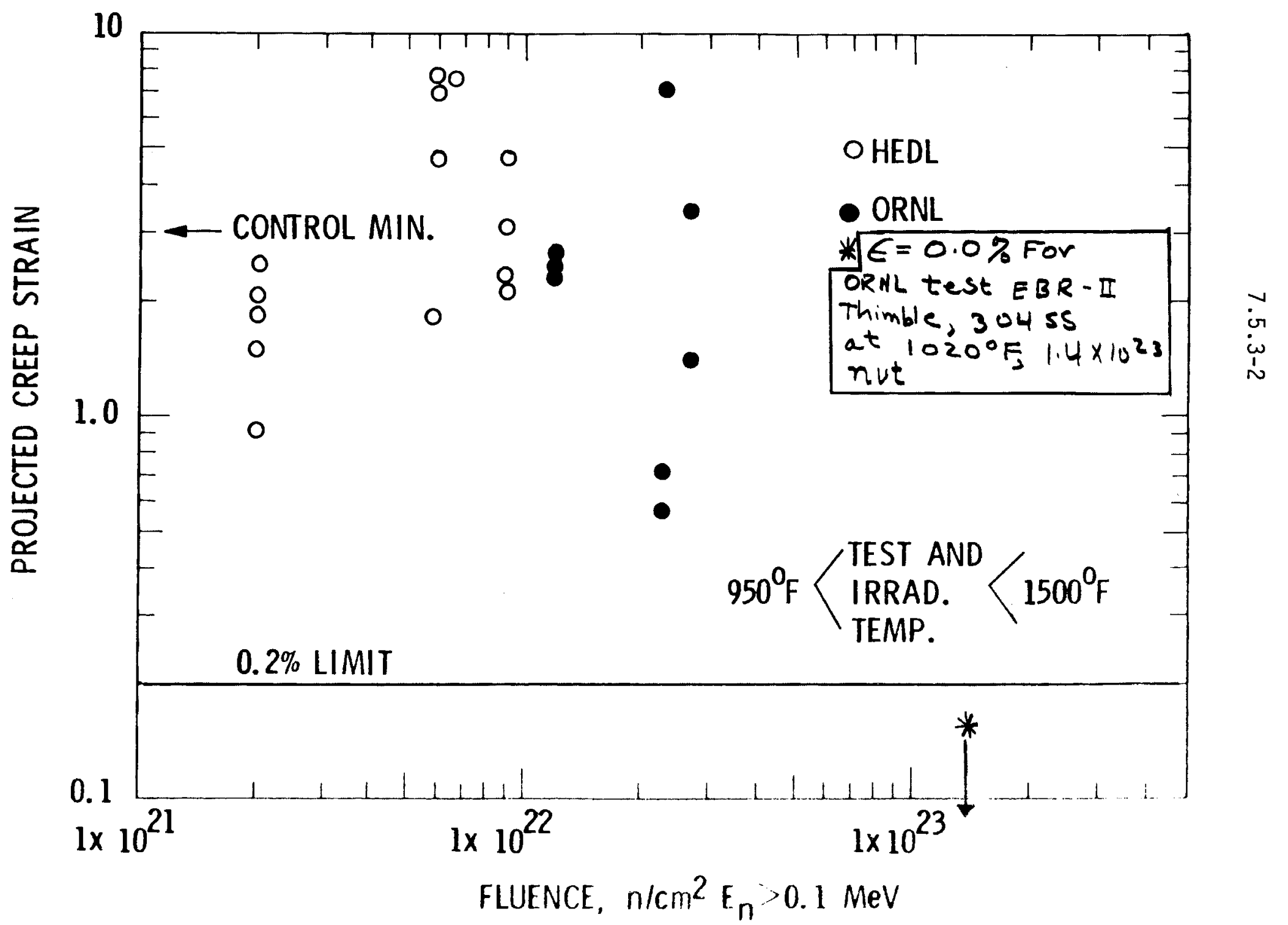


Figure 7.5.3-2

BIAXIAL STRESS RUPTURE ON $20 \%$ C.W. TYPE 316 CLADDING $^{(1)}$

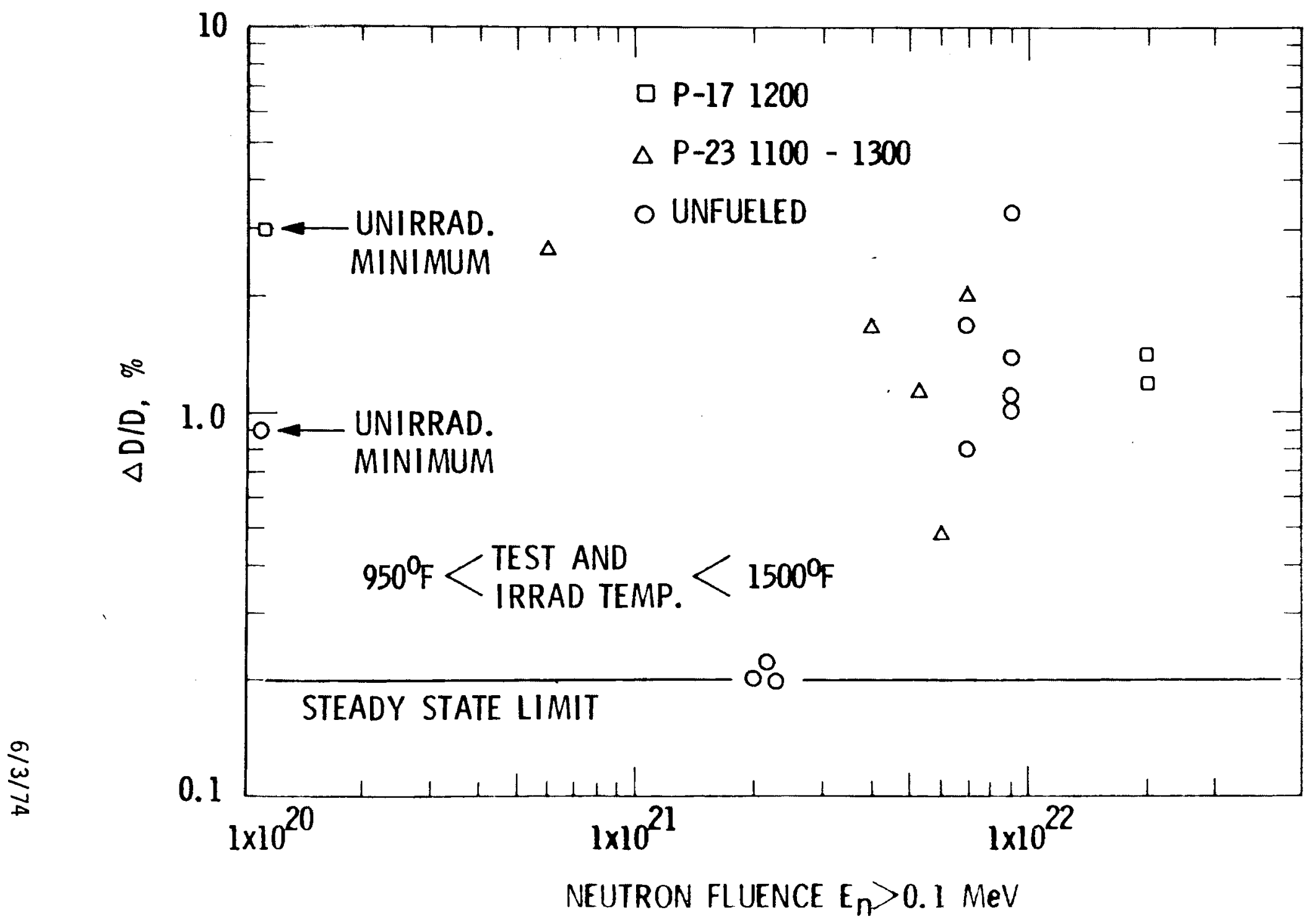




\section{$7 \cdot 5 \cdot 3-4$}

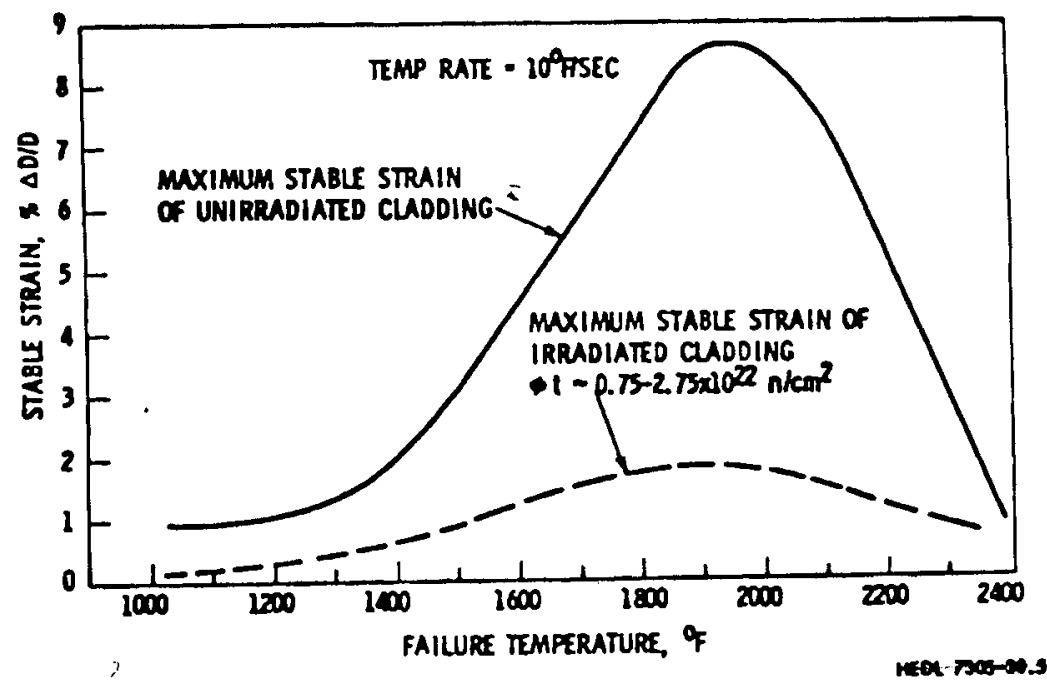

Effect of Irradiation on FTR eladding stratn during $10^{\circ} \mathrm{F} / \mathrm{sec}$ temperature transients (20s $\mathrm{CW}$ type $316 \mathrm{ss}$ ). Ref. 2

Figure $7 \cdot 5 \cdot 3-3$

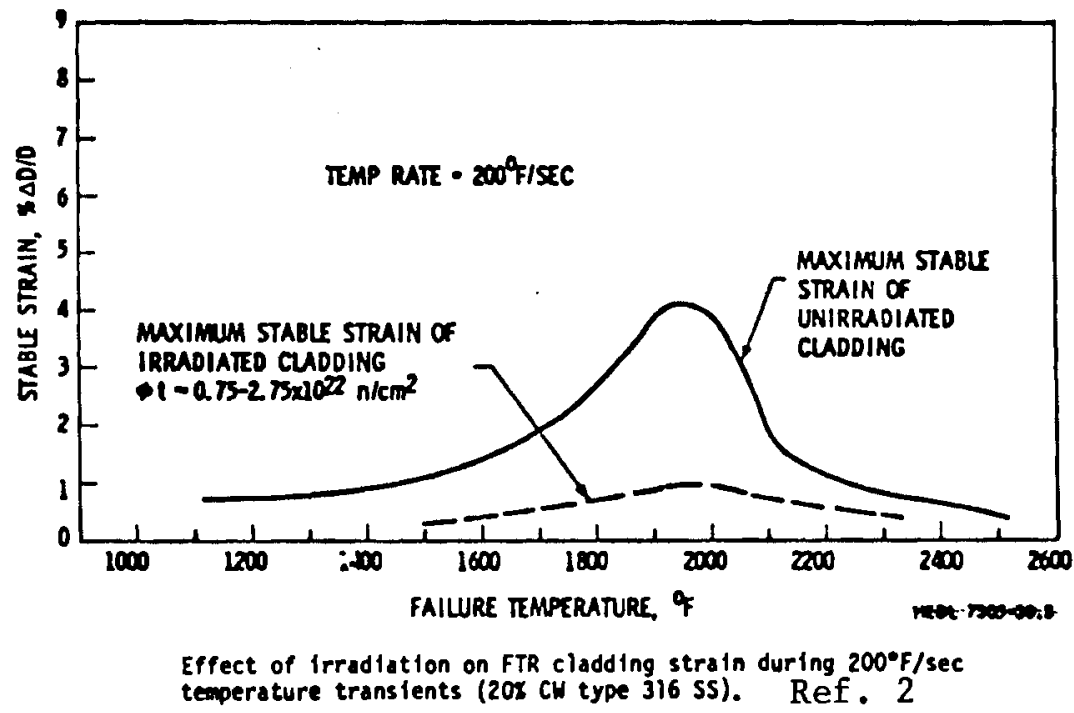

Figure 7.5.3-4 
7.5.3-5

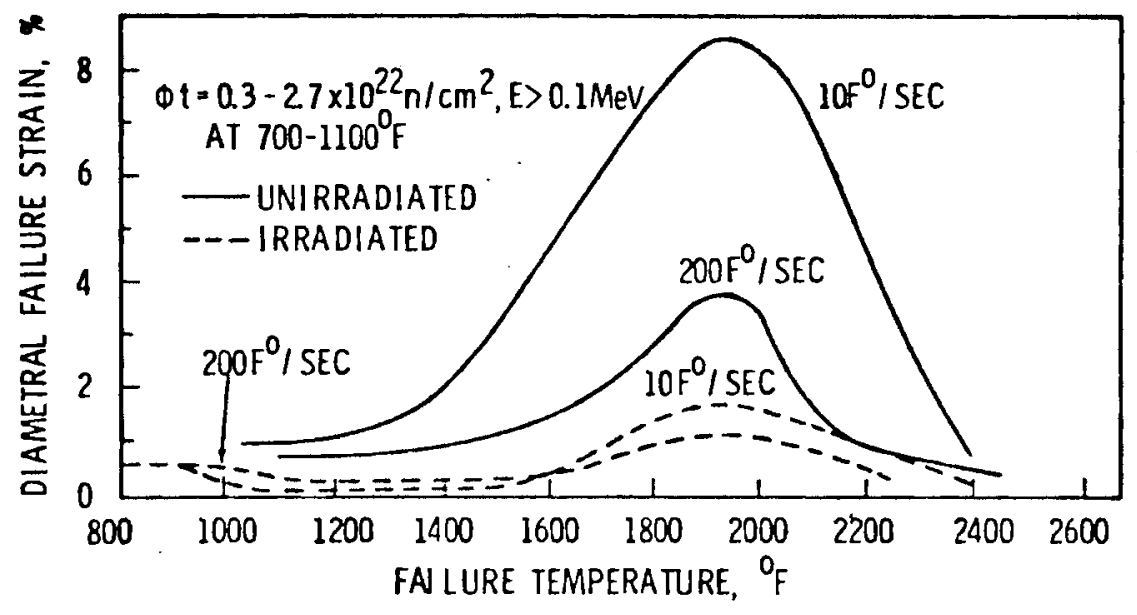

Figure $7 \cdot 5 \cdot 3-5^{(3)}$

Effect of Irradiation on $10 \% \mathrm{CW} 316$ SS Cladding 
Interestingly the failure strain curves cross at elevated temperatures demonstrating high temperature annealing of irradiation effects at the lower heating rate. Reference 3 also cites the difference between failure modes at different strain rates as the reason for the ductility crossover; at higher temperatures and lower strain rates, the failure mode is intergranular which takes place after considerable deformation. References 4 and 5 supply specimen profiles for clad failure. It appears that ducilities are low enough to not cause ballooning and channel blockage $(1,4)$. The ongoing TREAT tests will not fully demonstrate both the failure (axial) position, failure strains, and modes because these are not prototype preoperating conditions. Current design margins for transient clad integrity $(0.7 \%$ strain) may not be adequate since the relatively low fluence data in Figure 7.5.3-5 show failure strains considerably less than $0.7 \%$. The reader should refer to Section 3.2.4 of this report for a more detailed discussion of the transient failure phenomena.

Marked differences in failure strength occur due to irrdiation. Figure 7.5.3-6 ${ }^{(6)}$ shows failure strengths for unirradiated clad samples at a variety of heating rates. These samples are internally gas pressurized to cause failure. Figure $7.5 .3-7^{(3)}$ compares irradiated and unirradiated failure stresses; some of the irradiated specimens (not specified) contained fuel. The figure shows a minor $150^{\circ} \mathrm{F}$ shift (lowering) of failure temperature (at the same stress) for $200^{\circ} \mathrm{F} / \mathrm{sec}$ transients. A more significant $400^{\circ} \mathrm{F}$ lowering is shown at the $10^{\circ} \mathrm{F} / \mathrm{sec}$ transient rate. Reference 3 suggests failure mode as the reason for the transient rate difference in failure strength effects (transgranular versus intergranular). Perhaps annealing of irradiation effects and subsequent strength loss during heatup is also a factor.

The lowered (transient) failure ductility of irradiated material will lead to a greater number of fuel failures during accidents. The lowered failure threshold may change accident peak energy due to earlier fuel expulsion and thus may also change the consequence power excursion accidents. 


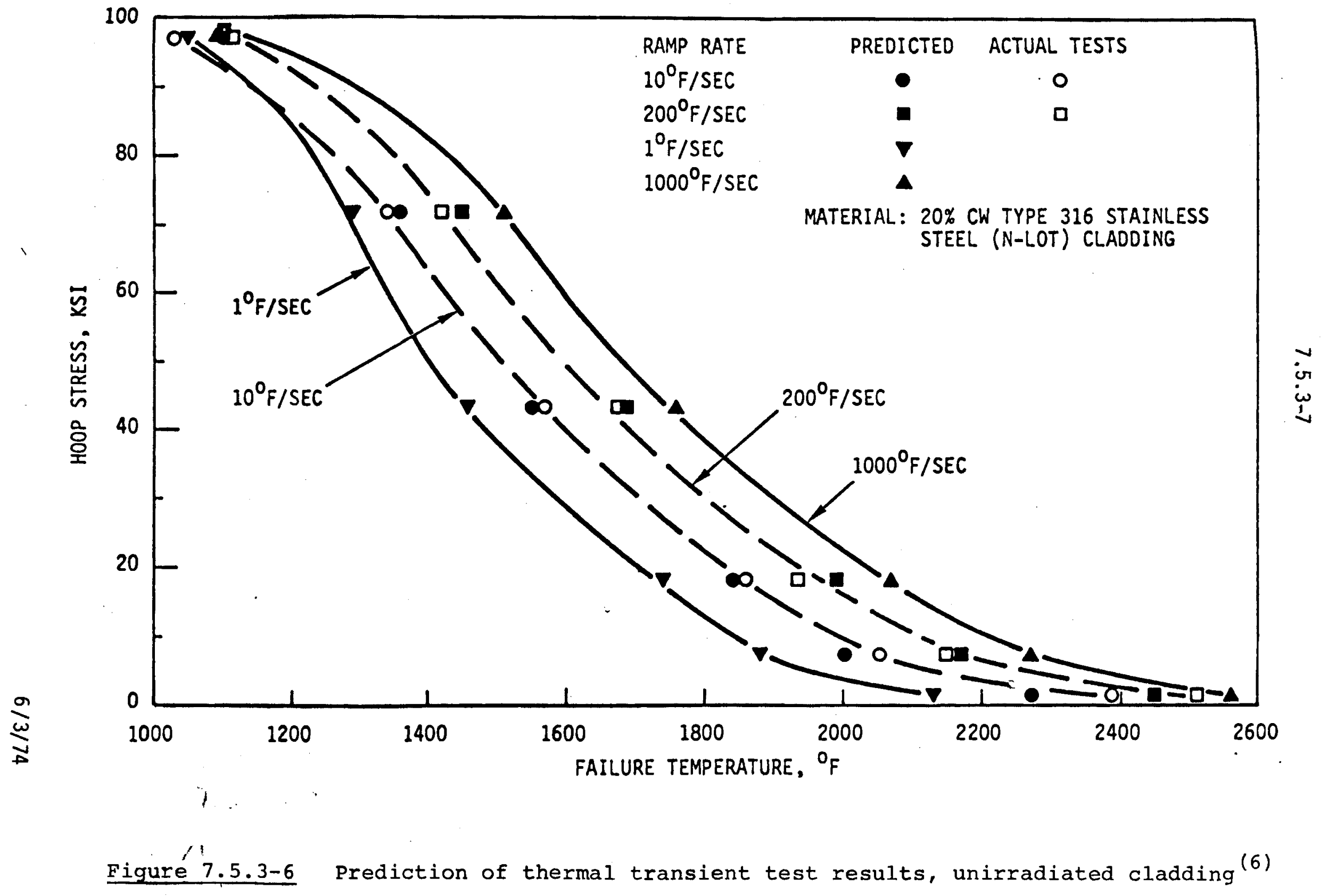




\subsection{3-8}

EFFECT OF IRRADIATION ON THE FAILURE STRENGTH OF

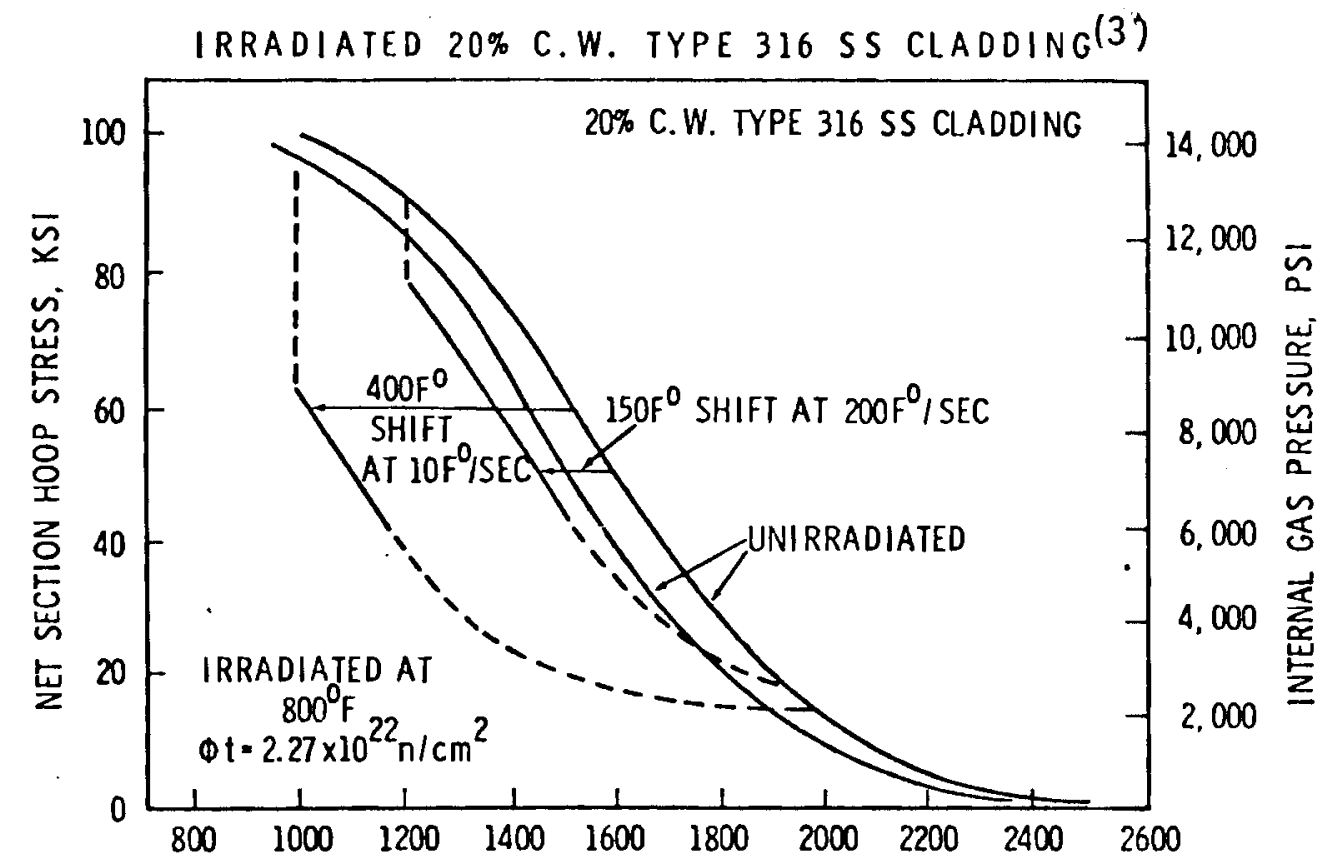

Figure $7.5 \cdot 3-7$ 


\section{$7.5 \cdot 3-9$}

\section{REFERENCES: $\quad 7.5 .3$}

1) USAEC-HEDL-BNW-WARD, LMFBR Materials Technology Information Meeting, Richland, WA, March 15-16, 1973.

2) HEDL-TME 73-4, HEDL Quarterly Technical Report, April-May-June 1973.

3) J. H. Scott, et. al., "Microstructural Dependence of Failure in Mixed-0xide LMFBR Fuel Pins, HEDL-SA-701, undatet.

4) C. W. Hunter and R. L. Fish, "Deformation and Failure of Fast Reactor Cladding During Simulated Loss-of-Flow Type Transients, HEDL-SA-645, undated.

5) HEDL-TME 72-12, HEDL Quarterly Technical Report, OctoberNovember-December 1972.

6) HEDL-TME 73-5, HEDL QUARTERLY TECHNICAL REPORT, Ju1y-AugustSeptember 1973, Vol I, Materials Technology. 

8. EFFECT OF SODIUM COOLANT INTERACTIONS ON MECHANICAL PROPERTIES

\section{TABLE OF CONTENTS}

8.1 INTRODUCTION ....................... 8.1-1

8.2 EFFECT OF SODIUM TEMPERATURE IN FLOWING SODIUM, $\Delta T$

SYSTEMS ......................... 8.2.1-1

8.2.1 Introduction ............... 8.2.1-1

8.2.2 Carburization not Simulated ....... 8.2.2.1-1

8.2.2.1 Effects on Composition ....... 8.2.2.1-1

8.2.2.2 Effects on Microstructure ..... 8.2.2.2-1

8.2.2.3 Effects on Mechanical Properties ... 8.2.2.3-1

8.2.3 Carburization Simulated ......... 8.2.3.1-1

8.2.3.1 Effects on Composition ....... 8.2.3.1-1

8.2.3.2 Effects on Mechanical Properties . . . 8.2.3.2-1

8.3 GENERAL RELATIONSHIP OF SODIUM COOLANT INTERACTIONS ON MECHANICAL PROPERTIES TO LMFBR PERFORMANCE ..... 8. 8.3.1-1

8.3.1 Introduction . . . . . . . . . 8.3.1-1

8.3.2 Influence of LMFBR Variables ....... 8.3.2.1-1

8.3.2.1 LMFBR Reactor Variables ...... 8.3.2.1-1

8.3.2.2 LMFBR Material Variables . . . . . 8.3.2.2-1

8.3.3 General Implications of Sodium Effects on

Mechanical Properties to LMFBR Components . . . 8.3.3.1-1

8.3.3.1 Pressure Vesse1 ........ 8.3.3.1-1

8.3.3.2 Core Components ........ 8.3.3.2-1 



\section{$8.1-1$}

8. EFFECT OF SODIUM COOLANT INTERACTION ON MECHANICAL PROPERTIES

\subsection{INTRODUCTION}

Studies of the effects of sodium coolant interactions on the mechanical properties of structural materials have been spurred by the development of the LMFBR concept. While several laboratories have taken one or more approaches to the problem, the sources of definitive data relevant to LMFBR are only one or two in number; and, as yet, no data exists on the combined effects of sodium and high fluence irradiation environments, though a USAEC-sponsored program to obtain such data has been initiated.

The corrosion and mass transfer processes that occur in sodium sys tems are dealt with in detail in Chapter 9.0. No attempt will be made to reproduce that information here, though some duplication may occur when it is felt that to do so would enhance the description of the effects of sodium on mechanical properties.

This chapter will focus upon data derived from tests in flowing sodium loops having large $\triangle T$ s and low oxygen levels, since such systems are more relevant to LMFBRs than are static or isothermal systems. Within this context, then, it will be the purpose of this chapter to review the available data; to point out the current unresolved problem areas; and to discuss, in a general way, the significance of sodium effects on mechanical properties to LMFBR performance. 


\section{$8.1-2$}

\section{REFERENCES}

1. "Reactor Development Program Progress Report, August 1973, Section VA-2: Sodium Effects in LMFBR Materials," ANLRDP-19, p. 5.6 . 


\subsection{EFFECT OF SODIUM TEMPERATURE IN FLOW SODIUM, $\triangle T$ SYSTEMS}

\subsubsection{INTRODUCTION}

Several factors have been elucidated as being important in sodium corrosion and mass transfer processes. These--sodium temperature, downstream or $\Delta T$ effects, oxygen level, carbon level and flow velocity--are detailed in Section 9.2 of Chapter 9: Mass Transport and Corrosion. In this chapter, much of the data presented, unless otherwise noted, will be from tests conducted in loops where oxygen was maintained at a low level to minimize corrosion ( $\sim 2.5 \mathrm{ppm})$; where flow was around $17 \mathrm{ft} / \mathrm{sec}(10 \mathrm{gal} / \mathrm{min})$; and where 1oop $\Delta \mathrm{Ts}$ were approximately $450-500^{\circ} \mathrm{F}$ to simulate LMFBR conditions. (1) Thus, only sodium temperature and carbon content, when purposely added, are system variables.

In this context, then, the effects on mechanical properties of flowing sodium exposure under non-carburizing conditions and simulated carburizing conditions will be discussed. 


\section{REFERENCES}

1. "Summary Report, Sodium Mass Transfer Program: Effect of Sodium Exposure on the Corrosion and Strength of Stainless Steels," GEAP-10394, August 1971, pp. 4-1 through 4-32. 


\subsubsection{CARBURIZATION NOT SIMULATED}

\subsubsection{Effects on Composition}

When carbon is not purposefully added to a stable flowing sodium $\Delta T$ loop, carbon transport will occur from newly inserted test specimens placed at or near the hot, or upstream, leg of the system to the cooler, or downstream, leg of the system. Selected alloying elements will also be removed. The extent of this decarburization and element removal from a test specimen depends on its temperature and its position relative to other sources of the same element (that is, whether it is upstream or downstream of the other sources). The major source of data for this section had test specimens downstream from the system heaters. (1) Thus, maximum corrosion rates and property degradations were not produced; and the results, therefore, are not conservative (i.e., more severe corrosion and degradation than that to be reported can occur). However, the comparative behavior of the various alloys tested can be usefully analyzed.

A brief description of the compositional changes that can occur in stainless steels under the flowing sodium conditions described in Section 8.2.1 is useful for understanding the resultant degradation in properties. Figure 8.2.2.1-1 ${ }^{(1)}$ shows the comparative weight losses of three austenitic steels at $1150^{\circ} \mathrm{F}$ and $1300^{\circ} \mathrm{F}$. Corrosion increases with sodium temperature; the most corrosion-resistant alloy is 316 stainless steel. The compositional changes occurring in austenitic steels with time of exposure in a surface layer $<0.1 \mathrm{mil}$ thick, as determined by fluorescence analysis, is presented in Figure 8.2.2.1-2. (1) Al1 alloys exhibited progressive losses of chromium, nickel and manganese with increasing exposure time. The alloys lost 65 to $80 \%$ of their manganese, 50 to $65 \%$ of their chromium, and 55 to $90 \%$ of their nickel content during these exposures. This selective depletion of alloying element leaves an iron-rich surface than can transform to a ferritic layer. At $1300^{\circ} \mathrm{F}$, steady-state conditions were only achieved after 10,000 hours. Bulk compositional changes were analyzed by electron 


\section{$8 \cdot 2 \cdot 2.1-2$}

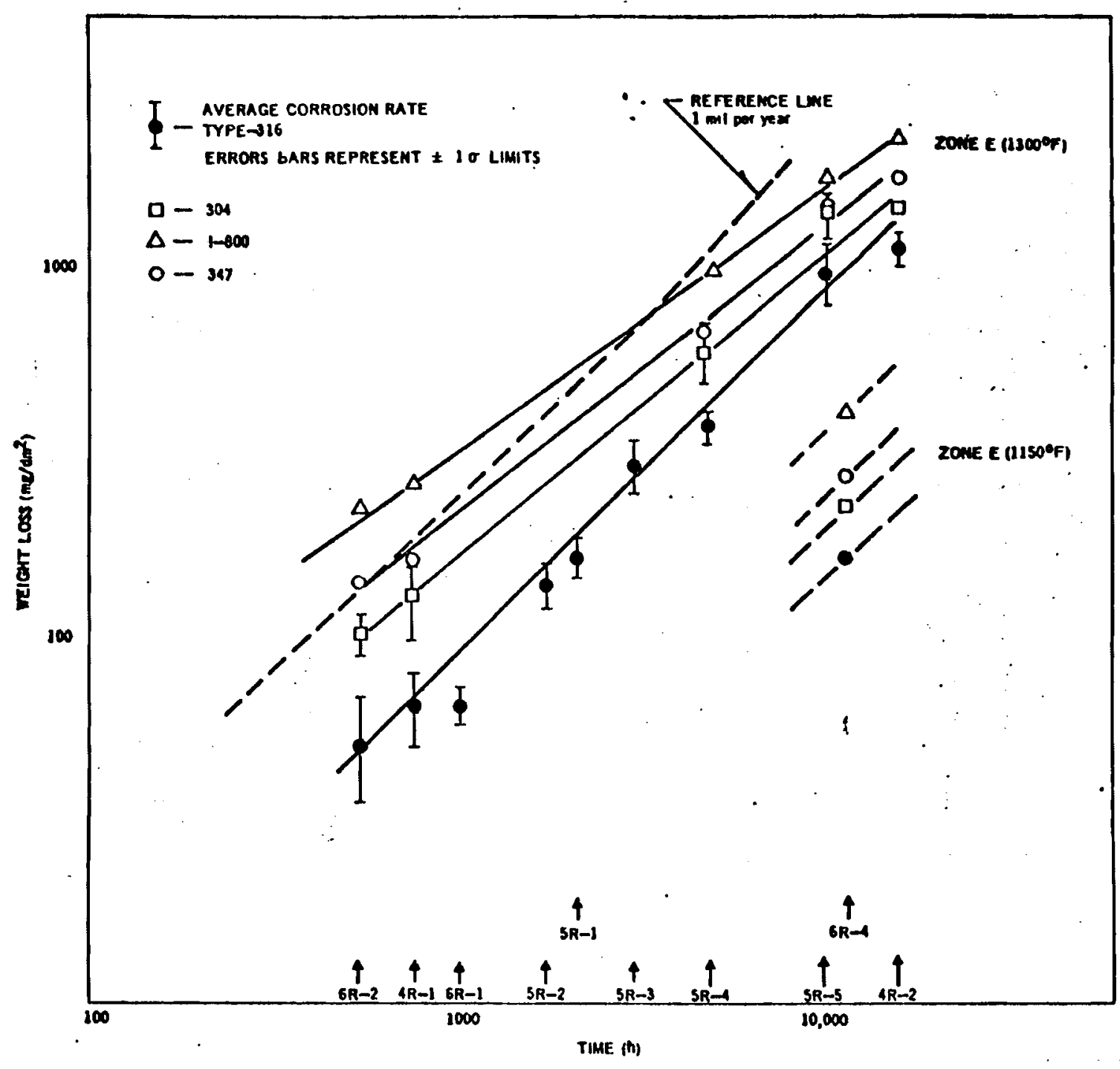

FIGURE 8.2.2.1-1 Corrosion of Stainless Steels in Flowing Sodium at $1150^{\circ} \mathrm{F}$ and $1300^{\circ} \mathrm{F}$. 
8.2.2.1-3

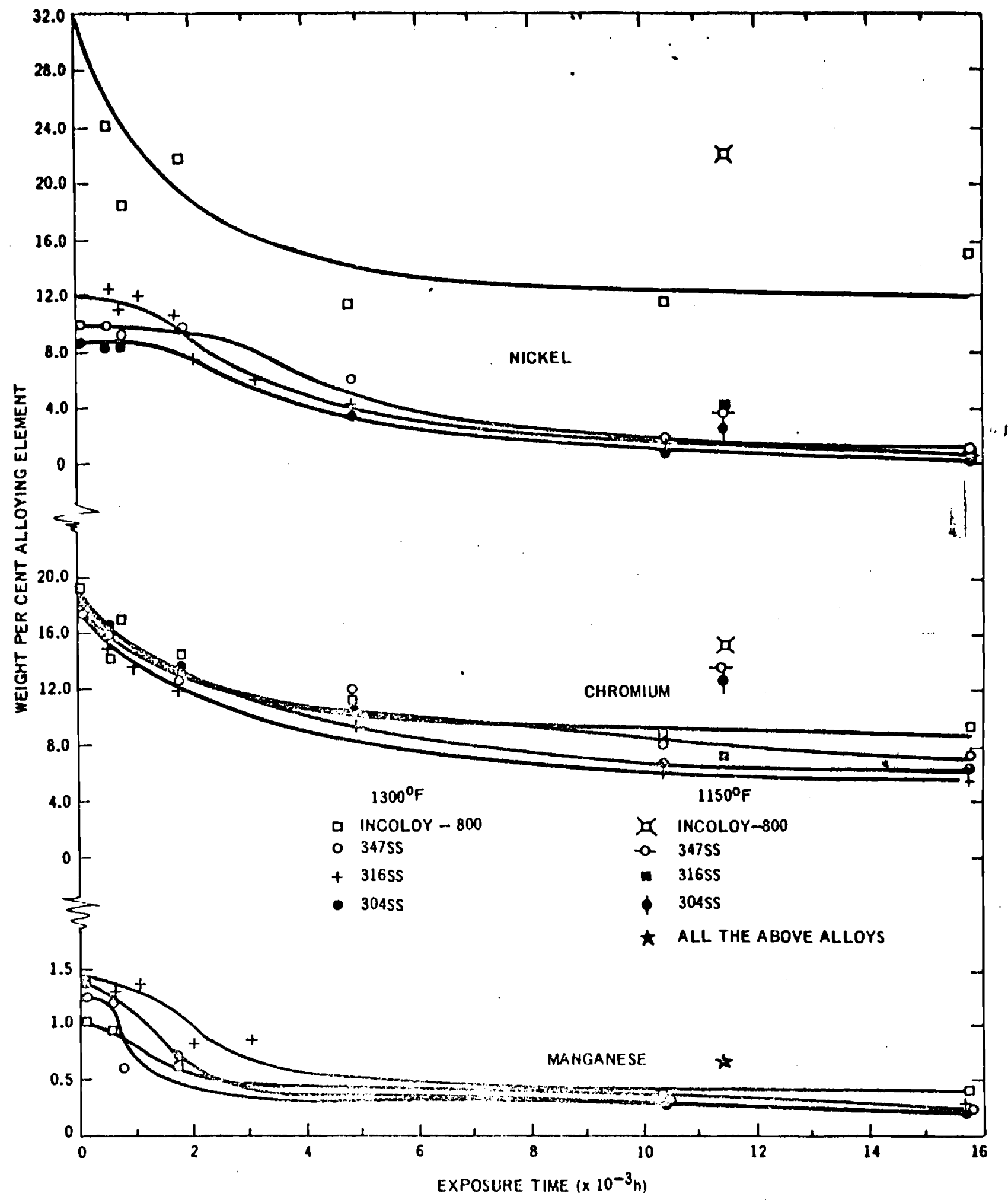

FIGURE 8.2.2.1-2 Surface Concentration of Alloying Element as a Function of Exposure Time in $1300^{\circ} \mathrm{F}$ and $1150^{\circ} \mathrm{F}$ Flowing Sodium. 


\subsubsection{1-4}

microprobe after 2,083 hours and 15,726 hours of exposure at $1300^{\circ} \mathrm{F}$; the results generally agree. The 15,726 hour exposure data is presented in Figures 8.2.2.1-3 through -5 for 316 stainless steel, 347 stainless steel and Incoloy 800 , respectively.

Changes in carbon contents were observed. (1) At $1300^{\circ} \mathrm{F}$, 304 and 316 stainless stee 1 decarburized while 321, 347 and Incoloy 800 carburized. The data is summarized in Tables 8.2.2.1-1 and -2. Examination of the data shows some inconsistances, some of which have to do with replacement of a heater in the section of the loop involved with the 5R-5 test, providing another carbon source. But the data was found to be consistent with observed degradations in stress-rupture properties, i.e., maximum carbon loss yielded maximum reduction in stress-rupture properties.

Changes in nitrogen content were also observed in these steels, as indicated in Figure 8.2.2.1-6. Losses were observed for both stabilized and non-stabilized steels in Zone $E$ tests, with the major changes occurring in the unstabilized 304 and 316 stainless steel. In addition, significant nitrogen loss occurred from 316 stainless steel during the $1150^{\circ} \mathrm{F}$ test. Results from the lower downstream position (Zone F) were not as consistent.

Results of analyses for boron, sulfur and phosphorous are shown in Table 8.2.2.1-3. As shown, sodium exposure did not affect sulfur or phosphorous contents at either 1150 or $1300^{\circ} \mathrm{F}$. However, substantial quantities of boron were lost, which is very significant because of the major positive effect this element has on the high-temperature creep-rupture properties of austenitic alloys. 


\section{$8 \cdot 2.2 .1-5$}

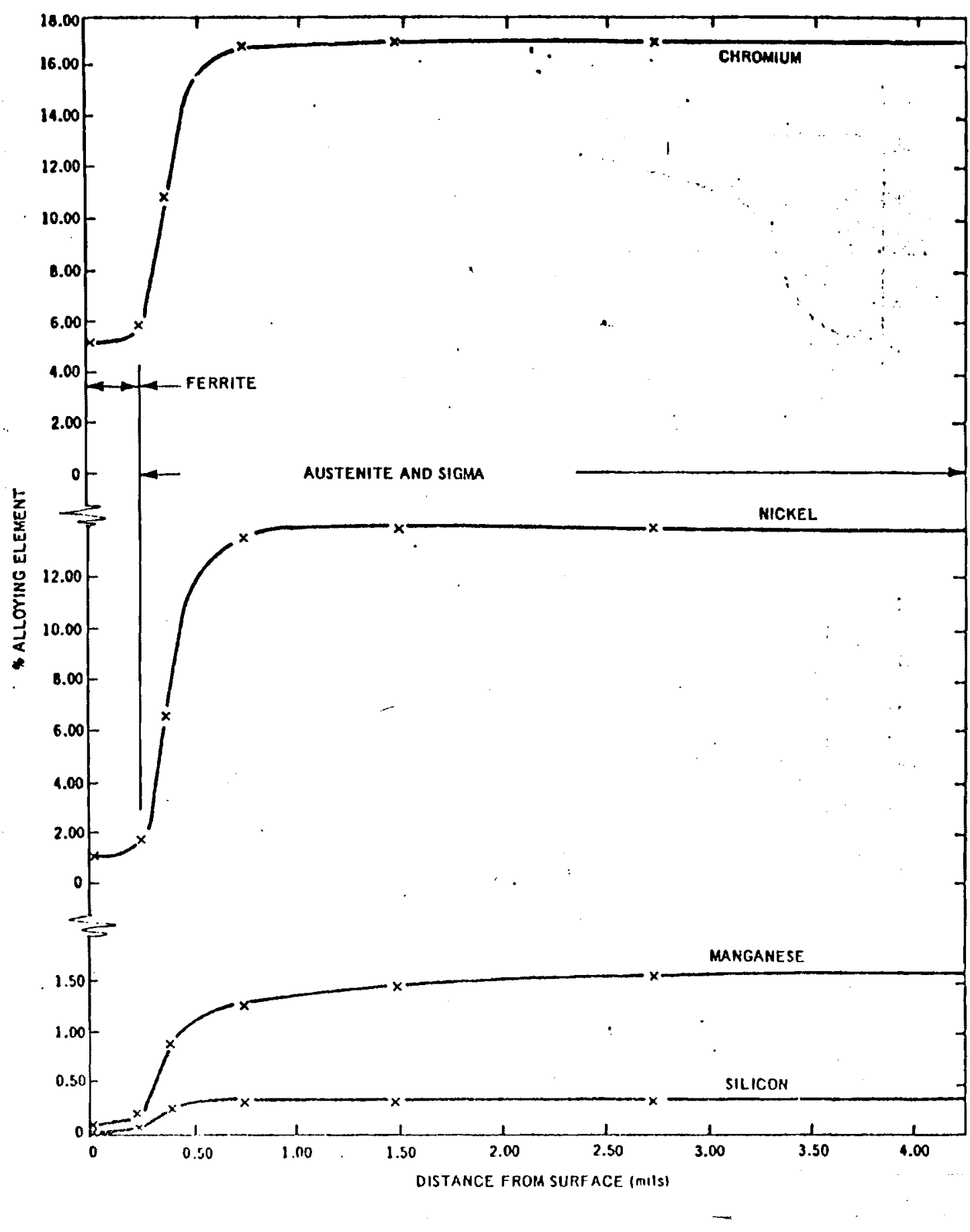

FIGURE 8.2.2.1-3 Composition Profile of Solution-Annealed

Type 316 Stainless Steel After 15,726 hours

Exposure to $1300^{\circ} \mathrm{F}$ Flowing Sodium 


\subsubsection{1-6}

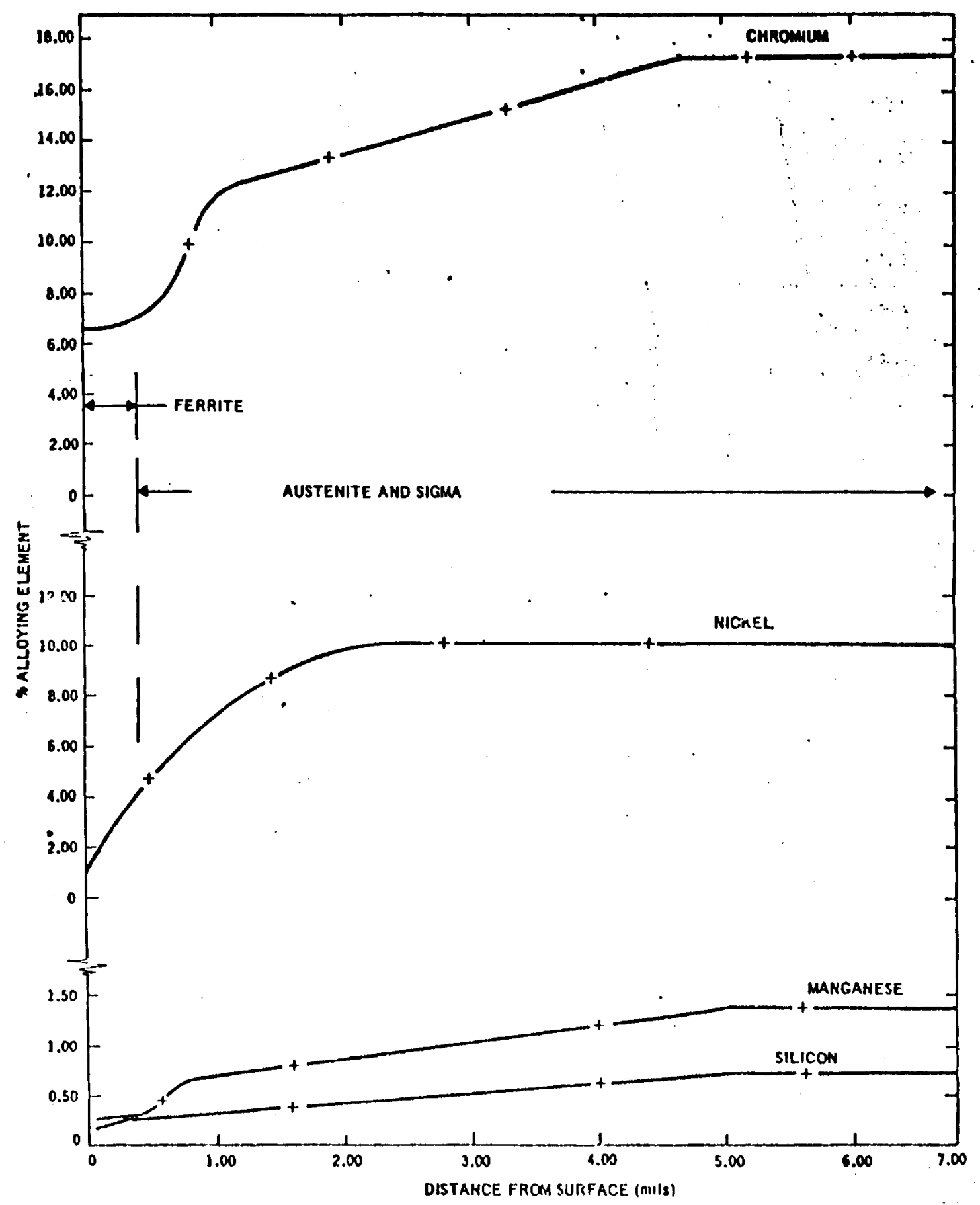

FIGURE 8.2.2.1-4 Composition Profile of Solution-Annealed Type 347 Stainless Stee1 After 15,726 hours Exposure to $1300^{\circ} \mathrm{F}$ Flowing Sodium. 


\subsubsection{1-7}

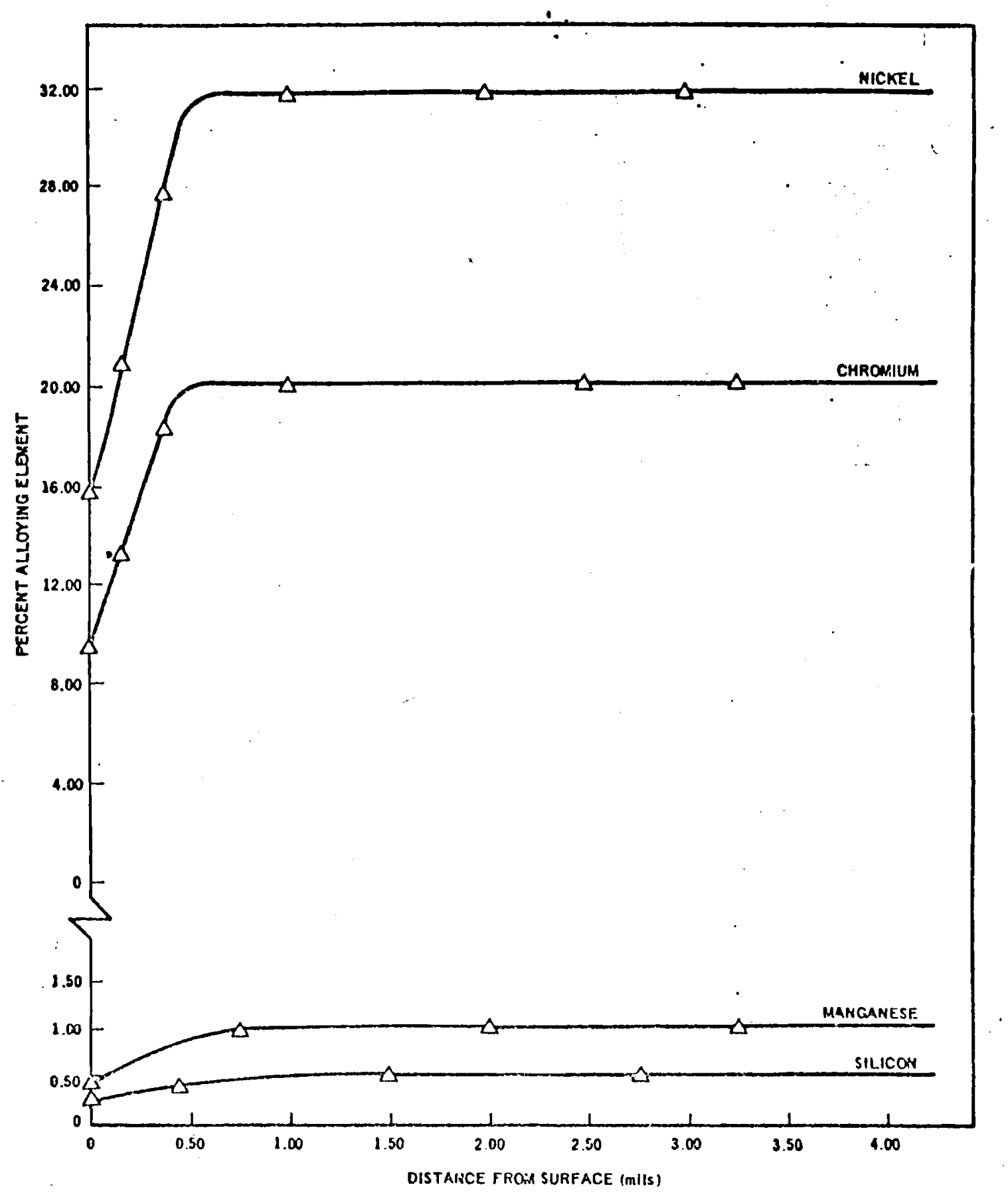

FIGURE 8.2.2.1-5 Composition Profile of Solution-Annealed Incoloy-800 After 15,726 hours Exposure ot $1300^{\circ} \mathrm{F}$ Flowing Sodium. 
TABLE 8.2.2.1-1 Carbon Analyses of Cladding Specimens From Zone $F(0.015 \times 0.250$ od $)$

\begin{tabular}{|c|c|c|c|c|c|c|c|}
\hline \multirow{2}{*}{$\begin{array}{l}\text { Run } \\
\text { Number }\end{array}$} & \multirow{2}{*}{$\begin{array}{c}\text { Temperature } \\
\left({ }^{\circ} \mathrm{F}\right)\end{array}$} & \multirow{2}{*}{$\begin{array}{l}\text { Time } \\
\text { (hours) }\end{array}$} & \multicolumn{5}{|c|}{ Weight Percent Carbon } \\
\hline & & & 304 & 316 & 347 & 1.800 & 321 \\
\hline & Standards & & $0.056,0.055,0.053$ & $0.068,0.060,0.061$ & $0.068,0.084$ & $0.075,0.069,0.078$ & $0.079,0.070,0.073$ \\
\hline & & & $0.054,0.051,0.055$ & $0.053,0.061,0.060$ & 0.076 & & \\
\hline $6 R-2$ & 1300 & 538 & $0.042,0.051$ & $0.055,0.057,0.051$ & 0.083 & 0.105 & - \\
\hline $6 R-1$ & 1300 & 1,008 & - & $\begin{array}{l}0.070,0.071,0.068 \\
0.069\end{array}$ & - & - & - \\
\hline $6 R-3$ & 1300 & 1.768 & $0.037,0.054$ & $0.064,0.052,0.058$ & 0.096 & 0.087 & 0.087 \\
\hline $5 R-4$ & 1300 & 4.838 & $0.012,0.015$ & $0.037,0.048,0.032$ & - & - & - \\
\hline $5 R-5$ & 1300 & 10.352 & 0.031 & 0.036 & 0.075 & 0.110 & 0.210 \\
\hline $4 R-2$ & 1300 & 15.726 & 0.003 & 0.013 & - & 0.190 & 0.160 \\
\hline $6 R-4$ & 1150 & 11,379 & 0.050 & 0.057 & 0.085 & 0.070 & 0.079 \\
\hline
\end{tabular}


TABLE 8.2.2.1-2 Carbon Analyses of Tube Specimens From Zone E $(0.035 \times 0.876$ od $)$

\begin{tabular}{|c|c|c|c|c|c|c|}
\hline \multirow[b]{2}{*}{$\begin{array}{l}\text { Run } \\
\text { Number }\end{array}$} & \multirow[b]{2}{*}{$\begin{array}{c}\text { Temperature } \\
\left.\qquad{ }^{\circ} \mathrm{F}\right)\end{array}$} & \multirow[b]{2}{*}{$\begin{array}{c}\text { Time } \\
\text { (hours) }\end{array}$} & \multicolumn{4}{|c|}{ Weight Percent Carbon } \\
\hline & & & 304 & 316 & 347 & $1-800$ \\
\hline & Standards & & $0.075,0.075,0.062$ & $0.074,0.073,0.076$ & $0.055,0.051,0.052$ & $0.088,0.095$ \\
\hline $6 R-2$ & 1300 & 538 & 0.052 & 0.056 & 0.049 & 0.096 \\
\hline $4 R-1$ & 1300 & 743 & 0.055 & 0.062 & 0.057 . & 0.097 \\
\hline $6 \mathrm{R}-1$ & 1300 & 1,008 & - & 0.075 & - & - \\
\hline $5 R-2$ & 1300 & 1.745 & - & 0.074 & - & - \\
\hline $5 R-1$ & 1300 & 2,083 & - & 0.042 & - & - \\
\hline $5 R-3$ & 1300 & 3,044 & - & 0.051 & - & - \\
\hline $5 R-4$ & 1300 & 4.838 & $0.027,0.017$ & $0.038,0.036$ & $0.052,0.053$ & 0.098 \\
\hline $5 R-5$ & 1300 & 10,352 & - & 0.051 & - & $\cdot$ \\
\hline $4 R-2$ & 1300 & 15,726 & $0.005,0.005$ & $0.025,0.005$ & $0.046,0.046$ & 0.116 \\
\hline $6 R-4$ & 1150 & 11.379 & - & 0.070 & - & $\ldots-$ \\
\hline
\end{tabular}




\subsubsection{1-10}
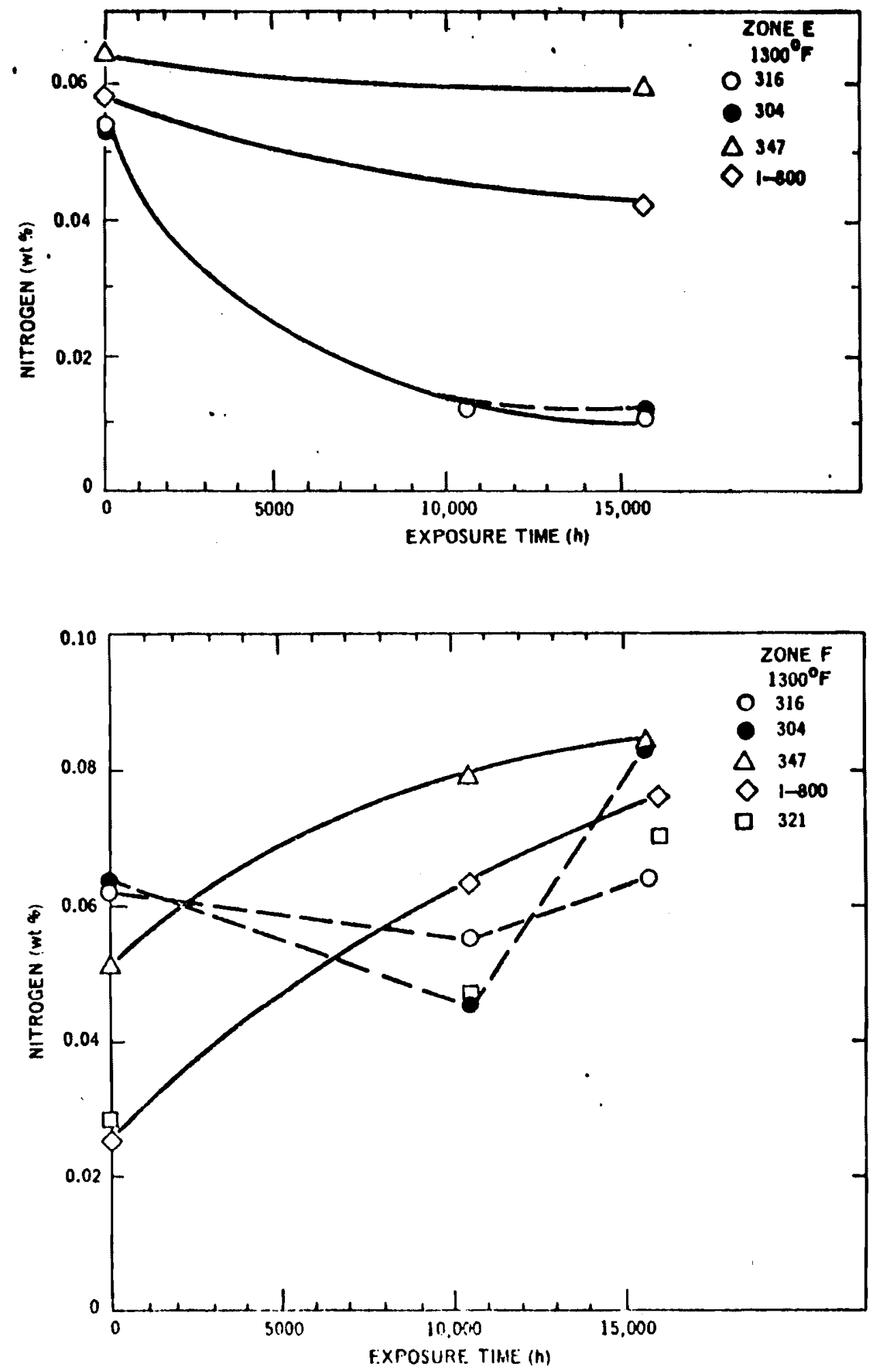

FIGURE 8.2.2.1-6 Effects of Exposure in Flowing Sodium on the Nitrogen Contents of Stainless Steels. 
TABLE 8.2.2.1-3 Minor Element ANalyses of Specimens From Zone $F(0.015 \times 0.250$ od $)$

\begin{tabular}{|c|c|c|c|c|c|}
\hline $\begin{array}{c}\text { Run } \\
\text { Number }\end{array}$ & $\begin{array}{c}\text { Temperature } \\
\left({ }^{\circ} \mathrm{F}\right)\end{array}$ & $\begin{array}{c}\text { Time } \\
\text { (hours) }\end{array}$ & $\begin{array}{l}\text { Boron } \\
\text { (ppm) }\end{array}$ & $\begin{array}{l}\text { Sulfur } \\
\text { (wt \%) }\end{array}$ & $\begin{array}{l}\text { Phosphorous } \\
\qquad(w t \%)\end{array}$ \\
\hline & Standard (316) & & $2.2,2.5$ & $0.022,0.015$ & $0.035,0.038$ \\
\hline $5 k-5$ & 1300 & 10.352 & 0.6 & 0.017 & 0.036 \\
\hline $6 R-4$ & 1150 & $11,37 \theta$ & 0.4 & 0.020 & 0.040 \\
\hline & Standard $(321)^{\circ}$ & & $1.1,1.1$ & $0.017,0.014$ & $0.046,0.038$ \\
\hline $5 R-5$ & 1300 & 10,352 & 0.9 & 0.011 & 0.030 \\
\hline GR-4 & 1150 & 11,379 & 0.2 & 0.014 & 0.039 \\
\hline \multicolumn{6}{|c|}{ From Zone G $(0.035 \times 0.875$ o.d. $)$} \\
\hline & Standard $(316)$ & & 1.7 & - & - \\
\hline \multirow[t]{2}{*}{$4 R-2$} & 1300 & 15,726 & 0.07 & - & - \\
\hline & Standard (321) & & 5.0 & - & - \\
\hline $4 R-2$ & 1300 & 15,726 & 0.08 & - & - \\
\hline
\end{tabular}




\subsubsection{1-12}

\section{REFERENCES}

1. "Summary Report, Sodium Mass Transfer Program: Effect of Sodium Exposure on the Corrosion and Strength of Stainless Stee1," GEAP-10394, August 1971, pp. 4-1 through 4-32. 


\subsubsection{Effects on Microstructure}

Significant microstructural changes occur in alloys subjected to high-temperature flowing sodium; ${ }^{(1)}$ these are related to the major compositional changes noted in Section 8.2.2.1.

In 316 stainless stee $1,{ }^{(1)}$ the loss of carbon along the grain boundaries causes the $M_{23} C_{6}$ grain boundary carbides to dissolve, nucleating a grain boundary network of sigma phase. This can be observed after only 538 hours exposure at $1300^{\circ} \mathrm{F}$. With longer exposure, larger sigma particles form. Stress (or more properly, strain) has been observed to increase the rate of growth of the sigma phase from comparison of stressed and unstressed specimens after 15,726 hours in $1300^{\circ} \mathrm{F}$ flowing sodium. (1) A ferritic layer is visible after $\sim 2000$ hours and reaches a maximum thickness ( 0.6 to $0.7 \mathrm{mil}$ ) between approximately 10,000 and 15,000 hours.

A major change in the microstructure of 304 stainless steel ${ }^{(1)}$ is the formation of martensite which transforms on cooling from austenite due to the concurrent losses of nickel, chromium, manganese and carbon .

In 347 stainless steel ${ }^{(1)}$ after 10,000 hours exposure, the microstructure consists predominately of grain boundary sigma phase, a 0.70 mil ferritic surface phase and void formation 4 to $5 \mathrm{mils}$ below the ferritic surface phase due to major depletion of chromi um, nickel and manganese.

In 321 stainless steel, (1) subsurface void formation also occurs along grain boundaries, due to elemental depletion; these voids seem to be connected to surface pits.

In Incoloy $800,{ }^{(1)}$ void formation has progressed to the point where it is obviously intergranular and interconnected to the exposed surface.

These cavities only appear in stabilized stainless steels and are readily detected only after long-term (15,000 hours) exposure to high-temperature $\left(1300^{\circ} \mathrm{F}\right)$ flowing sodium. 


\section{$8.2 .2 .2-2$}

\section{REFERENCES}

1. "Summary Report, Sodium Mass Transfer Program: Effect of Sodium Exposure on the Corrosion and Strength of Stainless Steel," GEAP-10394, August 1971, pp. 4-1 through 4-32. 


\section{$8 \cdot 2 \cdot 2 \cdot 3-1$}

\subsubsection{Effect on Mechanical Properties}

Stress-rupture tests were performed at 1150 and $1300^{\circ} \mathrm{F}$ on 304 and 316 stainless steel by pressurization of tubes during exposure to flowing sodium, and the results compared to both control tests in argon and to literature data. (1) The specimens were in two heat-treat conditions: the solution-annealed condition and an aged (carbide agglomerated, CA) condition. The data is presented in Figures 8.2.2.3-1 and -2 .

A reduction in stress-rupture life due to sodium exposure is evident. At $1150^{\circ} \mathrm{F}$, this degradation is only observed for solution-annealed 304 stainless steel; at $1350^{\circ} \mathrm{F}$, it is observed for both heat treatments in both alloys and represents approximately a $50-60 \%$ reduction in rupture 1 ife. (The smaller reductions observed in the 5R-5 test data for both alloys are due to smaller carbon loss in this test, as noted in Section 8.2.2.1.) Because the specimens were somewhat downstream from the loop heaters, the maximum degradation to properties produced in these tes ts are considered to probably be the minimum degradation that would be produced in the reactor core (for the same temperature, flows, oxygen, etc.).

Measurements of rupture strain $(\Delta D / D)$ indicate large reductions in ductility due to $1300^{\circ} \mathrm{F}$ exposure to sodium. (1) For tests lasting up to 6000 hours, the average value of $\Delta D / D$ for 304 s.s. was reduced $50 \%$ (from $\sim 15 \%$ to $\sim 7 \% \Delta D / D$ ). Similarly, for tests lasting up to 12,000 hours, the average value of $\Delta D / D$ for 316 s.s. was reduced $60 \%$ (from $\sim 10 \%$ to $\sim 4 \% \Delta D / D$ ).

It should be noted that mechanical property changes noted above will not occur in high-purity static or flowing isothermal sodium, but are generally confirmed for tests performed in $50^{\circ} \Delta T$ flowing sodium loops. (2) 
8.2.2.3-2

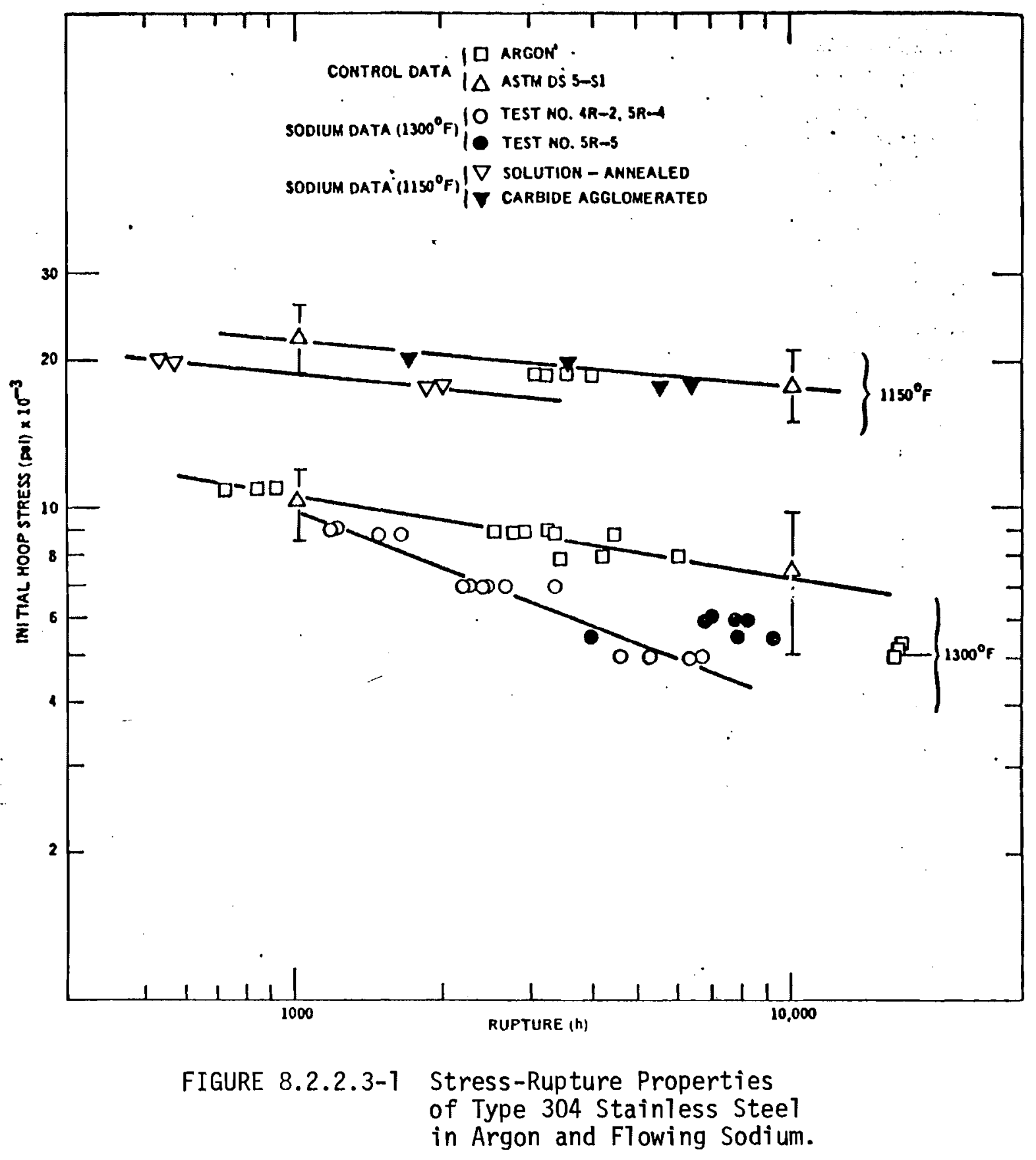


8.2.2.3-3

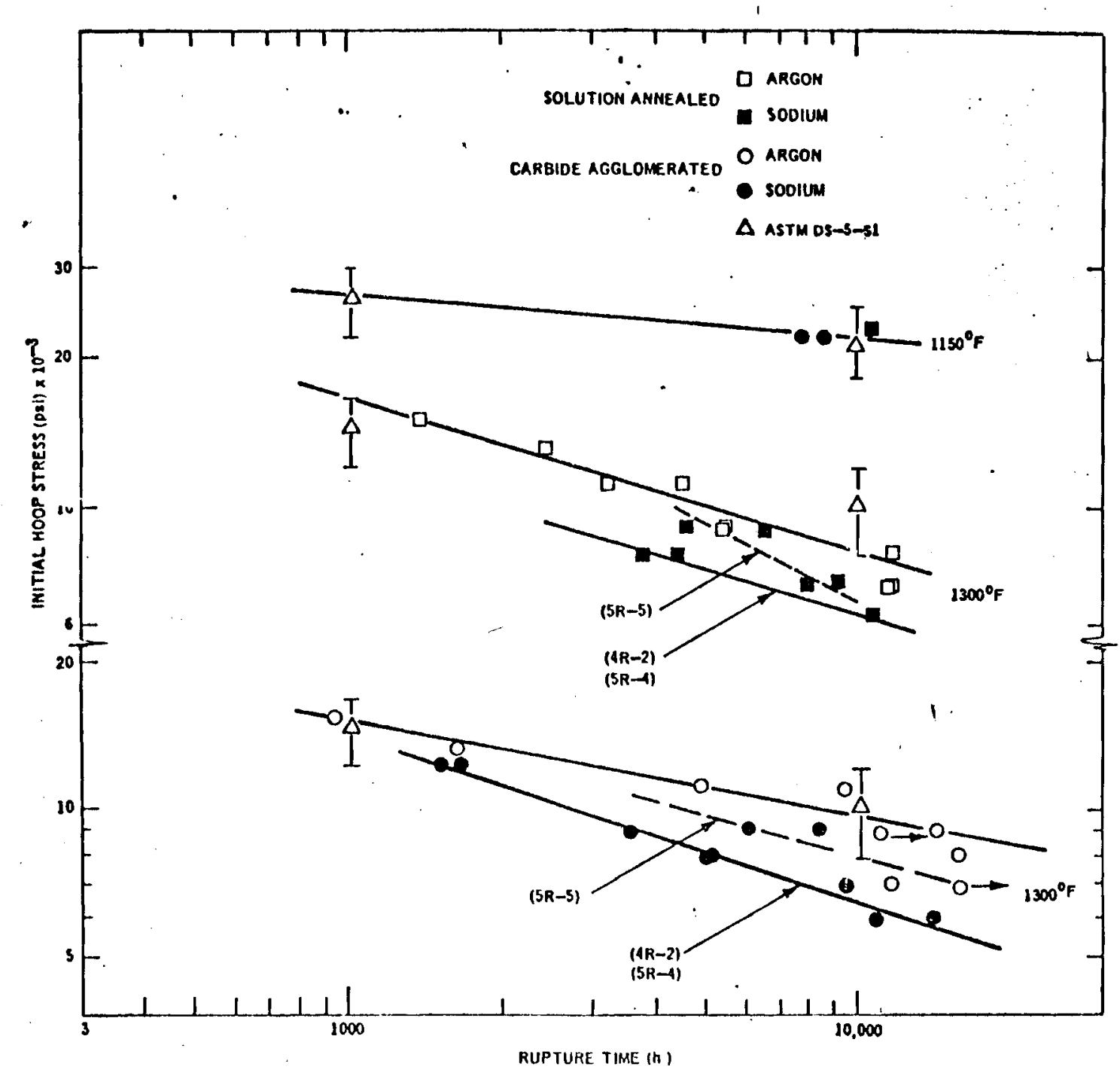

FIGURE 8.2.2.3-2 Stress-Rupture Properties of Type 316 Stainless Steel in Argon and Flowing Sodium 


$$
8.2 .2 .3-4
$$

\section{REFERENCES}

1. "Summary Report, Sodium Mass Transfer Program: Effect of Sodium Exposure on the Corrosion and Strength of Stainless Stee 1," GEAP-10394, August 1971, pp. 4-1 through 4-32.

2. Mechanical Properties of Stainless Steels in Sodium and Application to LMFBR Design," A1-AEC-13000, February, 25, 1972. 


\subsubsection{1-1}

\subsubsection{CARBURIZATION SIMULATED}

\subsubsection{Effects on Composition}

Carburization tes ts have been performed at 1000 and $1050^{\circ} \mathrm{F}$ in a flowing sodium loop at the same flow-rate $(10 \mathrm{gal} /$ min) described above in Section 8.2.1. Two carburization sources were used; 1040 carbon steel and $21 / 4 \mathrm{Cr}-1$ mo steel.

Figure 8.2.3.1-1 shows the relative carburization rates of various steels at $1000^{\circ} \mathrm{F}$ with $1040 \mathrm{C}$.S. as the carbon source. Figure 8.2.3.1-2 shows the relative carburization rate in flowing sodium of $304 \mathrm{~s} . \mathrm{s}$. exposed to $1040 \mathrm{C}$.S. and $21 / 4 \mathrm{Cr}-1$ Mo. Carburization is quite fast in flowing sodium, the actual rate depending on the carbon source. 


\subsubsection{1-2}

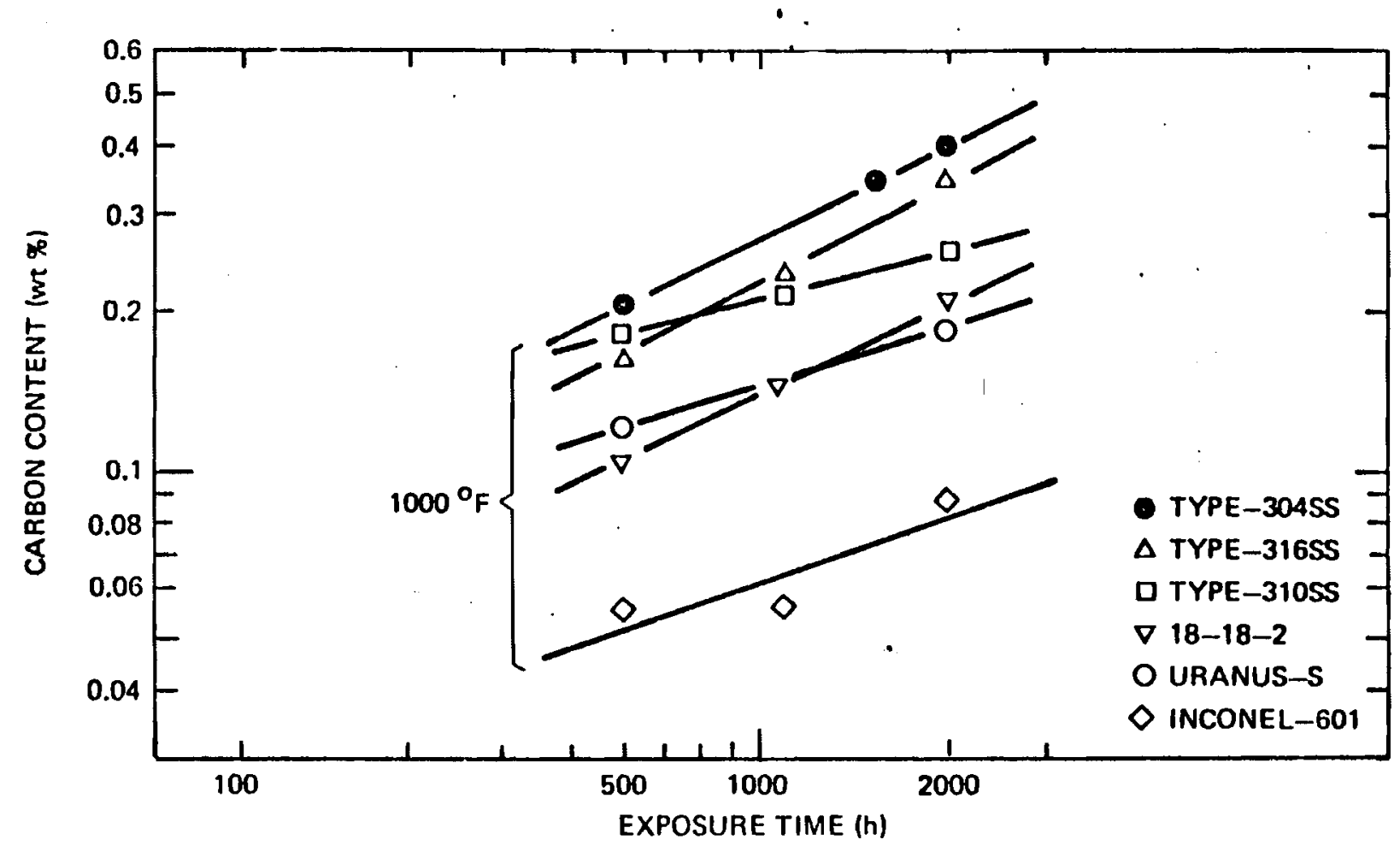

FIGURE 8.2.3.1-1 Carburization of Stainless Steel in Sodium at $1000^{\circ} \mathrm{F}$ with 1050 Carbon Steel as Carbon Source. 
$8 \cdot 2 \cdot 3 \cdot 1-3$

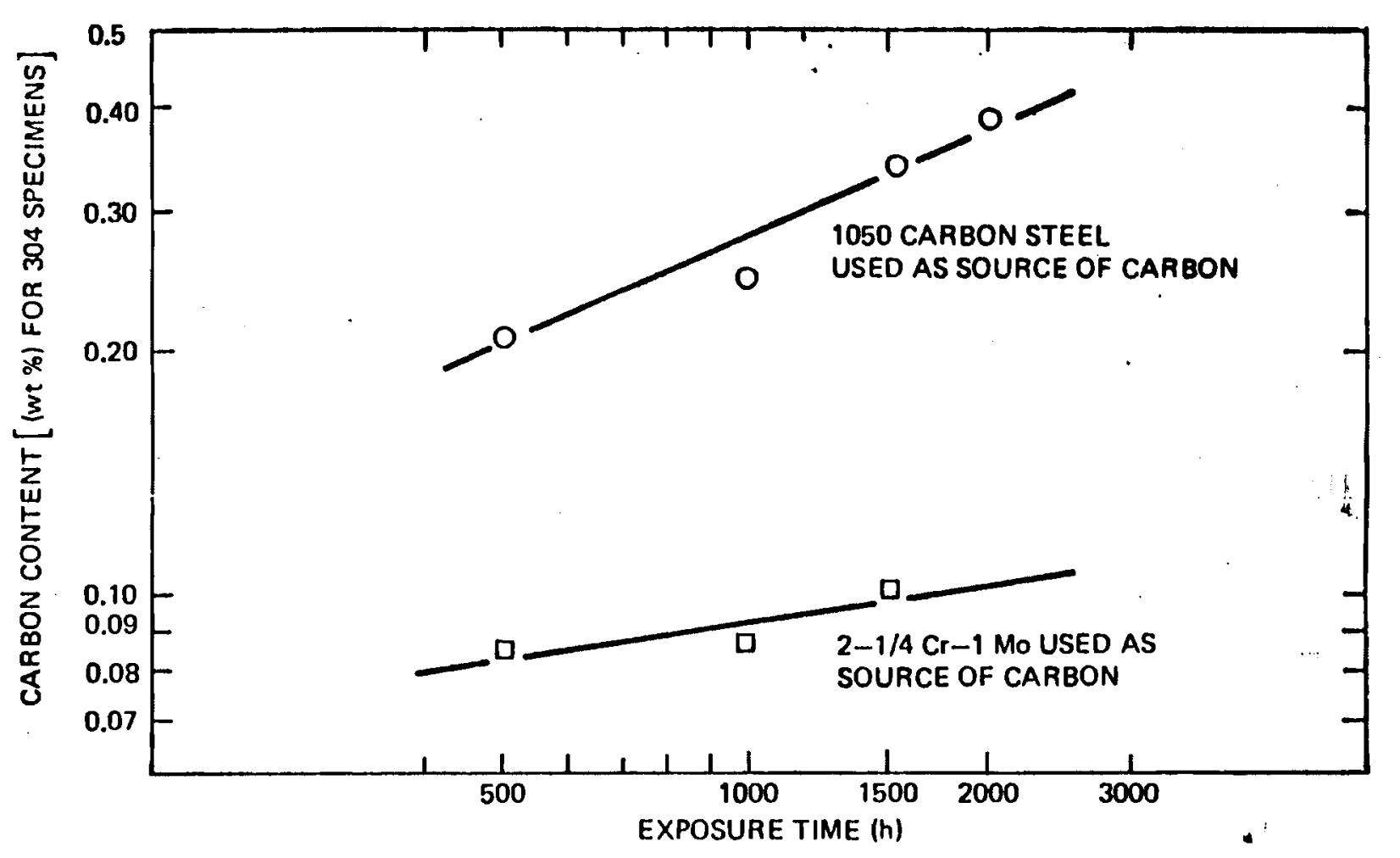

FIGURE 8.2.3.1-2 Carburization of Type 304 Stainless Stee1 at $1000^{\circ} \mathrm{F}$ in Flowing Sodium with Carbon Steel and Low Alloy Steel ad Carbon Source. 
$8.2 .3 .1-4$

REFERENCES

1. "LMFBR Heat Exchanger Materials Development Program, Second Quarterly Report, September-November 1972," GEAP-13919-2, December 1972, pp. 3-11 through 3-24. 


\section{$8 \cdot 2 \cdot 3.2-1$}

\subsubsection{Effects on Mechanical Properties}

Sheet coupons of the steels that had been shown above in Figure 8.2.3.1-1 were tensile stress-rupture, and impact tested after their carburization in flowing sodium. $(1)$ Figures 8.2.3.2-1 and -2 show the effect of carbon content on tensile properties (yield strength and rupture, or total tensile, elongation) at room and elevated $\left(1000-1100^{\circ} \mathrm{F}\right)$ temperature. (1) Yield strength increases and ductility decreases with carburization in sodium.

Stress-rupture tests were performed at $1000^{\circ} \mathrm{F}$. (1) The resultant data are shown in Figure 8.2.3.2-3 on a semilogarithmic plot to emphasize the effects of carbon. A marked effect on rupture life is observed with increasing carbon content.

Figure 8.2.3.2-4 shows that the room-temperature impact strength of subsize Charpy specimens of 304 stainless stee 1 decrease with increasing carbon content.

The reductions in rupture 1 ife and impact properties presumably result from the degradation to ductility by carburization since strength increases with carbon content. 


\subsubsection{2-2}

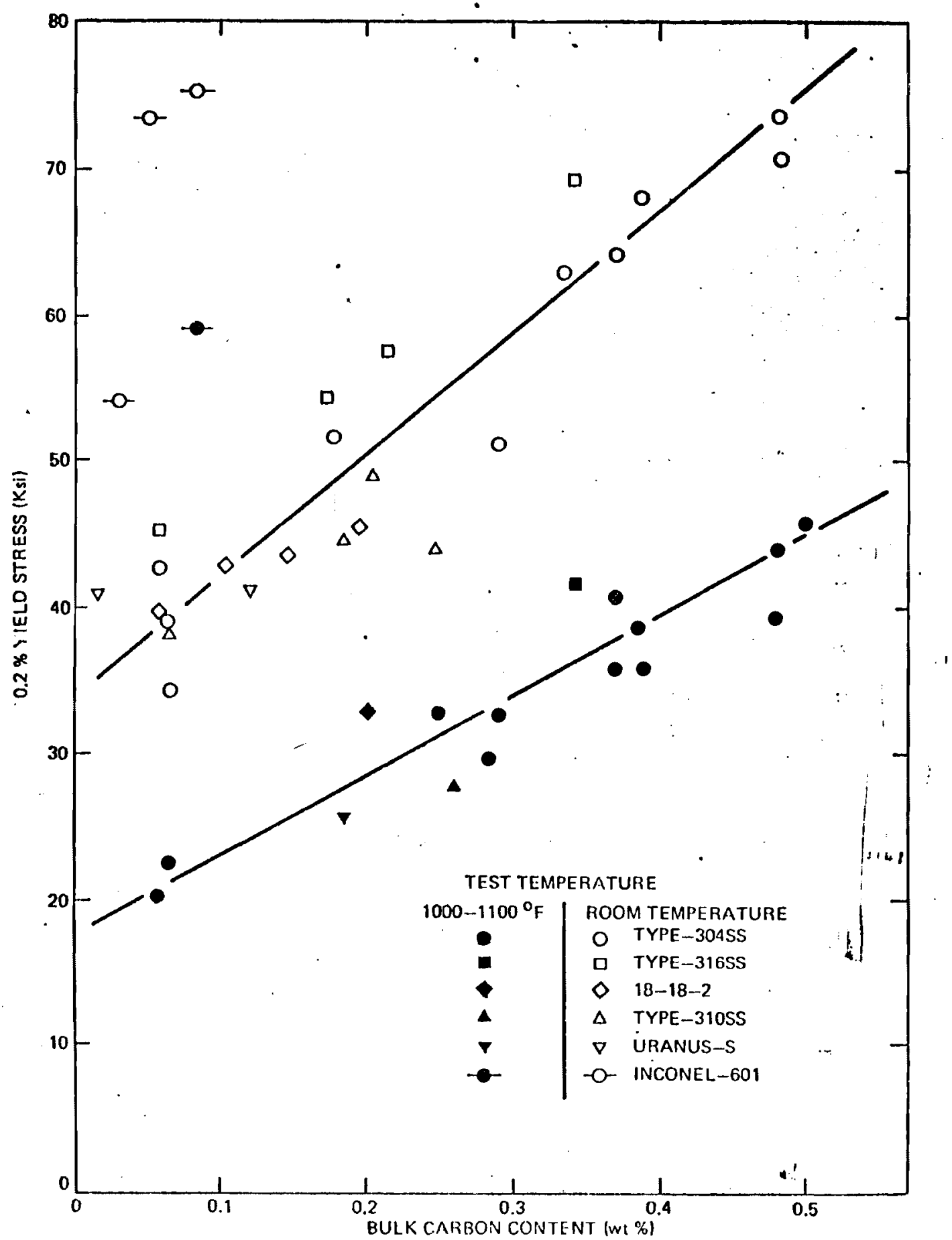

FIGURE 8.2.3.2-1 Effect of Carbon Content on Yield Strength of Austenitic Alloys After Sodium Exposure (sample thìckness 0.060 inch). 


\subsubsection{2-3}

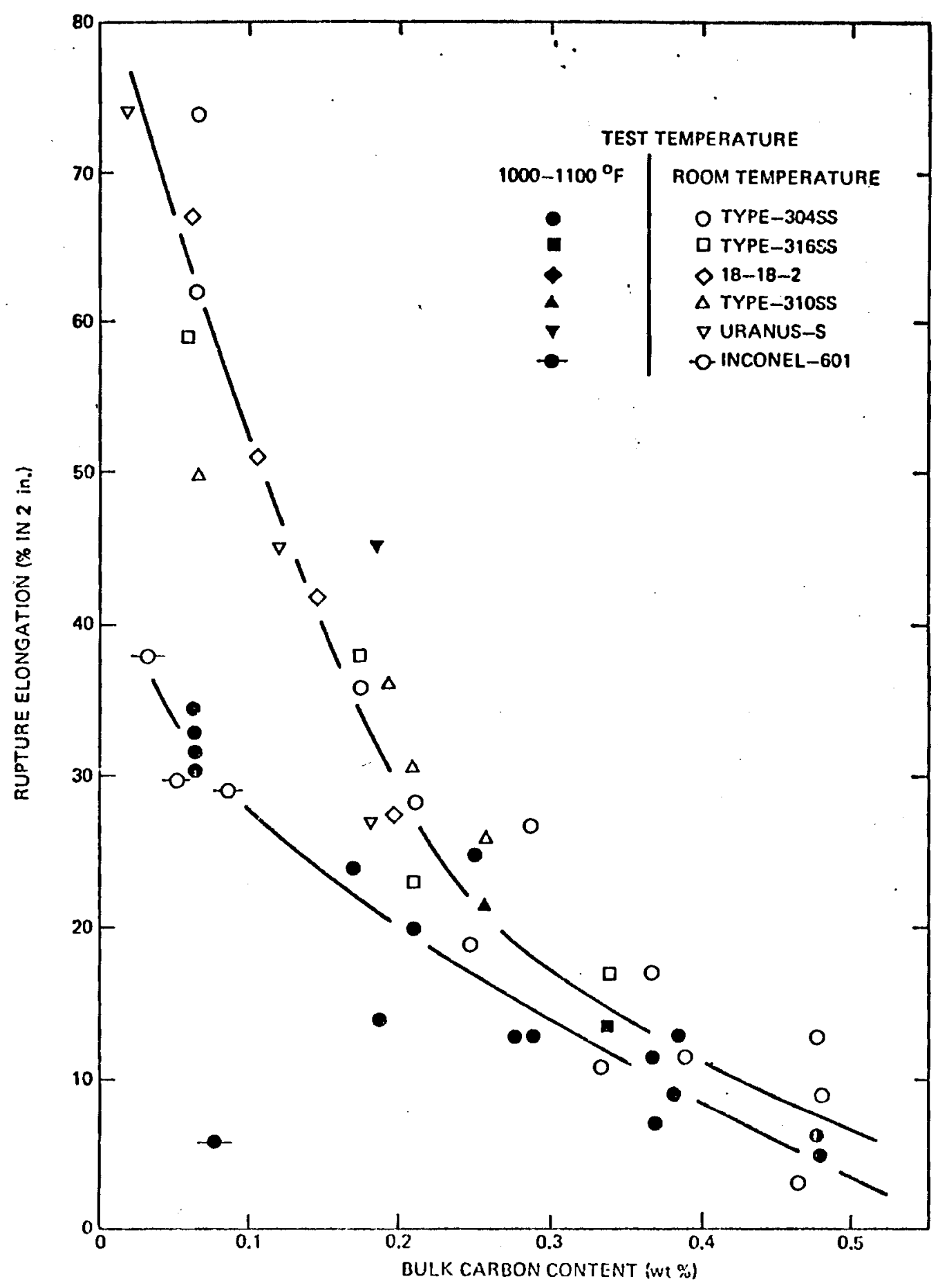

FIGURE 8.2.3.2-2 Effect of Carbon Content on Ductility of Austenitic Alloys After Sodium Exposure (sample thickness - 0.060 inch). 
8.2.3.2-4

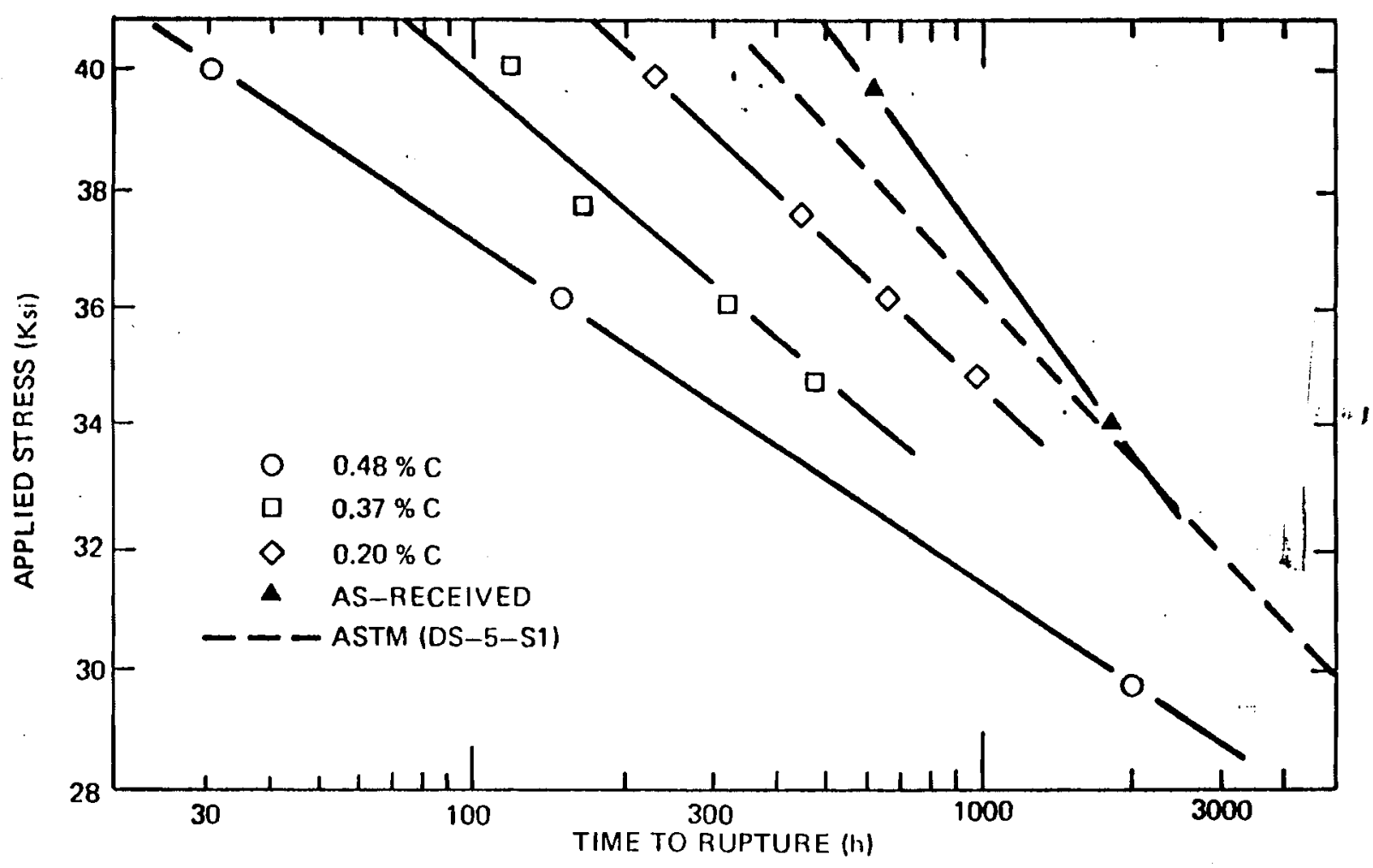

FIGURE 8.2.3.2-3 Effect of Carbon Content on Stress Rupture of Type 304 Stainless Steel at $1000^{\circ} \mathrm{F}$ in Air After Sodium Exposure (sample thickness 0.060 inch). 
$8 \cdot 2 \cdot 3 \cdot 2-5$

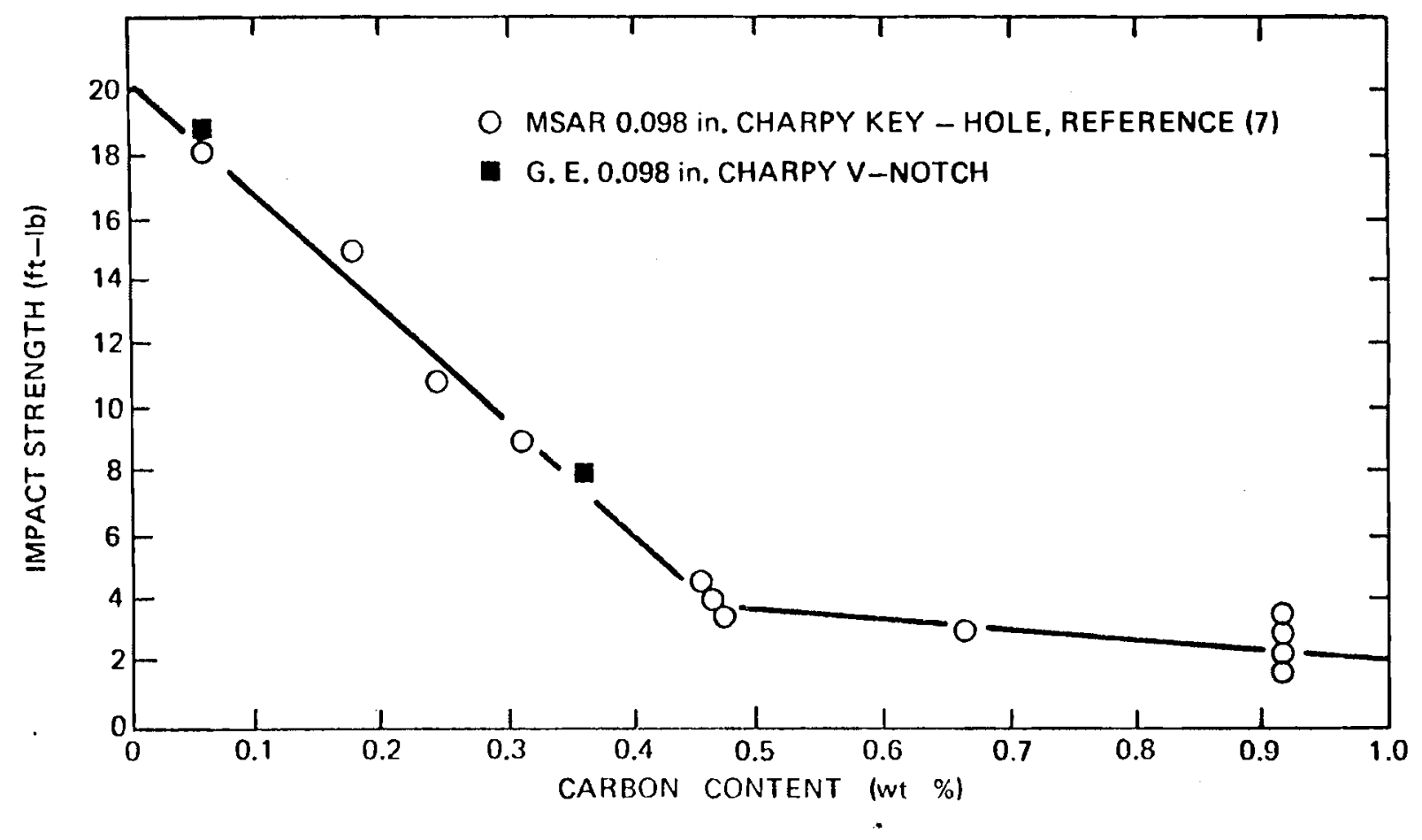

FIGURE 8.2.3.2-4 Effect of Carbon Content on Impact Strength of Type 304 Stainless Stee1 at Room Temperature After Sodium Exposure. 
$8 \cdot 2 \cdot 3 \cdot 2-6$

\section{REFERENCES}

1. "LMFBR Heat Exchanger Materials Development Program, Second Quarterly Report, September-November 1972," GEAP-13919-2, December 1972, pp. 3-11 through 3-24. 


\subsection{GENERAL RELATIONSHIP OF SODIUM COOLANT INTERACTIONS} ON MECHANICAL PROPERTIES TO LMFBR PERFORMANCE

\subsubsection{INTRODUCTION}

Mechanical properties, either in terms of allowable creep strain or residual tensile elongation, are specified for vessel and core components in LMFBRs. These properties are effected by both the sodium and fast neutron environments. As yet, insufficient data on sodium effects exist; and no relevant data has, as yet, been produced on the combined effects of sodium and irradiation. Prediction of properties based on extrapolations from existing data will be required until these gaps are filled. 


\subsubsection{1-1}

\subsubsection{INFLUENCE OF LMFBR VARIABLES}

\subsubsection{LMFBR Reactor Variables}

The major LMFBR reactor variables are high fluence (up to 2-3 $\times 10^{23}$ in a cormercial LMFBR), sodium and component temperatures (from 700 to $1400^{\circ} \mathrm{F}$ ), sodium velocity, and impurity $\left(0_{2}, \mathrm{C}\right.$, etc.) levels. Sodium velocity is to be about an average of $22 \mathrm{ft} / \mathrm{sec}$ in fuel pin region. (1) An oxygen level of $\leq 2.5 \mathrm{ppm}$ is planned. (2) 


\section{$8.3 .2 .1-2$}

\section{REFERENCES}

1. FOT-362: SDD-31, Rev. 5, "Reactor," Section 2.0, Design Description, January 19, 1973, p. 2.2-36.

2. "Fast Flux Test Facility Design Safety Assessment," HEDL-TME 72-92, July 1972, p. 2.2-5. 


\section{$8.3 \cdot 2 \cdot 2-1$}

\subsubsection{LMFBR Material Variables}

Current material concepts for LMFBR (FFTF) cal1 for $20 \%$ cold-worked 316 stainless steel for fuel assemblies and control and safety rod guide tubes, solution-annealed 304 for core support structure and the pressure vessel, and radial shields composed of 304 stainless steel, nickel, and Inconel 718, as noted in Section 2.4.2.2 of Chapter 2.0: Effect of Irradiation on Tensile Properties. The expected temperature/fluence ranges for the FFTF were presented in Figure 2.4.2.2-1.

The criteria for fuel pin performance is sufficient ductility to meet $\leq 0.2 \%$ creep strain for steady-state operation and $\leq 0.5 \%$ added creep and/or tensile strain for transient events. For large core components and the pressure vesse $1,10 \%$ residual elongation is specified.

Properties resulting from neutron irradiation alone, exclusive of sodium effects, show low steady-state creep and transient ductilities are available even after relatively low fluences. (See Sections 3.4.2.2 of Chapter 3.0 and Section 4.4.2.2 of Chapter 4.0.) Data on weld ductilities indicate potential problems (See Section 6.4.3.2 of Chapter 6.0).

The data presented in Section 8.2 of this chapter show substantial degradation $(50-60 \%)$ to ductility occurs either at high-temperature $\left(1300^{\circ} \mathrm{F}\right.$ ) in a non-carburizing environment, (Section 8.2.2.3), or at high and low temperatures in a carburizing environment (Section 8.2.3.2).

The combined effects of sodium interaction and neutron irradiation would, thus, be expected to be more severe than the effects of either alone. 


\subsubsection{1-1}

\subsubsection{GENERAL IMPLICATION OF SODIUM EFFECTS ON MECHANICAL}

PROPERTIES TO LMFBR COMPONENTS

\subsubsection{Pressure Vessel}

The pressure vessel will be operating under the influence of irradiation and sodium coolant interactions for the design life of twenty years at temperatures to $920^{\circ} \mathrm{F}$. As described in Sections 2.4.2.2 and 3.4.3.1, the $10 \%$ residual ductility criteria would not appear to be adversely affected by the low irradiation exposure $\left(3.8 \times 10^{19} \mathrm{n} / \mathrm{cm}^{2}, E>0.1 \mathrm{MeV}\right)$. Sodium coolant interactions with the 304 s.s. vessel, particularly should a carburizing environment exist, may have some deleterious effects on residual ductility even at $920^{\circ} \mathrm{F}$. Further data needs to be acquired in this area. 


\subsubsection{2-1}

\subsubsection{Core Components}

The core components will be subjected to a wide range of design requirements including fluence $\left(\sim 10^{21}\right.$ to $>10^{23}$ ), temperatures $\left(810\right.$ to $1400^{\circ} \mathrm{F}$ ) and design lifetimes ( 1 to 20 years).

With an average fuel pin temperature of about $1200^{\circ} \mathrm{F}$ and a peak hot spot-hot pin temperature of about $1400^{\circ} \mathrm{F}$, sodium degradation of clad properties can be expected. It is not clear that transient performance criteria can be met under the combined effects of neutron fluence and sodium coolant.

While the temperature of the other core components will be lower $\left(\leq 1000^{\circ} \mathrm{F}\right)$ and the effects of carbon-free flowing sodium would be expected to be slight, downstream mass transport of carbon or in-leakage of carbon to the system could have deleterious effects on residual tensile elongation and impact properties, particularly when combined with fluence effects. 


BNWL-1901

\section{DISTRIBUTION}

No. of

Copies

\section{OFFSITE}

2 Dr. George J. Fischer

Department of Applied Science Associated Universities, Inc. Brookhaven National Laboratory Building 130

Upton, NY 17973

Dr. John Weeks

Department of Applied Science Associated Universities, Inc. Brookhaven National Laboratory Building 130

Upton, NY 11973

Dr. James F. Proctor

Air/Ground Explosions Division

Naval Surface Weapons Center

White Oak

Silver Spring, MD 20910

Dr. Theo G. Theofanous

Purdue University

P.0. Box 1625

Lafayette, IN 47902

Dr. William Kastenberg

Energy \& Kinetics Department

University of California at Los Angeles

Los Angeles, CA 90024

Dr. Carl A. Erdman

Department of Nuclear Engineering

University of Virginia, Thornton Hall

Charlottesville, VA 22204

Mr. Daniel E. Simpson

Hanford Engineering Development Laboratory

P.0. Box 1970

Richland, WA 99352
No. of

Copies

2 Mr. Robert Avery, Director

Reactor Analysis \& Safety Division

Argonne National Laboratory

9700 South Cass Avenue

Argonne, IL 60439

2 Dr. William D. Dazey

Fission Program Manager

University of California

Los A7amos Scientific Laboratory

P.0. Box 1663

Los Alamos, NM 87544

Mr. John Graham, Manager

Nuclear Safety

Westinghouse Electric Corporation

Advanced Reactors Division

P.0. Box 158

Madison, PA 15663

Mr. K. Hikido, Manager

Systems Evaluation \& Safety

Engineering

Fast Breeder Reactor Department

310 DeGuigne Drive

Sunnyvale, CA 94086

Dr. Paul Greebler, Manager

Nuclear and Safety Engineering

Fast Breeder Reactor Department

310 DeGuigne Drive

Sunnyvale, CA 94086

Dr. Harry Morewitz, Program Manager LMFBR Physics and Safety

Atomics International

P.0. Box 309

Canoga Park, CA 91304

Mr. James McClellan

Aero Space Corporation

P.0. Box 95805

Los Angeles, CA 90045 

No. of

Copies

Mr. Robert Shane

National Academy of Science

2101 Constitution Avenue

Washington, DC 20418

5

U.S. Nuclear Regulatory Commission

Secretary, Advisory Committee on

Reactor Safeguards

$1717 \mathrm{H}$ Street, N.W.

Washington, DC 20555

Technical Information Center USNRC

P.0. Box 62

Oak Ridge, TN 37830

R. Denise, Assistant Director for Advanced Reactors

Division of Reactor Licensing

U.S. Nuclear Regulatory Commission Washington, DC 20555

T. Speis, Liquid Metal Fast Breeder Reactors Branch

Division of Reactor Licensing

U.S. Nuclear Regulatory Commission Washington, DC 20555

\section{A. Sinisgalli, Liquid Metal}

Fast Breeder Reactors Branch

Division of Reactor Licensing

U.S. Nuclear Regulatory Commission

Washington, DC 20555

3 H. Gearin, Licensing Assistant

Gas Cooled Reactors Branch

Division of Reactor Licensing

U.S. Nuclear Regulatory Commission

Washington, DC 20555

Pub1ic Document Room

U.S. Nuclear Regulatory Commission Washington, DC 20555

M. Silberberg

Research Coordination Office

Office of Nuclear Regulatory Research

U.S. Nuclear Regulatory Commission Washington, DC 20555
No. of

Copies

F. Schroeder, Deputy Director for Technical Review

Office of Nuclear Reactor Regulation

U.S. Nuclear Regulatory Commission Washington, DC 20555

3 R. R. Maccary, Assistant Director for Engineering

Office of Nuclear Reactor Regulation

U.S. Nuclear Regulatory Commission Washington, DC 20555

S. S. Pawlicki, Chief

Materials Engineering Branch

Office of Nuclear Reactor Regulation

U.S. Nuclear Regulatory Commission Washington, DC 20555

R. M. Gustafson, Section Leader

Materials Application Section

Office of Nuclear Reactor Regulation

U.S. Nuclear Regulatory Commission Washington, DC 20555

W. S. Hazelton, Section Leader

Materials Performance Section

Office of Nuclear Reactor Regulation

U.S. Nuclear Regulatory Commission Washington, DC 20555

C. Y. Cheng

Materials Performance Section

Office of Nuclear Reactor Regulation

U.S. Nuclear Regulatory Commission Washington, DC 20555

F. B. Litton

Materials Application Section

Office of Nuclear Reactor

Regulation

U.S. Nuclear Regulatory Commission Washington, DC 20555 

No. of

Copies

B. Turovlin

Materials Application Section

Office of Nuclear Reactor Regulation

U.S. Nuclear Regulatory Commission

Washington, DC 20555

James $P$. Knight, Chief

Mechanical Engineering Branch

Office of Nuclear Reactor Regulation

U.S. Nuclear Regulatory Commission

Washington, DC 20555

L. C. Shao, Chief

Structural Engineering Branch

Office of Nuclear Reactor Regulation

U.S. Nuclear Regulatory Commission

Washington, DC 20555

E. J. Brown

Structures and Components

Standards Branch

Office of Standards Development

U.S. Nuclear Regulatory Commission

Washington, DC 20555

H. B. Holz, Liquid Metal Fast

Breeder Reactors Branch

Division of Reactor Licensing

U.S. Nuclear Regulatory Commission

Washington, DC 20555

James F. Meyer, Liquid Metal Fast

Breeder Reactors Branch

Division of Reactor Licensing

U.S. Nuclear Regulatory Commission

Washington, DC 20555

S. Klein, Liquid Metal Fast Breeder Reactors Branch

Division of Reactor Licensing

U.S. Nuclear Regulatory Commission

Washington, DC 20555

2 C. N. Kelber, Assistant Director for Advanced Reactor Safety Research 2

Division of Reactor Safety Research

U.S. Nuclear Regulatory Commission

Washington, DC 20555
No. of

Copies

L. N. Rib, Chief, Experimental Fast Reactor Safety Research Branch

Division of Reactor Safety Research

U.S. Nuclear Regulatory Commission Washington, DC 20555

R. Curtis, Analytical Advanced Reactor Safety Research Branch Division of Reactor Safety Research U.S. Nuclear Regulatory Commission Washington, DC 20555

$L$. Rubenstein

Core Performance Branch

Division of Technical Review

U.S. Nuclear Regulatory Commission Washington, DC 20555

R. Lobel

Core Performance Branch

Division of Technical Review

U.S. Nuclear Regulatory Commission Washington, DC 20555

T. E. Murley, Acting Assistant Director for CRBR Program Management

Division of Reactor Research and Development

U.S. Energy Research and Development Administration Washington, DC 20545

W. R. Kornack, Acting Assistant Director for FFTF Program Management

Division of Reactor Research and Development

U.S. Energy Research and Development Administration Washington, DC 20545

W. H. Hannum, Assistant Director for Reactor Safety

Division of Reactor Research and Development

U.S. Energy Research and Development Administration Washington, DC 20545 

No. of

Copies

C. W. Cunningham, Assistant Director for Engineering and Technology

Division of Reactor Research and Development

U.S. Energy Research and Development Administration Washington, DC 20545

Victor Zackay Lawrence Berkeley Laboratories University of California Berkeley, CA 94720
No. of

Copies

ONSITE

Battelle Pacific Northwest Laboratories Richland, Washington 99352
JL Brimhall
PD Cohn
B Griggs
RS Kemper
IS Levy
RP Marshal1
C Pavloff
EB Schwenk
GE Zima
CE Beyer
FE Panisko
$\mathrm{NJ}$ 01sen
JW Wald

2 RL Dillon

2 S Goldsmith

Technical Library 



\section{Volume I}

Forward and Technical Summary

1.0 Swelling

2.0 Effect of Irradiation on Tensile Properties

3.0 Effect of Irradiation on High Strain Rate Properties

4.0 Effect of Irradiation on Creep-Rupture Properties

5.0 Effect of Irradiation on Fatigue Properties

6.0 Effect of Irradiation on Weld Properties

7.0 Effect of Fuel Clad Interactions on Mechanical Properties

8.0 Effect of Sodium Coolant Interactions on Mechanical Properties

9.0 Mechanical Property Considerations for Ferritic Steels of the Steam Generation System

\section{Volume II}

Forward and Technical Summary

9.0 Corrosion and Mass Transfer

10.0 Erosion

11.0 Wear and Self Welding

12.0 Sodium-Water Reactions

13.0 Corrosion (Externa1)

14.0 Corrosion/Mass Transfer Affecting Materials of the Steam Generation System 

STEAM GENERATOR MATERIALS

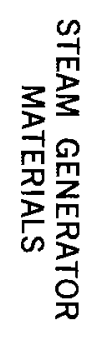




\subsection{MECHANICAL PROPERTY CONSIDERATIONS FOR FERRITIC STEELS OF THE STEAM GENERATION SYSTEM}

\section{TABLE OF CONTENTS}

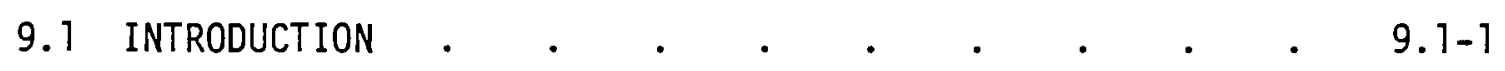

9.2 WORKING ENVIRONMENT FACTORS AFFECTING

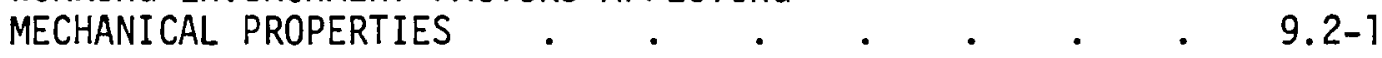

9.3 MECHANICAL PROPERTY CONSIDERATIONS . • • • • • 9.3.1-1

9.3.1 Tensile Properties . . . . . . 9.3.1-1

9.3.2 Impact Properties . . . . . . . 9.3.2-1

9.3.3 Creep Properties . . . . . . . . . . . 9.3.3-1

9.3.4 Fatigue . . . . . . . . . . 9.3.4-1

9.3.5 Fracture $. \quad . \quad . \quad . \quad . \quad . \quad . \quad .9 .3 .5-1$

9.4 WELDING AND EMBRITTLEMENT CONSIDERATIONS . . . 9.4.1-1

9.4.1 Embrittlement Phenomena Associated With Welding - 9.4.1-1

9.4.2 Welded Transition Joints . . . . . 9.4.2-1

9.5 SUMMARY AND CONCLUSIONS . . . . . . . . . . . 


\section{LIST OF FIGURES}

9.2.1 Sodium-Side and Water/Steam-Side Temperatures/Pressures Affecting Steam Generation System Materials of CRBRP . . 9.2-3

9.3.1-1 Tensile Properties for Annealed 2 1/4 $\mathrm{Cr}$-1Mo Steel . . . 9.3.1-3

9.3.1-2 Comparison of Tensile Properties for Three Heats of $21 / 4 \mathrm{Cr}$-1Mo Steel . . . . . . . . 9.3.1-5

9.3.1-3 Sensitivity of Strength (UTS) and Ductility (RA) of $21 / 4 \mathrm{Cr}$-1Mo Steei to Temperature and Strain Rate . . . 9.3.1-6

9.3.1-4 Decarburization of Various Ferritic Alloys by Static Sodium at $650^{\circ} \mathrm{C}\left(1200^{\circ} \mathrm{F}\right) . . \quad . \quad . \quad . \quad . \quad .9 .3 .1-7$

9.3.1-5 Various Strength Criteria for $21 / 4 \mathrm{Cr}$-1Mo Steel versus Gross Carbon Content . . . . . . . . . 9.3.1-9

9.3.1-6 TTT Diagram for $21 / 4 \mathrm{Cr}$-1Mo Steel . . . . . . 9.3.1-13

9.3.2-3 Fit of Equation (1) to Charpy V-Notch Impact Data for a Single Heat of Annealed $21 / 4 \mathrm{Cr}$-1Mo Steel . . . 9.3.2-3

9.3.2-2 Charpy V-Notch Data for $21 / 4 \mathrm{Cr}$-1Mo Steel Given Treatment $\underline{B} . \quad . \quad . \quad . \quad . \quad . \quad .9 .3 .2-6$

9.3.2-3 Charpy V-Notch Energy-Temperature Characteristics for $21 / 4 \mathrm{Cr}$-1Mo Steel Given $\underline{E}$ and $\underline{G}$ Treatments . . . . 9.3.2-7

9.3.2-4 Summary of Impact Energy-Temperature Characteristics for
$27 / 4 \mathrm{Cr}$-1Mo Steel Given Various Treatments . . . 9.3.2-8

9.3.2-5 Charpy V-Notch Impact-Temperature Characteristic for EBR-II Exposed $21 / 4 \mathrm{Cr}$-1Mo Steel . . . . . . 9.3.2-10

9.3.3-1 Time, Temperature and Stress Distribution of Creep Data
for $21 / 4 \mathrm{Cr}$-1Mo Stee 1 . . . 9.3.3-2

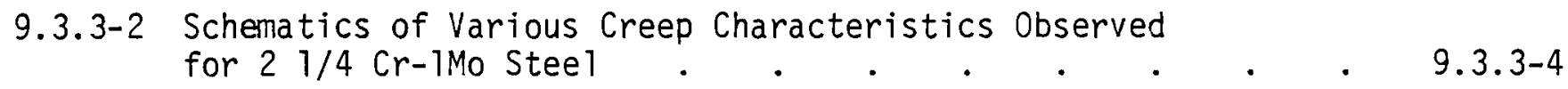

9.3.3-3 Schematic Showing Analysis of Creep Characteristic by
Above Equation. . . . . . . . . . . . . . . . . .

9.3.3-4 Comparison of Creep Predictions Using Current ORNL Equation,
Sterling and Hobson Equations. . . . . . . . . . . . 
9.3.3-5 Variation of Creep Properties Between Two Heats of 2 1/4 $\mathrm{Cr}$-1Mo Steel; Comparison of Creep Predictions

9.3.3-6 Comparison of Creep Characteristics of $21 / 4 \mathrm{Cr}-1 \mathrm{Mo}$ Steel-Expected Value Band for Unaged Material; In-Service Aged and Helium Aged Material . . .

9.3.4-1 Average Fatigue Life Curves for $21 / 4 \mathrm{Cr}$-1Mo Stee1 over Temperature Range: $\mathrm{RT}-593^{\circ} \mathrm{C}$. . . . . . 9.3.4-2

9.3.4-2 Total, Elastic and Plastic Strain Ranges versus Cycles to Failure for Isothermally Annealed $21 / 4 \mathrm{Cr}$-7Mo Steel . 9.3.4-2

9.3.4-3 Stress and Plastic Strain Ranges as Functions of Fraction of Cyclic Life for Isothermally Annealed $21 / 4 \mathrm{Cr}$-1Mo Stee 1 at $538^{\circ} \mathrm{C}\left(1000^{\circ} \mathrm{F}\right)$

9.3.4-4 Proposed ASME Fatigue Design Curves for $21 / 4 \mathrm{Cr}$-1Mo Steel in Annealed Condition . . . . . . 9.3.4-7

9.3.4-5 Fatigue Data for $21 / 4 \mathrm{Cr}$-1Mo Steel in Sodium, Air and Helium.

9.3.5-1 Fatigue-Crack Growth Rates for $21 / 4 \mathrm{Cr}$-1Mo Steel in Air at Room Temperature 9.3.5-2

9.3.5-2 Effects of Temperature and Frequency on Fatigue Crack Propagation of $21 / 4 \mathrm{Cr}$-1Mo Steel in Air. . . 9.3.5-2

9.3.5-3 Effects of Stress Ratio on Fatigue-Crack Propagation of $21 / 4 \mathrm{Cr}$-1Mo Steel at $510^{\circ} \mathrm{C}\left(950^{\circ} \mathrm{F}\right)$.

9.3.5-4 Effects of Steam on Fatigue-Crack Propagation of $21 / 4 \mathrm{Cr}$ - 1 Mo Steel at $510^{\circ} \mathrm{C}\left(950^{\circ} \mathrm{F}\right)$. . . . . 9.3.5-4

9.3.5-5 Fatigue-Crack Growth Behavior in Air and Sodium Environments at $427^{\circ} \mathrm{C}$ for $21 / 4 \mathrm{Cr}$-1Mo Steel . . 9.3.5-5

9.3.5-6 Comparison of Fracture Toughness of $21 / 4 \mathrm{Cr}$-1Mo Stee1 with ASME Code Section III K IR Curve . • • • 9.3.5-8

9.4.1-1 Effect of Chemistry on 50 F Charpy V-notch Impact Energy of Step-Aged, Highiy Temper Embrittled $21 / 4 \mathrm{Cr}$-1Mo Weldments

9.4.1-2 Shift in Transition Curve Due to Temper Embrittlement of Weld Deposit for $21 / 4 \mathrm{Cr}$-1Mo Steel . . . 9.4.1-3 
9.4.1-3 Charpy V-notch Energy Absorbed and Fracture Appearance as a Function of Test Temperature for the Full Thickness Weld of $21 / 4 \mathrm{Cr}$-1Mo Stee $1 . \quad . \quad . \quad . \quad$.

9.4.1-4 Percent Reduction in Area (RA) as Function of Time to Rupture at $900^{\circ} \mathrm{F}$ for $21 / 4 \mathrm{Cr}$-1Mo Stee 1 . . 9.4.1-6

9.4.1-5 Percent Reduction in Area (RA) as a Function of Time to Rupture at $1050^{\circ} \mathrm{F}$ for $21 / 4 \mathrm{Cr}$-7Mo Steel. . . 9.4.1-6 


\section{$\underline{\text { LIST OF TABLES }}$}

9.2-1 Materials for Major Components of the CRBRP Steam Generation System

9.3.1-1 Heat Treatments Used for 2 1/4 Cr-1Mo Steel . . 9.3.1-2

9.3.1-2 Expressions for Expected Values of Tensile Properties for Annealed $21 / 4 \mathrm{Cr}$-1Mo Steel . . . . 9.3.1-2

9.3.1-3 Tensile Properties for $21 / 4 \mathrm{Cr}$-1Mo Steel After Helium and Static Sodium Exposure . . . . . . 9.3.1-10

9.3.1-4 Changes in Tensile Properties for $21 / 4 \mathrm{Cr}$-1Mo Steel After Prolonged Exposure to Helium and to Sodium at $566^{\circ} \mathrm{C}\left(1050^{\circ} \mathrm{F}\right)$ 9.3.1-12

9.3.2-1 Chemical Composition of $21 / 4 \mathrm{Cr}$-1Mo Stee 1 Used in Impact and Fracture Mechanics Testing. . . . . 9.3.2-3

9.3.2-2 Material Conditions of $21 / 4 \mathrm{Cr}$-1Mo Steel Used in Impact and Fracture Mechanics Testing. . . . 9.3.2-4

9.3.2-3 Charpy V-Notch Data and P-3 Drop Weight Nil Ductility Transition (NDT) Data for $21 / 4 \mathrm{Cr}$-1Mo Steel. . 9.3.2-5

9.3.3-1 Chemistry and Heat Treatment for $21 / 4 \mathrm{Cr}$-1Mo Stee1 Used in ORNL Creep Program . . . . . 9.3.3-5

9.3.3-2 ORNL Creep Equation for $21 / 4 \mathrm{Cr}$-1Mo Stee1; Derived Characteristics; Expressions for Various Creep Equation Parameters.

9.3.3-3 Predicted Values of Various Design Stresses . . . 9.3.3-9

9.3.3-4 Creep-Rupture Properties of 2 1/4 Cr-1Mo Steel After Helium and Static Sodium Aging at $566^{\circ} \mathrm{C} / 26,500 \mathrm{Hr}$. 9.3.3-12

9.3.3-5 Biaxial Creep-Rupture Data for $21 / 4 \mathrm{Cr}$-1Mo Steel After Sodium Exposure . . . . . . . . 9.3.3-13

9.3.4-1 Values for the Elastic and Plastic Strain Range Constants for Strain-Controlled Tests Conducted at Strain Rate of $4 \times 10^{-3} / \mathrm{sec}$; Annealed $2 \mathrm{~T} / 4 \mathrm{Cr}$-1Mo Steel...

9.3.4-2 Polynomial Coefficients for Fatigue Design Curves for Annealed $27 / 4 \mathrm{Cr}$-1Mo Steel . . . . . . 9.3.4-5

9.3.5-1 Compact Tension Fracture Toughness Results for $2 \mathrm{l} / 4 \mathrm{Cr}$-1Mo Steel. . . . . . . . 9.3.5-5

9.3.5-2 Material Conditions of $21 / 4 \mathrm{Cr}$-1Mo Steel for Fracture Toughness Testing 



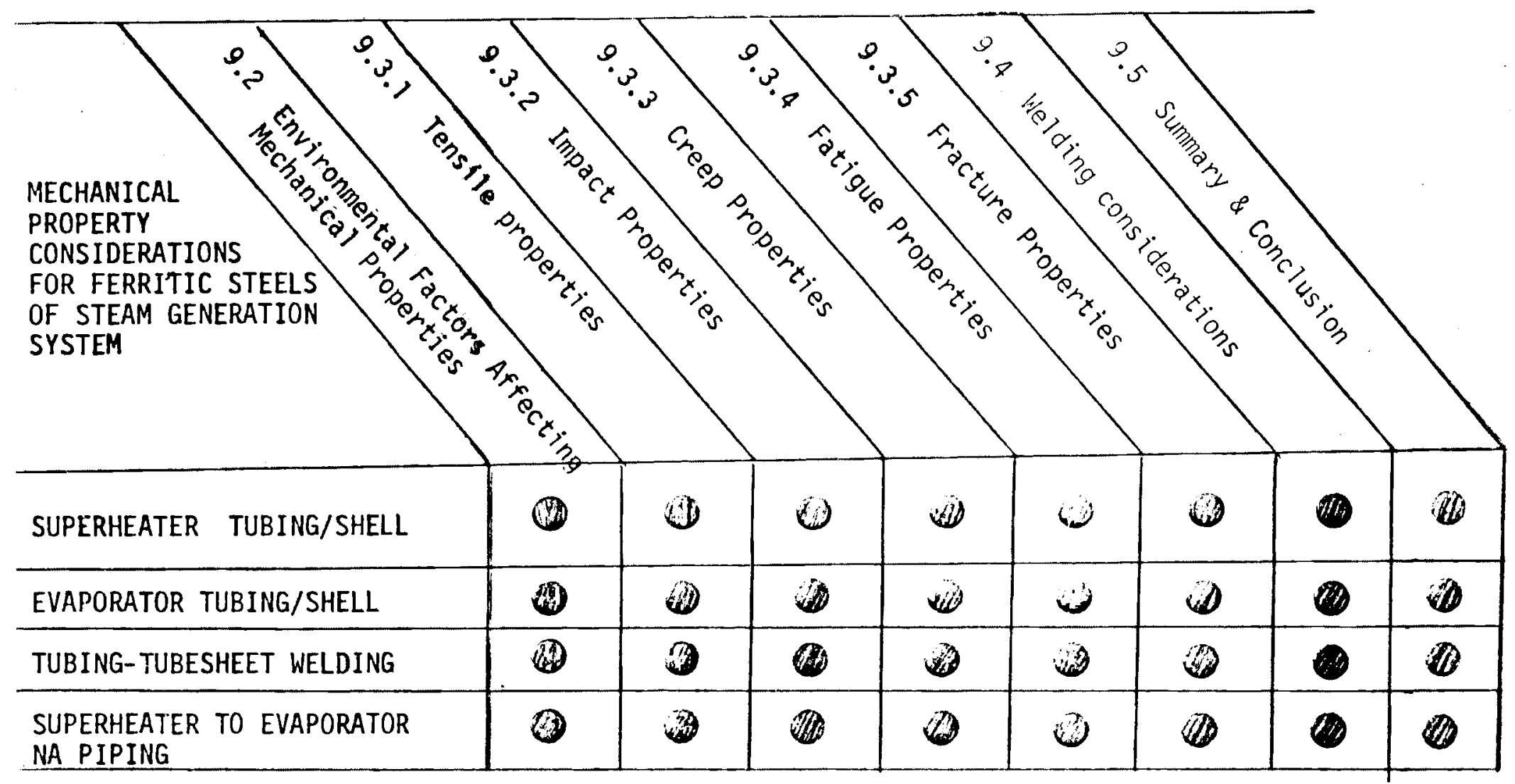





\subsection{INTRODUCTION}

The steam generation system of an LMFBR powerplant comprises the interface between the sodium cooling circuit of the reactor and the working fluid of the steam-electric power generating complex. The fundamental heat exchange responsibility of the steam generation system implies that the design of heat exchanger (superheater, evaporator) tubing must represent a compromise between strength redundancy and heat transfer efficiency. Some of the difficulties involved in achieving this compromise are indicated by the brief review of working environmental factors given in the following section.

In this chapter, a brief review will be made of various mechanical properties of ferritic steels that pertain to steam generation system service. In view of the prominence of the $21 / 4 \mathrm{Cr}$-1Mo steel among materials candidates for the tubing, tubesheet and shell of the superheater and evaporator components of USA LMFBR powerplants, attention in this chapter will be confined to this particular ferritic steel.

From analytical feasibility and data availability standpoints, it has been expedient to review mechanical properties with a minimum of interference from potentially troublesome corrosion/mass transfer procesese. The bulk of the mechanical property data for LMFBR steam generation system materials candidates is, unfortunately, so biased and this situation imposes a severe limitation on the practical utility of much of these data. For the purpose of comparison with other ferritic and austenitic steels, various mechanical property data appropriate for service where there is minimal corrosion involvement (i.e., air data) will be briefly reviewed. Some qualitative comments will be made on possible perturbations of these data arising from LMFBR steam generation system service. The superheater and evaporator components of the LMFBR system will involve extensive welding of the tubing. Accordingly, a brief review will be made of various considerations in the welding of $21 / 4 \mathrm{Cr}$-1Mo stee1. 



\subsection{WORKING ENVIRONMENT FACTORS AFFECTING MECHANICAL PROPERTIES}

Because of very substantial corrosion/mass transfer potentials for both the sodium-side and the water/steam-side of the steam generation system of an LMFBR powerplant, any practical analys is of mechanical properties pertaining to this service must recognize almost immediate involvement of corrosion/mass transfer processes in the long-term performance of structural materials. Some of the difficulties in effecting a synthesis of mechanical and physico-chemical property considerations are indicated by the partial list of working environment factors given below:

- a secondary sodium/water-steam interface in both the superheater and evaporator components, thereby subjecting heat exchanger tubing simultaneously to the gamut of corrosion/mass transfer agencies peculiar to both the sodium and water/steam circuits;

- tube vibration potential of the secondary sodium stream

- tube vibration potential of the multiphase regimes of the water/steam stream;

- metal-metal contact situations at tube shrouds, support plates, anti-vibration devices;

- a multiplicity of welded connections, principally between tubing/tubesheets;

- $\quad$ tubing temperature transients imposed by bulk temperature changes in the sodium and/or water/steam streams; by shifts in the heat transfer burden among tubes of the array due to variability of deposit buildup within the array;

- complex stress transients imposed on tubing by pressure, temperature and flow variations in the sodium and/or water/steam streams. 
Figure 9.2-1 is schematic of the CRBRP (Clinch River) sodium and water/steam circuits affecting steam generation system materials, giving nominal fullpower temperature and pressure values for various points of these circuits. Table 9.2-1 gives a few material assignments for the CRBRP steam generation system. As noted above, the $21 / 4 \mathrm{Cr}$-1Mo steel is proposed for the tubing/tubesheet/shell of the superheater and evaporator components. It is also planned to use this steel for the secondary sodium piping between the superheater outlet and the evaporator inlets (one superheater serves two evaporators).

The corrosion credentials of the $21 / 4 \mathrm{Cr}$-1Mo steel are discussed in Chapter 14 of Volume II of this report. The present chapter will confine its attention to a brief, general, review of $21 / 4 \mathrm{Cr}$-1Mo steel mechanical properties and to necessarily brief comments on the mechanical property implications of long-term LMFBR steam generation system service for this steel.

\section{References for 9.2}

1. Preliminary Safety Analys is Report; Clinch River Breeder Reactor Project, Section 5.1; Project Management Corporation.

2. Ibid., Section 5.5. 


\section{$9.2-3$}

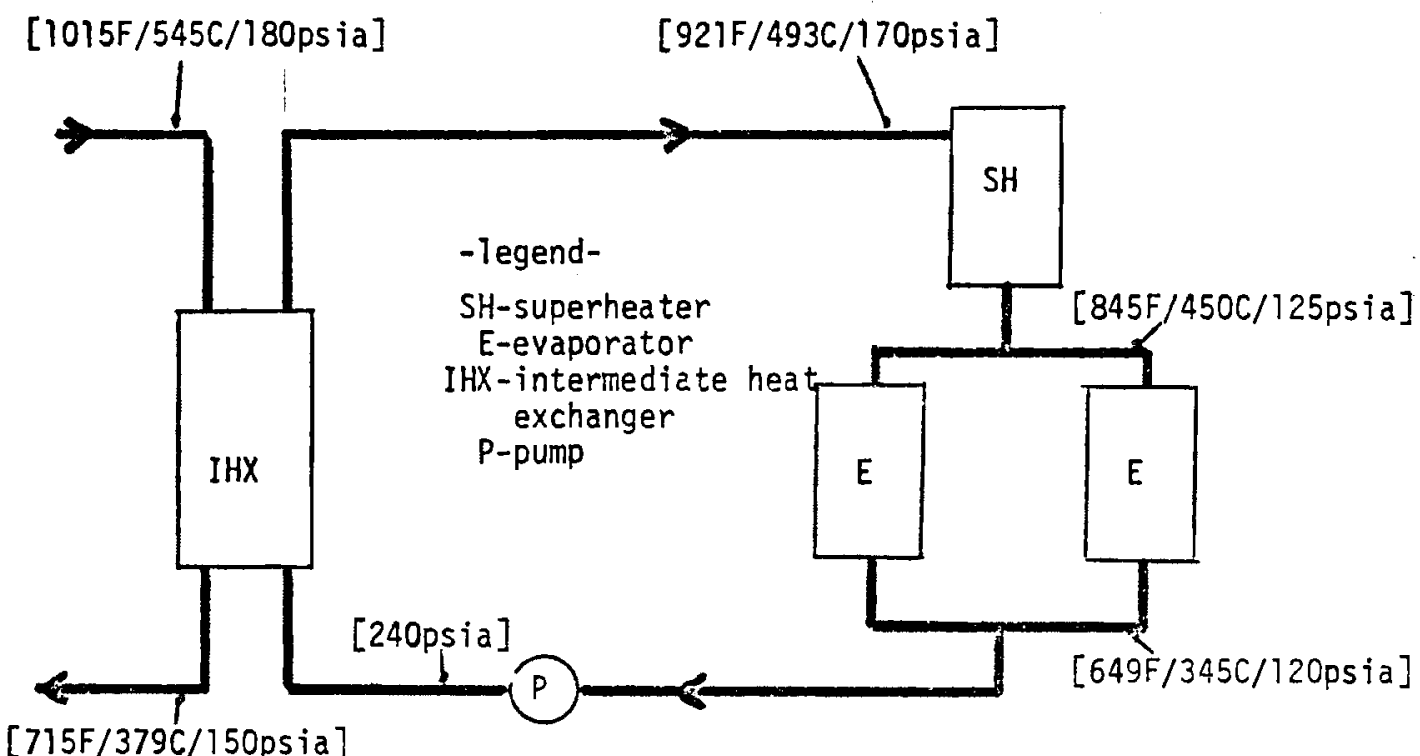

[715F/379C/150psia]

Sodium-Side Temperatures/Pressures

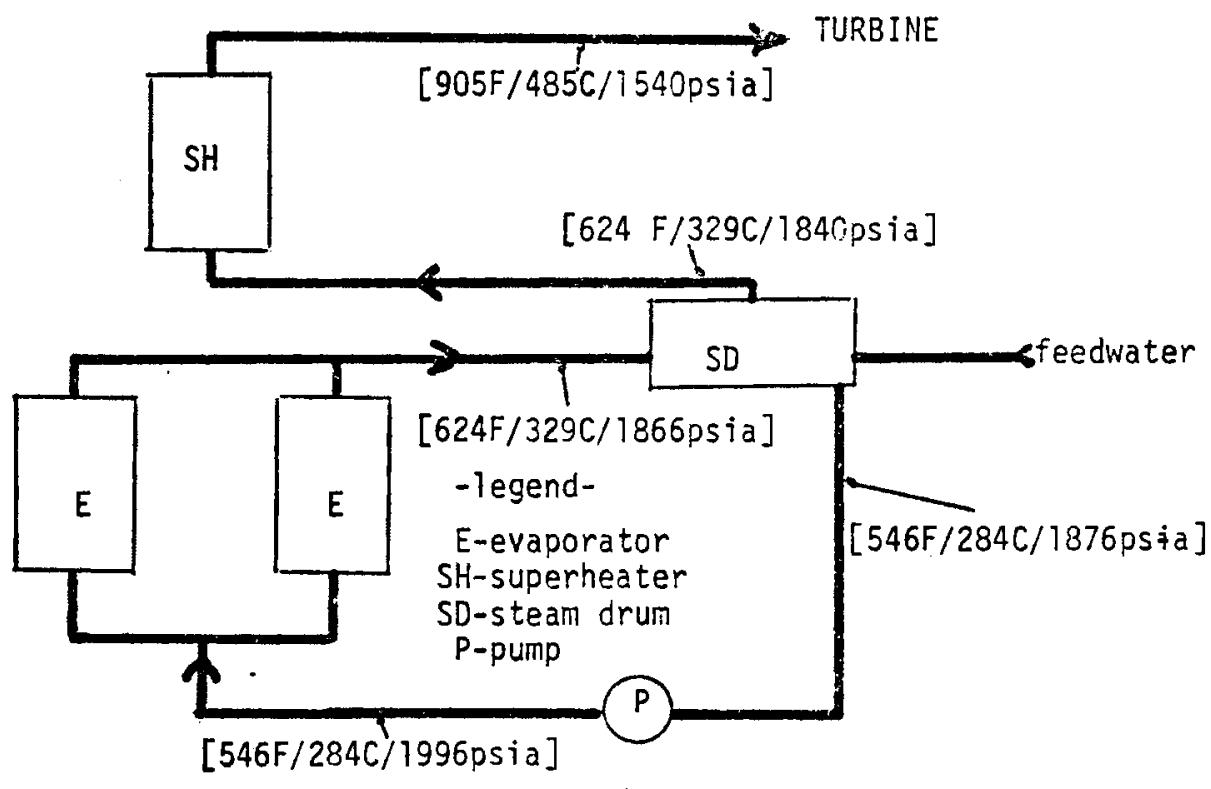

Water/Steam-Side Temperatures

FIGURE 9.2.1. Sodium-Side and Water/Steam-Side Temperatures/Pressures Affecting Steam Generation System Materials of CRBRP(1) 
TABLE 9.2-1. Materials for Major Components of the CRBRP Steam Generation System(2)

Major Components:

Superheaters

$2-1 / 4 \mathrm{Cr}-1 \mathrm{MO}$

Evaporators

Steam Drums

$2-1 / 4 \mathrm{Cr}-1 \mathrm{Mo}$

Recirc. Pumps

SA-516

Carbon Steel

Piping and Headers:

S.f. Subsyster. and Feedwater subsystem:

Fdwtr. Isolation Valve to Steam Drum

Drum to Pump Inlet Header

Pump Inlet Heider to Pump

Pump to Pump clutlet Header

Pump Headers (Inlet and Outlet)

Outlet Header to Evap.

Evap. to Drum Inlet Header

Drum Inlet Header

Inlet Header to Drum

Drum to Steam Outlet Header

Drum Outlet Header

Outlet Header to S.H.

S.H. to Isolation Valve

SA-106, far $B$

$S A-106$, fr $B$

$S A-106$, Gr B

SA-106, Gr B

$S A-106$, fr $B$

$S A-106$, frr $B$

SA-10E, fir B

$S A-106, G r B$

$S A-106$, Gr B

SA-106, fir B

SA-106, for B

$S A-106$, Gr B

$2-1 / 4 \mathrm{Cr},-1 \mathrm{MO}$

\section{Nominal Composition of Ferritic Steels Specified Above}

$\begin{array}{rllllllll} & \text { Mn } & \text { Si } & C r & \text { Mo } & N i & P_{\max } & S_{\max } & C \\ 2 \text { 1/4Cr-1Mo: } & 0.35 & 0.23 & 2.42 & 0.92 & 0.04 & 0.010 & 0.016 & 0.12 \\ \text { SA 106: } & .29-1.06^{*} & 0.10 & - & - & - & 0.048 & 0.058 & 0.30 \\ \text { SA 516: } & .56-1.25^{*} & .13-.33^{*}- & - & - & 0.035 & 0.04 & 0.18-.26^{*} \\ & * \text { depends on section size } & & & & & \end{array}$




\subsection{MECHANICAL PROPERTY CONSIDERATIONS}

\subsubsection{Tensile Properties}

Apart from environmental (i.e., corrosion/mass transfer) influence, the mechanical properties are sensitive to the microstructure and chemistry of the material, stress state/history (i.e., type of stress, loading rate) and temperature history during the service/testing. Many of these factors are interdependent. Material response to a given situation can vary substantially from batch-to-batch within a given heat of material, and from heat-to-heat for material satisfying nominal chemistry specifications. As noted within several mechanical property sub-sections of this chapter, the latter variability has been experienced with the $21 / 4 \mathrm{Cr}$-1Mo steel and has handicapped mechanical property appraisal for this steel even without the complication of environmental intervention. For a given service situation, those mechanical properties that can give the least ambiguous identification of limiting service conditions would be expected to be weighted most heavily in the mechanical property appraisal (i.e., creep properties where long-term, sensibly steady loading at creep active temperatures is involved; fatigue properties where appreciable stress and temperature variations of various magnitude-time characteristics are involved; creep-fatigue interaction where there is overlap between creep and fatigue regimes, etc.). Tensile data provide the most . readily accessible guide to the ability of a material to resist plastic deformation and structural instability leading to failure under a given set of strain rate, temperature, metallurgical state, and ambient environment conditions.

Table 9.3.1-1 gives some details of several heat treatments that will be referred to in this chapter. Tensile property data reported by Booker, et al. for air testing of annealed 2 1/4 Cr-1Mo steel are given in Figure 9.3.1-1. The boundary lines on these plots outline the region where it is expected (95\% confidence) that $90 \%$ of the data will fall. Table 9.3.1-2 presents 
TABLE 9.3.1-1. Heat Treatments Used for $21 / 4 \mathrm{Cr}-1$ Mo Steel

Ful1 Anneal: Austenitize at $927 \mathrm{C}(1700 \mathrm{~F}) 1 \mathrm{hr}$; furnace $\mathrm{co0l}$ at various rates to RT; yields ferrite-pearlite-bainite. structure, with bainite proportion increasing with increasing cooling rate

Isotherma]

Anneal

: Austenitize as above; furnace $\operatorname{co0} 1$ to $704 \mathrm{C}$ at about $83 \mathrm{C} / \mathrm{hr}$; hold at $704 \mathrm{C}$ for 2 hrs; furnace cool to RT(rate not critical); yields ferrite-pearlite structure with some bainite; bainite increases with increasing cooling rate from austenitizing temperature

Normalize \& Temper :

Austenitize as above; air cool to RT; temper at 704C(1300F) for $1 \mathrm{hr}$; air cool to RT; yields fully bainitic structure

TABLE 9.3.1-2. Expressions for Expected Values of Tensile Properties for Annealed 2 1/4 Cr-lMo Steel (1)

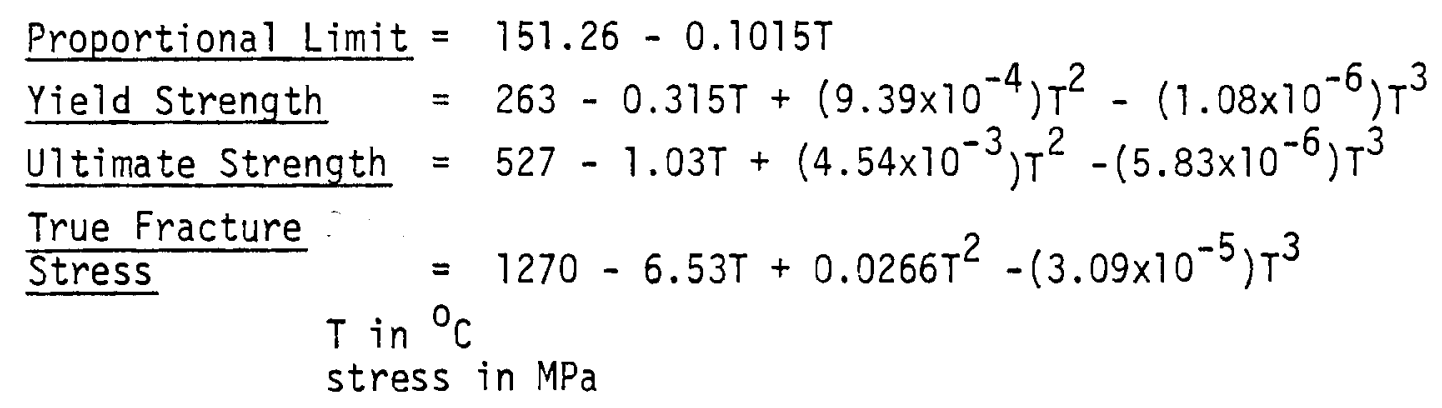




\subsection{1-3}
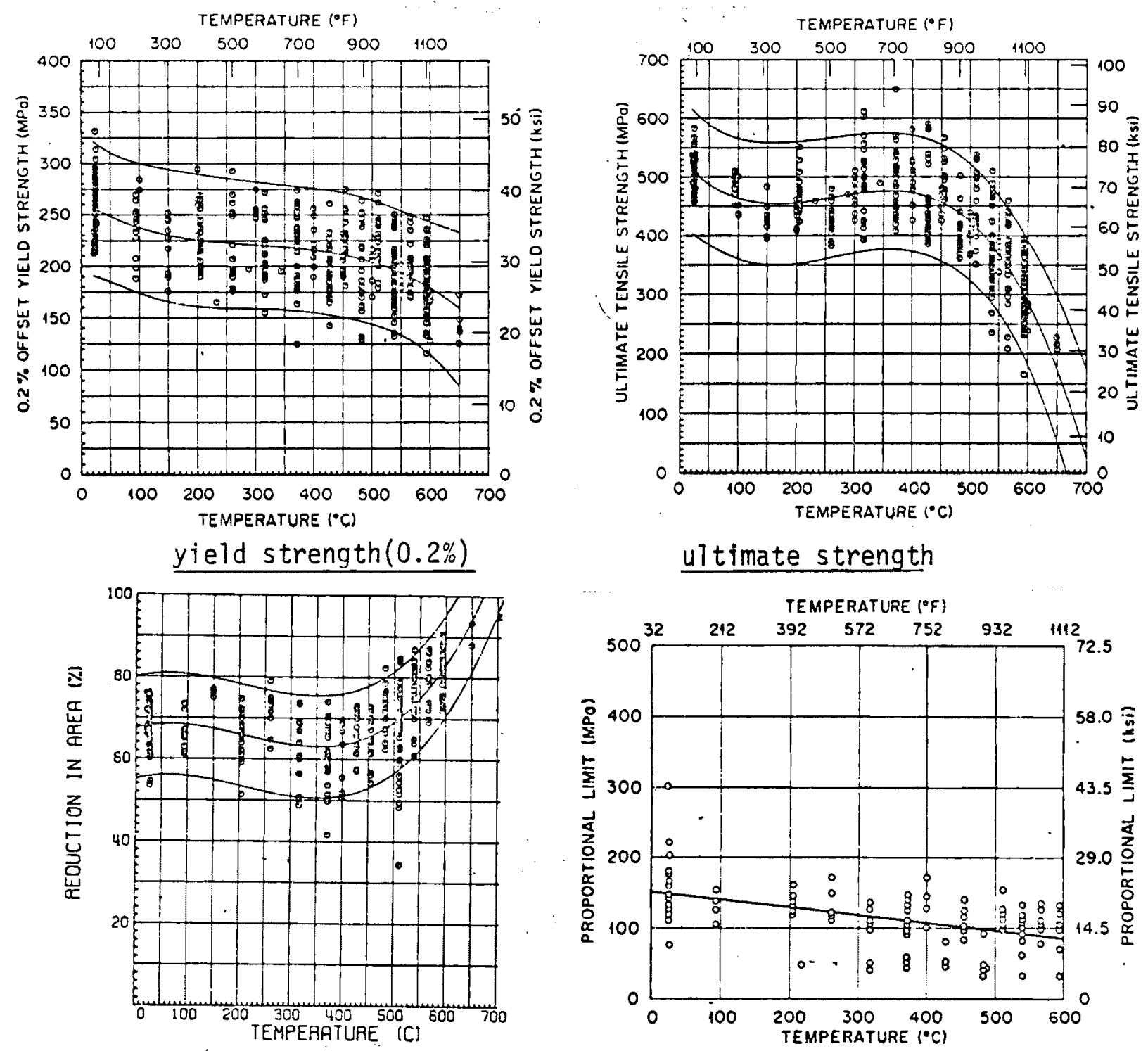

ultimate strength

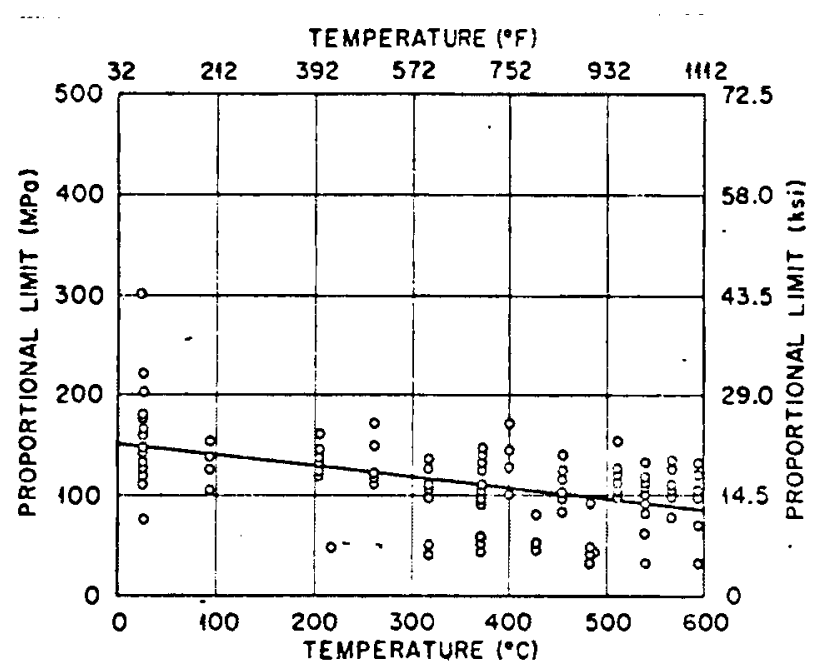

reduction in area

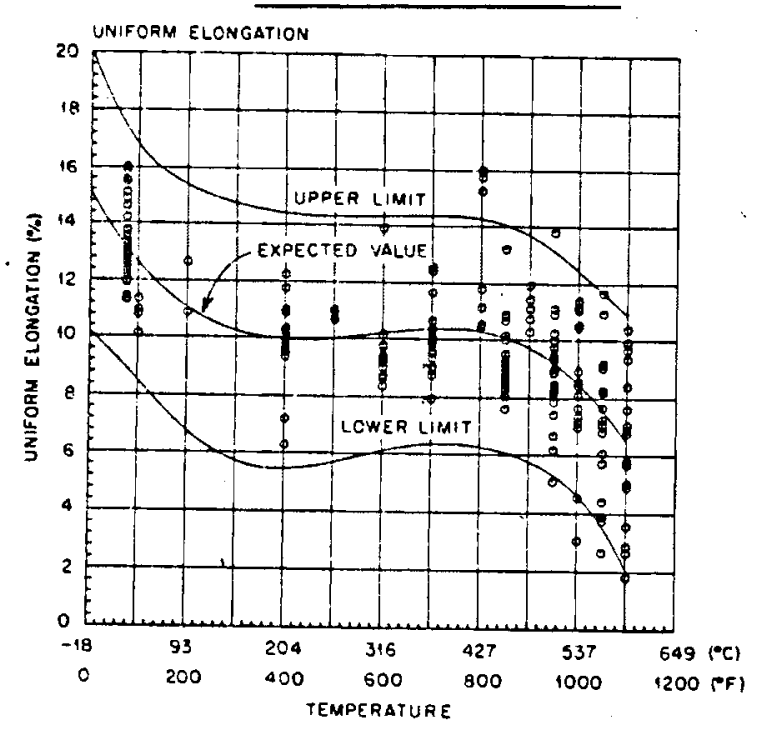

próportional limmit

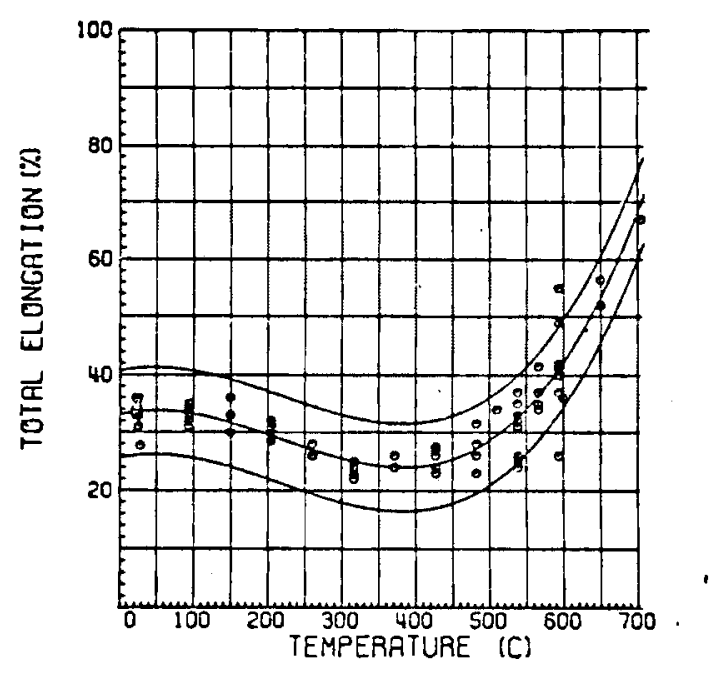

uniform elongation

total elongation 


\section{$9.3 \cdot 1-4$}

expressions given by these authors for expected values of tensile properties for annealed $21 / 4 \mathrm{Cr}$-iMo steel. It will be noted from the above figures that there is considerable data scatter, attributable by these authors to the factors mentioned above. An indication of the heat-to-heat variability of tensile properties for $21 / 4 \mathrm{Cr}$-1Mo steel is given in Figure 9.3.1-2, where strength and ductility data for three heats given annealing heat treatment are plotted versus temperature. With the exception of the proportional limit, the tensile strength data given above indicate a maximum in the temperature range of roughly $300-500^{\circ} \mathrm{C}$, with ductility properties exhibiting a minimum within this range. This is attributed by Booker, et al., (1) to a dynamic strain aging process, involving redisposition of interstitial and substitutional elements under straining, and changes in the structural interaction with dislocations.

A comprehensive picture of strain rate and temperature effects on tensile properties, for annealed $21 / 4 \mathrm{Cr}$-1Mo steel, is given by Brinkman, et al. (2) Figure 9.3.1-3, from that report, gives tensile strength (UTS) and ductility (RA) data as a function of temperature and strain rate for annealed $21 / 4 \mathrm{Cr}$-1Mo steel. The effect of slow strain rate in accentuating the dynamic strain aging phenomenon is shown in this figure within the temperature range of roughly $300-500^{\circ} \mathrm{C}$ (peak in strength, valley in ductility).

At temperatures where diffusion is possible, service times of the order of 20-30 years can involve a considerable alteration in microstructural details of the $21 / 4 \mathrm{Cr}$-1Mo steel, with changes in carbide constitution and morphology being of principal concern. Under sodium service, changes in these characteristics can be effected both by thermal aging and by the decarburization action of sodium, processes which will proceed simultaneously. Decarburization of $21 / 4 \mathrm{Cr}-1$ Mo steel is discussed in Chapter 14, Volume, II, of this report. An indication of the power of sodium to leach carbon from the ferritic matrix is given in Figure 9.3.1-4 where gross carbon content is plotted versus exposure time for a number of unstabilized and stabilized 


\subsection{1-5}

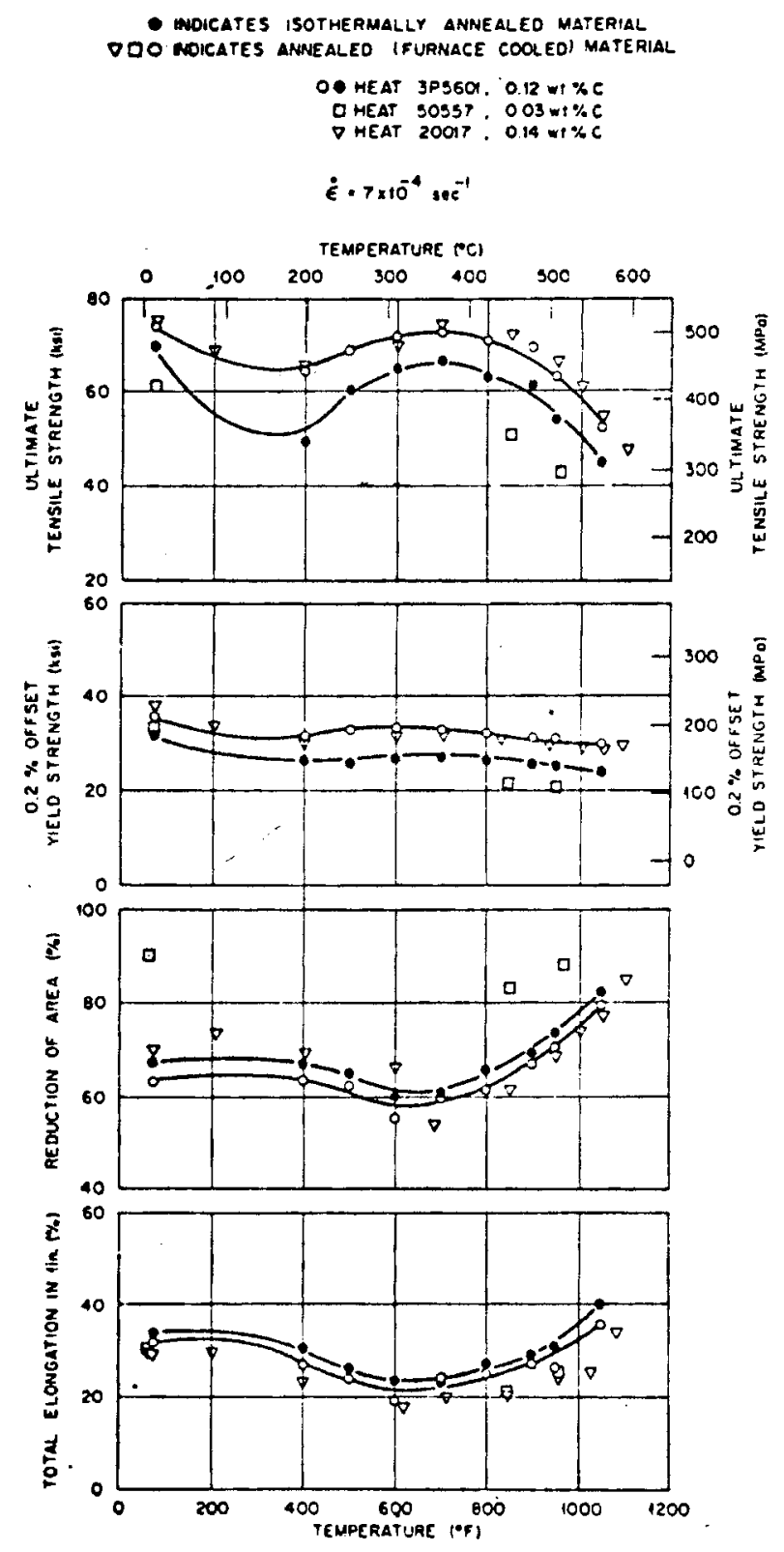

FIGURE 9.3.1-2. Comparison of Tensile Properties for Three Heats of $2 \mathrm{l} / 4 \mathrm{Cr}$-1Mo Steel 

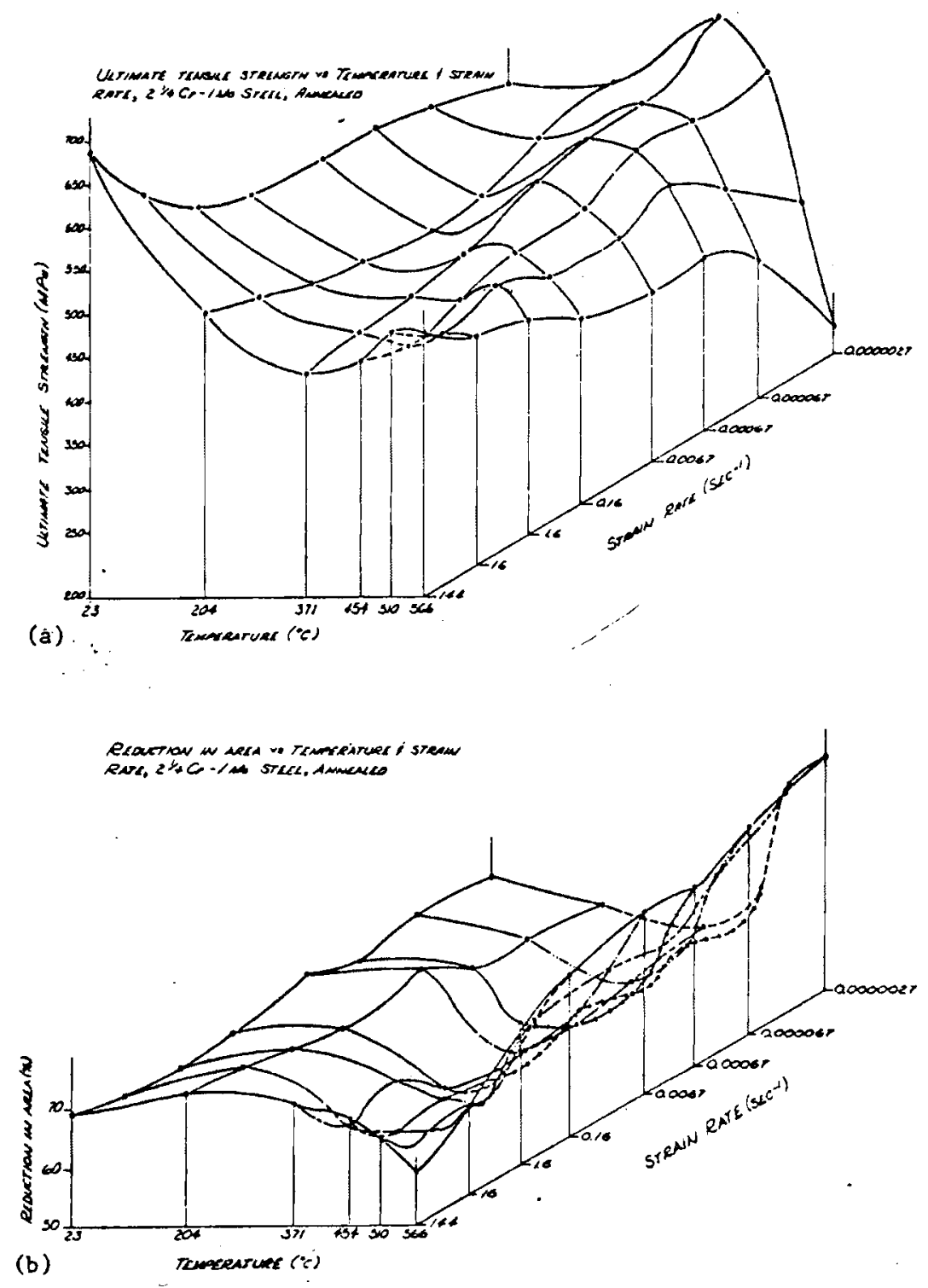

FIGURE 9.3.1-3. Sensitivity of Strength (UTS) and Ductility (RA) of
$2 \mathrm{l} / 4 \mathrm{Cr}$-1Mo Steel to Temperature and Strain Rate $(2)$ 


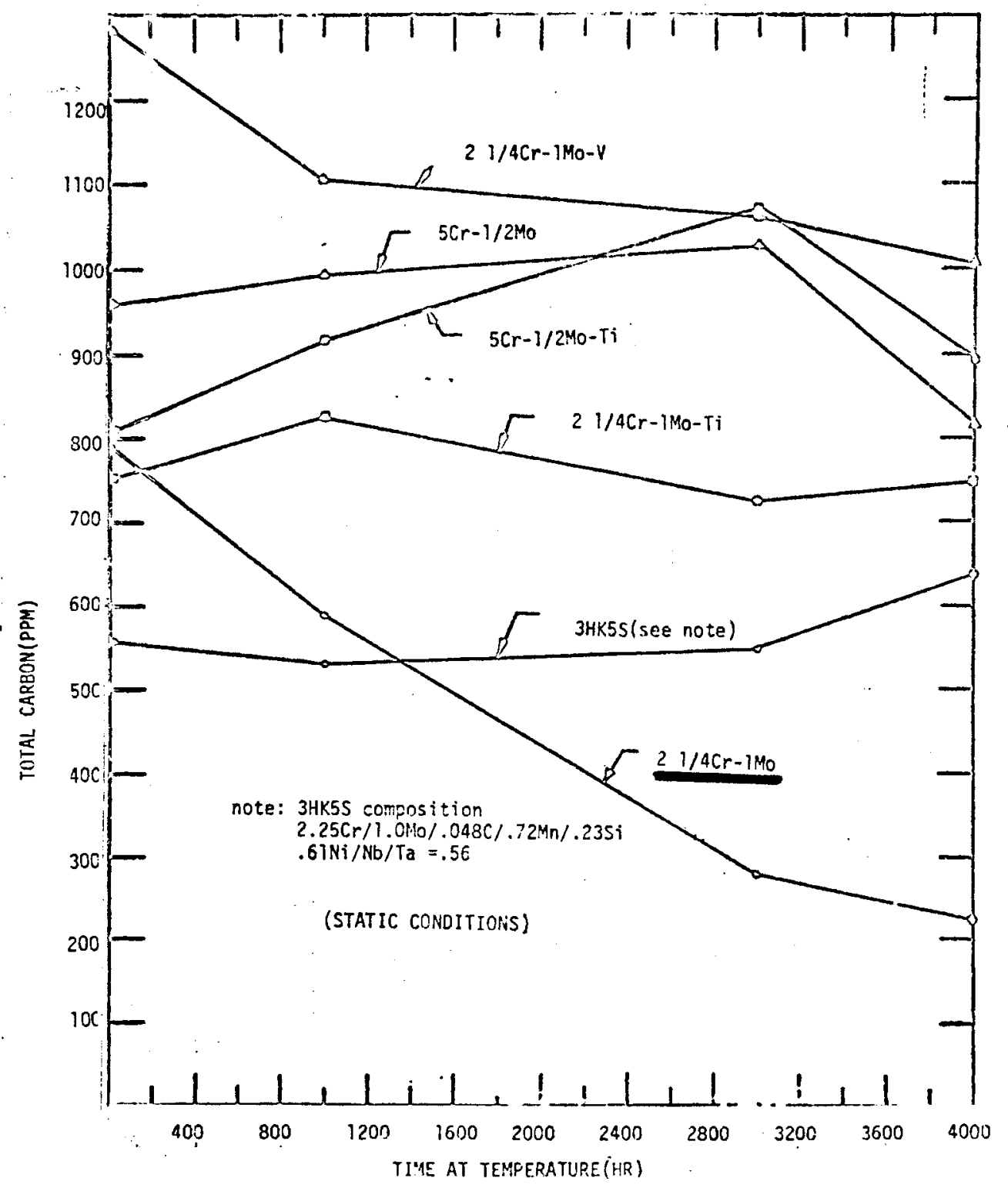

FIGURE 9.3.1-4. Decarburization of Various Ferritic Alloys by Static Sodium at $650^{\circ} \mathrm{C}\left(1200^{\circ} \mathrm{F}\right)(3)$ 


\section{$9.3 .1-8$}

(elements added to retard decarburization) ferritic alloys. Gross carbon content is of less interest, from a mechanical property standpoint, than the details of the carbon distribution and carbide morphology across the structural section. There has apparently been very little relation of such details to the mechanical properties of the $21 / 4 \mathrm{Cr}$-1Mo steel. Long-term decarburization influence on mechanical properties has generally been assessed on the basis of air testing of heats of $21 / 4 \mathrm{Cr}$-1Mo steel having various gross carbon levels corresponding to gross carbon levels estimated for various sodium exposure times at a given temperature. Krankota and Armijo ${ }^{(4)}$ give an equation for estimating the gross carbon loss ( $\Delta C$ in ppm) from $21 / 4 \mathrm{Cr}$-1Mo steel as a function of section thickness ( $\Delta X$ in mils) and temperature ( $T$ in ${ }^{\circ} \mathrm{K}$ for 237,000 hours (27 years) exposure:

$$
\Delta C=\frac{1.8467 \times 10^{10}}{\Delta X} \exp (-13949 / T)
$$

Figure 9.3.1-5 displays some tensile, creep and fatigue strength data for $21 / 4 \mathrm{Cr}$-1Mo steel as a function of gross carbon content for various temperatures. The fall-off of strength properties with gross carbon content below about $0.04 \mathrm{w} / 0$ (400 ppm) is well illustrated by the upper group of curves. Table 9.3.1-3 presents tensile property data for $21 / 4 \mathrm{Cr}$-1Mo steel after exposure to helium and static sodium for up to 10,000 hours. Gross carbon loss information is given at the bottom of the table. While the ductility (elongation and RA) properties were relatively unaffected by these exposure conditions, it is evident from the data in Table 9.3.1-3 that both thermal aging (helium) and sodium exposure (thermal aging plus decarburization) generally adversely affected the strength properties, with the sodium exposure consistently exhibiting the largest effect. In a recent ORNL report, (7) Klueh compares the tensile property effects of long exposure to helium and to sodium at $566^{\circ} \mathrm{C}\left(1050^{\circ} \mathrm{F}\right)$. While this temperature is somewhat above the highest sodium temperature of the steam generation system (see Figure 9.2-1), these data derive from the longest time and lowest temperature conditions 


\subsection{1-9}

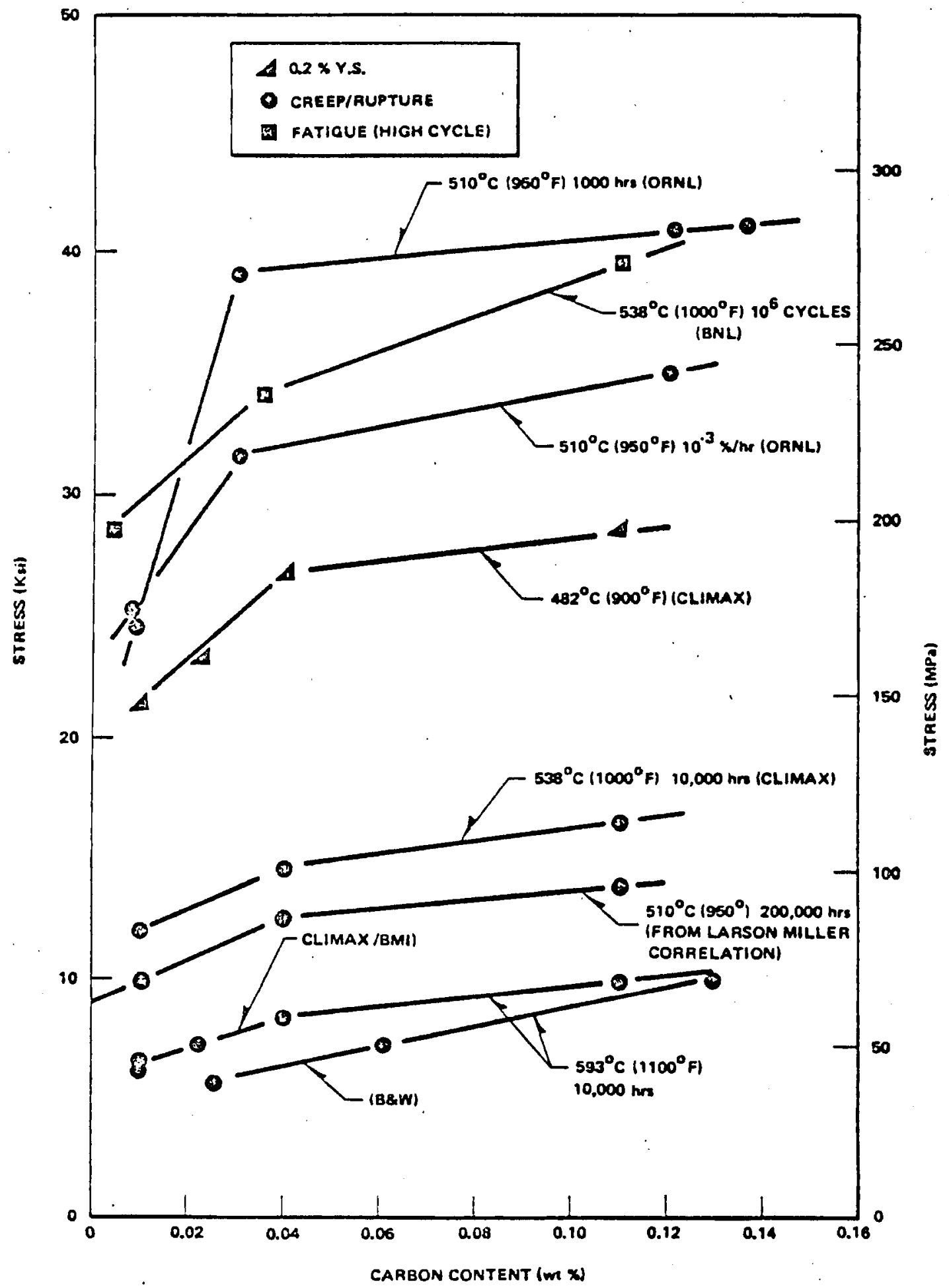

FIGURE 9.3.1-5. Various Strength Criteria for $21 / 4 \mathrm{Cr}$-1Mo Steel versus Gross Carbon Content (5) 

TABLE 9.3.1-3. Tensile Properties for $21 / 4 \mathrm{Cr}-1$ Mo Sfeel After
Helium and Static Sodium Exposure $(3,6)$

As-Received Material:

$\begin{array}{lccccc}\left.T^{\mathrm{O}} \mathrm{F}\right) & \begin{array}{c}\text { Yield St. } \\ (\mathrm{ksi})\end{array} & \begin{array}{c}\text { Tensile } \\ (\mathrm{ksi})\end{array} & \begin{array}{c}\text { Elongation } \\ \left(\begin{array}{l}\% \\ \%\end{array}\right)\end{array} & \begin{array}{c}\text { Reduction of Area } \\ (\%)\end{array} & \begin{array}{c}\text { Ref. } \\ (\%)\end{array} \\ \text { RT } & 35.4 & 73.2 & 32 & 68 \\ 1050 & 27.2 & 65.6 & 30 & 56\end{array}$

1000 Hours Static Helium at 1200F:

$\begin{array}{lllll}\text { RT } & 39.0 & 62.9 & 31 & 70 \\ 1050 & 20.2 & 34.6 & 32 & 66\end{array}$

1000 Hours Static Sodium at 1200F:

$\begin{array}{lllll}\text { RT } & 34.4 & 62.2 & 33 & 73 \\ 1050 & 18.2 & 31.3 & 42 & 78\end{array}$

3000 Hours Static Helium at 1200F:

$\begin{array}{lllll}\text { RT } & 40.1 & 63.3 & 30 & 69 \\ 1050 & 17.8 & 34.1 & 29 & 72\end{array}$

3000 Hours Static Sodium at 1200F:

$\begin{array}{lllll}\text { RT } & 24.3 & 56.0 & 34 & 74 \\ 1050 & 14.0 & 22.4 & 36 & 79\end{array}$

4000 Hours Static Helium at 1200F:

$\begin{array}{lllll}R T & 39.6 & 60.9 & 31 & 67 \\ 1050 & 16.3 & 29.2 & 45 & 75\end{array}$

4000 Hours Static Sodium at 1200F:

$\begin{array}{lllll}R T & 25.4 & 57.6 & 34 & 72 \\ 1050 & 15.0 & 26.8 & 49 & 79\end{array}$

10000 Hours Static Helium at 1050F:

$\begin{array}{llllll}\text { RT } & 39.7 & 69.0 & 40 & 68 & 3\end{array}$

10000 Hours Static Sodium at 1050F:

\begin{tabular}{lllll}
$R T$ & 32.2 & 61.9 & 39 & 68 \\
1050 & 17.2 & 28.7 & 43 & 76 \\
\hline
\end{tabular}

(a): average of two specimens for all data

- base(as-received) material had 800 pom carbon

- after 4000 hours sodium exposure at $1200 \mathrm{~F}$, gross C loss was 600ppm

- after 10000 hours sodium exposure at 1050F," 
reported for sodium exposure. Table 9.3.1-4 displays the RT and $566^{\circ} \mathrm{C}\left(1050^{\circ} \mathrm{F}\right)$ tensile property data resulting from helium and sodium exposure at $566^{\circ} \mathrm{C}$ out to 26,500 hours. Substantial tensile strength reductions are noted for the $566^{\circ} \mathrm{C}$ data for both the helium and the sodium exposures. The greatest change is manifested in the yield strength, with the sodium exposure exhibiting the greatest decrease with respect to the unexposed material.

Figure 9.3.1-6 is a time-temperature-transformation (TTT) diagram for $21 / 4 \mathrm{Cr}$-1Mo steel after it has been rendered completely austenitic. While the details of long-term aging effects are beyond the scope of this diagram, it is interesting that substantial tensile property effects of long-term aging have been observed (above) at a temperature $\left(566^{\circ} \mathrm{C}\right.$ ) considerably below the temperature range where maximum carbide precipitation activity is noted in the TTT study. Under sodium service, both thermal aging and sodium decarburication will proceed to some extent at temperatures up to the order of $490^{\circ} \mathrm{C}\left(920^{\circ} \mathrm{F}\right)$. The aggregate influence of these processes on mechanical properties, where service times in excess of a few years are involved, is not well understood, particularly under the complex stress histories characteristic of LMFBR steam generation system service. Furthermore, the ability of laboratory and prototypical equipment testing to duplicate the synergism among the factors of the working system, noted briefly in Section 9.2, is very limited. This implies that in-service experience will be the principal qualification recourse for LMFBR materials. 
TABLE 9.3.7-4. Changes in Tensile Properties for $21 / 4 \mathrm{Cr}$-1Mo Stee1 after Prolonged Exposure to Helium and to Sodium at $566^{\circ} \mathrm{C}\left(1050^{\circ} \mathrm{F}\right)(7)$

\begin{tabular}{|c|c|c|c|c|}
\hline \multirow{2}{*}{$\begin{array}{c}\text { Exposure } \\
\text { T1ro } \\
\text { (hr) }\end{array}$} & \multicolumn{2}{|c|}{ Streacth, $100(\operatorname{los} 1)$} & \multirow{2}{*}{$\begin{array}{c}\text { Elongation } \\
(\%)\end{array}$} & \multirow{2}{*}{$\begin{array}{c}\text { Reduction } \\
\text { of Area } \\
(\%)\end{array}$} \\
\hline & Yield & Ultiaste & & \\
\hline \multicolumn{5}{|c|}{ Test Teroarature $25^{\circ} \mathrm{C}\left(75^{\circ} \mathrm{F}\right)$} \\
\hline $\begin{array}{r}\text { Heliun } \\
0 \\
10,000 \\
26,500\end{array}$ & $\begin{array}{l}241(35) \\
276(40) \\
234(34)\end{array}$ & $\begin{array}{l}503(73) \\
4.5(69) \\
455(66)\end{array}$ & $\begin{array}{l}32 \\
40 \\
36\end{array}$ & $\begin{array}{l}68 \\
68 \\
59\end{array}$ \\
\hline \multicolumn{5}{|l|}{ Sodiva } \\
\hline $\begin{array}{r}0 \\
10,000 \\
20,000 \\
26,500 \\
26,500^{b}\end{array}$ & $\begin{array}{l}241(35) \\
221(32) \\
234(34) \\
207(30) \\
169(27.4)\end{array}$ & $\begin{array}{l}503(73) \\
423(62) \\
434(63) \\
414(60) \\
411(59.6)\end{array}$ & $\begin{array}{l}32 \\
39 \\
37 \\
39 \\
42\end{array}$ & $\begin{array}{l}68 \\
68 \\
57 \\
60 \\
51\end{array}$ \\
\hline \multicolumn{5}{|c|}{ Test Tepperature $566^{\circ} \mathrm{C}\left(1050^{\circ} \mathrm{F}\right)$} \\
\hline \multicolumn{5}{|l|}{ Helfug } \\
\hline $\begin{array}{r}0 \\
26,500\end{array}$ & $\begin{array}{l}186(27) \\
132(20)\end{array}$ & $\begin{array}{l}455(66) \\
193(28)\end{array}$ & $\begin{array}{l}30 \\
58\end{array}$ & $\begin{array}{l}56 \\
72\end{array}$ \\
\hline \multicolumn{5}{|l|}{ Soditz } \\
\hline $\begin{array}{r}0 \\
10,000 \\
20,000 \\
26,500 \\
26,500^{b}\end{array}$ & $\begin{array}{l}105(27) \\
117(17) \\
103(15) \\
131(19) \\
112(16.3)\end{array}$ & $\begin{array}{l}455(66) \\
230(29) \\
255(24) \\
200(29) \\
204(29.6)\end{array}$ & $\begin{array}{l}30 \\
43 \\
61 \\
50 \\
66\end{array}$ & $\begin{array}{l}56 \\
76 \\
71 \\
69 \\
65\end{array}$ \\
\hline
\end{tabular}

Taleen from Reference 62 ; straln rate was not given.

bested at ORNL; stain rate $0.05 / \mathrm{min}$.

$\therefore$ Gross Carbon Content Information for Above Test Material (7) as-received: 1100ppm

$10000 \mathrm{hrs}(\mathrm{Na}) \quad 930$

$20000 \mathrm{hrs}(\mathrm{Na}) \quad 750$

$26500 \mathrm{hrs}(\mathrm{Na}) \quad 750$ 


\section{$9.3 .1-73$}

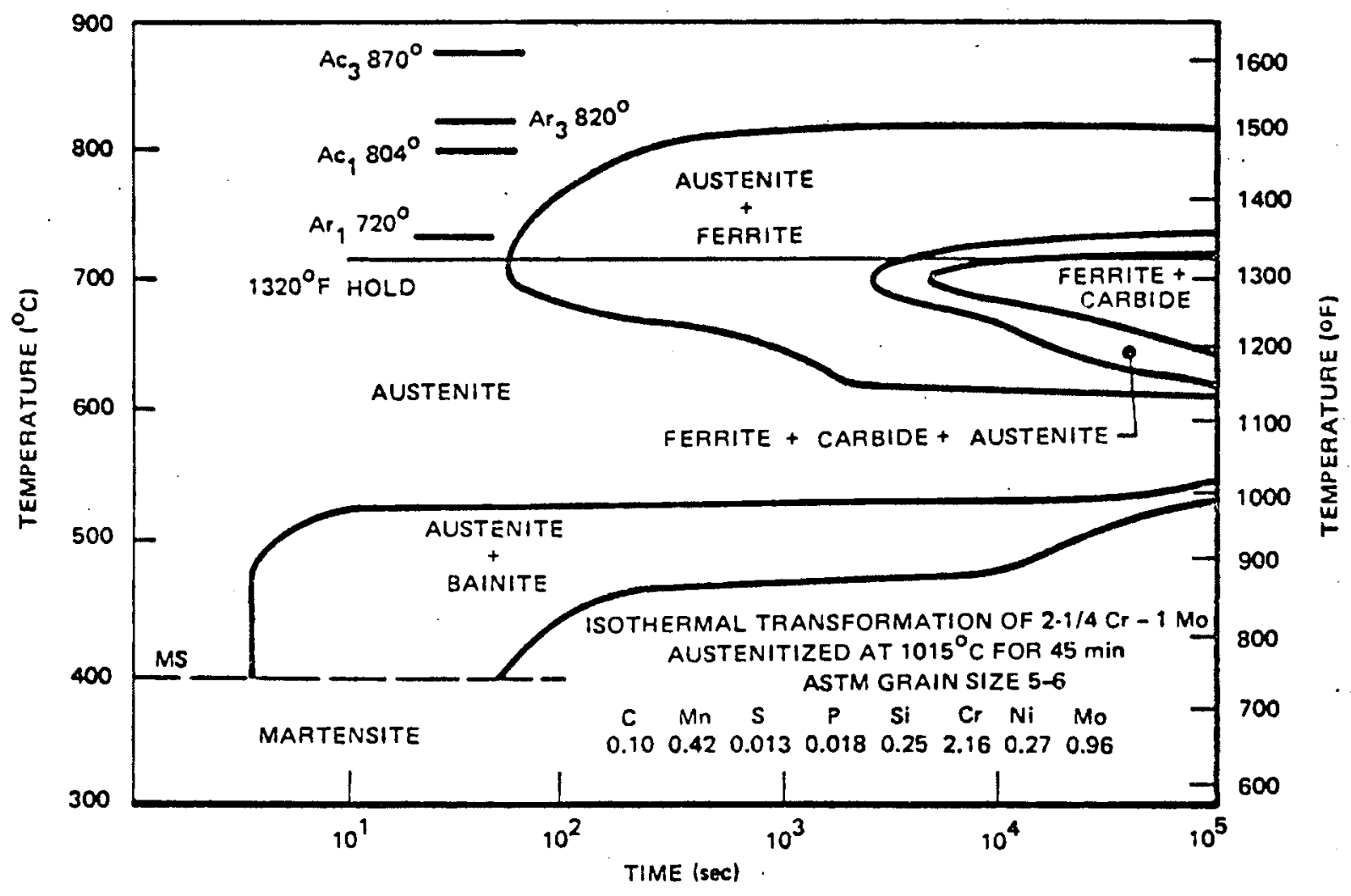

FIGURE 9.3.1-6. TTT Diagram for $21 / 4 \mathrm{Cr}-1$ Mo Stee ${ }^{(8)}$ 
References for 9.3.1

1. M. K. Booker, T. L. Hebble, D. O. Hobson, and C. R. Brinkman, Mechanical Property Correlations for $21 / 4 \mathrm{Cr}$-1Mo Steel in Support of NucTear Reactor Systems Design. ORNL/TM-5329, Oak Ridge National Laboratory, Oak Ridge, TN, June 1976.

2. C. R. Brinkman, W. R. Corwin, M. K. Booker, T. L. Hebble, and R. L. Klueh, Time Dependent Mechanical Properties of $21 / 4 \mathrm{Cr}$-1Mo Steel for Use in Steam Generator Design. ORNL-5125, Oak Ridge National Laboratory, Oak Ridge, TN, March 1976.

3. L. H. Kirschler, R. H. Hiltz, and S. J. Rodgers, Effect of High Temperature Sodium on the Mechanical Properties of Candidate Alloys for the LMFBR Program. MSAR 70-76, MSA Research Corporation, Evans City, PA, May 1970.

4. J. L. Krankota and J. S. Armijo, "The Kinetics of Decarburization of 2 1/4 Cr-1Mo Steel in Sodium." Nucl. Tech., Vol 24(11), p. 225, 1974.

5. G. J. Licina and J. F. Copeland, A Review of 21/4 $\mathrm{Cr}$-1Mo Steel for Steam Generator Applications in the Clinch River Breeder Reactor. GEAP-20589, General Electric Co., Sunnyvale, CA, October 1974.

6. R. H. Hiltz and L. H. Kirschler, MSAR Evaluation of Candidate Ferritic Alloys for LMFBR Service. MSAR 69-139, MSA Research Corp., Evans City, PA, July 1969.

7. Mechanical Properties Test Data for Structural Materials Quarterly Progress Report for Period Ending JuTy 31, 1976. ORNL-5200, Oak Ridge Nationa 1 Laboratory, Oak Ridge, TN, p. 181.

8. G. J. Licina and J. F. Copeland, A Review of $21 / 4 \mathrm{Cr}-1$ Mo Steel for Steam Generator Applications in the Clinch River Breeder Reactor. GEAP-20589, General Electric Co., Sunnyvale, CA, October 1974. 


\section{$9.3 .2-1$}

\subsubsection{Impact Properties}

The ability of a material to resist suddenly applied loads, particularly after long exposure to media that can exert both corrosion and mass transfer influence (in addition to such thermal and strain aging as may have occurred during the exposure), is a characteristic of considerable importance to LMFBR steam generation materials. Such loads could result from various accidents during equipment manipulations, seismic events, or from the chain of energy releasing events attending a sodium-water reaction after breach of the secondary sodium containment envelope within the superheater or evaporator components. Analysis of this characteristic of materials poses very difficult experimental and analytical problems even without active cognizance of corrosion/mass transfer effects resulting from the sodium-side and water/ steam-side exposures. The Charpy $V$-notch test provides some indication of resistance to rapid loading providing the test material is representative of in-service material states at various periods of the service history. Apparently most of the published impact data on $21 / 4 \mathrm{Cr}$-1Mo steel has been obtained with material having no environmental exposure other than that associated with the pre-test heat treatment.

Booker, et al., (1) presented the following expression for estimation of the Charpy $V$-notch energy of $2 \times 1 / 4 \mathrm{Cr}$-1Mo steel:

$$
E=A\left[1-\exp \left(-B(T-C)^{2}\right]\right.
$$

where $E$ is the impact energy (joules), $T$ is the temperature $\left({ }^{\circ} \mathrm{C}\right), A, B$, and $C$ are empirical constants. These authors state that the variation in impact properties, from batch-to-batch and under various heat treatments, was so large for $21 / 4 \mathrm{Cr}-1$ Mo steel that the above constants must be specialized for a particular batch of steel, given a particular heat treatment. They report the following ranges for the various constants: 


$$
\begin{aligned}
& \text { A: } 82-227 \text { joules } \\
& \text { B: } 2.2 \times 10^{-5}-6.3 \times 10^{-4} \\
& \text { C: }-90 \text { to } 4^{\circ} \mathrm{C}
\end{aligned}
$$

and that the expression for $E$ is valid only for temperatures greater than the $C$ value. Figure 9.3.2-1 shows a typical fit, using the above expression, to a set of Charpy data for a particular batch of annealed $21 / 4 \mathrm{Cr}$-1Mo steel.

The composition of $21 / 4 \mathrm{Cr}$-1Mo test material used in the GEAP mechanical properties test program for LMFBR materials (impact and fracture mechanics testing) is given in Table 9.3.2-1. Table 9.3.2-2 gives the various metal conditions/heat treatments used in the impact and fracture mechanics work with $21 / 4 \mathrm{Cr}$-1Mo Steel. In addition to conventional heat treatment, an attempt has been made to simulate the thermal history that a weld zone might experience, as well as to simulate thermal aging embrittlement. Table 9.3.2-3 presents a summary of the impact data (50 ft-1b transition temperature and upper shelf energy values, in addition to observations of $50 \%$ ductile fracture appearance transition temperature, and the nil ductility temperature [NDT]). Figure 9.3.2-2 shows a typical Charpy data summary for a particular heat treatment ( $B$, see Table 9.3.2-2), giving the energy values, the \% ductile fracture appearance, and the lateral expansion at fracture. Figure 9.3.2-3 shows the impact energy-temperature characteristics for the ' $F$ ' and ' $G$ ' heat treatments. A summary of the impact energy-temperature characteristics for some of the heat treatments/conditions listed in Table 9.3.2-2 is given in Figure 9.3.2-4. Conditions $B, F$ and $G$ simulate the base metal of a weld, the weld metal (actual weld deposit) and the heat affected zone (HAZ) of a weld, respectively. Referring to Figure 9.3.2-4, it is noted that the weld metal (F) is superior in impact resistance to the base metal (B) and does not display as much fall-off at high temperatures as the base metal. The HAZ condition $(G)$ exhibited the poorest impact resistance of all the tested conditions. The upper shelf impact energy for the HAZ material falls below the $50 \mathrm{ft}-1 \mathrm{~b}$ criterion, under the ASME Code NB 2300 for upper shelf impact energy, 


\section{$9.3 \cdot 2-3$}

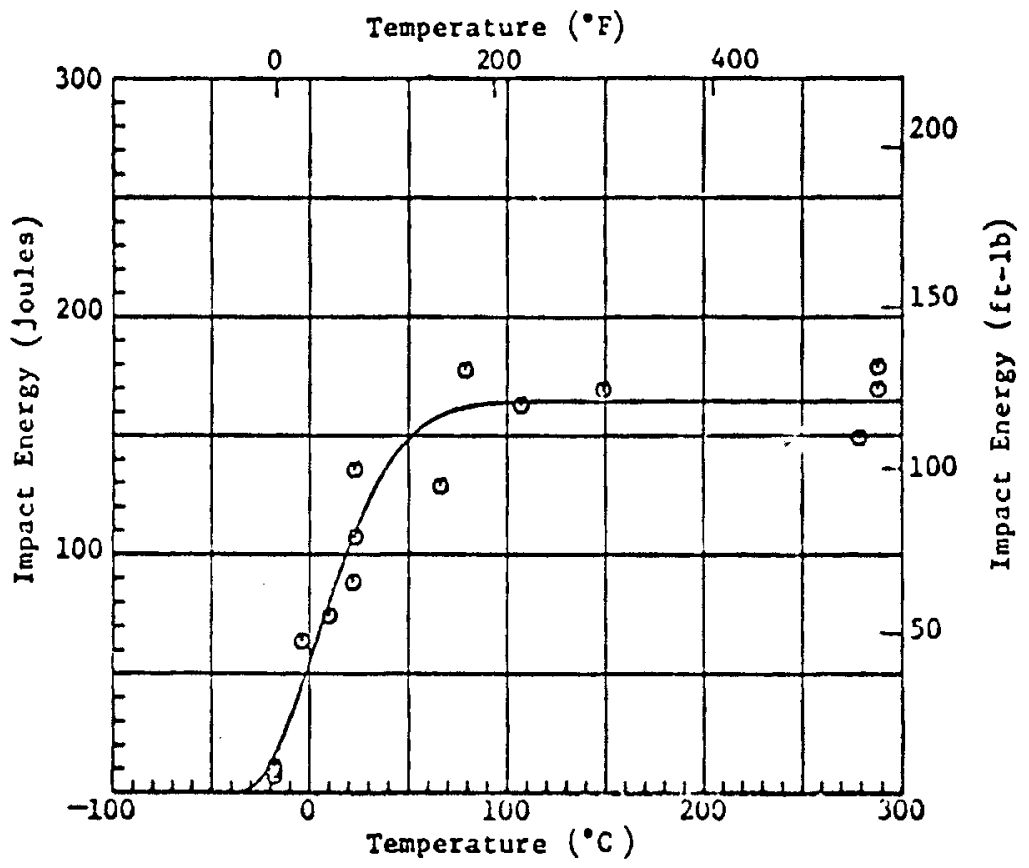

FIGURE 9.3.2-1. Fit of Equation (1) to Charpy V-Notch Impact Data for a Single Heat of Annealed 2 1/4 Cr-7Mo Steel(1)

TABLE 9.3.2-1. Chemical Composition of $21 / 4 \mathrm{Cr}$-1Mo Stee] Used in Impact and Fracture Mechanics Testing(2)

\begin{tabular}{|c|c|c|c|c|c|c|c|c|c|c|c|c|c|c|}
\hline $\begin{array}{l}\text { Melting } \\
\text { Process }\end{array}$ & Heat & & c & $M n$ & $\mathbf{P}$ & $s$ & $\mathbf{S i}$ & $\mathrm{Cr}$ & $\mathrm{Ni}$ & Mo & A1 & As & Sb & Sn \\
\hline \multirow{2}{*}{$A M$} & 86693 & Melt & 0.11 & 0.45 & 0.009 & 0.028 & 0.20 & 2.01 & - & 1.04 & - & - & - & - \\
\hline & & Check & 0.11 & 0.41 & 0.014 & 0.026 & 0.19 & 2.00 & 0.12 & 1.00 & $<0.005$ & 0.013 & 0.007 & 0.012 \\
\hline \multirow[t]{2}{*}{ VAR } & 55262 & Melt & 0.09 & 0.52 & 0.016 & 0.014 & 0.08 & 2.22 & - & 1.01 & - & - & - & - \\
\hline & & Check & 0.10 & 0.50 & 0.013 & 0.016 & 0.07 & 2.26 & 0.15 & 1.00 & $<0.005$ & 0.008 & $<0.002$ & 0.004 \\
\hline
\end{tabular}


TABLE 9.3.2-2. Material Conditions of $21 / 4 \mathrm{Cr}$-1Mo Steel Used in Impact and Fracture Mechanics Testing (2)

- A. Anneal (AM Heat 86693)

$927^{\circ} \mathrm{C}\left(1700^{\circ} \mathrm{F}\right)$ for 3 hours, furnace cool at maximum rate of $55.5^{\circ} \mathrm{C}\left(100^{\circ} \mathrm{F}\right)$ per hour to less than $482^{\circ} \mathrm{C}\left(900^{\circ} \mathrm{F}\right)$

B. Anneal + Post Weld Heat Treatment (PWHT) (AM Heat 86693)

$927^{\circ} \mathrm{C}\left(1700^{\circ} \mathrm{F}\right)$ for 3 hours, furnace cool at maximum rate of $55.5^{\circ} \mathrm{C}\left(100^{\circ} \mathrm{F}\right)$ per hour to less than $482^{\circ} \mathrm{C}\left(900^{\circ} \mathrm{F}\right)+727^{\circ} \mathrm{C}\left(1340^{\circ} \mathrm{F}\right)$ for 4 hours, air cool or furnace cool

C. Anneal + PWHT (VAR Heat 55262)

$927^{\circ} \mathrm{C}\left(1700^{\circ} \mathrm{F}\right)$ for 3 hours, furnace cool at maximum rate of $55.5^{\circ} \mathrm{C}\left(100^{\circ} \mathrm{F}\right)$ per hour to less than $482^{\circ} \mathrm{C}\left(900^{\circ} \mathrm{F}\right)+727^{\circ} \mathrm{C}\left(1340^{\circ} \mathrm{F}\right)$ for 4 hours, air cool

D. Anneal + PWHT + Embrittlement Treatment (AM Heat 86693)

$927^{\circ} \mathrm{C}\left(1700^{\circ} \mathrm{F}\right)$ for 3 hours, furnace cool at maximum rate of $55.5^{\circ} \mathrm{C}\left(100^{\circ} \mathrm{F}\right)$ per hour to less than $482^{\circ} \mathrm{C}\left(900^{\circ} \mathrm{F}\right)+727^{\circ} \mathrm{C}\left(1340^{\circ} \mathrm{F}\right)$ for 4 hours, air cool or furnace cool

$+510^{\circ} \mathrm{C}\left(950^{\circ} \mathrm{F}\right)$ for 1000 hours, air cool

E. Normalize + Temper (AM Heat 86693)

$927^{\circ} \mathrm{C}\left(1700^{\circ} \mathrm{F}\right)$ for 3 hours, air cool $+727^{\circ} \mathrm{C}\left(1340^{\circ} \mathrm{F}\right)$ for 4 hours, air cool

F. SMAW Weld Metal (AM Heat 86693)

$915^{\circ} \mathrm{C}\left(1680^{\circ} \mathrm{F}\right)$ for 3.5 hours, furnace cool at maximum rate of $55.5^{\circ} \mathrm{C}\left(100^{\circ} \mathrm{F}\right.$ per hour to less than $482^{\circ} \mathrm{C}\left(900^{\circ} \mathrm{Fi}+\operatorname{SMAW}\right.$ (see weld procedure)

$+727^{\circ} \mathrm{C}\left(1340^{\circ} \mathrm{F}\right)$ for 12 hours, furnace cool at maximum rate of $55.5^{\circ} \mathrm{C}\left(100^{\circ} \mathrm{F}\right)$ per hour

\section{G. SMAW Heat Affected Zone (HAZ) (AM Heat 86693)}

$915^{\circ} \mathrm{C}\left(1680^{\circ} \mathrm{F}\right)$ for 3.5 hours, furnace cool at maximum rate of $55.5^{\circ} \mathrm{C}\left(100^{\circ} \mathrm{F}\right)$ per hour to less than $482^{\circ} \mathrm{C}\left(900^{\circ} \mathrm{F}\right)+\operatorname{SMAW}$ (see weld procedure)

$+727^{\circ} \mathrm{C}\left(1340^{\circ} \mathrm{F}\right)$ for 12 hours, furnace cool at maximum rate of $55.5^{\circ} \mathrm{C}\left(100^{\circ} \mathrm{F}\right)$ per hour 
TABLE 9.3.2-3. Charpy V-Notch Data and P-3 Drop Weight Nil Ductility Transition (NDT) Data for $21 / 4 \mathrm{Cr}$-1Mo Steel(2)

Air-Melt $89 \mathrm{~mm}$ ( $3.5 \mathrm{in.}$ ) Thick Plate. Properties at 1/4 T Location. Rolling Ratio of 1.0.

Also, Transverse Results for VAR Heat $55262.51 \mathrm{~mm}(2 \mathrm{in.})$ Thick Plate.

\begin{tabular}{|c|c|c|c|c|c|c|c|c|c|c|}
\hline $\begin{array}{l}\text { Material } \\
\text { Condition }\end{array}$ & \multicolumn{2}{|c|}{$\begin{array}{l}68 \mathrm{~J} .(50 \mathrm{ft} \cdot \mid \mathrm{b}) \\
\frac{\text { Transition Temp. }}{\mathrm{C}\left({ }^{\circ} \mathrm{F}\right)}\end{array}$} & \multicolumn{2}{|c|}{$\begin{array}{l}0.89 \mathrm{~mm} \text { (35 mils) } \\
\text { Lateral Expansion } \\
\frac{\text { Transition Temp. }}{{ }^{\circ} \mathrm{C} \mathrm{(F)}}\end{array}$} & \multicolumn{2}{|c|}{$\begin{array}{c}50 \% \text { Fracture } \\
\text { Appearance } \\
\text { Transition Temp. } \\
{ }^{\circ} \mathrm{C} \quad\left({ }^{\circ} \mathrm{F}\right)\end{array}$} & \multicolumn{2}{|c|}{ NOT } & \multicolumn{2}{|c|}{$\begin{array}{c}\text { Reference } \\
\text { NDT } \\
\left(R T_{\text {NDT }}\right)^{a} \\
\end{array}$} \\
\hline A & 29 & (34) & 11 & (52) & 32 & (90) & -1 & (30) & -1 & (30) \\
\hline B & -10 & (14) & -13 & (8) & 19 & (66) & -1 & (30) & -1 & (30) \\
\hline$C\left(\right.$ VAR $^{b}$ & 18 & (64) & -4 & (25) & 29 & (85) & -7 & (20) & -7 & (20) \\
\hline$D$ & 36 & (96) & 14 & (58) & 30 & (86) & -7 & (20) & -7 & (20) \\
\hline E & 13 & (56) & 7 & (45) & 19 & (66) & -1 & (30) & -1 & (30) \\
\hline $\mathbf{F}$ & 7 & (45) & -8 & (18) & 8 & (46) & -1 & (30) & -1 & $(30)^{c}$ \\
\hline$\cdot \mathbf{G}$ & 15 & (59) & 0 & $(32)$ & -5 & (23) & & & -1 & $(30)^{c}$ \\
\hline
\end{tabular}

Dotermined according to ASME B\&PV Code, Section III, NE-23go.

${ }^{b}$ Bimodal fracture behavior at a given temperature resulted in a $33^{\circ} \mathrm{C}\left(59^{\circ} \mathrm{F}\right)$ wide transition scatter band; values in this teble are at the high temperature side of the scatter band. c Since Charpy transition values are similar to those of conditions $A-E$, assume that NDT is limiting and results in an RT NDT
of $-1{ }^{\circ} \mathrm{C}(30 \mathrm{~F})$.

\begin{tabular}{|c|c|c|c|c|c|c|c|c|c|c|}
\hline \multirow{2}{*}{$\begin{array}{c}\text { Material } \\
\text { Condition }\end{array}$} & \multicolumn{2}{|c|}{$93^{\circ} \mathrm{C}\left(200^{\circ} \mathrm{F}\right)$} & \multicolumn{2}{|c|}{$177^{\circ} \mathrm{C}\left(350^{\circ} \mathrm{F}\right)$} & \multicolumn{2}{|c|}{$288^{\circ} \mathrm{C}\left(550^{\circ} \mathrm{F}\right)$} & \multicolumn{2}{|c|}{$399^{\circ} \mathrm{C}\left(750^{\circ} \mathrm{F}\right)$} & \multicolumn{2}{|c|}{$510^{\circ} \mathrm{C}\left(950^{\circ} \mathrm{F}\right)$} \\
\hline & $\mathrm{J}$ & (ft-lb) & $\mathrm{J}$ & $(f t-1 b)$ & $\mathrm{J}$ & $|f t-| b \mid$ & $\mathrm{J}$ & $\overline{(f t-1 b)}$ & $J$ & $(f t-b)$ \\
\hline A & 118 & (87) & - & - & - & - & - & $\rightarrow$ & - & - \\
\hline$B$ & 193 & (142) & 195 & (144) & 193 & $(142)$ & 175 & (129) & 106 & (78) \\
\hline C & $>324$ & (239) & - & - & - & - & - & - & - & - \\
\hline D & 153 & (113) & 217 & $(160)$ & 217 & $(160)$ & 197 & (145) & - & - \\
\hline$E$ & 129 & (95) & - & - & - & - & - & - & - & - \\
\hline$F$ & 271 & (200) & 302 & (223) & 288 & (212) & 263 & (194) & 258 & (190) \\
\hline $\mathbf{G}$ & 95 & (70) & 95 & $(70)$ & 88 & $(65)$ & 75 & (55) & 57 & (42) \\
\hline
\end{tabular}

NOTE: Vaiues from CVN curves. All tabulated energy values correspond to $100 \%$ fibrous (ductile or shear) fracture appearance. 
9.3.2-6

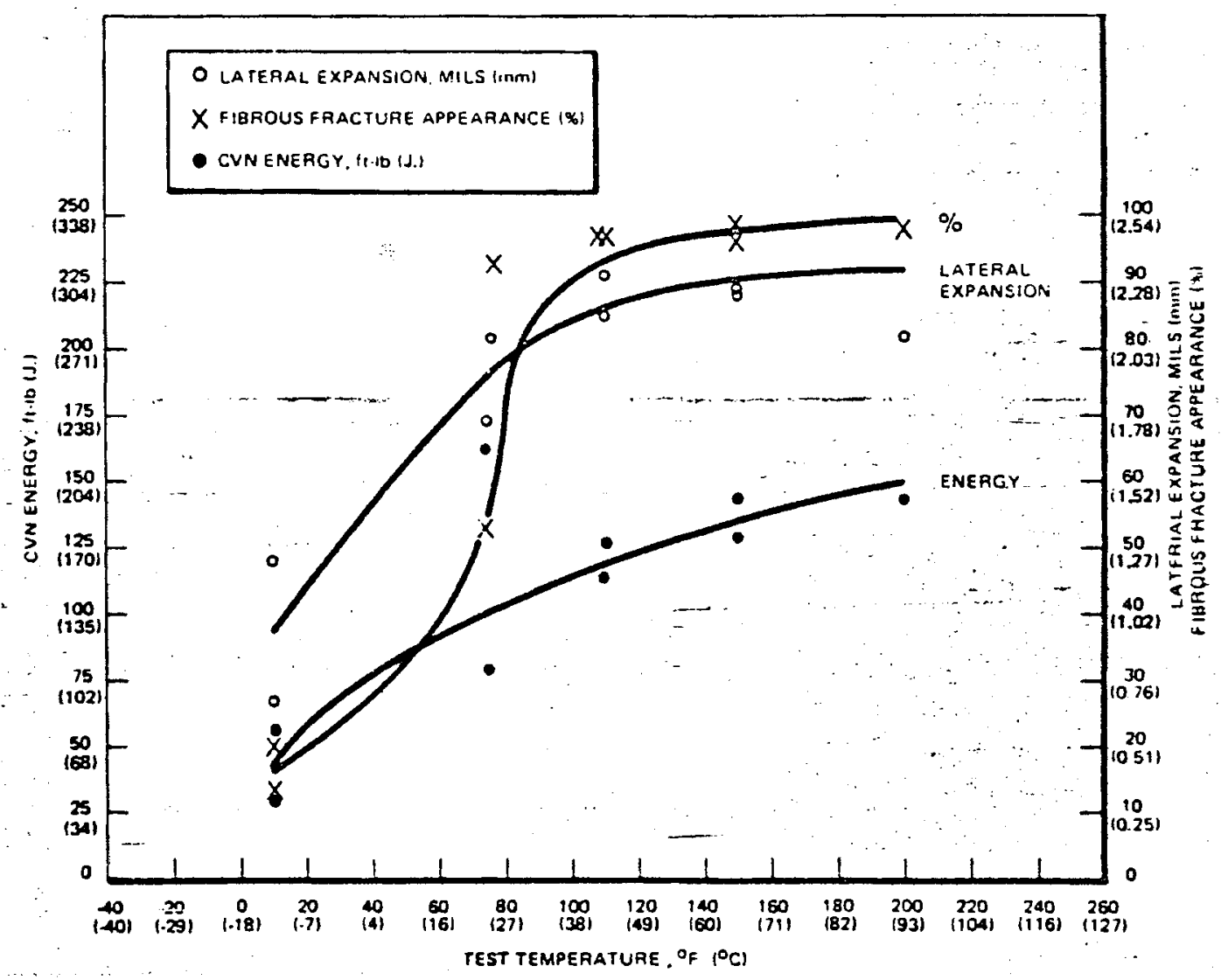

FIGURE 9.3.2-2. Charpy V-Notch Data for $21 / 4 \mathrm{Cr}$-1Mo Steel Given Treatment $\underline{B}$ (See Table 9.3.2-2)(3) 

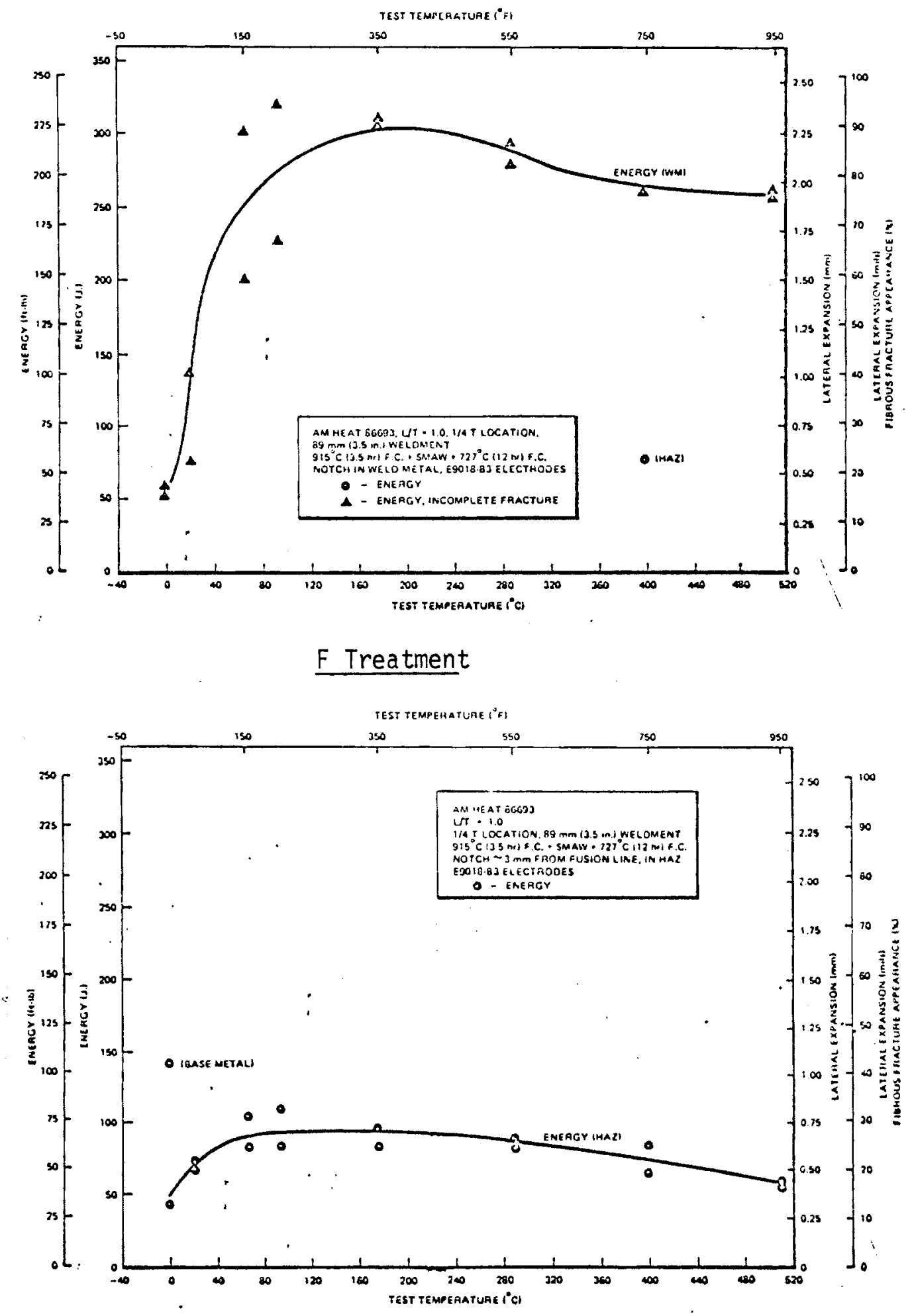

\section{G Treatment}

FIGURE 9.3.2-3. Charpy V-Notch Energy-Temperature Characteristics for $21 / 4 \mathrm{Cr}-1$ Mo Steel Given $\mathrm{F}$ and G Treatments
(See Table 9.3.2-2)(2) 
$9.3 \cdot 2-8$

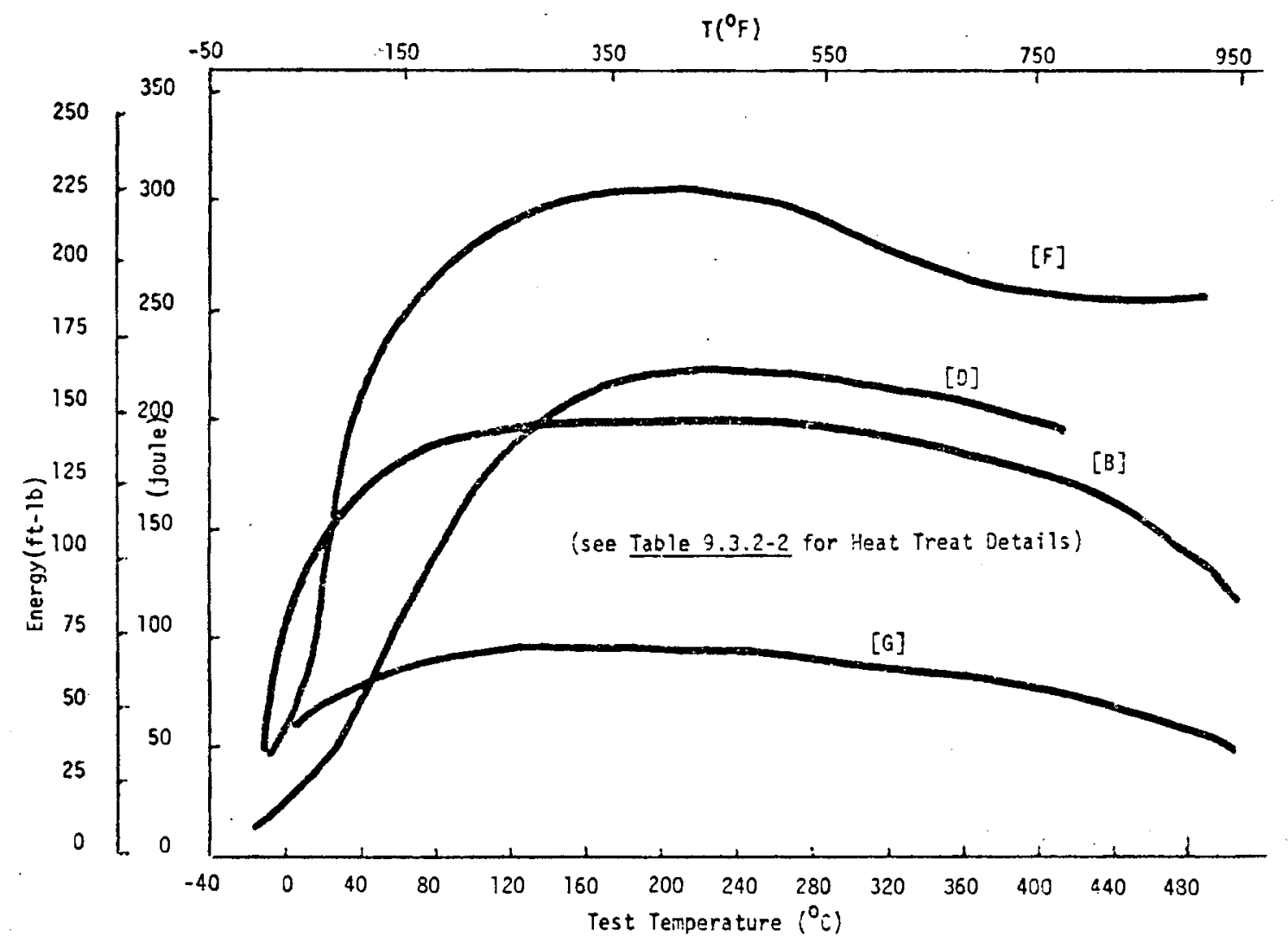

FIGURE 9.3.2-4. Summary of Impact Energy-Temperature Characteristics for 2 1/4 Cr-1Mo Steel Given Various Treatments $(2)$ 


\section{$9.3 .2-9$}

at temperatures above about $800^{\circ} \mathrm{F}$. Considering: the importance of welding to the construction of the steam generation system heat exchangers (evaporator and superheater); the fact that these data take no cognizance whatsoever of corrosion/mass transfer action from sodium and/or water/steam exposure that could adversely affect impact resistances (see Chapter 14, Volume II, of this report); the thermal treatments outlined in Table 9.3.2-2 involve only about 41 days in a thermally embrittling temperature range (condition ' $D$ ', Table 9.3.2-2), these impact data are not encouraging. No impact data have been noticed for $21 / 4 \mathrm{Cr}$-1Mo steel given static sodium exposures up to 26,500 hours by the MSA Research Corporation, ${ }^{(4)}$ some of which material was made available to ORNL for mechanical property testing. ${ }^{(5)}$ Shields and Longua ${ }^{(6)}$ reported on impact, tensile and fracture mechanics tests of $21 / 4 \mathrm{Cr}$-1Mo piping that had been exposed for about 90,000 hours in the EBR-II steam generation system. This piping section was exposed to superheated steam, over a temperature range of $304-438^{\circ} \mathrm{C}\left(580-820^{\circ} \mathrm{F}\right)$. Apparently the original material had been supplied in the quenched and tempered heat treat condition, but no archival material was available for the comparison with the in-service aged material. Metallurgical examination of the veteran material revealed that there was a fairly uniform dispersion of precipitated carbides as a result of this exposure. This structural change was manifested in somewhat lower tensile properties ( 23 and $5 \%$ reduction in yield and 41 timate strength, respectively) and somewhat increased toughness relative to expected value characteristics for similarly heat treated material. Figure 9.3.2-5 shows the Charpy $V$-notch energy-temperature characteristic obtained for this material using two different orientations (1ongitudinal and circumferential specimens). The extremely sharp transition region for the longitudinal specimens is noteworthy. On the basis of these Charpy tests, and pre-cracked fracture mechanics tests, these authors state that there was no significant embrittlement as a result of the EBR-II service. 


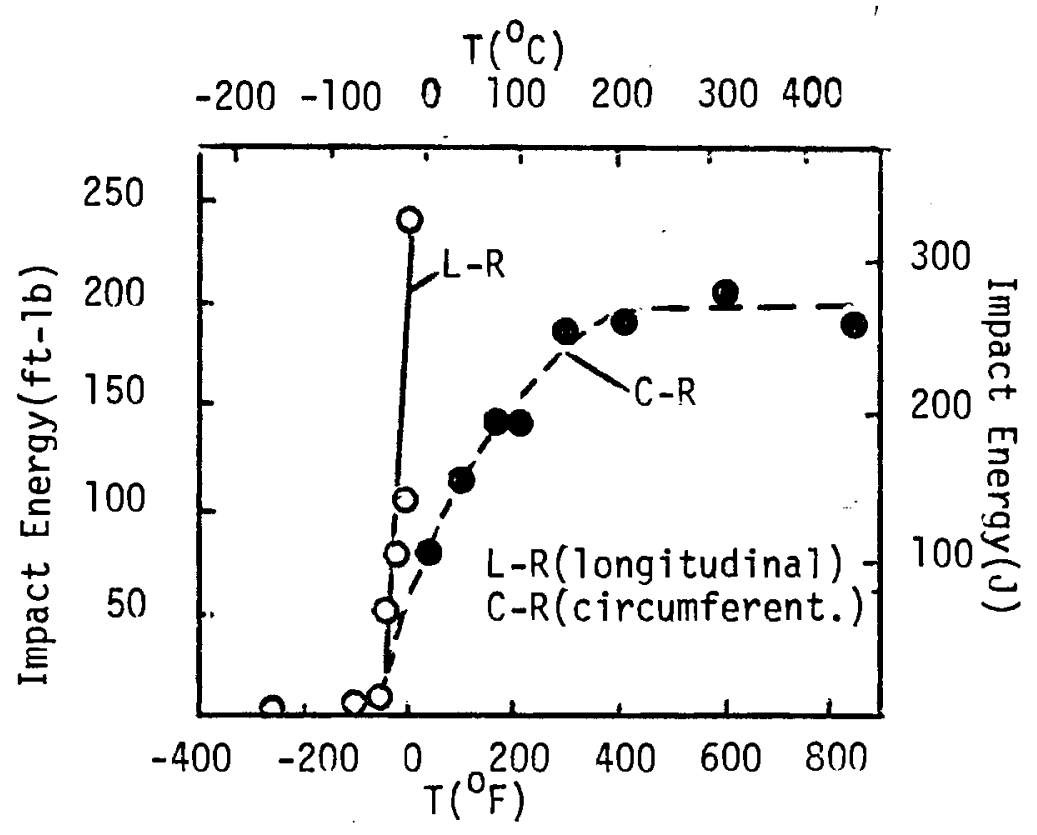

FIGURE 9.3.2-5. Charpy V-Notch Impact-Temperature Characteristic for EBR-II Exposed $21 / 4 \mathrm{Cr}$-1Mo Steel $(6)$

The interpretation of impact data in terms of resistance to the gamut of suddenly applied loads that are potential to the steam generation system components is a difficult problem of analysis. As with virtually all mechanical property data for $21 / 4 \mathrm{Cr}$-1Mo steel, the long-term working environmental influence is virtually unknown for impact resistance. Some considerations of the welding process for $21 / 4 \mathrm{Cr}$-1Mo steel that relate to toughness will be discussed briefly in Section 9.4 of this chapter. 
References for 9.3.2

1. M. K. Booker, T. L. Hebble, D. O. Hobson, and C. R. Brinkman, Mechanical Property Correlations for $21 / 4 \mathrm{Cr}-1$ Mo Steel in Support of NucTear Reactor System Design. ORNL/TM-5329, Oak Ridge National Laboratory, Oak Ridge, TN, June T976.

2. Steam Generator Materials Engineering. GEAP-14029-8, General Electric Co., Sunnyvale, CA, p. 9-7, July 1976.

3. Steam Generator Materials Engineering. GEAP-14029-6, General Electric Co., Sunnyvale, CA, p. 9-1, January 1976.

4. L. H. Kirschler, R. H. Hi Ttz, and S. J. Rodgers, Effect of High Temperature Sodium on the Mechanical Properties of Candidate Alloys for the LMFBR Program. MSAR 70-76, MSA Research Corp., Evans City, PA, May 1970.

5. Mechanical Properties Test Data for Structural Materials Quarterly Progress Report for Period Ending July 31, 1976. ORNL-5200, Oak Ridge National Laboratory, Oak Ridge, TN, p. 187.

6. J. A. Shields, Jr. and K. J. Longua, "The Effects of Ten Years Experimental Breeder Reactor II Service on 2 1/4 Cr-1Mo Steel." Nucl. Tech., Vol. 28(3), p. 471, 1976. 



\section{$9.3 .3-1$}

\subsubsection{Creep Properties}

The ability of a material to resist permanent deformation under essentially a constant stress state falls within the regime of creep properties. Generally, creep testing is done at a constant temperature and hold times range from a few to thousands of hours. Most service situations involve stress and temperate complexities somewhat beyond the scope of conventional creep testing, e.g., multiaxial stresses of periodic and aperiodic variable amplitude, variable temperature, variable constraints applied by contiguous structural members, simultaneous chemical and metallurgical changes caused by corrosion/mass transport by the ambient atmosphere(s) and by thermal aging phenomenon without corrosion intervention.

Considerable creep analys is has been done on the $21 / 4 \mathrm{Cr}$-1Mo steel, principally at temperatures and stresses substantially above working values of these parameters for the LMFBR steam generation system. Relatively high stress testing implies that the time frame for most of the creep-ruptuer data to date is short compared to the 10 to 30 year service life span of interest for LMFBR systems. This situation is indicated in Figure 9.3.3-1. The bulk of the current creep data apply to an air environment. Creep data reflecting even short exposure to either static or dynamic sodium are very sparce and no creep data have been noticed for material subjected to water/steam corrosion action. Thermal aging and decarburization will proceed simultaneously for sodium-side material of the steam generation system. Both of these processes (possibly interdependent to some extent) will have some adverse influence on long-term creep resistance. Some structural implications of long-term waterside corrosion of $21 / 4 \mathrm{Cr}$-1Mo steel are discussed in Chapter 14, Volume II, of this report. The current body of creep data for the $21 / 4 \mathrm{Cr}$-1Mo steel, and the prediction facility based on these data, make virtually no concession to corrosion/mass transport phenomena apart from some allowance for gross carbon loss. Some of the air data and analysis on the creep characteristics of $21 / 4 \mathrm{Cr}$-1Mo steel will be reviewed very briefly, followed by a short resume of recent data on the creep property effects of long-term thermal aging (helium exposure), long-term static sodium exposure, and short-term exposure to decarburizing sodium. 

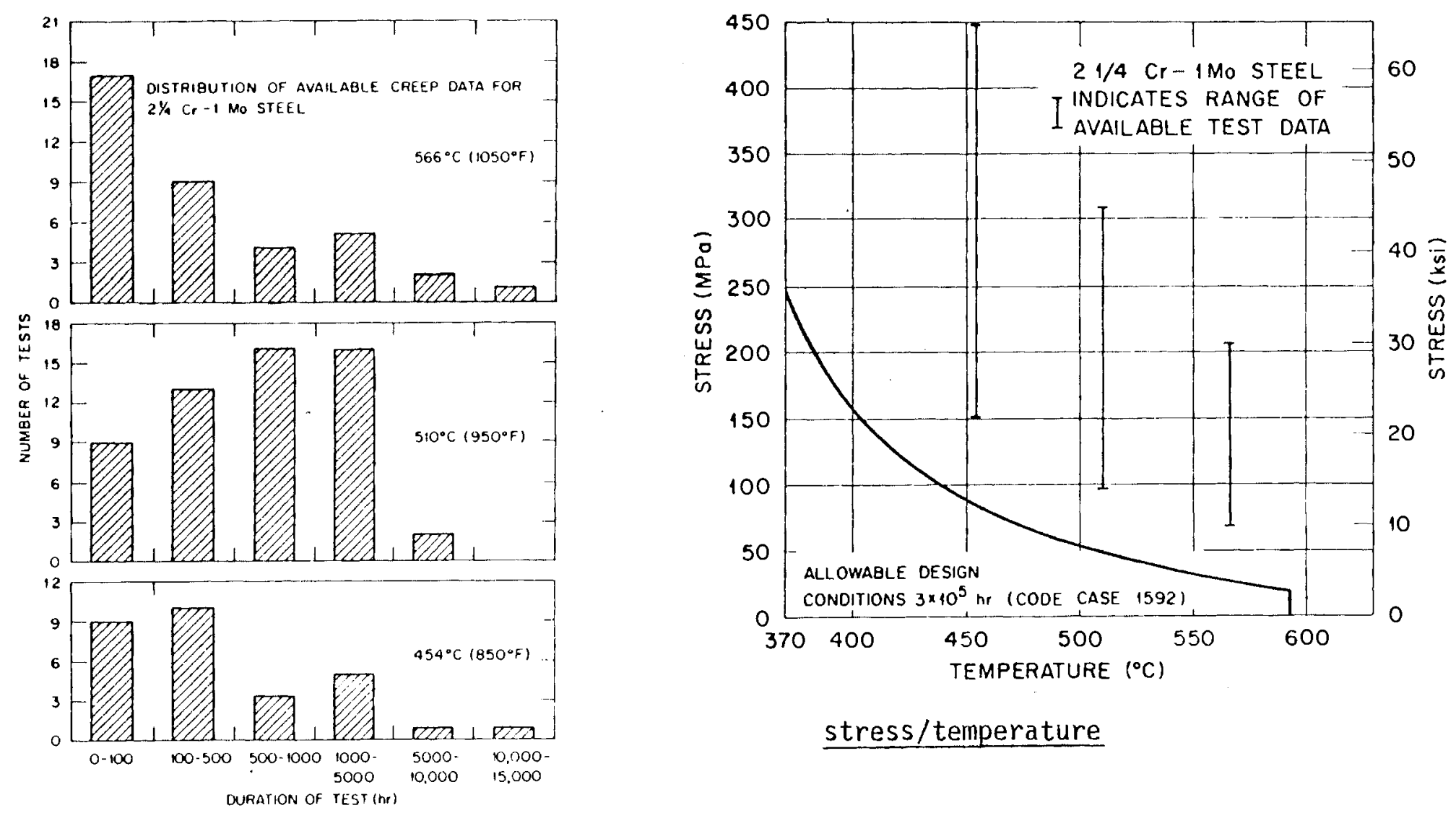

time/temperature

FIGURE 9.3.3-1. Time, Temperature and Stress Distribution of Creep Data for $21 / 4 \mathrm{Cr}$-1Mo Steel (1) 
ORNL analysis of the creep characteristics of the $21 / 4 \mathrm{Cr}$-1Mo steel has identified what is termed Type I and Type II creep behavior for this material. This is illustrated in Figure 9.3.3-2, where a 'classical' creep characteristic (A) is shown along with a typical $21 / 4 \mathrm{Cr}$-lMo characteristic at different scales $(B, C$, and $D)$. The 'Type I' regime follows the primary creep portion of the curve, and is the first linear portion. The 'Type II' regime is the second linear portion of the creep characteristic, with a substantially greater slope $(d(s t r a i n) / d t)$ than that for the Type I creep. The end of the Type II creep is the beginning of the tertiary creep regime, which culminates in creep rupture. Table 9.3.3-1 presents the chemistry and heat treatments pertaining to the test material used in the ORNL creep program.

Table 9.3.3-2 gives the polynomial equation developed by ORNL to describe the creep behavior of $21 / 4 \mathrm{Cr}-1$ Mo steel, together with instantaneous creep rate and initial creep rate expressions derived from the basic equation. This table also includes expressions developed by ORNL for the various parameters of the creep equation, for the Type I and the Type II regimes. It will be noticed that a number of these parameters are calculated using the ultimate tensile strength $(U)$ at room temperature. This expedient was found to be necessary to reduce the very substantial scatter in creep predictions resulting from batch-to-batch and heat treatment variations in creep properties, a variability that has been noted for other mechanical properties of $21 / 4 \mathrm{Cr}$-1Mo steel in previous sections of this chapter. Figure 9.3.3-3 is a schematic showing the analysis of a typical creep characteristic using the above creep equation. The use of several creep prediction techniques that do not take cognizance of this property variability is illustrated in Figure 9.3.3-4, where the Sterling ${ }^{(3)}$ and Hobson ${ }^{(4)}$ techniques are compared to the most recent ORNL technique described above. An example of creep property variability between two different heats of $21 / 4 \mathrm{Cr}$-1Mo steel, given two different heat treatments (see Table 9.3.3-1) is shown in Figure 9.3.3-5. The use of the room temperature UTS value for these materials enabled a good prediction of creep behavior for both materials, including the simulated welding heat treated specimen (B2) which displayed very poor creep resistance relative to the full annealed material (AN-1). 

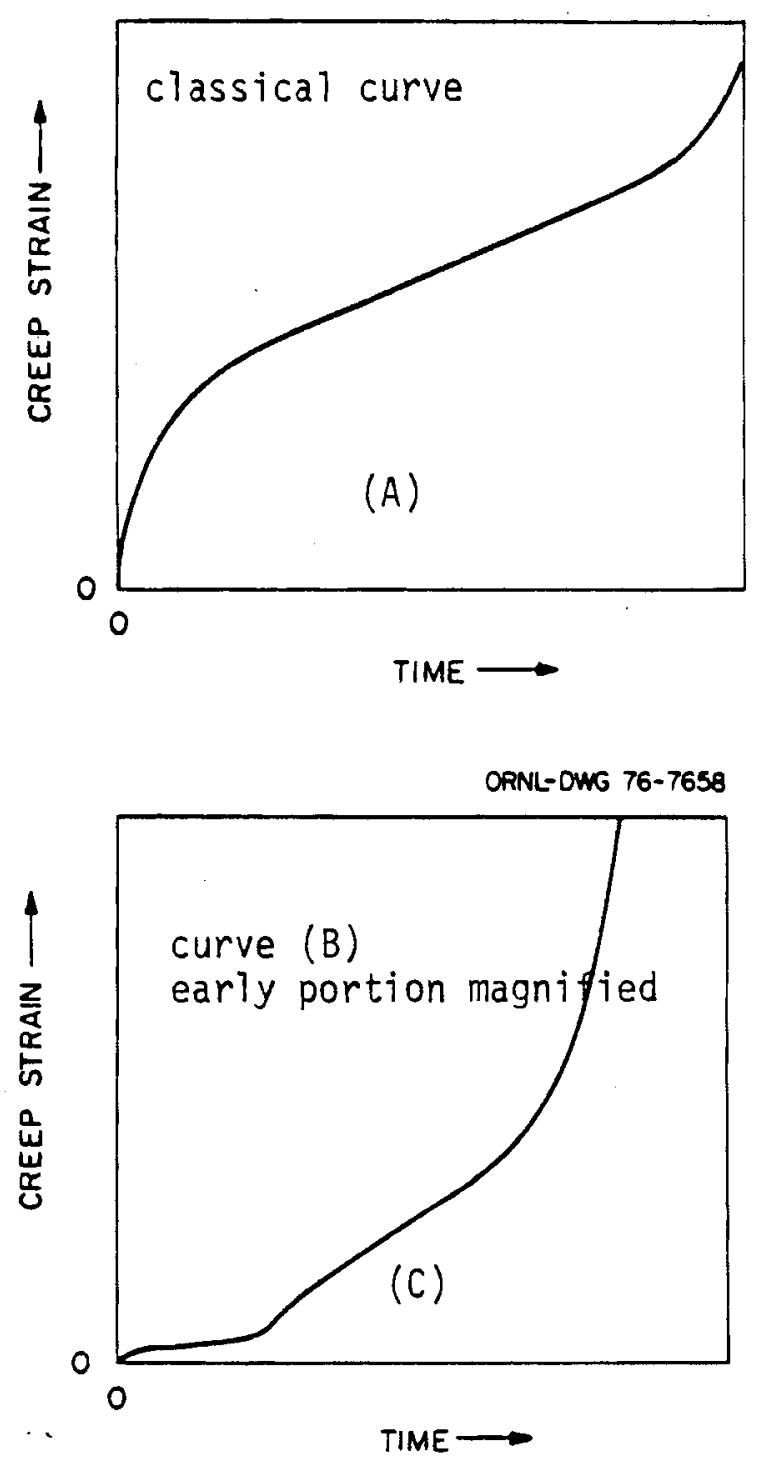
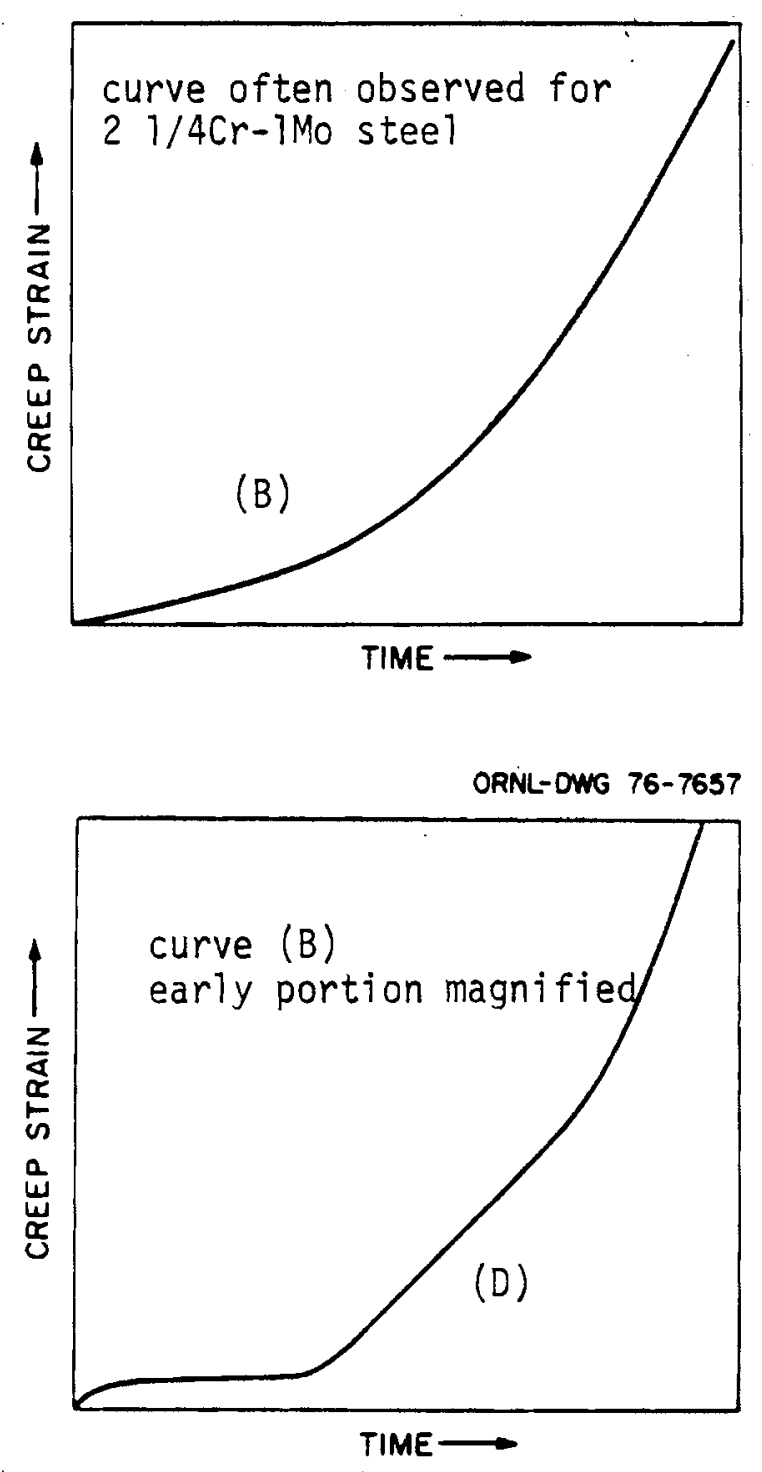

FIGURE 9.3.3-2. Schematics of Variqus Creep Characteristics Observed for 
TABLE 9.3.3-1. Chemistry and Heat Treatment for $21 / 4 \mathrm{Cr}$-1Mo Steel Used in ORNL Creep Program(1)

\begin{tabular}{|c|c|c|c|c|c|c|c|c|c|c|c|}
\hline \multirow{2}{*}{ Heat } & \multirow{2}{*}{ Source } & \multirow{2}{*}{$\begin{array}{l}\text { Melting } \\
\text { Practice }\end{array}$} & \multicolumn{9}{|c|}{ Content, $z$} \\
\hline & & & C & $M n$ & Si & $\mathrm{Cr}_{\mathrm{r}}$ & Mo & N1 & $\mathrm{S}$ & $\mathbf{P}$ & $\mathbf{N}$ \\
\hline 20017 & ORNL & Air & 0.135 & 0.57 & 0.37 & 2.2 & 0.92 & 0.16 & 0.016 & 0.012 & \\
\hline 91505 & GE & ESR & 0.087 & 0.47 & 0.26 & 2.31 & 0.99 & 0.05 & 0.003 & 0.007 & 0.008 \\
\hline R0110 & GE & ESR & 0.1 & 0.5 & 0.18 & 2.26 & 0.99 & 0.15 & 0.007 & 0.013 & 0.008 \\
\hline 91506 & $G E$ & VAR & 0.102 & 0.42 & 0.32 & 2.32 & 1.0 & 0.06 & 0.008 & 0.007 & 0.009 \\
\hline 55262 & $\mathrm{GE}$ & VAR & 0.099 & 0.5 & 0.07 & 2.26 & 1.0 & 0.15 & 0.016 & 0.013 & 0.008 \\
\hline
\end{tabular}

Heat Treatments Used on $21 / 4 \mathrm{Cr}-1$ Mo Steel

Heat $20017^{\mathrm{a}}$

AN-1: Austenitize 1 hr at $927^{\circ} \mathrm{C}\left(1700^{\circ} \mathrm{F}\right)$; furnace cool.

AN-2: Austenitize 1 hr at $927^{\circ} \mathrm{C}$; furnace cool (faster than AN-1).

IA: Austenitize 1 hr at $927^{\circ} \mathrm{C}$; furnace cool at about $83^{\circ} \mathrm{C} / \mathrm{hr}\left(150^{\circ} \mathrm{F} / \mathrm{hr}\right)$ to $704^{\circ} \mathrm{C}\left(1400^{\circ} \mathrm{F}\right)$; hold $2 \mathrm{hr}$; furnace cool.

Heats R0110 and 55262

A. Isothermal Anneal: $954^{\circ} \mathrm{C}\left(1750^{\circ} \mathrm{F}\right)$ for $0.5 \mathrm{hr}$.

Furnace cool to $710^{\circ} \mathrm{C}\left(1310^{\circ} \mathrm{F}\right)$; hold $2.5 \mathrm{hr}$.

Air cool to room temperature.

Postweld: $727^{\circ} \mathrm{C}\left(1340^{\circ} \mathrm{F}\right)$ for $4 \mathrm{hr}$.

(PWHT) Air cool to room temperature.

B. Anneal:

$916^{\circ} \mathrm{C}\left(1680^{\circ} \mathrm{F}\right)$ for $1.25 \mathrm{hr}$.

Furnace cool [at $27.7-55.6^{\circ} \mathrm{C} / \mathrm{hr}\left(50-100^{\circ} \mathrm{F} / \mathrm{hr}\right)$

to $\left.316^{\circ} \mathrm{C}\left(600^{\circ} \mathrm{F}\right)\right]$

Air cool to room temperature.

Postweld: $727^{\circ} \mathrm{C}\left(1340^{\circ} \mathrm{F}\right)$ for $4 \mathrm{hr}$.

Air cool to room temperature.

D. (Same as B without postweld)

Heats 91505 and 91506

D: Austenitize 1 hr at $927^{\circ} \mathrm{C}$; furnace $\operatorname{coo} 1$ to $316^{\circ} \mathrm{C}$ at $56^{\circ} \mathrm{C} / \mathrm{hr}$ max.

B2: Same as D plus postweld, $4 \mathrm{hr}, 727^{\circ} \mathrm{C}\left(1340^{\circ} \mathrm{F}\right)$.

$\mathrm{M}$ : Austenitize $0.5 \mathrm{hr} 927^{\circ} \mathrm{C}$; furnace cool to $704^{\circ} \mathrm{C}$ at $125^{\circ} \mathrm{C} / \mathrm{hr} \max$; hold $1.5 \mathrm{hr}$.

A2: Same as $\mathrm{M}$ plus postweld, $4 \mathrm{hr}, 727^{\circ} \mathrm{C}$. 
TABLE 9.3.3-2. ORNL Creep Equation for $21 / 4 \mathrm{Cr}$-1Mo Steel; Derived Characteristics; Expressions for Various Creep Equation Parameters $(7)$
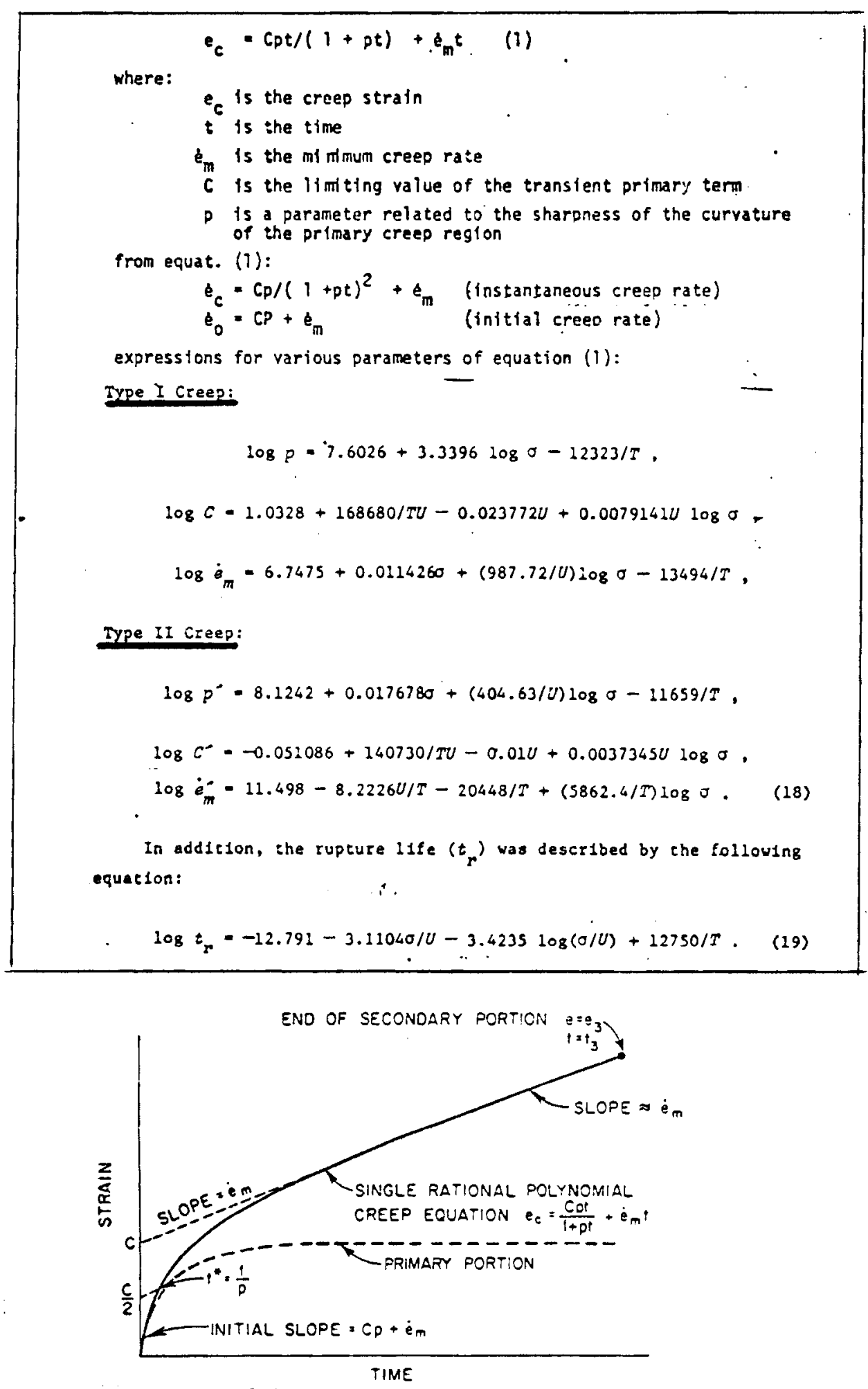

FIGURE 9.3.3-3. Schematic Showing Anatysis of Creep Characteristic by Above Equation $(1)$ 


\section{$9.3 \cdot 3-7$}
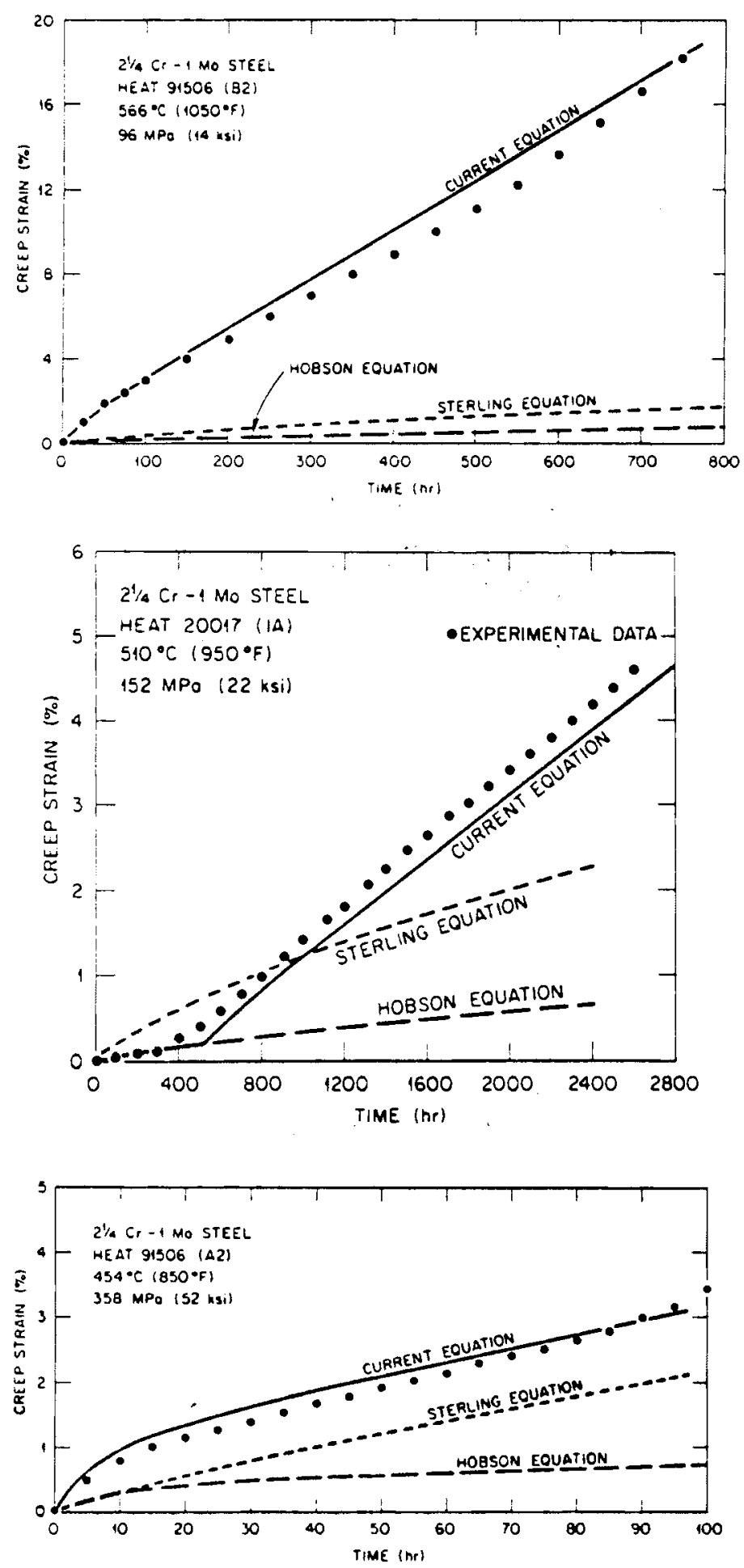

FIGURE 9.3.3-4. Comparison of Creep Predictions Using Current ORNL Equation, Sterling and Hobson Equations(1) 


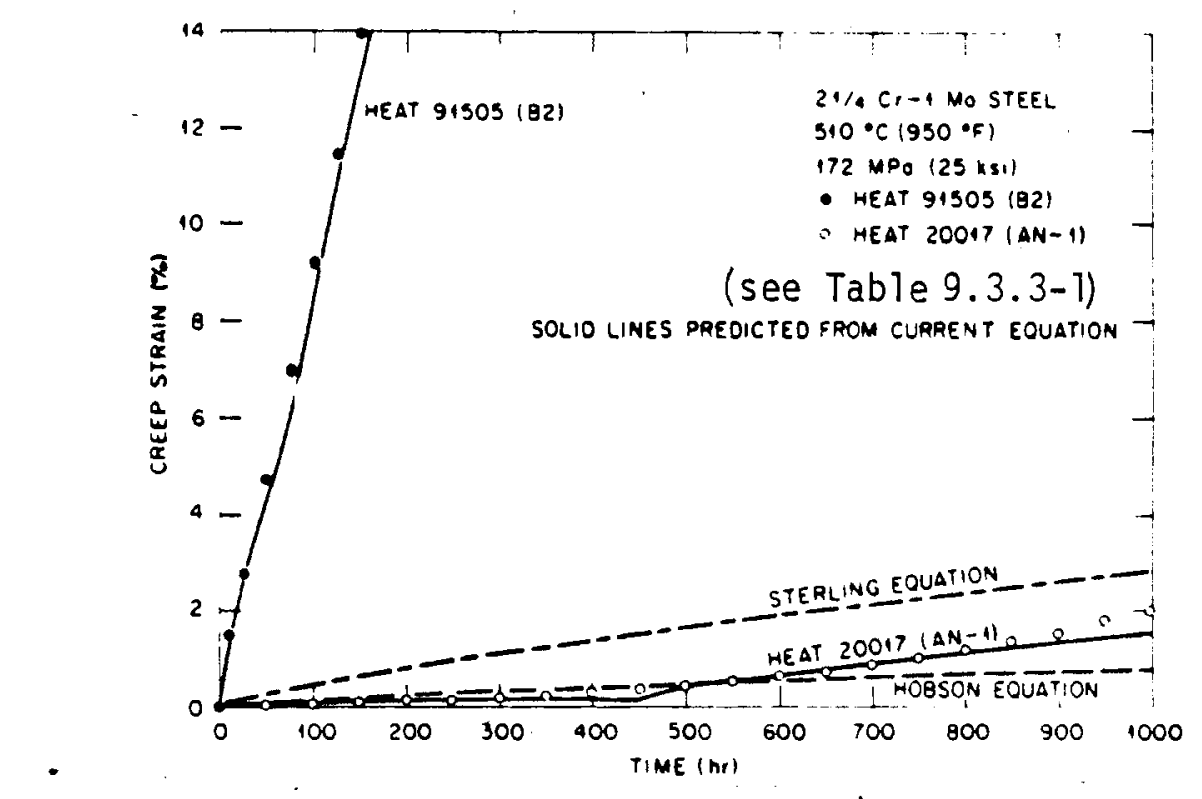

FIGURE 9.3.3-5. Variation of Creep Properties Between Two Heats of 2 1/4 Cr-jMo Steel; Comparison of Creep Predictions $(1)$

Various criteria for the time dependent maximum allowable stress $\left(S_{t}\right)$ are given in Table 9.3.3-3, together with values of these criteria calculated for $21 / 4 \mathrm{Cr}$-1Mo steel using the ORNL technique described above, the ASME Code Case 1592, and results from Booker, et al. ${ }^{(4)}$ The $S_{t}$ values for three temperature levels (lowest stress among the several criterla) are given at the bottom of the table. The practical significance of such data for LMFBR design purposes cannot be assessed without substantially more information on long-term thermal aging effects and on the general environmental (sodium-side and water-side) influence on the strength and ductility properties of the $21 / 4 \mathrm{Cr}$-1Mo steel. Even without corrosion/mass transport intervention, the complexity of the mechanical property analysis when cognizance is taken of variable stress and temperature conditions and fatigue superposition is indicated by a report by Pugh, et al. (5) 
TABLE 9.3.3-3. Predicted Values of Various Design Stresses $(1)$

\begin{tabular}{|c|c|c|c|}
\hline \multirow{2}{*}{ Stress Predicted } & \multicolumn{3}{|c|}{ Value, MPa (ksi), at each Temperature ${ }^{\star \star}$} \\
\hline & $454^{\circ} \mathrm{C}\left(850^{\circ} \mathrm{F}\right)$ & $510^{\circ} \mathrm{C}\left(950^{\circ} \mathrm{F}\right)$ & $566^{\circ} \mathrm{C}\left(1050^{\circ} \mathrm{F}\right)$ \\
\hline \multicolumn{4}{|c|}{ From ASME Code Case 1592} \\
\hline$S_{r}$, Minimum to rupture & $145(21.0)$ & $87(12.6)$ & $48(7.0)$ \\
\hline Allowable time-dependent & $97(14.0)$ & $58(8.4)$ & $32(4.7)$ \\
\hline \multicolumn{4}{|c|}{ From Booker et al. (4) } \\
\hline$S_{r}$, Minimum to rupture & $134(19.5)$ & $74(10.8)$ & $41(5.9)$ \\
\hline Average to rupture & $180(26.1)$ & $99(14.4)$ & $56(8.1)$ \\
\hline Allowable time-dependent ${ }^{a}$ & $90(13.0)$ & $50(7.2)$ & $27(3.9)$ \\
\hline \multicolumn{4}{|c|}{ From Current Analysis } \\
\hline Average to $1 \%$ strain & $162(23.5)$ & $72(10.4)$ & $37(5.4)$ \\
\hline$S_{1} \%$, Minimum to $1 \%$ strain & $94(13.6)$ & $50(7.2)$ & $27(4.0)$ \\
\hline Average to tertiary creep & $156(22.6)$ & $84(12.2)$ & $41(5.9)$ \\
\hline$S_{3}$, Minimum to tertiary & $121(17.5)$ & $63(9.2)$ & $28(4.1)$ \\
\hline $0.8 S_{3}$ & $97(14.0)$ & $51(7.4)$ & $23(3.3)$ \\
\hline Average to rupture & $169(24.5)$ & $93(13.5)$ & $46(6.7)$ \\
\hline$S_{p}$, Minimum to rupture & $131(19.0)$ & $70(10.2)$ & $32(4.7)$ \\
\hline$(2 / 3) S_{p}$ & $88(12.7)$ & $47(6.8)$ & $21(3.1)$ \\
\hline$S_{t}$, Allowable time-dependent ${ }^{b}$ & $88(12.7)$ & $47(6.8)$ & $21(3.1)$ \\
\hline
\end{tabular}


Conclusions given by $\mathrm{ORNL}(1)$ on the basis of the air environment creep analysis of $21 / 4 \mathrm{Cr}$-lMo steel made to date may be paraphrased as follows:

- creep strength variations of $21 / 4 \mathrm{Cr}$-1Mo steel can be very large, especially when post-weld heat treatment is used; recognition of the UTS (RT) property in the creep prediction equation has enabled good prediction capability;

- $21 / 4 \mathrm{Cr}$-1Mo steel has a strong tendency to show nonclassical creep behavior, described by a so-called Type I creep behavior, succeeded by a Type II behavior; much more information is needed about the metallurgical factors that affect the creep behavior of $21 / 4 \mathrm{Cr}-1$ Mo steel, particularly the influence - of long-term thermal aging and environmental influence;

- simulated post-weld heat treated material can be significantly weaker than predicted by the Sterling, or Hobson equations; as a result, average isochronous stress-strain curves given in ASME Code Case 1592 significantiy overestimate the creep strength of this material;

- predictions from the current analysis (above) indicate that $S_{t}$ values given in Code Case 1592 may not be conservative for post-weld heat treated material; it is suggested that the Code introduce some measure of heat treatment effects;

Figure 9.3.3-6 shows some creep data obtained from material that had seen about 10 years of industrial exposure prior to creep testing (Norris, et al.) and from material that had been given an exposure of 26,500 hours ( $\sim 3$ years) to static helium (thermal aging). The latter data (Klueh), exhibit a particularly large deviation from the expected value band established for $21 / 4 \mathrm{Cr}-1$ Mo steel without prior thermal aging. Table 9.3.3-4 gives the helium aged creep data plotted in Figure 9.3.3-6, together with static sodium aged material, given the same exposure time and temperature as for the helium aged material $\left(26,500\right.$ hours, $\left.566^{\circ} \mathrm{C}\right)$. The decarburized 


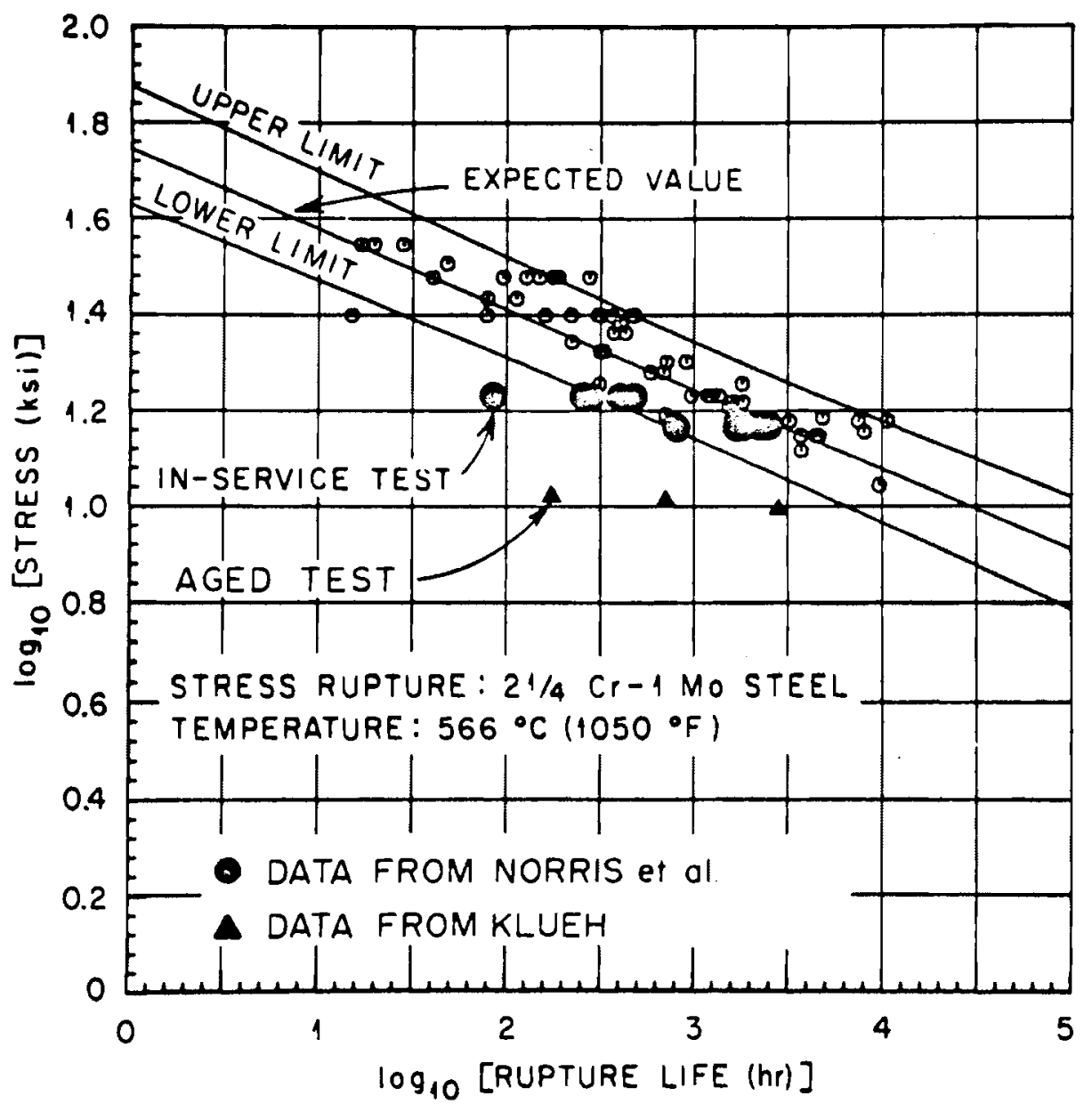

Comparison of Expected Rupture Life from Analytical Model with Data Used In Formulating Model at $566^{\circ} \mathrm{C}\left(1050^{\circ} \mathrm{F}\right)$. Upper and lower tolerance levels are also given. Data from post-elevated temperature service and aging are also superimposed to show influence of pretest thermal aging. ONorris, E. B., Schnabel, G. J., and Wylle, R. D., "Properties of Cr-Mo P1ping Materials After Service at $1000^{\circ} \mathrm{F}-1050^{\circ} \mathrm{F}$," Intermational Conference on Creep and Fatigue in Elevated Temperature Applications, Philadelphia, Sept. 1973 and Sheffield UK April 1974, Institution of Mechanlcal Englneers Conference, Publication 13, 1973, Pp. 227.1-227.7. AKlueh, R. L., Creep Rupture Properties of Decarbumized and Aged 2 1/4 Cr-1 Mo Steel, ORNL Report (to be published).

FIGURE 9.3.3-6. Comparison of Creep Characteristics of $21 / 4 \mathrm{Cr}$-1Mo Steel-Expected Value Band for Unaged Material; In-Service Aged and Helium Aged Material (1) 
TABLE 9.3.3-4. Creep-Rupture Properties of $21 / 4 \mathrm{Cr}$-1Mo Steel After Helium and Static Sodium Aging at $566^{\circ} \mathrm{C} / 26,500 \mathrm{Hr}(7)$

\begin{tabular}{|c|c|c|c|c|c|c|c|}
\hline \multicolumn{2}{|c|}{$\begin{array}{c}\text { Test } \\
\text { Temperature }\end{array}$} & \multicolumn{2}{|c|}{ Stress } & \multirow{2}{*}{$\begin{array}{l}\text { Rupture } \\
\text { Life } \\
\text { (hr) }\end{array}$} & \multirow{2}{*}{$\begin{array}{c}\text { Elongation } \\
(\%)\end{array}$} & \multirow{2}{*}{$\begin{array}{l}\text { Reduction } \\
\text { of Area } \\
(\%)\end{array}$} & \multirow{2}{*}{$\begin{array}{l}\text { Minimum } \\
\text { Creep Rare } \\
(\% / \mathrm{hr})\end{array}$} \\
\hline$\left({ }^{\circ} \mathrm{C}\right)$ & $\left({ }^{\bullet} \vec{F}\right)$ & (MPa) & (ksi) & & & & \\
\hline & & \multicolumn{6}{|c|}{ Decarburized (SODIUM) } \\
\hline \multirow[t]{4}{*}{566} & 1050 & 138 & 20.0 & 10.0 & 56.7 & 54.4 & 2.44 \\
\hline & & 103 & 15.0 & 114.0 & 76.8 & 62.4 & 0.24 \\
\hline & & 83 & 12.0 & 395.5 & 79.8 & 66.7 & 0.0817 \\
\hline & & 69 & 10.0 & 1517.5 & 64.0 & 53.2 & 0.0184 \\
\hline \multirow[t]{4}{*}{510} & 950 & 172 & 25.0 & 26.5 & 66.3 & 53.3 & 1.07 \\
\hline & & 138 & 20,0 & 190.9 & 77.5 & 1.0 & 0.199 \\
\hline & & 121 & 17.5 & 463.2 & 76.0 & 74.7 & 0.0646 \\
\hline & & \multicolumn{6}{|c|}{ Aged (HEL IUM) } \\
\hline \multirow[t]{3}{*}{566} & 1050 & $\cdot 102$ & 15.0 & 158.0 & 90.5 & 64.5 & 0.202 \\
\hline & & 83 & 12.0 & 692.0 & 108.5 & 62.3 & 0.0475 \\
\hline & & 69 & 10.0 & 2940.1 & 67.0 & 46.3 & 0.0109 \\
\hline
\end{tabular}

(sodium exposed) material was creep tested at $566^{\circ} \mathrm{C}$ and $510^{\circ} \mathrm{C}$, while only $566^{\circ} \mathrm{C}$ data are reported for the helium aged material. At the common temperature $\left(566^{\circ} \mathrm{C}\right)$, the sodium exposed material displays a rupture life inferiority relative to the helium exposed material, particularly at the two lowest stress levels reported (10 and $12 \mathrm{ksi}$ ). Minimum creep rate data for the two lowest stress levels are roughly a factor of 2 larger for the sodium aged material. Lower stress (longer rupture time) tests are in progress to give a more comprehensive picture of sodium aging effects.

Table 9.3.3-5 presents some creep data from the GEAP program on $21 / 4 \mathrm{Cr}$-1Mo steel. ${ }^{(8)}$ These data were obtained with biaxial creep specimens (pressurized, axially loaded, specimens). The results of short-term (up to 100 hour) exposure to sodium, prior to the creep testing, are given. The rupture time is, as noted, inversely proportional to the sodium exposure. 
TABLE 9.3.3-5. Biaxial Creep-Rypture Data for $21 / 4 \mathrm{Cr}$-1Mo Steel After Sodium Exposure(8)

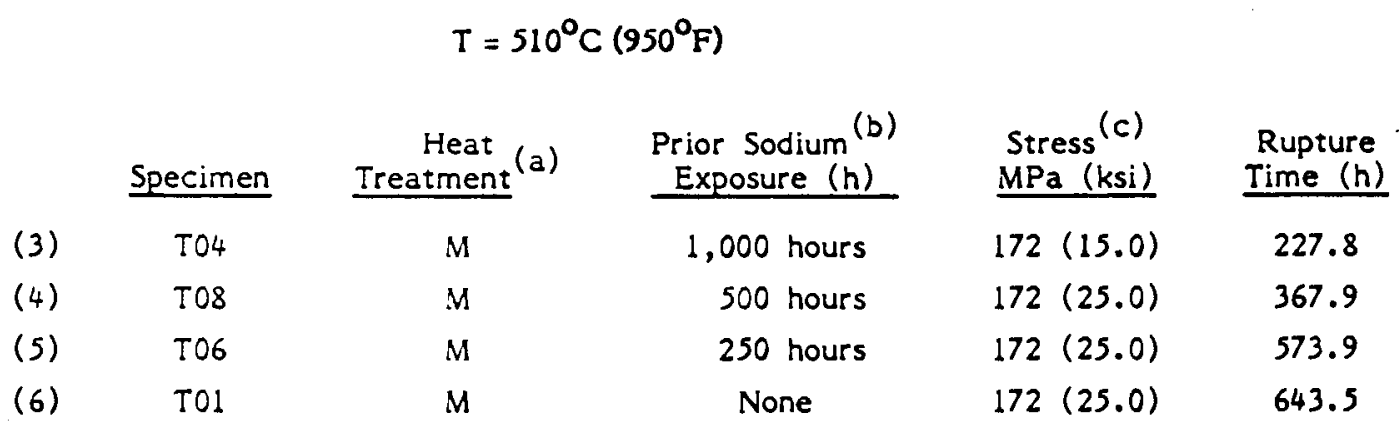

NOTES: (a) Heat Treatment $M$ is a simulated CRBR isothermal anneal with no post-weld heat treatment. The details of this heat treatment are outlined in Table 9.3.1-1

(b) Specimens were preexposed to titanium-gettered sodium at $510^{\circ} \mathrm{C}\left(950^{\circ} \mathrm{F}\right)$ for the indicated times, prior to pressurization.

(c) The test stress is an equivalent stress, calculated from the thin cylinder approximation.

$$
\sigma_{E}=0.866 \frac{\overline{P r}}{t}
$$

where $P$ is the pressure, $\vec{r}$ is the mean radius of the pressure pin, and $t$ is the wall thickness.

The authors attribute this effect more to thermal aging $\left(510^{\circ} \mathrm{C}\right)$ than to sodium action. It is interesting that, even within the short span of 1000 hours, sodium exposure (and/or thermal aging) has effected a reduction in rupture life by a factor of 0.35 . The GEAP creep program will include in-sodium creep testing. Preliminary creep data for $21 / 4 \mathrm{Cr}$-1Mo steel reported by GEAP, ${ }^{(8)}$ confirm the strong sensitivity of creep behavior to heat treatment observed in the ORNL program. (1) The GEAP results indicate that the temperature range for creep significant thermal aging extends down to a temperature $\leq 950^{\circ} \mathrm{F}\left(510^{\circ} \mathrm{C}\right)$. 
References for 9.3 .3

1. Mechanical Properties Test Data for Structural Materials Quarterly Progress Report for Period Ending January 31, 1977. ORNL-5255, Oak Ridge National Laboratory, Oak Ridge, TN, p. 139, March 1977.

2. R. L. Klueh, Creep and Rupture Behavior of Annealed $21 / 4 \mathrm{Cr}$-1Mo Steel. ORNL-5219, Oak Ridge National Laboratory, Oak Ridge, TN, December 1976.

3. S. A. Sterling, A Temperature-Dependent Power Law for Monotonic Creep. GA-A13027 (Rev.), General Atomics, San Diego, CA, June 1974, (Revised March 1976).

4. M. K. Booker, T. L. Hebble, D. 0. Hobson, and C. R. Brinkman, Mechanical Property Correlations for $21 / 4 \mathrm{Cr}$-1Mo Steel in Support of Nuclear Reactor Systems Design. ORNL/TM-5329, Oak Ridge Nationa] Laboratory, Oak Ridge, TN, June 1976.

5. C. E. Pugh, et al., Background Information for Interim Methods of Inelastic Analys is for High-Temperature Reactor Components of $2 \mathrm{~T} / 4 \mathrm{Cr}$-1Mo Steel. ORNL/TM-5226, Oak Ridge National Laboratory, Oak Ridge, TN, May 1976.

6. C. R. Brinkman, W. R. Corwin, M. K. Booker, T. L. Hebble, and R. L. Klueh, Time Dependent Mechanical Properties of $21 / 4 \mathrm{Cr}$-1Mo Steel for Use in Steam Generator Design. ORNL-5125, Oak Ridge National Laboratory, Oak Ridge, TN, March 1976.

7. Mechanical Properties Test Data for Structural Materials Quarterly Progress Report for Period Ending October 31, 1976. ORNL-5237, Oak Ridge Nationa7 Laboratory, Oak Ridge, TN, p. 197, December 1976.

8. Steam Generator Materials Engineering; October-December, 1976. GEAP-14029-10, General Electric Co., Sunnyvale, CA, p. 3-1, January 1977. 


\subsubsection{Fatigue}

In proposed applications for the ferritic $21 / 4 \mathrm{Cr}$-1Mo steel in the heat exchangers of the LMFBR steam generation system, fatigue due to cyclic loading can result from a number of operational factors, including: vibrations imposed by the sodium and water/steam streams, departure from nucleate boiling in the evaporator component, thermal stresses from the overall system operation and from shutdown-startup sequences. Corrosion fatigue becomes operative whenever the various corrosion processes affecting this material (see Chapter 14, Volume II, of this report) are active simultaneous with the fatigue loading.

Figure 9.3.4-1 presents some fatigue data reported recently by Booker, et al. (1) for the $21 / 4 \mathrm{Cr}$-1Mo steel, over the temperature range RT to $593^{\circ} \mathrm{C}\left(1100^{\circ} \mathrm{F}\right)$. Continuous cycling/fatigue tests can be described by the so-called low cycle and high cycle regimes, where the former is strain controlled and the latter stress controlled (primarily elastic strains). Usually, full reversed cycling is involved. Total strain range can be partitioned into elastic and plastic components. When the elastic $\left(\Delta \mathrm{e}_{\mathrm{e}}\right)$ and plastic $\left(\Delta e_{p}\right)$ strains are plotted against cycles to failure $\left(N_{f}\right)$ on a $\log -\log$ basis, linear characteristics usually result, in accordance with the Coffin-M anson fatigue law (referring to the plastic component):

$$
\Delta e_{p}=A N_{f}^{-B} \text {, where } A \text { and } B \text { are constants. }
$$

Figure 9.3.4-2 gives a typical plot showing the above characteristics. The cyclic transition life $\left(N_{t r}\right)$ is defined as the point where the plastic and elastic strain ranges of the total strain are equal. This point generally shifts toward lower cyclic life values with increasing temperature and is usually close to the point where the plastic strain- $N_{f}$ characteristic exhibits a change in slope (the bilinear break point). 


\section{$9 \cdot 3 \cdot 4-2$}
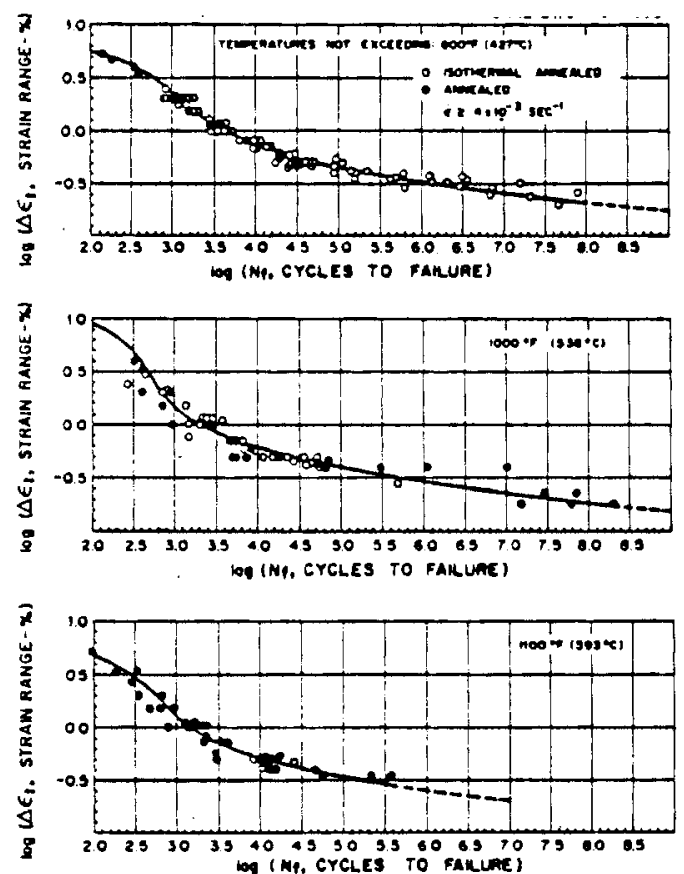

\section{FIGURE 9.3.4-1. Average Fatigue Life Curves for 2 1/4 Cr-1Mo Steel over Temperature Range: $\mathrm{RT}-593^{\circ} \mathrm{C}(\mathrm{T})$}

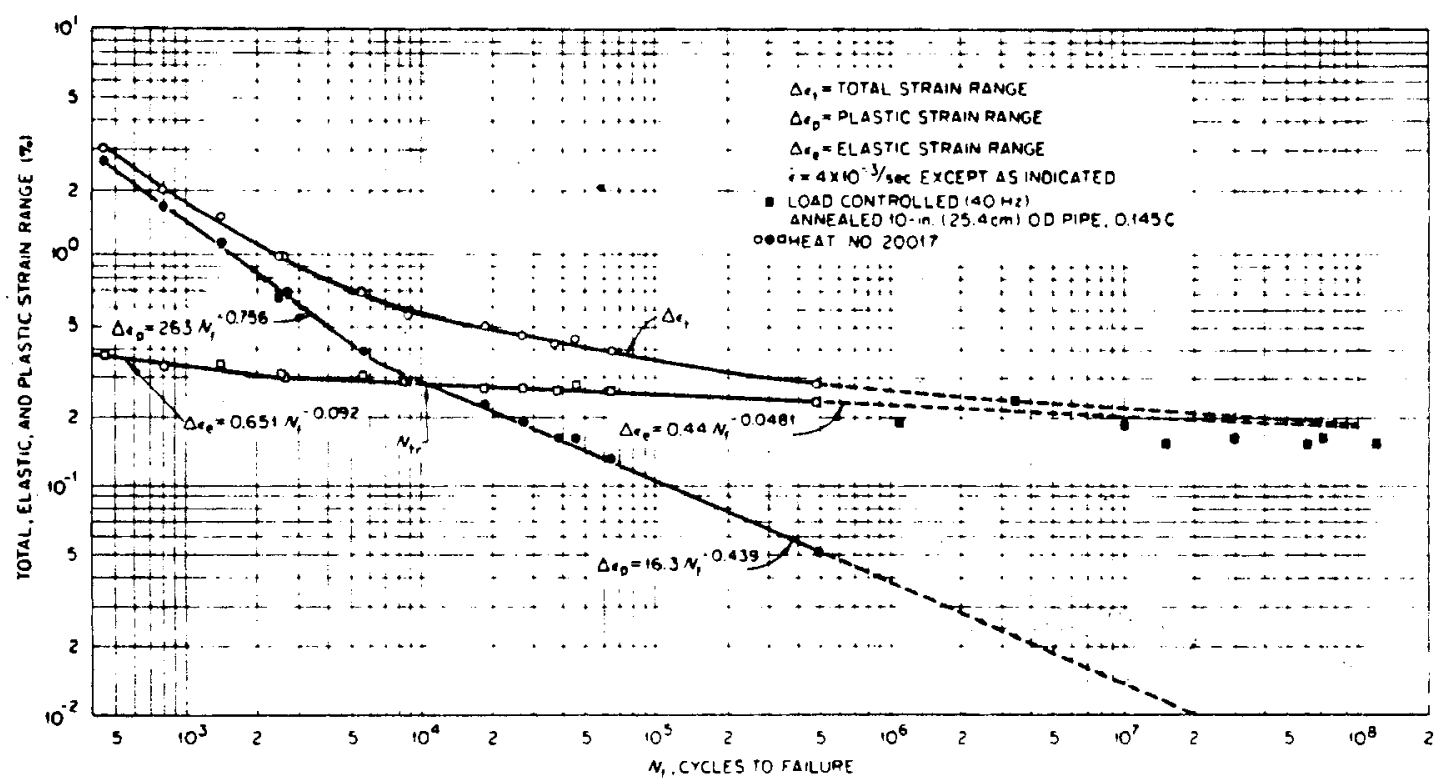

FIGURE 9.3.4-2. Total, Elastic and Plastic Strain Ranges versus Cycles to Failure for Isothermally Annealed 2 1/4 Cr-1Mo Steel(2) 
Figure 9.3.4-3 shows the stress and plastic strain ranges as a function of the fraction of cycle life $\left(\mathrm{N} / \mathrm{N}_{\mathrm{f}}\right)$ for both the low cycle and high cycle regimes. These plots display some of the hardening and softening behavior exhibited by $21 / 4 \mathrm{Cr}$-1Mo steel under fatigue loading, namely: initial, rapid, hardening (primary), followed by either a gradual hardening (secondary), or a softening, or a stabilization. Close to the cyclic life $\left(N / N_{f}=1\right)$, a softening (stress decrease) with an increase in the plastic strain component of the total strain is usually observed. These effects are strain range and temperature sensitive. A large strain range usually gives the continuous hardening, or stabilization, behavior, while a low strain range tends to give a continuous softening. A high temperature tends to reduce the secondary hardening of large strain ranges and to increase the softening of lower strain ranges. The increase in the plastic strain component at low total strain range (high cycle regime) denotes that a significant amount of plasticity remains in the steel out to very high cyclic lives.

Tests at ORNL ${ }^{(2)}$ have determined the air fatigue behavior of annealed and isothermally annealed $21 / 4 \mathrm{Cr}-1$ Mo steel from RT to $593^{\circ} \mathrm{C}\left(1100^{\circ} \mathrm{F}\right)$. It has been found that the total strain range $\left(\Delta e_{t}\right)$ can be given by the following equation:

$$
\Delta e_{t}=A N_{f}^{-a}+B N_{f}^{-b} \text {, where } N_{f} \text { is the cyclic life, } A, B, a \text { and } b \text { are }
$$
constants. Table 9.3.4-1 is a summary of the constants for the above equation from RT to $593^{\circ} \mathrm{C}\left(1100^{\circ} \mathrm{F}\right)$.

Fatigue design curves for annealed $21 / 4 \mathrm{Cr}$-1Mo steel were developed by ORNL ${ }^{(2)}$ from a number of data sources. Fourth degree polynomials in $1 \mathrm{nN}_{\mathrm{d}}$ $\left(N_{d}\right.$ is the design life) where fitted to plots of these data. The polynomial, together with the constants appropriate to various temperatures, are given in Table 9.3.4-2. The proposed design curves, based on the lesser of safety factors of 2 on strain, or 20 on number of cycles, ${ }^{(3)}$ are given in Figure 9.3.4-4. 

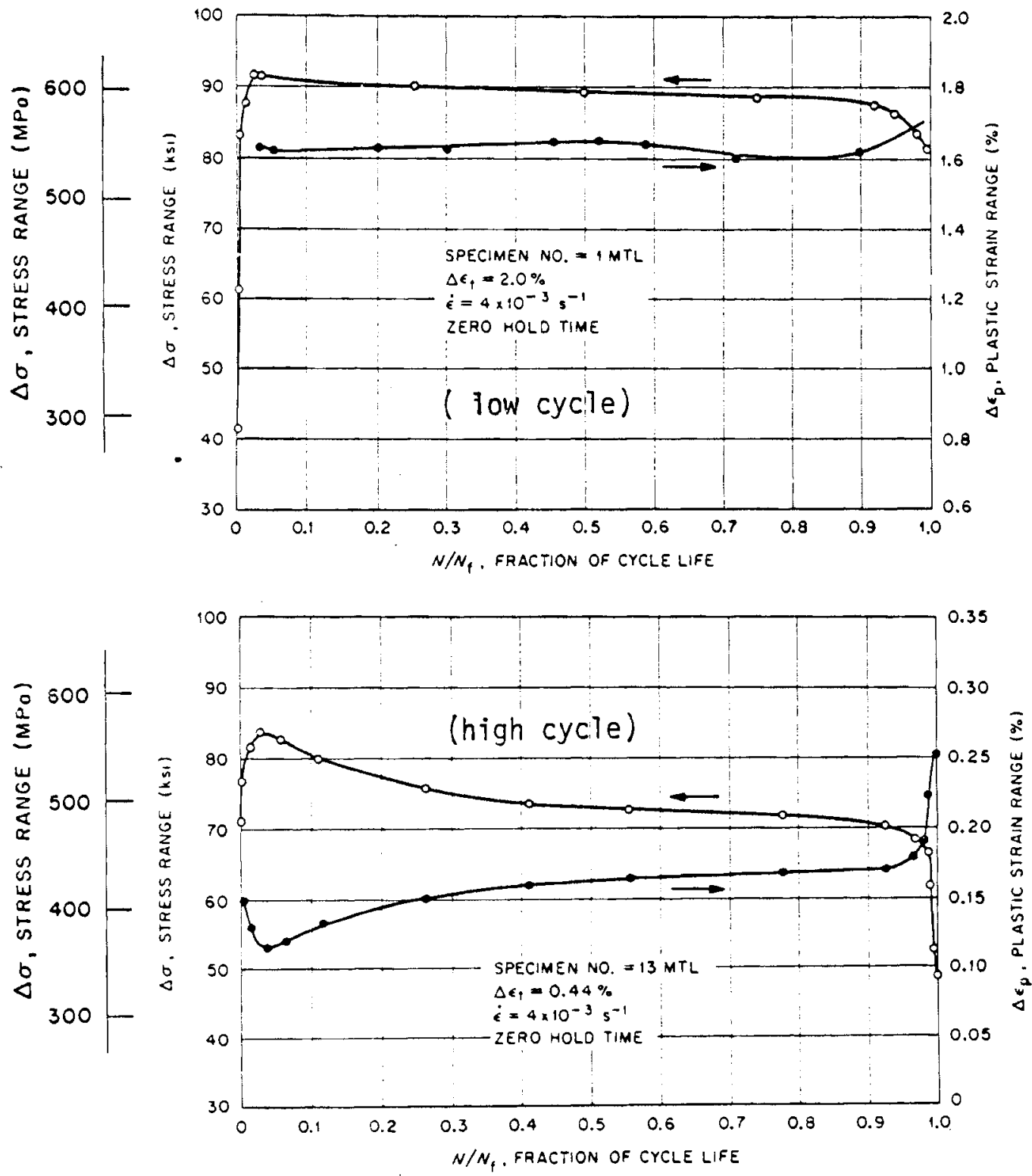

FIGURE 9.3.4-3. Stress and Plastic Strain Ranges as Functions of Fraction of Cyclic Life for Isothermally Annealed 2 1/4 Cr-iMo Steel at $538^{\circ} \mathrm{C}\left(1000^{\circ} \mathrm{F}\right)(2)$ 
TABLE 9.3.4-1. Values for the Elastic and Plastic Strain Range Constants for Strain-Controlled Tests Conducted at Strain Rate of $4 \times 10^{-3} / \mathrm{sec}$; Annealed $21 / 4 \mathrm{Cr}$-1Mo Steel (2)

\begin{tabular}{|c|c|c|c|c|c|c|}
\hline \multicolumn{2}{|c|}{ Temperature } & \multirow{2}{*}{$\begin{array}{c}N_{f} \\
\text { Ranke } \\
\text { (cycles) }\end{array}$} & \multicolumn{4}{|c|}{$\begin{array}{l}\text { Values of Constants in } \\
\qquad E_{t}-A N_{f}^{-a}+B N_{f}^{-b}\end{array}$} \\
\hline$\left({ }^{\circ} \mathrm{C}\right)$ & $\left({ }^{\circ} \mathrm{F}\right)$ & & $A$ & $a$ & $B$ & $b$ \\
\hline \multicolumn{2}{|c|}{ Roon } & $6 \times 10^{5}$ & 112 & 0.585 & 0.684 & 0.082 \\
\hline \multirow[t]{2}{*}{315} & 600 & $<6 \times 10^{4}$ & 112 & 0.585 & 0.684 & 0.082 \\
\hline & & $>6 \times 10^{4}$ & 1.03 & 0.164 & 0.684 & 0.082 \\
\hline \multirow[t]{2}{*}{371} & 700 & $<10^{5}$ & 102 & 0.602 & 0.713 & 0.081 \\
\hline & & $>10^{5}$ & 0.214 & 0.063 & 0.713 & 0.081 \\
\hline \multirow[t]{4}{*}{427} & 800 & $<1.8 \times 10^{4}$ & 166 & 0.661 & 0.407 & 0.031 \\
\hline & & $>1.8 \times 10^{4}$ & 8.23 & 0.349 & 0.407 & 0.031 \\
\hline & & $<1 \times 10^{4}$ & 166 & 0.661 & 0.407 & 0.031 \\
\hline & & $>1 \times 10^{4}$ & 3.755 & 0.232 & 0.396 & 0.032 \\
\hline \multirow[t]{2}{*}{539} & 1000 & $\times 10^{4}$ & 263 & 0.756 & 0.440 & 0.048 \\
\hline & & $>1 \times 10^{4}$ & 16.3 & 0.439 & 0.440 & 0.048 \\
\hline \multirow[t]{2}{*}{593} & 1100 & $<7.5 \times 10^{3}$ & 210.6 & 0.744 & 0.445 & 0.064 \\
\hline & & $27.5 \times 10^{3}$ & 3.768 & 0.284 & 0.445 & 0.064 \\
\hline
\end{tabular}

TABLE 9.3.4-2. Polynomial Coefficients for Fatigue Design Curves for Annealed 2 1/4 Cr-lMo Steel (2)

$$
\ln e_{t}=a_{0}+a_{1}\left(\ln N_{d}\right)+a_{2}\left(\ln N_{d}\right)^{2}+a_{3}\left(\ln N_{d}\right)^{3}+a_{4}\left(\ln N_{d}\right)^{4}
$$

\begin{tabular}{|c|c|c|c|c|c|c|}
\hline \multicolumn{2}{|c|}{ Temperature } & $a_{0}$ & $a_{1}$ & $a_{2}$ & $a_{3}$ & $a_{4}$ \\
\hline Room Tem & erature & -0.8591 & -0.9376 & $5.859 \times 10^{-2}$ & $-1.793 \times 10^{-3}$ & $2.257 \times 10^{-5}$ \\
\hline 316 & 600 & -0.8424 & -0.9391 & $5.579 \times 10^{-2}$ & $-1.272 \times 10^{-3}$ & $5.900 \times 10^{-6}$ \\
\hline 427 & 800 & -0.5925 & -1.1732 & $9.899 \times 10^{-2}$ & $-4.246 \times 10^{-3}$ & $7.103 \times 10^{-5}$ \\
\hline $482-538$ & $900-1000$ & -0.3689 & -1.3912 & 0.1374 & $-6.852 \times 10^{-3}$ & $1.299 \times 10^{-4}$ \\
\hline 593 & 1100 & -1.2561 & -1.0595 & $8.821 \times 10^{-2}$ & $-3.9100 \times 10^{-3}$ & $7.007 \times 10^{-5}$ \\
\hline
\end{tabular}




\section{$9 \cdot 3 \cdot 4-6$}

At a given temperature, fatigue data are sensitive to strain rate and to the loading waveform (i.e., tensile, or compressive holds, etc.). Within the temperature range $\left(\sim 370-550^{\circ} \mathrm{C}\right)$ where strain aging is operative (see previous mechanical property sections), low strain rates tend to lower fatigue life. Booker, et al. (2) cite the following data for example: isothermally annealed material; $371^{\circ} \mathrm{C}\left(700^{\circ} \mathrm{F}\right) ; \Delta e_{t} 1.0 \% ; N_{f}=4,007$ cycles for a strain rate of $4 \times 10^{-3} \mathrm{sec}^{-1}$ and $N_{f}=2,799$ cycles for a strain rate of $4 \times 10^{-5} \mathrm{sec}^{-1}$.

Creep-fatigue interaction is a complex phenomenon which has barely been explored for the $21 / 4 \mathrm{Cr}$-1Mo steel. Preliminary results obtained by ORNL (1) indicate the following: compression hold times are somewhat more damaging than tensile holds; hold time effects are greater at low strain ranges than at higher strain ranges; at a given temperature and strain rate, imposition of hold times results in an increase in the plastic strain range and a decrease in the total stress range.

Virtually all of the current fatigue data for the $21 / 4 \mathrm{Cr}$-1Mo stee 1 pertain to an air environment. Figure 9.3.4-5 presents some MSA Research Corp. data reported by ORNL. (4) Here, air fatigue data are compared with data obtained under helium, clean sodium, and high oxygen sodium. It is interesting that the high oxygen sodium (a situation generally regarded as harmful to the structural integrity of sodium containing materials) give the best fatigue performance (highest cycles to failure for a given stress range), while the air data appear to give very conservative results relative to clean (presumably, operational) sodium. The implications of these fatigue results are, however, highly tentative and much more work is needed to clarify environmental influence on the fatigue behavior of the $21 / 4 \mathrm{Cr}$-1Mo steel, par-. ticularly under the complex stress and chemical (corrosion/mass transport) conditions which will exist under LMFBR service conditions.

In previous mechanical property sections of this chapter, it was noted that considerable variability of mechanical properties has been experienced among batches of $21 / 4 \mathrm{Cr}$-1Mo steel which presumably satisfy chemical and heat treatment standards. This situation exists with fatigue properties as well, as reported by Brinkman, et al. (2). 


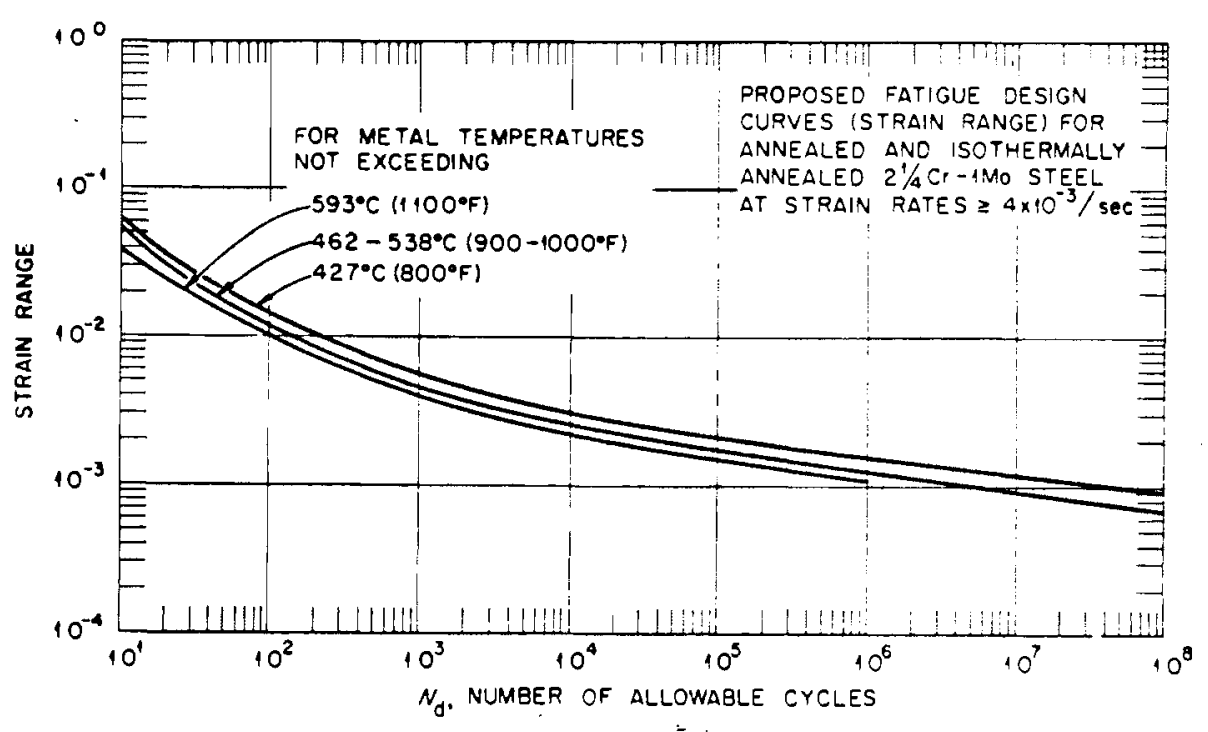

FIGURE 9.3.4-4. Proposed ASME Fatigue, Design Curves for $21 / 4 \mathrm{Cr}$-1Mo Stee1 in Annealed Condition (2)

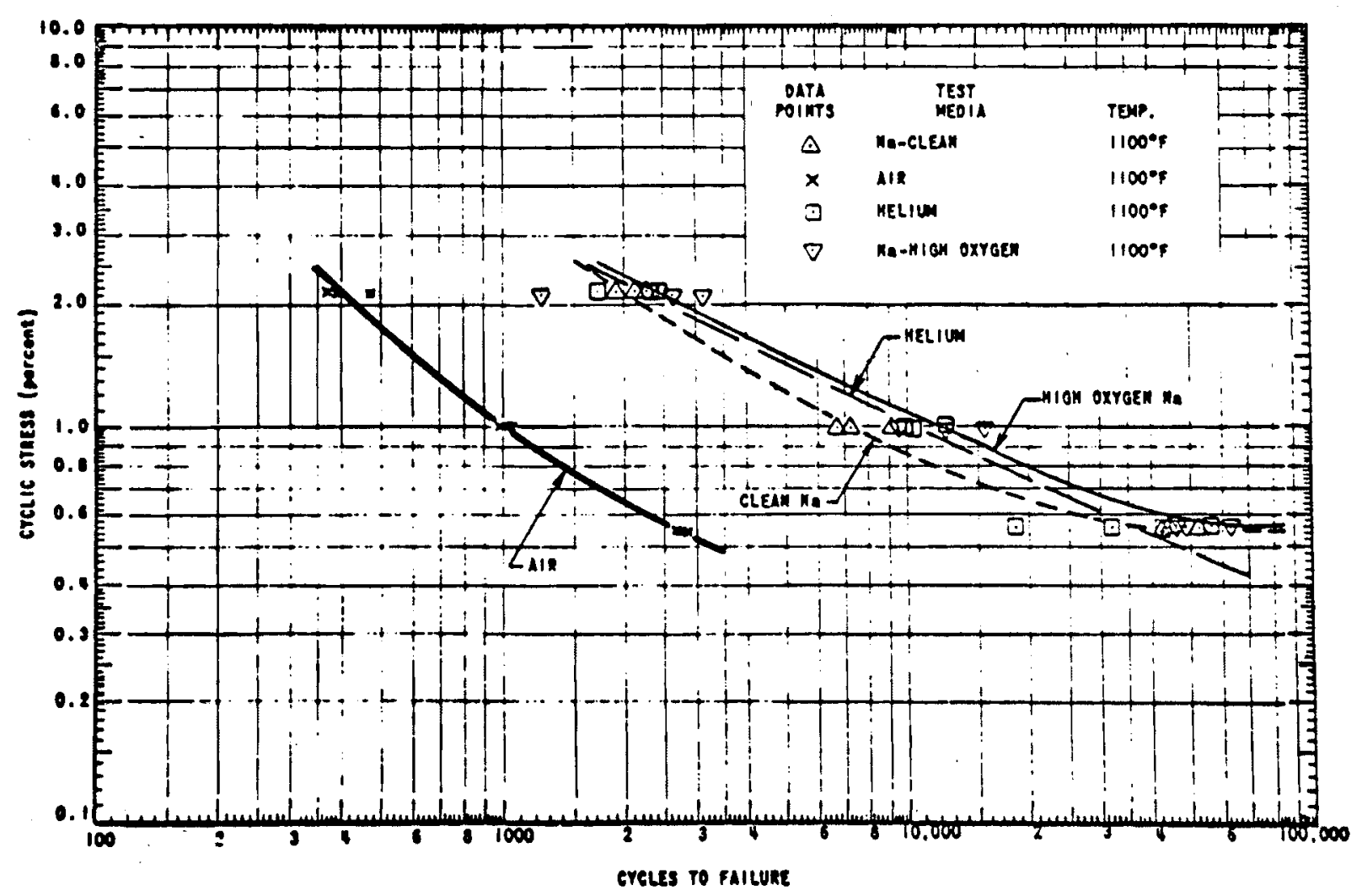

FIGURE 9.3.4-5. Fatigue Data for $21 / 4 \mathrm{Cr}$-1Mo Stee 1 in Sodium, Air and Helium (4) 
References for 9.3 .4

1. M. K. Booker, T. L. Hebble, D. 0. Hobson, and C. R. Brinkman, Mechanical Property Considerations for $21 / 4 \mathrm{Cr}-1$ Mo Steel in Support of Nuclear Reactor Systems Design. ORNL-TM-5329, Oak Ridge National Laboratory, Oak Ridge, TN, June 1976.

2. C. R. Brinkman, M. K. Booker, J. P. Strizak, W. R. Corwin, J. L. Frazier, and J. M. Leitnaker, Interim Report on the Continuous Cycling Elevated Temperature Fatigue Behavior and Subcritical Crack Growth Behavior of 2 1/4 Cr-1Mo Steel. ORNL-TM-4993, Oak Ridge National Laboratory, Oak Ridge, TN, December 1975.

3. Criteria for Design of El evated Temperature Class I Components in Section III of the ASME Boiler and Pressure Vessel Code. The Americal Society of Mechanical Engineers, New York, NY, 1974.

4. C. R. Brinkman, W. R. Corwin, M. K. Booker, T. L. Hebble, and R. L. Klueh, Time Dependent Mechanical Properties of $21 / 4 \mathrm{Cr}$-1Mo Steel for Use in Steam Generator Design. ORNL-5125, Oak Ridge National Laboratory, Oak Ridge, TN, March 1976. 


\section{$9 \cdot 3 \cdot 5-1$}

\section{3 .5 Fracture}

The growth of flaws or cracks in a material due to fluctuating loads at elevated temperature is of considerable importance to LMFBR steam generation system material candidates, such as the ferritic 2 1/4 $\mathrm{Cr}$-1Mo stee1. Fracture toughness and crack growth testing is used to determine a critical crack size and to give an estimate of the time required for a given flaw size to grow to critical dimensions (resulting in thru-section penetration of the crack under appropriate stress stimulus). Variables in fracture testing include: temperature; frequency of loading; mean stress; geometry of specimen; metallurgical variables, such as chemistry and microstructure; environmental influence, such as steam/water corrosion and sodium corrosion/mass transfer.

Room temperature crack growth tests at ORNL (1) show no frequency effects between 40 and 6000 cycles per minute (Figure 9.3.5-1). The curve exhibits the characteristic knee, above which the data can be represented by the relation:

$$
\frac{\mathrm{da}}{\mathrm{dN}}=3.26 \times 10^{-22} \Delta \mathrm{k}^{3.65}
$$

where $a$ is the crack length (in.), $N$ is the cycles under a loading program where $R$ is 0.05 (minimum 10ad/maximum load, assigning a negative sign to compressive loads), and $\Delta K$ is the change in stress intensity factor ( $K$ in psi (in. $)^{0.5}$ ).

Results from tests at higher temperatures are shown in Figure 9.3.5-2. Increasing the temperature results in an increase in crack growth rate. There is also a small frequency effect over the range of 40 to $300 \mathrm{cpm}$ at $510^{\circ} \mathrm{C}$ $\left(950^{\circ} \mathrm{F}\right)$. At $593^{\circ} \mathrm{C}\left(1100^{\circ} \mathrm{F}\right)$, there is a more pronounced frequency effect over the range of 4 to $40 \mathrm{cpm}$, with a decrease in frequency resulting in an increase in the crack growth rate. 


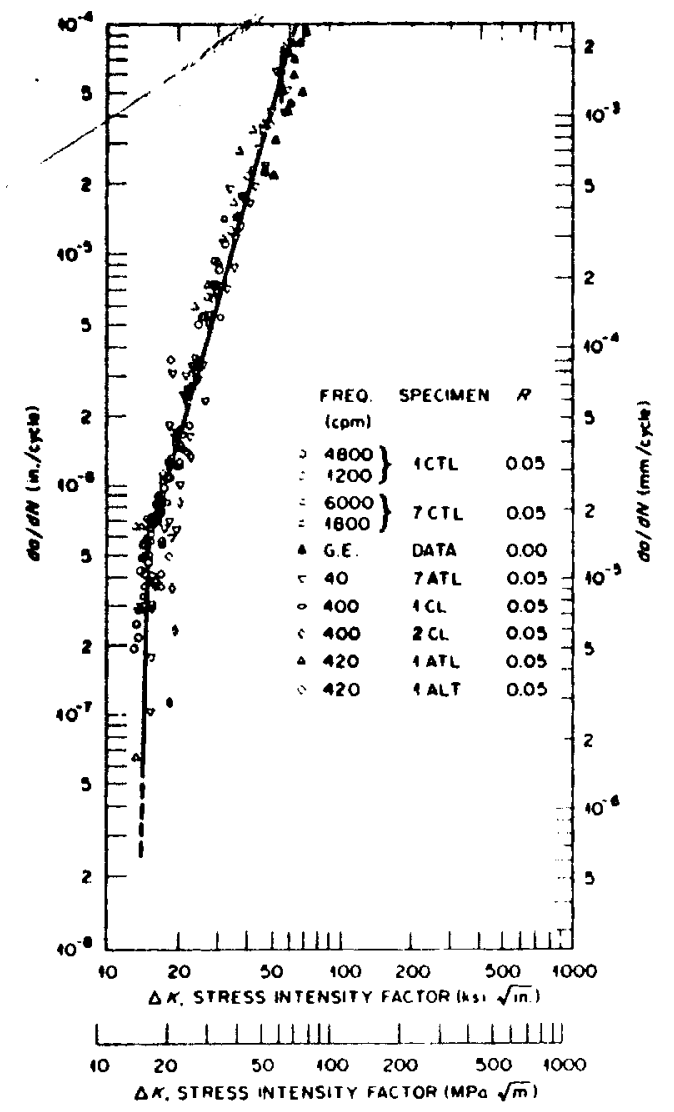

FIGURE 9.3.5-1. Fatigue-Crack Growth Rates for $21 / 4 \mathrm{Cr}$-1Mo Stee] in Air at Room Temperature (1)

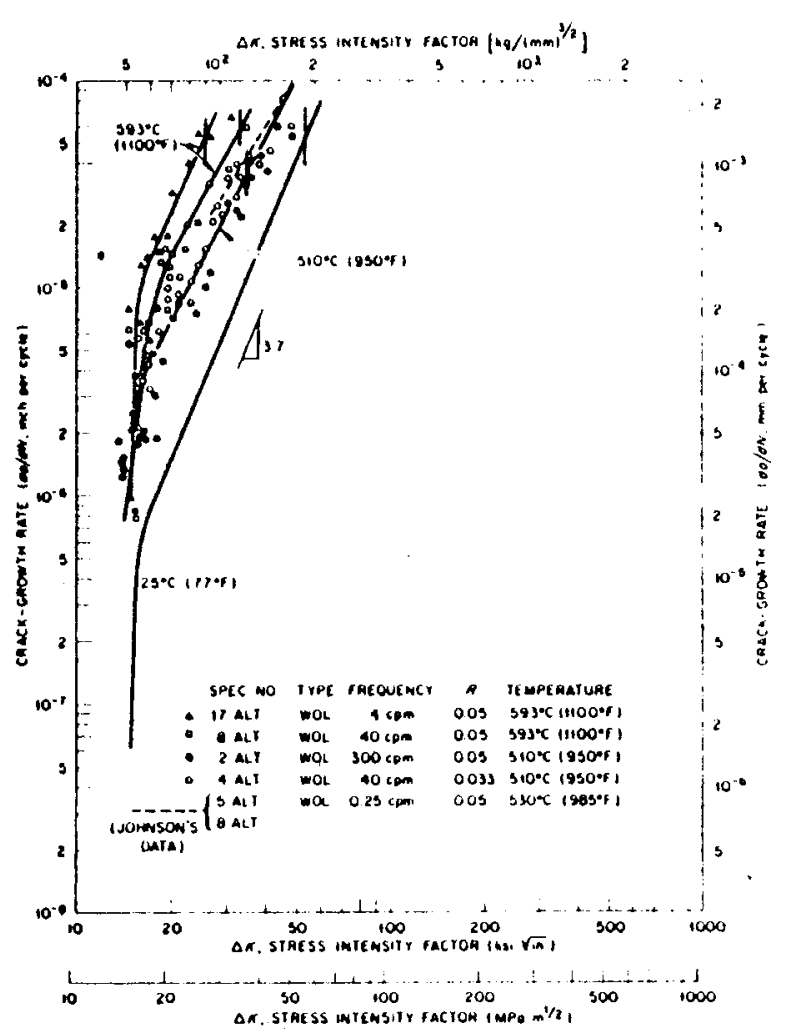

0
$\omega$
$i n$
1

FIGURE 9.3.5-2. Effects of Temperature and Frequency on Fatigue Crack Propagation of $21 / 4 \mathrm{Cr}-1$ Mo Stee 1 in Air (1) 
Mean stress effects have to be evaluated in crack growth testing. Figure 9.3.5-3 shows the effect of varying $R$ (minimum stress/maximum stress) at $510^{\circ} \mathrm{C}\left(950^{\circ} \mathrm{F}\right)$, with data points for $R=0.05$ shown for comparison. The rate of crack growth increases markedly with increase in the mean stress level.

Using the concept of effective stress intensity factor, ${ }^{(2)} K_{e f f}$ is given by the relation:

$$
K_{e f f}=K_{\max }(1-r)^{m}
$$

where $m$ is a constant which varies with the material. The results shown on the right of Figure 9.3.5-3 were obtained with a value of $m=0.5$. Above the knee, the equation of the line is:

$$
\frac{d a}{d N}=3.852 \times 10^{-15} K_{e f f}^{2.17}
$$

where $K_{\text {eff }}$ is in units of psi (in. $)^{0.5}$.

Limited testing in a steam environment at $510^{\circ} \mathrm{C}\left(950^{\circ} \mathrm{F}\right)$ and atmospheric pressure has been performed at ORNL. (1) Results are shown in Figure 9.3.5-4, suggesting a minimal effect of the steam atmosphere on crack growth characteristics.

Testing in flowing sodium ${ }^{(3)}$ at $427^{\circ} \mathrm{C}\left(800^{\circ} \mathrm{F}\right)$ has shown that the crack growth rate is approximately five times lower than in air at the same temperature (Figure 9.3.5-5). This result was attributed to the low level of oxygen in the sodium (1-3 ppm).

General Electric is conducting a fracture toughness program for steam generation system materials, including the $21 / 4 \mathrm{Cr}$-1Mo steel. (4) Table 9.3.5-1 gives some fracture toughness $\left(K_{I C}\right)$ data recently reported for $21 / 4 \mathrm{Cr}$-1Mo. Table 9.3.5-2 gives the heat treatment for the base metal, HAZ (weld heat affected zone), and weld metal used in this program. As noted in Table 9.3.5-1, elevated temperature fracture toughness values for the 


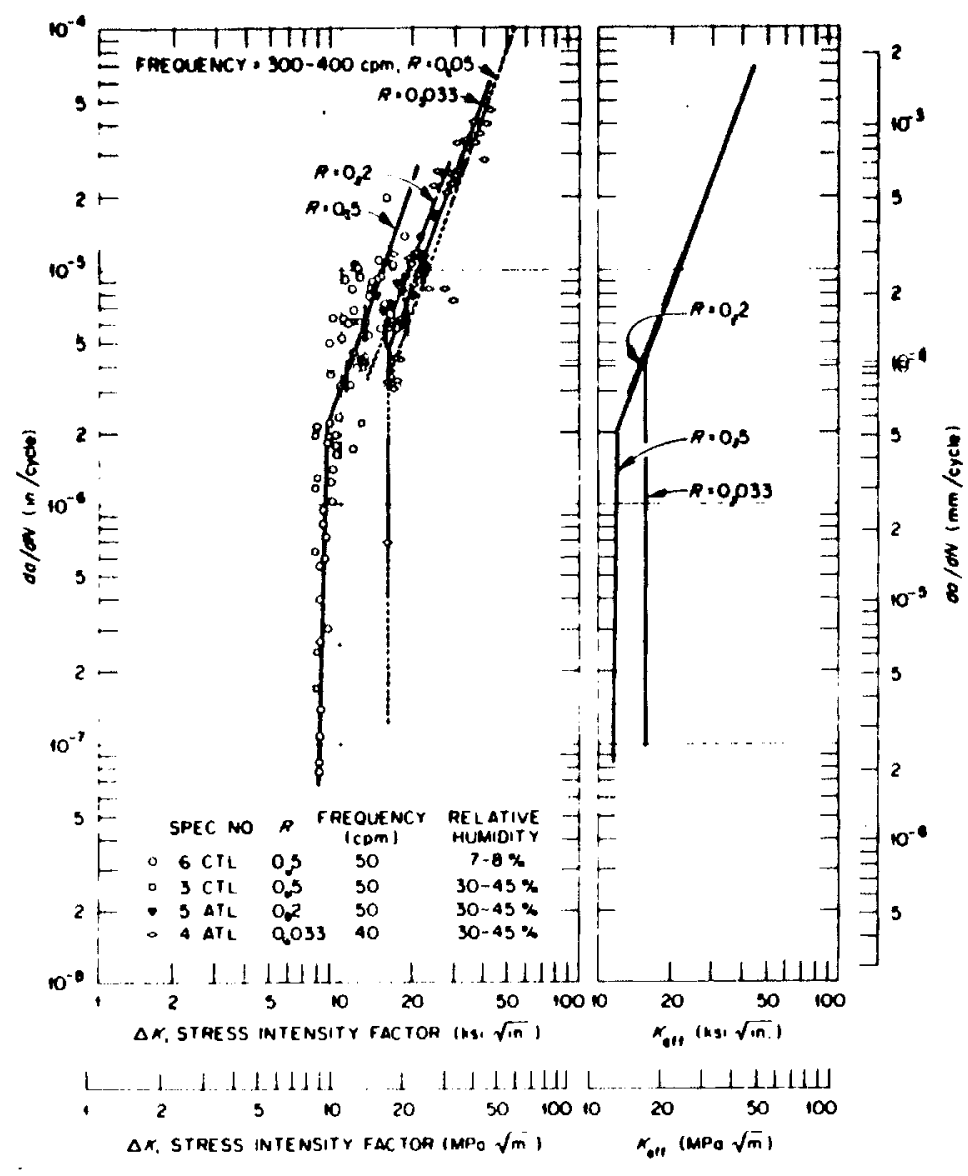

FIGURE 9.3.5-3. Effects of Stress Ratio on Fatigue-Crack Propagation of $21 / 4 \mathrm{Cr}-1$ Mo Steel at $510^{\circ} \mathrm{C}$ $\left(950^{\circ} \mathrm{F}\right)(1)$

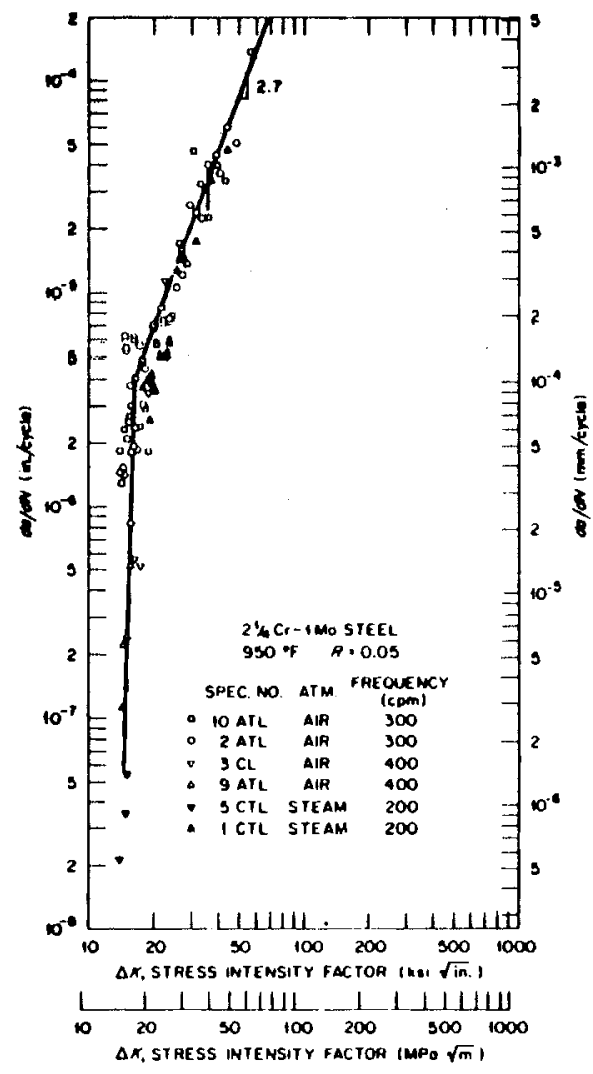

0
$\vdots$
$i$
1

FIGURE 9.3.5-4. Effects of Steam on Fatigue-Crack Propagation of $21 / 4 \mathrm{Cr}-1$ Mo Steel at $510^{\circ} \mathrm{C}\left(950^{\circ} \mathrm{F}\right)(1)$ 


\subsection{5-5}

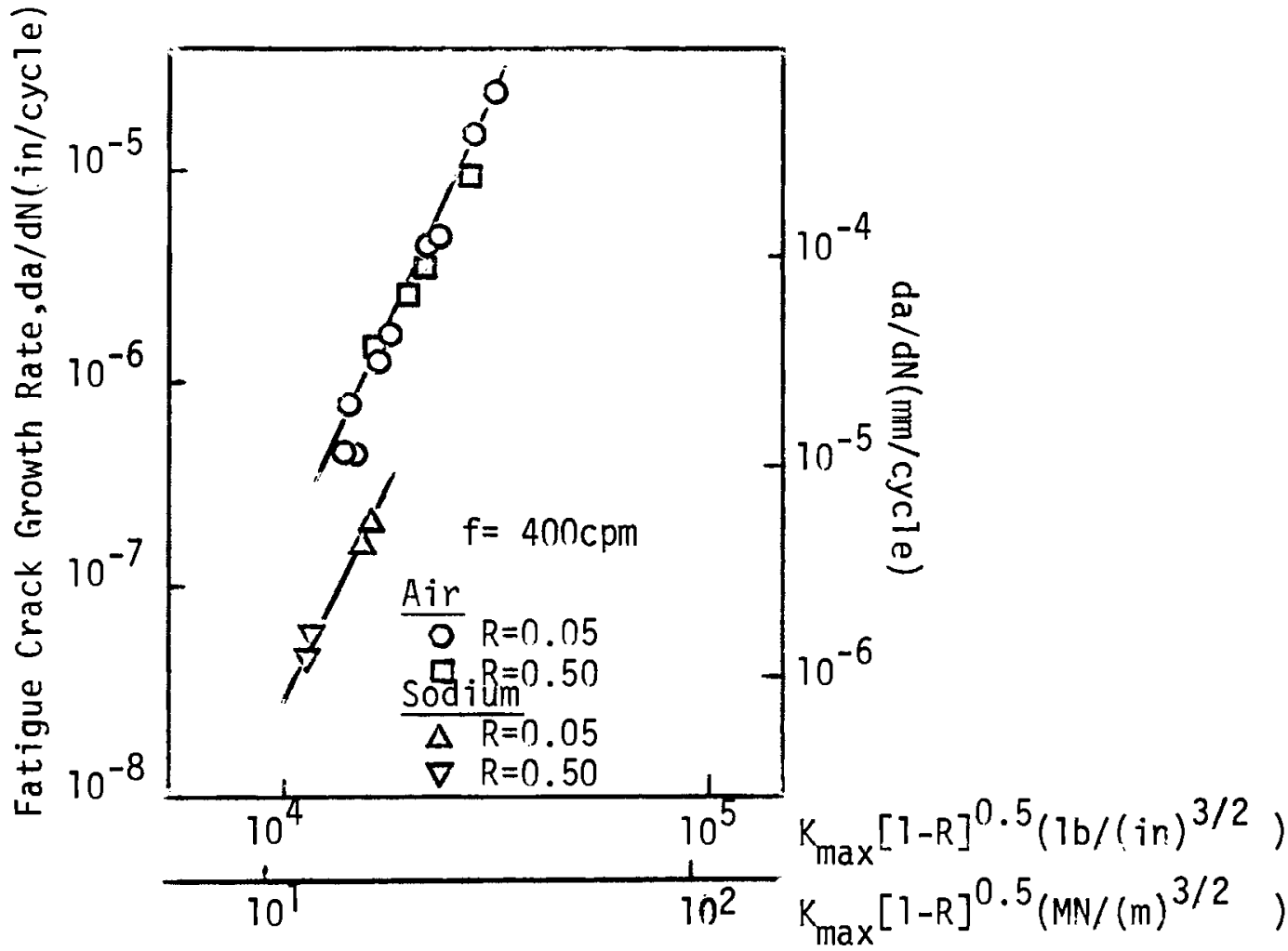

FIGURE 9.3.5-5. Fatigue-Crack Growth Behavior in Air and Sodium Environments at $427^{\circ} \mathrm{C}$ for $21 / 4 \mathrm{Cr}$-1Mo Steel (3)

TABLE 9.3.5-1. Compact Tension Fracture Toughness Results for 2 1/4 $\mathrm{Cr}$-1Mo Steel (4)

[Air melt, $89 \mathrm{~mm}$ thick plate with rolling ratio of 1.0; specimen loading rate of $1.52 \mathrm{~mm} / \mathrm{min}(0.06 \mathrm{in.} / \mathrm{min})]$

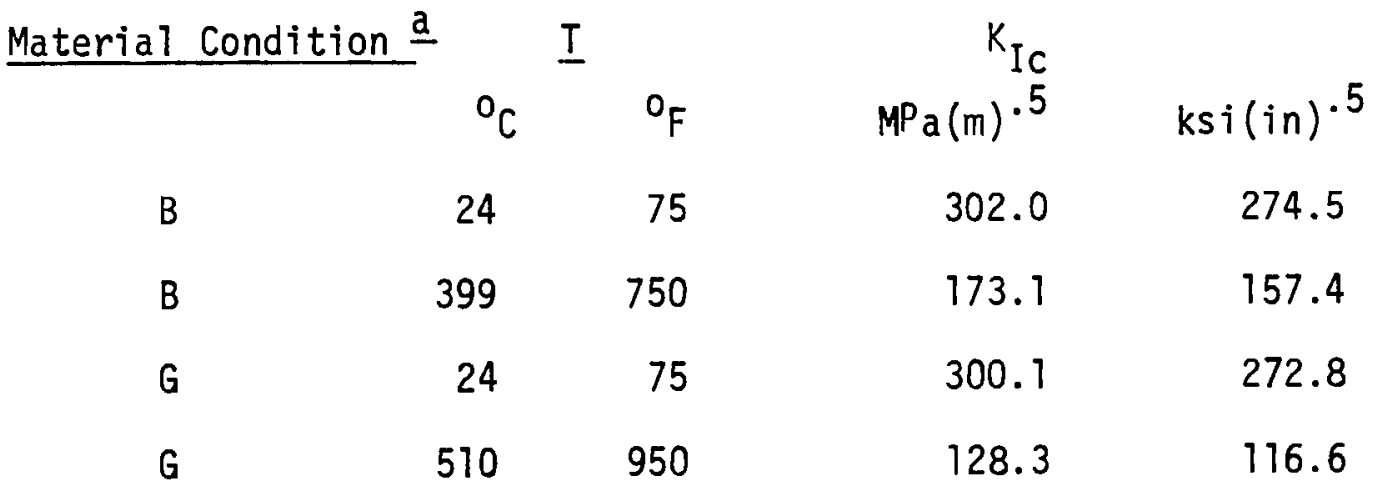

a: : see Table 9.3.5-2 


\section{$9 \cdot 3 \cdot 5-6$}

annealed + post-weld heat treated and HAZ specimens are substantially lower than the RT values. These and earlier data are plotted against temperature in Figure 9.3.5-6. The solid line of this figure is the ASME Code $K_{I R}$ curve. Fracture toughness values for most of the conditions listed in Table 9.3.5-2 lie above the code line at RT. There is, however, a progressive lowering with temperature of fracture toughness for the $B$ and $G$ conditions (see Table 9.3.5-2) below the assumed upper shelf value of the ASME curve (dotted line). A brief analysis of the design implications of the above fracture toughness behavior is given in Reference 4. A study is in progress of the effects of thermal aging and temper embrittlement on fracture toughness of $21 / 4 \mathrm{Cr}$-1Mo steel. (4)

The ability of steam generation system materials to resist crack development and propagation to failure under the service conditions is a critically important characteristic. Unfortunately, the current fracture mechanics dicipline makes virtually no formal concession to environmental influence, i.e., corrosion processes. The principal fracture mechanics related test to determine environmental influence has been the determination of the stress corrosion cracking parameter, $K_{\text {ISCC: }}$ Precracked specimens are loaded to various stress intensities under the environment of interest. That stress intensity which does not cause propagation of the crack to failure under reasonable observation times is designated the $\mathrm{K}_{\text {ISCC. }}$. $\mathrm{K}_{\text {ISCC }}$ data for the $21 / 4 \mathrm{Cr}$-1Mo steel have not been noticed. Considering the potential for environmental interaction with $21 / 4 \mathrm{Cr}$-1Mo in the proposed LMFBR service environment (see Chapter 14, Volume II, this report), the practical value of conventional fracture mechanics testing under a relatively benign environment (i.e., laboratory air) is questionable. K ISCC type testing of material which had experienced various corrosion histories, or testing simultaneous with corrosion, would be of considerable interest. This procedure would, at least, take more cognizance of the inevitable corrosion action to be experienced by this material than is now possible under conventional fracture mechanics testing. 
TABLE 9.3.5-2. Material Conditions of 2 1/4 Cr-1Mo Steel for Fracture Toughness Testing (4)

A. Anneal (AM Heat 86693)

$927^{\circ} \mathrm{C}\left(1700^{\circ} \mathrm{F}\right)$ for 3 hours, furnace cool at maximum rate of $55.5^{\circ} \mathrm{C}\left(100^{\circ} \mathrm{F}\right)$ per hour to less than $482^{\circ} \mathrm{C}\left(900^{\circ} \mathrm{F}\right)$.

B. Anneal + Post-Weld Heät Treatment (PWHT) (AM Heat 86693)

$927^{\circ} \mathrm{C}\left(1700^{\circ} \mathrm{F}\right)$ for 3 hours, furnace ccol at maximum rate of $55.5^{\circ} \mathrm{C}\left(100^{\circ} \mathrm{F}\right)$ per hour to less than $482^{\circ} \mathrm{C}\left(900^{\circ} \mathrm{F}\right)+727^{\circ} \mathrm{C}\left(1340^{\circ} \mathrm{F}\right)$ for 4 hours, air cool or furnace cool.

c. Anneal + PWHT (YAR Heat $\$ 57.52)$

$927^{\circ} \mathrm{C}\left(1700^{\circ} \mathrm{F}\right)$ for 3 hours furnace cool at maximum rate of $55.5^{\circ} \mathrm{C}\left(100^{\circ} \mathrm{F}\right)$ per hour to less than $482^{\circ} \mathrm{C}\left(900^{\circ} \mathrm{F}\right)+727^{\circ} \mathrm{C}\left(134 \mathrm{0}^{\circ} \mathrm{F}\right)$ for 4 heurs, air cool.

D. Anneal + PWHT + Embrittlement Treatment (AM Heat 86693)

$927^{\circ} \mathrm{C}\left(1700^{\circ} \mathrm{F}\right)$ for 3 hours, iurnace ccol at maximum rates of $55.5^{\circ} \mathrm{C}\left(190^{\circ} \mathrm{F}\right)$ per hour to less than $482^{\circ} \mathrm{C}\left(900^{\circ} \mathrm{F}\right)+727^{\circ} \mathrm{C}\left(1340^{\circ} \mathrm{F}\right)$ lor 4 hours, air cool of turnace cool $+210^{\circ} \mathrm{C}\left(950^{\circ} \mathrm{F}\right)$ for 1,000 tours, air cool.

E. Normalize + Temper (AM Heat 86693)

$927^{\circ} \mathrm{C}\left(1700^{\circ} \mathrm{F}\right)$ for 3 hours, air cool to roorn temperature $+727^{\circ} \mathrm{C}\left(1340^{\circ} \mathrm{F}\right)$ for 4 hours, air cool.

F. SMAW Weld Metal (AMi Heat 86693)

$915^{\circ} \mathrm{C}\left(1680^{\circ} \mathrm{F}\right)$ for 3.5 hours, furnace cool at maximum rate of $55.5^{\circ} \mathrm{C}\left(100^{\circ} \mathrm{F}\right)$ per hour to less than $482^{\circ} \mathrm{C}\left(900^{\circ} \mathrm{F}\right)+\operatorname{Sin} A \mathrm{~W}$ (gie weld procedure, Reterence 5.1$)+727^{\circ} \mathrm{C}\left(1340^{\circ} \mathrm{F}\right)$ for 12 hours, furnace cool at maximum rate of $55.5^{\circ} \mathrm{C}\left(100^{\circ} \mathrm{F}\right)$ per hour.

G. SMAW Heat Affected Zone (HAZ) (AM Heat 86693)

$915^{\circ} \mathrm{C}\left(1680^{\circ} \mathrm{F}\right)$ for 3.5 hours, furnace cool at maximum rate of $55.5^{\circ} \mathrm{C}\left(100^{\circ} \mathrm{F}\right)$ per hour to less than $482^{\circ} \mathrm{C}\left(900^{\circ} \mathrm{F}\right)+\operatorname{SMAW}$ (gee weig procedure, Reference 5.1$)+727^{\circ} \mathrm{C}\left(1340^{\circ} \mathrm{F}\right)$ for 12 hours, furnace cool at maximum rate of $55.5^{\circ} \mathrm{C}\left(100^{\circ} \mathrm{F}\right)$ per hour.

H. Anneal + PWHT (24 hours, AM Heat 86693)

$927^{\circ} \mathrm{C}\left(1700^{\circ} \mathrm{F}\right)$ for 3 hours furnace cool at maximum rate of $55.5^{\circ} \mathrm{C}\left(100^{\circ} \mathrm{F}\right)$ per hour to less than $482^{\circ} \mathrm{C}\left(900^{\circ} \mathrm{F}\right)+727^{\circ} \mathrm{C}\left(1340^{\circ} \mathrm{F}\right)$ for 24 hours, furnace cool at maximum rate of $55.5^{\circ} \mathrm{C}\left(100^{\circ} \mathrm{F}\right)$ per hour. 


\subsection{5-8}

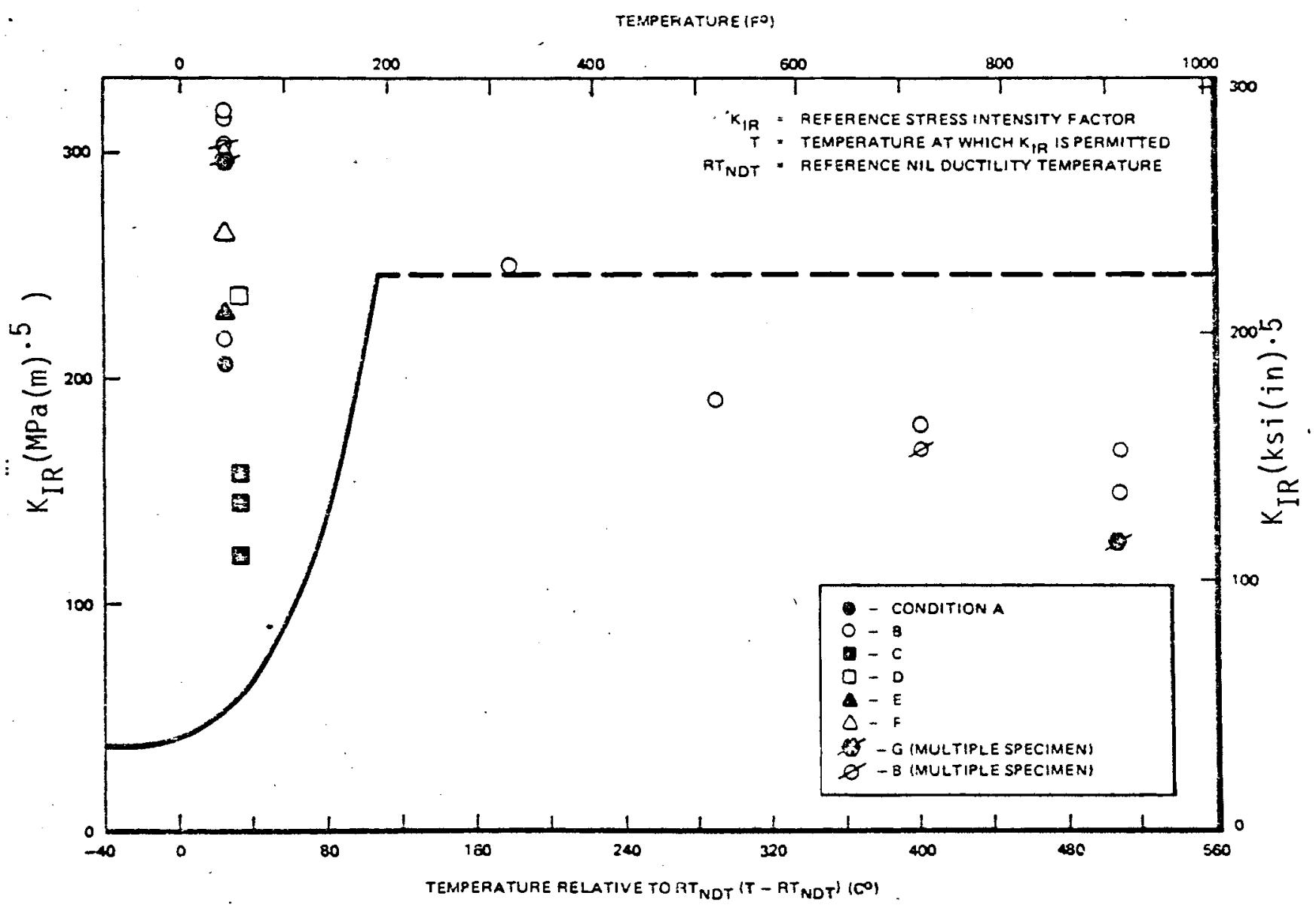

FIGURE 9.3.5-6. Comparison of Fracture Toughness of 2 1/4 $\mathrm{Cr}$-1Mo Stee 1 with ASME Code Section III K IR Curve(4) 


\section{$9 \cdot 3 \cdot 5-9$}

References for 9.3 .5

1. C. R. Brinkman, M. K. Booker, J. P. Strizak, W. R. Corwin, J. L. Frazier, and J. M. Leitnaker, Interim Report on the Continuous Cycling Elevated Temperature Fatigue Crack Growth Behavior of 2 1/4 Cr-1Mo Steel. ORNL-TM-4993, Oak Ridge Nationa1 Laboratory, Oak Ridge, TN, December 1975.

2. E. K. Walker, "An Effective Strain Concept for Crack Propagation and Fatigue Life with Specific Applications to Biaxial Stress Fatigue." Proc. Air Force Conf. Fatigue and Fracture of Aircraft Structures and Materials, AFFDL-TR-70-144, p. 225, 1970.

3. L. A. James, "Effect of a Liquid Sodium Environment upon Fatigue-Crack Growth in a Pressure Vessel Steel." Scripta Met., vol. 10, p. 1039, 1976.

4. Steam Generator Materials Engineering. GEAP-14029-10, General Electric Co., Sunnyvale, CA, p. 5-1, January 1977. 



\subsection{WELDING AND EMBRITTLEMENT CONSIDERATIONS}

\subsubsection{Embrittlement Phenomena Associated With Welding}

Changes in strength and ductility of steel weldments subjected to static and cyclic stress environments at elevated temperature is of vital concern to design and operation of thermally efficient heaters and heat exchangers. Gradual loss of alloy ductility with time leads to increased susceptibility to crack propagation and ultimately, unexpected failure. The consequences of failure are particularly critical in steam generating systems for the liquid metal cooled reactors, where reactive metal coolant and water can be brought into contact by a weld metal failure.

The literature identifies three mechanisms by which welds in ferritic steels are embrittled. The first two, Temper Embrittlement and Stress Relief Embrittlement, are strongly dependent on time-at-temperature. The third mechanism, Creep Embrittlement, is obviously related to time-dependent deformation as well as temperature.

Temper embrittlement is usually ascribed to structural changes resulting from holding the metal within, or slowly cooling through, a certain temperature range (e.g., 700 to $1100^{\circ} \mathrm{F}$ ). The loss of ductility is manifested by a shifting of the ductile to brittle transition temperature (DBTT) to higher temperatures. Fracture changes from transcrystalline to intercrystalline with embrittlement, and fracture travels through prior austenite grain boundaries.

Although this temperature and time-dependent problem has been recognized for many years, the work of Steven and Balajiva(1) in 1959 first determined that this embrittlement was peculiar to certain alloy steels containing certain impurity elements. It was found that trace quantities of $\mathrm{Sb}, \mathrm{Sn}, \mathrm{P}$ and As appear to induce temper embrittlement, and that larger quantities of $\mathrm{Si}$ and $\mathrm{Mn}$ also contribute to the embrittling condition. Bruscato ${ }^{(2)}$ has shown that an Embrittlement Factor $\underline{X}=(10 P+5 S b+4 S n+A s) / 100$ can be used to correlate alloy chemistry and temper embrittlement. 


\section{$9.4 .1-2$}

Brittleness develops when the alloy steels with the aforementioned impurities are held within or slowly cooled through a temperature range below the transformation range, usually between 700 to $1100^{\circ} \mathrm{F}$. Baumert and Polk ${ }^{(3)}$ showed that quenched and tempered $21 / 4 \mathrm{Cr}$-1Mo plate should not experience rapid embrittlement when used at or below $750^{\circ} \mathrm{F}$. In fact, they report that no temper embrittlement was found in quenched and tempered $21 / 4 \mathrm{Cr}$-1Mo plate which had been exposed to 700 to $750^{\circ} \mathrm{F}$ temperatures for three years.

The control of temper embrittlement by alloy chemistry is graphically shown in Figure 9.4.1-1, where the $50^{\circ} \mathrm{F}$ Charpy $V$-notch impact energy value is plotted on a grid consisting of Embrittlement Factor $(X)$ and (\% $i+\% M n)$ axes. The lines delineate various ranges of the impact value. As can be seen, welds with lower $(M n+S i)$ content can tolerate a greater quantity of embrittling impurity elements without developing severe temperature embrittlement. Also, temper embrittlement can be controlled by limiting the impurity content, for a given $(\mathrm{Mn}+\mathrm{Si})$ content. Control of $\mathrm{P}$ and $\mathrm{Sb}$ is considered to be most effective. There is a limit, however, to the reduction of the $(\mathrm{Mn}+\mathrm{Si})$ content in controlling embrittlement. Below about $0.5 \% \mathrm{Mn}$, weldability is greatly impaired. It should be emphasized that notch toughness properties of the weld experience only a shift to higher temperatures when temper embrittled (Figure 9.4.1-2). No deterioration of the intrinsic impact energy levels of the welds was found. This is important since many $21 / 4 \mathrm{Cr}$-1Mo pressure vessels operate in the 700 to $900^{\circ} \mathrm{F}$ temperature range. The only problem would be experienced during shutdown and startup periods. Above about $200^{\circ} \mathrm{F}$ no deterioration in notch toughness of $21 / 4 \mathrm{Cr}$-1Mo shielded metal arc weldments was found. (4)

In summary, alloy steels such as 2 1/4-1Mo experience temper embrittlement when held in or allowed to slowly pass through the 700 to $1100^{\circ} \mathrm{F}$ temperature range. The embrittlement is reversible when the steel is heated above the embrittlement range and quickly cooling through the range. Embrittlement appears to be strongly influenced by small levels of impurity such as phosphorus and antimony. Holding $\mathrm{Mn}+\mathrm{Si}$ levels low, but not below $0.5 \% \mathrm{Mn}$, increases the weld tolerance level for embrittling impurity elements. 


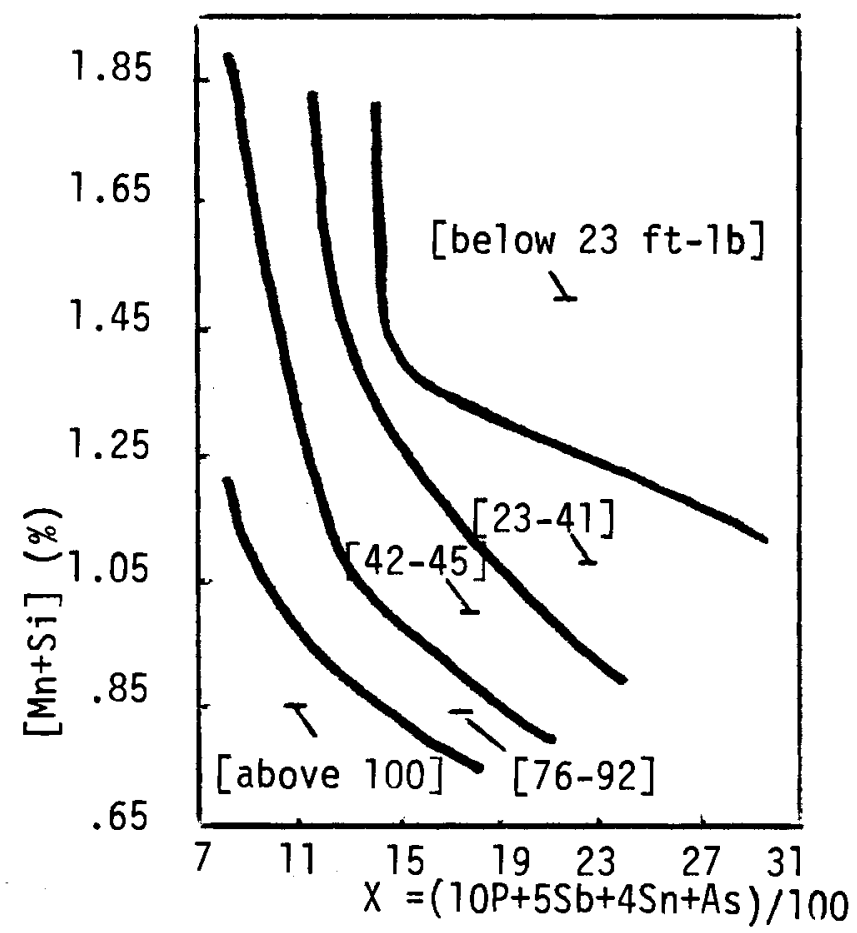

FIGURE 9.4.1-1. Effect of Chemistry on $50 \mathrm{~F}$ Charpy V-notch Impact Energy of Step-aged, Highly Temper Embrittled 2 1/4 Cr-1Mo Weldments (4)

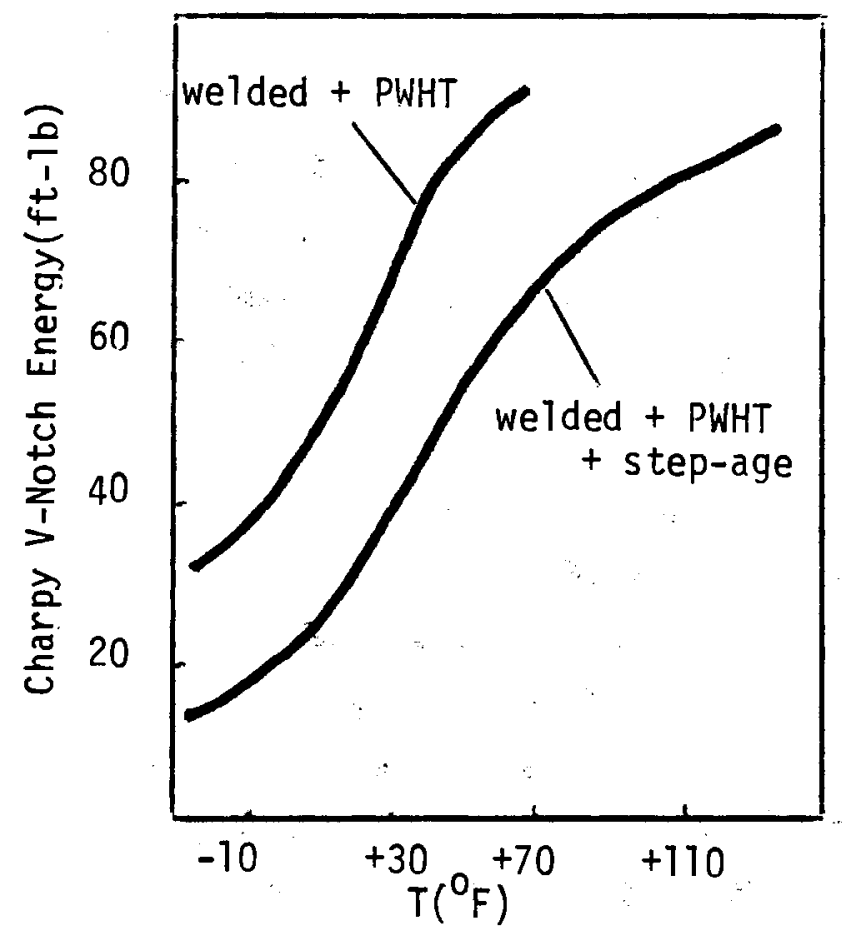

FIGURE 9.4.1-2. Shift in Transition Curve Due to Temper Embrittlement of Weld Deposit for $21 / 4 \mathrm{Cr}$-1Mo Steel (4) 
When used in thick section at high temperature and pressure, $21 / 4 \mathrm{Cr}$-1Mo weldments must be postweld stress relieved at a minimum temperature of $1250^{\circ} \mathrm{F}$ to minimize subsequent in-service cracking in the weld zone.

When the weldment is heat treated, or slowly cooled within the temperature range 600 to $1100^{\circ} \mathrm{F}$, a loss in notch toughness, termed stress relief embrittlement, occurs. This type of embrittlement, described by Swift and Rogers $(5)$ is characterized by a decrease in the upper shelf energy as well as the upward shift in the charpy $V$-notch impact energy transition temperature (see Figure 9.4.1-3). This is unlike classical temper embrittlement which only causes an increase in the charpy transition temperature. In addition, once the weld has been stress relieved above the stress relief embrittlement range, it cannot be reembrittled by the same mechanism. Classical temper embrittlement, however, can take place.

The stress relief embrittlement appears to be due to formation of precipitates inherent in the alloy and does not result from the presence of residual impurity elements. The precipitate mainly causing the embrittlement is $\mathrm{Mo}_{2} \mathrm{C}$, partially coherent with the metal matrix. The coherency strains cause a reduction in the notch toughness. When the precipitates have grown to a size where the coherency strains can no longer be accommodated by the matrix, the notch toughness improves.

The phenomena of creep embrittlement and temper embrittlement appear to be closely related since both are influenced by the degree of metal purity. Creep embrittlement appears to also be dependent on the temperature and stress level as well as chemistry and microstructure. Both types of embrittlement must be considered in construction of pressure vessels and related structures since operating temperatures and fabrication procedures quite often involve embrittling temperature ranges.

Weldments done in fabrication of $21 / 4 \mathrm{Cr}$-1Mo vessels have been found to be more susceptible than unwelded plate material to both the degree and rate of creep embrittlement. (2) creep rupture ductility, however, is difficult to predict because of the multiplicity of microstructures developed by several weld passes during thick section joining. 


\section{$9.4 .1-5$}
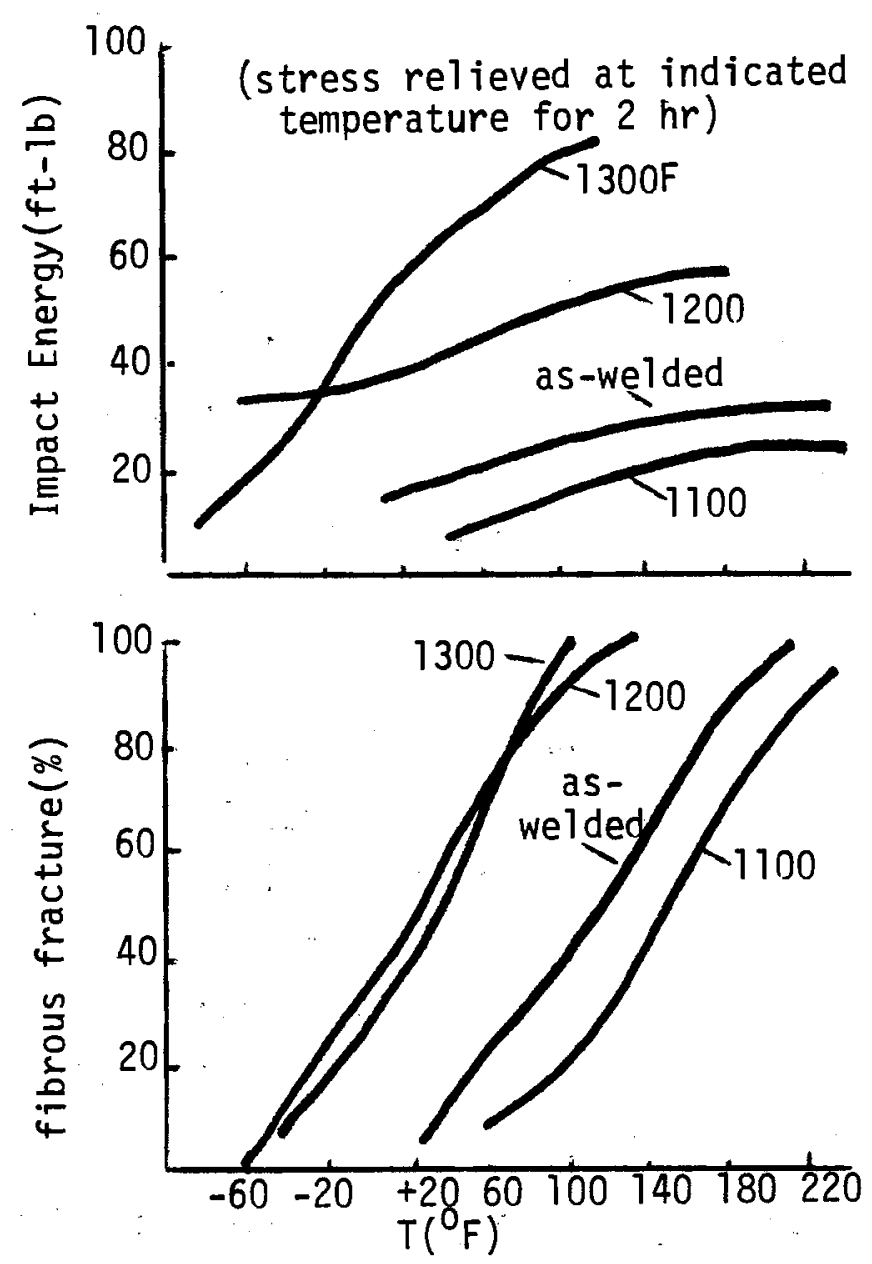

FIGURE 9.4.1-3. Charpy V-notch Energy Absorbed and Fracture Appearance as a Function of Test Temperature for the Full Thickness Weld of $21 / 4 \mathrm{Cr}$-1Mo Steel

Buscato (2) investigated the similarities between creep and temper embrittlement in $21 / 4 \mathrm{Cr}$-1Mo steel. Both phenomena can cause intergranular failure of the material. Weld deposits with both very high level and very low level impurities were made. Two heat treating conditions were used: 1) quench in water after 20 -hour postweld heat soak at $1275^{\circ} \mathrm{F}$ to prevent temper embrittlement; 2) furnace cool to $600^{\circ} \mathrm{F}$ from the $1275^{\circ} \mathrm{F}$ soak followed by a step age to induce high temper embrittlement. Reduction in area at 


\subsection{1-6}

rupture is plotted versus the rupture time for test temperatures of 900 and $1050^{\circ} \mathrm{F}$ in Figures 9.4.1-4 and -5 , respectively. As can be seen, weld deposits with high impurity suffers deterioration of ductility to a much greater degree than the metal with low level impurity. An interesting observation is that the high impurity material heat treated to induce maximum embrittlement does not creep embrittle as rapidly as its counterpart which was heat treated to prevent temper embrittlement. The temper embrittlement mechanism appears to retard the creep embrittlement mechanism. The overall results imply that temper and creep embrittlement both are strongly influenced by impurity elements in the weld metal.

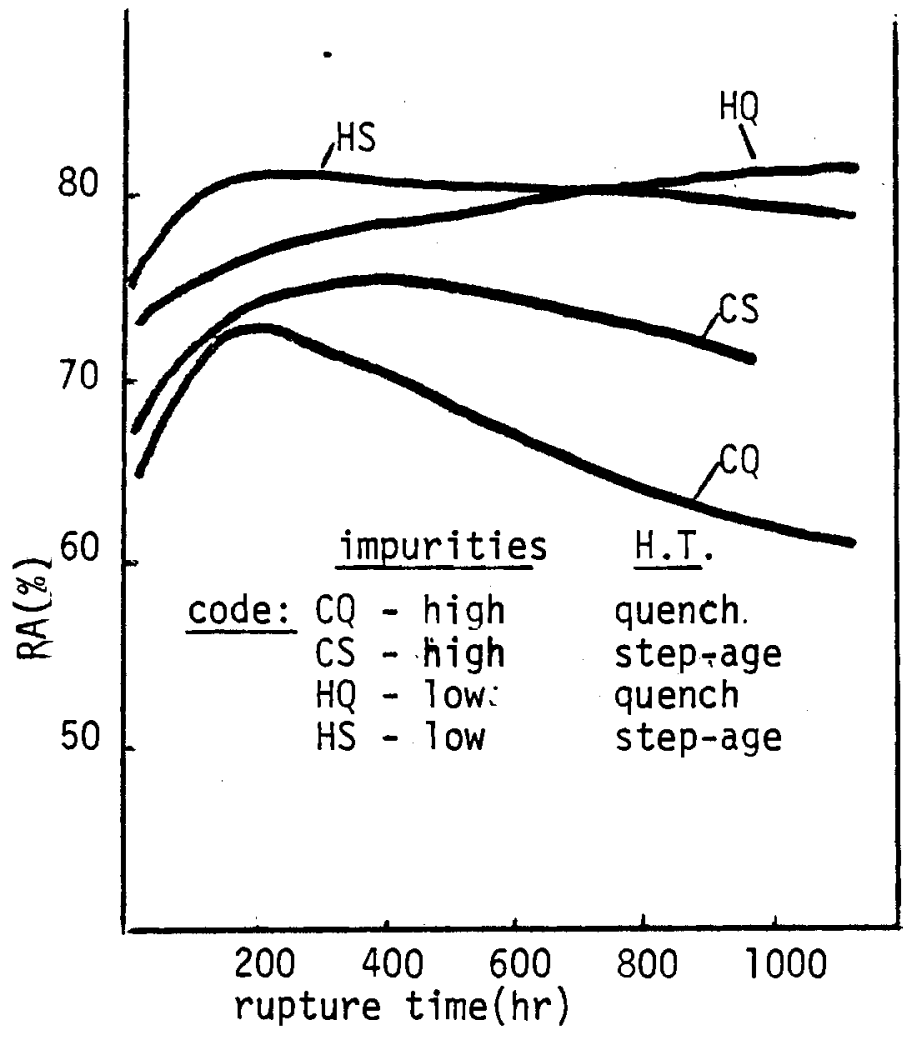

FIGURE 9.4.1-4. Percent Reduction in Area (RA) as Function of Time to Rupture at $900^{\circ} \mathrm{F}$ for $21 / 4 \mathrm{Cr}-1 \mathrm{Mo}$ Steel (2)

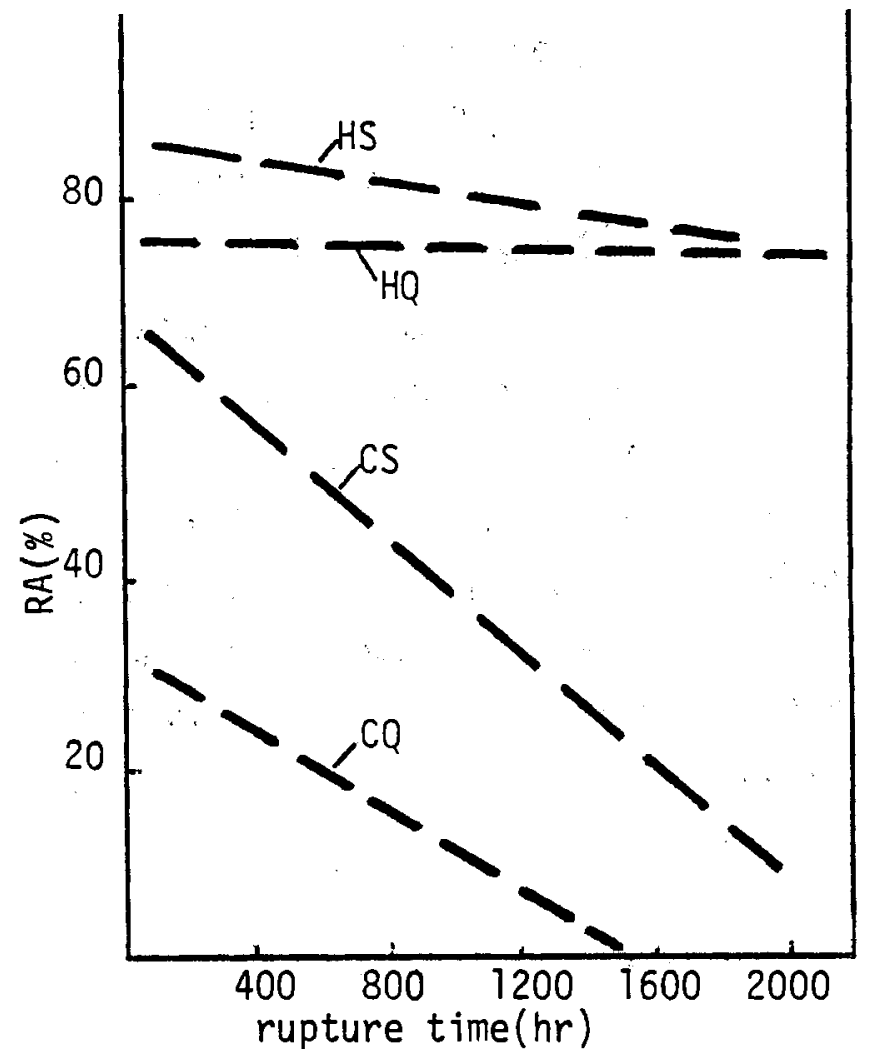

FIGURE 9.4.1-5. Percent Reduction in Area (RA) as a Function of Time to Rupture at $1050^{\circ} \mathrm{F}$ for $21 / 4 \mathrm{Cr}-1 \mathrm{Mo}$ Steel (2) 


\subsection{1-7}

Swift and Rogers ${ }^{(6)}$ have reported several observations related to creep embrittlement of $21 / 4 \mathrm{Cr}$-1Mo steel:

1) Stress rupture ductility decreases with increasing time to rupture, reaching a minimum; beyond the minimum the ductility increases with increasing rupture life.

2) Postweld heat treating within the temperature range 900 to $1150^{\circ} \mathrm{F}$ results in poor creep ductility at $1100^{\circ} \mathrm{F}$; postweld heat treating at $900^{\circ} \mathrm{F}$ results in the most severe creep embrittlement.

3) Postweld heat treating at $1300^{\circ} \mathrm{F}$ gives the best rupture ductility under all test conditions.

4) The mechanism of creep embrittlement is related to the generation of intergranular voids. This is caused by the formation of zones adjacent to grain boundaries which are depleted of alloy elements and the segregation of residual $l^{\circ}$ elements to the intergranular precipitation/matrix interfaces.

Before reviewing the state of knowledge of welded transition joints, a comment on the effect of porosity on $-21 / 4 \mathrm{Cr}$-1Mo weldments is in order. Buchanan and Young $(7)$ report that approximately 5 to $8 \%$ porosity in this alloy weldments reduced the fatigue life at $1200^{\circ} \mathrm{F}$ by $98 \%$. The porosity generated in the laboratory for these results was the same type of porosity as would be generated in production by inadequate shielding, air currents, etc. Creep properties are also probabily strongly influenced by the level of weld metal porosity. 


$$
9 \cdot 4 \cdot 1-8
$$

\section{References for 9.4.1}

1. W. Steven and K. Balajiva, "The Influence of Minor Elements on Isothermal Embrittlement of Steels." Journal of the Iron and Steel: Institute, vol. 93, pp. 141-147, 1959.

2. R. Bruscato, "Temper Embrittlement and Creep Embrittlement of $21 / 4 \mathrm{Cr}$-1Mo Shielded Metal-Arc Weld Deposits." Welding J., vol. 49, pp 148-156, Apri1 1970.

3. K. L. Baumert and C. J. Polk, "Temper Embrittlement Studies on $21 / 4 \mathrm{Cr}$-1Mo Steel." Materia1 Performance, pp. 39-45, September 1976.

4. R. Bruscato, "High Temperature Embrittlement Phenomena of $21 / 4 \mathrm{Cr}$-1Mo Weldments." ASME 71-Pet-19, 1971.

5. R. A. Swift and H. C. Rogers, "Embrittlement of $21 / 4 \cdot \mathrm{Cr}-1$ Mo Steel Weld Metal by Postweld Heat Treatment." Welding Research Supplement, pp. 145-172, Apri1 1973.

6. R. A. Swift and H. C. Rogers, "Study of Creep Embrittlement of 2 1/4 Cr-1Mo Steel Weld Meta1." Welding Research Supplement, pp. 188-198, July 1976.

7. R. A. Buchanan and D. M. Young, "Effect of Porosity on Elevated Temperature Fatigue Properties of 2 1/4 C4-1Mo Steel Weldments." Welding Research Supplement, pp. 296-301, 1975. 


\subsubsection{Welded Transition Joints}

The range of operating conditions present in both fossil and nuclear fueled power plants is such that both ferritic steels, (e.g., $21 / 4 \mathrm{Cr}$-1Mo) and austenitic stainless steels, (e.g., AISI 304 or AISI 316) are used in the same loop or generator system. As a result, transition joints (weldments) are necessary. Although welding technology has improved constantly over the years, such transition welds are still incompletely understood and the consequences of weld failure are particularly serious for the LMFBR steam generation system. King ${ }^{(1)}$ has published a comprehensive review of the current state-of-the-art in ferritic-austenitic transition welding and the following discussion is based primarily on this report.

Technology related to welding of dissimilar metals has slowly developed over the past three decades. Austenitic steel electrodes of the $18 \% \mathrm{Cr}-8 \% \mathrm{Ni}$, $25 \% \mathrm{Cr}-12 \% \mathrm{Ni}$, and $25 \% \mathrm{Cr}-20 \% \mathrm{Ni}$ were primarily used, but problems were prevalent. Preferential stress oxidation at the interface and accelerated creep in ferritic material adjacent to the interface are still considered important potential failure mechanisms. Migration of carbon from the ferritic steel into the austenitic weld metal is thought to be a factor leading to failure of transition joints.

simulated service tests indicated that dissimilar-metal joints could be produced but care must be taken to prevent microfissures, transition-zone cracking, carbon depletion, and oxide penetration.

Experimentation using various iron- and nickel-base austenitic filler metals indicated that nickel-base filler metals were superior to iron-base under the test conditions studied. The nickel-base filler should be highly oxidation-resistant with a thermal expansion coefficient close to that of the ferritic material. Type Mi1-8 N12 (Inconel 182) is judged to be an excellent electrode for joining ferritic steels to austenitic steels for some applications. A disadvantage of nickel-base weld metal is its high sensitivity to notches, such as slag inclusions, along the fusion line. A need exists for a nickel-base filler metal that produces a weld of lower creep resistance and higher ductility than existing alloys to reduce shear stresses along the interface. 
Complex microstructures found at the fusion line between ferritic steel and nickel-base weld metals are thought to be agglomerates of carbides that have precipitated during stress relief from decomposition of martensite and metastable austenite. There is, however, little evidence that transition joint failures are caused by the fusion line phase.

Although thousands of ferritic-austenitic steel transition welds have been made using nickel-base filler metals, a reasonable doubt remains about the reliability of this type weld for critical piping joints with 300,000-hour design life. The British feel that transition joints are a weak link in the power generating circuit and that failures may occur in those that undergo the most severe conditions of cyclic temperature service. (1) Current understanding of properties, failure mechanisms, and detailed stress-strain relationships of transition joints is not adequate to accurately predict service behavior.

\section{Reference for 9.4.2}

1. J. F. King, "Behavior and Properties of Welded Transition Joints Between Austenitic Stainless Steels and Ferritic Steels." ORNL-TM-5T63, November 1.975. 


\section{$9.5-1$}

\subsection{SUMMARY AND CONCLUSIONS}

There are few, if any, powerplant concepts that do not have a considerable potential for degrading the mechanical properties of structural materials by physico.chemical action of the working environment. The LMFBR steam generation system presents a gamut of such factors that is probably uniquely severe within the current perspective of powerplant systems that are close to commercial realization.

The serviceability of $21 / 4 \mathrm{Cr}$-1Mo steel, i.e., the load carrying ability for a structural element of given size, geometry and pre-service metallurgical state, must be currently judged on the basis of mechanical property data largely pertaining to an air environment, plus a quite limited body of information on environmental effects. Among the factors that must be accommodated in reasonable design with this material are: long-term thermal aging and decarburization; wide variation in mechanical properties among heats and batches of this steel that satisfy nominal chemistry and heat treatment specifications; the mechanical and chemical property perturbation caused by the very prominent welding process in proposed service assignments. In addition, the predictable and potential corrosion/mass transfer processes associated with the working fluids affecting this material will exact a mechanical property penalty whose long-term severity is exceedingly difficult to assess at this time. In the latter respect, the water/steam-side of the evaporator component is of greatest concern, as discussed in Chapter 14, Volume II, of this report.

Apart from a 'uniform' corrosion allowance for the sodium and water/steam sides of the evaporator and superheater components, there is virtually no current basis for quantitative design accommodation to corrosion for this steel. As noted in Chapter 14, Volume II, of this report, even the uniform corrosion allowance must be questioned until there is more information on the effects of high heat flux on the water/steam-side corrosion. Macro- and micro-structural change due to inter- and intragranular influence of corrosion processes, local strength and ductility perturbation by corrosion-derived hydrogen, are processes that appear to have a significant potential for 
degrading the serviceability of $21 / 4 \mathrm{Cr}$-1Mo steel under conceivable LMFBR working conditions. Corrosion of this steel during steam generation system service will occur under complex stress and temperature histories whose synergistic action with the basic corrosion characteristics of this material have barely been explored.

A11 known structural materials are subject to most of the above considerations to some extent. The mechanical properties of the $21 / 4 \mathrm{Cr}$-1Mo steel, plus certain economies associated with the low alloy content, appear to be the principal defensible basis for its current popularity. The prospects for a serious warping of these attributes by in-service corrosion intervention are particularly strong in the case of this material and this situation recommends considerable caution in making assignments for the $21 / 4 \mathrm{Cr}$-1Mo steel in commercial scale LMFBR powerplants.

Good fabricability has frequently been advanced as an attribute of the $21 / 4 \mathrm{Cr}$-1Mo steel. The welding (self-self and dissimilar) involved in the fabrication of the LMFBR steam generation heat exchangers and sodium piping couplings will pose the most formidable challenge to fabricability this material has experienced to date. Whether it is possible to achieve an acceptable control over the structure and chemistry of these weld zones, on a massive scale, has not yet been demonstrated. 
Volume I

Forward and Technical Summary

1.0 Swelling

2.0 Effect of Irradiation on Tensile Properties

3.0 Effect of Irradiation on High Strain Rate Properties

4.0 Effect of Irradiation on Creep-Rupture Properties

5.0 Effect of Irradiation on Fatigue Properties

6.0 Effect of Irradiation on Weld Properties

7.0 Effect of Fuel Clad Interactions on Mechanical Properties

8.0 Effect of Sodium Coolant Interactions on Mechanical Properties

9.0 Mechanical Property Considerations for Ferritic Steels of the Steam Generation System

Volume II

Forward and Technical Summary

9.0 Corrosion and Mass Transfer

10.0 Erosion

11.0 Wear and Self Welding

12.0 Sodium-Water Reactions

13.0 Corrosion (External)

14.0 Corrosion/Mass Transfer Affecting Materials of the Steam Generation System 
HANFORD TECHNICAL LIBRARY

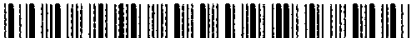

3 3679000625501 